
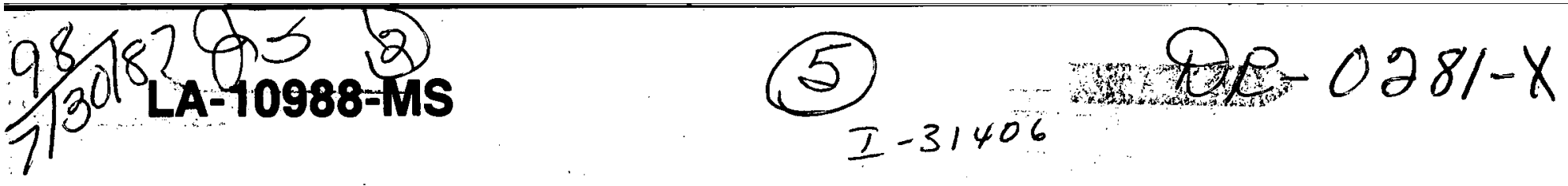

Los Alamos National Laboratory is operated by the University of California for the United States Department of Energy under contract W.7405-ENG.36.

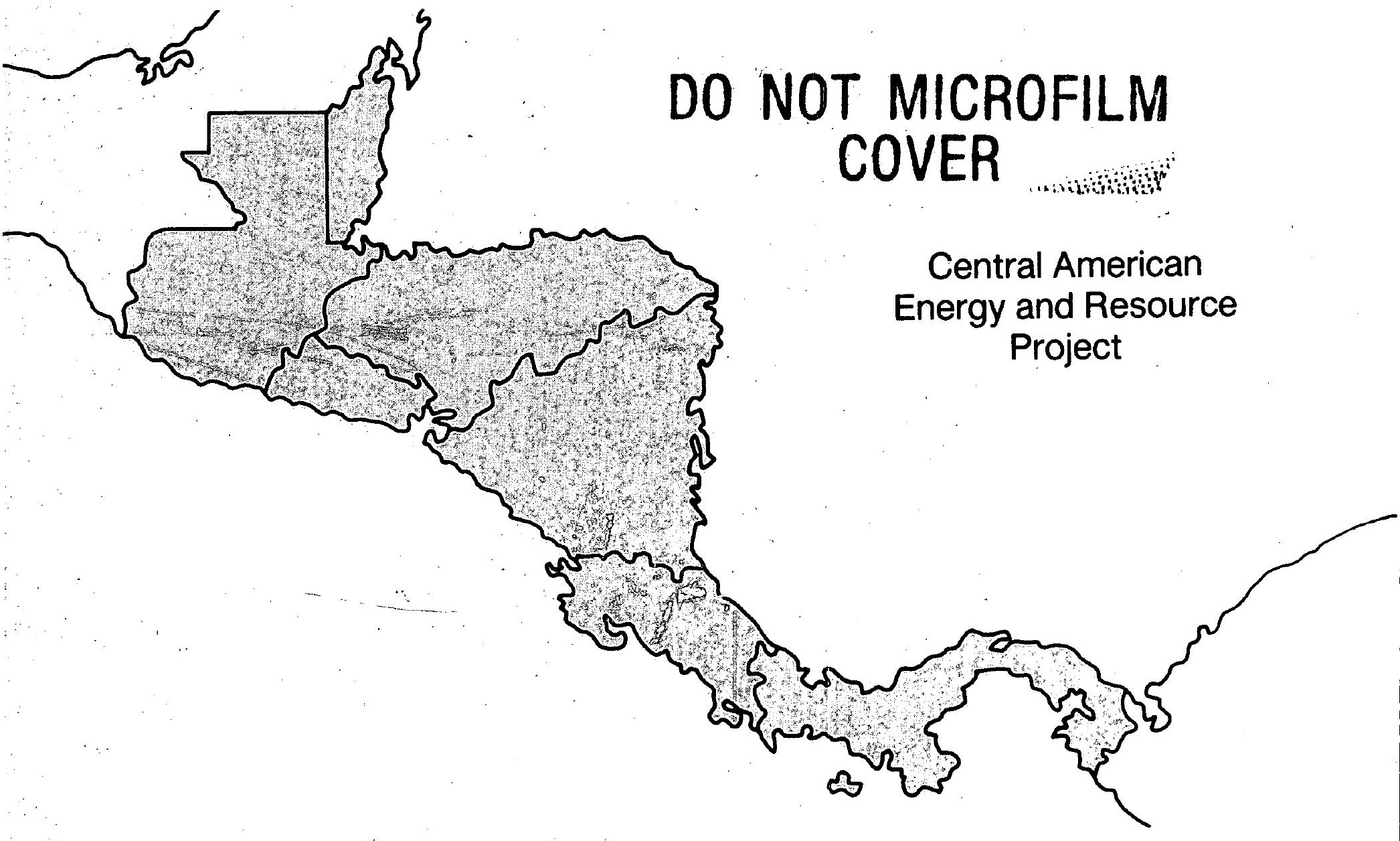

\title{
The Energy Situation in Five Central American Countries
}

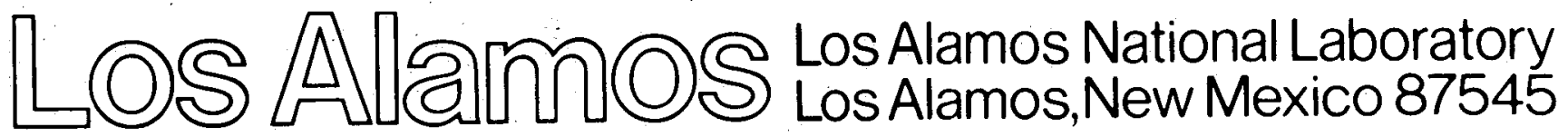




\section{DISCLAIMER}

This report was prepared as an account of work sponsored by an agency of the United States Government. Neither the United States Government nor any agency Thereof, nor any of their employees, makes any warranty, express or implied, or assumes any legal liability or responsibility for the accuracy, completeness, or usefulness of any information, apparatus, product, or process disclosed, or represents that its use would not infringe privately owned rights. Reference herein to any specific commercial product, process, or service by trade name, trademark, manufacturer, or otherwise does not necessarily constitute or imply its endorsement, recommendation, or favoring by the United States Government or any agency thereof. The views and opinions of authors expressed herein do not necessarily state or reflect those of the United States Government or any agency thereof. 


\section{DISCLAIMER}

Portions of this document may be illegible in electronic image products. Images are produced from the best available original document. 


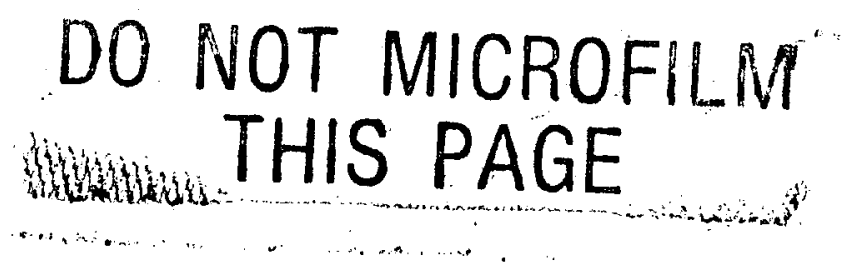

This work was supported by the U.S. Agency for International Development.

This report was prepared as an account of work sponsored by an agency of the United States Government. Neither the United States Government nor any agency thereof, nor any of their employees, makes any warranty, express or implied, or assumes any legal liability or responsibility for the accuracy, completeness, or usefulness of any information, apparatus, product, or process disclosed, or represents that its use would not infringe privately owned rights. Reference herein to any specific commercial product, process, or service by trade name, trademark, manufacturer, or otherwise, does not necessarily constitute or imply its endorsement, recommendation, or favoring by the United States Government or any agency thereof. The views and opinions of authors expressed herein do not necessarily state or reflect those of the United States Government or any agency thereof. 
This report was prepared as an account of work sponsored by an agency of the United States Government. Neither the United States Government nor any agency thereof, nor any of their employees, makes any warranty, express or implied, or assumes any legal liability or responsibility for the accuracy, completeness, or usefulness of any information, apparatus, product, or process disclosed, or represents that its use would not infringe privately owned rights. Reference herein to any specific commercial product, process, or service by trade name, trademark, manufacturer, or otherwise does not necessarily constitute or imply its endorsement, recommendation, or favoring by the United States Government or any agency thereof. The views and opinions of authors expressed herein do not necessarily state or reflect those of the United States Government or any agency thereof.

\title{
The Energy Situation in Five Central American Countries
}

\author{
Principal Investigators \\ Linda Trocki \\ Steven R. Booth \\ Alvaro Umaña Q.* \\ Collaborators \\ Patricia C. Aragon \\ Annette Youngblood Turpin \\ Robert H. Drake \\ Donald W. Morris \\ Fred Roach \\ Guillermo Selva T.*
}

\section{LA-10988-MS}

UC-98

Issued: June 1987
LA--10988-MS

DE87 012708

\footnotetext{
Work Performed in Cooperation with

Dirección Sectorial de Energia, Costa Rica

Comision Ejecutiva Hidroeléctrica del Río Lempa, El Salvador

Ministerio de Energia y Minas, Guatemala

Consejo Superior de Planificación Económica, Honduras

Comisión Nacional de Energía, Panamá

Secretaría Permanente del Tratado General de Integración Económica Centroamericana

Instituto Centroamericano de Investigación y Tecnología Industrial
}

"Instituto Centroamericano de Administración de Empresas, Apartado 960, 4050, Alajuela, COSTA RICA.
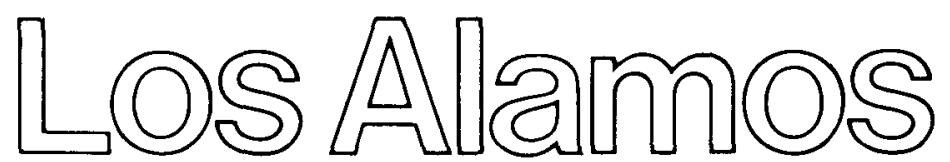

Los Alamos National Laboratory

MASTER Los Alamos,New Mexico 87545 


\section{CONTENTS}

ABSTRACT ........................... vii

ACKNOWLEDGMENTS. ....................... viii

\section{PART I \\ OVERVIEW FOR FIVE COUNTRIES}

\section{OVERVIEW}

Linda Trocki, Steven R. Booth, and Alvaro Umaña Q....................

\section{PART II}

ENERGY SITUATION REPORTS FOR FIVE COUNTRIES

\section{COSTA RICA}

Linda Trocki and Alvaro Umaña $Q$.

EL SALVADOR

Donald W. Morris, Linda Trocki, and Guillermo Selva T.

\section{GUATEMALA}

Fred Roach and Steven R. Booth. . . . . . . . . . . . . . . . . . . . .

HONDURAS

Steven R. Booth. . . . . . . . . . . 237

\section{PANAMA}

Annette Youngblood Turpin. . . . . . . . . . . . . . . . . . . . . . . . . . . . 289 


\section{ABSTRACT}

This study describes the energy resources and the changes that have taken place in energy supply and demand in five Central American countries between 1970 and 1984. Economic changes are also reviewed because they influence and are affected by changes in the energy sector. The work was performed under the auspices of the US Agency for International Development.

The Central American countries of Costa Rica, El Salvador, Guatemala, Honduras, and Panama are highly dependent on fuel wood as a source of energy, particularly in the residential sector. They also rely upon imported oil products to supply a growing modern sector. Most countries have significant hydroelectric and geothermal resources, and most countries produce a large portion of their electricity from hydroelectric projects. Demand for electricity has grown rapidly. Relative shares of primary versus secondary energy in the five countries vary significantly and strongly correlate with average per capita income. Consumption of secondary energy has declined during the recent economic recession suffered by the region. 


\section{ABSTRACT}

This study describes the energy resources and the changes that have taken place in energy supply and demand in five Central American countries between 1970 and 1984. Economic changes are also reviewed because they influence and are affected by changes in the energy sector. The work was performed under the auspices of the US Agency for International Development.

The Central American countries of Costa Rica, El Salvador, Guatemala, Honduras, and Panama are highly dependent on fuel wood as a source of energy, particularly in the residential sector. They also rely upon imported oil products to supply a growing modern sector. Most countries have significant hydroelectric and geothermal resources, and most countries produce a large portion of their electricity from hydroelectric projects. Demand for electricity has grown rapidly. Relative shares of primary versus secondary energy in the five countries vary significantly and strongly correlate with average per capita income. Consumption of secondary energy has declined during the recent economic recession suffered by the region. 


\section{ACKNOWLEDGMENTS}

This work owes a great deal to the energy planners in each country who so graciously received us, shared their views with us, and provided the information contained in this report. Scientists and engineers who contributed include members of the energy directorate or ministry in each country, the national utilities, the forestry ministries, and the central banks. We are especially indebted to the following people and their staffs for their extensive cooperation and their comprehensive review of the draft document: Jorge Blanco Roldan of the Energy Sector Directorate of Costa Rica, Oscar Melgar of the Rio Lempa Hydroelectric Commission in El Salvador, Rolando Yon Siu of the Ministry of Energy and Mines in Guatemala, Rafael Ochoa of the Economic Planning Council of Honduras, Ramon Argote of the National Energy Commission of Panama, and Julio Obiols Gomez of the Permanent Secretariat for Central American Economic Integration. Thanks are also owed the officers of the US Agency for International Development (AID): Heriberto Rodriguez, Costa Rica; Peter Deinken, El Salvador; Lawrence "Doc" Odle, Guatemala; Lynn Sheldon, Honduras; Jose Sanchez, Panama; Carl Duisberg and Ronald Bloom, Regional Office for Central America and Panama; and James Hestor and Alberto Sabadell, Washington. Without their support, this work could not have been accomplished. Our efforts have benefited significantly from the strong support that we have received from our managers, Verne W. Loose, Joseph A. Frank, and Ronald K. Lohrding.

Wilma J. Bunker provided many helpful suggestions for organization of the document and contributed much of her time to editing it. This report was typed by Petrita Montano, Hazel Kutac, E. Corine Ortiz, and Kay Grady. Special thanks are owed Myrle Johnson and Flavio Gurule, who supervised the preparation of the figures done by Loyola C. Martinez, Donna S. Williams, Dixie E. Hanks, and Janice L. Gorlitz. 


\section{ACKNOWLEDGMENTS}

This work owes a great deal to the energy planners in each country who so graciously received us, shared their views with us, and provided the information contained in this report. Scientists and engineers who contributed include members of the energy directorate or ministry in each country, the national utilities, the forestry ministries, and the central banks. We are especially indebted to the following people and their staffs for their extensive cooperation and their comprehensive review of the draft document: Jorge Blanco Roldan of the Energy Sector Directorate of Costa Rica, Oscar Melgar of the Rio Lempa Hydroelectric Commission in El Salvador, Rolando Yon Siu of the Ministry of Energy and Mines in Guatemala, Rafael Ochoa of the Economic Planning Council of Honduras, Ramon Argote of the National Energy Commission of Panama, and Julio Obiols Gomez of the Permanent Secretariat for Central American Economic Integration. Thanks are also owed the officers of the US Agency for International Development (AID): Heriberto Rodriguez, Costa Rica; Peter Deinken, El Salvador; Lawrence "Doc" Odle, Guatemala; Lynn Sheldon, Honduras; Jose Sanchez, Panama; Carl Duisberg and Ronald Bloom, Regional Office for Central America and Panama; and James Hestor and Alberto Sabadell, Washington. Without their support, this work could not have been accomplished. Our efforts have benefited significantly from the strong support that we have received from our managers, Verne W. Loose, Joseph A. Frank, and Ronald K. Lohrding.

Wilma J. Bunker provided many helpful suggestions for organization of the document and contributed much of her time to editing it. This report was typed by Petrita Montano, Hazel Kutac, E. Corine Ortiz, and Kay Grady. Special thanks are owed Myrle Johnson and Flavio Gurule, who supervised the preparation of the figures done by Loyola $\mathrm{C}$. Martinez, Donna S. Williams, Dixie E. Hanks, and Janice L. Gorlitz. 


\section{PART I OVERVIEW FOR FIVE COUNTRIES}





\section{OVERVIEW}

\section{CONTENTS}

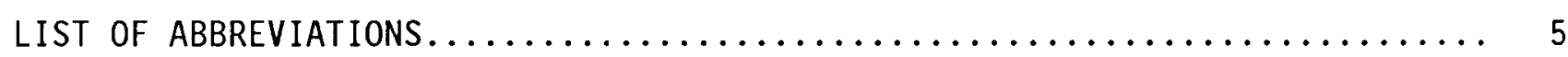

LIST OF TABLES $\ldots \ldots \ldots \ldots \ldots \ldots \ldots \ldots \ldots \ldots \ldots \ldots \ldots \ldots \ldots \ldots \ldots$

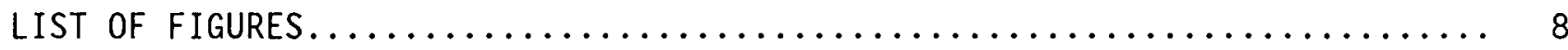

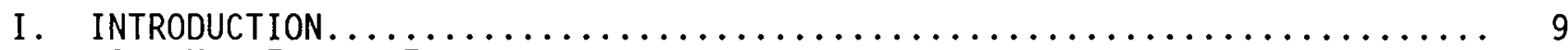

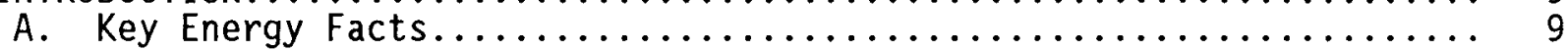

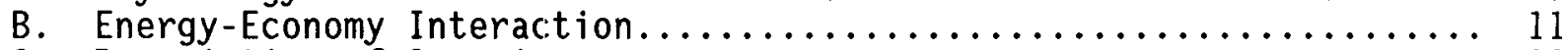

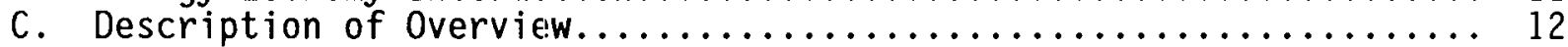

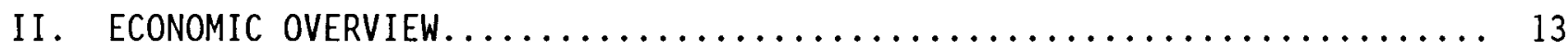

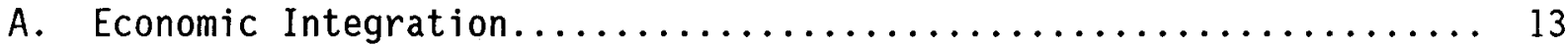

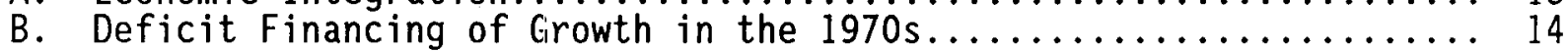

C. Economic Crisis of the Late 1970s and Early 1980s............... 14

D. Country Characteristics.......................... 16

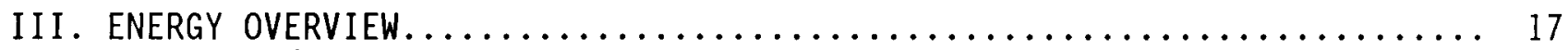

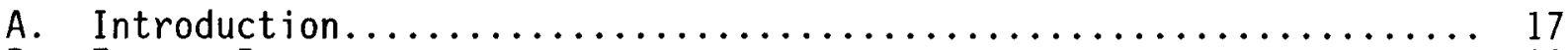

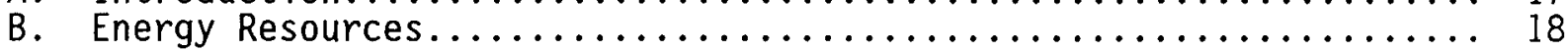

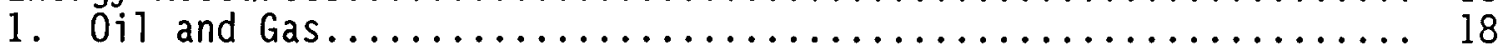

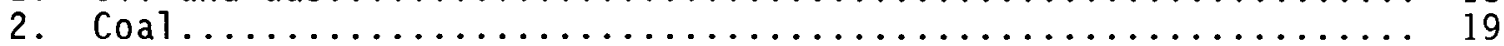

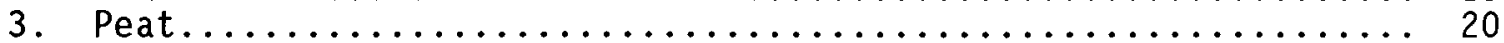

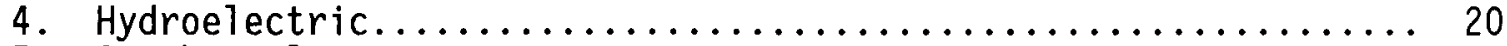

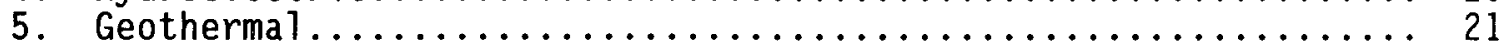

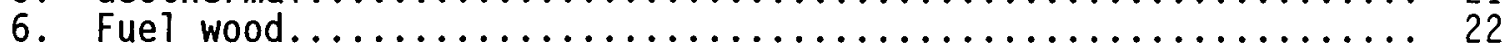

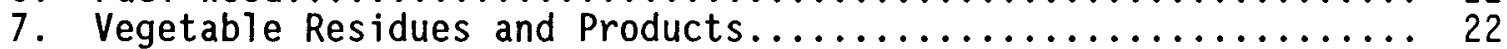

8. Summary of Energy Resources..................... 23

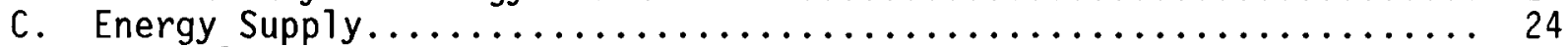

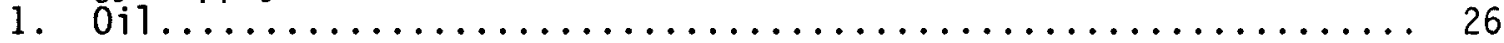

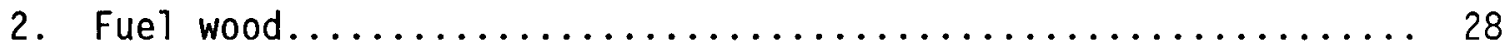

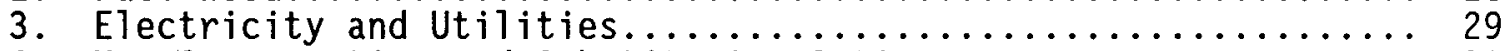

4. Key Conservation and Substitution Options................ 32

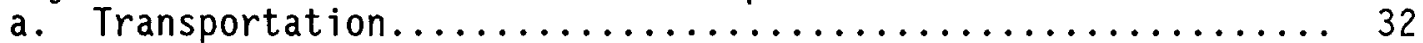

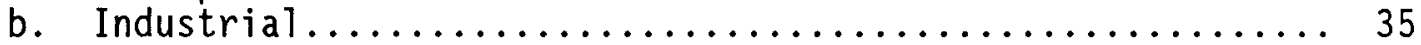

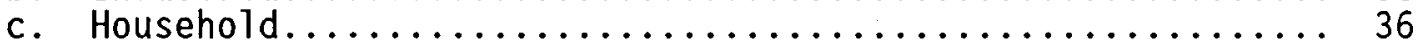

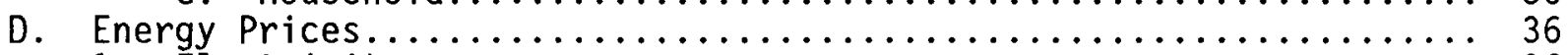

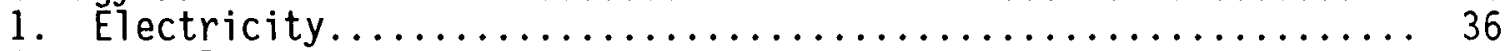

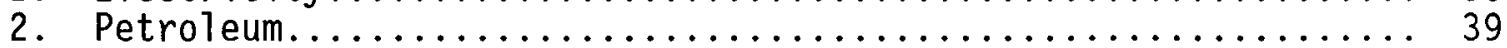

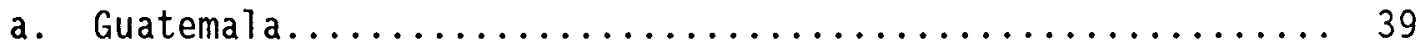


b. El Salvador................................... 40

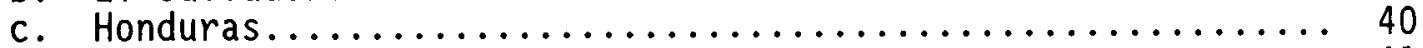

d. Costa Rica..................................... 41

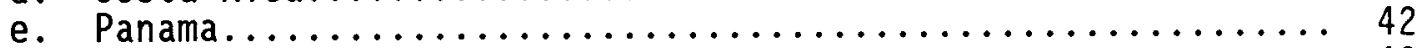

3. Fuel wood and other Biomass......................... 42

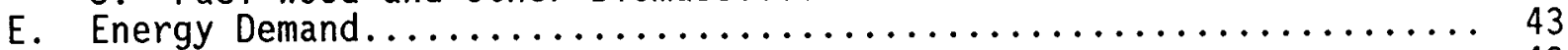

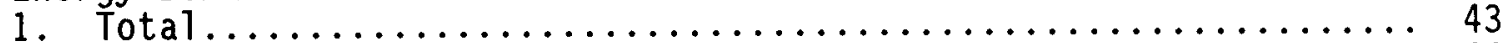

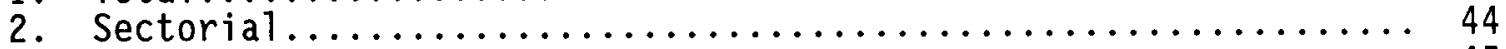

3. Per Capita..................................... 45

4. Details on Key Energy Products...................... 47

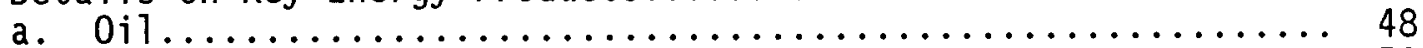

b. Fuel wood........................................... 50

c. Electricity................................ 53

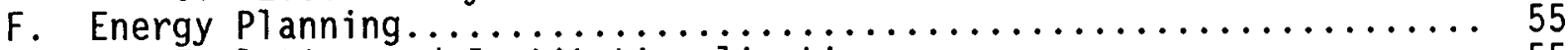

1. Evolution and Institutionalization.................... 55

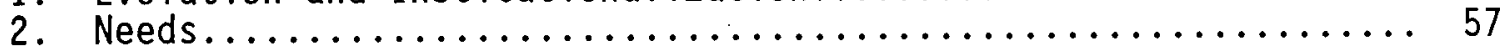

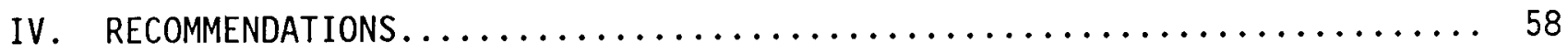

REFERENCES........................................... 62 


\section{LIST OF ABBREVIATIONS}

AID US Agency for International Development

BEP Barrels Equivalent of Petroleum

CACM Central American Common Market

CEL Comision Ejecutiva Hidroelectrica del Rio Lempa (Lempa River Hydroelectric Commission), El Salvadora

CATIE Centro Agronomico Tropical de Investigacion y Ensenanza (Research and Instruction Center for Tropical Agronomy)

CONSUPLANE Consejo Superior de Planificacion Economica (Economic Planning Council), Honduras

DGMH Direccion General de Minas E Hidrocarburos (General Directorate of Mining and Hydrocarbons), Honduras

DSE Direccion Sectorial de Energia (Sectorial Directorate of Energy), Costa Rica

ECLA Economic Comission for Latin America

ENEE Empresa Nacional de Energia Electrica (National Electric Energy Company), Honduras

FAO Food and Agriculture Organization

GDP

Gross Domestic Product

IBM PC International Business Machines Personal Computer

ICAITI Instituto Centroamericano de Investigacion y Technologia Industrial (Central American Institute of Industrial Technology and Research)

ICE Instituto Costarricense de Electricidad (Costa Rican Institute of Electricity)

IDB Inter-American Development Bank

INCAE Instituto Centroamericano de Administracion de Empresas (Central American Institute of Business Administration)

INDE Instituto Nacional de Electrificacion (National Electrification Institute), Guatemala

IRHE Instituto de Recursos Hidraulicos y Electrificacion (Institute of Hydro Resources and Electrification), Panama

LANL Los Alamos National Laboratory

MEM Ministerio de Energia y Minas (Ministry of Energy and Mines), Guatemala 
OLADE Organizacion Latinoamericana de Energia (Latin America Energy Organization)

OPEC Organization of Petroleum Exporting Countries

PEICA Programa Energetica del Istmo Centroamericano, UNDP (Energy Program of the Central American Isthmus)

PEMEX Mexican National Oil Company

RECOPE Refineria Costarricense de Petroleo, S.A. (Costa Rican Refinery of Petroleum, Incorporated)

ROCAP Regional Office for Central American Programs, AID

UNDP United Nations Development Program 


\section{LIST OF TABLES}

1. Central American Economic, Demographic, and Energy Statistics......... 12

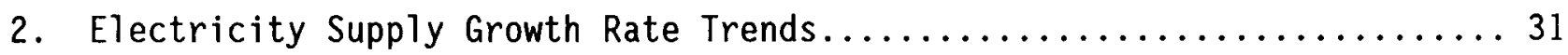

3. Recent New Hydroelectric Projects...................... 32

4. Energy Used to Generate Electricity.................... 34

5. Petroleum Prices of Main Products..................... 40

6. $0 i 1$ Consumption by Product (percentage) $\ldots \ldots \ldots \ldots \ldots \ldots \ldots \ldots$

7. $0 i 1$ Consumption by Product (thousands of barrel equivalents

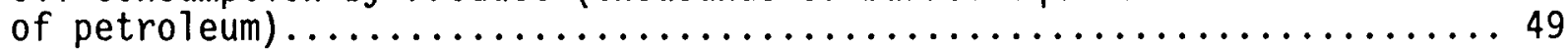

8. $0 i 1$ Consumption Annual Growth Rates (percentages) ............. 50

9. $0 i 1$ Product Consumption by Sector (thousands of barrel equivalents

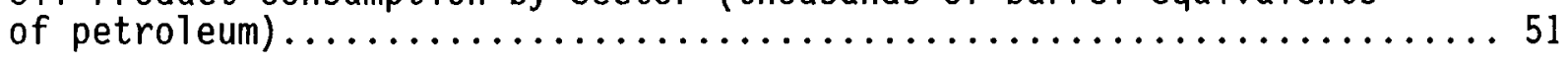

10. $0 i 1$ Product Consumption by Sector (percentages) $\ldots \ldots \ldots \ldots \ldots \ldots \ldots$

11. Fuel-wood Use by Sector (percentages) .................. 52

12. Annual Componded Growth Rates of Fuel-wood Consumption............ 52

13. Fuel-wood Use by Sector (thousands of barrel equivalents of

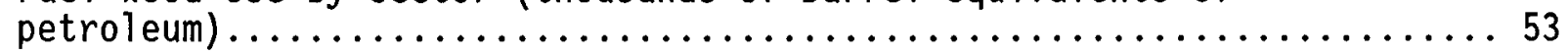

14. Electricity Use by Sector (percentages) ................... 54

15. Electricity Use by Sector (thousands of barrel equivalents

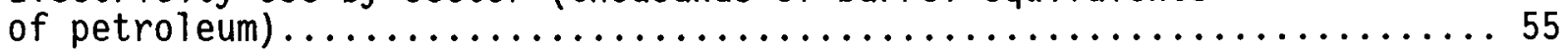

16. Annual Compounded Growth Rates of Electricity Demand............ 56 


\section{LIST OF FIGURES}

1. Value of petroleum imports................................ 10

2. $0 i 1$ imports as a percentage of total exports................... 10

3. External debt as a percentage of gross domestic product............ 15

4. Energy supply for the five countries by fuel type, 1970-1984......... 25

5. Quantity of petroleum imports............................ 26

6. Installed electric generating capacity...................... 33

7. Total electricity generation............................... 33

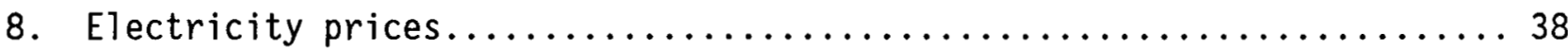

9. Petroleum product prices............................. 41

10. Total energy consumption............................... 44

11. Per capita consumption of $0 i 1$ products...................... 46

12. Per capita gross dol.estic product.......................... 46

13. Per capita consumption of firewood......................... 46

14. Per capita consumption of electricity...................... 46 


\section{INTRODUCTION}

This study was sponsored by the US Agency for International Development (AID) under an agreement with the US Department of Energy. This report analyzes the energy situation in five Central American countries--Costa Rica, El Salvador, Guatemala, Honduras, and Panama. Our study focuses mainly on changes that have taken place since 1977. Part I presents an overview which compares and summarizes the energy situation for these countries. Part II contains detailed reports on each country.

A. Key Energy Facts

The most striking fact about energy utilization in Central America is the relatively low intensity of its use, which at present stands at the equivalent of approximately 3.6 barrels of oil per person per year, down from 4.5 barrels per person per year in 1978. That present usage is roughly equivalent to the average energy consumption in developing countries, and is only about one-eighth to one-tenth of the level of usage found in industrialized countries. Clearly more energy per person will be used as development proceeds. Thus it is vitally important that careful choices be made.

The Central American population is highly dualistic, with the rural sector still representing about 60 percent of the total population. This fact has important implications for energy utilization patterns, which are strongly dominated by petroleum products and firewood.

In relative terms, petroleum products are heavily utilized, especially in the transport sector, which consumes almost half of the imports. Per capita consumption averaged 1 barrel per person per year in 1984, with considerable differences among the countries (Panama and Costa Rica have consumption values twice as large as that of the other countries). $0 i 1$ imports represent a major economic burden in Central America--approximately $\$ 1$ billion US in 1984--which comprised 5 to 20 percent of the value of the countries' exports (Figs. 1 and 2).

Approximately 27 million tons of fuel wood were utilized by these countries in 1984, equivalent to 1.2 tons of firewood per person per year. Total fuelwood consumption, traditionally associated with rural and urban relative low income households, showed an increasing trend throughout the 1970 s that persists up to present. This trend, compounded by rapid population growth, has resulted in additional pressures toward deforestation and land degradation, the most important ecological changes now taking place in Central America. 


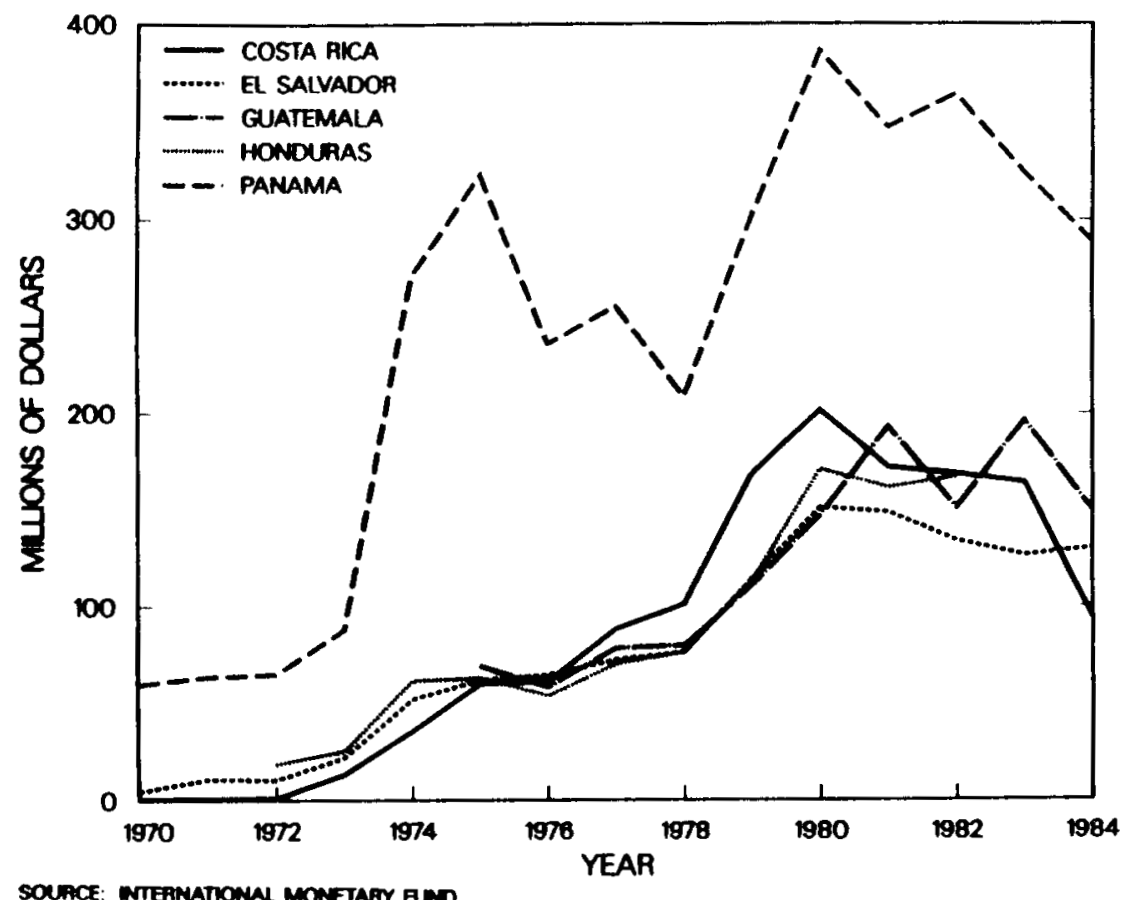

Fig. I. Value of petroleum imports. (Imports for Panama and EI Salvador are only crude petroleum. Both countries import very small quantities of refined petroleum products.)

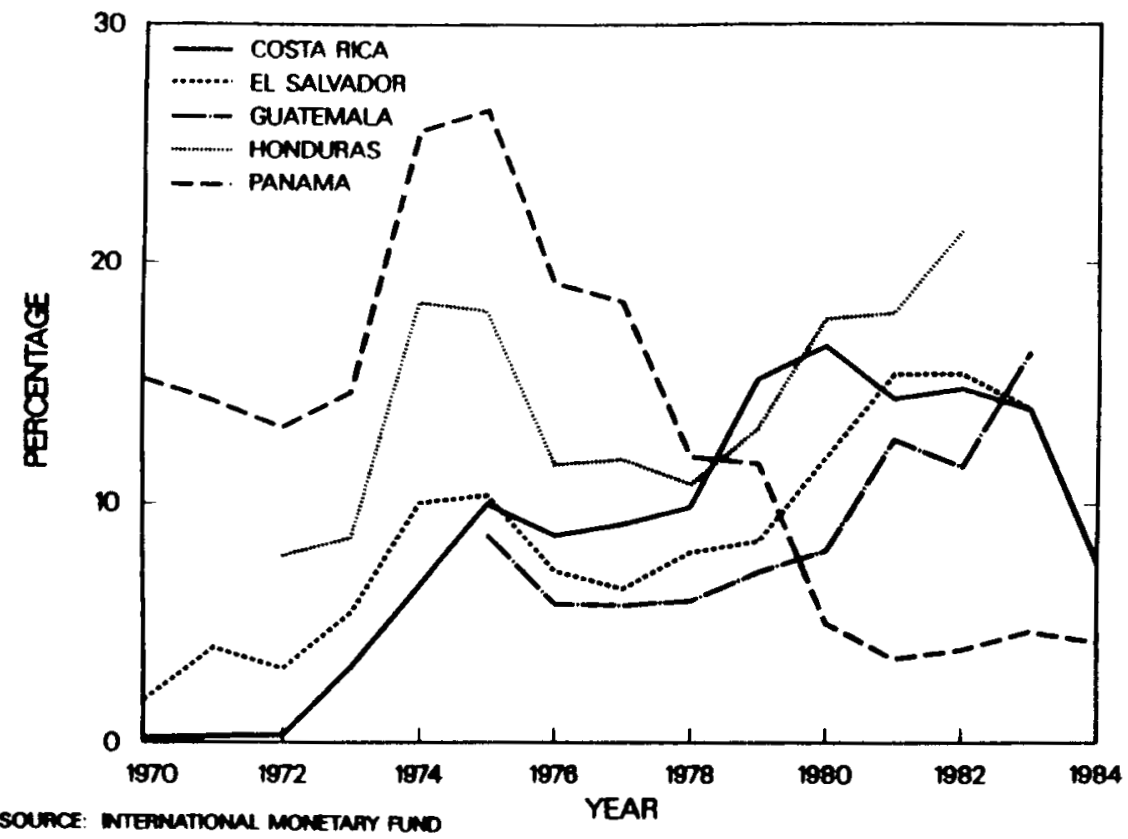

Fig. 2. $0 i l$ imports as a percentage of total exports. (0il imports for Panama and El Salvador are only crude petroleum. Both countries import very small quantities of refined petroleum products.) 
A1though other energy resources make less of a contribution than petroleum products and fuel wood, their contribution is nevertheless significant in all the countries. Important efforts have been devoted to developing hydroenergy resources in the last 15 years, with $2000 \mathrm{MW}$ of capacity being developed at a cost that exceeded $\$ 3$ billion US. Debt incurred to construct large hydroelectric projects constitutes a large portion of national debt in countries such as Guatemala and Honduras. All countries have moved to expand hydroelectric generation, and some have developed geothermal resources. Only Guatemala and Panama generate a significant amount of electricity from thermal capacity (approximately 50 and 30 percent, respectively, in 1984). Rising foreign debt and the present financial crisis cast a shadow over the ability of the countries to continue to undertake large, costly electricity expansion projects. B. Energy-Economic Interaction

A key number of demographic, economic, and energy utilization indicators are presented in Table 1 to illustrate some of the main characteristics of each country.

The economic structure of Central American societies has important implications with respect to energy utilization patterns. As shown in Table 1, Central American economies show wide variations in per capita gross domestic product (GDP) and other basic economic indicators. Per capita incomes vary by a factor of three from those of El Salvador and Honduras to those of Costa Rica and Panama. Although these figures should be taken with caution owing to persistent and rapid devaluations that have taken place in several countries during the past years or months, the differences reflect real disparities among the levels of development and the quality of 1 ife in the region.

Despite the efforts made through the Central American Common Market (CACM) in the last decades to industrialize the countries, they remain largely agricultura1. In most of the region, the GDP for agriculture exceeds that for manufacturing, and in all cases, at least one-third of the labor force is dedicated to agriculture; in Honduras, El Salvador, and Guatemala the agricultural labor force makes up from 50 to 60 percent of the total labor force. The economic integration process (CACM) and its demise will be analyzed later in this report as a critical input to understanding the present crises.

The drop in GDP of almost 3 percent between 1980 and 1984 affected energy utilization heavily. Because this sudden drop has dramatically changed energy consumption patterns of particular fuels, the fuel mix of sectorial consumption must be interpreted with caution. 
TABLE 1

CENTRAL AMERICAN ECONOMIC, DEMOGRAPHIC,

AND ENERGY STATISTICS

Demearaphic Dato

Ceste Rica El Solvader Guatemelo Henduras

Panamg

ECONOMIC OATA

\begin{tabular}{|c|c|c|c|c|c|}
\hline 1984 per capita gross national product (1982 \$US) & $1,565.4$ & 707.9 & $1,194.3$ & 663.1 & 2.021 .7 \\
\hline Total population in 1984 (millions) & 2.46 & 5.39 & 8.18 & 4.23 & 2.01 \\
\hline \multicolumn{6}{|l|}{ Urban population } \\
\hline (percentage) & 48.7 & 40.8 & 32.7 & 39.0 & 56.0 \\
\hline \multicolumn{6}{|l|}{ Rural population } \\
\hline$($ percentage) & 51.3 & 59.2 & 67.8 & 61.0 & 44.8 \\
\hline Birth rate in 1984 (per 1.000 inhabitants) & 30.8 & 30.5 & 42.0 & 38.7 & 26.4 \\
\hline Death rate in 1984 (per 1.000 inhabitants) & 3.9 & 6.9 & 10.3 & 4.7 & 4.1 \\
\hline Life expectancy in 1984 (years) & 73.1 & 64.8 & 59.0 & 59.9 & 71.0 \\
\hline Literacy rate in 1984 (percentage) & 89.8 & 57.1 & 56.4 & 59.5 & 88.1 \\
\hline \multicolumn{6}{|l|}{ ENERGY UTILIZATION DATA } \\
\hline Households (percent electrified) & 85 & 34 & 28 & 25 & 53 \\
\hline Population (percent fuel wood users) & 66 & 66 & 72 & 75 & 47 \\
\hline Per copita energy $\left(\mathrm{BEP}^{\alpha} / \mathrm{y} r\right)$ & 4.0 & 3.0 & 3.9 & 3.4 & 4.2 \\
\hline Commercial $\left(B^{a} a / y r\right)$ & 2.7 & 1.0 & 1.5 & 1.3 & 3.3 \\
\hline Fuel wood $\left(\mathrm{BEP}^{\mathrm{a}} / \mathrm{yr}\right)$ & 1.3 & 2.0 & 2.4 & 2.1 & 0.9 \\
\hline
\end{tabular}

Sources: InterAmericon Development Bank, World Bank, Country data.

${ }_{B \text { BEP }}=$ Barrels of equivalent petroleum (converted from tons of oil equivalent using a foctor of 7.33 barrels of oil per metric ton.)

Although the nature and determinants of the crisis are unique for each country and the timing of events has followed a different trend for each society, there are important common elements that underlie Central America's situations, and these aspects will be analyzed in this report.

C. Description of Overview

The following overview of specifics is presented in this document. An economic overview is presented of the economic integration process, the present crisis, and the particular characteristics of each country. An energy overview encompasses the structure of major resources, supply and demand for the different energy sources, the role of utilities, and the key conservation and substitution options. The evolution of prices and demand are considered both in 
terms of sectors and countries. Energy planning is analyzed with respect to needs, capabilities, and ability to influence policy. A final section summarizes the main conclusions and recommendations.

\section{ECONOMIC OVERVIEW}

\section{A. Economic Integration}

Many attempts at political and economic integration have taken place in Central America since independence from Spain was achieved in 1821. The countries shared the colonial heritage, and although the Spanish domination over this area was at times more apparent than real, the notions of political and geographical unity were strong during the post-independence era, and they have lasted until recent times.

During the middle of the nineteenth century, the Central American countries began their integration into the international economy through the adoption of policies to promote agricultural exports. Coffee exports initially, followed by banana exports a few decades later, became the dynamic factor that opened these economies to the world market and until World War I provided for rapid and sustained growth.

In the interim period between World War I and II, the Central American economies stagnated, and the income from exports was no longer a viable alternative for economic growth, partly as a result of the serious disturbances caused by the war and the generalized depression that affected the world economy at that time.

Through stimulated trade between the Central American countries, this group of small and open economies sought to establish an internal market that would allow them to reach the following goals:

- Diversify production in order to reduce the extreme dependence on exports of a few primary agricultural commodities.

- Accelerate their rate of economic growth in order to raise the standard of living and reduce chronic unemployment.

- Modernize their productive structure in order to exploit their natural resources to greater advantage.

The integration program of the CACM can be divided into four stages. The first stage covers the period between 1951-1958 and is characterized by the formation of bilateral agreements among the countries. The process was slow and somewhat difficult because the countries had little experience in making such 
agreements and wanted to observe results before embarking on more ambitious programs. The second stage was a relatively short but important one lasting 2 years, from mid-1958, with the signing of the Multilateral Treaty of Free Trade and Integration to the 1960 signing of the General Treaty on Economic Integration. This stage marks the transition from bilateral to multilateral cooperation, and during this period some tensions existed between the countries that wanted to move rapidly toward integration (Guatemala, El Salvador, and Honduras) and those that desired a more cautious approach (Costa Rica and Nicaragua).

The third stage started with the signing of the General Treaty and saw the consolidation and flourishing of the CACM that lasted until the Honduras-El Salvador conflict began in 1969 .

The fourth stage, which itself can be subdivided into several periods, includes the crisis period of CACM that encompasses the social and political pressures of the 1970 s and the virtual collapse of CACM during the present decade.

B. Deficit Financing of Growth in the 1970 s

Except for the short recession of 1974 and 1975, the 1970 s were years of relatively steady economic growth for Central America: from 1970 to 1978 the average rate of growth in GDP for the five countries was over 5 percent. For several reasons, the countries were able to recover quickly from the recession that followed the first Organization of Petroleum Exporting Countries (OPEC) $0 i 1$ price hike. First, international loans were abundantly available. Second, the countries had relatively small external debts at the time--in 1970, external debt as a percentage of GDP averaged just 12 percent (see Fig. 3)--and third, domestic price inflation was relatively low. These conditions allowed the countries to undertake growth-oriented domestic policies that were financed by increased external indebtedness. By 1978, debt as a percentage of GDP had risen considerably.

C. Economic Crisis of the Late 1970s and Early 1980s

The deficit financing policies of the early 1970 s worked well for a while, but they came to haunt the countries during the severe recession of the $1980 \mathrm{~s}$. International credit conditions had radically changed since the previous recession: high inflation in the industrialized countries had led to restrictive monetary policies and subsequent increases in international interest rates. In addition, the Central American countries had run up 1 arge debts, which, when combined with record high interest rates, caused capital inflows to decrease dramatically (see Fig. 3). The international recession had repercussions that 


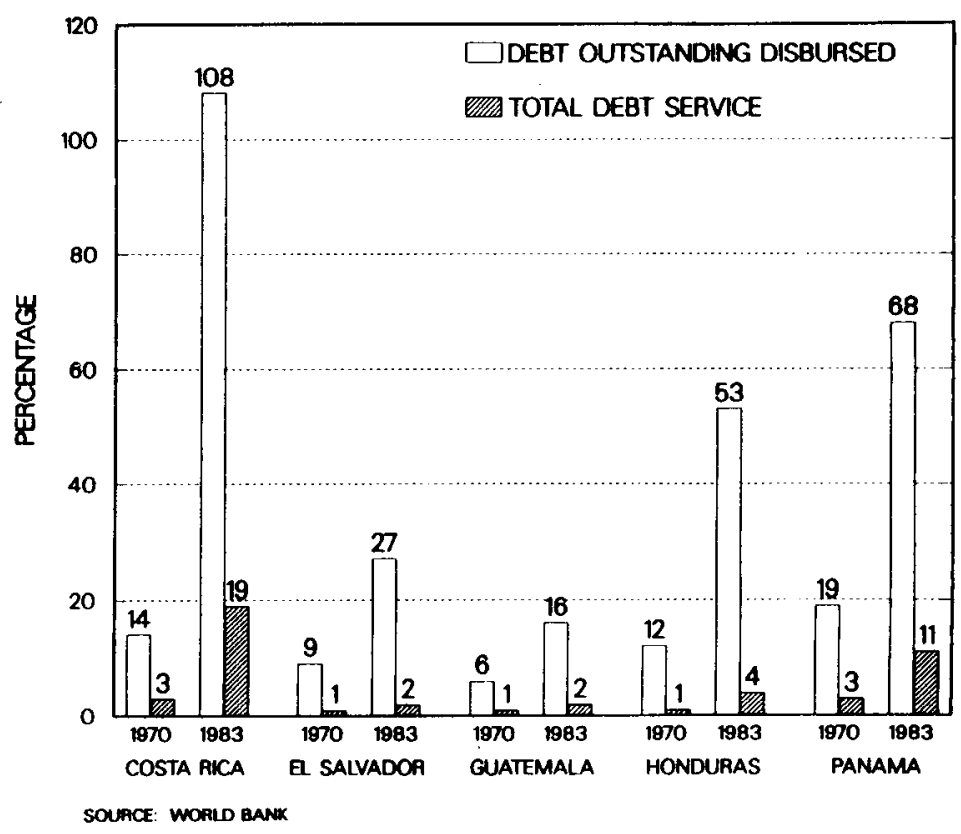

Fig. 3. External debt as a percentage of gross domestic product.

varied in intensity, depending on the particular characteristics of each country, and affected the countries at different times during a period of five to six years, starting in 1979. Different monetary and fiscal policies were enacted by the countries to attempt to deal with the crisis, and although the effectiveness of these policies has been mixed, in general the countries have suffered severe setbacks in their development plans.

The crisis hit first in Costa Rica in 1981 in the form of a severe recession caused by high inflation and rapid devaluation of the colon brought about partly by the alarming growth in the external debt between 1979 and 1981 . Over a period of eighteen months, the colon was devalued by almost 500 percent, and inflation reached values close to 100 percent per year in 1982. The new administration took over in 1982 and stabilized the economy considerably by following policies to promote growth in employment, attempting to distribute the burden of the economic crisis between the groups affected, and following a policy of small currency devaluation.

On the other hand, Honduras and Guatemala had been able to avoid devaluation through restrictive fiscal and monetary policies that led to lower growth and higher unemployment. Honduras has experienced high unemployment and slow growth, on the order of one percent annually. Guatemala, whose industrial sector had been affected severely by the downfall of the CACM, used this strategy 
up until 1984 but in recent months has suffered a devaluation approaching 200 to 300 percent.

El Salvador's economy has suffered the effects of a six year armed insurgency, massive capital flight, and a drop of over 20 percent in its real GDP between 1978 and 1984; nevertheless, it has been able to manage inflation and avoid massive devaluations. The Salvadoran colon has been devalued by approximately 100 percent.

Panama's particular economic structure with heavy reliance on the international service sector forced the country into a recession and unemployment owing to the international recession. Devaluation is not an option open to the country since Panama has no Central Bank and relies mainly on the US dollar for its currency.

\section{Country Characteristics}

The particular economic and social characteristics of the different countries are summarized here. Although the countries share a common heritage, economic and social development has proceeded at different rates and in various ways.

Guatemala is characterized by the dualistic nature of its economy, with over 60 percent of its native population living in rural areas in a subsistence economy with many of them not sharing the same language. Superimposed on this base is a modern sector and the largest industrial infrastructure of the countries considered. The agricultural sector employs over half the labor force and contributes more than 25 percent of GDP. Guatemalan politics have been dominated by authoritative regimes; however, currently there exists a movement to consolidate democratic traditions, and elections have been held successfully in the past year.

Honduras is one of the Teast-developed countries in Latin America. Given the lack of a well-developed industrial sector, it is even more dependent on agriculture than Guatemala. Over half of total employment is in agriculture and over 30 percent of GDP comes from this sector. About three-quarters of the rapidly growing population lives in rural areas; per capita income is low, and a large subsistence sector exists. Politically, Honduras has experienced military governments and dictatorships, but recently there has been a strong trend to democratic rule, and the second consecutive free election has been held.

El Salvador is the smallest country in Central America and has the highest population density of all the countries considered. For long-standing social and political reasons, land ownership has been relatively concentrated. About 
60 percent of the people live in rural areas, and agriculture generates 40 percent of the employment. The industrial sector used to rank second in the region, after Guatemala, but it has suffered severe setbacks. The society has been plagued by a six-year armed insurgency that has been extremely costly in terms of lives, resources, and suspended production. In the political arena, the influence of the military has been predominant, but elections with large participation and attempts at civilian rule have made significant progress. Although total stabilization of the country will have to wait for a solution to the armed conflict, economic recovery is paralleling the civilian reform.

Costa Rica is the single Central American country in which the contributions of manufacturing and services to GDP are larger than that of agriculture; nevertheless agriculture still generates 28 percent of employment. The population is roughly equally divided between rural and urban sectors, and the quality of life is high relative to Latin American standards, owing to the state's active and successful efforts in providing health and welfare care to a significant percentage of the population and the relatively high per capita GDP. Costa Rica has one of highest levels of per capita indebtedness in the world. It has a large government sector. It has long been recognized as a free country with strong democratic traditions.

Panama's strategic geographic location makes it unique in many ways. The presence of the canal and the very important commercial and trade activities that it brings have caused the economy of Panama to evolve into one dominated by services and trade. Manufacturing GDP is around 10 percent of the total, and banking and services activities are well developed. Politically, Panama has been influenced considerably by military governments.

\section{ENERGY OVERVIEW}

\section{A. Introduction}

Energy use in Central America depends mainly on fue 1 wood and $0 i 1$ products, with a rapid, but sporadic, growth in electricity use. Patterns of energy use go hand in hand with per capita income; e.g., the people of Costa Rica and Panama, the higher income countries, consume relatively more oil and electricity and less wood per person. This pattern of consumption arises from the dual nature of the economies, with the traditional rural sector relying most on fuel wood for energy and the industrialized urban sector relying on commercial fuels.

The countries of Central America are blessed with a large endowment of energy resources that has helped them to reduce their oil dependence and $c$ an be counted on to foster their economic growth. They already have a substantial 
reliance on indigenous fuel wood and hydroelectric energy. El Salvador and Nicaragua produce electricity from geothermal energy, and such energy is under development in Costa Rica and Guatemala. Guatemala is an oil producer. Costa Rica and Panama have known peat deposits, and all others have potential for peat deposits. Costa Rica has proven coal resources, and most have potential for wind and solar development.

\section{B. Energy Resources}

1. 0 il and Gas. Guatemala is the only Central American country with proven oil and gas reserves. Serious exploration in the country began in the 1950 s, and the first production was in 1974. Daily production has averaged 3000 to 5000 barrels during the last two years from a total of eleven wells in the four fields, Chinaja Oeste, Rubelsanto, Caribe, and San Diego. Production may increase substantially in 1986, possibly to 4000 to 6500 barrels per day or more.

In Guatemala, exploration is carried out exclusively by private companies. A new hydrocarbon law was recent7y enacted, and the first new contract under the law was signed with Exxon in August 1985. Under the terms of the contract, Exxon is committed to spend $\$ 30$ million US during the first exploratory phase of this contract. Several other private companies are active in Guatemala. Hispanoil is the prime operator for all of the currently operating wells. A total of at least 71 significant wells has been drilled in Guatemala from the 1950 s through January 1984. Although there are many encouraging developments, exploratory activity has been slowed recently, and several areas have been abandoned.

The level of oil exploration in the other countries has been significantly lower. Private activity in the twentieth century has comprised the following: 28 wells drilled in Honduras (all with the possible exception of one well were abandoned); 22 significant wells in Costa Rica; and 32 in Panama. No oil wells have been drilled in El Salvador.

Responsibility for oil exploration differs from country to country. In Costa Rica, oil exploration is the exclusive right of the state. Refineria Costarricense de Petroleo, S.A. (RECOPE), the national oil company, is carrying out an exploratory and data-gathering project of the sedimentary basins of the country and has drilled 3344 holes totaling $88,000 \mathrm{~m}$ since 1982. RECOPE, with technical assistance from the Mexican national oil company, PEMEX, drilled one deep stratigraphic test we11. Costa Rica has received financial assistance from the World Bank for oil exploration. Since 1981, the country's legislature has been considering a hydrocarbon law that would increase private participation in 
oil exploration, but no final decision has been made by Congress with respect to this law.

In Panama, private oil companies were active through 1981, but in that year a new hydrocarbon 1 aw was being considered and applications for offshore acreage were pending. With a $\$ 6$ million loan from the World Bank, the Panamanian government, through the Bureau of Mines, is reassessing the petroleum potential of the country.

In Honduras, exploration is performed exclusively by private companies. The Honduran General Directorate of Mining and Hydrocarbons (DGMH) also has a $\$ 6$ million loan from the World Bank to organize existing exploration data and to promote exploration in the country. A law that would allow for private exploration under risk contracts was passed by the Honduran legislature in late 1984.

The Lempa River Hydroelectric Commission (CEL), the national utility of El Salvador, has a hydrocarbons branch but does not perform exploration. CEL has recently attracted bids from private companies for offshore exploration, although the results of this first round of bids are not particularly encouraging.

2. Coal. The only country known to have a coal deposit that is of possible commercial quality is Costa Rica. The three potential areas are Volio, Venado, and Zent. As of 1983, the Sectorial Directorate of Energy (Direccion Sectorial de Energia--DSE) reported that Costa Rica had proven reserves of approximately 2.5 million tons and total resources (proven plus possible plus probable) of 8.8 million tons. Most of this is presumably sub-bituminous coal around Volio, where the most exploration had been done.

Panama is considered to have favorability for coal resources in the region to the south of the Volio deposit of Costa Rica. The Panamanian national utility, Hydroelectric Resources Institute (Instituto de Recursos Hidraulicos y Electrificacion--IRHE), has performed limited investigations of the coal potential of this region in the Bocas del Toro province.

In El Salvador, CEL undertook preliminary exploration with the assistance of the Latin American Energy Organization (OLADE) and some German geologists and discovered several small deposits that contained negligible amounts of coal.

No coal exploration has been carried out in Honduras or Guatemala since 1977, when a MITRE Corporation report ${ }^{1}$ stated that $15 \mathrm{million}$ tons of lignite exist in the Ocotopeque province in Honduras. According to Bohnenberger and Dengo, ${ }^{2}$ Honduras has three locations with Cenozoic coal beds over $1 \mathrm{~m}$ in thickness--Rio Frio (Laguna Seca) in the 01 ancho department, El Pataste in the El Paraiso department, and El Chile in the Francisco Morazan department. 
Lignite beds over $1-m$ thick also exist in the Francisco Morazan department at Sabana Grande near Rancho Maldonado.

Guatemala has occurrences of lignite and peat in southwestern Peten. According to Bohnenberger and Dengo, ${ }^{2}$ these deposits are not known to be as much as 1 meter thick.

3. Peat. Brief peat reconnaissance missions have been carried out in Costa Rica and Panama. Costa Rica is considered to have good potential for significant peat deposits. In the limited exploration that has been done, three sites have been examined: the Rio Medio Queso flood plain on the northern border, the Talamanca Mountain cloud forest region, and a small site on the northeastern coastal plain near siquirres. A peat reconnaissance program will be conducted by RECOPE with assistance from Los Alamos National Laboratory (LANL) to better define Costa Rica's peat resource.

During a brief mission to Panama, LANL peat experts determined that the low-lying Atlantic coastal region probably has great potential for exploitable peat deposits. A deep deposit in the Changuinola area of good quality peat was recently discovered, and other exploitable deposits are expected in the Bocas del Toros region.

No peat exploration has been carried out in Honduras or El Salvador, but exploitable peat deposits are expected. Guatemala is known to have peat and lignite deposits in the southwestern Peten area, as was mentioned above. Preliminary studies in Belize by LANL scientists suggest the potential for large deposits there.

4. Hydroelectric. Along with biomass and geothermal, hydroenergy constitutes Central America's major energy resource, and hydroenergy shares the important characteristic of being renewable.

In 1980 the Economic Commission for Latin America (ECLA) summarized the hydroelectric potential. From studies done through the 1970 s for the five countries, ECLA estimated the potential installed capacity at almost 24,700 MW and an annual average energy production of more than 100,000 GWh. More recent information obtained from individual electric utility reports set the potential installed capacity at a more conservative 18,000 MW.

Perhaps the most important achievement in Central America during the past 15 years has been development of most of the region's hydroelectric capacity in existence today, which has led to a more than tripling of the electricity generated from this source. In 1970 the installed hydroelectric capacity in those countries was approximately $400 \mathrm{MW}$, and the annual hydroelectric generation reached some 2232 GWh. In 1984, the installed capacity was a little more than 
$2000 \mathrm{MW}$, and over $7000 \mathrm{GWh}$ was generated in a single year. This effort has consumed a significant share of public investment in these countries--more than $\$ 3$ billion US has been invested by public utilities in the past 15 years.

5. Geothermal. Another significant achievement in the electrical sector has been the rapid development of geothermal resources, which were completely undeveloped until 1975 when the first geothermal plant started operating in Ahuachapan, El Salvador. During the 10 years since, every country has become interested and involved in the assessment and development of these important resources. Given the countries' difficult financial situation, geothermal energy appears attractive because its kilowatt-hour cost is competitive with hydroelectric and it allows for development of smaller, less expensive projects that better match the demand curve and system size.

CEL has explored the geothermal resources of El Salvador, delineating five areas that have potential for electricity generation. They are Ahuachapan, which has been in production since 1975, Chipilapa, Berlin, Chinameca, and San Vincente. A range of estimates for El Salvador's geothermal potential is between $270 \mathrm{MW}$ and $4140 \mathrm{MW}$, with an average of $1080 \mathrm{MW}$. Currently, CEL and LANL are developing a joint program to examine why the Ahuachapan Plant has decreased output recently.

Systematic geothermal exploration has yet to be done in Costa Rica. Feasibility studies have been performed at Miravalles, which is under development, and prefeasibility studies were done at Pailas-Rincon de la Vieja. At least four other geothermal locations are known to exist. Until systematic reconnaissance has been carried out, an estimate of geothermal potential cannot be made for the country. Along these lines, ICE and LANL have recently begun a we1l-logging effort at Miravalles to help estimate the development potential of that site. Miravalles is being developed with technical assistance from the Japanese and financing from the Inter-American Development Bank (IDB).

Geothermal exploration in Guatemala in the early 1970s identified more than 10 areas that were thought to have steam fields. More intensive exploration focused on three areas that were later narrowed to two--Zunil and Amatitian, and the national utility, Instituto Nacional de Electrification (INDE) was given the responsibility for exploration of these fields. The potential of Zunil is estimated at a minimum of $50 \mathrm{MW}$, and there are plans to begin power production in the near future. Amatitlan has received less attention, and the geothermal potential is uncertain. INDE and LANL are now involved in an analys is of the potential for direct-heat uses of geothermal energy. The Amatitlan site is ideally located near industries that currently use diesel oil and fuel oil for 
direct-heat applications. A demonstration project is planned for the future. Because Zunil already has wells available, the first direct-heat demonstration is hoped to be constructed there. As geothermal exploration expands north toward the town of Quetzaltenango, industrial direct-heat uses are expected to become feasible.

The Honduran geothermal resources are now being explored by National Electric Power Company (ENEE) geologists with assistance from LANL. Both geophysical and geochemical analyses have been completed on six sites and the preliminary results are positive for three: Platanares, San Ignacio, and Azacualpa. Additional reconnaissance is required before firm potential electric generation estimates can be made.

The limited geothermal exploration in Panama has concentrated on the BaruColorado complex in the northwest. An IRHE-IDB-OLADE geothermal advisory panel has advised that the El Valle de Anton region in the northern part of the country may have promise.

6. Fuel wood. Fuel wood has traditionally been the primary fuel utilized in Central America owing to the rich endowment of forest resources that has characterized these countries until recent times. As a matter of fact, Central America shows the highest use of biomass within its energy supply of all countries in Latin America, both in the household as well as the industrial sectors.

The last decade has been characterized by an increased awareness of potential firewood resource problems in a growing number of areas, and from this awareness has evolved a better understanding of the situation in each of the Central American countries. In 1981, the Food and Agriculture Organization (FA0) prepared maps showing supply and demand conditions for firewood in Central America with the objective of identifying present and potential critical areas as well as zones with excess supply. At the same time, FAO estimated the amount of dense forest cover remaining as well as deforestation rates for the countries under consideration. Dense forest cover represents about 59 percent of total 1 and area in Guatema 1a, 37 percent in Panama, 53 percent in Honduras, 40 percent in Costa Rica, and 22 percent in El Salvador. The rate of deforestation is highest in Costa Rica, equal7ing 1.3 percent of the total 1 and area per year. The rate is 0.8 percent in Guatemala and Honduras and 0.5 percent in Panama. ET Salvador has the slowest rate of deforestation, only 0.2 percent. Even though El Salvador's rate of deforestation is lowest, the country has one of the greatest fuel-wood problems.

7. Vegetable Residues and Products. A variety of vegetable residues provide energy in Central America. These include sugar cane bagasse (by far, the 
largest energy source among the different types of vegetable wastes), coffee husks, rice hulls, and African palm oil shells. In general, agricultural processors burn these waste products to generate heat for their operations. In addition, some sugar refineries use bagasse to generate electricity used within the sugar mi11. The main vegetable product with potential for energy generation is sugar cane, which is used to produce fuel ethanol. Two countries at present produce ethanol from sugar cane--Costa Rica and El Salvador--and Guatemala has plans for a distillery installation.

AID recently supported a study of cane energy potential in Central America, and the following summarizes the results. ${ }^{3}$ The estimate of energy potential is based on the following assumptions: sugar exports and internal consumption remain constant at 1984 levels; lands devoted to sugar cultivation are not expanded but are more intensively planted; 15 tons of field residues are collected for combustion per every 100 tons of green cane harvested; and mills in the five countries under consideration are used at 100 percent of capacity rather than the 1984 average of 72 percent. A total of 17 distilleries could operate in the region to produce about $100 \mathrm{million}$ gallons of ethanol. If old, inefficient boilers are replaced with new, high pressure equipment, approximately 450 MW of electric generating capacity could be supported by utilization of bagasse. ${ }^{3}$ This represents over 10 percent of the region's electric generating capacity.

\section{Summary of Energy Resources}

The use of energy resources in Central America has been influenced by the easy availability of fuel wood for energy uses in the rural household sector and by the technology of more developed countries that relied heavily on oil products for electricity generation and for transportation and industry. Whereas these two sources were abundantly available and inexpensive, the hydroelectric resource developed at a very slow pace.

However, because of 0 il price increases, more attention has been given lately to the development of hydroelectric resources as well as to geothermal and other renewable sources of energy.

The predicted scarcity of fuel wood has increased the interest in this resource because of the social implications for the vast majority of low income rural inhabitants. Even though there are few quantitative assessments of this resource, it is apparent that there has been an increase in the deforestation rate, resulting in a sharp decrease in the dense forest cover, particularly in El Salvador and Costa Rica.

0 il exploration has been carried out in the five countries, but only Guatemala has been able to produce a small amount of oil. Exploration continues 
in Costa Rica and Guatemala, and it is expected that in the near future El Salvador and Panama will initiate exploration. However, with the exception of the oil reserves in Guatemala, there are no proven $0 i 1$ reserves in the region.

It is expected that interest in geothermal energy will continue to grow and that more detailed investigations will be made, including studies of the use of this resource for industrial process-heat applications. At present, the electric generation expansion programs of El Salvador, Guatemala, and Costa Rica call for the installation of $400 \mathrm{MW}$ of geothermal capacity within the next twelve years, and Honduras is still determining its needed generating capacity.

Hydroelectric programs constitute the base for electric generation in the five countries, with capacity additions of more than $800 \mathrm{MW}$ in the region planned through the year 2000. Overcoming logistics engineering, systems planning, and financial barriers will be necessary to carry out this ambitious program.

At present, only Costa Rica shows proven reserves of commercial coal deposits, even though it is expected that future exploration may show positive results in Panama, Honduras, and Guatemala.

Increased use of vegetable wastes and products, particularly sugar cane and bagasse, could provide significant energy resources. Price incentives to ethanol production depend on the world prices of gasoline and sugar. The amount of electricity generation by sugar mills will be heavily dependent on incentives to cogeneration.

Most of the countries have undertaken serious efforts to analyze the possibilities of using wind as an energy resource, but, because of the lack of reliable data, it is not anticipated that significant development of these resources will occur in the near future. The same is true of solar energy, a1though some applications of solar energy exist.

Most countries have taken steps toward definition of their energy resource base. Resource definition followed by sound development and conservation of energy (both indigenous and imported) is of utmost importance to future growth of the Central American countries.

\section{Energy Supply}

A significant portion of the region's energy comes from fuel wood, an indigenous resource that is becoming increasingly scarce. As growth and development have occurred, demand for petroleum derivatives and electricity have increased, a pattern exhibited by developing countries in general. Figure 4 illustrates these changes in final demand that have taken place since 1970 . The 


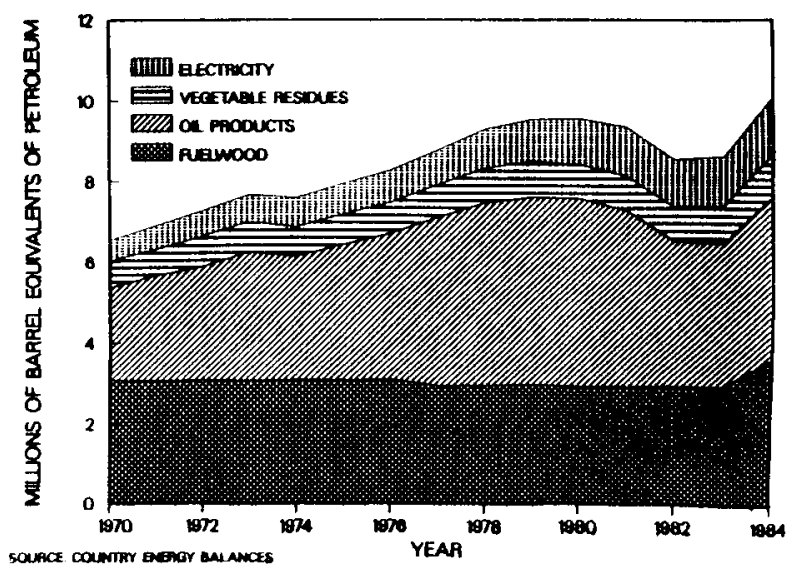

Costa Rica

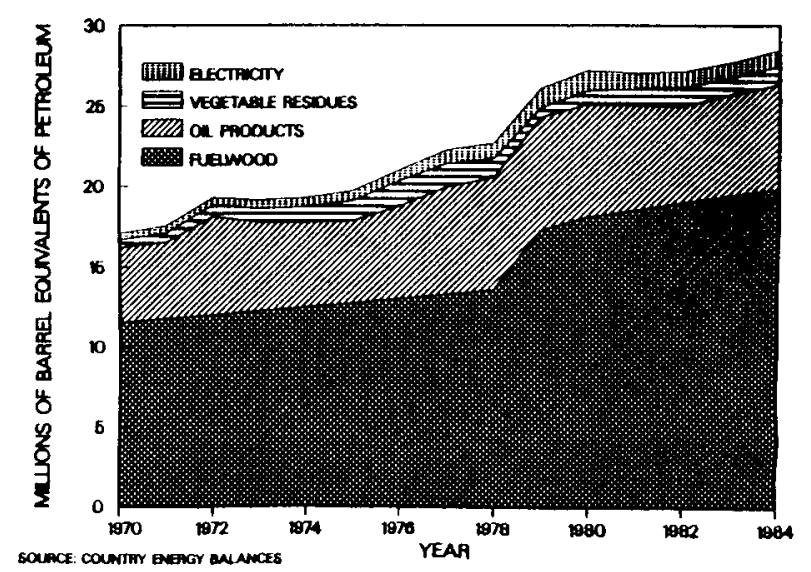

Guatemala

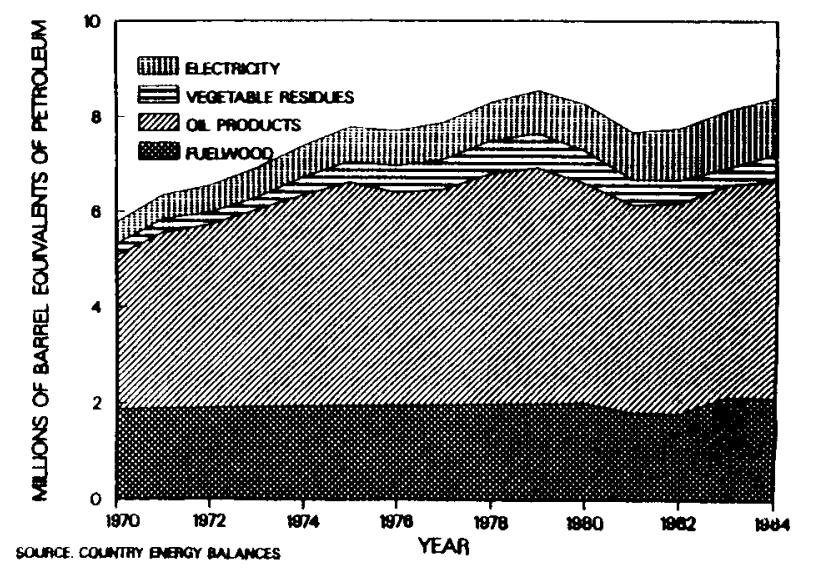

Panama

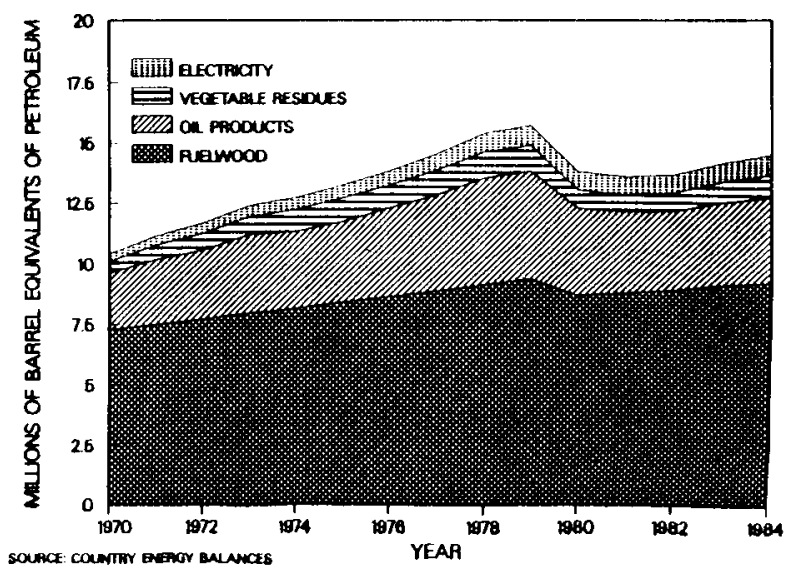

El Salvador

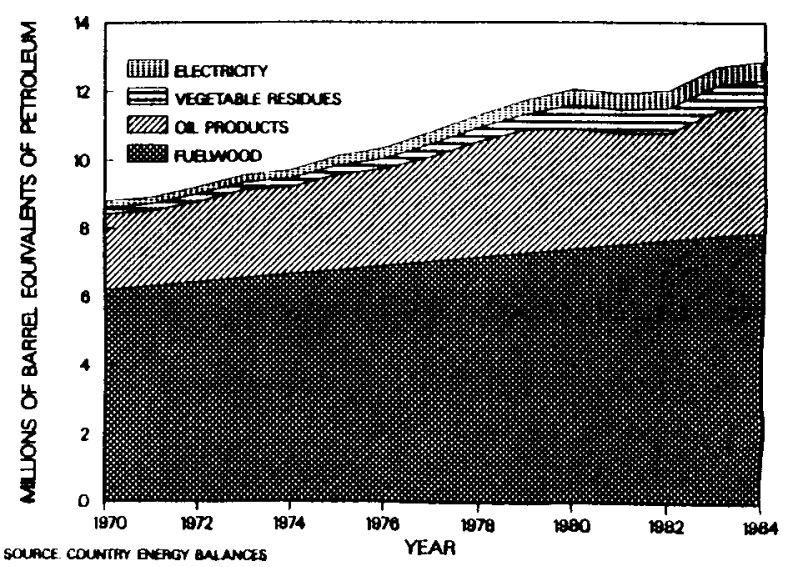

Honduras

Fig. 4. Energy supply for the five countries by fuel type, 1970-1984. 
figures also illustrate the striking differences among the countries: El Salvador, Honduras, and Guatemala derive approximately 70 percent of their energy from fuel wood whereas Panama and Costa Rica rely far more on oil products and electricity. The changes that have taken place in supply and the implications of these changes will be discussed in this supply section.

1. 0il. In 1984, crude $0 i 1$ and petroleum derivative imports to the region amounted to approximately $30 \mathrm{million}$ barrels equivalent of petroleum at a net cost of almost $\$ 850$ million US. This $0 i 1$ was imported from Venezuela and Mexico under the San Jose Accord. The oil import bill almost doubled between 1978 and 1980 , when it peaked at approximately $\$ 1.1$ billion US.

The costs of oil imports are comparable for all countries in the region, averaging between approximately $\$ 150 \mathrm{million}$ and $\$ 200 \mathrm{million}$ between 1978 and 1984. The exception is Panama, where the costs generally have been about a factor of two greater than the above average since 1978 (see Figs. 1 and 5).

The countries must pay oil import bills with hard currency that is usually gained through international loans or exports. The percentage of export earnings required to pay the oil import bill is shown graphically in Fig. 2. The oil price shock of 1973 manifests itself strongly: the percent basically doubled for all countries. Most countries were also hard hit by the 1979 price increase. El Salvador, Costa Rica, and Guatemala all spent the equivalent of about 15 percent of their export earnings on the $0 i 1$ bill in 1983, Honduras is estimated to have spent more than 20 percent, and Panama, less than 5 percent.

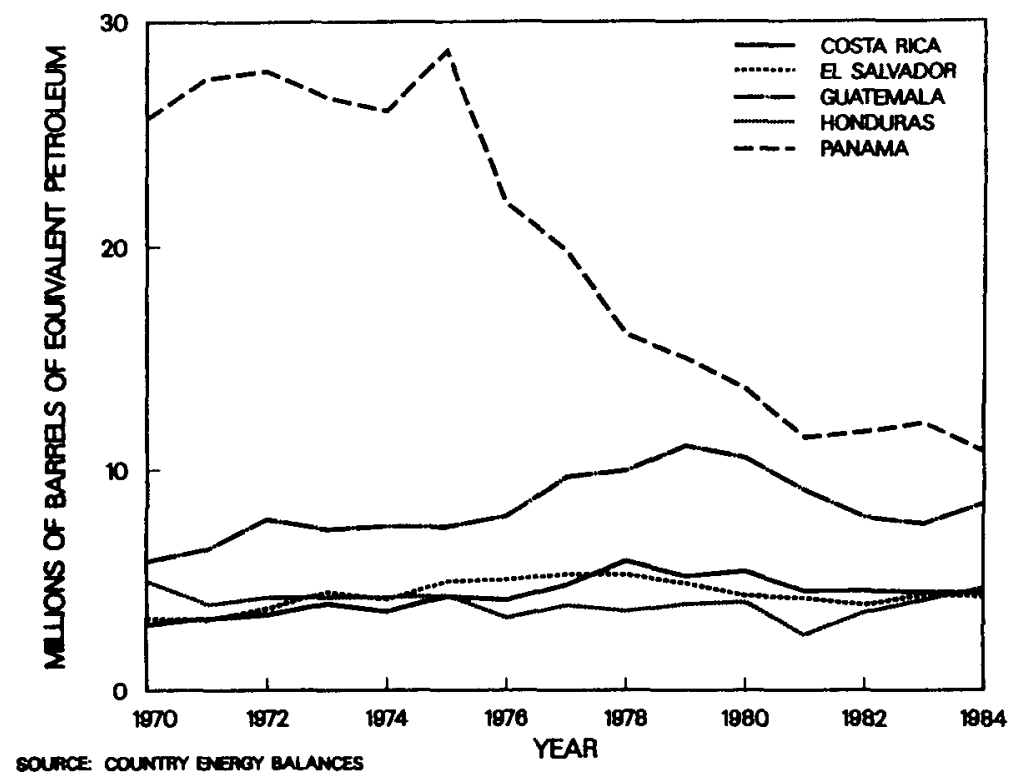

Fig. 5. Quantity of petroleum imports. 
Between 1970 and 1984, the quantity of 011 products supplied has increased at a compound annual rate ranging from 2.2 percent per year in Guatema 1 a to 4.0 percent per year in Costa Rica. As a percentage of total energy supply (commercial plus noncommercial), oil products have not changed dramatically between 1970 and 1984. As a percent of commercial energy supplied, the oil product share has generally decreased between 1970 and 1984 as the share of electricity has increased.

Internal consumption of petroleum products for the countries in question stood at approximately 90,000 barrels per day in 1984. With the rapid dieselization process that has occurred in some countries, notably Honduras and Costa Rica, the structure of petroleum products generated by the refineries in the countries are generally inadequate to meet demand. The existing refineries in Central America, with the exception of the 80,000-barrel-per-day Texaco refinery in Panama that refines oil for export, are small atmospheric distillation units that range from 12,000 to 17,000 barrels per day. These refineries have little, if any, secondary processing capabilities. Therefore, the structure of refined products is heavily influenced by the characteristics of the crude oil processed, and it has become virtually impossible to bridge the gap between the composition of demand and that of domestically refined products. In 1982 , the composition of domestically refined products was only 20 percent gasoline, 35 percent diesel, and 45 percent fue 1 oil and other products, whereas demand was composed of approximately 30 percent gasoline, 40 percent diesel and 30 percent heavy products.

In the early 1970s, domestically refined products supplied virtually all of the countries' needs. But as $0 i 1$ demand has grown and refineries' competitiveness has declined relative to large, efficient refineries built in the Caribbean during the 1970s, the import of final products has increased. With the exception of Panama, where the refinery supplies virtually all of domestic needs and produces for export, domestically refined products generally supply approximately one-third to one-half of total product supply.

By 1984 , oil products constituted about 25 percent of final energy supplied in El Salvador, Honduras, and Guatemala, over 40 percent in Costa Rica, and about 50 percent in Panama (See Fig. 4). In addition, a significant amount of $0 i 1$ was used to produce electricity in Guatemala during repair of the Chixoy hydroelectric plant tunnel, and in Panama.

If commercial and noncommercial energy (fuel wood) are considered separately, as is usually done in discussion of energy supply of developing 
countries, oil plays a much larger role, comprising approximately 60 to 90 percent of the countries' commercial energy supply in 1984. In 1984, the percentage of total commercial energy supply constituted by oil products varied significantly. In general, the percentage of commercial energy supplied by $0 i 1$ depends on the degree of electrification in the country and whether vegetable residuais are an important component of supply.

The main oil products supplied are those required in transport (mainly diesel and gasoline) and those consumed by industry (mainly fuel oil).

Whereas the state has played a dominant role in all the countries in Central America in the electrical sector, the situation in the petroleum sector is quite different, with a strong and dominant participation of the private sector in both the refining and distribution of oil products. Costa Rica is an exception: RECOPE, the state-owned petroleum company, operates the country's only refinery, handles the import of crude oil and refined products, and operates over 800 kilometers of small pipelines for distribution of petroleum products within the country.

Because of the strategic character of the petroleum sector, there is state control over prices of oil products and purchases of crude oil. In most countries, crude oil purchases through the San Jose Agreement are controlled by the state, which then resells to the refineries. In all cases, the role of central banks to allocate foreign exchange for crude oil purchases is critical. At the same time, central banks have been the primary beneficiaries of the credits allocated through the San Jose Agreement. Only a small percentage of these funds have been utilized for energy development projects.

2. Fuel wood. Assessment of fuel wood and other biomass supply in quantitative terms presents some difficulties. In the past, fuel wood was traditionally available in such ample supplies relative to the population density that it was mostly appropriated directly by the users without going through market transactions and without passing through national income accounts or a well-defined supply sector. The lack of this supply sector, which in the cases of petroleum and electricity constitutes the information-generating nucleus, helps explain the lack of accurate statistics for fuel wood and other noncommercial sources of energy.

In recent decades the combined effects of population growth and deforestation have placed significant pressures on the resource base and have led to questions about the long-term supply picture for fuel wood. Additionally, the coffee-growing regions of Central America have used the prunings of the coffee plants and their shade trees to provide considerable quantities of woody biomass 
on a renewable basis. Recent introduction of shadeless coffee plants, with higher productivity of coffee per area, may have some impact on the fuel-wood supply, given the smaller size of the coffee plants and the lack of shade trees. However, no quantitative data exists to estimate the potential effect.

To help fill the fuel-wood data void, with support from AID through its "Fuel wood and Alternative Energy Sources" program, CATIE carried out a series of socioeconomic surveys to identify "critical areas" and "potential critical areas" for fuel-wood supply. Regions within each country were categorized in three groups: (1) areas with abundant resources and without supply problems, (2) areas with abundant supply but with rapidly growing population, and (3) areas with scarce wood resources and relatively high population densities. Category 1 includes the Colon, 01 ancho, and Gracias a Dios regions of Honduras as well as all of Panama. Category 2 includes all of Costa Rica and parts of Honduras. Category 3 includes the entire country of El Salvador and most of Guatemala, with the exception of the Peten region. ${ }^{4}$

3. Electricity and Utilities. The electrical sector in most of the Central American countries started to take its present form during the $1950 \mathrm{~s}$ when governments established national agencies responsible for development of the power system and the utilization of natural resources for purposes of electrical energy generation. The creation of ICE in Costa Rica in 1949 marks the beginning of this process, which continued throughout the region.

In their initial steps national agencies acquired and integrated many of the small companies that provided services to small cities and villages throughout the countries. With support from international development agencies, especially the World Bank and the IDB, power companies in the 1960 s started to develop stronger generating systems that allowed for quality improvements in the services provided. In Panama, IRHE was founded during those years, and in general the same pattern followed in the rest of Central American countries.

A7so, during the 1960 s the Central American Common Market started to grow, and the local markets were supplied with products manufactured within the region as a by-product of import substitution strategies, which were part of the economic justification of the integration process. The installation of these new industries and the improvement in the general economic conditions throughout the region led to capacity constraints on the utilities. Demand started to grow at annual rates that in most countries exceeded 10 percent, reaching levels between 10 and 25 percent for the commercial sectors and between 8 and 24 percent for the industrial sector. 
The heritage of considerable thermal generation in the region was laid during the 1960s, as Central American utilities expanded their power system with oil-fired generating units. This decision was due primarily to two factors: very rapid installation periods and very low operating costs that resulted from the low cost of $0 i 1$ at that time. In Panama the dominant factor in demand increments was caused by increases in international trade flowing through the Canal and the considerable demands for air conditioning created by the establishment of an international banking system there.

At the start of the 1970 s total installed generating capacity in the Central American countries stood at approximately $800 \mathrm{MW}$. In 1984, the installed capacity had increased to approximately 3200 MW. Whereas in 1970, thermal generation capacity accounted for almost 55 percent of the electrical energy consumed, by 1984 it had decreased to less than 28 percent. The resulting reduction in dependence on petroleum for electrical generation is one of the most positive developments in the Central American energy situation and one that has had a considerable impact in terms of global levels of indebtedness. In the countries that have developed large hydroelectric capabilities, this item's cost tends to dominate public investment and foreign debt.

Another important achievement of the Central American electric utilities through the 1960s and 1970s was their consolidation as highly professional and technically oriented governmental agencies. The systematic planning of the power systems and the development of hydroelectric resources that had started during the middle 1960s was bolstered by the first oil price increase in 1973. More detailed attention was given to the different stages of exploiting hydroelectric resources, and efforts were devoted to estimating potential resources and to the different stages of project evaluation. Interest in geothermal exploration and development has also been high in Costa Rica, and recently in Honduras and Guatemala as well. In El Salvador the analysis and development of the Ahuachapan geothermal field was accelerated, and with the third unit installed in 1982, total geothermal capacity reached 95 MW.

Utilities were able to react to the economic crisis that started in 1979 because of the level of organization and professionalism that they have cultivated for many years. When the first efforts were made throughout the region to focus on a global analysis of the energy sector, these electric utilities were designated by the governments to carry out global energy planning activities. In most countries these responsibilities have now been passed to Energy Ministries, but even today in El Salvador and Panama, the electric utilities remain as the lead institutions of the energy sector. 
In percentage terms, electricity has continued to be the fastest growing of all the energy forms in Central America. Growth rates were particularly high between 1970 and 1980, with the electricity supply to the final consumer growing at an average rate of over 9 percent per year (Table 2). During this period, most of the utilities were either constructing or planning large expansions based on the assumption that demand would continue to increase at a rate of 8 percent or more per year. By comparing the percentages in the 1970-1980 column of the table with those in the 1980-1984 column, a drastic reduction in energy use occurred owing to the economic recessions experienced by these countries and the armed insurgency in El Salvador.

With the recent commissioning of several new large hydroelectric projects such as El Cajon in Honduras, Fortuna in Panama, and Chixoy in Guatemala (Table 3), Costa Rica, Panama, and especially Honduras have temporary excess capacity.

The dramatic shift from reliance on thermal power plants to hydroelectric plants is illustrated in Fig. 6, and the large additions to hydroelectric capacity between 1970 and 1983-1984 are also apparent. (The effect of El Cajon, which came on line in 1985, is omitted from this figure.) Through their investments in hydroelectric capacity and, in El Salvador's case, geothermal capacity, the Central American countries have significantly decreased dependence on oil products to generate electricity (Fig. 7).

In 1984 the five countries together consumed 1.17 million barrels equivalent of petroleum (BEP) of diesel $0 i 1$ and 2.35 million BEP of fuel oil to

TABLE 2

ELECTRICITY SUPPLY GROWTH RATE TRENDS

(Compound annual average)

\begin{tabular}{|c|c|c|c|c|c|c|}
\hline \multirow[t]{2}{*}{ Beginning in: } & \multicolumn{3}{|c|}{1970} & \multicolumn{2}{|c|}{1978} & \multirow{2}{*}{$\frac{1980}{1980-198}$} \\
\hline & $1970-1978$ & $1970-1980$ & $1970-1984$ & $1978-1980$ & $1978-1984$ & \\
\hline Costa Rica & 8.4 & 8.3 & 7.3 & 7.9 & 6.1 & 5.2 \\
\hline El Salvador & 10.7 & 9.0 & 6.8 & 2.4 & 1.8 & 1.5 \\
\hline Guatemala & 11.5 & 10.4 & 6.0 & 6.0 & -0.9 & -4.1 \\
\hline Honduras & 8.1 & 9.1 & 7.8 & 13.1 & 7.6 & 4.9 \\
\hline Panama & 7.8 & 8.1 & 7.1 & 9.4 & 6.2 & 4.7 \\
\hline
\end{tabular}


TABLE 3

RECENT NEW HYDROELECTRIC PROJECTS

\begin{tabular}{|c|c|c|}
\hline Project & $\begin{array}{l}\text { Size } \\
(M W)\end{array}$ & Date of Commission \\
\hline Arenal-Corobici, Costa Rica & 331 & $1979 / 82$ \\
\hline Chixoy, Guatemala & $250^{\circ}$ & $1983,1986^{b}$ \\
\hline El Cojon, Honduras & 292 & $1985 / 86$ \\
\hline Fortuna, Panama & 300 & 1984 \\
\hline
\end{tabular}

\footnotetext{
Guaranteed capacity is $180 \mathrm{MW}$.

${ }^{b}$ Chixoy has shut down during much of 1984 and 1985 for repair of a tunnel. It resumed operation in 1986 .
}

generate electricity. Table 4 shows that over 60 percent of these products were consumed in Panama in 1983. Panama halved its oil consumed to generate electricity in 1984 when Fortuna came on 1 ine.

In 1984, the percentage of $0 i 1$ imports used to generate electricity ranged from about 2 percent in Costa Rica and about 5 percent in El Salvador to 33 and 46 and 55 percent in Honduras, Guatemala, and Panama, respectively.

The size of expansions in capacity in the near future will be 1 imited by two factors: (1) the excess capacity that has resulted from the relatively large projects that have come on line recently, and (2) the utilities' indebtedness and its impact on their ability to obtain loans for large projects. It can be expected that plants to be constructed in the next 10 years will generally be of about $100 \mathrm{MW}$ or less in size. This is reflected in the expansion plans of most utilities.

4. Key Conservation and Substitution Options. Given the countries' heavy reliance on imported $0 i 1$ and favorable endowment of hydroelectric and biomass resources, it would appear that there are potentially effective substitution opportunities that would reduce the dependence on petroleum. 0il is utilized primarily in the modern sectors of the economy, mostly transportation, industry, and electricity generation. Electricity generation was discussed above.

a. Transportation. As was mentioned earlier, over half of the imported oil is consumed by the transportation sector, which is dominated by road transport in all the countries in question. Therefore, this sector appears to be a critical one for interfuel substitution. However, the transportation 


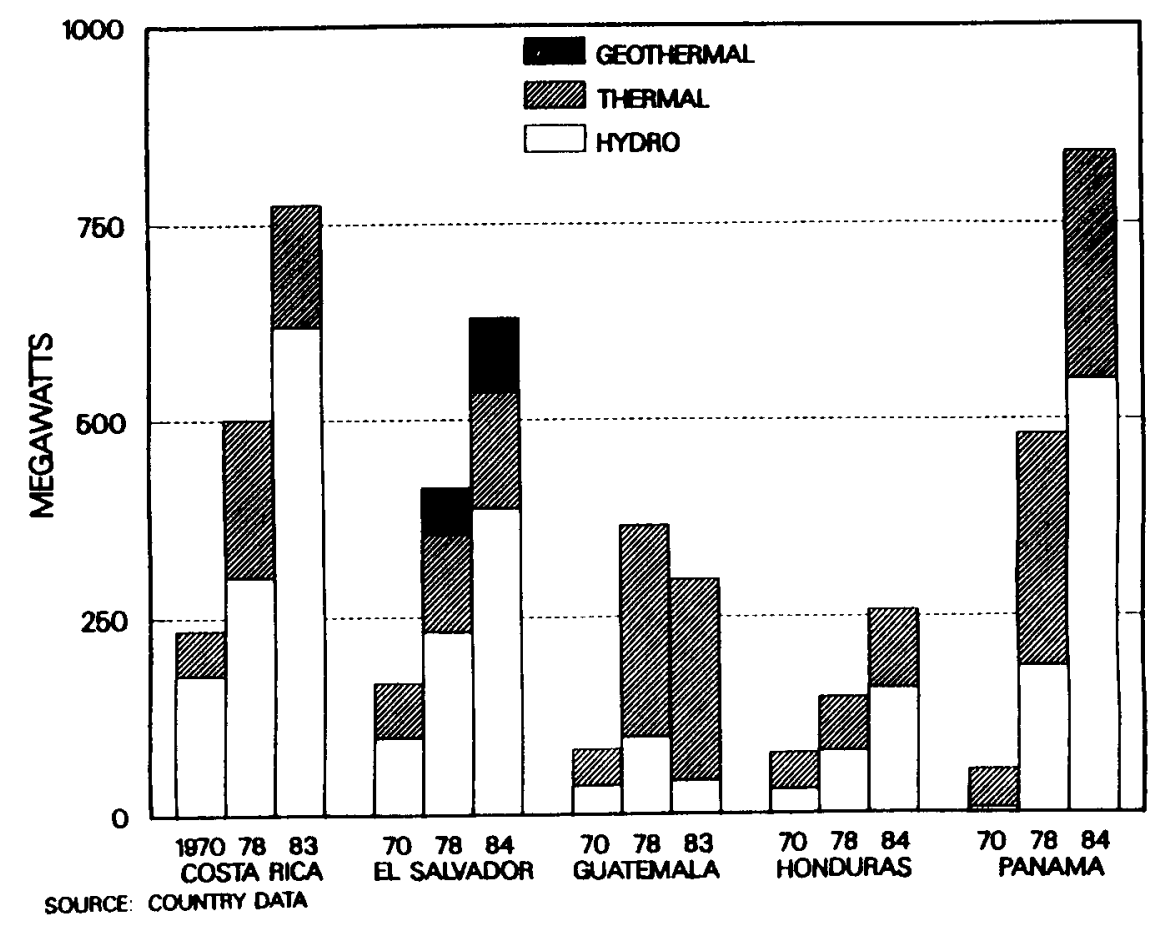

Fig. 6. Installed electric generating capacity.

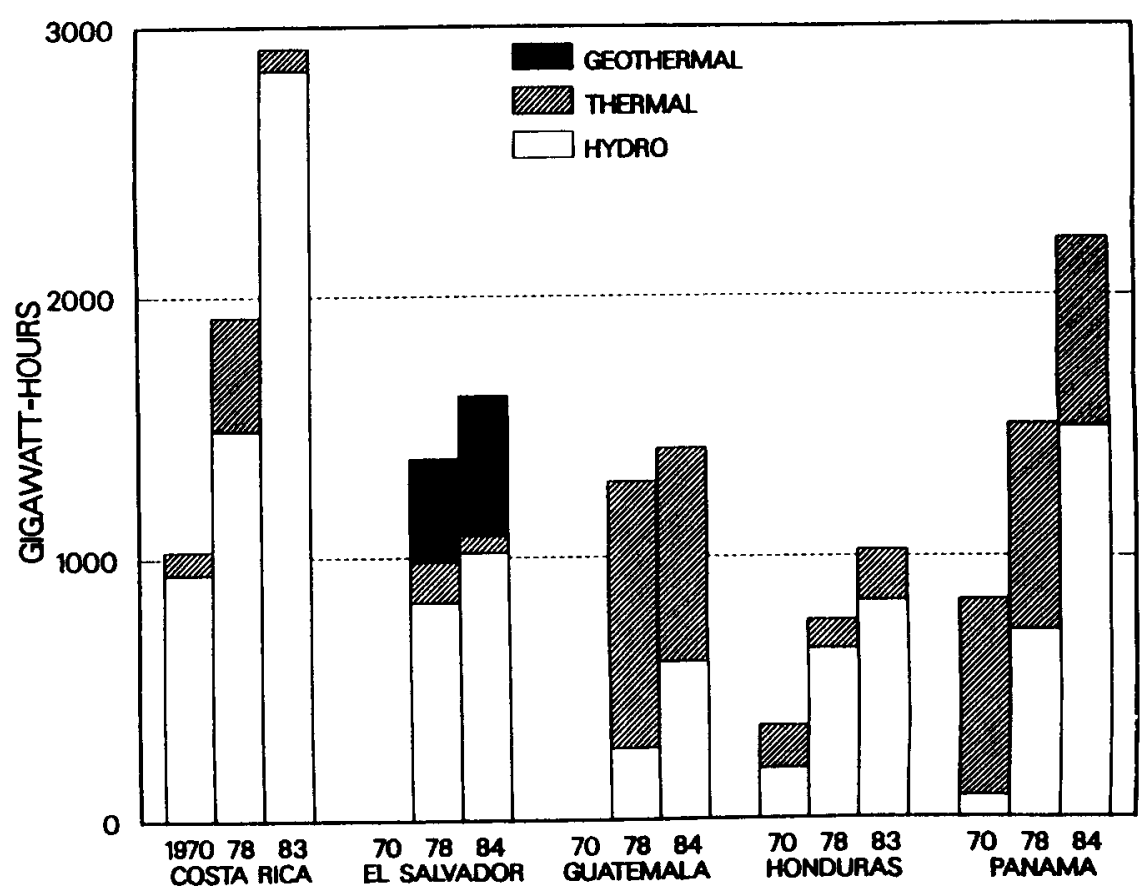

SOUACE: COUNTHY DATA, COUNTHY ENERGY BALANCES

Fig. 7. Total electricity generation. 
TABLE 4

ENERGY USED TO GENERATE ELECTRICITY

(thousands BEP)

\begin{tabular}{|c|c|c|c|c|}
\hline & 1970 & 1978 & 1983 & 1984 \\
\hline \multicolumn{5}{|l|}{ Costa Rica } \\
\hline Hydropower & 651 & 1077 & 1912 & 2155 \\
\hline Vegetable residue & 18 & 19 & 24 & 24 \\
\hline Diesel oil & 121 & 609 & 133 & 4 \\
\hline Fuel oil & 15 & 290 & 1 & 1 \\
\hline \multicolumn{5}{|l|}{ El Salvador } \\
\hline Hydro & 295 & 602 & 724 & 790 \\
\hline Vegetable residue & 30 & 68 & 54 & 55 \\
\hline Geothermal & $\theta$ & 1730 & 2149 & 2175 \\
\hline Diesel oil & 21 & 82 & 51 & 67 \\
\hline Fuel oil & 332 & 293 & 113 & 98 \\
\hline \multicolumn{5}{|l|}{ Guatemala } \\
\hline Hydropower & 187 & 220 & 630 & 473 \\
\hline Vegetable residue & 79 & 617 & 689 & 690 \\
\hline Diesel oil & 302 & 1156 & 286 & 428 \\
\hline Fuel oil & 468 & 1672 & 757 & 950 \\
\hline Crude oil & 0 & 23 & 308 & 483 \\
\hline \multicolumn{5}{|l|}{ Honduras } \\
\hline Hydropower & 137 & 459 & 589 & 616 \\
\hline Vegetable residue & 0 & $\theta$ & $\theta$ & $\theta$ \\
\hline Diesel Oil & 298 & 174 & 229 & 167 \\
\hline Fuel oil & 0 & 44 & 125 & 132 \\
\hline \multicolumn{5}{|l|}{ Panama } \\
\hline Hydropower & 71 & 455 & 664 & 1072 \\
\hline Vegetable residue & 7 & 57 & 287 & 295 \\
\hline Diesel Oil & 313 & 440 & 1020 & 503 \\
\hline Fuel Oil & 1520 & 1313 & 1957 & 1166 \\
\hline \multicolumn{5}{|c|}{ Total for Five Countries } \\
\hline Hydroelectric & 1341 & 2813 & 4519 & 5106 \\
\hline Vegetable residue & 134 & 761 & 1054 & 1064 \\
\hline Geothermal & 0 & 1730 & 2149 & 2175 \\
\hline Oiesel oil & 1055 & 2461 & 1719 & 1169 \\
\hline Fuel oil & 2335 & 3612 & 2953 & 2347 \\
\hline Crude oil & $\theta$ & 23 & 308 & 483 \\
\hline
\end{tabular}

Source: Country Energy Balances.

sector poses peculiar difficulties because of its individualistic nature and of the technological rigidities present as a result of the composition of the automotive fleet. Given these barriers, substitution is limited to liquid fuels, and the only one that has considerable potential is sugar cane-based alcohol. The alcohol can be utilized as an octane booster as part of the refining strategy to be mixed with all the gasoline sold; it can be sold as a separate product known in some countries as gasohol; or it can be sold as an independent 
fuel for specially adapted vehicles. At the present time, only Costa Rica and El Salvador are actively producing large quantities of alcohol from sugar cane. Costa Rica expected to produce over 30 million liters in 1985 for export to the United States. This fuel could also be utilized in the internal market, where it would be sufficient for over 20 percent substitution of all gasoline sold there.

Besides substitution, programs carried out in many countries have demonstrated a considerable potential for conservation and efficiency improvements in this sector through driver training, improved maintenance, radial tires and other measures. These savings have been estimated to be on the order of 15 to 20 percent of total consumption in the transportation sector.

b. Industrial. Ample conservation and substitution options exist in the industrial sector, which consumes up to 25 percent of petroleum imports in the countries of Central America. Commercial energy use is dominated by fuel oil and diesel fuel, with a smaller share going to electricity. Firewood and other biomass residues are also heavily utilized in some industries, such as bagasse in sugar mills. Nevertheless, biomass-based substitution opportunities are the most important option to reduce petroleum dependence in this sector.

The cement industry alone accounts for close to half of the total industrial fuel consumption, and there are a few key substitutions taking place in cement plants in Central America. Costa Rica's INCSA cement factory has successfully substituted palm-0il coconut shell for over 20 percent of its fuel oil consumption. Several other cement plants in Honduras, El Salvador, and Guatemala are rapidly following this lead.

The Regional Industrial Energy Efficiency Project of the Regional Office for Central American Program (ROCAP), AID and the Central American Institute of Industrial Technology and Research (ICAITI) has contributed to the industrial firms' capability to identify conservation and substitution options, but little implementation has taken place. Conservation potential is estimated to be between 10 and 20 percent of total consumption, and substitution outside the cement industry with available biomass residues could cause another 20 percent reduction in fuel use. Therefore, options available to the industrial sector could result in a reduction of petroleum imports in this sector by close to onethird. However, important barriers exist related to the investment required to carry out these options as well as the excess of fuel oil present in the area. Excess supply and pressures from the industrial sector have resulted in fuel oil price subsidies that set a ceiling to conservation and substitution options. 
Industrial cogeneration could also prove to be an important substitution option; however, this alternative is now 1 imited by the fact that most utilities are not allowed to, or choose not to, buy power from private generators. In most cases, legal and institutional changes are required to facilitate this option.

c. Household. The main substitution is that generated by the penetration of rural electrification in some countries, which has resulted in a reduction of the percentage of the population that relies on fuel wood. Nevertheless, pressures from growing total population has resulted in fuel-wood scarcity and price increases. Introduction of fuel-efficient wood-burning cooking stoves appears to be the primary option available to promote conservation of the resource; the substitution of peat for wood may also be a possibility.

D. Energy Prices.

Energy pricing in Central America will be analyzed separately for each one of three main products utilized: fuel wood and other biomass sources, petroleum products, and electricity. There are different characteristics and institutional mechanisms for each one of these sources that justify a separate treatment. In addition, there is a virtual absence of coherent and comprehensive energy-pricing policies that cut across these different products, so individual treatment of the subsector more accurately reflects the prevailing situation.

1. Electricity. Until recent years, electricity prices in the Central American countries had been set to generate the revenue necessary to comply with rate-of-return-on-investment criteria required by major lending institutions, mainly the World Bank and the IDB. Development banks require that electric rates generate sufficient funds to cover operating costs, including service of debt, and provide a reasonable amount of funds to cover expansion programs.

Once these global revenue criteria were attained, electric utilities were free to adjust individual sectorial prices according to governmental and political policies, leading to subsidies from one sector to another, or to differential rates among the different types of users.

During the last decade, the World Bank and IDB have tried to persuade utilities to establish prices for the different types of customers according to long-range, marginal-cost criteria. Although utilities in all five countries considered have carried out marginal-cost-pricing studies, as a result of social and political pressures, only Honduras has applied it, whereas the other four remaining utilities have utilized the studies only as reference points. 
Electricity prices in the five Central American countries have differed not only in the global, aggregate level but especially at the sectorial level because of the mix in generating capacity between hydroelectric and thermal resources and debt payment for investments in generation, transmission and distribution systems. National economic policies have also played an important role. An important factor contributing to frequent price increases has been the recent inflation and devaluation trend that has affected all countries in the region, with differences only in intensity and timing. These factors have caused revenues in terms of foreign exchange to decrease considerably, and electric utilities have seen the debt-service component increase to levels that are becoming unmanageable, making short-term financial criteria the most important factor in establishing electric rates.

Even with this critical situation in most of the countries, price structures still do not reflect the real cost of service to their customers in the different sectors, the widest gap being the one related to the large subsidies to the household sector for low-income, residential consumers.

A general discussion on electricity prices in the countries will be presented in the following paragraphs. However, care must be exercised in interpreting the data, since sectorial classifications vary from one country to another, and current values have been used based on official exchange rates.

The countries can be divided into three groups according to the level of prices: (1) Guatemala and Panama, with the highest average prices for most sectors, reflect their high thermal generation component; (2) Honduras stands at intermediate levels; and (3) Costa Rica and El Salvador, with a more pronounced hydroelectric generation (and geothermal for the case of El Salvador), have the lowest levels of electricity prices.

Prices have almost tripled for the first and second groups of countries since the early 1970s and more than doubled for the third group (see Fig. 8). One of the most dramatic cases of increased price is the one dealing with the industrial sector in Guatemala where prices went from 0.024 quetzales/kWh in 1973 to 0.136 quetzales/kWh in 1984, over a 500 percent increase in a little over 10 years. In general, higher rates of change in prices occurred between 1970 and 1978 than from 1978 to 1984. At the same time, the residential sector is the one that shows the smallest change increments, followed by the industrial and general sectors. Subsidies to low-income, residential consumers exist in virtually all the countries although the levels of subsidies and relative prices vary considerably. 
RESIDENTIAL

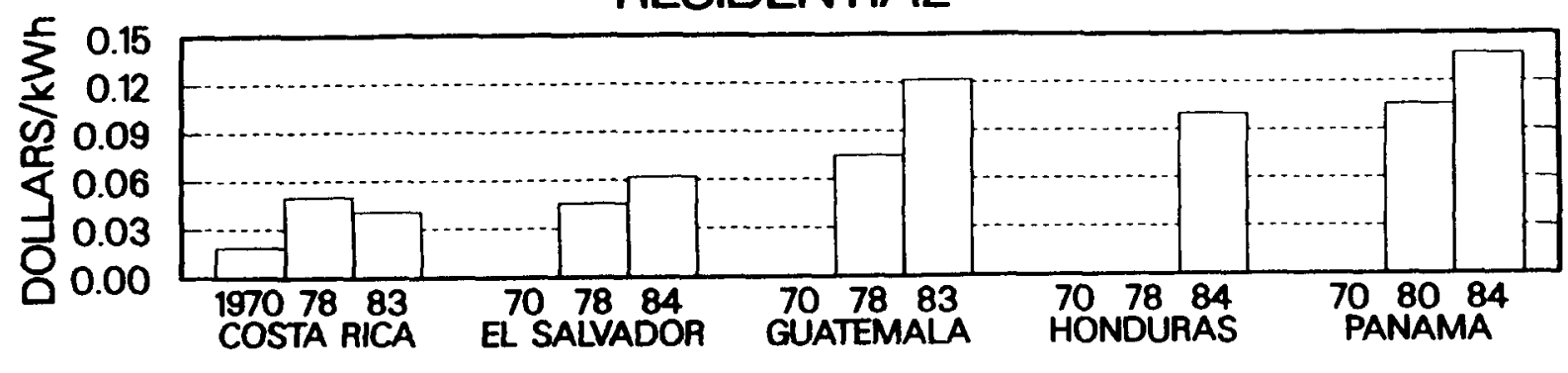

GENERAL

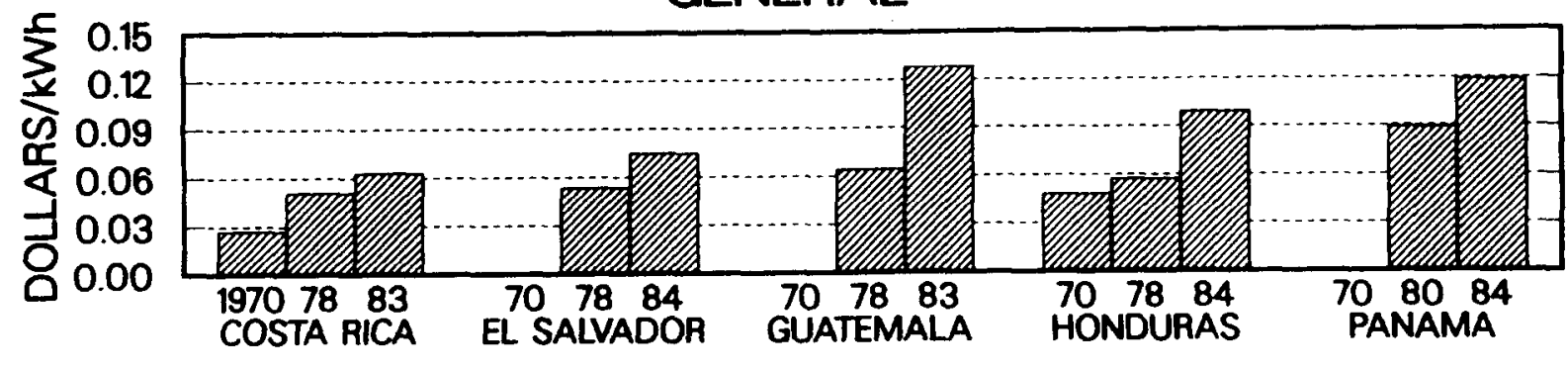

INDUSTRIAL

SOURCE: COUNTRYDATA

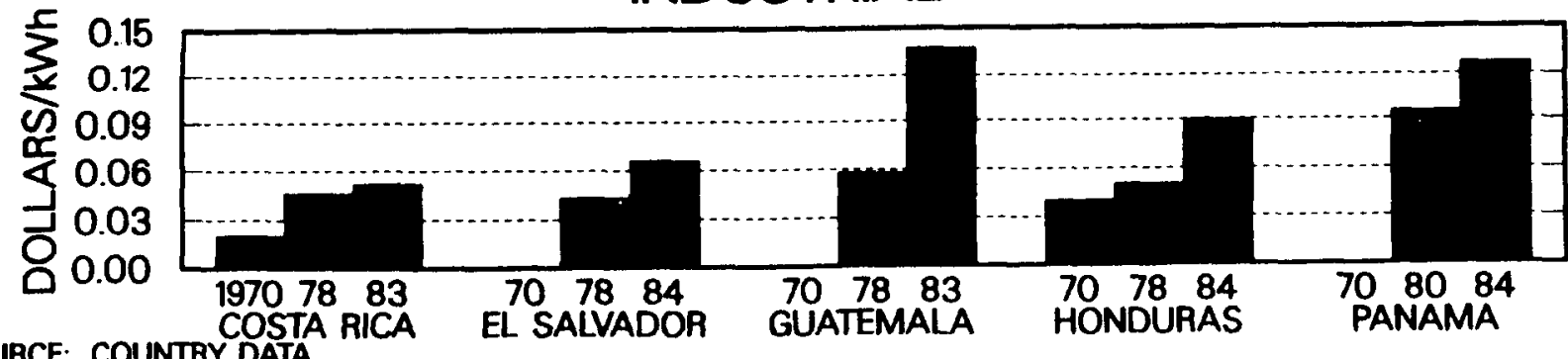

Fig. 8. Electricity prices.

During recent years, utilities in the electrical sectors have tried to structure more coherent rates, penalizing the higher level residential users, and to create incentives for the productive use of electricity. However, political and social considerations still exert a large influence in electricity pricing. This helps explain why the average residential prices are lower than the average industrial prices in Costa Rica, El Salvador, and Guatemala; in Honduras and Panama, the opposite is true (see Fig. 8).

With the commissionings of new hydroelectric power plants in Panama and Honduras in 1984 and 1985, respectively, prices are expected to decrease in these countries. Panama's national utility, IRHE, plans a 15 percent price reduction, and it is expected that ENEE will decrease prices in Honduras to promote electricity use. It is possible that Guatemala may also experience a price decrease when chixoy resumes operation. 
All countries are striving to structure sound electric energy price policies, but there are major difficulties associated with this process for several reasons: there is a need to balance the impact of higher operating costs, higher debt service, and higher investments, which are required to maintain previous levels of availability and quality of service with the subsidization of low-income users in response to political pressures from the governments.

2. Petroleum. Pricing mechanisms for petroleum products have followed different trends in the Central American countries, partly as a result of differences in the institutional frameworks and government policies and partly as a result of global market conditions for oil. In general, pricing of petroleum products did not become an issue until after the first shock in the world oil market in late 1973. After that, the situation deteriorated steadily until 1979, and after the second shock, which came in that year, it acquired crisis dimensions that have lasted almost until the present. Even after the softening of the oil market during the last three years, the situation has not improved significantly because devaluations and inflation have afflicted almost all the countries involved. Therefore, in most cases, current prices of oil products have increased or at least remained constant in these Central American countries in the 1980s. Governments have tended to use decreases in crude oil prices to generate extra revenue rather than to decrease consumer prices.

Historical data on prices of petroleum products are presented in Table 5 and Fig. 9. Although some differences exist in price levels for similar products among the countries, the general trends are fairly common. Once again, care must be exercised in interpreting recent price data because the values shown in the table are based on official prices that do not necessarily reflect the value of foreign exchange in open markets.

a. Guatemala. In Guatemala gasoline prices have been consistently higher than diesel prices by approximately 50 to 60 percent, and this trend has remained constant for the last decade, or until mid-1985, when a devaluation of over 300 percent hit the Guatemalan economy, forcing the country to buy foreign exchange in the free market to pay for oil imports. In general, given the volatile economic conditions, prices of petroleum products are in a state of flux and can be expected to remain so until the value of foreign exchange is stabilized. It appears likely that price increases will be necessary to reflect the new economic conditions, but their increase has already created severe problems, as was the case with a recent increase in public transportation prices, which caused riots and other disturbances. 
TABLE 5

PETROLEUM PRICES OF MAIN PRODUCTS

(in dollars per gollon at official exchange rates)

\begin{tabular}{|c|c|c|c|c|}
\hline & 1975 & 1978 & 1981 & 1984 \\
\hline \multicolumn{5}{|l|}{ Guatemala } \\
\hline Gasoline (regular) & 0.83 & 0.94 & 2.04 & 1.90 \\
\hline Diesel & 0.55 & 0.56 & 1.24 & 1.17 \\
\hline Fuel oil & 0.32 & 0.35 & 0.90 & 0.85 \\
\hline \multicolumn{5}{|l|}{ El Solvodor } \\
\hline Gasoline (regular) & 0.86 & 0.97 & 2.49 & 2.49 \\
\hline Diesel & 0.48 & 0.48 & 1.70 & 1.70 \\
\hline Fuel oil & 0.28 & 0.34 & 0.71 & 0.78 \\
\hline \multicolumn{5}{|l|}{ LPG } \\
\hline \multicolumn{5}{|l|}{ Honduras } \\
\hline Gosoline (regular) & 0.93 & 1.05 & 1.96 & 1.96 \\
\hline Diesel & 0.52 & 0.54 & 1.21 & 1.22 \\
\hline Fuel oil & 0.26 & 0.30 & 0.66 & 0.66 \\
\hline \multicolumn{5}{|l|}{ Costa Rica } \\
\hline Gasoline (regular) & 0.98 & 0.98 & 2.16 & 1.90 \\
\hline Diesel & 0.48 & 0.46 & 1.30 & 1.51 \\
\hline Fuel oil & 0.35 & 0.34 & 0.47 & 0.48 \\
\hline \multicolumn{5}{|l|}{ Panama } \\
\hline Gasoline (regular) & 0.86 & 1.00 & 2.18 & 2.14 \\
\hline Diesel & 0.36 & 0.55 & 1.40 & 1.20 \\
\hline Fuel oil & 0.38 & 0.39 & 0.93 & 0.84 \\
\hline
\end{tabular}

Source: Prepored by LANL/INCAE on the basis of official information supplied by the countries as well as on regional reports from ECLA and SIECA.

b. El Salvador. In El Salvador, prices of gasoline have also been higher than those of diesel by a percentage that has varied between 50 and 70 percent, and this level has been maintained in local currency, although the real price in dollars has decreased owing to the devaluation from 2.5 colones per dollar to the current value of 4.5 colones per dollar. Diesel prices have followed a very similar trend in the period 1975 to 1982.

c. Honduras. The same trend in the relative prices of diesel and gasoline is present in Honduras where the dieselization process has reached the level where this fuel accounts for half the total demand for petroleum products. It is worth noting that Honduras is the only country in Central America that has not changed its official exchange rate, which stands at 2 lempira per dollar. 


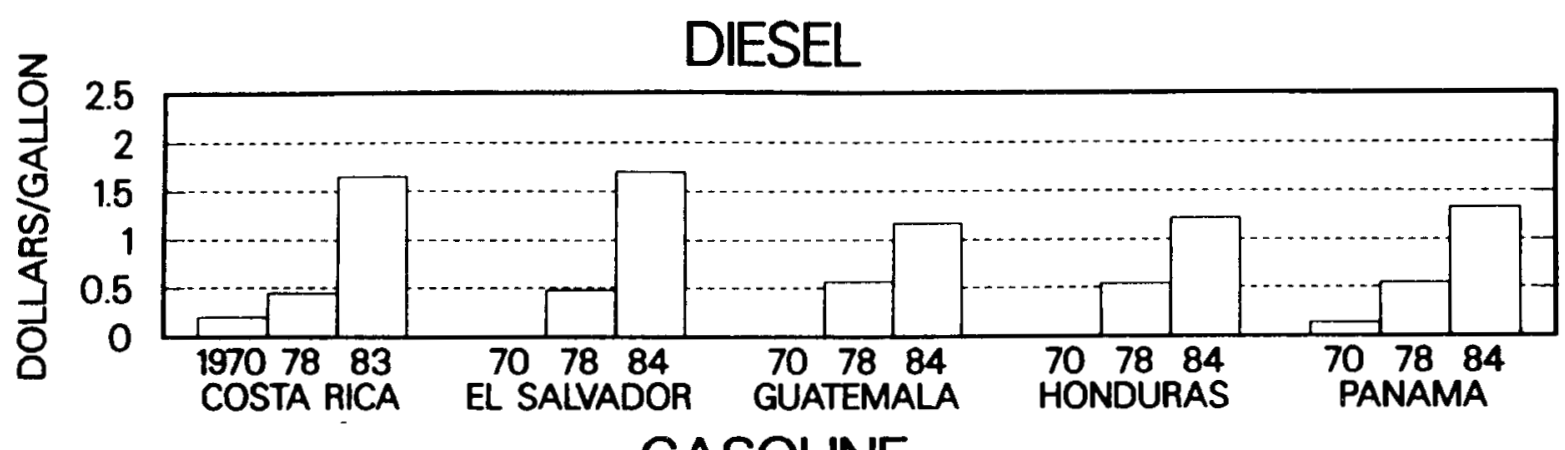

GASOLINE

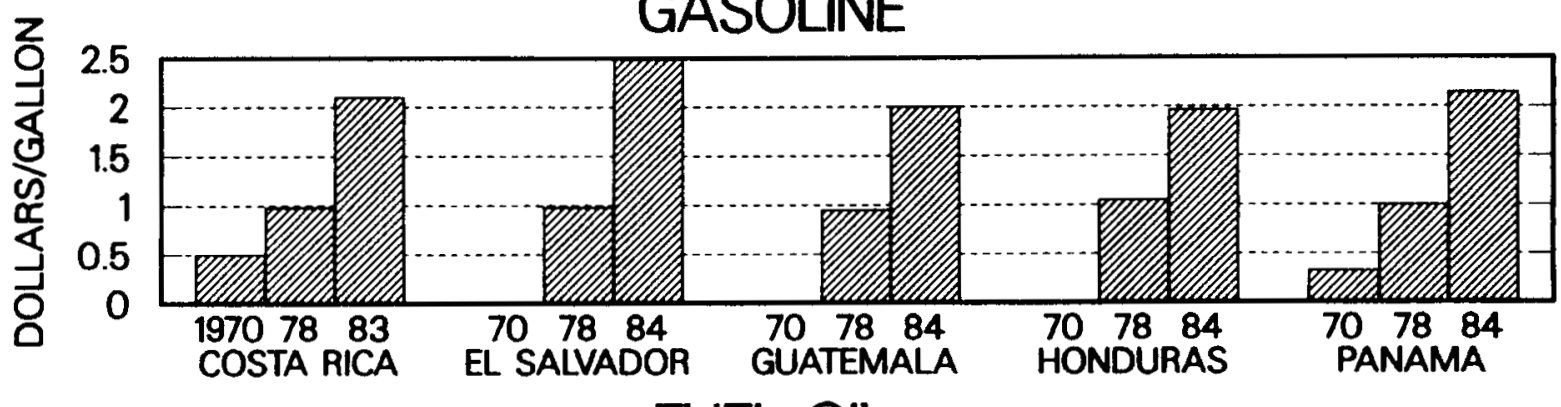

FUEL OlL

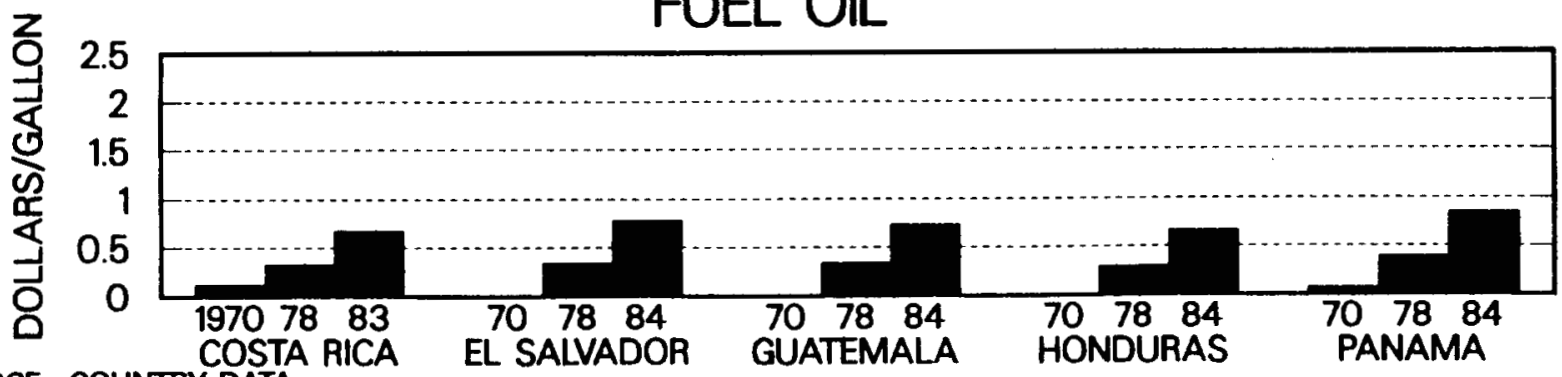

SOURCE: COUNTRY DATA

Fig. 9. Petroleum product prices.

Nevertheless, the free market rate is closer to 2.5 lempira per dollar; therefore, prices in dollar terms can be considered to have decreased in recent months. The differential in the prices of diesel and gasoline stood at 78 percent in 1975 and is at present close to 61 percent. Consistently lower diesel prices have promoted heavy utilization of this fuel, which is used in electrical generation in isolated areas as well as in transportation.

d. Costa Rica. In Costa Rica, gasoline prices were more than double the level of diesel prices throughout the 1970s. This differential, accompanied by tax policies that favored the importation of light diesel trucks and pickups, has created a situation where diesel consumption is almost twice that of gasoline. Since 1982, the price differential between diesel fuel and gasoline has been narrowed to slightly over 25 percent. Prices of fuel oil were subsidized again in 1982 and the fue $10 i 1$ price was set at $\$ 0.43 /$ gal in 1985 . 
Subsidies of bunker fuel oil for industrial use have been granted through pressures from the industrial sector, but these subsidies pose important barriers to conservation and biomass-based substitution, some of the main alternatives left to these countries to reduce their oil dependence.

e. Panama. In Panama the gasoline price fluctuated until 1983 when it reached $\$ 2.14$ gal where it stabilized. The 1985 level for diesel fuel was $\$ 1.33 /$ gal and for fuel $0 i 1, \$ 0.85 / \mathrm{gal}$.

In conclusion, there is a general trend of higher levels of prices for gasoline vis-a-vis diesel, and these prices are well above international prices and tend to reflect a higher taxation level for gasoline, a fuel that is general1y consumed by higher income groups. Diesel consumption, more directly associated with industry, electricity production, and public transportation, has not been affected by price rises as much. Fuel $0 i 1$ prices have tended to be subsidized to different degrees in the countries considered, partiy reflecting protectionist industrial policies derived from the integration effort and partly reflecting the relative abundance of this fuel in the Caribbean basin, which is in turn related to the number of small refineries with 1 imited secondaryprocessing capabilities.

3. Fuel wood and Other Biomass. Fuel wood is generally considered a noncommercial energy source owing to the lack of organized markets similar to those in the petroleum and electrical sector; nevertheless, in Central America fuel wood constitutes the main energy source for the rural population. Fuel wood is increasingly being traded in regional markets, which are determined largely by land-use patterns and other socioeconomic determinants. Traditionally, fuel wood had been appropriated directly by the users from forest exploitation residues, coffee prunings, road fence clearings and from a variety of other sources that did not involve market transactions or any record in national income accounts. This has made it somewhat difficult to study the prevailing prices for a resource that has not been traded for a very long time.

Recentiy, pressures stemming from increasing population density, deforestation, and competition from industrial users have caused fuel wood to be traded more intensely than in the past. Fuel-wood prices have continued to increase steadily throughout the $1970 \mathrm{~s}$ and 1980s, and, in fact, its prices have increased faster than those for some of the commercial energy sources. Informal surveys conducted by the Central American Institute of Business Administration (INCAE) have confirmed that this trend has occurred in all the countries considered. In Costa Rica, a study of bioenergy resources conducted by Metasystems concluded that fuel-wood prices had increased, on the average, 30 percent faster than the 
general inflation rate during the last 5 years. In Guatemala, Honduras, and El Salvador, prices have continued to rise despite the stabilization in commercial energy prices after 1981. Even in Panama, where the level of fuel-wood utilization is lowest, prices have risen considerably. This trend clearly reflects the rising scarcity value of this resource, which is being depleted rapidly through deforestation, an issue that was mentioned earlier in this report.

Although a larger percentage of the fuel wood utilized in these countries is being traded, the markets are regional. A significant portion of fuel wood is still appropriated directly by the users, sometimes as part of the payment to workers on coffee farms and in other types of activities. Because of these conditions, it is difficult to make a more detailed analysis of fuel-wood prices without first making complete surveys in the different regions where markets exist. Several countries have performed these surveys in the past, but recent data are available only for costa Rica.

other biomass residues that exist in considerable quantities are those associated with sugar cane processing and with rice and corn growing and processing. Bagasse from sugar cane is utilized primarily within the sugar mills themselves and is seldom sold or traded. Some rice hulls are utilized as filler in animal feed, but considerable quantities are wasted because the hulls' low density does not make transportation feasible. Corn husks are produced in many areas but are not generally traded. The only residue for which there is an emerging market is that of shells from African palm trees. These shells have been utilized for several years by costa Rican cement plants, which transport them from a distance of 300 kilometers and pay about $\$ 50 /$ ton for a fuel with considerable heat value and desirable characteristics. This experience has now been implemented in Honduras and Guatemala as well.

E. Energy Demand

Several measurements of demand will be used in this section, including total, sectorial, and per capita consumption. The similarities and differences among the countries are noted and areas of potential energy problems are pointed out.

1. Total. Total energy consumption is perhaps the crudest of the three measurements. This variable mainly is determined by the level of economic development and population size, so the largest country might be expected to have the largest demand. Fig. 10 shows total consumption for each country over the 1970 to 1984 period. 


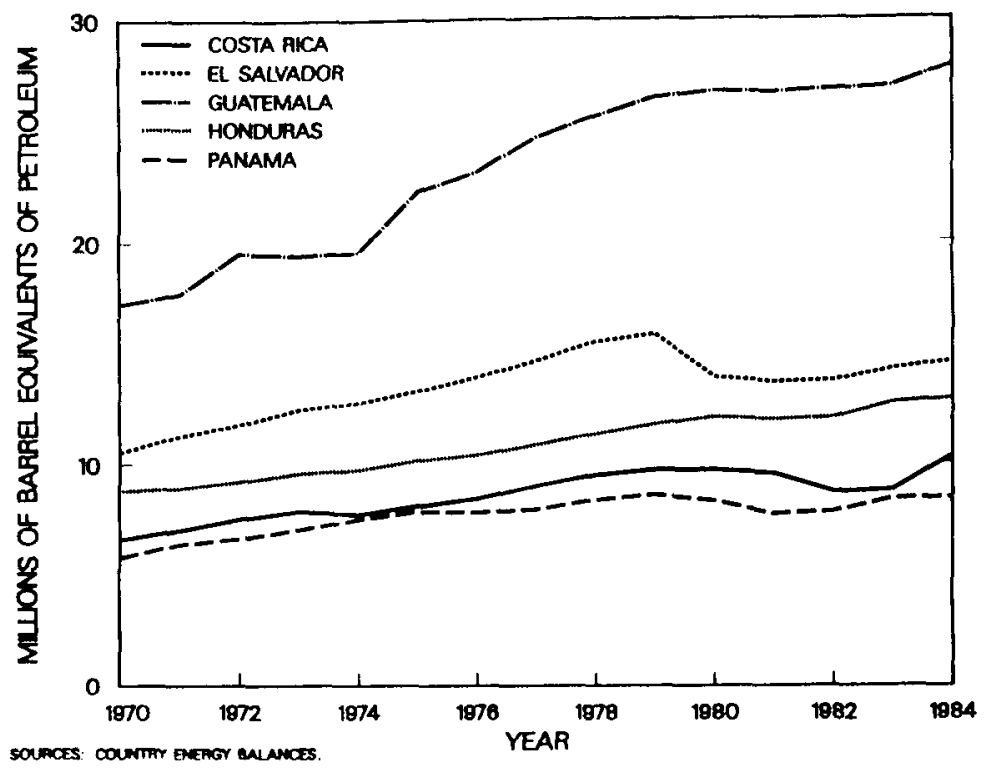

Fig. 10. Total energy consumption.

The growth rate of total demand reflects economic and population growth as we 11 as changes in demographic patterns such as urban migration. (Urban migration generally leads to increased commercial energy consumption.) El Salvador experienced the fastest energy demand growth during the 1970 to 1978 period with 5 percent annualiy on average, and Honduras experienced the slowest at 3.2 percent.

The later period, 1978 to 1984, was much more difficult for Central America. The combination of a severe international financial crisis, a second oil panic, and the worst recession since the 1930s caused energy consumption to decline in three countries through 1983--El Salvador, Costa Rica, and Panama-even though El Salvador and Costa Rica had experienced the fastest growth in the earlier period. Remarkably, energy demand continued to increase in both Honduras and Guatemala. Indeed, the consumption in Guatemala continued to grow at a 3.9 annual percentage rate, the same rate as during the 1970 to 1978 period, so that by the end of 1984, Guatemala consumed twice as much energy as El Salvador, the next largest user. However, much of Guatemala's apparent demand increase arises because of the upward adjustment in the fuel-wood consumption estimate in 1979. Thus, one should not place too much emphasis on the reported growth rate.

2. Sectorial. Identifying the quantity of energy consumed by each sector allows us to compare the relative economic development and structure of the countries. In addition, looking at the consumption patterns over time may indicate potential energy problem areas. 
For all of the countries except Guatemala, the share of energy consumption has generally declined over time in the residential/commercial/public sector and increased in the transport and industrial/agricultural sectors owing to economic growth during the 1970s. There was little change in the proportion of primary versus secondary energy sources used within the sectors during the 1970 to 1984 period.

Guatemala's sectorial energy shares appear to have changed dramatically, and in a manner contrary to that of its neighbors. The data show that, instead of increasing, the industrial/agricultural sector's share suffered a decrease from about 24 to 20 percent over the 1970 to 1984 period. At the same time, residential/commercial and public useage of energy increased by about 5 percent. This is most likely because a 1979 fuel-wood survey caused fuel-wood consumption estimates to rise by 25 percent and because this fuel is used mainly in the residential sector.

In examining the 1984 sectorial shares of the five countries, one can identify two country groups, each of which has similar consumption splits among its sectors. The group composed of Honduras, El Salvador, and Guatemala is characterized by relatively high consumption in the residential/commercial/public sector (of about 65 percent) and by a much lower consumption (of about 14 to 20 percent) in the transport and industrial/agricultural sectors. Panama and Costa Rica form a second group and have higher transport and industrial/agricultural shares of about 25 percent and lower residential/commercial/public shares of about 40 percent. An additional difference between the two groups is the level of primary fuel use. The poorer countries (e.g., Honduras) tend to depend more on traditional energy sources such as fuel wood than the richer countries (e.g., Panama) do.

3. Per Capita. An alternative way to compare the energy use of these countries is to examine the consumption of energy per person. Per capita data are presented in Figs. 11-14. Total energy demand is higher in countries with larger populations, other things being equal; per capita figures do not have this bias.

The amount of oil products consumed per person is graphed in Fig. 11. The highest consumption is in Panama, with about 2.25 barrels per person per year in 1984; the lowest is in El Salvador with only 0.6 barrels. Actually, El Salvador, Honduras, and Guatemala have very similar oil consumption figures, whereas the consumption in Costa Rica is twice that figure and in Panama is three times that figure. Both Costa Rica and Panama are relatively affluent in other per capita measurements as we11, for example, GDP per capita (see Fig. 12). 


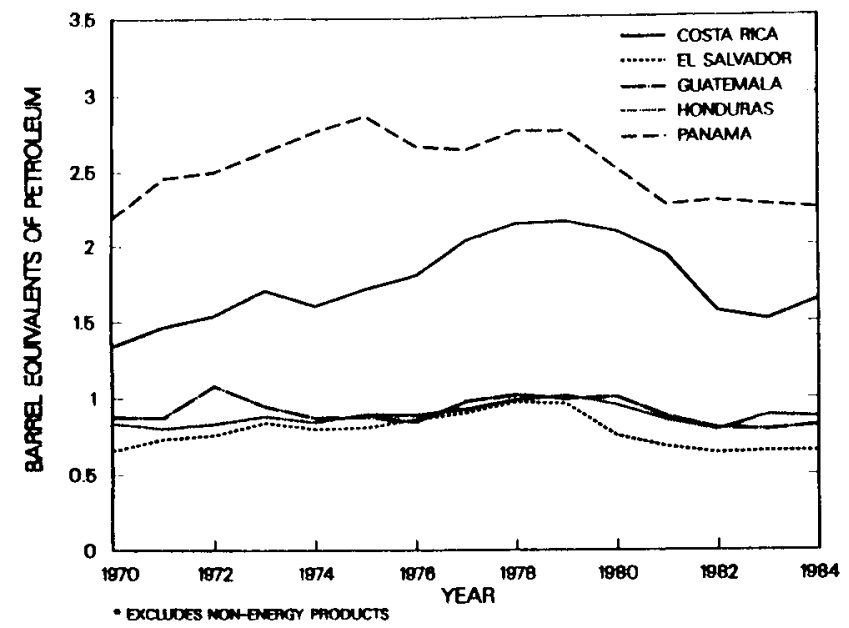

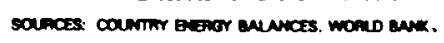

Fig. 11. Per capita consumption of oil products. Excludes nonenergy products.

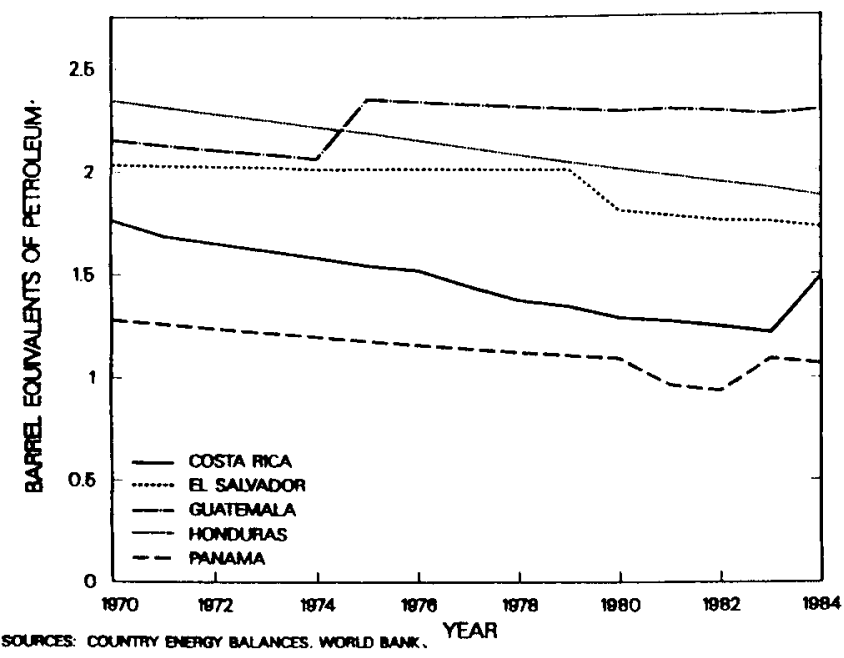

Fig. 13. Per capita consumption of firewood.

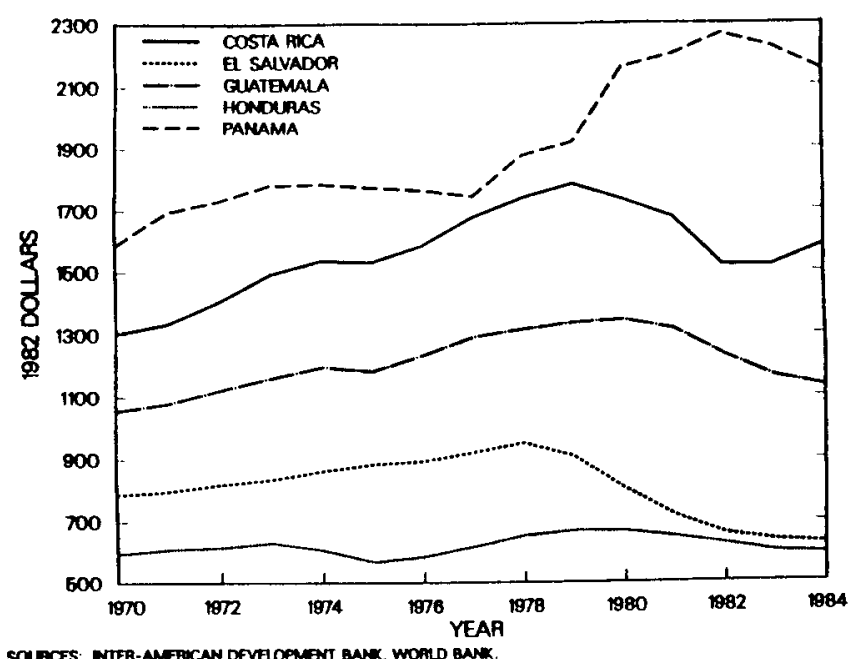

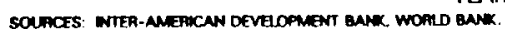

Fig. 12. Per capita gross

domestic product.

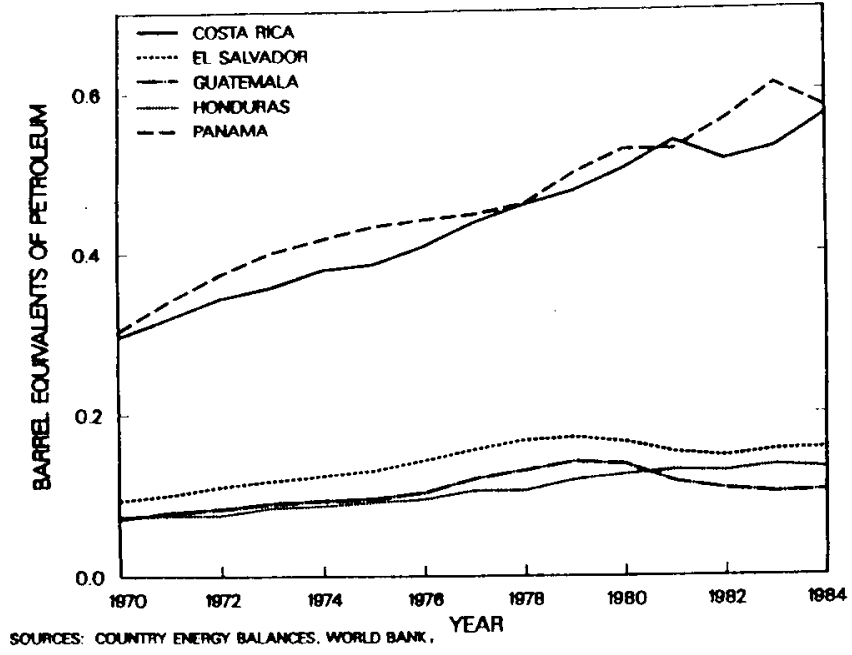

Fig. 14. Per capita consumption of electricity. 
Over time, oil consumption has experienced both increases and decreases, generally following economic conditions (see Fig. 11). In general, oil use rose during the 1970s, when the region experienced relatively rapid economic growth. $0 i 1$ consumption per person has decreased since about 1980, as the economies slowed down and financial conditions within the countries forced them to restrict all imports including oil.

Costa Rica and Panama, the countries with the largest per capita consumption of oil products, have the lowest consumption of fuel wood per person, as shown in Fig. 13. The smooth lines in the graph result because fuel wood and population data are estimated using sporatic surveys instead of actual annual data. The jumps in Guatemala's plot in 1979 and Costa Rica's in 1984 are owing to new survey information becoming available and not to a fundamental shift in consumption patterns. All of the countries exhibit downward trends in per capita fuel-wood use as urban migration, regional shortages, and higher fuelwood prices have reduced demand. In 1984, Guatemala had the highest fuel-wood consumption with about 2.5 barrels of oil equivalent per person per year. This is almost twice as high as the demand in Panama and Costa Rica.

The per capita consumption of electricity (Fig. 14) also demarcates two groups within Central America: Panama and Costa Rica have a relatively high annual consumption of electricity per person (about $0.6 \mathrm{BEP}$ ), whereas the other three countries have very low annual consumption (about $0.15 \mathrm{BEP}$ ). In addition, the demand growth for the former two countries appears to be much faster; consequently, the gap between the two groups is steadily widening. The recession of the early $1980 \mathrm{~s}$ in part caused the decline or slowing of growth in electricity consumption in three countries: Guatemala, Costa Rica, and El Salvador.

Overall, the per capita consumption of oil, fuel wood, and electricity makes clear the distinction among the five countries: Costa Rica and Panama use significantly more of "modern" energies relative to their neighbors, who use larger amounts of "traditional" fuel. Remarkably, this difference does not seem to have mitigated to any great extent during the 1970 s and 1980s. In fact, in the case of electricity, the gap actually widened. The underlying cause of this phenomenon is most likely the continued rapid population growth in the three poorer countries coupled with social/political hindrances to development.

4. Details on Key Energy Products. The sectorial consumption of the three major energy types--oil products, fuel wood, and electricity--are described here, and the changes that have occurred over time and the differences among the countries are discussed. 
a. $0 i 1$. The consumption shares of oil products in Central America have changed significantly since 1970. The most important trend has been the increased use of diesel fuel at the expense of fuel oil. Following is a brief description of the share changes in each country.

Honduras, Panama, and Guatemala all have similar trends in the increasing diesel oil share and declining fuel oil and gasoline shares (see Table 6). Panama's numbers indicate a large reduction in the "other" category during 1970 to 1978. This indicates that the refinery was decreasing its output during this time, since that category includes oils used mainly in the refining process.

There are various explanations for the fuel share trends--diesel's share increasing while gasoline's share declined. First, the oil product pricing policies in the countries were designed to tax the drivers of gasoline-powered vehicles and subsidize mass transit and agricultural vehicles. Among other things, this caused a shift toward diesel oil use in the transport sector. Second, the rapid expansion of hydroelectric capacity in the region allowed several countries to shut down many of their oil-fired generation plants. Finally, the recession of the early $1980 \mathrm{~s}$ caused industrial production to be

TABLE 6

OIL CONSUMPTION BY PRODUCT

(percentages)

\begin{tabular}{|c|c|c|c|c|c|c|c|}
\hline & $\begin{array}{l}\text { Diesel } \\
\text { Liل }\end{array}$ & $\begin{array}{l}\text { Fuel } \\
\text { Qil }\end{array}$ & Gosoline & Kerosene & $\begin{array}{l}\text { Kerosene and } \\
\text { Jet Fuel }\end{array}$ & Qther & Iotal \\
\hline \multicolumn{8}{|c|}{ Costa Rica } \\
\hline 1970 & 40.0 & 21.9 & 28.6 & - & 7.7 & 1.8 & 100.0 \\
\hline 1978 & 47.3 & 19.0 & 24.2 & - & 6.8 & 2.7 & 100.0 \\
\hline 1984 & 46.7 & 22.5 & 22.3 & - & 4.8 & 2.8 & 100.0 \\
\hline \multicolumn{8}{|c|}{ El Salvador } \\
\hline 1970 & 31.3 & 22.5 & 28.2 & $\longrightarrow$ & 14.1 & 3.9 & 100.0 \\
\hline 1978 & 34.4 & 25.4 & 25.7 & $\longrightarrow$ & 8.0 & 6.5 & 100.0 \\
\hline 1984 & 35.2 & 20.6 & 26.9 & - & 9.2 & 8.1 & 100.0 \\
\hline \multicolumn{8}{|c|}{ Guatemala } \\
\hline 1970 & $25.0^{\circ}$ & 23.4 & 28.4 & - & 14.6 & 8.6 & 100.0 \\
\hline 1978 & $34.2^{a}$ & 17.3 & 33.5 & $\longrightarrow$ & 9.7 & 5.3 & 100.0 \\
\hline 1984 & $40.3^{0}$ & 12.6 & 28.0 & - & 10.2 & 8.9 & 100.0 \\
\hline \multicolumn{8}{|c|}{ Honduras } \\
\hline 1970 & 34.2 & 25.5 & 26.0 & 10.9 & - & 3.4 & 100.8 \\
\hline 1978 & 43.1 & 18.6 & 21.6 & 12.1 & - & 4.6 & 100.0 \\
\hline 1984 & 50.5 & 16.5 & 19.1 & 10.7 & - & 3.2 & 100.0 \\
\hline \multicolumn{8}{|l|}{ Panana } \\
\hline 1970 & 11.2 & 20.1 & 36.8 & - & 4.1 & 27.8 & 100.0 \\
\hline 1978 & 27.1 & 20.7 & 35.8 & - & 1.4 & 15.0 & 100.0 \\
\hline 1984 & 34.8 & 16.5 & 31.9 & $-\cdots$ & 1.1 & 15.7 & 100.0 \\
\hline
\end{tabular}


reduced which in turn reduced overall demand for the heavy oils used in that sector.

In terms of actual oil consumption, Guatemala is by far the largest user of oil products within the region under study, consuming about 6.6 million BEP in 1984 (see Table 7). In comparison, the other four countries used an average of 3.9 million BEP of $0 i 1$ products in the same year. This disparity can be explained by Guatemala's relatively high GDP and its former heavy reliance on oilfired electricity generation capacity.

Table 8 reports annual growth rates for oil consumption in the region. There exists a clear slowdown of growth after 1978, as the countries restricted imports of all kinds (including oil) and industrial production slowed during the recession. During the 1978 to 1984 period, four out of the five countries actually decreased their oil consumption: in El Salvador, after growing at 8.2 percent per year from 1970 to 1978, oil consumption fell by 3.7 percent annually for the following 6 years. The 1970 to 1984 average annual growth rates ranged from a high of 4 percent in Costa Rica to a low of 2.5 percent in Guatemala and Panama.

TABLE 7

OIL CONSUMPTION BY PRODUCT

(thousonds of borrel equivalents of petroleum)

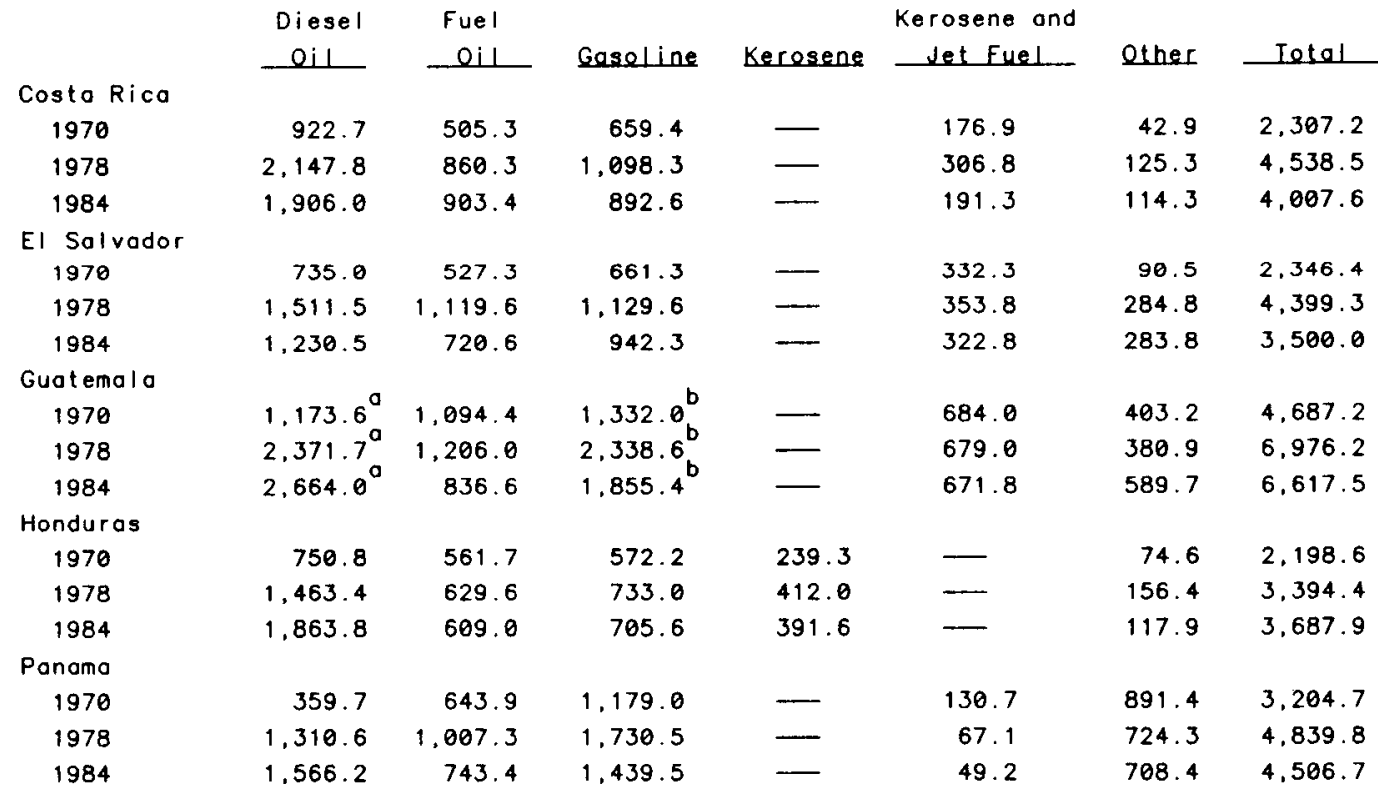

Source: Reference

Includes gasoil.

Includes napthos. 


$\begin{array}{lccc} & 1970-1978 & 1978-1984 & 1970-1984 \\ \text { Honduras } & 5.6 & 1.4 & 3.8 \\ \text { Costa Rica } & 8.8 & -2.1 & 4.0 \\ \text { Guatemalo } & 5.1 & -0.9 & 2.5 \\ \text { Panama } & 5.3 & -1.2 & 2.5 \\ \text { El Salvodor } & 8.2 & -3.7 & 2.9\end{array}$

Statistics relevant to the sectorial consumption of oil are contained in Tables 9 and 10. In all five countries, the transportation sector is the largest consumer of oil, generally making up over half of total consumption. The second largest oil-using sector is industry and agriculture, which equaled about half of the transportation consumption of 1984. Honduras is somewhat different than the other countries in that its transportation sector is not quite as dominant in terms of oil use. This reflects the country's relatively undeveloped road system and low average income levels. In addition, Honduras is the only country where transportation oil consumption continued to rise throughout the 1970 to 1984 period; during the recession of the $1980 \mathrm{~s}$, the other countries were forced to restrict oil imports, and all sectors experienced declines in consumption. For example, in Costa Rica, one of the hardest hit by the foreign exchange shortage, transportation consumption declined a total of 13 percent, from 3 million BEP in 1978 to 2.6 million BEP in 1984 (see Table 9).

The recession also had a negative effect on the industrial sector of the countries. In a11 cases except Honduras and Panama, industrial consumption of oil decreased during the 1978 to 1984 period. In some countries, the decline was substantial: El Salvador's and Guatemala's industrial sectors oil use experienced a 27 percent decrease. The use of $0 i 1$ in the residential, commercial, and public sectors also declined over this period for all countries except Guatemala.

b. Fuel wood. Fuel wood is a very important energy source in central America (Tables 11-13), and the residential/commercial/public sector comprised over 90 percent of total fuel-wood demand in all five countries in 1984 (see Table 11); the industrial sector is the other user of fuel wood. Although in per capita terms fuel-wood use has declined, the total consumption of fuel wood continued to grow throughout the 1970 to 1984 period in all countries (see Table 12). 
TABLE 9

OIL PROOUCT CONSUMPTION BY SECTOR

(thousonds of barrel equivalents of petroleum)

\begin{tabular}{|c|c|c|c|c|c|c|c|}
\hline & Iranspertation & Industrial & Agriculture & $\begin{array}{l}\text { Industriol/ } \\
\text { Agriculture }\end{array}$ & $\begin{array}{l}\text { Residentiol/ } \\
\text { Commerciol/ } \\
\text { Public } \\
\end{array}$ & Qther & Tetol \\
\hline \multicolumn{8}{|c|}{ Costa Rica } \\
\hline 1970 & $1,515.9$ & - & 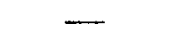 & 495.2 & 164.9 & 131.4 & $2,307,4$ \\
\hline 1978 & $3,013.0$ & - & - & 1.163 .9 & $254 . \theta$ & 107.1 & $4,538.0$ \\
\hline 1984 & 2.639 .2 & - & - & 998.6 & 163.9 & 206.5 & $4,007.6$ \\
\hline \multicolumn{8}{|c|}{ EI Solvodor } \\
\hline 1970 & 1.237 .5 & - & - & 719.6 & 286.8 & 102.6 & $2,346.5$ \\
\hline 1978 & $2,483.0$ & - & - & 1.427 .8 & 360.5 & 128.0 & $4,399.3$ \\
\hline 1984 & 2.132 .5 & - & - & 1.044 .2 & 304.2 & 19.2 & $3,500.1$ \\
\hline \multicolumn{8}{|c|}{ Guatemalo } \\
\hline 1976 & $2,361.6$ & $1,512.0$ & - & - & 554.4 & 259.2 & $4,687.2$ \\
\hline 1978 & 4.147 .9 & $1,676.2$ & 308.9 & - & 653.0 & 190.1 & $6,976.1$ \\
\hline 1984 & $3,823.9$ & 1.443 .6 & 340.6 & - & 869.8 & 139.7 & $6,617.6$ \\
\hline \multicolumn{8}{|c|}{ Honduras } \\
\hline 1970 & 906.2 & 682.2 & 91.1 & - & 341.4 & 177.7 & 2.198 .6 \\
\hline 1978 & $1,379.5$ & 1.071 .7 & 142.8 & - & 596.7 & 203.7 & $3,394.4$ \\
\hline 1984 & 1.722 .1 & $1,337.3$ & 19.8 & - & 478.6 & 130.0 & $3,687.8$ \\
\hline \multicolumn{8}{|l|}{ Ponamo } \\
\hline 1970 & $1,388.8$ & - & $\ldots$ & 571.3 & 280.9 & 963.7 & 3.204 .7 \\
\hline 1978 & 2.537 .4 & - & - & 967.9 & 374.8 & 959.8 & 4.839 .9 \\
\hline 1984 & 2.299 .6 & - & - & $1.122 .9^{a}$ & 405.8 & 679.0 & $4,506.7$ \\
\hline
\end{tabular}

a 1981-1984 energy balances cotegorize this sector as agriculture and onimat husbandry onty.

TABLE 10

OIL PRODUCT CONSUMPTION BY SECTOR

(percentages)

\begin{tabular}{|c|c|c|c|c|c|c|c|}
\hline \multirow{5}{*}{ Costo Rico } & \multirow[b]{3}{*}{ Iransportation } & \multirow[b]{3}{*}{ Industrial } & \multirow[b]{3}{*}{ Agriculture } & \multicolumn{4}{|c|}{ Residentiol/ } \\
\hline & & & & \multirow{3}{*}{$\begin{array}{l}\text { Industrial/ } \\
\text { Agriculture }\end{array}$} & \multirow{2}{*}{$\begin{array}{l}\text { Commercial/ } \\
\text { Public }\end{array}$} & \multirow{3}{*}{ Qther } & \multirow[b]{2}{*}{ Iotel } \\
\hline & & & & & & & \\
\hline & & & & & & & \\
\hline & 65.7 & - & - & 21.5 & 7.1 & 5.7 & 100.0 \\
\hline 1978 & 66.4 & - & - & 25.6 & 5.6 & 2.4 & 100.0 \\
\hline 1984 & 65.9 & - & - & 24.9 & 4.1 & 5.1 & 100.0 \\
\hline \multicolumn{8}{|c|}{ EI Salvador } \\
\hline 1970 & 52.7 & - & - & 30.7 & 12.2 & 4.4 & 100.0 \\
\hline 1978 & 56.4 & - & - & 32.5 & 8.2 & 2.9 & 100.0 \\
\hline 1984 & 60.9 & - & - & 29.8 & 8.7 & 0.6 & 100.0 \\
\hline \multicolumn{8}{|c|}{ Guatemala } \\
\hline 1970 & 50.4 & 32.3 & 0.0 & - & 11.8 & 5.5 & 100.0 \\
\hline 1978 & 59.5 & 24.0 & 4.4 & - & 9.4 & 2.7 & 100.0 \\
\hline 1984 & 57.8 & 21.8 & 5.2 & - & 13.1 & 2.1 & 100.0 \\
\hline \multicolumn{8}{|c|}{ Honduras } \\
\hline 1970 & 41.2 & 31.0 & 4.2 & - & 15.5 & 8.1 & 100.0 \\
\hline 1978 & 40.6 & 31.6 & 4.2 & - & 17.6 & 6.0 & 100.0 \\
\hline 1983 & 46.7 & 36.3 & 0.5 & - & 13.0 & 3.5 & 100.0 \\
\hline \multicolumn{8}{|l|}{ Ponama } \\
\hline 1970 & 43.3 & - & $\longrightarrow$ & 17.8 & 8.8 & 30.1 & 100.0 \\
\hline 1978 & 52.4 & - & - & 20.0 & 7.7 & 19.8 & 100.0 \\
\hline 1983 & 51.0 & - & - & $24.9^{a}$ & 9.0 & 15.1 & 100.0 \\
\hline
\end{tabular}

o 1981-1984 energy balances categorize this sector os agriculture ond onimal husbandry only. 
TABLE 11

FUEL-WOOD USE BY SECTOR

(percentoges)

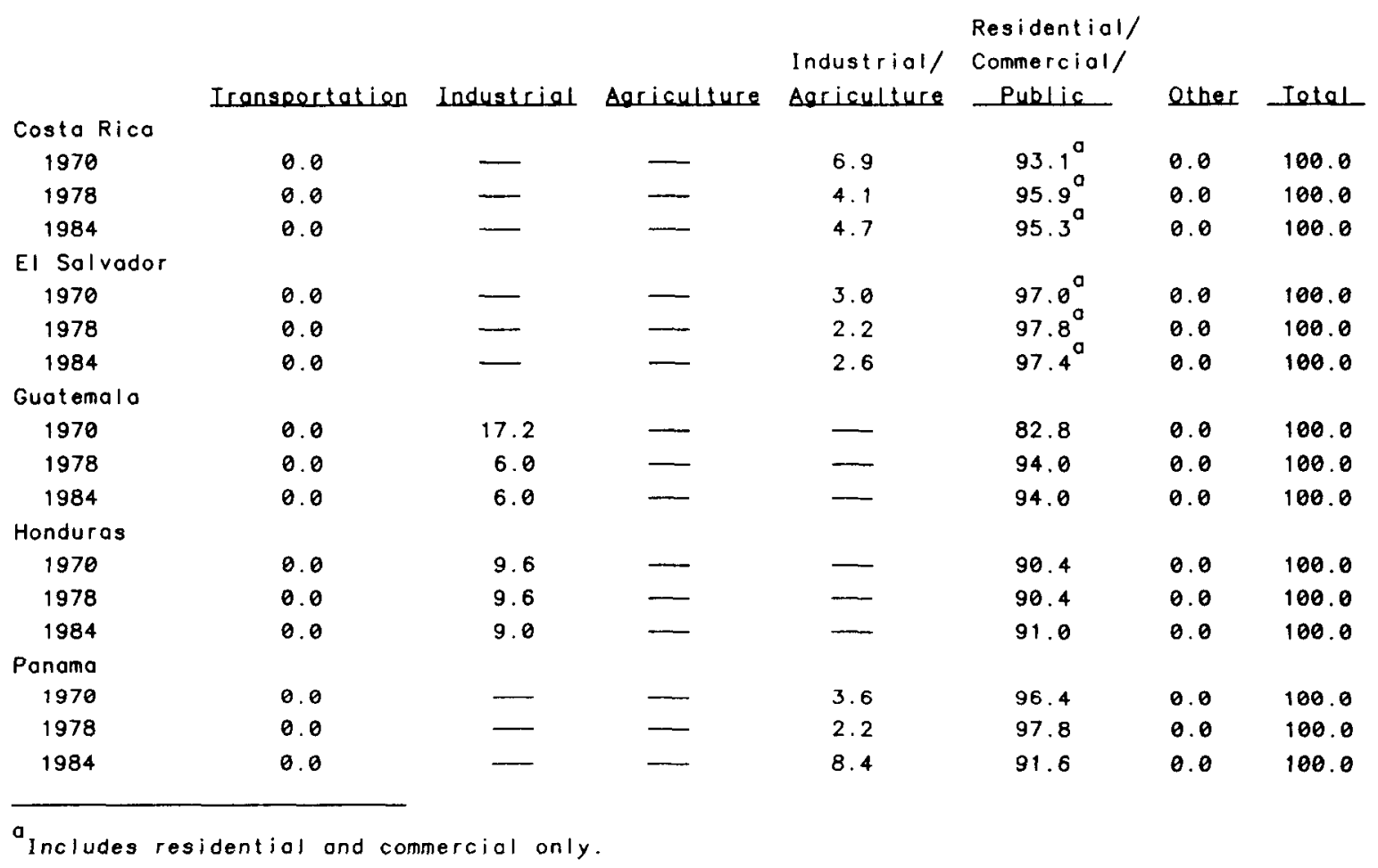

TABLE 12

ANNUAL COMPOUNDED GROWTH RATES OF FUELWOOD CONSUMPTION

$\begin{array}{lccc} & 1970-1980 & 1978-1984 & 1970-1984 \\ \text { Honduras } & 1.8 & 1.8 & 1.8 \\ \text { Costa Rica } & -0.5 & 3.7 & 1.2 \\ \text { Guatemala } & 3.7 & 2.7 & 3.5 \\ \text { Panamo } & 0.6 & 1.4 & 0.9 \\ \text { El Salvador } & 1.8 & 0.3 & 1.7\end{array}$


TABLE 13

FUEL-WOOD USE BY SECTOR

(thousonds of barrel equivalents of petroleum)

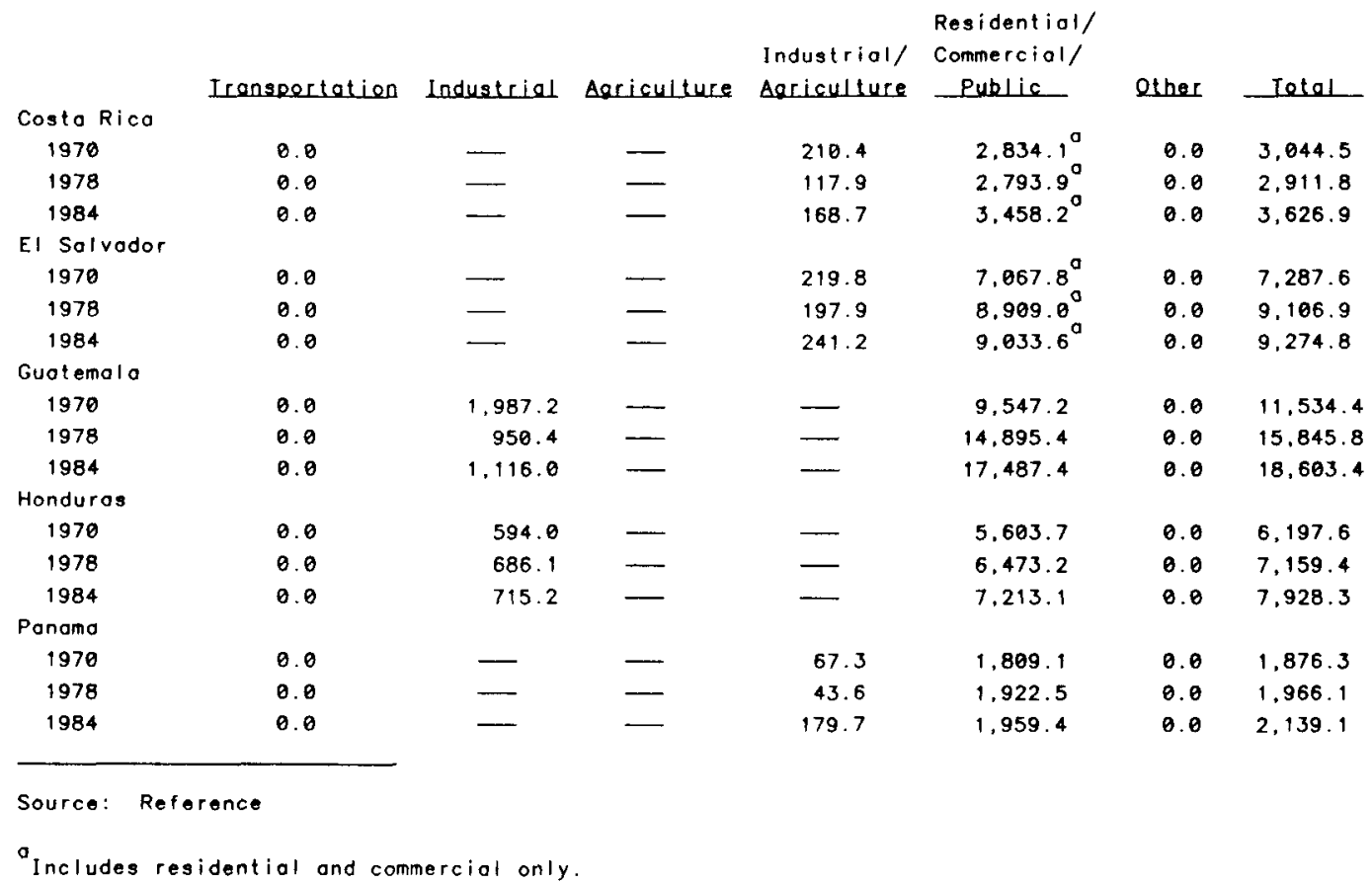

Table 13 reports the actual levels of fuel-wood consumption in the five countries. As the country with the highest population, Guatemala also had by far the highest level of fuel-wood use--almost 19 million BEP in 1984 . The next highest consumption in 1984 was 9.3 million BEP in El Salvador. As was the case with per capita fuel-wood consumption, Panama and Costa Rica have a much lower total fuel-wood consumption level than the other three countries.

c. Electricity. Central American electricity use is substantially different across countries. Consequentiy, it is difficult to summarize the situation into a single concept. Therefore, we address the high points for each country in turn, beginning with sectorial shifts, then proceeding to the overall growth rates.

Costa Rica, Guatemala, and El Salvador experienced similar sectorial adjustments: industrial use increased and residential/commercial use decreased during the 1970 to 1978 period, with a reverse trend during the next 5 years, mostly because of the recession in the 1980s (see Table 14). The most dramatic example of the trend is in Guatemala, where industrial use was 42 percent of total electricity use in 1970 and then dropped to 31 percent by 1984 . The 
TABLE 14

\begin{tabular}{|c|c|c|c|c|c|c|c|}
\hline & & ELE & $\begin{array}{l}\text { CTRICITY USE } \\
\text { (percentag }\end{array}$ & $\begin{array}{l}\text { BY SECTOR } \\
\text { es) }\end{array}$ & & & \\
\hline & & & & & Residentiol/ & & \\
\hline & & & & Industriol/ & Commercial/ & & \\
\hline & Iranspertation & Industrial & Agriculture & Aariculture & Puble & Qther & Total. \\
\hline Costa $R$ & & & & & & & \\
\hline 1970 & 1.3 & - & - & 29.5 & $67.3^{\circ}$ & 1.9 & 100.0 \\
\hline 1978 & 0.6 & - & - & 33.6 & $63.2^{\mathrm{c}}$ & 2.6 & 100.0 \\
\hline 1984 & 0.4 & $\longrightarrow$ & - & 30.7 & $65.6^{\circ}$ & 3.3 & 100.0 \\
\hline El Salve & & & & & & & \\
\hline 1970 & 0.0 & - & - & 45.0 & $40.2^{\circ}$ & 14.8 & 100.0 \\
\hline 1978 & 0.0 & $\longrightarrow$ & - & 48.3 & $38 \cdot 4^{\circ}$ & 13.3 & 100.0 \\
\hline 1984 & 0.0 & - & $\cdots$ & 38.5 & $45.4^{\circ}$ & 16.1 & 100.0 \\
\hline Guatema & & & & & & & \\
\hline 1970 & 0.0 & 41.5 & 0.0 & - & 45.3 & 13.2 & 100.0 \\
\hline 1978 & 0.0 & 40.3 & 0.3 & $\longrightarrow$ & 56.2 & 3.2 & 100.0 \\
\hline 1984 & 0.0 & 30.6 & 0.3 & - & 66.0 & 3.1 & 100.0 \\
\hline Hondura & & & & & & & \\
\hline 1970 & 0.0 & 51.7 & 11.4 & $\longrightarrow$ & 36.8 & 0.1 & 100.0 \\
\hline 1978 & 0.0 & 48.8 & 5.1 & - & 46.0 & 0.1 & 100.0 \\
\hline 1984 & 0.0 & 41.4 & 6.0 & - & 52.5 & 0.1 & $100 . \theta$ \\
\hline Panoma & & & & & & & \\
\hline 1970 & 0.0 & $\longrightarrow$ & - & 25.4 & 66.7 & 7.9 & 100.0 \\
\hline 1978 & 0.0 & - & - & 18.4 & 76.9 & 4.7 & 100.0 \\
\hline 1984 & 0.0 & - & - & 23.2 & 72.6 & 4.2 & 100.0 \\
\hline
\end{tabular}

ancludes residential and commercial only.

residential share followed an opposite pattern in the country: it was 45 percent in 1970 and then it rose to 66 percent in 1984 . What is probably causing this phenomenon is the variable nature of industrial electricity consumption. Looking at the actual electricity consumption numbers for Guatemala in Table 15, it becomes clear that its industrial use is much more volatile than that of the other countries, with the possible exception of El Salvador. Guatemala's case may be explained by the fact that a large nickel plant (with a very electricityintensive production process) began operations in 1977 and subsequently shut down in 1980 .

In Honduras the residential/commercial/public sector's electricity consumption grew at a faster rate than that of the industrial sector over the 1970 to 1984 period. Consequently, industry's share of the total electricity consumption steadily declined over time, from 52 percent in 1970 to 41 percent in 1984.

Panama's residential/commercial share flucuated slightly from a high of 60 percent in 1977 to a low of 54 percent in 1984, and public use also increased from only 11 percent in 1970 to 18 percent in 1984 .

Because of rural electrification efforts and power plant construction, the overall growth rate in electricity consumption for the region has been faster in 
TABLE 15

ELECTRICITY USE BY SECTOR

(thousands by borrel equivalents of petroleum)

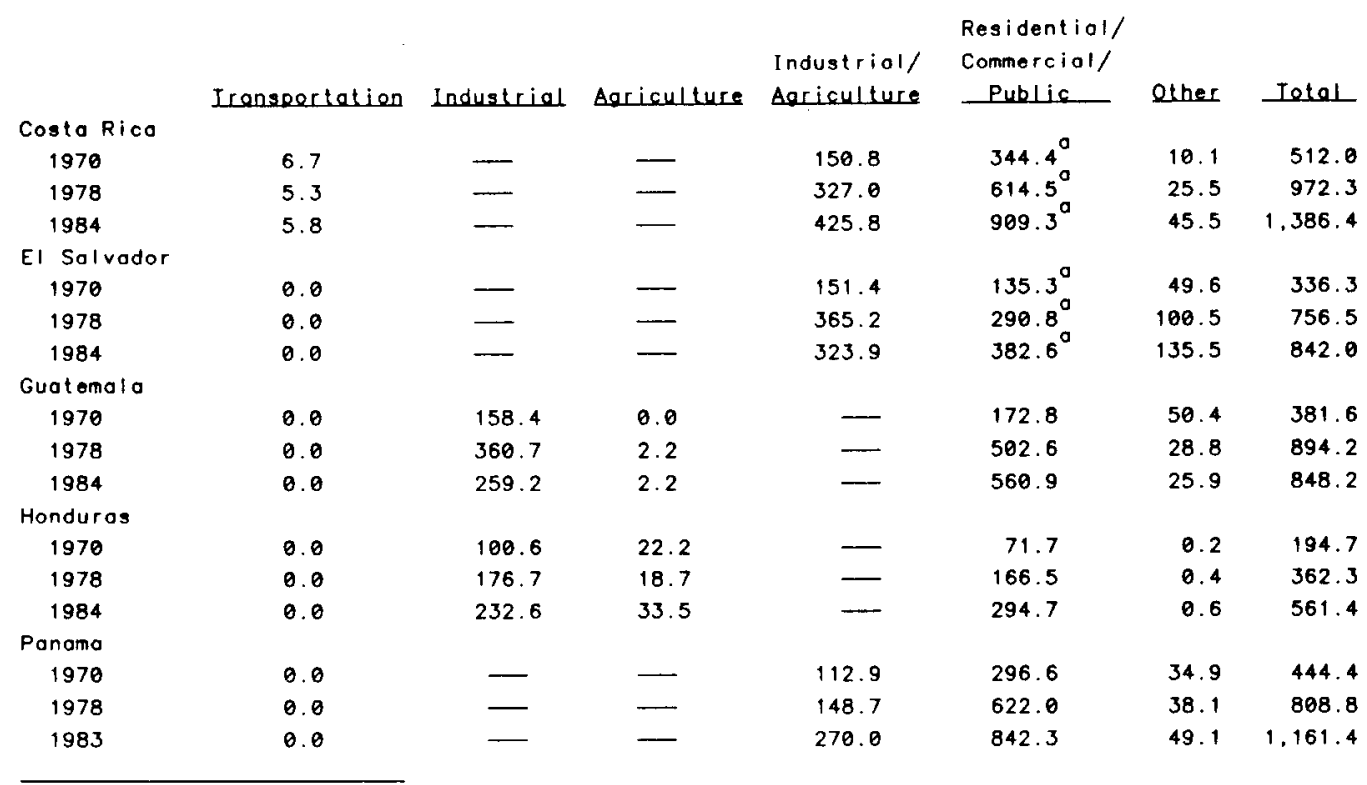

ancludes residential ond commercial only

general than that of the population or the economy. The average annual percentage increase over the 1970 to 1984 period was remarkably similar for the five countries: Honduras experienced an electricity demand growth of 7.9 percent, Guatemala had a rate of 5.9 percent and the other three countries all had growth rates of about 7 percent (see Table 16). All countries experienced a period of slower demand growth in the period 1978 to 1984.

\section{F. Energy Planning}

1. Evolution and Institutionalization. The Programa Energetica del Istmo Centroamericano (PEICA Project) funded by OPEC through the United Nations Development program (UNDP), started in 1978 and lasted through 1981. It provided the resources for an energy balances component that was the first systematic effort to analyze the national energy situation. National work groups were created within different agencies in the countries, but in general, the electric utilities hosted the groups as was the case in El Salvador, Costa Rica, and Panama. In Honduras, the economic planning council (Consejo. Superior de Planificacion Economica--CONSUPLANE) was responsible for this activity. Guatemala did not participate in this component. UNDP resident advisors were assigned to the different groups, and fuel-wood utilization surveys were made for the household and industrial sectors. 
TABLE 16

ANNUAL COMPOUNDED GROWTH RATES OF ELECTRICITY DEMAND

$\begin{array}{lccc} & 1970-1978 & 1978-1984 & 1978-1984 \\ \text { Honouras } & 8.1 \% & 7.6 \% & 7.9 \% \\ \text { Costa Rico } & 8.4 & 6.1 & 7.4 \\ \text { Guatemala } & 11.2 & -0.9 & 5.9 \\ \text { Panama } & 7.8 & 6.2 & 7.1 \\ \text { El Salvodor } & 10.7 & 1.8 & 6.8\end{array}$

In Panama, a National Energy Commission was created in 1980 with a Technical Secretariat within the electric utility (IRHE). This group, one of the strongest in the region, has had additional support from the World Bank, and both in terms of size and expertise, its growth in the last few years has been considerable.

In Costa Rica, a sectorial planning system was put into practice in 1979 , and an energy-sector secretariat was formed basically with the original ICE group that had participated in the energy balances project. A UNDP advisor remained with this group. The new administration that took over in 1982 created a Ministry of Industry, Energy, and Mines with a Sectorial Energy Directorate within its jurisdiction. This group has had considerable support from US AID and UNDP, which has also provided two resident advisors. Surveys of energy utilization in all sectors have been carried out, and studies made to identify conservation and substitution options. The completion of a national energy plan occurred recently, formulated by a Sectorial Energy Directorate that has also grown considerably in size and depth.

In El Salvador, the electric utility CEL was designated as the national counterpart for the PEICA Project, and energy planning activities have been taking place systematically at CEL since 1979. An energy planning group developed and matured there, and this institution sought support from the IDB to help strengthen its national energy planning capabilities. An IDB-sponsored advisor was provided as were resources for consultants and specific studies of demand in the different sectors. The IDB project has moved rapidly, and an impressive group of energy planners has been assembled at CEL.

In Guatemala, the centralization of the energy planning process was somewhat slower because that country did not participate in the PEICA energy balances project. With the creation of the Ministry of Energy and Mines and the 
support of UNDP, energy planning activities have been institutionalized, and considerable progress has been achieved in recent years.

Honduras is the only country in Central America where the centralization of the energy planning process is not complete; there still is not a governmental agency with an explicit mandate to carry out energy-planning activities. CONSUPLANE, the planning council, was the national counterpart in the PEICA energy balances project, and an energy planning unit from CONSUPLANE still prepares the energy balances, which is the only systematic planning effort in Honduras. The secretary of Natural Resources is in charge of all oil-related activities including exploration but does not sit on the board of the Commission to Administer Petroleum Imports and Pricing. ENEE, the electric utility, also has a small planning group, but no interinstitutional cooperation mechanism has been effective in coalescing a national group. This problem has persisted in Honduras, where an advisory group was set up by the Economic Cabinet in 1975 to develop alternative solutions. The advisory group suggested a number of alternatives, but a political decision has not been made as to the appropriate jurisdiction and mandate for energy planning.

2. Needs. Although the five Central American countries have made significant strides in recent years toward the development of energy plans, the agencies in charge of planning still desire assistance in particular areas. Some needs are country-specific, whereas others are common to all five. In the discussion that follows, the common needs are described first, followed by a more detailed look at each country.

In order to construct an energy model and plan, accurate data on energy consumption and production is necessary. These data are best stored in a data management computer program that allows easy access and updating. Some countries are in the data base construction phase and have data bases running on computers. However, all of the countries except Costa Rica are lacking up-todate data on energy consumption in at least two sectors, namely transport and rural residential. Assistance has been requested for the design and implementation of surveys to obtain this information. The survey process in each country is in different stages of completion: Costa Rica's surveys are virtually complete, and El Salvador's and Guatemala's are in progress. Of course, the political situation in the latter two countries makes rural energy surveys very difficult, so data bases may remain incomplete for a time. Industrial energy use is also being surveyed in several countries. Guatemala has requested help in this area, as has El Salvador. 
The specific needs of the countries are as follows. Panama has received and is using a computerized data base from LANL and spread sheets in FRAMEWORK software for its national energy model. Assistance will be required in development of the country's national energy plan.

Besides energy consumption surveys, Honduras has also requested and received a data base and a computer to handle it. In addition, model-building assistance is needed. El Salvador has been participating in an IDB-sponsored project with the goal of producing an energy plan in May or June of 1986 . The planning agency, located in the national utility, has a good start on a data base and has requested help with the networking of personal computers.

In addition to work on the national energy plan by the Ministry of Energy and Mines (MEM), Guatemala is now undertaking a project funded by UNDP to construct a framework for policy option analysis for long-term energy planning. Specific requests for assistance include assistance in design and implementation of an information system and energy and mineral planning assistance in general.

Costa Rica currently has a data base running on personal computers, along with an energy model. Specific requests from this country are for help in building a macroeconomic planning model to take account of energy/economy interactions, help with the incorporation of prices in their energy demand model, and help with the analysis of demand management alternatives. They also require assistance in incorporating fuel substitution and conservation in their model.

Because energy and economic planning is a relatively new phenomenon in Central America, the planning institutions have experienced difficulties in getting their plans implemented. The political mechanism for putting plans into action are simply not in existence now, and some time will elapse before things change.

\section{RECOMMENDATIONS}

AID has defined its long-term objectives in energy assistance as the following: "to help (i) develop sound national energy policies that are integrated with national economic policies and supportive of sustained economic growth; (ii) expand production of indigenous energy sources, substituting for higher cost imported energy wherever economically justified; and (iii) improve the efficiency of energy use." *

* AID Policy Paper, "Energy," July 1984, p.l. 
The following recommendations to AID on energy assistance to Central America address the long-term objectives enumerated above. Some recommendations also relate to short-term energy problems that exist in the region. The suggestions for assistance are based upon an analysis of the current energy situation in Central America that is described in Part II.

The critical energy problems in Central America include the following: the drain on foreign reserves required to pay for $0 i 1$ imports; rapid deforestation and degradation of hydroelectric resources; large debts that have been accumulated by the national utilities; the lack of programs to carry out conservation and substitution; the absence of comprehensive energy-pricing policies; and the lack of critical energy data and a means to analyze these data in some countries.

The recommendations follow:

- Provide continued support to energy planning efforts in Central America through assistance in energy use surveys, and further training in energy policy analysis, energy modeling, and energy pricing.

Although considerable progress has been achieved by some of the countries in consolidating and institutionalizing an energy sector as well as an appropriate energy planning organization, the shortage of manpower and computer facilities 1 imits their effectiveness. Assistance and training in basic areas such as survey design and preparation, data base development and management, energy demand models and forecasting, and pricing would strengthen the agencies and help them toward their goal of identifying and planning for efficient energy use in their respective countries. Training workshops at the regional level on topics such as survey design and analysis, energy pricing, data base management, and modeling would benefit planners from all countries. More specific recommendations on energy planning needs are described in the discussion of individual countries.

- Assist all countries in definition of their indigenous energy resources.

Although most of the countries are not considered to have strong favorability for the occurrence of oil, they are known or thought to be rich in other resources. They have already exploited large hydroelectric resources and fuel wood. The countries also have favorability for geothermal energy (a resource that is already being exploited in some countries), peat, coal, wind, solar, and biomass energy. Support should take the form of technical assistance and training in exploration methods as well as financial assistance to support the cost of these efforts. Regional training courses will be beneficial, but intensive technical support and individual training in field methods and data interpretation will be required for geothermal, peat, and coal resource assessment. Wind, solar, and biomass assessments require ass istance by meteorologists, engineers, and agronomists. Evaluation of geothermal resources should be supported in Honduras, Costa Rica, and Guatemala. 
Panama has lower favorability for geothermal energy development, and El Salvador needs assistance in specific regions of the country rather than at a regional level. All countries could benefit from assistance in peat resource identification. Past efforts to identify coal resources should also be followed up. Wind and solar energy resources have been examined to varying degrees in all countries. In some countries, better measurement grids are required whereas in other countries, prefeasibility and feasibility studies are needed. Biomass resources in the form of fuel wood, bagasse, and other vegetable residuals already play a major role in the energy supply in most countries. Assistance in the determination of best uses for biomass resources would be helpful.

o Support the demonstration of new energy resources and technologies in the region.

As indigenous resources are quantified, feasibility of their use will need to be demonstrated. Prefeasibility and feasibility studies should be supported by AID, and advice on project financing should be provided. Smal1-scale demonstration of new technologies will be critical in some cases in fostering private interest in application of the resources and the technology of use. AID has already provided such assistance under their support for the end-use studies of peat and geothermal energy.

- Provide additional assistance in forest and watershed management and support efforts to foster conservation and substitution of fuel wood.

Rapid deforestation and resulting soil erosion, products of the unplanned expansion of agricultural frontier and other 1 and tenure problems, pose a serious threat to many watersheds that are currently used for hydroelectric generation. In the future, this alarming trend could have a double impact on the energy situation because deforestation reduces available fuel-wood supplies and soil erosion degrades existing watersheds and reservoirs. The latter result would decrease the size of the hydroelectric resources. Forest and watershed management will be critical for sustainable development strategies in the region. It is recognized that AID already provides significant support for fuel-wood studies on a worldwide basis; ROCAP and the Research and Instruction Center for Tropical Agronomy's (CATIE's) fuel-wood and watershed management projects are two important efforts in this direction. Additional support should be considered to include small demonstration projects and technical/economic feasibility studies for measures that could be implemented in the near term. The feasibility of energy farms and other agroforestry approaches as well as the possible use of peat, coal, and biogas as substitutes for fuel-wood need to be demonstrated. Concurrently, the creation of stable and organized markets for fuel-wood substitutes will require assistance. In addition, fuel wood could be conserved through the use of more efficient cooking stoves, an alternative that has been developed but one that deserves further efforts toward implementation. ICAITI has developed a more efficient stove, and a joint effort by Los Alamos and ICAITI is designed to test the use of peat in these stoves. 
The recommendations on programs to encourage substitution and conservation of $0 i 1$ products are based on efficiency concerns and reflect uncertainity over future oil prices. Most alternatives that are recommended will require costbenefit analyses to compare their favorability with continued use of oil under a variety of assumptions about future oil prices.

- Support a region-wide study of fue 1 oil substitutes and refined product supply.

With the exception of Panama, the refineries of Central America are generally small and rely mainly on atmospheric distillation of crude oil. If the refineries are operated to supply a large share of diesel or gasoline consumption, excess fuel oil results. The sale of this fuel oil has been subsidized to assist industries that purchase it. AIDsponsored studies, such as the study of wood substitution in Costa Rican industries performed by Meta Systems and LoS Alamos' studies of application of geothermal energy and peat for process heat, have or are expected to demonstrate that economic substitutes for fuel oil exist. It is recommended that AID support the systematic evaluation and comparison of all of the potential substitutes for fuel oil. Price subsidies to fuel oil should be re-examined. Such an effort can be carried out on a regional level.

Optimal supply of refined products is an issue that is related to continued operation of the refineries and to the subsidies on fuel oil. Under current market conditions for refined products in the Caribbean, where a series of large, newer refineries exist, continued operation of the small Central American refineries needs to be seriously examined. A free-market approach to oil product supply in Central America could prove to be beneficial.

- Support studies on incentives to cogeneration by the private sector and optimal sizing of electric capacity additions.

In addition to capacity expansions by national utilities, it is possible that the private sector could economically and willingly provide additional capacity if the proper incentives existed. The barriers to process heat sales by utilities al so need to be addressed. A study should be supported that examines the legal and institutional barriers to cogeneration and describes the possible benefits of electricity generation by the private sector. A seminar on optimal sizing of capacity additions could also benefit utility planners in the region. Interconnection of grids is a third method to improve the efficiency of electricity generation in Central America. The Economic Commission of Latin America and the IDB have sponsored studies of interconnection, and progress has been made. A Secretariat for interconnection of grids in the region has been recently established. Intercountry electricity sales have already occurred, and future sales will not depend upon whether agreements between neighboring governments can be reached. 
- Provide assistance for a regional study of fuel use in transportation.

Transport is expected to remain the largest oil-consuming sector in the region. To address the possibility of reducing oil imports, a study to evaluate the potential for conservation and substitution in the transport sector would be beneficial. Preliminary efforts carried out in Costa Rica with the support of AID confirmed that ample opportunities exist to conserve energy in transport. The relatively high price of gasoline and diesel in most countries should already encourage conservation of these fuels by individual motorists. Two countries produce alcohol from sugar cane; although this alcohol is exported, it could also substitute for gasoline. A comparative study of fuels to substitute for gasoline should also be performed.

The above recommendations address AID's objectives in energy assistance. The suggested areas of support include energy policy, resource identification and development, and efficient use of energy. Efficient use of imported energy and expanded use of indigenous resources, where economically feasible, will also contribute to broader goals of sustained economic growth in the region.

\section{REFERENCES}

1. Phil ip Palmedo, Andres Doernberg, Keith Oberg and Steven Kyle, "Energy and Development in Central America, The MITRE Corporation, February 1980.

2. Otto H. Bohnenberger and Gabriel Dengo, "Coal Resources in Central America," in Coal Resources of America, F. E. Kottlowski, A. T. Cross, and A. A. Meyerhoff, Eds., Geological Society of America Special Paper 179 (1978).

3. F. Tugwel1, "Cane/Energy Potential in AID Caribbean and Central American Countries," draft report to AID, January $6,1986$.

4. Richard E. Donovan, Hans Gregersen, Ian Hutchinson, Alan Randall, and Gina Green, "Final report of the Fuel wood and Alternative Energy Sources Project--CATIE-ROCAP," report prepared for ROCAP, U.S. Agency for International Development, San Jose, Costa Rica (July 15, 1986). 


\section{PART II \\ ENERGY SITUATION REPORTS FOR FIVE COUNTRIES}

COSTA RICA

EL SALVADOR

GUATEMALA

HONDURAS

PANAMA 



\section{COSTA RICA}

\section{CONTENTS}

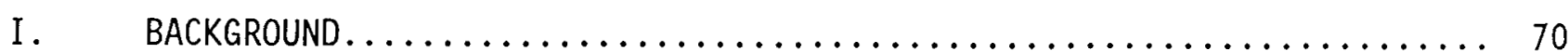

A. Political Situation/Government Structure................. 70

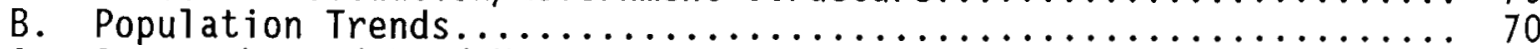

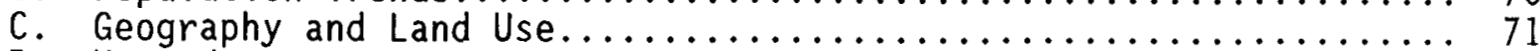

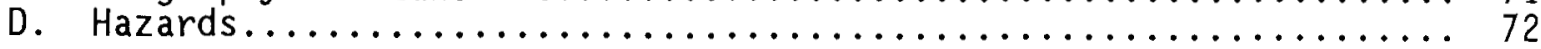

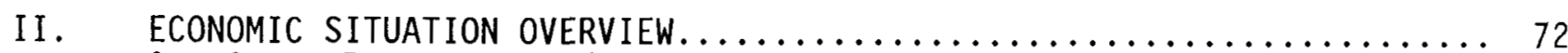

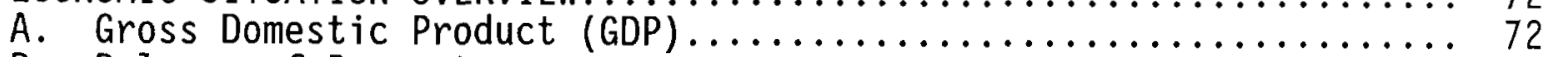

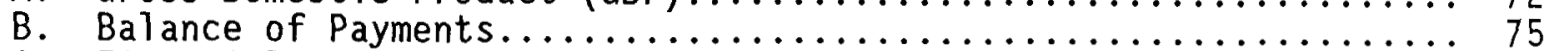

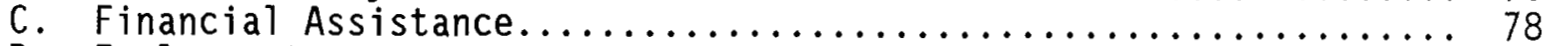

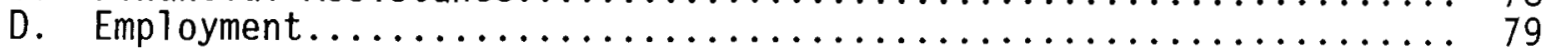

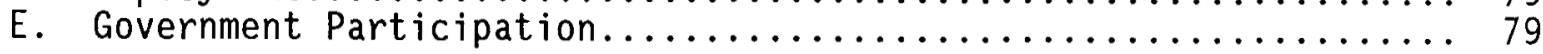

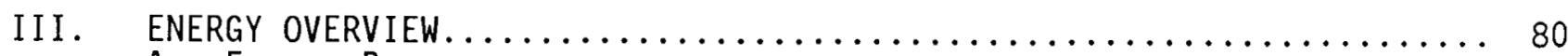

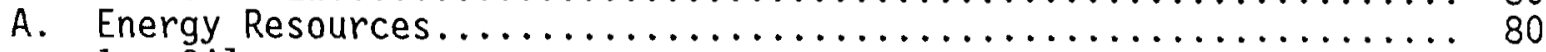

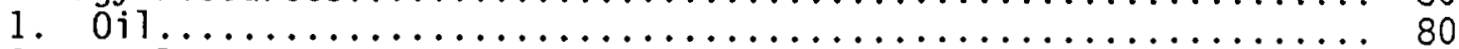

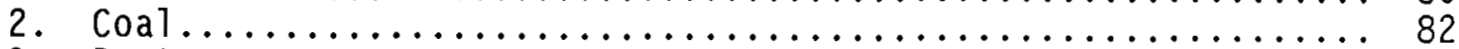

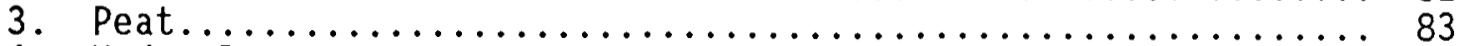

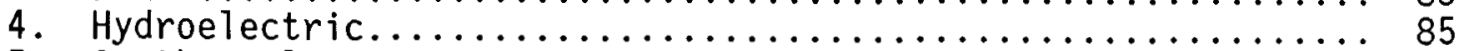

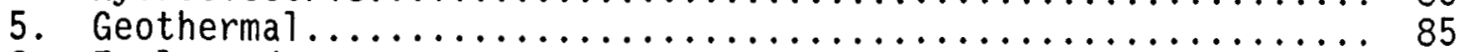

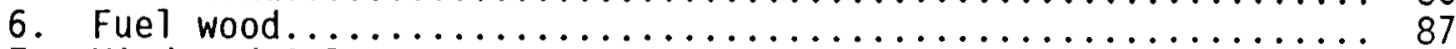

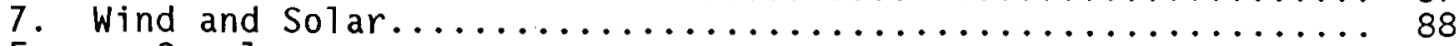

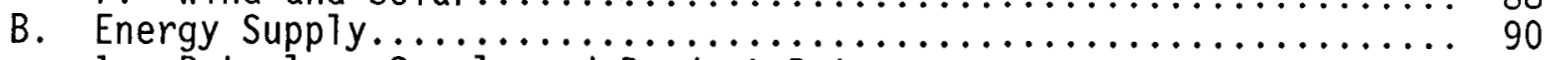

1. Petroleum Supply and Product Prices.................. 92

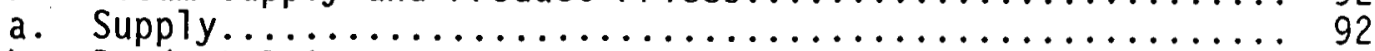

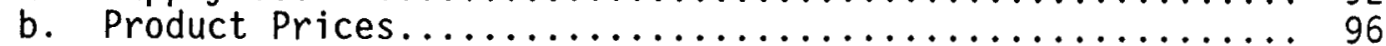

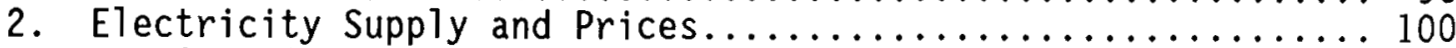

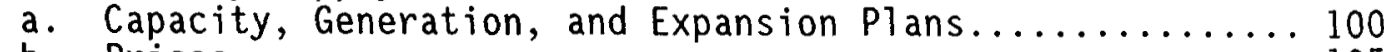

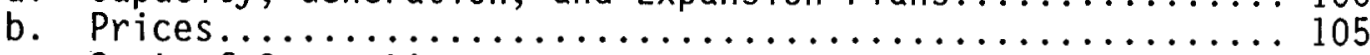

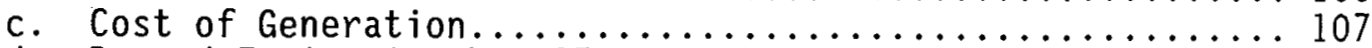

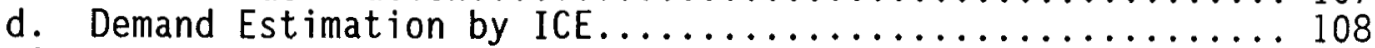

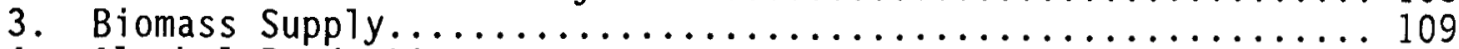

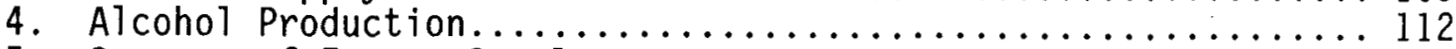

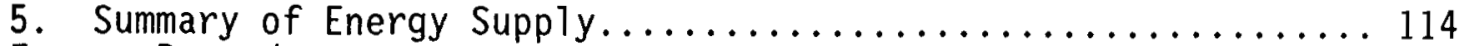

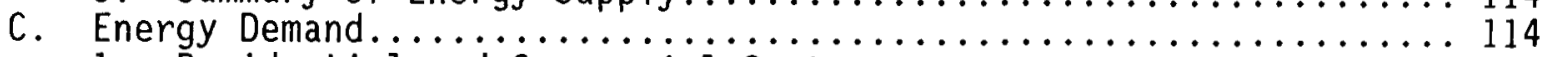

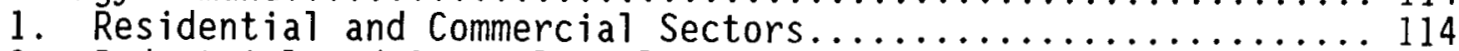

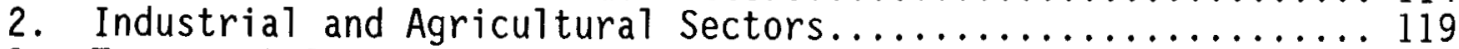

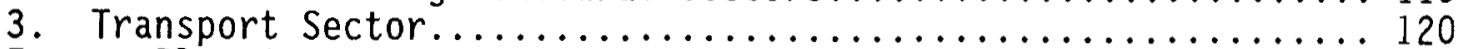

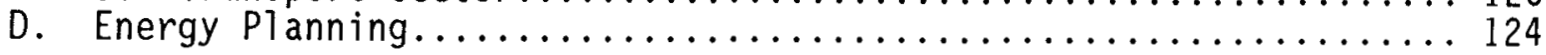




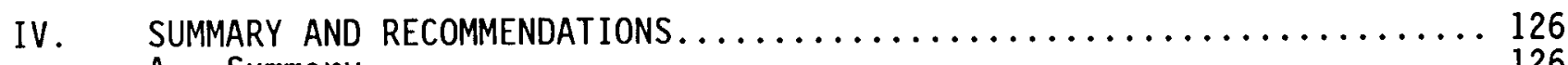

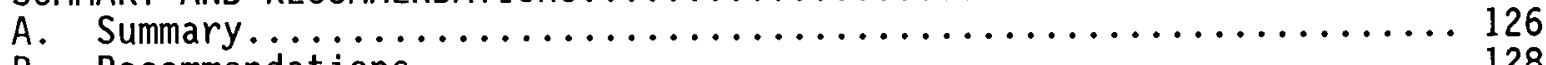

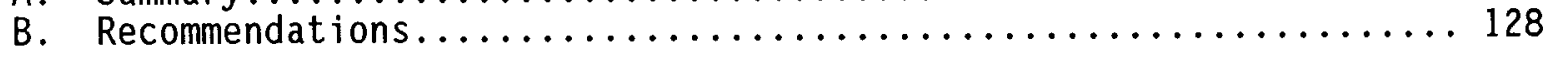

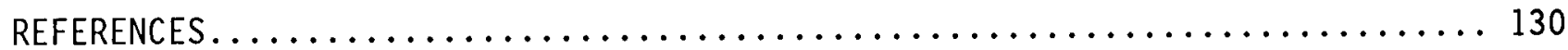




\section{LIST OF TABLES}

1. Costa Rica: Gross Domestic Product......................... 73

2. Costa Rica: Gross Domestic Product Growth Rates.................. 73

3. Costa Rica: Sectorial Contribution to Gross Domestic Product.......... 74

4. Costa Rica: External Public Indebtedness........................ 75

5. Costa Rica: Exports and Imports.......................... 77

6. Costa Rica: Exports and Imports (percentage of total)............ 78

7. Costa Rica: Estimated Peat Resources at Three Potential

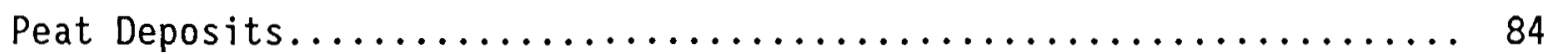

8. Costa Rica: Hydroelectric Resources........................ 86

9. Costa Rica: Information About Geothermal Localities................. 87

10. Costa Rica: Petroleum Imports............................ 93

11. Costa Rica: Refinery Production........................... 94

12. Costa Rica: Exports of Petroleum Products..................... 94

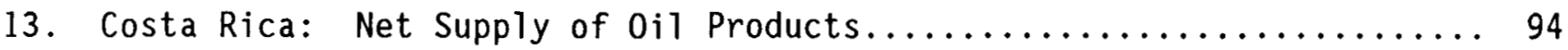

14. Costa Rica: Percentage of $0 i 1$ Products Imported................... 95

15. Costa Rica: Value of Petroleum Imports...................... 97

16. Costa Rica: Breakdown of Diesel and Gasoline Prices................ 97

17. Costa Rica: 0i1 Product Prices (colones)........................ 99

18. Costa Rica: Petroleum Product Prices (dollars)................... 99

19. Costa Rica: Petroleum Product Prices (1982 colones)............... 99

20. Costa Rica: Installed Electric Generating Capacity.............. 100

21. Costa Rica: Characteristics of Power Plants Owned by Public Sector.... 101

22. Costa Rica: Electric Generation............................. 102

23. Costa Rica: Energy Used to Generate Electricity................. 102

24. Costa Rica: Expansion Plans for Instituto Costarricense de

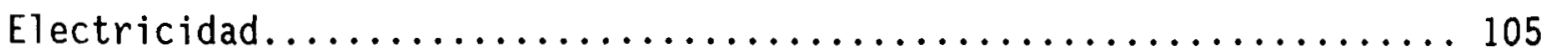

25. Costa Rica: Price of Electricity by Sector.................. 106

26. Costa Rica: Electricity Rates.......................... 106

27. Costa Rica: Sources of Wood Suppiy......................... 110

28. Costa Rica: Compounded Annual Average Growth Rates for

Energy Consumption, by Sector for Selected Years............... 115

29. Costa Rica: 1984 Energy Consumption (thousands of BEP) ............ 115

30. Costa Rica: 1984 Energy Consumption (percentage of total)............116

31. Costa Rica: 1984 Energy Consumption (percentage of fuel use

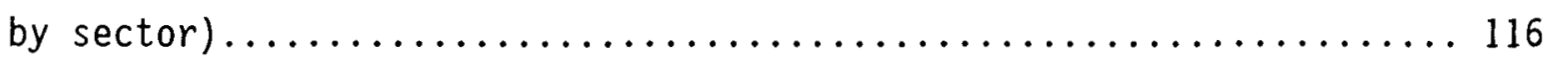


32. Costa Rica: Energy Consumption by Type for Residential and

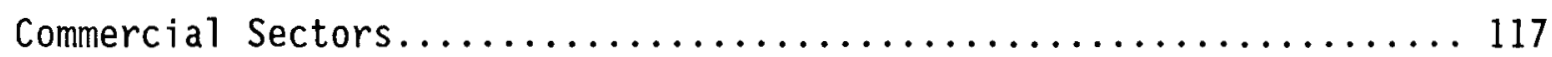

33. Costa Rica: Energy Consumption by Type in Industry and

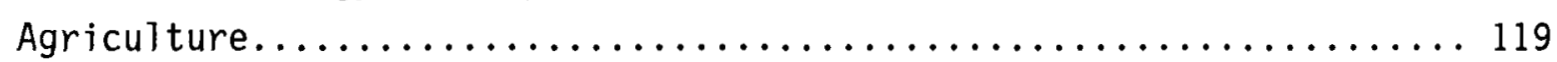

34. Costa Rica: Energy Consumption by Type for Transport Sector......... 121

35. Costa Rica: Motor Vehicles in Circulation According to Category

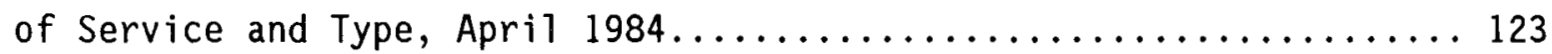

36. Costa Rica: Estimated Average Annual Consumption of Fuel by

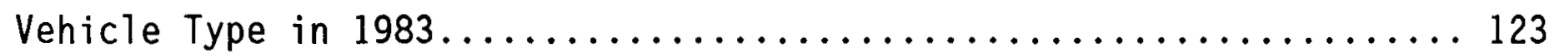

37. Costa Rica: Highway Vehicle Consumption by Vehicle Type, $1981 \ldots . . . .124$ 


\section{LIST OF FIGURES}

1. Costa Rica: GDP by major sector, $1970-1984 \ldots \ldots \ldots \ldots \ldots \ldots \ldots \ldots \ldots \ldots$

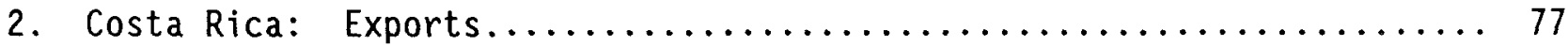

3. Costa Rica: Labor force by sector for $1983 \ldots \ldots \ldots \ldots \ldots \ldots \ldots \ldots \ldots \ldots . \ldots 79$

4. Costa Rica: Locations of $0 i 1$ exploration..................... 81

5. Costa Rica: Coal, peat, and geothermal resources.............. 82

6. Costa Rica: Energy flow diagram for $1984 \ldots \ldots \ldots \ldots \ldots \ldots \ldots \ldots \ldots \ldots \ldots$

7. Costa Rica: Changes in energy use....................... 91

8. Costa Rica: Value of oil imports as a percentage of GDP, exports,

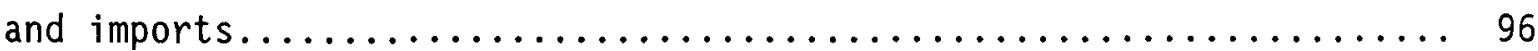

9. Costa Rica: Electricity transmission lines and locations of

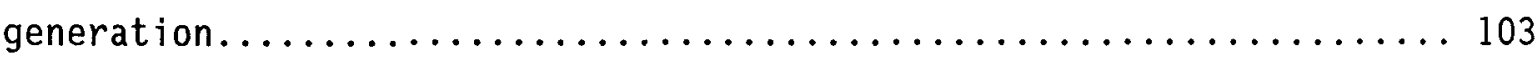

10. Costa Rica: Electricity load curve....................... 104 


\section{BACKGROUND}

A. Political Situation/Government Sturcture

Costa Rica enjoys a stable government. It has held regular elections since its independence in 1821. Beginning in 1981, the country faced a difficult financial crisis. The crisis required that Costa Rica institute austerity measures, such as wage controls, hiring freezes, and other measures. The new administration that took office in May 1986 is expected to continue many of the policies of the previous governments.

Costa Rica has a number of large autonomous national institutions that include the utility, Instituto Costarricense Electricidad (ICE), and the refinery Refinadora Costarricense de Petroleo, S.A. (RECOPE). In order to exercise control over these institutions, the president appoints the director of each. There is also an institution that regulates energy prices called Servicio Nacional de Electricidad (SNE). Another large institution, Corporacion Costarricense de Desarollo, S.A. (CODESA), was created in 1973 to help provide financing for industrial development. CODESA has been active in at least one energy project, the Tempisque sugar factory and distillery in Guanacaste province that produces alcohol. 'Because of the institution's unprofitability, the government is currently divesting itself of CODESA.

B. Population Trends

The current population is approximately 2.4 million. ${ }^{2}$ Costa Rica has one of the lowest population densities in Central America, with 47 people per square kilometer. The most recent census was in 1984, but these numbers were unavailable for inclusion in the report; hence, 1973 figures were used. The rate of population increase began to slow dramatically in the 1970s. In the 1960s, the rate of increase was approximately 4 percent per year, but this decreased to 2.6 percent per year in the 1970s, a trend that continues to the present. ${ }^{3}$ Much of the population is concentrated in the Central Valley, where roughly one half of the population lives in an area that equals approximately 5 percent of the land area of the total country. ${ }^{1}$ Approximately 48 percent of the population is considered urban. ${ }^{3}$ Migration from rural to urban areas is causing urban population to grow more rapidly than total or rural population. According to the census of 1973, the urban population was 40 percent of the total. According to the Direccion Sectorial de Energia (DSE), more than 85 percent of households have electricity, whereas ICE's figure is 75 percent. Houses that lack electricity are generally in isolated rural areas. As the Costa Rican population becomes more urbanized, and assuming that economic conditions do not drastically worsen, 
the consumption of fuel wood can be expected to gradually decrease because fuelwood use is generally focused in the rural areas.

Costa Rica has the lowest mortality rate in the region and the second lowest birthrate, 29.7 per 1000 inhabitants. Average 1 ife expectancy is highest for the region, at 72.5 years. ${ }^{3}$ Life expectancy is comparable to that in Panama but a third to a quarter higher than El Salvador, Honduras, and Guatemala.

c. Geography and Land Use

From northeast to southwest, Costa Rica comprises extensive lowlands along the $210-\mathrm{km}-1$ ong Caribbean coast, a sequential series of volcanic mountain ranges that run northwest-southeast, enclosing the fertile Central Valley, and a 1016$\mathrm{km}$-long Pacific coastline, which is fairly rugged and contains limited lowlands. Costa Rica has one of the highest annual rainfalls in the world, averaging 3300 $\mathrm{mm}$ per year. The rainy season starts in late April or early May and extends through mid-November. ${ }^{1}$

Approximately 19 percent of the country is covered by soils that are suitable for sustained production of clean-tilled field crops, and an additional 9 percent contains soils in the next lower class that are suitable for sustained grazing. Intermediate quality soils that can sustain coffee, cocoa, and citrus fruits cover an additional 16 percent of the area. In conclusion, 44 percent of the country's land is suitable for agricultural production. As of 1980 , pasture lands covered 37 percent of the country and clean-tilled crops, 4 percent, with pasture lands covering a substantial portion of the lands best suited to cleantilled field crops. Approximately 7 percent of the country's area is covered by swamps, lakes, and other inundated areas. The remaining approximate 20 percent comprises mainly protected areas. ${ }^{4}$

Deforestation is a significant problem in Costa Rica, as will be discussed in the section on fuel wood resources. As of 1977, 31 percent of the 1 and was covered with forests, and this percentage was decreasing at a rate of 1 percent of total land area per year. 4

According to the 1973 census, approximately 85 percent of Costa Rica's 77,000 farms are 1 to 50 hectares in size, and the remaining 15 percent are larger than 50 hectares. Small to medium farms covered about one-fifth of the farmland, and large farms covered four-fifths. ${ }^{1}$ This pattern of ownership favors small farmers more than in the most of Central America.

The major agricultural crops grown for export are bananas, coffee, cocoa, sugarcane, and a few "nontraditional crops" such as macadamia nuts and pineapple. Beef is also a significant food export. The major crops grown 
mainly for domestic consumption include beans, maize, plantains, potatoes, and rice.

The manufacturing sector is characterized mainly by light-and agroindustries. The establishment of the Central American Common Market was a significant stimulus to Costa Rican industries in the 1960s. Government policies in the 1970s favored the establishment of relatively capital intensive industries to produce goods that would substitute for imported final goods.

D. Hazards

The Cordillera de Guanacaste and the Cordillera Central are volcanic mountain ranges, and the latter contains two active volcanoes, Poas and Irazu. Costa Rica suffers occasional earthquakes. The most recent earthquake occurred in mid-1983 in San Isidro where it destroyed property and caused deaths and injuries.

\section{ECONOMIC SITUATION OVERVIEW}

A. Gross Domestic Product (GDP)

The per capita GDP of Costa Rica in 1984 was $\$ 1565$ in 1982 US dollars. This per capita GDP is the second highest in the region. ${ }^{3}$ Between 1970 and 1975, Costa Rica enjoyed a 6.0 percent per year average increase in real GDP and between 1975 and 1980, a 5.2 percent per year increase (Tables 1-2 and Fig. 1). By 1979, the latest oil price increase, the increase in interest rates, and the decreases in the price of exports all began to manifest themselves on the economy. Between 1979 and 1980, real GDP grew at only 0.8 percent. As Costa Rica entered a recession, GDP decreased for two years in a row, by 2.3 percent in 1981 and 7.3 percent in 1982. In 1982, the debt situation reached a cris is stage, as will be discussed in the balance of payments section. With the implementation of some austerity measures, refinancing of debt, and the worldwide recovery from the recession, Costa Rica's situation has improved. Real GDP increased by 2.3 percent between 1982 and 1983, and by a further 6.3 percent from 1983 to 1984. As of 1984, it had not yet reachieved its 1980 high.

The sectorial composition of Costa Rica's GDP has changed little since 1970, although the share contributed by the agricultural sector varies by crop yield and commodity prices (Table 3 ). Since 1980, it has ranged from a low of 18.0 percent in 1980 to 20.3 percent in $1982 .{ }^{5}$ On average, the biggest contributors to GDP are agriculture (20-25 percent); manufacturing (20 percent); trade (15-20 percent); and public administration and defense (10 percent) (percentages are general approximations). In general, the largest contributors to the GDP were not severely affected by the 1981-82 recession. Agriculture's 
TABLE 1

COSTA RICA: GROSS DOMESTIC PRODUCT

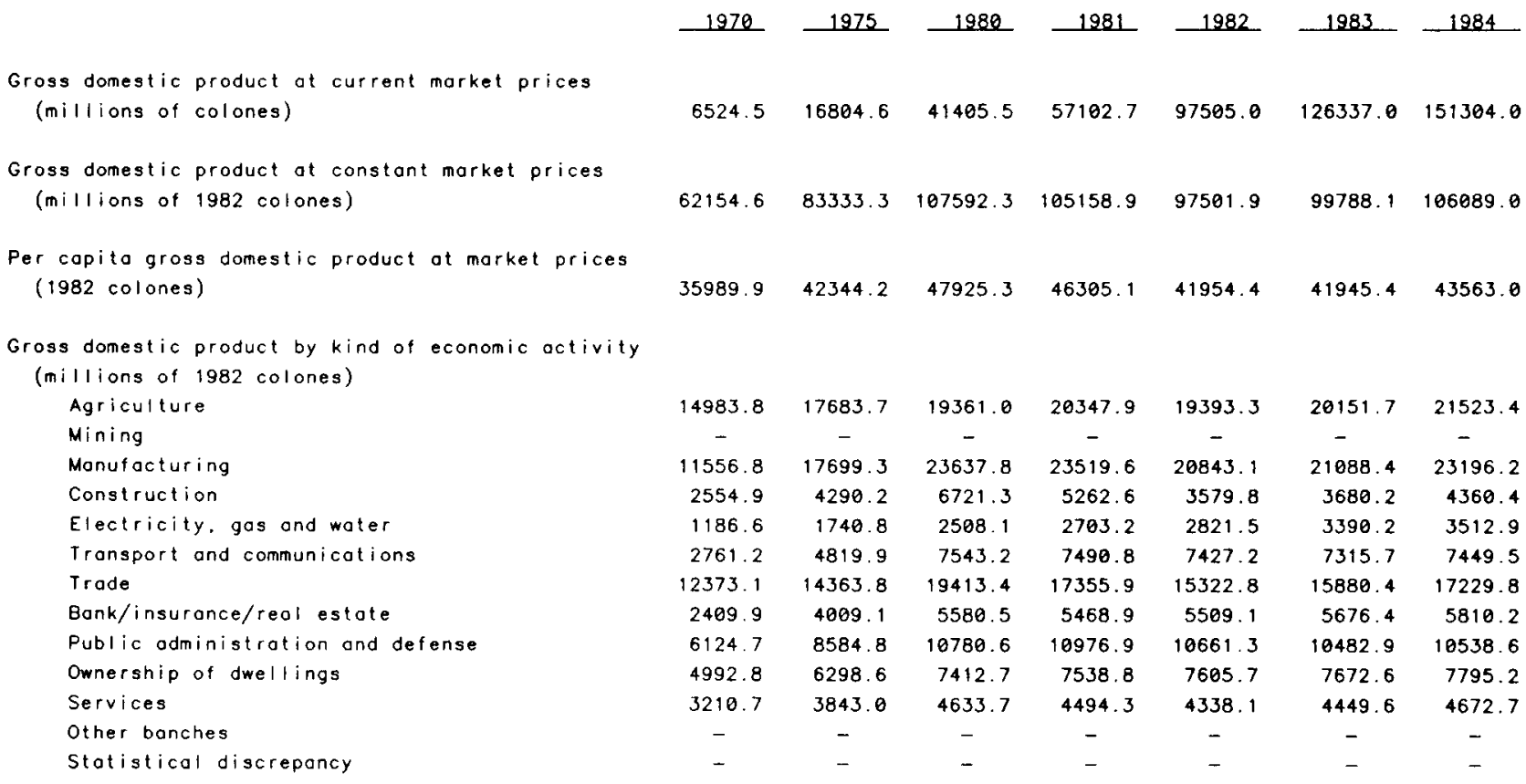

Source: Reference 2

TABLE 2

COSTA RICA: GROSS DOMESTIC PRODUCT GROWTH RATES

(percentage bosed on 1982 colones)

\begin{tabular}{|c|c|c|c|c|c|c|c|}
\hline & $1970-1975$ & $1975-1980$ & 1980 & 1981 & 1982 & 1983 & 1984 \\
\hline Gross domestic product ot constant market prices & 6.0 & 5.2 & 0.8 & -2.3 & -7.3 & 2.3 & 6.3 \\
\hline \multicolumn{8}{|l|}{ Gross domestic product by kind of economic activity } \\
\hline Agriculture & 3.4 & 1.8 & -0.5 & 5.1 & -4.7 & 3.9 & 6.8 \\
\hline Mining & - & - & - & - & - & - & - \\
\hline Monufacturing & 8.9 & 6.0 & 0.8 & -0.5 & -11.4 & 1.2 & 10.0 \\
\hline Construction & 10.9 & 9.4 & -1.1 & -21.7 & -32.0 & 2.8 & 18.5 \\
\hline Electricity, gas and water & 8.0 & 7.6 & 11.8 & 7.8 & 4.4 & 20.2 & 3.6 \\
\hline Transport and communications & 11.8 & 9.4 & 5.2 & -0.7 & -0.8 & -1.5 & 1.8 \\
\hline Trode & 3.0 & 6.2 & -3.0 & -10.6 & -11.7 & 3.6 & 8.5 \\
\hline Bank/insurance/real estate & 10.7 & 6.8 & 2.9 & -2.0 & B. 7 & 3.0 & 2.4 \\
\hline Public odministration and defense & 7.0 & 4.7 & 3.6 & 1.8 & -2.9 & -1.7 & 0.5 \\
\hline Ownership of dwellings & 4.8 & 3.3 & 2.4 & 1.7 & 0.9 & 0.9 & 1.6 \\
\hline Services & 3.7 & 3.8 & 0.8 & -3.0 & -3.5 & 2.6 & 5.0 \\
\hline Other branches & - & - & - & - & - & - & - \\
\hline Statistical discreponcy & - & - & - & - & - & - & - \\
\hline
\end{tabular}




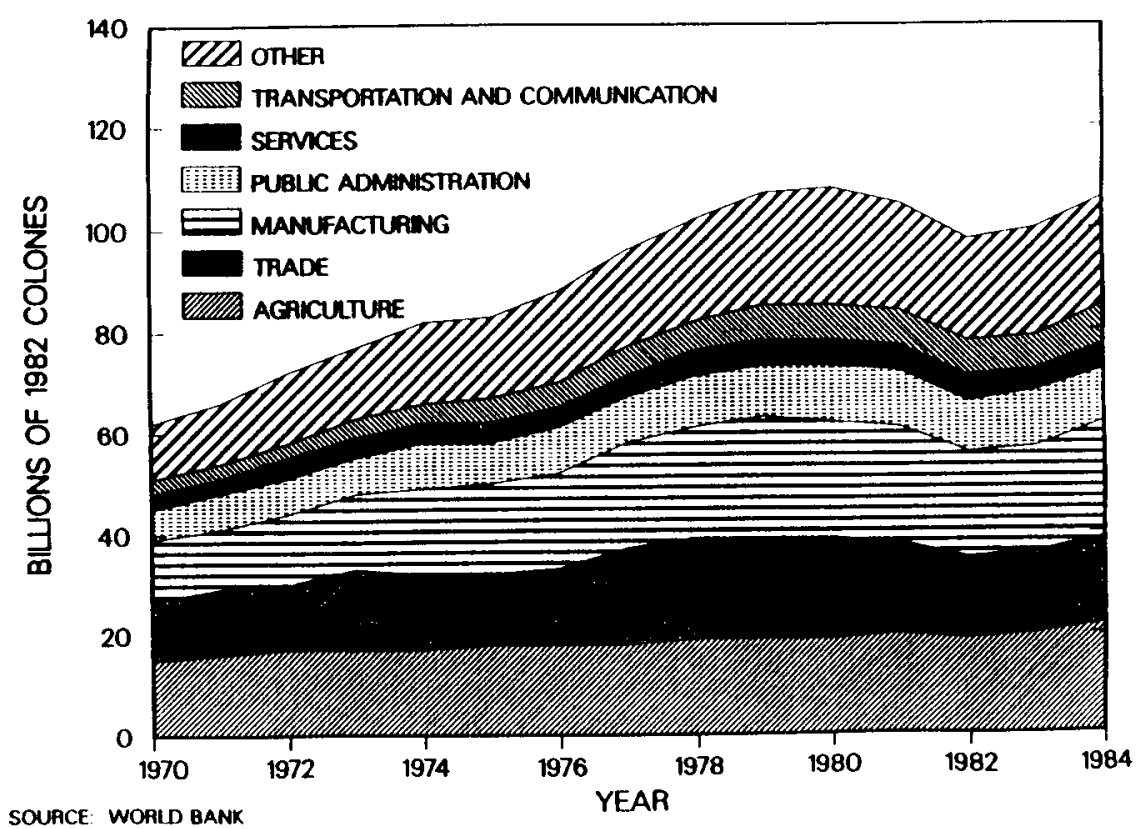

Fig. 1. Costa Rica: GDP by major sector, 1970-1984.

TABLE 3

COSTA RICA: SECTORIAL CONTRIBUTION TO GROSS DOMESTIC PRODUCT (percentoge based on 1982 colones)

\begin{tabular}{|c|c|c|c|c|c|c|c|}
\hline & 1970 & 1975 & 1980 & 1981 & 1982 & 1983 & 1984 \\
\hline \multicolumn{8}{|c|}{ Gross domestic product by kind of economic activity } \\
\hline Agriculture & 24.1 & 21.2 & 18.6 & 19.3 & 19.9 & 20.2 & 20.3 \\
\hline Mining & - & - & - & - & - & - & - \\
\hline Manufacturing & 18.6 & 21.2 & 22.8 & 22.4 & 21.4 & 21.1 & 21.9 \\
\hline Construction & 4.1 & 5.1 & 6.2 & 5.0 & 3.7 & 3.7 & 4.1 \\
\hline Electricity, gas and woter & 1.9 & 2.1 & 2.3 & 2.6 & 2.9 & 3.4 & 3.3 \\
\hline Transport and communicotions & 4.4 & 5.8 & 7.0 & 7.1 & 7.6 & 7.3 & 7.0 \\
\hline Trade & 19.9 & 17.2 & 18.0 & 16.5 & 15.7 & 15.9 & 16.2 \\
\hline Bank/insurance/real estate & 3.9 & 4.8 & 5.2 & 5.2 & 5.7 & 5.7 & 5.5 \\
\hline Public administration and defense & 9.9 & 10.3 & 10.0 & 10.4 & 10.9 & 10.5 & 9.9 \\
\hline Ownership of dwellings & 8.0 & 7.6 & 6.9 & 7.2 & 7.8 & 7.7 & 7.3 \\
\hline Services & 5.2 & 4.6 & 4.3 & 4.3 & 4.4 & 4.5 & 4.4 \\
\hline Other bronches & - & - & - & - & - & - & - \\
\hline Statistical discrepancy & - & - & - & - & - & - & - \\
\hline
\end{tabular}


contribution actually increased by 5.1 percent in 1981 , helping to mitigate the severity of the depression. Manufacturing decreased slightly in 1981 and by 11.4 percent in 1982 but then recovered to grow at a rate of 10 percent between 1983 and 1984. Hardest hit during the 1980-82 recession were manufacturing, construction, and trade. These sectors had recovered by 1983, and in 1984 their output grew at between 8.5 and 18.5 percent.

\section{B. Balance of Payments}

Like many of the developing countries, Costa Rica maintained a relatively high economic growth rate during the 1970s with the help of large loans available from foreign banks to cover shortfalls between production and consumption and exports and imports. When coffee prices began their decline in 1979 and reached their bottom in the middle of 1981, Costa Rica's ability to earn enough foreign exchange to service its debt was seriously affected. At the same time, interest rates began to climb, making it infeasible to borrow more money to service debt. The oil price increase of 1978-79 had already put a strain on foreign exchange requirements for necessary imports.

By 1982, Costa Rica had the highest per capita foreign debt in the world, amounting to more than $\$ 1000$. The total debt was $\$ 2.6$ billion, which increased to $\$ 3.4$ billion in 1984 (Table 4 ). In what was characterized as the worst economic crisis in thirty years, President Carazo Odio's government suspended debt servicing on loans to commercial banks in August 1981, while debt service

TABLE 4

COSTA RICA: EXTERNAL PUBLIC INDEBTEDNESS

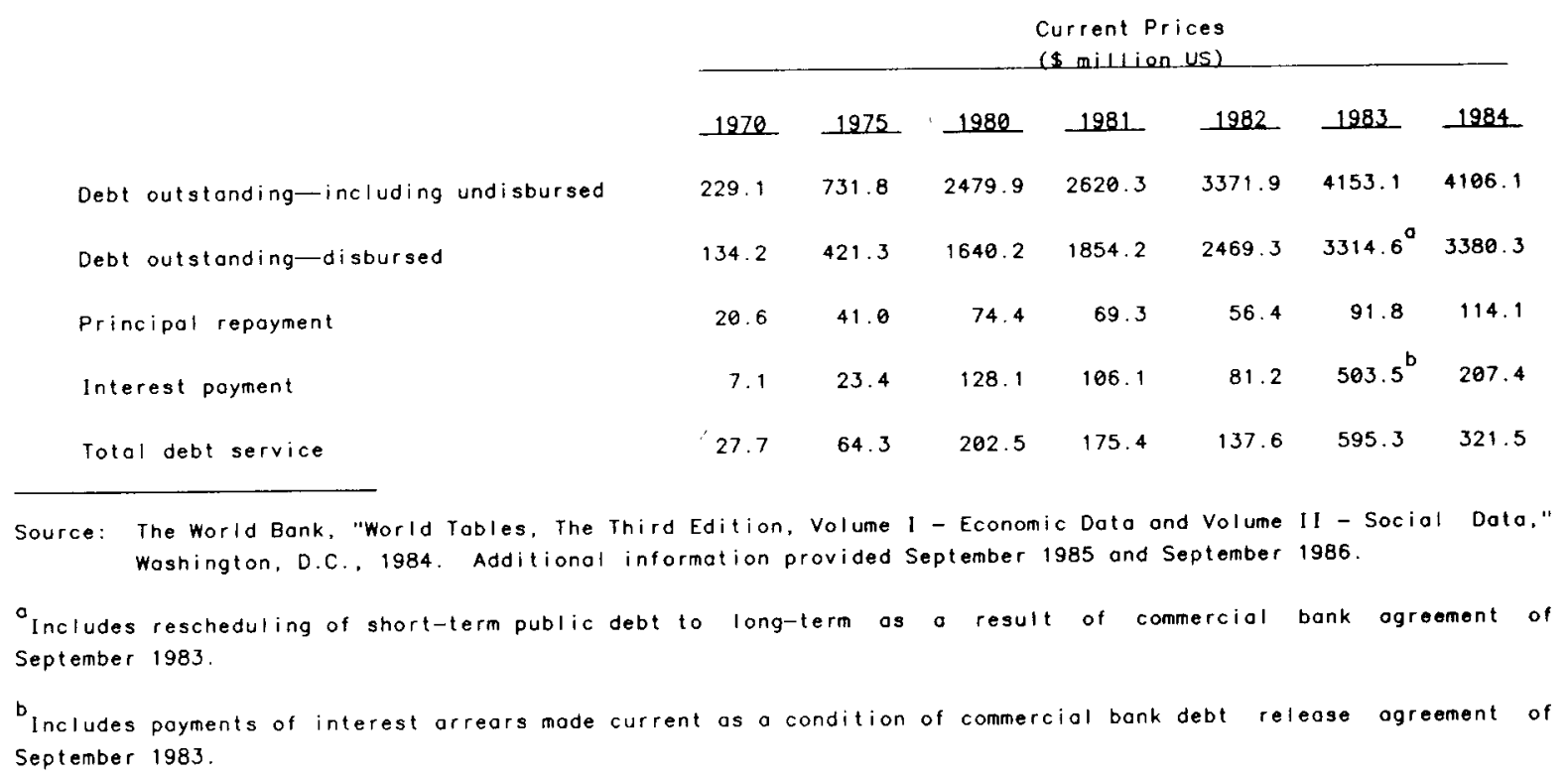


to multilateral banks continued. The International Monetary Fund (IMF) authorized emergency aid in both 1980 and 1981 but had twice rescinded it when not all of the required austerity measures were imposed. The colon was allowed to float in 1981. When President Monge took office, he inherited a nearly bankrupt country and took immediate steps to alleviate the situation by imposing austerity measures and procuring emergency aid from the IMF. Only a fraction of the scheduled payments due commerical banks was paid in the latter half of 1982 and in September 1983 , payments to commercial banks were renegotiated. Bilateral loans were also rescheduled in 1983. Because debt service payments were resumed in 1983, debt service grew from approximately $\$ 140$ million in 1982 to almost $\$ 600$ million in 1983 . In 1983 , debt service amounted to approximately 36 percent of the value of goods and nonfactor services exports. In 1984, this percentage decreased to 26.5 percent, in part because some scheduled interest and amortization were not paid. ${ }^{3}$ Given the country's indebtedness, debt service will remain large.

With the exception of 1982 , when the country could not afford many imports, Costa Rica has had a negative trade balance for the period under consideration. Costa Rica's main imports are crude petroleum and petroleum products (which generally account for one-eighth to one-fifth of the total value of imports), raw materials for industry (comprising about one-third of imports), and consumer durables. The quantity of petroleum imports significantly decreased in 1981 and 1982.

Costa Rica's main exports are coffee, bananas, sugar, and beef. Since 1980 , total exports of approximately $\$ 900$ to $\$ 1000$ million have comprised approximately 25 percent coffee, 20-25 percent bananas, 4-7 percent beef, and 2-4 percent sugar (Fig. 2 and Tables 5-6). Costa Rica has been hard hit by changes in prices of its export commodities. Coffee prices almost doubled during 1979 from $\$ 1.25$ to $\$ 2.50$ per pound and then collapsed to less than $\$ 1.00$ per pound by the first quarter of 1981. During 1984 and 1985, the price has been approximately $\$ 1.50$ per pound. Costa Rica's coffee production equals about 2 percent of world production of almost 100 million bags. Costa Rica's quota for exports under the International Coffee Organization was 220,000 60-kilogram bags, and Costa Rica sought a 150,000-bag increase in its quota in 1985 . The country had a 1 -million bag surplus in $1984 . .^{5}$ The volume of Costa Rican coffee exports was roughly equal in 1970 and 1980. Since 1980, coffee exports have increased by 50 percent.

According to IMF statistics, the unit value of banana exports increased significantly, almost tripling between 1980 and 1981. This is owing to the 


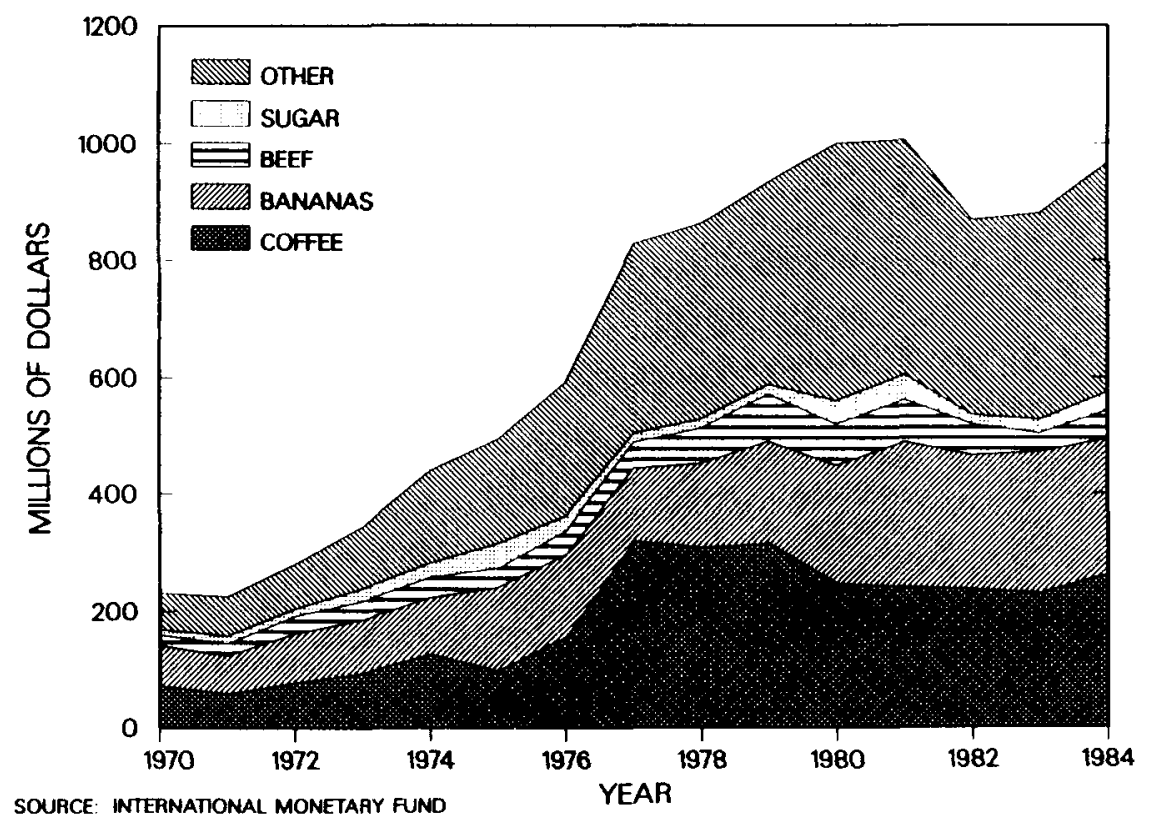

Fig. 2. Costa Rica: Exports.

TABLE 5

COSTA RICA: EXPORTS AND IMPORTS

\begin{tabular}{|c|c|c|c|c|c|c|}
\hline \multicolumn{7}{|c|}{$\begin{array}{l}\text { Current Prices } \\
\text { (\$ million US) }\end{array}$} \\
\hline 1970 & 1975 & 1980 & 1981 & 1982 & 1983 & 1984 \\
\hline 231.2 & 493.3 & 1001.8 & 1008.1 & 870.4 & 882.4 & 966.8 \\
\hline 73.1 & 96.9 & 246.5 & 240.7 & 236.9 & 230.1 & 261.8 \\
\hline 66.8 & 144.1 & 201.2 & 246.9 & 228.1 & 240.3 & 231.8 \\
\hline 10.1 & 42.3 & 40.5 & 43.1 & 16.6 & 23.9 & 31.6 \\
\hline 18.0 & 32.6 & 70.7 & 74.0 & 53.1 & 31.9 & 49.2 \\
\hline 316.7 & 694.0 & 1540.4 & 1208.5 & 889.0 & 987.8 & 1087.0 \\
\hline 0.5 & 60.0 & 201 & 171.9 & 168.7 & 164.3 & 93.6 \\
\hline 284.8 & 624.6 & 1387.7 & 1088.8 & 800.9 & 889.9 & 979.3 \\
\hline & & & Indexes & & & \\
\hline
\end{tabular}

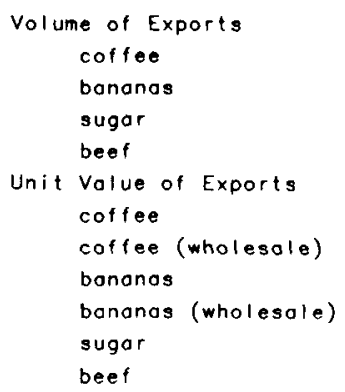

$\begin{array}{rr}96.8 & 108.0 \\ 88.0 & 113.6 \\ 94.3 & 98.3 \\ 67.4 & 115.1 \\ & \\ 23.7 & 36.4 \\ 25.9 & 48.1 \\ 29.2 & 63.1 \\ 34.2 & 65.5 \\ 20.5 & 106.2 \\ 29.2 & 40.1\end{array}$

$\begin{array}{rrr}100.0 & 135.0 & 131.4 \\ 100.0 & 103.0 & 104.1 \\ 100.0 & 192.8 & 76.7 \\ 100.0 & 128.0 & 93.5 \\ 100.0 & 183.7 & 319.2 \\ 100.0 & 195.1 & 363.8 \\ 100.0 & 392.6 & 475.5 \\ 100.0 & 271.8 & 436.1 \\ 100.0 & 262.5 & 233.0 \\ 100.0 & 207.5 & 350.1\end{array}$

$151.8 \quad 153.1$ $104.0 \quad 103.1$

Source: International Monetary Fund, "International Financiol Statistics Yearbook 1985," Washington. D.C. 
TABLE 6

COSTA RICA: EXPORTS AND IMPORTS

(percentoge of total)

Exports

coffee

bonanas

sugar

beef

other

Imports, c.i.f

petroleum
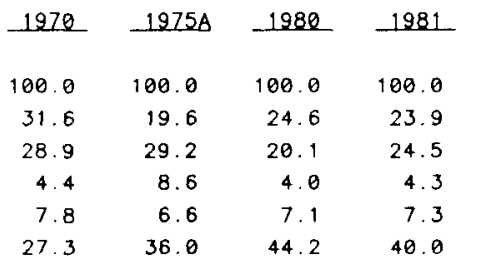

0. 2

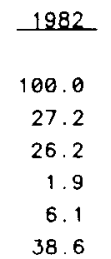

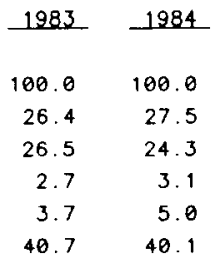

$\begin{array}{llllll}8.7 & 13.1 & 14.2 & 19.0 & 16.6 & 13.3\end{array}$

devaluation of the colon. Costa Rica's center of banana production is shifting from the Pacific to the Atlantic coast. Bananas from the Pacific coast were shipped to Japan and California, but the Philippines have taken over the Japanese market, and other Latin American countries are competing in the California market. 6 Costa Rica has a disadvantage because of a relatively high export tax of $\$ 0.70$ per box (based on a per box-price of \$3.40). United Fruit decreased banana plantings by 3400 hectares on the Pacific side, but the government hopes to increase plantings on the Atlantic side by 3000 hectares. A hurricane in May 1985 destroyed 3000 hectares of banana plants in the At 1 antic side of the country. ${ }^{5}$ Prices have fluctuated significantly between 1970 and 1984 , peaking at $\$ 429$ per metric ton in 1983 , the last year in which price data were available to the author.

Sugar prices increased sharply from $\$ 0.08$ per pound in July of 1979 to reach a peak of $\$ 0.46$ per pound in late 1980 . A precipitous decline followed, and prices decreased to $\$ 0.08$ per pound again by July of 1982 . Prices are currently at one of their lowest levels since World War II. * The volume of Costa Rican sugar exports has fluctuated considerably between 1970 and 1980 owing to crop yield. For example, the volume declined by 25 percent in 1982 but greatly increased in 1984. Approximately one-third of 1985 production will be devoted to alcohol production.

C. Financial Assistance

During the 1970s, Costa Rica received only a few million dollars per year in financial assistance. However, that picture changed in the 1980s. In 1985,

* Information obtained from the Coffee, Sugar, and Cocoa Exchange.

**Information obtained from Liga Agricola Industrial de Cana de Azucar. 
Costa Rica received approximately $\$ 200$ million in financial assistance from the US government. The country has been the recent recipient of $\$ 50$ million from the IMF, $\$ 75$ million from commercial banks to pay interest on existing debt, and $\$ 80$ million from the World Bank. ${ }^{7}$

D. Employment

In 1984 or 1985, the government employed 34 percent of the 1 abor force, agriculture employed slightly more than one-quarter of the labor force, and manufacturing was the third largest employer, with over 15 percent of the labor force (Fig. 3). The unemployment rate was 8 percent in 1984; underemployment is estimated at approximately 20 percent. Real wages declined by one-third between 1980 and $1984 .^{8}$

\section{E. Government Participation}

The Costa Rican government is trying to stimulate investment, decrease the public debt, and diversify exports. The main state-owned holding company, CODESA, is being divested. Much of the 1970's growth was stimulated by debt financing of large public projects, some of which turned out to be unprofitable in the long run.

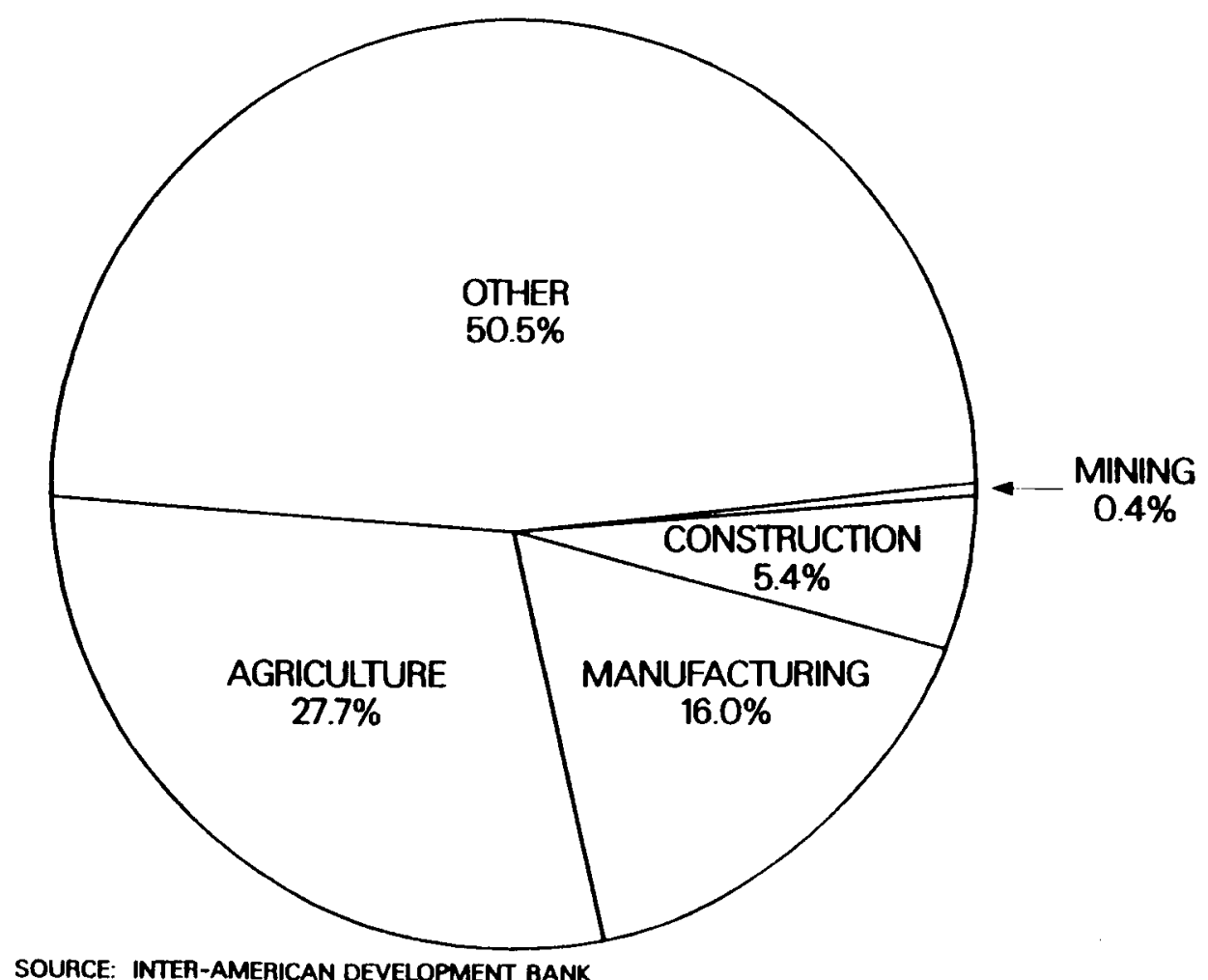

Fig. 3. Costa Rica: Labor force by sector for 1983. 


\section{ENERGY OVERVIEW}

\section{A. Energy Resources}

1. 0il. Costa Rica has no petroleum reserves, but parts of the country are considered to have potential for oil discovery. Potential petroleum resources are estimated to be $10-20$ million TEP in small deposits; ${ }^{4}$ i.e., they are relatively small. Currently, the responsibility for petroleum, coal, and peat exploration rests with RECOPE, the national petroleum company.

Past exploration that has been done in Costa Rica is described briefly below. Historically, oil exploration had been carried on by US firms. From 1918 through 1924, a subsidiary of Sinclair 0il drilled five holes in Limon Sur and found indications of $0 i 1$ in all of them. From 1951 through 1959, Union 011 carried out exploration in the region and transferred its rights to Gulf oil, which explored until 1963. The companies conducted geologic, aeromagnetic and seismic reflection studies. A total of sixteen holes were drilled and most of these contained $0 i 1$ and gas showings, with a flow of 1300 barrels per day from one of the holes for a short time. From 1966 through 1975, a French company, ELF of Costa Rica, explored for oil, focusing mainly on the Atlantic platform. ${ }^{9}$

Starting in 1980, the government decided to carry out exploration through RECOPE and CODESA. Much information gathered by RECOPE since 1980 confirms that there is potential along areas of the Pacific coast and that the areas of potential along the Caribbean are far more extensive than previously thought. The scope and coverage of RECOPE's exploratory activities are shown in Fig. 4. A11 sedimentary basins, except in the country's center, have been covered with some exploration. The Gulf of Nicoya, the Limon Sur basin, the northern part of the San Carlos-North Limon Basin and a few isolated areas have been the subject of more detailed studies. RECOPE's studies have culminated in the drilling of a hole referred to as San Jose No. 1 by PEMEX, the Mexican state oil company, in the Limon Sur basin, not far north of the Panamanian border. The hole achieved a depth of $4843 \mathrm{~m}$, and exposed four zones with potential for production. The drilling done by PEMEX was under a contract with RECOPE that stated that any oil discovered belongs to RECOPE. There have been problems between PEMEX and RECOPE concerning the drilling contract. The original agreement to dri11 10,000 $\mathrm{m}$ in two wells was not fulfilled. ${ }^{9}$

Since 1982, RECOPE has drilled 3344 holes, totaling $88,000 \mathrm{~m}$ in depth. San Jose No. 1 is the deepest hole. In addition to the San Jose No. 1 activity, RECOPE has been intensely involved in a second project referred to as Campo 

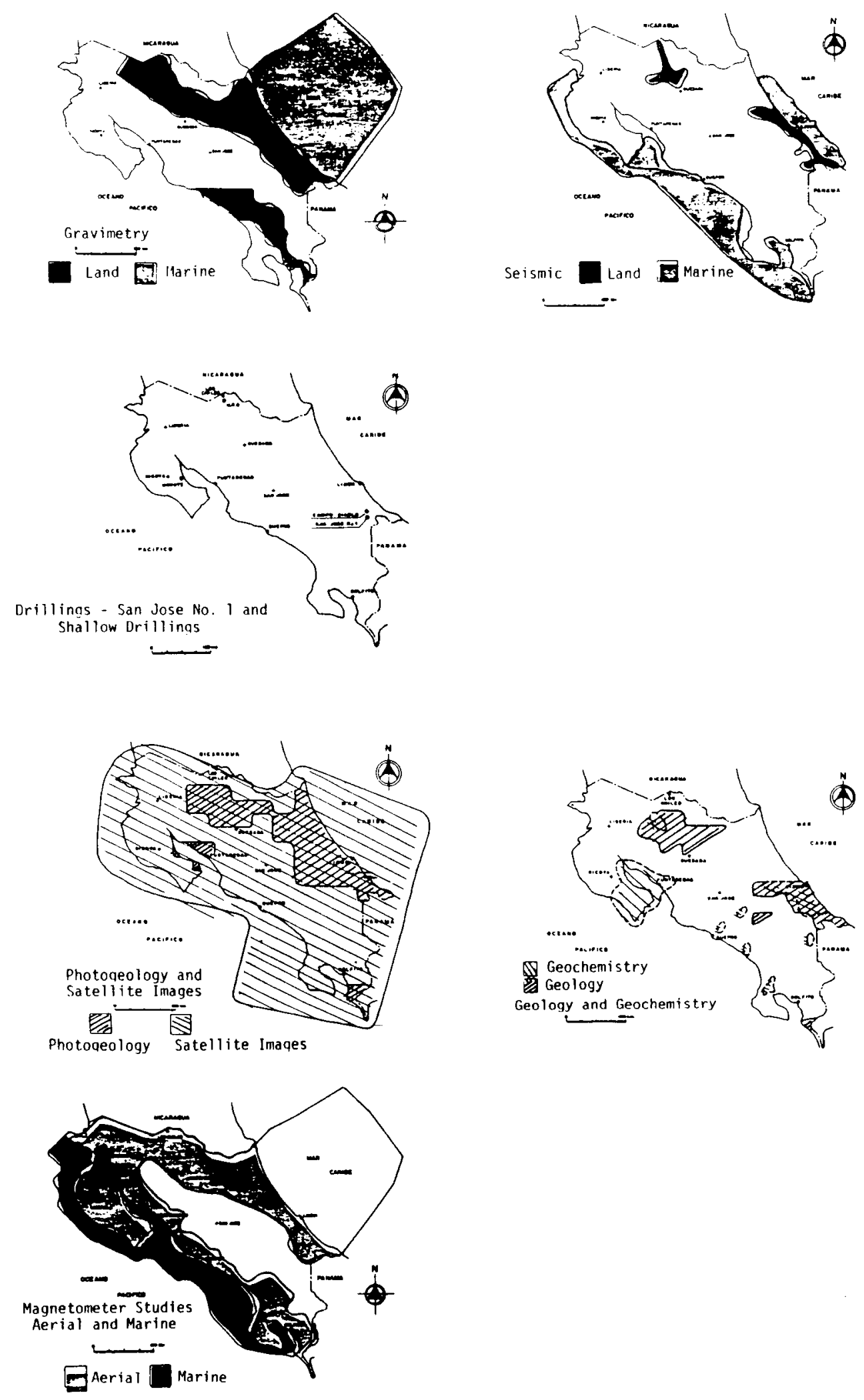

Fig. 4. Costa Rica: Locations of oil exploration. 
Diablo in the Talamanca, where the company is following up work done by Gulf 0i1. They have found small to medium indications of gas and oil. 9

The zones considered to have the most potential by RECOPE are Limon Norte, Limon Sur, the Atlantic Platform, the San Carlos Basin, the Pacific Platform, the Southern Pacific Platform, and the Northern Pacific platform. ${ }^{9}$

RECOPE has been assisted in their exploration efforts by the World Bank, PEMEX, the University of British Columbia, and may have potential projects with Petrocanada, Rompetrol, and other companies. ${ }^{10}$

Implementation of a hydrocarbon 1 aw was being considered that would also allow exploration by private state or multinational corporations under a risk contract. The law has yet to be approved by the Costa Rican Congress. Under the proposed legislation, RECOPE's annual exploration budget would decrease slightly to form its current level of approximately $\$ 6$ million per year, and it is hoped that private exploration expenditure would greatly increase to a level of over $\$ 30$ million per year by 1990.11

2. Coal. Areas in Costa Rica with known coal potential are shown on Fig. 5. The areas that have been most thoroughly investigated are Zent, Volio (also referred to as Uatsi), and Venado.

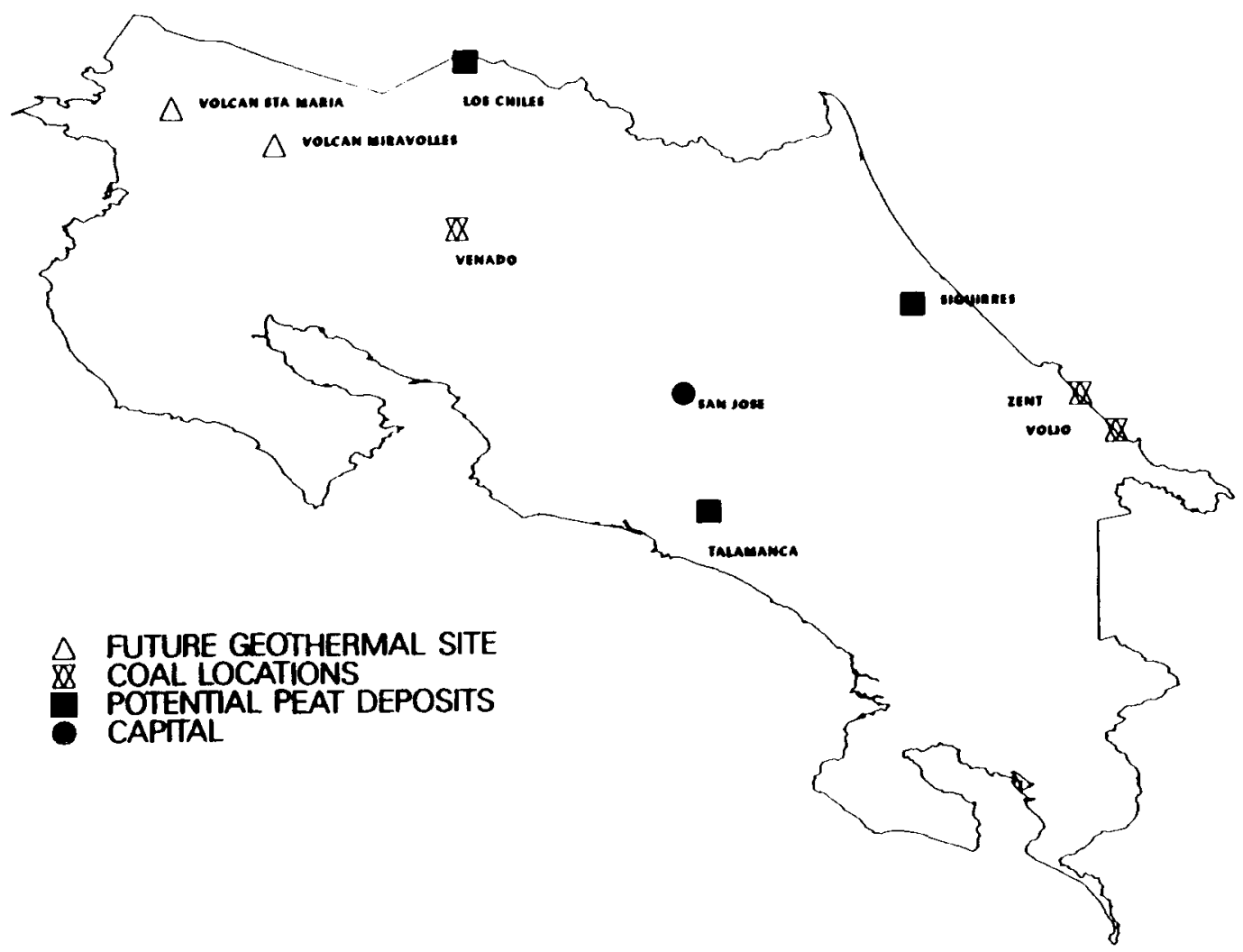

Fig. 5. Costa Rica: Coal, peat, and geothermal resources. 
Limited coal exploration was carried out in Costa Rica between 1850 and 1964. In 1964, the Direction of Geology, Mines, and Petroleum reported the occurrence of coal at Zent. In the same year, Instituto Costarricense de Electricidad (ICE) began reconnaissance exploration around Venado. In 1966, ICE studied the coal around Zent and Venado. In 1979, ICE embarked on a reconnaissance exploration around Uatsi (Volio) that was to lead to prefeasibility work. ICE obtained technical assistance from Japan in 1981 to conduct their work at Uatsi. In the same year, a US Geological Survey mission visited Costa Rica to obtain information on coal resources. RECOPE was given responsibility for coal exploration and development in 1982. Since that time, they have carried out work in eight areas in the country. A summary of the results of some of this work follows: ${ }^{12}$

Volio--A 1983 estimate of reserves was 10 million tons of subbituminous coal with a heat content of $5200-5500 \mathrm{Kcal} / \mathrm{kg}$. Feasibility work started in this area in 1984. A 1985 estimate of the thickness of the coal-bearing zone was $1.8 \mathrm{~m}$.

Venado--Prefeasibility work conducted here during 1984 indicated the presence of a $4-m$-thick zone that varies in type from lignite to subbituminous coal. The heat content of this material varies from $3600-4200 \mathrm{Kcal} / \mathrm{kg}$. Reserves were estimated in the beginning of 1985, and RECOPE expects to begin feasibility work here in 1985.

Zent--Reconnaissance work started here in 1984. A carboniferous zone is $7 \mathrm{~m}$ thick. Material from this zone has a heat content that ranges from 4500 $5000 \mathrm{Kcal} / \mathrm{kg}$. Prefeasibility work was scheduled to begin here in August 1985.

3. Peat. The peat resources of Costa Rica have not been systematically explored, but Costa Rica is considered to have great potential for economic deposits of peat. RECOPE is in charge of peat exploration and development. The following information is summarized from results of a preliminary examination of a few peat occurrences by RECOPE and LOS Alamos scientists. * The location of the potential peat deposits of Costa Rica are shown in Fig. 5. As more thorough exploration is conducted, this map is expected to change. The three locations that have been examined thus far are the Rio Medio Queso flood plain on the northern border, the Talamanca Mountain cloud forest region in south-central Costa Rica, and a sma11, swampy jungle site on the northeastern coastal plain

* A. D. Cohen, R. Raymond, Jr., and W. Spackman, "Trip Report: Peat End-Use Study, Costa Rica," Los Alamos National Laboratory memorandum, June 5, 1985. 
near Siquirres. A summary of the peat resource estimate is shown in Table 7 . The resource potential of Costa Rica is considered to be far greater than the sum of the resource estimates for three particular sites. The reader is cautioned that peat quality, like coal quality or grade, varies considerably and tonnages of peat from various deposits cannot be simply added together without regard to chemical or physical characteristics.

The Rio Medio Queso potential peat area is $70 \mathrm{sq} \mathrm{km}$ with a peat thickness of $60 \mathrm{~cm}$. An initial estimate of the resource is $8.4 \mathrm{million}$ tons (dry). These peats have the highest heating value, fixed carbon and total carbon of the costa Rican peats sampled, but the lowest volatile matter.

The Talamanca peats have a potential aerial extent of $175 \mathrm{sq} \mathrm{km}$ and an average thickness of $1 \mathrm{~m}$. The estimate of the resource is 38.5 million tons (dry). The relative inaccessibility of some of these peats suggests that exploitation for energy production on a large scale may be less attractive than local exploitation of small, deep deposits for local use. The peats sampled in the Talamancas had the highest acidity and were the most decomposed, but they had a high volatile content, suggesting that they could be used for agricultural purposes or energy purposes.

The Siquirres site is relatively small (2 sq $\mathrm{km}$ ) but it represents only one of several such deposits that are thought to exist in the vicinity. It is felt that much larger deposits exist in the region, and further exploration is needed. The peats are more than $7 \mathrm{~m}$ thick. The heat content of the peat was lower than that of the other sites. The peat has the highest fiber content, the lowest bulk density, and a relatively high sulfur content $(0.6 \%)$.

A study of potential end uses for peat is being conducted jointly by Los Alamos and RECOPE. Given the chemical and physical variability of peat among deposits, not all peats are suited for all applications. A preliminary report summarizing potential end uses for Costa Rican peats has been completed.

TABLE 7

COSTA RICA: ESTIMATED PEAT RESOURCES AT THREE POTENTIAL PEAT DEPOSITS

\begin{tabular}{|c|c|c|c|c|}
\hline Site & $\begin{array}{l}\text { Depth } \\
\text { (m) }\end{array}$ & $\begin{array}{l}\text { Aerial Extent } \\
-(\mathrm{se} . \mathrm{km})\end{array}$ & $\begin{array}{c}\text { Heot } \\
(B T U / \mid b) \\
(d r y) \\
\end{array}$ & $\begin{array}{l}\text { Resource } \\
\text { Estimate } \\
(\text { MiLion t) }\end{array}$ \\
\hline Talamanca Mts. & 1 & 175 & 7743 & 38.5 \\
\hline Rio Medio Queso & 0.6 & 70 & 7980 & 8.4 \\
\hline Siquirres & 7 & 2 & 7463 & $\underline{-}$ \\
\hline
\end{tabular}

Source: A. D. Cohen, R. Raymond, Jr. and W. Spackman. "Trip Report, Peot End Use Study, Costa Rica," Los Alamos National Laboratory, June 5, 1985. 
4. Hydroelectric. ICE is responsible for development and protection of the hydroelectric resources of the country. ICE monitors flow rates of the major rivers, which are characterized as short rivers with steep gradients. The general characteristics of the major watersheds in Costa Rica are summarized in Table 8. Water resources are considered to be Costa Rica's major energy resource. ICE generated 98.5 percent of the country's electricity from utilization of hydropower in 1983. The total maximum theoretical hydro potential of the country, based on average gross runoff, is estimated to be approximately 223,000 GWh per year. Of this total, the economically exploitable hydroelectric resource is considered to be $37,000 \mathrm{GWh}$ per year, or a potential of plant capacity totaling $8,550 \mathrm{MW}$, assuming a 49 percent utilization factor. ${ }^{13}$

The amount to which the hydroelectric resource can be utilized depends on costs of construction of new hydroelectric facilities relative to other alternatives and the need for new electricity generating capacity. According to Hartshorn et al., 4 "Virtually every major watershed in the country is being degraded by deforestation and inappropriate land use... ICE should be protecting critical watersheds even before start of a hydroelectric project, rather than after construction is completed."

5. Geothermal. The following discussion of Costa Rica's geothermal potential is based on Corrales (1985). ${ }^{14}$ Areas of Costa Rica that are considered to have potential for geothermal development are listed in Table 9. Miravalles is under development with assistance from Italy, but very little is known about the other locations. No systematic geothermal reconnaissance has been performed in Costa Rica, but Los Alamos geologists may begin a reconnaissance program there around the beginning of 1986 .

In 1963 and 1964, the first examination of Costa Rica's geothermal potential occurred with visits by United Nations experts who recommended that Miravalles and Rincon de la Vieja volcanoes of the Guanacaste Range had potential for geothermal energy development. In response to the oil price increase in 1973, ICE geologists began a more detailed examination of these two areas. Inter-American Development Bank (IDB) funding was acquired in 1976 to perform a prefeasibility study of Miravalles, done with the help of Rogers Engineering and Geothermex of California. Drilling programs were carried out in 1978-1979 and in 1984-1985, with success at all six wells drilled. There has been a problem with calcite scaling at the first three wells drilled, but these wells have been cleaned. ICE is currently in what they refer to as the Third Phase in field development, which will entail drilling five to six deep, exploratory wells, three of which were completed as of February 1985. The total of six wells that 
TABLE 8

COSTA RICA: HYDROELECTRIC RESOURCES

Hydroelectric Eneray

\begin{tabular}{|c|c|c|c|c|c|c|c|c|}
\hline$N^{\prime}$ & River & $\operatorname{Area} \mathrm{Km}^{2}$ & $\begin{array}{l}\text { Mean Annual } \\
\text { Beinfoل }(\mathrm{mm})\end{array}$ & $\begin{array}{l}\text { Meon } \\
(\mathrm{mm})\end{array}$ & $\begin{array}{l}\text { Outflow } \\
1 / x / \mathrm{km}^{2}\end{array}$ & Projects & $\begin{array}{l}\text { Potentiol } \\
\text { LM }\end{array}$ & $\begin{array}{l}\text { Energy } \\
\text { cwh }\end{array}$ \\
\hline 1 & Sixoloo & 2.330 .0 & 4,790 & 3.905 & 123.8 & 9 & 1.385 & 6.104 \\
\hline 2 & Lo Estrollo & 1.002 .1 & 2.877 & 2.125 & 67.4 & - & - & - \\
\hline 3 & Banano & 204.3 & 4,379 & 3,722 & 118.0 & - & - & - \\
\hline \multirow[t]{2}{*}{4} & Bononito & & & & & & & \\
\hline & \& others & 285.3 & 2,951 & 2,444 & 77.5 & - & - & - \\
\hline 5 & $\begin{array}{l}\text { Moin } \\
\text { Others }\end{array}$ & 361.6 & 3,956 & 2,582 & 81.9 & - & - & - \\
\hline 6 & Motino & 1.415 .6 & 3.626 & 3,086 & 97.9 & 2 & 600 & 2.600 \\
\hline \multirow[t]{2}{*}{7} & Madre de Dios & & & & & & & \\
\hline & othors & 443.1 & 3,402 & 1.888 & 59.9 & - & - & - \\
\hline 8 & Pocuare & 802.4 & 4,021 & 3.032 & 96.1 & 2 & 764 & 2,992 \\
\hline \multirow[t]{2}{*}{9} & Reventazon & & & & & & & \\
\hline & Parismina & $2,950.3$ & 3,777 & 2,646 & 83.9 & 5 & 686 & 3.853 \\
\hline 10 & Tortuguero & & & & & & & \\
\hline \multirow[t]{2}{*}{11} & Chirripo & 1.644 .3 & 3.887 & 2,486 & 10.0 & - & - & - \\
\hline & Atlontico & $1,635.1$ & 4.326 & 3,671 & 116.4 & 3 & 365 & 1,768 \\
\hline 12 & Saropiqui & $1,923.3$ & 5.156 & 3,987 & 126.4 & 3 & 256 & 1,147 \\
\hline 13 & Curena & 342.8 & 4.100 & 2,918 & 92.5 & - & - & - \\
\hline \multirow[t]{2}{*}{14} & Son Corlos & & & & & & & \\
\hline & $\&$ No 20 & $2,646.3$ & 3.961 & 3,143 & 99.7 & 5 & 967 & 2,631 \\
\hline 15 & \& others & & & & & & & \\
\hline 16 & frio & 551 & 2,010 & 1,0 & 7. & - & 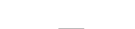 & - \\
\hline \multirow[t]{2}{*}{17} & Zapote & & . & 年 & 0.0 & & & \\
\hline & \& others & $2,593.8$ & 2,858 & 1,643 & 52.1 & - & - & - \\
\hline \multirow[t]{3}{*}{18} & Nicoyo & & & & & & & \\
\hline & Poninsula & & & & & & & \\
\hline & North Coost & $4,202.0$ & 2,043 & 936 & & - & - & - \\
\hline 19 & Tempi sque & 3.405 .8 & 2,040 & 768 & 24.35 & 一 & - & - \\
\hline \multirow[t]{2}{*}{20} & Bebedero & & & & & & & \\
\hline & soo No. 14 & $2,050.0$ & 2,118 & 865 & 27.42 & - & - & - \\
\hline \multirow[t]{2}{*}{21} & Abongares & & & & & & & \\
\hline & others & 1.362 .5 & 2,382 & 1.240 & 39.3 & - & - & - \\
\hline 22 & Borranco & 504.5 & 3,750 & 1.999 & 63.4 & 1 & 50 & 195 \\
\hline 23 & Joeus Morio & 358.5 & 2,593 & 1,322 & 41.9 & - & - & - \\
\hline \multirow[t]{2}{*}{24} & Grande de & & & & & & & \\
\hline & Torcoles & $2,168.5$ & 2,456 & 1.520 & 48.2 & 3 & 350 & 1.720 \\
\hline \multirow{2}{*}{25} & Tusubres & & & & & & & \\
\hline & $\$$ others & 830.1 & 2,947 & 1.152 & 36.5 & - & - & - \\
\hline 26 & Porrito & 1.272 .5 & 3,254 & 1.988 & 63.0 & 5 & 460 & 1,947 \\
\hline \multirow[t]{2}{*}{27} & Damas & & & & & & & \\
\hline & others & 458.2 & 4,407 & 1,864 & 59.1 & - & - & - \\
\hline 28 & Naranjo & 332.2 & 6,387 & 3,973 & 126.0 & 2 & 195 & 820 \\
\hline 29 & Sovegre & 593.2 & 5.890 & 3.557 & 112.8 & 3 & 650 & 2,652 \\
\hline \multirow[t]{2}{*}{30} & Boru \& & & & & & & & \\
\hline & others & 561.1 & 3,351 & 2,121 & 67.3 & - & - & - \\
\hline \multirow[t]{2}{*}{31} & Grande de & & & & & & & \\
\hline & Terraba & $5,075.8$ & 3,358 & 2,198 & 69.7 & 7 & 2,065 & 8.233 \\
\hline \multirow[t]{2}{*}{32} & Oso & & & & & & & \\
\hline & $\begin{array}{l}\text { Peninsula } \\
\text { Esquinas }\end{array}$ & 1.968 .1 & 4,408 & 2,830 & 69.7 & - & - & - \\
\hline 33 & others & 1.827 .6 & 3,886 & 2,699 & 85.6 & - & - & - \\
\hline 34 & $\begin{array}{l}\text { Changuinola, } \\
\text { Costo Rican }\end{array}$ & & & & & & & \\
\hline & port & 255.5 & 3,800 & 2.690 & 85.3 & - & - & - \\
\hline
\end{tabular}

Source: Refarence No. 8. 
TABLE 9

COSTA RICA: INFORMATION ABOUT GEOTHERMAL LOCALITIES

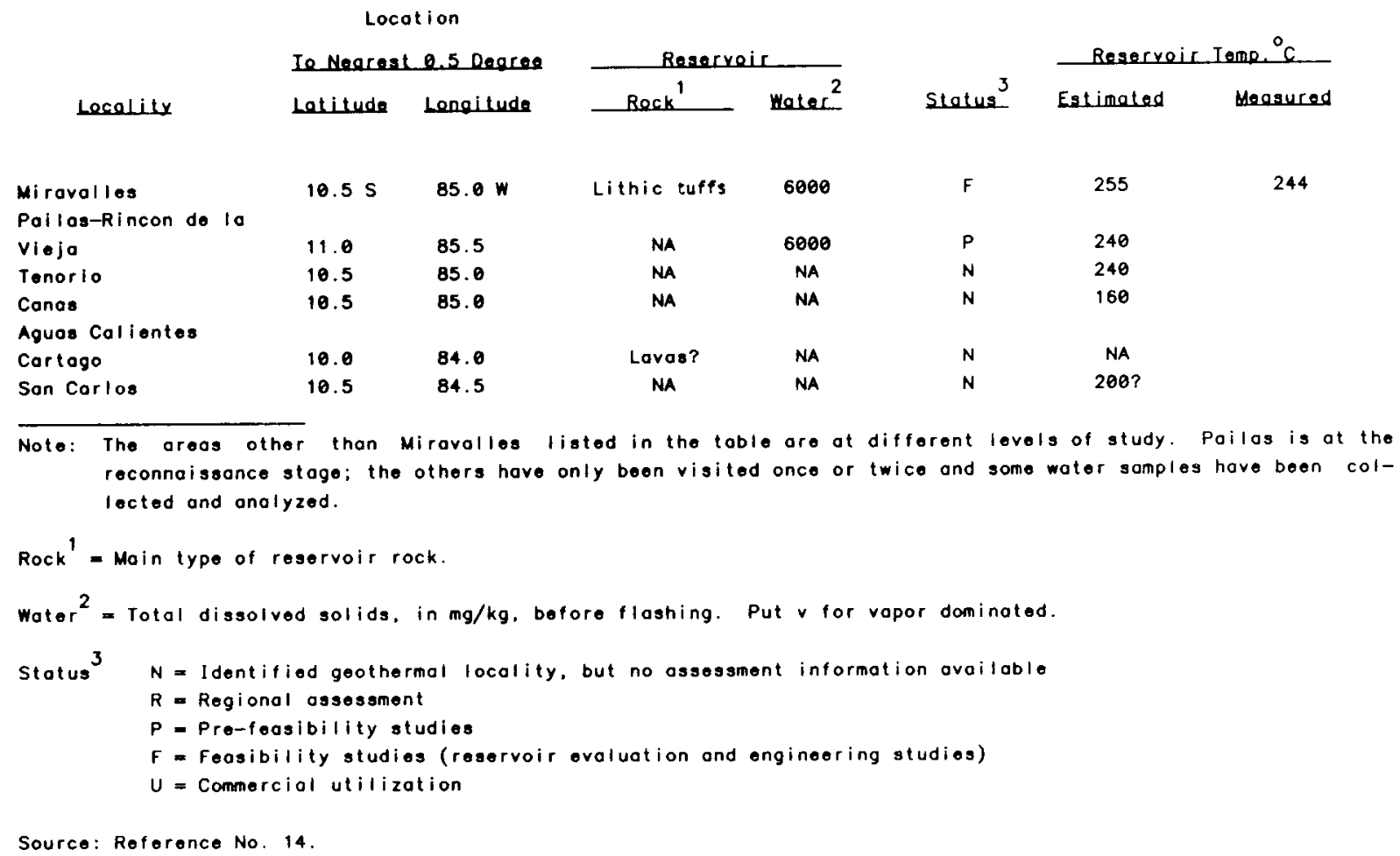

have been drilled have a combined well head potential of 23 MW (single flash) and $32 \mathrm{MW}$ (double flash). " The feasibility report was to be completed in 1985. The following Fourth Phase that is planned will involve drilling 21 additional wells and construction of a 55-MW power plant. This last phase is expected to be completed in 1990, when ICE plans to generate the first electricity from Miravalles. Available information indicates that the cost of electricity is expected to be US $\$ 0.04$ to $\$ 0.05$ per $\mathrm{kWh}$, which was similar to ICE's cost of generation from hydropower and half the cost of generation from bunker-oil-fired steam turbines of a comparable size in 1984.14

6. Fuel wood. Fuel wood is derived from five principal sources in Costa Rica: woods on cattle ranches and in hedges $(40 \%)$, coffee plantations (30\%), dense thickets and abandoned fields (15\%), refuse from lumbermills and sawmills

* Double flash usage may be undesirable because it would cool the fluid too much. 
(10\%), and natural forests (5\%). ${ }^{15}$ A more detailed discussion of these sources will be presented in the following section.

The deforestation issue is considered to be serious in Costa Rica. From a natural forest cover of 99.8 percent, the forest coverage had been reduced to 31 percent of the country in 1977. Half of this deforestation occurred after 1950. The main cause of deforestation is not, however, fuel-wood use. It stems from land clearing for agriculture. Policies in effect in Costa Rica through 1969 allowed settlers to claim land by clearing it and possessing it for five to ten years. Although this practice has been outlawed for public lands, it is difficult to enforce, and illegal squatting and possession continue. In 1977, $15,900 \mathrm{sq} \mathrm{km}$ of forest remained. Of this amount, a 11 but $4,600 \mathrm{sq} \mathrm{km}$ were protected in national parks, forest reserves, and Indian lands. The average deforestation rate between 1977 and 1983 was 52,200 hectares per year. 16

According to some estimates, ${ }^{4}$ approximately $1.8 \mathrm{million}$ hectares of 1 and that are presently being used for agriculture or grazing would be best suited to reforestation. An environmental study of Costa Rica recommended the immediate reforestation of 450,000 hectares.

A study done by DGF/CATIE/ROCAP recommended a reforestation plan that would result in 38,535 hectares reforested by the year 2000 . The total cost of the reforestation for the years 1985 through 1988, when 6800 hectares would be reforested, would be approximately 122 million colones. The estimated cost of a tree farm to grow fuel wood was 9.94 colones per tree to plant and grow the tree. This does not include the cost of harvesting. 15

7. Wind and Solar. In 1981, ICE contracted with Electrowatt Engineering Services Ltd. of Zurich, Switzerland to evaluate ICE's estimates of wind potential in Costa Rica. This work was carried out under International Bank for Reconstruction and Development (IBRD) Loan No. 1713/CR and culminated in a report in 1984 that forms the basis for this summary of wind resources. 17 Costa Rica has wind velocity and direction measurements for varying lengths of time from 25 wind monitoring stations. Of these 25 stations, 16 have a complete and reliable set of measurements for a minimum of five years. The data from these sixteen stations formed the basis of the analysis. The study concluded that Costa Rica has a total theoretical wind energy potential of 14,400 MW over an area of 8500 square kilometers. If one considers wind energy development only in the regions with greatest extractable power where it would be most economic, the total theoretically extractable power is $600 \mathrm{MW}$ over 70 to 100 square kilometers. In reality, only a small percentage of this resource can be used, and further studies would be required to ascertain whether wind energy is an 
economic option for Costa Rica. The Electrowatt company considered the potential for small applications to areas that are not connected to the national grid to be very limited because the majority of the population lives in regions that have no potential for wind energy. Partial reliance on wind energy could be beneficial because of complementary effects with run-of-river hydroelectric. Wind energy is also dependent on the time of day and peaks around noon, at the same time as the peak in energy demand.

Before ICE can seriously consider generating electricity from wind, a series of studies would need to be done. More permanent wind stations are needed for the north central highlands. Macroeconomic studies of the role of wind energy would need to be performed as well as prefeasibility and feasibility studies. Electrowatt recommended a six year program that included construction of a 1-MW pilot plant, possibly in the valley of the Rio Naranjo or alternatively, near Arenal. They suggested a possible configuration of five 200-kW turbines, at an estimated cost of US $\$ 1.37$ million, or US $\$ 1370$ per kilowatt. The estimated cost of electricity from this pilot plant, assuming a 20-year plant life, a 10 percent interest rate, and an annuity of 11.7 percent, is $\$ 0.071 / \mathrm{kWh}$. For 1 arger scale wind systems (e.g., $20 \mathrm{MW}$ ), they expect that the cost of electricity would be approximately US $\$ 0.05 / \mathrm{kWh}$. Electrowatt's proposed schedule of construction of a pilot plant and studies of its operation to determine the feasibility of large-scale wind generation in Costa Rica would take approximately 10 years. 17

Electrowatt also performed a study ${ }^{17}$ of the potential for use of solar energy in Costa Rica. Solar radiation measurements exist from 21 stations, some of which have operated since the 1950s. As of 1982, 14 stations were in operation. These stations are maintained by the National Meteorological Institute, ICE, and the University of Costa Rica. Electrowatt produced a solar radiation map of Costa Rica that divides the country into four regions with the following radiation levels: (1) less than 170 watts per square mile (isolated mountain areas); (2) 170-192 watts per square mile (the Caribbean lowlands and much of the south-central part of the country); (3) 192-218 watts per square mile (part of Guanacaste and the northern border, a small region in the south, and a small area on the Caribbean adjacent to Panama); and (4) greater than 218 watts per square mile (the central part of the Guanacaste province). The Central Valley, where most of the population lives, occurs in Zones 2 and 3 . Most of Costa Rica's surface receives between 350 and 450 calories per square centimeter per day of solar radiation. An average value of 400 calories was used to calculate 
a gross theoretical potential of approximately 50 billion barrels of oil equivalent $\left(7.3 \times 10^{19}\right.$ calories). This estimate of gross potential does not take into account the diffusivity of solar radiation in Costa Rica, which is high, nor the daily and seasonal fluctuations. More than 50 percent of the total annual radiation falls on the country's surface in diffuse form. ${ }^{17}$

When economic and engineering feasibility were taken into account, Electrowatt estimated that approximately 2.5 percent of the gross potential may be usable. The most promising applications appeared to be solar water heating, $10 \mathrm{w}$ temperature process heat $\left(50-80^{\circ} \mathrm{C}\right)$, and small-scale $(0.1-10 \mathrm{kw})$ photovoltaic electricity generation in isolated areas. It was felt that there is enough information on solar radiation to implement a solar energy use scheme in the country. The study also recommended areas in which more data were needed and suggested pilot plants that should be considered for demonstration. 17

B. Energy Supply

The energy flow diagram for 1984 is shown in Fig. 6. The primary energy inputs are fuel wood, imported crude petroleum, hydropower, and vegetable residues. In addition to these primary energy inputs, the country imports a considerable quantity of refined petroleum products, which are considered secondary energy because they have been transformed. Fuel wood is considered noncommercial energy, but the amount traded in markets is increasing so that the designation as "non-commercial" is not wholly applicable. No strong distinctions are made between commercial and noncommercial energy nor between primary and secondary energy in this report. This discussion of energy supply focuses mainly on the supply of energy in its final form, i.e. in the form in which it is consumed. The discussion is therefore categorized into petroleum products, electricity, and biomass. Biomass includes fuel wood and vegetable residues, which are discussed separately.

Effective or net energy supply is considered to be the sum of primary energy supply minus transformation plus secondary energy supply. This amount equals total consumption in the energy balances, so a discussion of changes in total supply to final uses is also in effect a discussion of total consumption. Changes in supply are shown in Fig. 7. In 1984, petroleum products supplied 40 percent, biomass 46 percent, and electricity 13 percent of total energy in Costa Rica. Since 1970, the percentage of energy supplied by electricity has doubled; the percentage of petroleum products has increased from 35 percent to 40 percent; and the share of biomass has decreased from 57 percent of the total to the present 46 percent. In summary, there has been a significant increase in electricity generation and petroleum use since 1970, with a concomitant decrease 


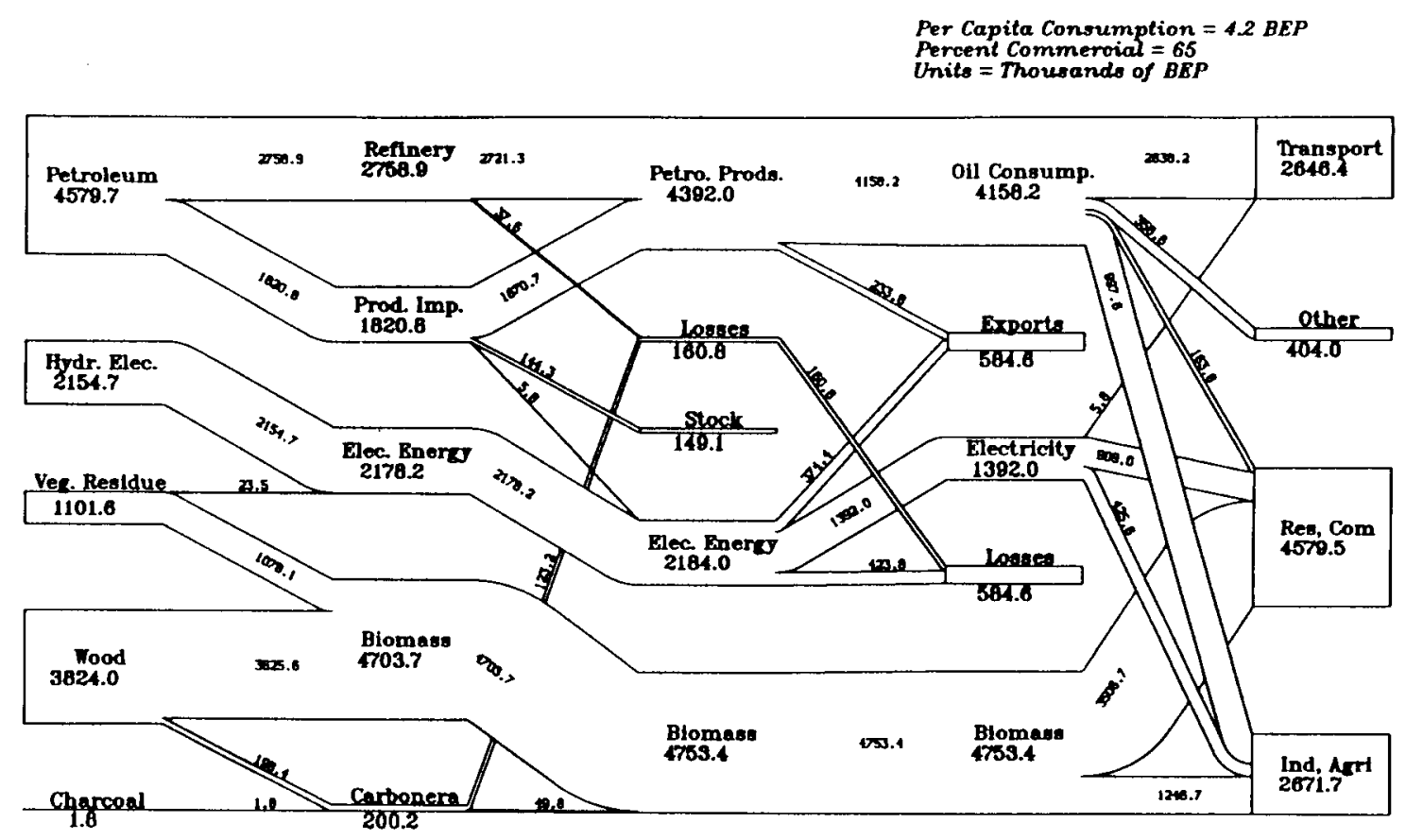

Fig. 6. Costa Rica: Energy flow diagram for 1984.

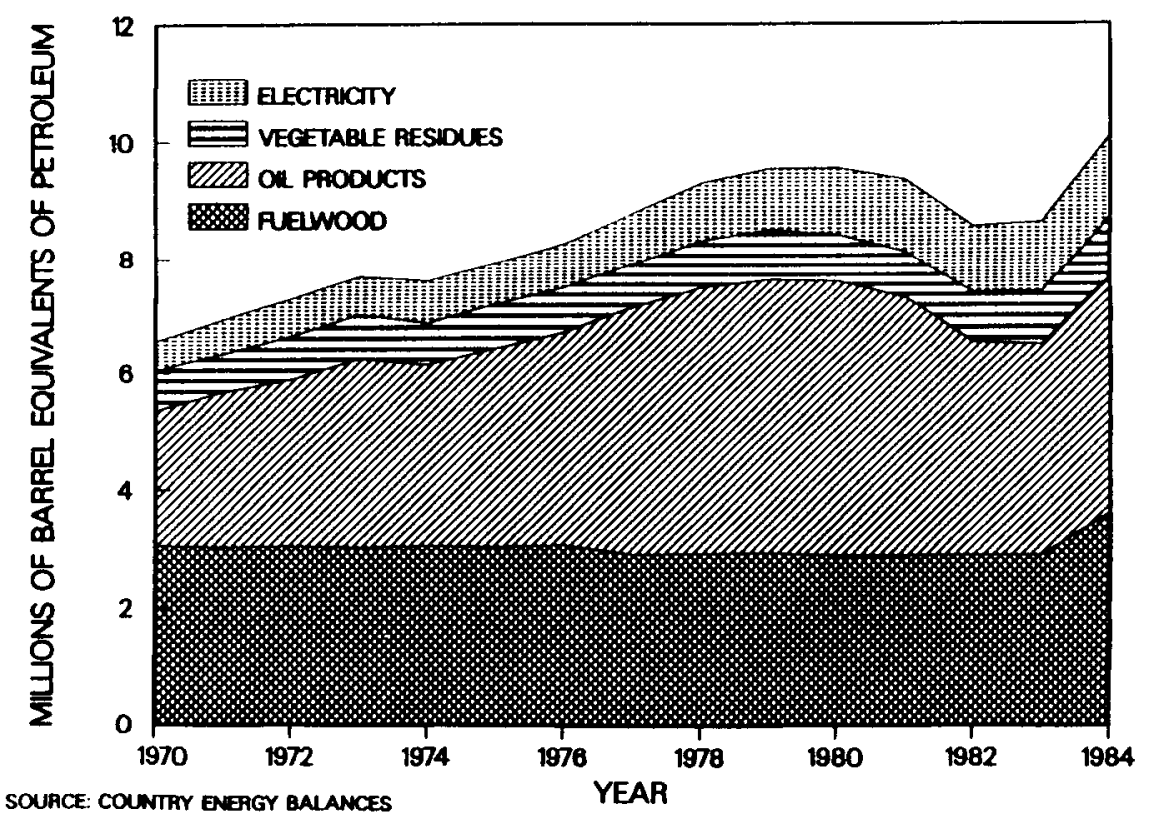

Fig. 7. Costa Rica: Changes in energy use. 
in the share of energy supplied by biomass. Since 1980, a trend toward substitution of biomass for expensive petroleum products has operated.

1. Petroleum Supply and Product Prices

a. Supply. Petroleum products make up almost half of the energy supplied in Costa Rica. Costa Rica has no domestic oil production and must import all of its oil products. Owing to Costa Rica's economic condition, oil imports decreased by almost 20 percent from 1980 to 1981 and have remained relatively constant from 1981 through 1983. On average, approximately two-thirds of the petroleum products are imported in the refined form, and one-third are refined domestically. Imported oil originates in either Mexico or Venezuela and is imported under conditions outlined in the San Jose Accord.

The terms of the San Jose Accord, which applies to all of the Central American countries, is described below. In August of 1980, Presidents Jose Lopez Porti110 of Mexico and Luis Herrera Campins of Venezuela signed an agreement in Costa Rica, which became known as the "San Jose Agreement," to supply Central American and a few Caribbean countries (Jamaica, Dominican Republic) with crude oil on concessionary terms. Mexico and Venezuela agreed to suppiy beneficiary countries on an equal basis with up to 160,000 barrels of oil per day, with a credit program equivalent to 30 percent of the value of the $0 i 1$. The credit program had unique characteristics related to the fact that if the loan was used to finance energy development projects the rate of interest was 2 percent per year with a maturity period of 20 years. On the other hand, if the credit was utilized for nonenergy related purposes, the rate of interest was 4 percent with a maturity period of five years.

Unfortunately, many factors have contributed to a low level of utilization of these credits for energy development projects, and in most cases the credits have been utilized by the Central Bank for broader economic objectives.

Venezuela and Mexico have revised the terms of the accord since 1983 and have emplaced more rigid terms owing to the economic and financial difficulties of their respective countries. Cash payment is required for the oil, and the loans now represent 20 percent of the $0 i 1$ bill (down from 30 percent previousiy), with the remainder to be paid for over five years at 8 percent (up from 4 percent interest). For approved energy projects, the interest rate is 6 percent with a 20-year term.

In 1984, RECOPE renegotiated its $0 i 1$ debt with Mexico, which totalled $\$ 78$ million. 10 This debt was mainly accumulated during 1981 when Costa Rica received extended credits from Mexico owing to the former's severe financial crisis. 
Costa Rica is the only Central American country with a state-owned refinery (RECOPE) and distribution system for petroleum products. RECOPE owns the refinery and pipeline network to transport finished products from the refinery on the Atlantic coast to the rest of the country. Except for a few cases, gas stations are privately owned, and the distribution system from RECOPE outlets to the stations is also private. This fact has important implications for quality control.

Tables 10-14 show the total supply of petroleum and the amounts of various products imported versus refined domestically. The major products supplied in 1983 were diesel oil (30 percent), gasoline (15 percent) and fuel oil (11 percent). The refinery began operations in 1967 and was nationalized in the early 1970s. When construction of the refinery was planned, it was assumed that Costa Rica would require an output mix with a large percentage of fuel $0 i 1$. This assumption turned out to be incorrect and RECOPE now must export approximately 20-25 percent of the fuel oil that it produces at a price of approximately $\$ 8.86$ per barrel. In 1983 , the Costa Rican refinery produced a mix that contained 41 percent fuel $0 i 1,24$ percent diesel, and 22 percent gasoline and aviation fuel, with the remaining 13 percent comprising kerosene, jet fuel, liquid propane gas, and asphalt. The percentage output of diesel, the main fuel supplied in the country, has varied from a low of 20 percent to a high of 30 percent in the past five years. The output in part depends on the composition of the crude oil input. In the past (1978-1983), domestically-refined diesel has supplied anywhere from 25 percent to 50 percent of requirements, depending on the refinery annual production and output mix. Annual refinery production has been decreasing from 3.7 million barrels in 1980 to 2.3 million barrels in 1983 .

TABLE 10

COSTA RICA: PETROLEUM IMPORTS

(thousands of barrels)

\begin{tabular}{|c|c|c|c|c|c|c|c|c|}
\hline & -1970 & 1977 & 1978 & 1979 & 1980 & 1981 & 1982 & 1983 \\
\hline Crude oil & 2237 & 2570 & 3377 & 2927 & 3771 & 3489 & 3371 & 2514 \\
\hline Liquified gas & 69 & 97 & 101 & 167 & 191 & 182 & 59 & 155 \\
\hline Gasoline & 255 & 508 & 719 & 648 & 457 & 208 & 373 & 576 \\
\hline Kerosene ond jet fuel & 84 & 16 & 0 & 0 & 20 & 19 & 22 & 28 \\
\hline Diesel oil & 330 & 2024 & 2287 & 2006 & 1539 & 1029 & 1133 & 1540 \\
\hline Fuel oil & 233 & 0 & 0 & $\theta$ & 0 & $\theta$ & 0 & 60 \\
\hline Asphalt & 72 & 82 & 10 & 0 & 0 & 0 & 21 & 20 \\
\hline Totol & 3280 & 5297 & 6494 & 5748 & 5978 & 4927 & 4979 & 4893 \\
\hline
\end{tabular}


TABLE 11

COSTA RICA: REFINERY PRODUCTION

(thousands of barrels)

\begin{tabular}{|c|c|c|c|c|c|c|c|c|}
\hline & 1970 & 1977 & 1278 & 1979 & 1980 & -1981 & 1982 & 1983 \\
\hline Liquified gas & $\theta$ & 76.6 & 98.6 & 83.5 & 95.1 & 76.6 & 76.8 & 29.3 \\
\hline Gasoline and oviation & 494.9 & 551.1 & 632.1 & 596.7 & 742.0 & 706.1 & 501.0 & 501.0 \\
\hline Kerosene ond jet fuel & 140.4 & 297.3 & 345.0 & 409.7 & 284.8 & 214.2 & 197.4 & 168.5 \\
\hline Diesel oil & 853.0 & 521.5 & 703.7 & 619.7 & 1091.4 & 1062.3 & 863.4 & 561.7 \\
\hline Fuel oil & 851.8 & 1069.4 & 1140.4 & 1157.4 & 1432.4 & 1406.2 & 1166.4 & 954.1 \\
\hline Aspholt & .0 & 99.4 & 134.2 & 114.2 & 100.6 & 83.4 & 66.6 & 85.6 \\
\hline Totol & 2140.1 & 2615.3 & 3054.0 & 2981.2 & 3746.3 & 3548.8 & 2871.6 & 2300.2 \\
\hline
\end{tabular}

Source: Country Energy Bolances.

TABLE 12

COSTA RICA: EXPORTS OF PETROLEUM PRODUCTS

(thousands of barrels)

\begin{tabular}{|c|c|c|c|c|c|c|c|c|}
\hline & -1970 & 1977 & 1978 & 1979 & 1980 & -1981 & 1982 & 198.3 \\
\hline Liquified gos & $\theta$ & $\theta$ & $\theta$ & 0 & $\theta$ & 0 & $\theta$ & $\theta$ \\
\hline Gasoline and oviation & $\theta$ & $\theta$ & $\theta$ & B & 40 & 29 & $\theta$ & 40 \\
\hline Kerosene and jet fuel & 0 & $\theta$ & $\theta$ & 0 & $\theta$ & 0 & $\theta$ & 0 \\
\hline Diesel oil & 0 & $\theta$ & 0 & 0 & $\theta$ & $\theta$ & 0 & 0 \\
\hline Fuel oil & 361 & $\theta$ & $\theta$ & 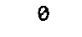 & 280 & 362 & 220 & 257 \\
\hline Aspholt & $\theta$ & $\theta$ & 0 & $\theta$ & $\theta$ & $\theta$ & $\theta$ & $\theta$ \\
\hline Total & 361 & $\theta$ & 0 & $\theta$ & 320 & 391 & 220 & 297 \\
\hline
\end{tabular}

Source: Country Energy Bolances.

TABLE 13

COSTA RICA: NET SUPPLY OF OIL PRODUCTS

(thousands of barrels)

\begin{tabular}{|c|c|c|c|c|c|c|c|}
\hline 1970 & 1977 & 1978 & 1979 & 1280 & 1981 & 1982 & 1983 \\
\hline 69.0 & 173.6 & 199.6 & 250.5 & 286.1 & 76.6 & 76.8 & 29.3 \\
\hline 749.9 & 1059.1 & 1351.1 & 1244.7 & 1159.0 & 706.1 & 501.0 & 501.0 \\
\hline 224.4 & 313.3 & 345.0 & 409.7 & 304.8 & 214.2 & 197.4 & 168.5 \\
\hline 1183.0 & 2545.5 & 2990.7 & 2625.7 & 2630.4 & 1062.3 & 863.4 & 561.7 \\
\hline 523.8 & 1069.4 & 1140.4 & 1157.4 & 1152.4 & 1406.2 & 1166.4 & 954.1 \\
\hline 72.0 & 181.4 & 144.2 & 114.2 & 100.6 & 83.4 & 66.6 & 85.6 \\
\hline 2282.1 & 5342.3 & 6171.0 & 5802.2 & 5633.3 & 4595.8 & 4259.6 & 4382.2 \\
\hline
\end{tabular}

Source: Country Energy Balances 
TABLE 14

COSTA RICA: PERCENTAGE OF OIL PROOUCTS IMPORTEO

(thousands of borrels)

\begin{tabular}{|c|c|c|c|c|c|c|c|c|}
\hline & 1970 & 1977 & 1978 & 1979 & 1980 & 1981 & 1982 & 1983 \\
\hline Liquified gas & 100 & 56 & 51 & 67 & 67 & 70 & 43 & 84 \\
\hline Gasoline & 34 & 48 & 53 & 52 & 39 & 24 & 43 & 56 \\
\hline Kerosene and jet fuel & 37 & 5 & 0 & 0 & 7 & 8 & 10 & 14 \\
\hline Diesel oil & 28 & 80 & 76 & 76 & 59 & 49 & 57 & 73 \\
\hline Fuel oil & 44 & 0 & 0 & 0 & $\theta$ & $\theta$ & 0 & 8 \\
\hline Asphalt & 100 & 45 & 7 & 0 & 0 & 0 & 24 & 19 \\
\hline Total & 37 & 67 & 68 & 66 & 39 & 31 & 38 & 54 \\
\hline
\end{tabular}

This heavy dependence on lighter hydrocarbons has made it necessary for RECOPE to import directly a significant proportion of diesel and gasoline, as well as to export fuel oil, thereby increasing the cross-haulage of petroleum products. In order to reduce this cross-haulage, RECOPE had, until 1984, followed a policy of refining crude to meet the fuel oil demand and to import additional diesel and gasoline directly to meet their respective demands.

Another important action taken by RECOPE to improve the balance between the structure of the refinery's products and that of demand was to install a 5000 barrel per day thermocracker to increase the proportion of diesel by "cracking" some of the heavier hydrocarbons. During the past few years the refinery has either imported refined products or refined crude oil itself depending on the relative costs of each method.

The oil bill in 1983 was $\$ 164.32$ million, constituting 5.4 percent of GDP, 16.6 percent of imports, and 18.8 percent of the value of export earnings (Fig. 8). The percent of commodity exports required to pay the oil import bill had almost doubled from 10.7 percent in 1977 to 20.1 percent in 1980 . The devaluations of the colon, discussed in Chapter II, have had an enormous effect on the cost of oil imports and the domestic price of petroleum in the costa Rican economy. Between 1980 and 1981, when the average exchange rate increased from 8.57 to 21.76 colones per US dollar, a 150 percent increase, the average price per barrel of oil in colones increased by 163 percent. Concurrently, the value of oil imports increased from 4.2 percent of GDP in 1980 to 6.6 percent in 1981 . The 1981 devaluation was accompanied by an increase in the amount of colones earned through exports, so the percent of exports required to pay the oil bill decreased slightly from its peak of 20.1 percent in 1980 to 17.1 percent in 1981. This effect is not the result of an increase in the volume of exports but 


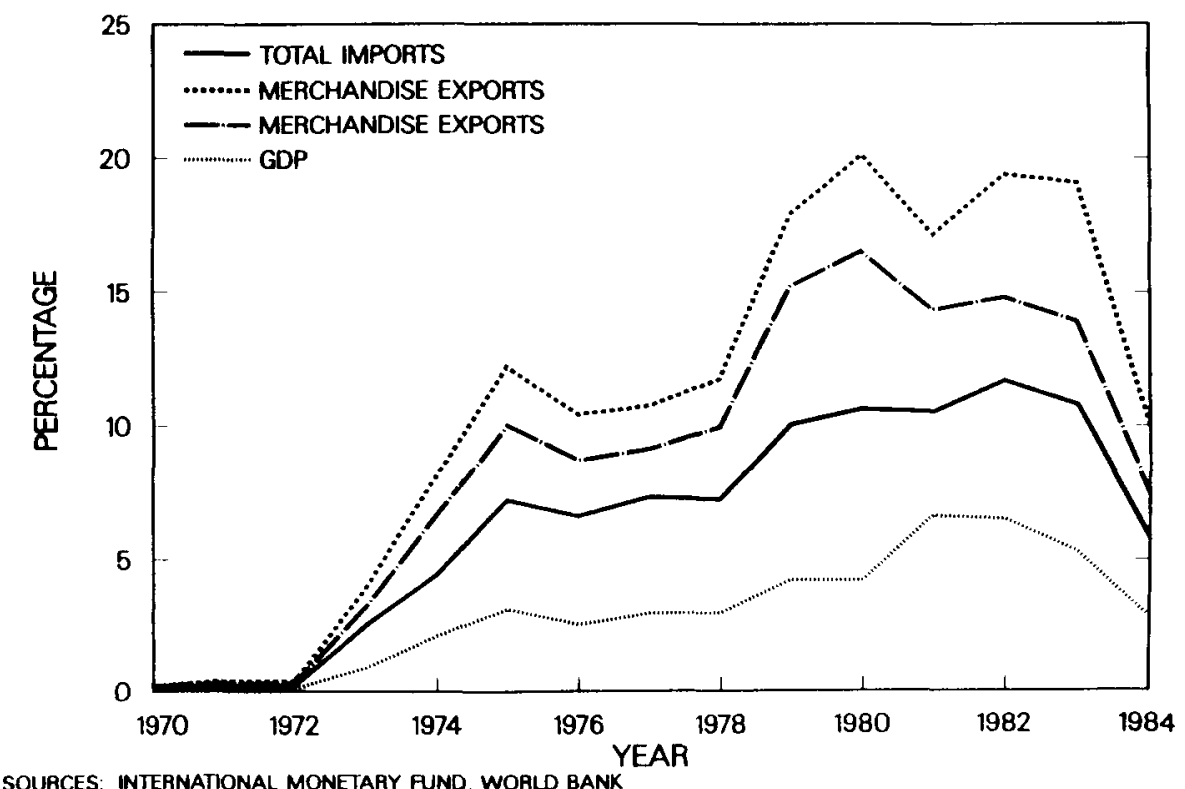

Fig. 8. Costa Rica: Value of oil imports as a percentage of GDP, exports, and imports.

rather to an increase in the unit value, in colones, of all major exports except sugar between 1980 and 1981 .

b. Product Prices. The average cost per barrel for imported crude and imported products is shown in Table 15. Between 1977 and 1980, the colon cost of a barrel doubled and then between 1980 and 1983 almost quintupled. The average cost in dollars increased 24 percent between 1977 and 1980 and has remained relatively constant between 1980 and 1983 .

Petroleum product prices in Costa Rica are set by the Servicio Nacional de Electricidad (SNE). The breakdown of prices is shown in Table 16. The prices at the refinery gate are basically equal for gasoline and diesel, at 10 colones per liter. The final consumer price is 19 colones per liter for diesel and 24 colones per liter for gasoline. Transport, distribution, and sales costs add an additional 1.9 colones per liter to the cost of each. Taxes are slightly higher on gasoline than on diesel in absolute terms. The difference between the price to the public and the subtotal of refinery costs, transport, distribution, sales, and taxes are substantial for gasoline, amounting to 24 percent of the price of gasoline. For diesel, the difference is only 8 percent. 18

RECOPE followed for many years a pricing policy that allowed it to cover the economic cost of supplying the products, be it crude oil and refining costs, or direct importation of finished products, plus associated transportation costs to the distribution outlets. At the same time, petroleum products were 
TABLE 15

COSTA RICA: VALUE OF PETROLEUM IMPORTS

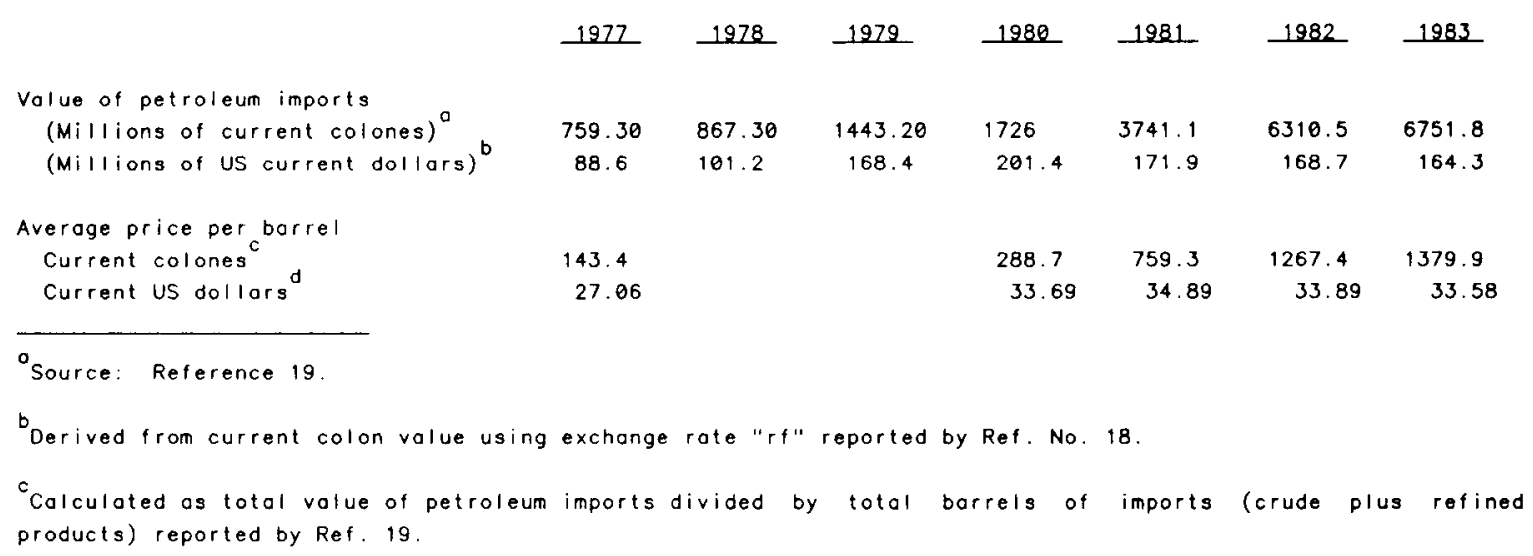

TABLE 16

COSTA RICA: BREAKDOWN OF DIESEL AND GASOLINE PRICES

\begin{tabular}{|c|c|c|c|c|}
\hline & \multicolumn{2}{|c|}{ Diese L } & \multicolumn{2}{|c|}{ Gasoline } \\
\hline & $\begin{array}{l}\text { Colones per } \\
\text { Liter }\end{array}$ & $\begin{array}{l}\text { Percent of } \\
\text { Price te Public }\end{array}$ & $\begin{array}{l}\text { Colones per } \\
\text { Liter }\end{array}$ & $\begin{array}{l}\text { Percent of } \\
\text { Erice te Publis }\end{array}$ \\
\hline Price o refinery gate & 10.22 & 54 & 10.4 & 43 \\
\hline Tronsport & 0.43 & 2 & 0.43 & 2 \\
\hline Distribution & 0.46 & 2 & 0.46 & 2 \\
\hline Soles & 1.0 & 5 & 1.0 & 4 \\
\hline Toxes & 5.35 & 28 & 5.85 & 24 \\
\hline Subtotal & 17.46 & 92 & 18.14 & 76 \\
\hline Price to public & 19.00 & 100 & 24.00 & 100 \\
\hline
\end{tabular}

traditionally priced by taxing some products heavily (particularly gasoline) while subsidizing others (diesel and bunker). Throughout the 1970 s decade, the price of diesel was maintained at about one-third the level of gasoline. Additional fiscal incentives to importation of diesel vehicles also contributed to the rapid dieselization of the automotive fleet, which led to the present situation in which the country consumes roughly twice as much diesel as gasoline.

Up to 1981, RECOPE itself was responsible for setting the prices of petroleum products. However, in 1981 a law (No. 6588) was passed that transferred this responsibility to SNE. Whenever RECOPE needs a price increase, it must submit a proposal to SNE with appropriate justification and financial information. SNE reviews the proposal, verifies the justification and information 
submitted, and decides on pricing levels that will insure "a reasonable rate of return" to the company (in practice 10 percent on revalued assets) as well as protecting the consumer from overcharges. Actually a very important role of law 6588 was to prohibit RECOPE from making donations or establishing subsidies, a common practice before that time. In fact, the Cabinet, acting as board of stockholders of RECOPE, had directed the institution's resources to a variety of uses unrelated to RECOPE's objectives, including the construction of the Moin Port Complex which is now the main component of RECOPE's debt.

RECOPE still subsidizes public transportation rather heavily, and retail prices for most petroleum products in 1983 were considerably higher than international border prices or refinery gate costs (over 2.5 times for gasoline and over 2 times for diesel). Bunker oil is subsidized so that its sales price is lower than its cost. The basic philosophy in the last three years has been to reduce the price differential between diesel and gasoline, while maintaining gasoline at higher levels and both prices above international levels. The jus tification provided is that gasoline is used by higher income groups that can be taxed more heavily and affect production less severely than taxes on diesel. Bunker subsidies have come about through pressures from the industrial sector, and they represent an important barrier to conservation and substitution in this sector.

Prices in colones have increased substantially each year for the period 1978 through 1983 (Table 17). The largest jump occurred between 1980 and 1981, when the prices in current colones more than doubled for most products, with diesel having the highest increase of 142 percent. Even with these large increases, the price of petroleum products failed to keep pace with the devaluation, and prices in dollars actually declined between 1980 and 1981 (Table 18). Between 1978 and 1983, the average annual percentage increase in diesel prices has been 30 percent per year in dollars and 78 percent per year in colones. These increases are a leading factor in inflation in costa Rica. When deflated by the GDP deflator and expressed in constant 1982 colones, petroleum product prices still exhibit large annual increases (Table 19). In the past five years for which data are available $(1978$ - 1983), the real price of diesel, in colones, has increased at an average rate of 33 percent per year. This has caused economic hardships for consumers, but it is undoubtedly responsible for holding down Costa Rica's oil imports and the resulting oil bill. The effect on demand will be discussed in Section III.C. 
TABLE 17

COSTA RICA: OIL PRODUCT PRICES

(colones per gollon)

\begin{tabular}{|c|c|c|c|c|c|c|}
\hline Year & Diesel Qil & Gosoline & Evel Qil & $\begin{array}{c}\text { Liquid Propane Gas } \\
\text { Industrial }\end{array}$ & $\begin{array}{l}\text { Liquid Propane Gos } \\
\text { Residential }\end{array}$ & Kerosene \\
\hline 1970 & 1.34 & 3.30 & .81 & 2.93 & 4.08 & 1.96 \\
\hline 1971 & 1.34 & 3.30 & .81 & 2.93 & 4.08 & 1.96 \\
\hline 1972 & 1.41 & 3.44 & .86 & 3.12 & 4.30 & 2.06 \\
\hline 1973 & 1.41 & 3.74 & 1.10 & 3.41 & 4.64 & 2.06 \\
\hline 1974 & 3.60 & 7.94 & 2.83 & 6.93 & 7.35 & 3.77 \\
\hline 1975 & 3.90 & 8.40 & 2.85 & 7.79 & 7.94 & 4.01 \\
\hline 1976 & 3.90 & 8.40 & 2.85 & 7.82 & 7.94 & 4.01 \\
\hline 1977 & 3.90 & 8.40 & 2.85 & 7.82 & 7.94 & 4.01 \\
\hline 1978 & 3.90 & 8.40 & 2.85 & 7.82 & 7.94 & 4.01 \\
\hline 1979 & 6.26 & 14.64 & 3.19 & 7.57 & 7.94 & 5.80 \\
\hline 1980 & 9.95 & 23.44 & 3.94 & 11.79 & 11.99 & 9.67 \\
\hline 1981 & 23.91 & 38.83 & 8.05 & 25.04 & 25.48 & 25.86 \\
\hline 1982 & 50.27 & 65.94 & 23.14 & 57.73 & 57.82 & 49.60 \\
\hline 1983 & 67.89 & 86.41 & 27.50 & 66.16 & 66.27 & 63.58 \\
\hline
\end{tabular}

Source: Reference 20.

Note: Unknown as to whether oil product prices ae beginning, mid-. or end of year prices.

TABLE 18

COSTA RICA: PETROLEUM PROOUCT PRICES

(U.S. dollors per gollan)

$\begin{array}{lrrrrrrr} & 1977 & 1978 & 1979 & 1980 & 1981 & 1982 & 1983 \\ & & & & & & & \\ \text { Diesel Oil } & .44 & .44 & .75 & 1.15 & 1.10 & 1.35 & 1.65 \\ \text { Gosoline } & .97 & .97 & 1.72 & 2.74 & 1.79 & 1.76 & 2.10 \\ \text { Fuel Oil } & .35 & .35 & .35 & .44 & .35 & .61 & .64 \\ \text { Liquid Propone Gas (Ind.) } & .93 & .93 & .88 & 1.37 & 1.15 & 1.55 & 1.61 \\ \text { Liquid Propane Gas (Res.) } & .93 & .93 & .88 & 1.41 & 1.17 & 1.55 & 1.61 \\ \text { Kerosene } & .49 & .49 & .66 & 1.15 & 1.18 & 1.33 & 1.55\end{array}$

Source: Derived from current colon value reported in Table III.11 using exchange rate "rf" reported by the IMF.

TABLE 19

COSTA RICA: PETROLEUM PRODUCT PRICES

(1982 colones/liter)

\begin{tabular}{lrrrrrr}
\multicolumn{1}{l}{ Product } & 1978 & 1979 & 1980 & 1981 & 1982 & 1983 \\
Diesel Oil & & & & & & \\
Gasoline & 3.4 & 5.2 & 6.9 & 11.7 & 13.3 & 14.1 \\
Fuet Oil & 7.4 & 12.1 & 16.3 & 19.0 & 17.4 & 17.8 \\
Liquid Propane Gos (Ind.) & 2.5 & 2.6 & 2.7 & 4.1 & 6.1 & 5.7 \\
Liquid Propane Gas (Com.) & 6.9 & 6.2 & 8.2 & 12.3 & 15.3 & 13.8 \\
Kerosene & 7.0 & 6.4 & 8.3 & 12.5 & 15.3 & 13.8 \\
& 3.5 & 4.8 & 6.7 & 12.6 & 13.1 & 13.2
\end{tabular}

Source: Reference 18

Note: Deflated by GDP deflator reported by World Bank. 


\section{Electricity Supply and Prices.}

a. Capacity, Generation and Expansion Plans. Costa Rica has an installed electric generating capacity of $775 \mathrm{MW}$ (Table 20). Of this capacity, approximately $734 \mathrm{MW}$, or 95 percent, is owned by the national utility, ICE. The characteristics of the publicly owned generation plants are shown in Table 21. In 1983, ICE generated 91 percent of the net 2821 GWh of electricity produced by publicly owned plants. ${ }^{19}$ In addition, DSE estimates that private producers generated another $58 \mathrm{GWh}$ of electricity in 1983. In 1983, 98.6 percent of generated electricity came from hydro plants (Table 22). The fuels consumed to generate electricity are shown in Table 23. Petroleum product consumption devoted to electricity generation equaled approximately 3.5 percent of the country's consumption of oil products in 1983. Tables 20-23 all display the increase in hydro generation that has occurred in Costa Rica since 1970. During the 1970s and 1980s, Costa Rica's public producers have traditionally had a high reliance on hydro. From 1970 through 1983, electricity generation grew at a rate of 8.7 percent per year. Percentage of electricity generated from therma 1 sources during this period was a maximum of 21.6 percent in $1977 .{ }^{19}$

The largest plant to come on stream in recent years has been the ArenalCorobici project. The plant on the Rio Arenal came on stream in 1979, and the water that passes through the Arenal tunnel also drives the generators at Corobici, which went into operation in 1982. The commissioning of the ArenalCorobici project from 1979 through 1982 more than doubled the hydro capacity of

TABLE 20

COSTA RICA: INSTALLED ELECTRIC GENERATING CAPACITY

(MN)

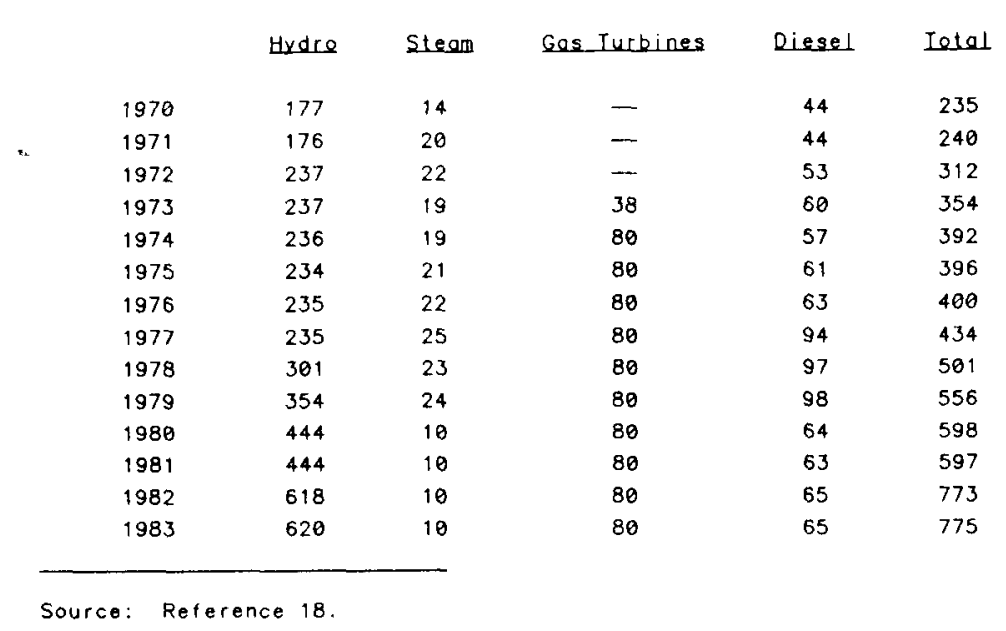


TABLE 21

COSTS RICA: CHARACTERISTICS OF POWER PLANTS ONNED BY PUBLIC SECTOR

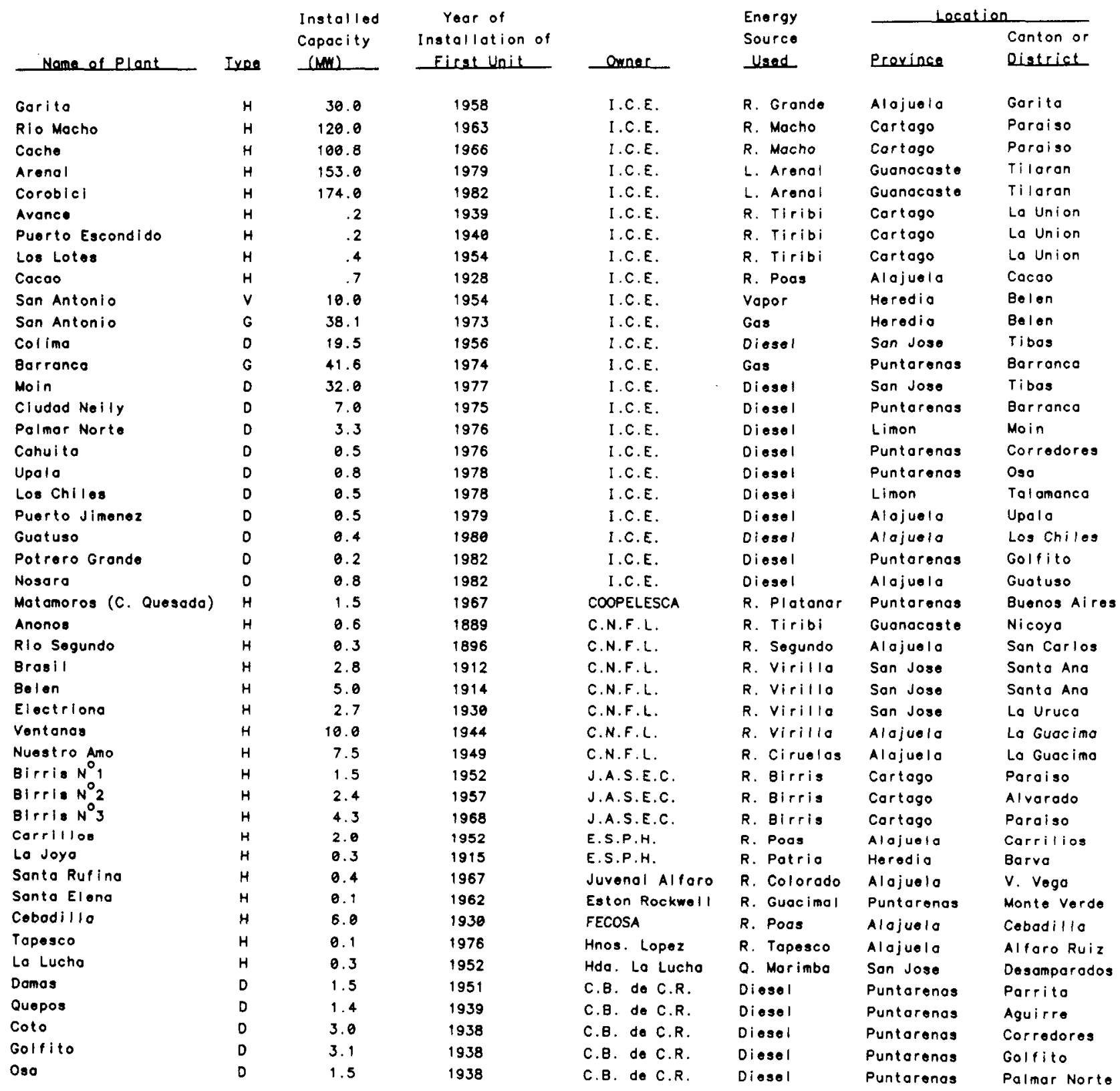

$H$ designotes hydro

$\checkmark$ designates steom

D designotes diesol

G dealgnates gas turbine

Source: Reference No. 21 
ABLE 22

COSTA RICA: ELECTRIC GENERATION

(GWh)

\begin{tabular}{lrrr} 
& Hydre & Inermed & Ietel \\
\cline { 3 - 4 } & & & \\
1970 & 939.7 & 88.0 & 1027.7 \\
1971 & 1034.8 & 112.7 & 1147.5 \\
1972 & 1105.1 & 161.3 & 1266.4 \\
1973 & 1137.5 & 208.1 & 1345.6 \\
1974 & 1253.8 & 213.7 & 1467.5 \\
1975 & 1300.2 & 229.8 & 1530.0 \\
1976 & 1454.8 & 191.2 & 1646.0 \\
1977 & 1344.6 & 415.3 & 1759.3 \\
1978 & 1485.2 & 440.1 & 1925.3 \\
1979 & 1629.3 & 371.5 & 2000.8 \\
1980 & 2125.6 & 99.3 & 2224.9 \\
1981 & 2291.7 & 77.7 & 2369.4 \\
1982 & 2393.6 & 81.9 & 2475.5 \\
1983 & 2834.4 & 86.9 & 2921.3
\end{tabular}

Source: Reference 20

TABLE 23

COSTA RICA: ENERGY USED TO GENERATE ELECTRICITY

(thousands of barfel equivalent of petroleum)

Hydroelectric

Diesel oil

Fuel oil

Bogosse

Source: Reference 20 .
1970

650.63

120.68

15.37

18.09

1977
967.71
658.00
198.95
23.53

1978

1076.87

608.54

289.54

19.37

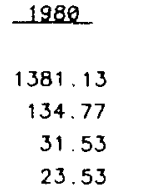

$-1982$

1633.71

125.97

0.0

23.53
$-1983$

1911.72

131.73

0.64

23.53

the country, increasing the hydro capacity from 60 to 80 percent of total capacity. Average generation from this project can supply almost half of the electricity. Arenal represents an important resource because it is Costa Rica's only hydro plant with substantial storage capacity, thus playing a significant role in dry season generation.

According to ICE statistics, generation in 1984 was 2568 GWh. Since 1975, ICE's transmission losses have averaged 2-4 percent, and its distribution losses, 6-12 percent. Distribution losses have been declining since 1977 . They equaled 6 percent in 1984 .

ICE sold 2178 GWh of electricity in 1984, with 35 percent sold directly to consumers and 65 percent to distributors. The transmission lines are shown in 
Fig. 9. In 1984 ICE's sales equaled 94 percent of total sales, and ICE generated 92 percent of total electricity.

Costa Rica is one of the few countries where peak load is determined by residential cooking requirements. Peak load varies with the season. There are two peaks; the first and slightly smaller one is between 10:00 and 12:30 and the second occurs between approximately 16:00 and 19:00. During the rainy season, the afternoon peak generally exceeds the morning peak because of more lighting demand. The maximum peak load for the past calender year was 481 MW in December 1984. The minimum peak load was $434 \mathrm{MW}$ in July 1984. Intermediate load, which occurs from approximately 6:00 through 21:30 excluding peak hours is approximately 67 percent to 72 percent of peak load. In 1984, intermediate load measured between 300 and 375 MW. Base 10ad, between $21: 30$ and 6:00 in the morning, is 34 percent to 42 percent of peak load, measuring 160 to 195 MW. A typical load curve is shown in Fig. 10.

Regarding the idea that ICE has a significant excess capacity, it was pointed out by Mr. Manuel Corrales of ICE that a utility that relies mainly on

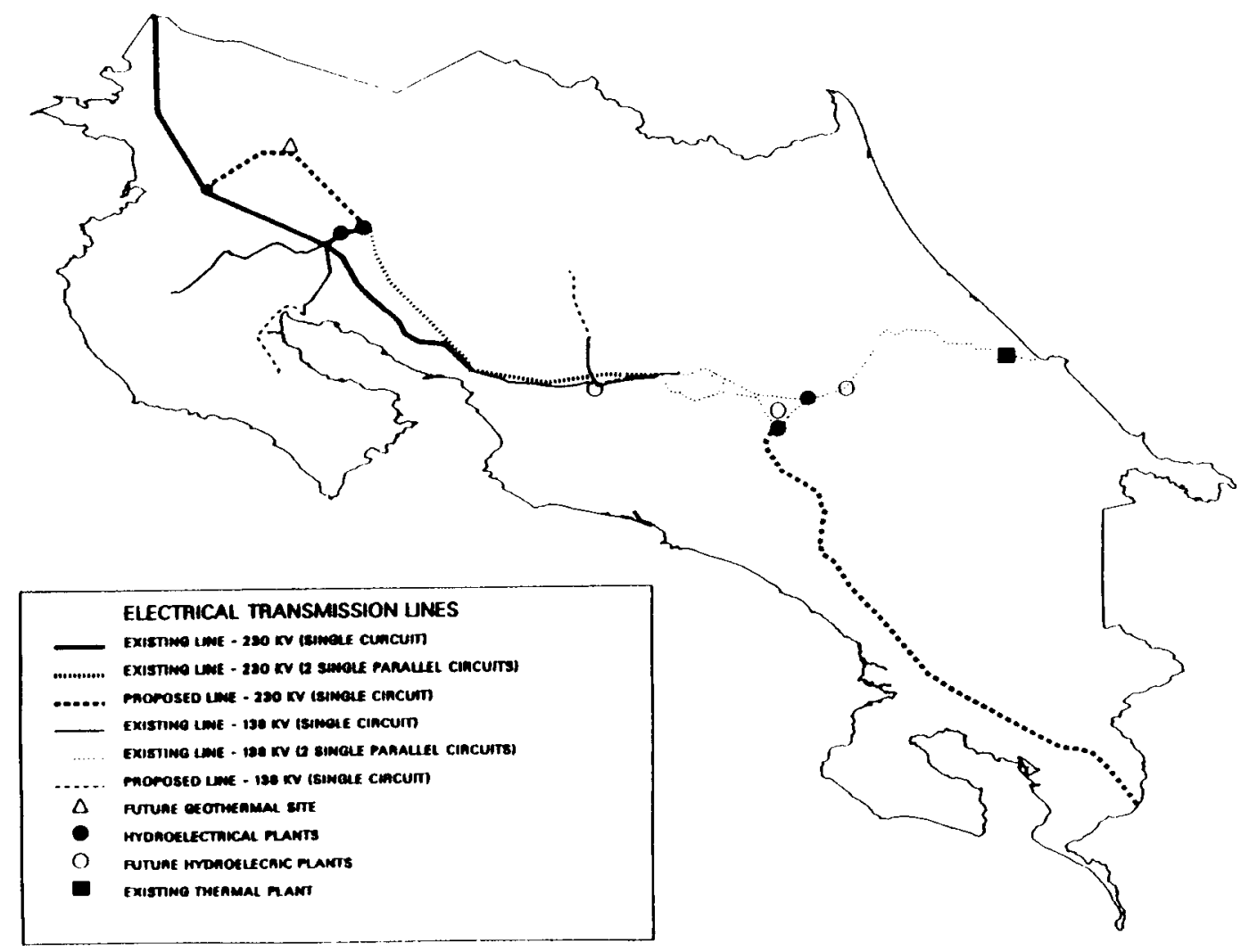

SOURCE: ICE.

Fig. 9. Costa Rica: Electricity transmission lines and locations of generation. 


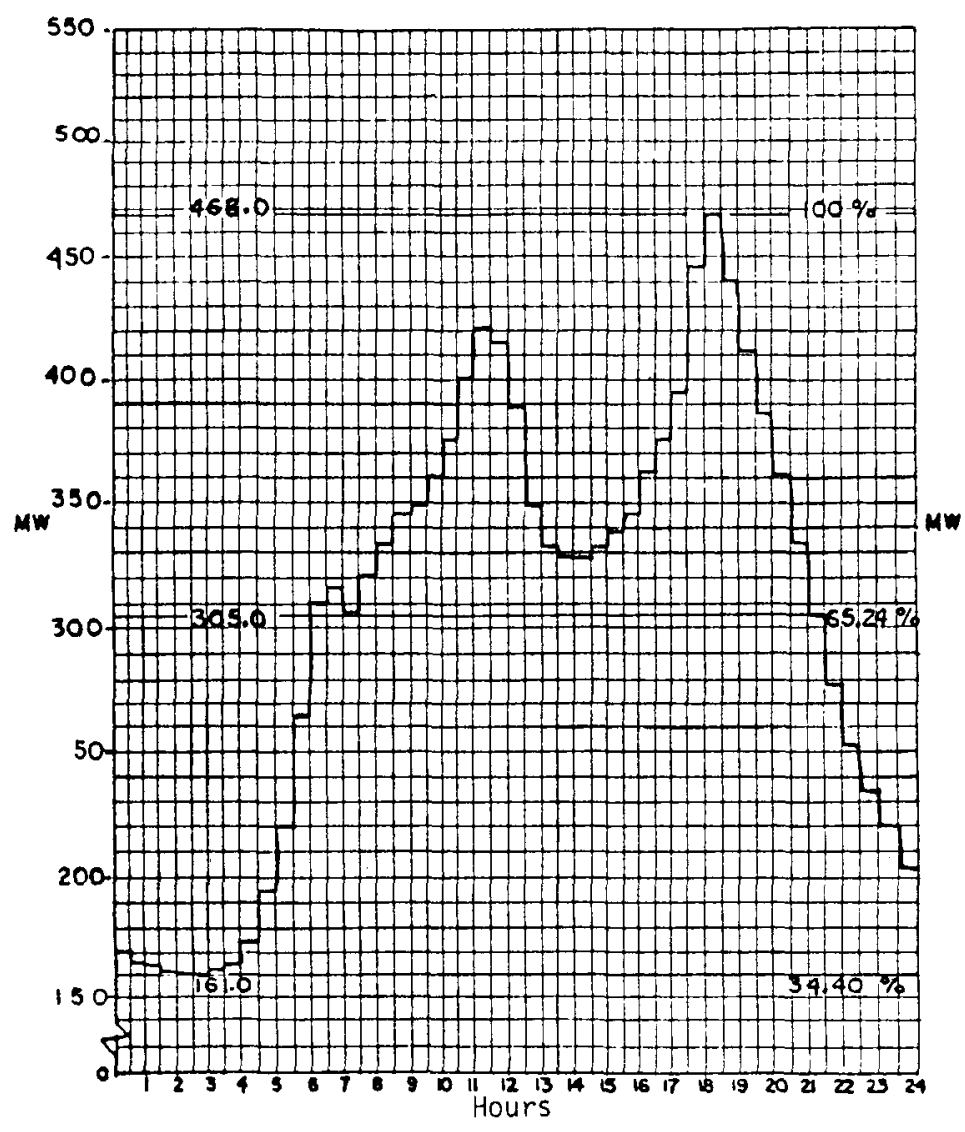

SOURCE: ICE

Fig. 10. Costa Rica: Electricity load curve.

run-of-river hydro must base their supply on the critical rainfall year. The critical year is considered to be the year with the lowest rainfall in 20 years. In a critical year, it is possible that the country could experience a brownout. There is a 30 percent difference in capacity between normal and average years. Therefore, the utility almost always has a 30 percent excess capacity. This is intentional.

If ICE needs to plan for the critical years and have 30 percent reserve capacity in the average year, it will take only 2.5 years of normal growth ( 5 percent per year) to eradicate excess capacity.

1984 sales increased 8.2 percent over 1983 sales. Costa Rica began selling electricity to Nicaragua and Honduras in 1982. Sales to Honduras stopped in 1985 when El Cajon came on line. Connection of the grid to Panama will not be completed in the near future.

ICE's preliminary expansion plans are shown in Table 24 . The lead time to bring a new plant on stream, such as a small hydro project, is three years for 
TABLE 24

COSTA RICA: EXPANSION PLANS FOR INSTITUTO COSTARRICENSE de ELECTRICIDAD (preliminary)

\begin{tabular}{|c|c|c|c|c|c|}
\hline Project Nome & Iyoe & Stage & $\begin{array}{l}\text { Expected Cost } \\
(\$ \text { mithion US) }\end{array}$ & $\begin{array}{l}\text { Copocity } \\
\text { (n) }\end{array}$ & $\begin{array}{r}\text { Expected Doto } \\
\text { of Commissiening }\end{array}$ \\
\hline Sandi I lal & hydro & feosibility & 41.76 & 32 & 1990 \\
\hline Goothermal I & geothermal & feasibility & 109.99 & 55 & 1991 \\
\hline Angostura & hydro & feosibility & 219.50 & 170 & 1993 \\
\hline Geothermol II & geothermat & prefeasibility & 107.70 & 55 & 1996 \\
\hline Palomo & hydro & feosibility & 43.78 & 28 & 1997 \\
\hline Guayabo & hydro & prefeasibility & 305.34 & 180 & 1997 \\
\hline Siquirres & hydro & prefeosibility & 318.69 & 330 & 2000 \\
\hline
\end{tabular}

Source: Instituto Costorricense de Electricidad

the feasibility study, two years for planning and finance, and four years for construction. ICE expects to have the $92 \mathrm{MW}$ (e) Ventanas-Garita project on stream in 1987, and they are studying two projects now for the future: Miravalles geothermal (50-55 MW) and Sandillal hydroelectric (32 MW).

ICE's financial condition has seriously deteriorated owing to large debts incurred from past investments, the devaluation of the colon (which greatly increased the effective debt), and the inability to increase power tariffs. In 1984 , costs exceeded sources of funds by 3 percent, or 305 million colones. Revenues from sales covered only 56 percent of the total of operating costs, investments, and debt service. Debt service is 55 percent of this total and is roughly equal to revenues from sales. Existing loans and loan agreements constituted approximately 40 percent of ICE's funds, and these funds cover slightly more than investments. For qualification for loans from organizations such as the World Bank or the IDB, an institution is expected to earn an internal rate of return of at least 9 percent. As a result of cash flow problems, ICE's credit worthiness has severely declined.

b. Prices. As with oil products, electricity prices are set by SNE. The theoretical criteria used for fixation of tarriffs is that the income from electricity sales should equal the cost of production less depreciation and produce a reasonable rate of return.

Increases in electricity tariffs have not been as large as those for 011 . Tables 25-26. show prices in current colones, current dollars, and 1982 colones. ${ }^{20}$ The GDP deflator was used to deflate fuel prices rather than the consumer price index. In current colones, prices began to sharply increase in 1981, but, as shown by the changes in constant colones, price changes did not keep up with inflation until 1983, so that between 1979 and 1982, there was a 
TABLE 25

COSTA RICA: PRICE OF ELECIRICITY BY SECTOR

(colones/kWh)

Residential General Industrial

$\begin{array}{llll}1970 & .129 & .179 & .133 \\ 1971 & .135 & .176 & .127 \\ 1972 & .141 & .178 & .128 \\ 1973 & .151 & .188 & .123 \\ 1974 & .214 & .235 & .190 \\ 1975 & .291 & .305 & .272 \\ 1976 & .352 & .353 & .323 \\ 1977 & .404 & .418 & .368 \\ 1978 & .428 & .435 & .390 \\ 1979 & .442 & .469 & .405 \\ 1980 & .503 & .546 & .448 \\ 1981 & .684 & .773 & .622 \\ 1982 & 1.089 & 1.268 & 1.038 \\ 1983 & 1.702 & 2.591 & 2.119\end{array}$

Source: Reference 20

TABLE 26

COSTA RICA: ELECTRICITY RATES

$\begin{array}{llllllll}1970 & 1977 & 1978 & 1979 & 1980 & 1981 & 1982 & 1983\end{array}$

Current colones per kWh:

$\begin{array}{lllllllll}\text { Residentiol } & 0.13 & 0.40 & 0.43 & 0.44 & 0.50 & 0.68 & 1.09 & 1.70\end{array}$

General

$\begin{array}{llllllll}0.18 & 0.41 & 0.44 & 0.47 & 0.55 & 0.77 & 1.27 & 2.59\end{array}$

Industrial

$\begin{array}{lllll}0.13 & 0.37 & 0.39 & 0.41 & 0.45\end{array}$

$0.62 \quad 1.04 \quad 2.12$

Current dollars per kWh: Residential

General

$0.05 \quad 0.05 \quad 0.06$

$\begin{array}{lll}0.03 & 0.03 \quad 0.04\end{array}$

Industriol

$\begin{array}{lllll}0.03 & 0.05 & 0.05 & 0.05 & 0.06\end{array}$

0.04

$0.03 \quad 0.06$

1982 colones per kWh:

$\begin{array}{llllllllll}\text { Residential } & 1.24 & 1.48 & 1.43 & 1.37 & 1.32 & 1.26 & 1.09 & 1.34\end{array}$

General

Industrial

$1.71 \quad 1.52$

1.47

1.47

1.45

1.46

1.27

2.04

$\begin{array}{llllllll}1.24 & 1.37 & 1.30 & 1.28 & 1.18 & 1.15 & 1.04 & 1.67\end{array}$

Source: Reference 20

"Converted using exchange rate "rf" reported by the International Monetary Fund.

beflated with the GDP deflator reported by the World Bank.

real decrease in the price of electricity. Sharp increases in prices in 1982 current terms were intended to improve revenues and the critical situation of ICE. Nominal tariffs were increased by 92 percent but, owing to public outcry, residential tariffs had to be lowered. By 1983, the real price of electricity 
to the residential sector was still below the the maximum level that it had attained for the period under consideration in 1977. Real prices increased sharply in 1983, by 23 percent for the residential sector and 60 percent for the other sectors. Nominal prices increased by 9 percent in 1984 and by 12.5 percent in 1985, according to ICE.

The determination of prices was explained by ICE as follows. There are individual prices for three separate sectors--residential, commercial, and industrial. Base residential prices are determined by demand; i.e., there is a minimum charge for $30 \mathrm{kWh}$, and demand above that is charged according to block pricing schedules, with price per unit increasing as consumption increases. Rates for commercial and industrial users are determined in a similar manner, but these consumers pay higher prices, especially the commercial sector, and the blocks are much larger. In the $0-3000 \mathrm{kWh}$ block, users are charged only for energy used. In the 3000-20,000 kWh block, customers are charged for energy used plus a charge for potential energy. Potential energy is the maximum amount demanded at a given time by the business or industry. Industrial users are divided into two groups, according to how much they consume. Large industries pay lower average rates than small industries. The ten largest users in the country are a fertilizer plant in Puntarenas; CEMPA (Pacific Cement); INCSA (cement); TEXTILE (textiles for export); 01ympic Fibers; two water-pumping stations for Institute of Costa Rica aquaducts (ICAA); VICESA (window manufacturer); ALUNASA (aluminum sheet and plate manufacture); and Firestone tires. A large industry may consume as much electricity as an entire province.

Since 1978, there have been different prices for peak and off-peak consumption, at least for industry. But industry was slow to respond while electricity prices were relatively low. They began to take notice as prices rose, especially industries that consume more than $20,000 \mathrm{kWh}$. The industrial tariff is based on consumption during the 10:00 - 12:30 peak. If an industry consumes little or no electricity during this period, its tariffs are lower.

c. Cost of Generation. ICE's reliance on hydro for 98.5 percent of its power generation keeps operating costs very low. Thermal generation is only used in isolated cases. The average cost of generation from ICE's hydro capacity was 0.21 colones per $k W h$ in 1983 . In contrast, the cost of generation from thermal was 9.19 colones per kWh. Of the 9.19 colones, almost two-thirds was the fuel cost. In 1983, ICE generated 39 GWh from thermal and 2576 GWh from hydro. Average operating expenses were 0.34 colones per $\mathrm{kWh}$. (This includes indirect costs such as depreciation.) Since hydro is very capital intensive, especially for the relative size of projects such as Arenal-Corobici, the main 
cost to be dealt with is debt servicing on loans that were secured to cover the cost of capital. As discussed earlier, the value of these loans more than quadrupled since the devaluation of the colon began.

d. Demand Estimation by ICE. Electricity demand is expected to grow by 5 percent per year in the near future, according to ICE's estimates. Demand projections critically determine the success of ICE's investment program to increase supply and help to explain the current overcapacity in the country. While residential demand growth is relatively constant, growth in industrial demand varies considerably. In the 1960s, total demand grew at 7 percent per year, from 1970-77, at 8 percent per year, and from 1971-81, at 9 percent per year. Owing to the serious economic problems that Costa Rica began to experience in 1981, total demand grew at only 1 percent in 1980 (caused mainly by a 14 percent drop in industrial output). In 1982, when the economy began to recover, demand increased by 3 percent per year and in 1983 by 9 percent per year. In 1984, demand again increased by 9 percent per year, while the value of real industrial output grew at a rate of 18.5 percent per year. In 1 ight of the large fluctuations in demand in Costa Rica, it has been very difficult to devise optima 7 plans to supply expected demand.

ICE estimates demand based on a method recommended by the Inter-American Development Bank (IDB).

Forecasting is done for the three sectors individually. The main variables used are as follows: the number of customers $(N)$ and energy consumption per customer $(q)$. The following equations are used:

$q($ residential $)=(k W h / a b) * f(G D P, P$ of electricity, $P$ of gas $)$

Residential Demand $=N * q($ residential $)$

The $q$ (commercial) equations are similar to the residential equations, but the price of gas does not enter the equation.

For the industrial sector, the total number of customers is not used. Instead, ICE uses total consumption:

$Q($ industrial $)=f(P$ of electricity and gas, $P$ of electrical machinery, GDP)

ICE has the following problems in estimation. First, it is difficult to forecast the increase in GDP. This is determined by the Central Bank, the World Bank, and the Ministry of $\mathrm{Pl}$ anning, who give three scenarios. These agencies generally agree within about 0.5 percent in growth rates. All provide "realistic," high and low projections. Second, residential demand seems to be elastic. They need to increase tariffs in order to build a new plant, but then demand decreases, so they may plan to meet a pessimistic or low growth option. 
ICE could benefit from a better methodology to deal with the elasticity in demand.

The IDB methodology depends critically on the number of new customers connected to the grid per year, the growth in income per household or establishment, and changes in the real price of electricity. This methodology contrasts with methods that simply depend on aggregate economic growth or extrapolation. These latter methods are deemed unacceptable in developing countries because of the effect of continued electrification, based on the connection of new customers every year, and because, in light of fluctuating conditions, extrapolation is unrealistic. During his study of electricity demand in Costa Rica, Westley determined the following long-run income elasticities of demand for Cost Rica: 0.15-0.25 for the residential sector and 0.40.6 for the commercial sector, including government. According to Westley's estimates, Costa Rican residential demand is significantly more inelastic than the Dominican Republic's, where the residential elasticity was 0.45 . Since ICE has expressed a concern that residential demand seems to be more elastic than expected, the low elasticity should be reexamined in light of new data.

3. Biomass Supply. Sources of biomass energy supply include fuel-wood and vegetable residues from agriculture. Fuel wood is by far the largest biomass energy supplied, providing approximately one-third of Costa Rica's total energy needs. In 1970, fuel wood supplied almost half of Costa Rica's energy needs. Since then, its use has diminished while diesel oil and electricity use has increased. Fue 1 wood use, as a percentage of total energy used, reached a minimum in 1980-81 and has increased slightly since then. In 1983, 98 percent of the wood was consumed directly, and 2 percent was consumed after transformation into charcoal. Vegetable residues are used in agriculture and industry, and they totalled 10 percent of effective supply in 1983. As a percent of total energy consumed, use of vegetable wastes has varied only a little over the past 14 years. Trends in its use are very similar to those for fuel wood, with a minimum as a percent of supply in 1980, which has increased slightly through the present. This presumably is the result of substitution of vegetal matter for petroleum products after 1980 . Less than 3 percent of the vegetal matter supplied is used to produce electricity.

The sources of fuel wood are shown in Table 27. The major sources of wood, totaling 60 percent of wood supply, are from woods from cattle ranches and cuttings from coffee plantations. A report ${ }^{15}$ based on the DGF/CATIE/ROCAP study predicted the following changes in sources of supply through the year 2000. A decrease in the area of cattle ranches will be compensated by improved regrowth 
TABLE 27

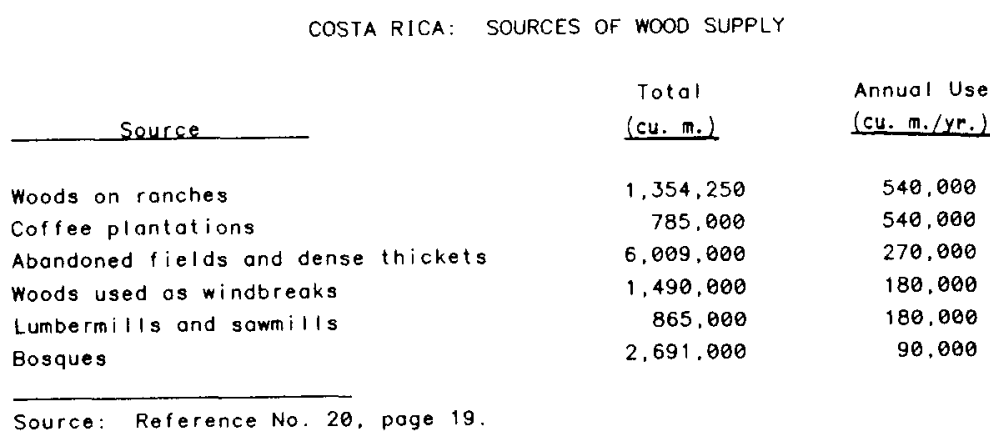

and wood harvesting so that fuel wood from trees and hedges around ranches should remain constant. This source of fuel wood is most common in the dry Pacific region of the country where most of the cattle ranches are. It was predicted that the number of shade trees in coffee plantations would decrease because growers are substituting a more sun-resistant coffee plant for existing plants. However, the diminished clippings from shade trees was expected to be balanced by an increase in the size of coffee plantations and by more intensive pruning (of coffee $\mathrm{plants}$ and shade trees). Coffee plantations provide much of the fuel wood for the Central Valley. Abandoned fields and dense thickets generally occur marginal to farms in inaccessible regions, e.g. areas deforested for farming and then abandoned. The supply of fuel wood from these sources is expected to decrease as the size of these regions decreases. A large decrease in supply is expected from lumbermills and sawmills because the area harvested for lumber is expected to decrease.

A study done by Meta Systems ${ }^{21}$ concerning the possibility of substitution of fuel wood for fuel oil by industry contradicts the DGF/CATIE/ROCAP study somewhat and predicts that there could be an increase in supply from lumbermills and sawmills because of present underutilization of scrap. Fuel wood from forests is expected to diminish because harvesting of such wood is usually done illegally to produce charcoal. Increased law enforcement is expected to decrease the supply of wood from this source. In summary, according to projections from "Proyecto Lena y Fuentes Alternas de Energia," 21 demand would exceed supply by 1987 .

Mr. Canet of the General Directorate of Forestry (DGF) stated the current fuel-wood price in Costa Rica is $\$ 20-\$ 25 /$ ton. Price data in colones per cubic meters is available only for the years 1980-1984. The longest distance for transport of domestic fuel wood is between $3-5 \mathrm{~km}$ round trip utilizing 4-ton trucks. The longest distance traveled for fuel wood procurement for industrial 
use is $50-\mathrm{km}$ round trip using a $10-$ ton or 1 arger truck. Ten percent of fue 1 wood is consumed in urban areas and 90 percent in rural areas. Of the 10 percent urban consumption, 5 percent have a "free" wood source, such as a relative who owns a farm and provides them with wood, and the other 5 percent buy wood. of the 90 percent rural consumption, 85 percent obtain wood from their own 1 and; the other 5 percent buy wood. An unofficial statistic given by Mr. Fernandez of DGF indicates that in 198315,000 hectares were cut down without permission and that illegal tree-cutting accounts for 5 percent of current wood use.

In the last three to four years the coffee industry has decided to phase out coffee shade trees. These shade trees are pruned twice a year and the wood is used as fuel. Currently a smaller, more sun-resistant type of coffee tree is being planted. More trees can be planted per acre increasing the amount of coffee produced.

Moreover, during the 1984 coffee harvest a tree disease called "roya" was detected among the shade trees. The shade provided by the trees allows the disease to diffuse along the tree bases. The tree disease together with the coffee industry's decision means that coffee shade trees will cease to be planted. As shade tree prunings gradually diminish, the consumer will look to other traditional wood sources such as wood from trees on pasture land, thicket areas, and forests. At present, coffee plantations provide 30 percent of the fuel wood for the population. This percentage will decrease, and there will be a marked increase in the use of other traditional wood sources. Only a few small isolated areas will continue to implement shade trees. Mr. Canet of DGF believes the situation will reach a crisis stage soon.

In the last two or three years, the DGF has recognized the need for reforestation, but to date no programs have been initiated. The interest is there, but there is no capital available. Mr. Fernandez thinks that initiatives might not be taken until deforestation reaches a real "crisis." Costa Rican industry such as Cemento Pacifico in Guanacaste would like to reforest, but banks do not have the necessary funds to lend for reforestation programs. Cartago Agua Caliente de Industria Nacional de Cemento located $30 \mathrm{~km}$ from San Jose would like to see 50 percent of their bunker fuel substituted with wood.

At this time there are 130 tree farms of about 5,000 hectares each, and about 16,000 hectares have been reforested. The wood is utilized for construction purposes only. The tree farms are funded with tax money in the form of government fiscal incentives.

The industrial sector does not use charcoal at all. The wood used in the charcoal-making process comes from trees in protected forest areas. In the 
residential sector, charcoal use is insignificant, and therefore no figures were available for the years 1970-1984.

Given the regional nature of the fuel-wood market resulting from the cost of transportation and the fact that much fuel wood is noncommercial, the number of consumers likely to be affected by a fuel-wood price increase is uncertain.

Peat resources, currently being evaluated by RECOPE with LANL support, could prove to be an important substitute for fuel wood.

4. Alcohol production. During the final months of the oduber Administration (1974-1978), CODESA, the state-owned holding company, was authorized by Decree 7775 to purchase and install an alcohol distillery with a maximum capacity of 240,000 iters of anhydrous alcohol per day. The basic strategy was that the sugar cane-based alcohol should be purchased by RECOPE to be mixed and sold as "gasohol": a mixture of 80 percent gasoline and 20 percent alcohol. In February 1978, CODESA signed a "turn-key" contract with Interbras of Brasil, although at that time there were already serious doubts regarding the potential availability of sugar cane for its operation.

The distillery was located adjacent to the sugar mill of the central Azucarera del Tempisque (CATSA) near Guardia, Guanacaste. Construction was completed by the end of 1979. The distillery was closed shortly thereafter because it was felt that it would not be economical. There were numerous statesponsored alcohol projects, yet none of them ever got beyond the drawing board. CATSA's distillery never operated above 10 percent capacity, and RECOPE was directed to purchase the alcohol.

In April of 1980 RECOPE started distributing gasohol to some government vehicles, and a year later the "new national energy" started to be sold in a few selected gas stations, with a small price differential with respect to gasoline to favor the new product. The gasohol program was plagued by serious problems from its inception. Alcohol acted as a detergent in the gas tanks of older vehicles, removing sediments and other residues and clogging gas 1 ines and carburetors. In addition, about 80 percent of all gas stations had infiltrations; therefore, gasohol could be sold only in a small number of stations, and even then, there were consumer doubts about the quality of the product.

Although there were serious flaws in the commercialization strategy, the most serious objections were raised by the University of Costa Rica (UCR) sponsored study coordinated by the Economics Research Institute. The main arguments brought forth were related to the high cost of production (US $\$ 0.46$ 0.50 per liter at 1980 exchange rates), the fact that the national value-added was less than 50 percent owing to the high level of imports involved in the 
production of cane and alcohol, and the relative prices of sugar and alcohol, which at that time favored direct sugar exports. It should also be clarified that at that time Costa Rica was not meeting its quota in the preferential U.S. sugar market.

Al1 these factors contributed to the short life of the gasohol experiment. Sales dropped quickly to a few percent of total gasoline sales, and CATSA remained virtually closed from 1982 to 1984, with an installed capacity equivalent to close to 20 percent of national gasoline consumption.

Cane production has increased considerably in the last two years; at the same time sugar prices hit bottom levels in the world market. The situation is even more critical given the fact that the U.S. sugar quota for the 1985 - 1986 period was reduced by 40 percent to 31 thousand tons. The quota price is nearly five times higher than the free-market price.

Costa Rica's cane production of nearly a quarter million tons leaves a significant surplus when the U.S. quota and sugar for internal consumption are subtracted, and recently the Liga Agricola Industrial de Cana de Azucar (Laica), a body made up of private producers and Government representatives, has moved quickly to reactivate alcohol production for export to the U.S. under the Caribbean Basin Initiative (CBI). LAICA and CATSA agreed to process the cane surplus into alcohol, and a shipping terminal was built to export the alcohol. About 15 million liters of alcohol were exported in 1985.

LAICA is now getting a price of US $\$ 1.25$ gallon, which according to its president, does not cover the cost of production, but allows the capture of three times more revenue than what would be gotten for the sugar in the freemarket.

For the 1985-1986 harvest of approximately 230 thousand metric tons of sugar, 50 thousand metric tons will go for alcohol production, and a new private distillery at the Taboga sugar mill has been installed to reach an expected total production of 32 million liters of alcohol, coming from both CATSA and Taboga.

LAICA would like to continue the alcohol exports under the CBI, and the product is used in the U.S. as an additive to gasoline to make it "superunleaded." But, U.S. grain-alcohol producers have filed a suit in Federal Courts against Costa Rican alcohol, claiming that there are subsidies in its production. It this suit is successful, Costa Rica may have to look for alternative markets for its considerable alcohol production, including the internal market for gasohol or its use as a lead substitute in all gasoline sold in the country. 
Despite its boom and bust history, alcohol production represents the most important substitution opportunity for energy in the transportation sector and is one that is likely to be debated extensively in the coming years.

5. Summary of Energy Supply. The most critical supply problems facing Costa Rica are summarized below. The first concerns the cost of oil supply to the country. With the decrease in the terms of trade, the real cost of oil has increased enormously, placing a drain on the foreign exchange of the country. Foreign exchange spent to pay the $0 i 1$ bill subtracts from the total amount available for consumption and investment. The expense of the oil supply is exacerbated by the inefficiencies of the refinery. ICE is in serious financial trouble as a result of unforseen decreases in electricity demand and resulting overcapacity, a huge increase in its debt owing to the devaluation of the colon, and mobility to increase tariffs to reflect the true cost of electricity.

The fuel-wood situation is unclear, but there is a potential for significant price increases in fuel wood resulting from diminished supply and increased demand. There are already rumors to this effect that are causing stockpiling of fuel wood around San Jose. Deforestation, although not an insignificant problem in Costa Rica, is not directly linked to fuel-wood harvesting but rather to land clearing for cultivation.

c. Energy Demand

Total energy consumption in Costa Rica peaked in 1980 and then it was significantly affected by the economic recession, particularly in the industrial and agricultural and transportation sectors. Between 1970 and 1978, total consumption grew at an average annual rate of 4.5 percent, decreasing to 1.4 percent growth for the following six-year period, 1978 through 1984 . If the period of the recession and recovery is considered separately, 1980 through 1983, the decrease is more significant, being 2.7 percent per year.

Energy consumption by fuel type and sector is shown in Tables 28-31 for 1984. The major drivers in energy consumption, from largest to smaller follow: fuel-wood use in the residential sector, diesel consumption in transport, electricity consumption in the residential/commercial sector, vegetable residue use in agriculture/industry, gasoline use in transport, and fuel oil use in industry. Together, these uses consume 85 percent of total energy in the country. A discussion of the characteristics of consumption by sector follows.

1. Residential and Commercial Sectors. The residential/commercial sector used half of the country's energy supply in 1970. But, as the economy grew in the 1970s, this share of total consumption decreased to approximately 40 percent in 1980, after which it increased slightly to 44 percent after the recession in 
TABLE 28

COSTA RICA: COMPOUNDED ANNUAL AVERAGE GROWTH RATES

FOR ENERGY CONSUMPTION, BY SECTOR FOR SELECTED YEARS

(percentoges)

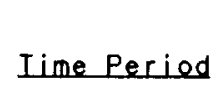

$1970-1978$

$1978-1984$

$1980-1984$

$1970-1984$
Residential/

Commercial.

Iranspert
1.16
3.54
4.77
2.16

8.93

$-2.17$

$-3.67$

4.01
Industrial/

Agriculture

Qther Iotal

6.14
1.22
1.31
3.98

3.42

4.52

$6.84 \quad 1.37$

$7.13 \quad 1.47$

$4.84 \quad 3.14$

TABLE 29

COSTA RICA: 1984 ENERGY CONSUMPTION

(thousands of barrels equivalent of petroleum)

Coal and coke

Residentiol

and Commercial

Wood

Vegetable residues

Charcoal

Alcohol

Electricity

LPG

Gasol ine

Kerosene and jet fuel

Diesel oil

Gas oil

Fuel oil

Nonenergy oil

Total

4581
Ironsperts

$\theta$

0

0

$\theta$

0

6

0

893

84

1663

0

0

0

2647

\begin{tabular}{crr} 
Industry & \\
and Agriculture & Other & Iotal \\
\hline 2 & 0 & 2 \\
169 & 0 & 3627 \\
1078 & 0 & 1078 \\
0 & 0 & 50 \\
0 & 0 & 2 \\
426 & 45 & 1386 \\
20 & 0 & 108 \\
0 & 0 & 893 \\
31 & 0 & 191 \\
210 & 33 & 1906 \\
6 & 0 & 6 \\
730 & 173 & 903 \\
0 & 152 & 152 \\
2673 & & 10305
\end{tabular}

Source: Country Energy Balances. 
TABLE 30

COSTA RICA: 1984 ENERGY CONSUMPTION

(percentoge of totol)

Residential

ond

cemmercial

0
34
0
0
0
9
1
0
1
0
0
0
0

44
Industry

and

Iransport Aariculture

Qther Ietol

Cool and coke

Wood

Vegetable residues

Chorcoal

Alcohol

Electricity

LPG

Gasoline

Kerosene and jet fuel

Diesel oil

Gosoline

Fuel oil

Nonenergy oil

Totol

Note: Total may not sum to 100 due to rounding

TABLE 31

COSTA RICA: 1984 ENERGY CONSUMPTION
(percentage of fuel use by sector)

Residential

and

commercial

Ironsport

Industry

and

$\begin{array}{rrr}0 & 0 & 0 \\ 2 & 0 & 35 \\ 10 & 0 & 10 \\ 0 & 0 & 0 \\ 0 & 0 & 0 \\ 4 & 0 & 13 \\ 0 & 0 & 1 \\ 0 & 0 & 9 \\ 0 & 0 & 2 \\ 2 & 0 & 18 \\ 0 & 0 & 0 \\ 7 & 2 & 9 \\ 0 & 1 & 1\end{array}$

26

4

Other Iotel
Cool and coke

wood

Vegetoble residues

Charcoal

Alcohol

Electricity

LPG

Gasoline

Kerosene and jet fue

Diesel oil

Gas oil

Fuel oil

Nonenergy oil

Total

0
95
0
100
0
66
81
0
40
0
0
0
0
44

0
0
0
0
100
0
0
100
44
87
0
0
0
26

100
5
100
0
0
31
19
0
16
11
100
81
0

Note: Totals may not sum to 100 due to rounding. 
the 1980 s caused by a relative decline in energy consumption in the other sectors. The growth rate of residential consumption has been relatively constant at approximately 1 percent per year, exhibiting only a slight income and price elasticity during the recent recession.

Fue 1-wood use in the residential/commercial sector amounts to 34 percent of energy use in the country, equal to 95 percent of wood consumption. Fuel wood is considered by DSE to be noncommercial energy, although 25 percent of it is purchased. Rural households use 90 percent of the fuel wood, and city dwellers use only 10 percent.

Since 1970, there has been a substitution of electricity for fuel wood in the sector, with the share of electricity doubling from 10 percent to more than 20 percent of total energy consumed in the sector (Table 32). A large increase in electricity prices in 1982 may have had a small effect in slowing the annual rate of increase in electricity consumption in the residential/commercial sector. In general, the share of electricity in total energy consumption in the sector had been increasing at roughly 2 percent per year from 1979 through 1982. After the price increase in 1982, there was virtually no increase in the share of electricity used in this sector. In real terms, the price of electricity to this sector peaked in 1979, almost halved by 1981, and, despite the large real increases in 1982, sti1l has not attained its 1979 level. In 1983, the price was $\$ 0.04$ per $\mathrm{kWh}$. There is some debate over the percentage of households connected to the grid; ICE considers it to be 75 percent and DSE estimates it at 85 percent. The residential/commercial sector consumed 68 percent of electricity sales in 1983, with industry consuming most of the rest.

A1 though LPG use comprises a very small percent of energy use by the residential/commercial sector, it had grown steadily from 1 percent to almost 4 percent by 1980. As the real price of LPG more than tripled between 1978 and

TABLE 32

COSTA RICA: ENERGY CONSUMPTION BY TYPE FOR RESIDENTIAL

AND COMMERCIAL SECTORS

(percentoges)

\begin{tabular}{|c|c|c|c|c|c|c|c|c|c|}
\hline & 1970 & 1977 & 1978 & 1979 & 1980 & 1981 & 1982 & 1983 & 1984 \\
\hline Electricity & 10.2 & 15.5 & 16.5 & 16.0 & 18.4 & 20.0 & 22.1 & 22.3 & 19.8 \\
\hline LPG & 1.0 & 2.5 & 2.9 & 3.7 & 3.8 & 3.4 & 1.9 & 2.4 & 1.9 \\
\hline Kerosene ond jet fuel & 3.9 & 3.9 & 4.0 & 3.6 & 2.9 & 1.5 & 1.2 & 1.2 & 1.7 \\
\hline Wood & 83.5 & 76.6 & 75.1 & 75.1 & 73.3 & 73.5 & 73.2 & 72.5 & 75.5 \\
\hline Charcool & 1.4 & 1.5 & 1.5 & 1.6 & 1.6 & 1.6 & 1.6 & 1.6 & 1.1 \\
\hline Total & 100.0 & 100.0 & 100.0 & 100.0 & 100.0 & 100.0 & 100.0 & 100.0 & 100.0 \\
\hline
\end{tabular}


1982 , its use sharply dropped from almost 4 percent of total energy used in the sector to only 2.4 percent in 1983.

Possible fuel-wood price increases will have the most significant effect on the residentia! consumers who must purchase their fuel wood. Policies to mitigate this hardship include encouraging substitution by LPG or electricity. However this would require the purchase of new stoves, which would be a sizeable expenditure for most residential consumers of fuel wood. Because electricity price increases are warranted to match ICE's costs, encouraging substitution of fuel wood by electricity needs to be further examined from a welfare point of view.

Energy utilization in the household sector in Costa Rica is dominated by firewood and electricity. About 85 percent of all the households use electricity for illumination, approximately three quarters of them have a television set, and over 50 percent have a refrigerator. At the same time close to 40 percent of a 11 households cook with firewood; therefore, approximately one million Costa Ricans still rely on this energy source for cooking. This represents about one million tons of firewood per year.

About 15 percent of the households utilize LPG for cooking, with about twothirds of the users located in urban areas and the remaining third in rural areas. Close to 12 percent of the households utilize kerosene, and less than 5 percent rely on charcoal for cooking.

Many substitutions have taken $\mathrm{place}$ in the household sector during the past decades. ICE's ambitious rural electrification program has resulted in large increases in the number of residential customers, up to the point where nearly 45 percent of ICE's revenues come from residential sales. In addition, because of the large number of residential users that cook with electricity, national electrical demand peaks coincide with lunch and dinner times (12:00 and 18:00 respectively). Given that ICE's hydroelectric-based system has only one reservoir with biannual storage capacity, the expansion needs of the entire electrical system are strongly correlated to the cooking requirements of the population.

In addition, electricity price increases since 1973 have forced some users who cooked with electricity to return to firewood or charcoal. A similar situation has occurred with respect to LPG use, although this latter fuel has slowly lost its share in the market since the Arenal hydroelectric project came on 1 ine in 1979. Prior to that date, brownouts and shortages had forced a significant portion of the urban population to cook with LPG. 
Relatively little effort has been placed on conservation programs for the household sector through mechanisms other than pricing. The same is true with substitutions, which have been adopted by the consumer following relatively haphazard price signals, but without an explicit governmental strategy.

Given ICE's precarious financial condition, it is likely that more effort will be devoted to conservation-substitution in the household sector to reduce daily demand peaks and total energy use during the dry season.

2. Industrial and Agricultural Sectors. This sector uses one-quarter of the energy consumed in the country. The largest items of consumption are vegetable residues (burned to provide process heat and some electricity for the sugar and coffee industries), fuel oil, and electricity (Table 33). In 1984, these three fuels supplied over 80 percent of the energy consumed in the sector. This sector's energy consumption is closely related to output from the sector. Between 1970 and 1980, energy consumption grew at an average rate of 6.2 percent per year. Because of the recession, energy consumption actually decreased by 4.5 percent per year between 1980 and 1983.

The vegetable residues, which supply 10 percent of the country's total energy consumption, are consumed in the industrial/agricultural sector. They comprise sugar-cane bagasse, coffee wastes, and, to a minor extent, materials such as rice husks. The percentage of total energy consumed supplied by vegetable residues in this sector has varied slightly from 35 percent in 1970 to almost 40 percent in 1983 and 1984. It appears that from 1977 through 1981, fuel oil was used as a substitute for some of the vegetable residues. In 1981, fuel oil share of consumption reached its maximum, and the share of vegetable residues reached its minimum.

TABLE 33

COSTA RICA: ENERGY CONSUMPTION BY TYPE IN INDUSTRY AND AGRICULTURE (percentages)

LPG

Kerosene and jet fuel

Diesel oil

Fuel oil

Coal and coke

Wood

Vogotoble residues

Total

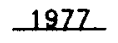

1970

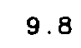

.6

6.6

24.9

13

13.6

44.4

100.0

12.3

.9

15.7

31.5

.1

4.5

35.0

100.0

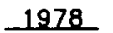

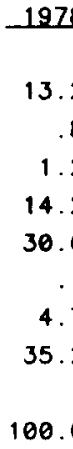

13.2

1.2

14.2

30.6

.1

4.7
35.2

100.0

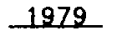

15.7

.6

1.2

10.1

32.3

.1

4.9
35.1

35.1

100.0

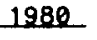

15.9

.7

1.1

10.3

34.2

.1

4.3

33.4

100.0

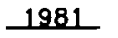

1982

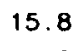

1.0

1.0

9.3

37.5

.1
3.9

31.2

100.

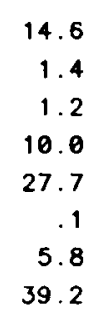

100.0
$1983 \quad 1984$

16.0

$.4 \quad 8$

$1.2 \quad 1.2$

$6.5 \quad 7.9$

$29.6 \quad 27.3$

$.1 \quad .1$

5.96 .3

$39.9 \quad 40.3$

$100.0 \quad 100.0$ 
Fuel oil use in the agricultural/industrial sector amounted to 7 percent of Costa Rica's total energy consumption in 1984. Four-fifths of the fue $10 i 1$ used in the country is consumed in this sector. The share of fuel oil in total energy consumed in the sector increased from almost one-quarter to more than one-third by 1981 , but then dropped precipitously from 37 percent to 28 percent between 1981 and 1982, when cement production declined owing to decreased construction activity. The real price of fuel $0 i 1$ doubled between 1978 and 1980 and then doubled again by 1982 . However, there was little price response or substitution apparent until 1982. According to a survey performed by the Instituto Tecnologico de Costa Rica (ITCR), 18 large industries use almost 90 percent of the fuel oil consumed by industry. Over half of the fuel oil provides energy for cement making, 39 percent is used in steam generation, and 10 percent is used to provide process heat. ${ }^{21}$ over three-fourths of the large users are in the Central Valley. A regional study conducted for AID/ROCAP ${ }^{22}$ estimated that approximately 28 percent of the fuel oil could be conserved through relatively simple measures. The study performed by Meta Systems and ITCR ${ }^{21}$ estimated that fuel wood, if priced at $\$ 30$ per ton, could substitute for about 20 percent of the fuel oil used in the country in 1981 at prevailing prices. If fuel oil was priced at import value, they estimated that the degree of substitution could increase to 35 to 40 percent. Unless the refinery is closed, excess fuel oil will have to be exported if it is not consumed directly.

The third major fuel consumed by the industrial/agricultural sector is electricity. In 1984, industry consumed almost one-third of the electricity sold in Costa Rica. Electricity supplied 16 percent of the energy used in the sector in 1984. With the exception of the recent recession, electricity's share of energy consumed by the sector has steadily increased from approximately 10 percent in 1970 to 16 percent in 1984 . The real price of electricity decreased from 1977 through 1981; although the nominal price increased during this period, the increases failed to keep pace with inflation. To alleviate this disparity and to address ICE's increasing costs, real prices increased by a factor of 2.5 between 1981 and 1983. Industry responded by decreasing its share of electricity consumption in 1982.

3. Transport Sector. In 1984, the transport sector consumed approximately one-quarter of the country's total energy. Virtually all of this energy was in the form of diesel oil, gasoline, and jet fuel (Table 34). Between 1970 and 1980 , the rate of increase of energy consumption by transport was highest of all the sectors, being an average of almost 9 percent per year. The devaluations, the recession, and sharp price increases hit the transport sector hard so that 
TABLE 34

COSTA RICA: ENERGY CONSUMPIION BY TYPE FOR TRANSPORT SECTOR

(percentoges)

Electricity

Gasoline

Kerosene ond jet fuel

Diesel oil

Alcohol

Total

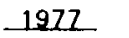

1978

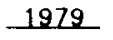

1986

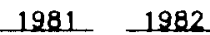

1983

1984

0.4
43.3
3.0
53.3
-
100.0

0.2
37.1
4.2
58.5

0.2

0.2

33.3

4.7

0.2

36. 2

0.3

0.2

0.3

0.2

4.3

4.9

64.7

59.1

61.8

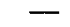

100.0

100.0

$100.0 \quad 100.0 \quad 100.0 \quad 100$.

4.24 .5

$65.4 \quad 62.9$

0.2

0.2

4.2

62.9

0.1

33.7

3.2

62.8

0.1

$100.0 \quad 100.0$

between 1980 and 1983, consumption decreased by an average of over 10 percent per year. From 1970 through 1979, energy consumption by transport had increased from less than one-quarter of the country's total to almost one-third. Sharp price increases in 1974 only temporarily halted this rate of increase. The 70 percent increase between 1978 and 1979 did not have an immediate effect. It is conjectured that the recession was more important in decreasing energy consumption by the sector, implying that the income elasticity is greater than the price elasticity of demand.

Between 1970 and 1980, diesel oil has gradually substituted for gasoline. In 1970, gasoline supplied 43 percent and diesel 53 percent of the sector's energy needs. By 1980, gasoline supplied less than one-third and diesel almost two-thirds of transport's energy. Since at least 1970, diesel has always been priced substantially below gasoline, being a factor of two to three times less expensive until 1981. Since 1981, the percentage price increases for diesel have been greater than for gasoline, somewhat narrowing the price gap. As a result, the share of gasoline consumption increased and diesel consumption decreased somewhat between 1981 and 1983. A lower elasticity of substitution was expected, because fuel type depends on the stock of vehicles, which changes slowly. Virtually all of Costa Rica's private vehicles have gasoline motors, whereas most buses have diesel engines. The recent decrease in the share of diesel consumption (1980-1983) was mainly owing to a decrease in cargo transport by 1 arge trucks, resulting from decreased economic activity.

With the exception of fuel oil use by industry and minor diesel consumption 
by industry and the utility, transport consumes virtually all of the hydrocarbons in the country. Conservation of oil products in the transport sector is thus the key to reducing oil imports.

Costa Rica's transportation system is dominated by road transport, with highway vehicles accounting for close to 98 percent of the passenger kilometers and nearly three-quarters of ton-kilometers. At the same time, energy consumption for transportation represents 60 percent of total petroleum and refined products imports and nearly 50 percent of total secondary energy used in Costa Rica.

Since highway transportation represents such an overwhelming proportion of total energy use in the sector, it is desirable to obtain data on total energy consumption per vehicle type for purposes of estimating conservation and substitution potential. The only direct source of information on energy use by vehicle type is data on taxi and bus energy use provided by TRANSMESA, the state-owned enterprise that controls part of the public transportation system. Estimates for the total transportation fleet have been obtained by multiplying the number of registered vehicles of each type by relatively crude estimates of average annual usage and specific consumption rates:

Fuel use per vehicle type $=$

(No. of vehicles of a given type) $\times$ (annual $\mathrm{kms} /$ vehicle) $\times$ (liters $/ \mathrm{km}$ )

The Ministry of Public Works and Transportation (MOPT) keeps records of registered vehicles per fuel type, which are shown in Table 35. MOPT has estimated consumption of diesel and gasoline in transportation utilizing the method described above, and the results appear in Table 36 for 1983.

The main shortcoming of this method lies in the estimates or educated guesses that are required for annual vehicle use and specific consumption of fuel per kilometer. The results can be checked against RECOPE sales of diesel and gasoline for transportation. Table 36 shows that the agreement between sales and the estimated value is fairly good for gasoline but rather poor for diese1. Despite the obvious drawbacks, the method at least provides an indication of the relative importance of vehicle types. A similar effort for the year 1981 is shown in Table 37 with respect to total energy consumption. Heavy vehicles (trucks, buses, and special vehicles) account for over 50 percent of total transportation energy use, with heavy trucks capturing almost 30 percent of the total. Second in importance are light vehicles (automobiles, pickups, jeeps, etc.) with almost 40 percent of total energy use. Jeeps and taxis, included in this category, account for about 5 percent each whereas medium-weight trucks and microbuses represent the remaining 10 percent. 
TABLE 35

COSTA RICA: MOTOR VEHICLES IN CIRCULATION ACCORDING

TO CATEGORY OF SERVICE AND TYPE, APRIL 1984

\begin{tabular}{|c|c|c|c|c|}
\hline & Letal Ne. & Ne. & \multicolumn{2}{|c|}{ Percent } \\
\hline Possenger & 101.533 & & $(48$ & percent) \\
\hline Aut omobile & & 58,710 & $(28$ & percent) \\
\hline Station wagon & & 12,561 & $(6$ & percent) \\
\hline Jeep & & 30.262 & $(14$ & percent) \\
\hline Corgo & 62,579 & & $(29$ & percent) \\
\hline Pickup & & 44.851 & $(21$ & percent) \\
\hline Panel van & & 5.578 & $(3$ & percent) \\
\hline \multicolumn{5}{|l|}{ Truck } \\
\hline Troctor & & 1.904 & $(1$ & percent) \\
\hline Other & & 8.342 & (4 & percent) \\
\hline Buses & 3,320 & & (2 & percent) \\
\hline Microbus & & 387 & $(\theta$ & percent) \\
\hline Bus & & 2,933 & $(1$ & percent) \\
\hline Taxi & 1,792 & & $(1$ & percent) \\
\hline Motoreycles and mopeds & 32,724 & & $(15$ & percent) \\
\hline Motorcycles & & 28,413 & $(13$ & percent) \\
\hline Mopeds & & 4,311 & (2 & percent) \\
\hline Speciol Equipment & 10.890 & & $(5$ & percent) \\
\hline Agricultural & & 7,729 & $(4$ & percent) \\
\hline Nonagricultural & & 3.161 & $(1$ & percent) \\
\hline
\end{tabular}

Total

212,838

Source: Ministry of Public Works and Transportotion (MOPT).

TABLE 36

COSTA RICA: ESTIMATED AVERAGE ANNUAL CONSUMATION

OF FUEL BY VEHICLE IYPE IN 1983

\begin{tabular}{|c|c|c|c|c|c|c|c|c|c|c|}
\hline \multirow[b]{2}{*}{ Tree ef rehicle } & \multicolumn{2}{|c|}{$\begin{array}{c}\text { Number } \\
\text { ef vehicles }\end{array}$} & \multicolumn{2}{|c|}{$\begin{array}{c}\text { Consumption } \\
(1 \text { ilers } / \mathrm{km})^{\circ}\end{array}$} & \multicolumn{2}{|c|}{$\begin{array}{c}\text { Annual } \\
\text { Lave L }(\mathrm{km})^{b}\end{array}$} & \multicolumn{2}{|c|}{$\begin{array}{c}\text { Total consumption } \\
(v \text { Lerg/yr) }\end{array}$} & \multicolumn{2}{|c|}{ Percent. } \\
\hline & Diesel & Gasoline & Diesed & Gasoline & Diesel. & Gaseline & D. Diesel & Gasoline & Diesel & Easeline \\
\hline Aut onobile & 1.148 & 55.666 & 0.088 & 0.115 & 11,000 & 7.000 & 1.111 .264 & 44.811 .130 & D. 36 & 30.92 \\
\hline Pickup & 16.549 & 27.730 & e. 104 & D. 135 & 13.000 & 9.000 & 22.374 .248 & $33,691,950$ & 7.25 & 23.25 \\
\hline Ponol & 169 & 5,364 & 0.104 & 0.135 & 12,000 & 9,000 & 210,912 & 6.517 .260 & 0.07 & 4.50 \\
\hline Jeep & 15.479 & 13.599 & 0.100 & 0.130 & 12.000 & 9.008 & 18.574 .800 & 16.028 .810 & 6.02 & 11.86 \\
\hline Station wagon & 123 & 12.053 & 0.092 & 0.120 & 10.000 & 7,000 & 113.160 & $10.124,520$ & 0. 04 & 6. 99 \\
\hline Truck & 10.312 & 1.319 & 0.366 & 0.475 & 41.000 & & 154.741 .872 & 18.795 .750 & 50.12 & 12.97 \\
\hline Spocial equipment & 9.731 & 324 & 0.700 & 0.910 & 7,000 & 5.000 & 47.681 .900 & 1.474 .200 & 15.44 & 1.02 \\
\hline Microbus & 115 & 257 & 0.220 & 0.280 & 100.000 & 80.000 & $2,530,000$ & 5.750 .800 & 0.82 & 3.97 \\
\hline Bus & 2.722 & 146 & 0.233 & 0. 300 & 57.000 & 35.000 & $36,158.882$ & $1.533,000$ & 11.71 & 1.06 \\
\hline Taxi & 1.384 & 395 & 0.172 & B. 224 & 106.000 & 70.000 & 25.233 .089 & 6.193 .000 & 8.17 & 4.27 \\
\hline Total & 57,732 & 116.947 & & & & & 308.722 .126 & 114.927 .020 & & \\
\hline & & & & & & & $(11.218 .96 \mathrm{I}$ & ) $\quad(4,733.32$ & J) & \\
\hline
\end{tabular}

Soles of diesel to tronsport sector reporled by RECOPE $1983=8.261$ TJ.

Soles of gasoline to transport sector reported by RECOPE $1983=4,727 \mathrm{iJ}$

Dota on consumption por kitometer were oxtimotod using ongineoring curvos for speod vergus valocity for various sized vehiclas in the Uniled States and do not necessarily represent octual conditions in Costa Rico.

Estimated.

Source: Department of Economic Studies, General Ptonning. 
TABLE 37

COSTA RICA: HIGHWAY VEHICLE CONSUMPTION BY VEHICLE TYPE, 1981

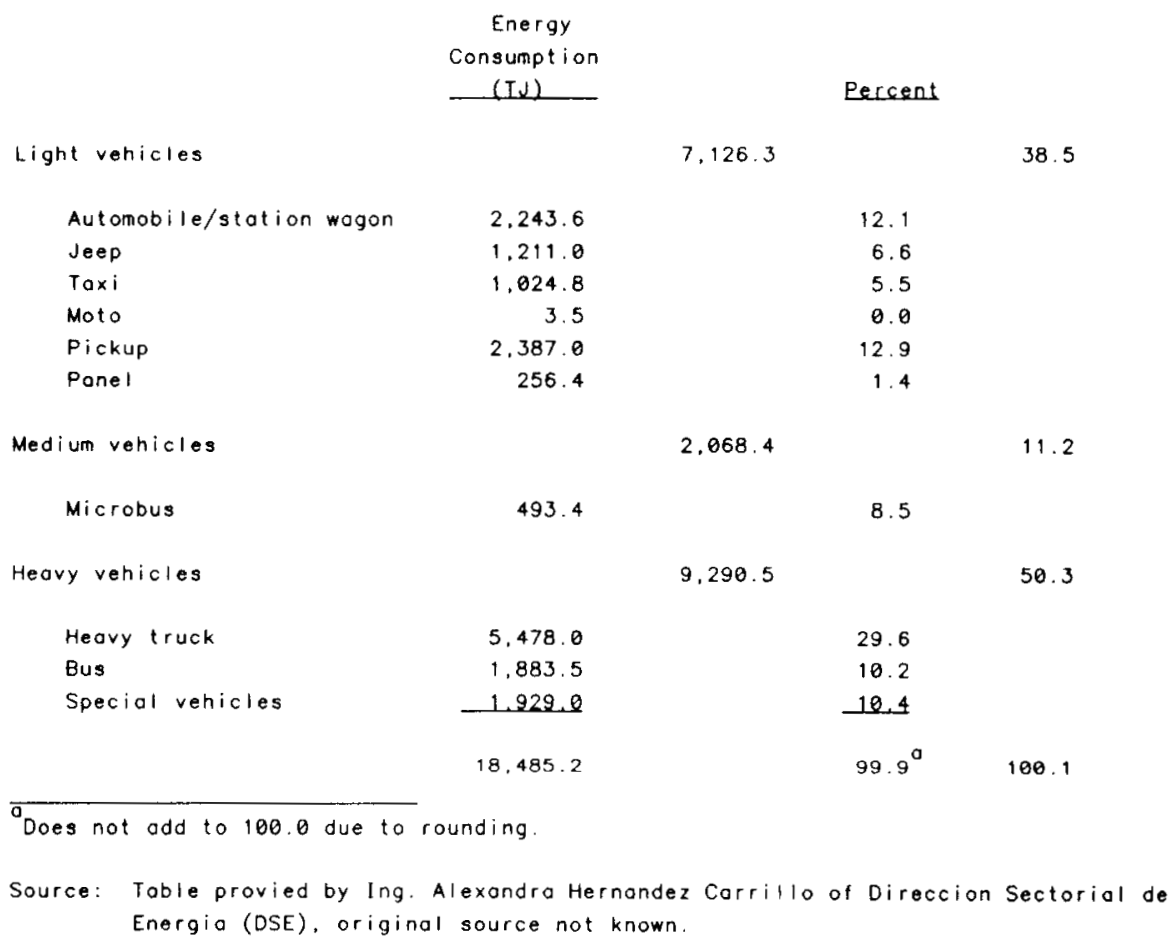

As mentioned earlier, this method has considerable built-in error, and it overestimates considerabiy diesel energy use in transportation. However, at the present time it provides the only data available on fuel consumption per vehicle type, and it is useful for order of magnitude estimates and to identify the main users.

\section{Energy Planning}

Energy planning started in Costa Rica in 1978 under the auspices of the United Nations Development Program (UNDP)--PEICA Project, Proyecto Energetico del Istmo Centroamericano, which provided funds for a small group to start working with ICE support on the national energy balances. An external resident advisor was also provided to train the group. End-use surveys were conducted for noncommercial energy sources, primarily firewood, and a methodology for energy balances was adopted.

The group evolved into an Executive Secretariat for Energy Sector Planning in 1980 as a new sectorial planning system was implemented by oficina de PTanificacion y Politica Economica now MIDEPLAN or Planning Ministry (OFIPLAN), 
but resources were not forthcoming and the group remained relatively unchanged in composition and functions.

In 1982, the Monge Administration created a Ministry of Industry, Energy and Mines, with an Energy Directorate, Direccion Sectorial de Energia (DSE), charged with preparing a national energy plan, formulating strategies and policies, coordinating technical assistance projects, performing policy-related studies, developing an energy information data base, and reviewing financial and operating plans for the institutions within the energy sector.

DSE has been functioning under an interim arrangement that makes it functionally dependent on the Minister of Industry, Energy and Mines, while administratively and financially dependent on RECOPE, with some additional support from ICE. During the last three years, DSE has been given considerable support, both from international donor agencies (AID and UNDP primarily) as well as from RECOPE. Its permanent staff includes about 15 full-time professionals organized in two major areas: planning and development.

Among the major accomplishments of DSE during the last years are completion of end-use surveys in all sectors of the economy including a nation-wide household survey as we11 as surveys of transportation, manufacturing, commerce, public services, agriculture and government. In addition, a complete survey of bioenergy resources and an estimate of the conservation/substitution potential in the industrial sector was completed along with energy audits for the main users in the industrial sector.

Finally, a computerized energy data base and information system has been developed to serve as a national resource, as well as to lay the basis for a comprehensive planning and energy sector development model.

At this time, DSE is in the final stages of reviewing the National Energy Development Plan, which will be completed in mid-1986.

DSE has developed a model referred to as MIPE that is used to model the supply and demand of energy in the economy. It resides on an IBM-XT personal computer and uses FRAMEWORK as the software. The model consists of six modules that describe macroeconomic activity, energy demand, supply, conservation, substitution, and investment.

At present, DSE is working on construction of a macroeconometric model. In the meantime, they are using exogenous growth rates of GDP as inputs to the demand mode1. Demand is described by an econometric model that comprises equations to predict demand by four sectors for each fuel type. The demand model does not include prices as a variable and they need to be incorporated so that DSE can examine the responsiveness of demand to price changes. The conservation 
model exogenously applies percentages of energy that could theoretically be saved in certain sectors and then recalculates final consumption. The substitution module works in a similar manner, applying exogenously determined percentages of fuels that could be substituted by other fuels. Supply of electricity is calculated by taking account of final demand and various supply parameters.

\section{SUMMARY AND RECOMMENDATIONS}

A. Summary

Like most nonoil exporting developing countries, Costa Rica was seriously affected by the worldwide recession in the early 1980s, which included large reductions in the prices for export commodities. Costa Rica's situation was further exacerbated by a severe debt crisis, in part caused by the recession. Growth in GDP ceased in 1980 and decreased in 1981 and 1982. In an attempt to realign the economy, the colon was allowed to float in 1981 and the exchange rate with the dollar has increased from more than 8.5 colones per dollar to a current value of approximately 50 colones per dollar. This move made costa Rica's exports more competitive in world markets, and it has fostered some import restraint. At the same time, however, it effectively increased foreign debt. After restructuring its debt in 1982 and receiving emergency loans from the IMF, Costa Rica's economy began to improve in 1983. The real GDP grew at 6 percent between 1983 and 1984 .

The largest contributors to GDP are agriculture (approximately one-fifth to one-fourth), manufacturing, and trade, with one-fifth each. A significant portion of the value-added in manufacturing and trade comes from processing and exports of food products, so that the agriculturally-based component of GDP is considerably large. The main exports are coffee, bananas, sugar, and beef. Manufacturing relies heavily on import of intermediate goods.

Debt service comprised 19 percent of GDP in 1983. Costa Rica receives substantial amounts of foreign aid from the U.S. $0 i$ i imports as a share of the value of exports doubled between 1977 and 1980 to amount to 20 percent in 1980 .

Like many medium-income developing countries, Costa Rica's energy needs are supplied by roughly equal amounts of petroleum products and biomass (mainly fuel wood), with emerging electricity use. Rapid GDP growth in the 1970 s (5.7 percent per year) was accompanied by an approximate 7 percent per year average increase in total oil consumption. Urbanization and development has been accompanied by an increased stock of private vehicles and a better developed infrastructure, with reliance mainly on trucks for transport of commercial 
goods. Transport uses almost twice as must diesel as gasoline. Although energy consumption in the transport sector had grown fastest among all sectors in the 1970s, it also decreased the most during the economic hardships of the early 1980 s. The only other significant petroleum products user is industry, which consumes nearly all of the fuel oil used in the country. A large percentage of this fuel oil goes to the cement industry. Costa Rica can reduce its dependence on imported oil in one of two ways: One way is by substituting other energy forms, such as electricity, renewable biomass, peat, or heat from geothermal energy for industrial uses of fuel oil. However, this will decrease the market for a product that the refinery produces in excess and must export. The other alternative, which is far more difficult to tackle, is to decrease diesel and gasoline use in the transport sector, where the number of users that would have to be targeted in the substitution or conservation program is much larger. Costa Rica has taken steps in this direction by instituting production of alcohol from sugar cane, but this alcohol is at present exported.

Fuel wood, the next largest source of energy supply in Costa Rica, provides about one-third of the total amount of energy used in the country. It comes mainly from ranches, coffee shade tree trimmings, and thickets or abandoned farms. Rural households consume nearly all of the fuel wood, where it is used for cooking. Approximately 25 percent of the country's fuel wood is sold in commercial markets, and prices may increase significantly. If coffee growers replace a significant number of their coffee trees with a more sun resistant variety, there will be no need for shade trees and an important source of fuel wood could be gone. Fuel wood could be conserved through use of more efficient stoves, or replaced by LPG, electric stoves, or use of pelletized peat. With the exception of a one-time cost for buying a more efficient wood-burning stove, any substitution for fuel wood will force the user into a commercial market to procure his or her cooking fuel.

Electricity supplies about 13 percent of the total energy consumed in Costa Rica or 23 percent of the commercial energy. Installed electricity generating capacity has almost tripled since 1970. Nearly all of this increase has come from construction of hydroelectric power plants. In 1983, 98.5 percent of the country's electricity was supplied by hydro. With the exception of the most recent project to come on line, all of Costa Rica's hydro facilities are basically run-of-river, and the country therefore needs a 30 percent reserve hydro capacity. In addition to the reserve, significant excess capacity exists. In the 1970s, expansion plans assumed at least a 5 percent annual rate of growth in demand, but the recession dashed this expectation. 
Costa Rica is one of the few countries in the world where peak demand arises from residential cooking needs. Approximately 85 percent of the households have electricity, giving the country the highest electrification rate in the region.

Energy prices in the country are the main method of influencing demand. Abrupt changes in oil prices, necessitated by world price changes and especially by the devaluation of the colon, have sent sharp messages to oil consumers. $0 i 1$ products, with the exception of fuel oil, have been priced at or above costs to encourage rational use of these products. A disparity between diesel and gasoline prices, intended to place more of a burden on the private auto owners, encouraged the purchase of diesel autos and recreational vehicles to the point where diesel use is almost double gasoline use. The gap between diesel and gasoline prices has narrowed during recent price increases.

Regarding energy resources, Costa Rica is richly endowed with hydroelectric resources. Significant geothermal resources exist and peat resources may be uncovered during reconnaissance, adding to the indigenous resource base that would be developed to meet future energy requirements. The knowledge of the oil resource base needs to be refined by further exploration, and it is hoped that the new hydrocarbon law can be implemented and that it will foster private sector $0 i 1$ exploration. This would transfer the costly risk of oil exploration from the government to private oil companies. RECOPE, with the assistance of the United States Geological Survey, has determined that the country contains a moderate amount of subbituminous coal. According to a DGF/ROCAP/CATIE study, sources of fuel wood are expected to remain constant. The impact of a possible decrease of coffee shade trees needs to be assessed.

Regarding prices and planning, Costa Rican planners recognize the need for an integrated pricing policy. Planning has been centralized in one organization, DSE, which will focus on long-term planning while organizations such as ICE, the national utility, focus on shorter-term projections. The creation of a centralized energy planning organization is a big step toward establishment of integrated energy planning that can foster efficient use of energy that leads to optimal economic growth. This organization, DSE, deserves continued strong support.

B. Recommendations

In addition to the assistance programs recommended for the entire region, it is recommended that AID consider the following projects specifically for Costa Rica. 
- Support should be continued for DSE for its modeling and planning efforts.

Costa Rica took an important step toward integrated energy planning when it created DSE, and DSE has made significant accomplishments by organizing existing information into a data base, undertaking consumption surveys to better understand energy demand, developing a simple model to describe energy supply and demand, and formulating a national energy plan. Regarding planning needs, DSE now should have a wealth of information from the recently completed surveys. In light of this new information, assistance should be provided to re-examine and, perhaps, modify the demand model. Basic energy indicators should be determined for comparison with other countries. AID should consider providing as sistance to incorporate prices in the demand model to predict changes in demand that would arise from various pricing policies. DSE has requested assistance in construction of a simple macroeconomic model to link with their energy model. Such a model is required to provide consistent estimates of sectorial growth in gross domestic product. DSE can play a very important role in shaping an efficient energy future. A thorough understanding of energy demand and response to prices and income by DSE is crucial to planning what resources need to be developed and the timing of their development.

- Provide assistance to help determine the efficient prices of energy products in the country.

Regarding inequities in energy prices, a preliminary study has been done that examined past pricing policies for energy products. Efficient relative and absolute prices of oil products and electricity now need to be determined. The future cost of continuing with inefficient price policies needs to be estimated so that the government can evaluate the costs and benefits of continuing with the present policy and the effect of this policy on conservation and substitution.

o Support an evaluation of the fuel-wood problem in the country and the formulation and implementation of policies to lessen the problem.

With regard to fuel-wood consumption, the areas with the most potential for severe shortages need to be better defined, and studies need to be undertaken to address these shortages. The survey of residential energy consumption that was recently completed will be useful for this task. The development of direct substitutes, such as wood from tree farms, peat, or coal pellets, as well as structural substitutes, such as a switch to LPG or kerosene for cooking in areas where fuel-wood shortages are imminent needs to be seriously considered. The repercussions and possible timing of fuel-wood price increases also need to be examined. It is expected that prices will increase sharply.

- Assist ICE in areas that complement the activities of other organizations such as the IDB. 
The large debt incurred by ICE is likely to be a long-term problem, especially if real electricity prices are not significantly increased soon. Selection of smaller projects that can be executed with less lead-time and capital, a strategy which might be required by lending institutions, would help to prevent further large debt increases. ICE could be as sisted by AID in at least three areas. First, planners in ICE feel that household demand responds more sharply to price changes than their model predicts. ICE has received excellent help in demand estimation from the IDB and needs further assistance in a simple refinement of their household-demand model. Second, ICE will also benefit from the geophysical logging equipment provided by Los Alamos with AID funds to determine critical downhole geothermal measurements at Miravalles. Third, ICE could benefit from assistance in examining the costs and benefits of electricity for cooking and in the formulation and implementation of incentives to encourage a switch from electricity, if it is deemed beneficial. Costa Rica is one of the few countries in the world where the need for new capacity is driven by residential cooking requirements. Reducing peak demand in the residential sector could reduce the size of capacity increments that are needed in the future. Fourth, assistance in evaluation of cogeneration options should be considered.

- Assist Costa Rica in coal, peat, geothermal, and wind resource assessment and end-use studies.

RECOPE has already begun strong efforts to evaluate the country's fossil resources. The evaluation of peat and coal resources deserves further support. In the light of the costly nature of oil exploration, it is hoped that the new petroleum law will be passed and that it will provide incentives for private oil exploration.

- Assist energy planners in assessing the benefits of selling locally the alcohol produced from sugar cane rather than exporting it.

Domestic alcohol sales were attempted in the past but failed owing to problems with consumers. Costa Rica's alcohol is currently exported to US market. The alcohol would substitute for gasoline in transport, there-by decreasing requirements for imports of light distillates somewhat.

\section{REFERENCES}

1. Costa Rica, A Country Study H. D. Nelson, ed. (U.S. Government Printing Office, Washington, D.C., 1984) p. 356.

2. World Bank, "EDP Data Bank," 1985.

3. Economic and Social Progress in Latin America, External Debt: Crisis and Adjustment (Inter-American Development Bank, Washington, D.C., 1985), pp. 234-240. 
4. G. Hartshorn, L. Hartshorn, A. Atmella, L.D. Gomez, A. Meta, L. Mata, R. Morales, R. Ocampo, D. Pool, C. Quesada, C. Solera, R. Solorzano, G. Stiles, J. Tosi, Jr., A. Umana, C. Villalobos, and R. Wells, "Costa Rica Country Environmental Profile, A Country Study," Tropical Science Center, San Jose, Costa Rica (December 1982), 123 p.

5. Latin America Newsletter, July 28, 1985.

6. "Costa Rica: Economy: Effort to Keep Bananas Growing," Latin America Weekly Report, June 28, 1985, p. 5.

7. H. Banks, "Bankruptcy Without Pain," Forbes, April 29, 1985, p. 110.

8. A. Riding, "Costa Rica Tightens Its Belt," New York Times, June 29, 1982, p. D-1.

9. Gerencia de Exploracion, "Actualizacion Potencial Petrolero, Costa Rica," RECOPE, San Jose, Costa Rica (May 1985).

10. "RECOPE Memoria 82-84," RECOPE report, San Jose, Costa Rica (1984).

11. R. Dobles, "Estrategias para el Desarollo de Actividades de Exploracion Petrolera a Traves de la Futura Ley de Hidrocaburos," RECOPE Document No. 5, San Jose, Costa Rica (1985).

12. Gerencia de Exploracion, "Actualizacion Potencial Carboner a Costa Rica," RECOPE report, San Jose, Costa Rica (May 1985).

13. "Alternativas de Desarollo Energetico, Periodo 1981-2000, Republica de Costa Rica," Energia y Minas, ICE, UN Program for Planning and Department of Technical Cooperation, Programa Energetico del Istmo Centroamericano Projecto RLA/76/012.

14. M. Corrales, "Costa Rica, A Country Update Report," Proc., 1985 International Symposium on Geothermal Energy, Int1. Vol., Geothermal Resource Council, August 1985, p. 57-63.

15. G. Canet B., "Perspectivas del Consumo y Oferta de Lena al Ano 2000," Unpublished Report, Direccion General Forestal, San Jose, Costa Rica (1984).

16. "Localizacion y Valorizacion de la Masa Forestal en Costa Rica; Primera Fase: Localizacion y Caracterizacion," Direccion General Forestal, Ministerio de Agricultura y Ganaderia, Work Paper No. 34, 1985.

17. Electrowatt Engineering Services, Ltd, "Non-Conventional Energy Sources: Volume I, Wind Energy" and Volume II, Solar Energy," ICE report (January 1984).

18. "RECOPE y Desarollo Energetico en Costa Rica," RECOPE report, San Jose, Costa Rica (June 1984).

19. A. Hernandez C. and L. Torres C., "Anuario Estadistico, 1983," Direccion Sectorial de Energia, San Jose, Costa Rica (January 1985). 
20. "Anuario Estadistico, 1983," Servicio Nacional de Electricidad, San Jose, Costa Rica (1984).

21. "1983, Lena y Fuentes Alternas de Energia, Estudio Sobre Leyes y Politicas en America Centra1." ICAITI-ROCAP No. 596-0089. Meta Systems and ITCR, 1982 , p. 163.

22. Hill, E. C., "Regional Industrial Energy Efficiency Project Baseline Data Survey Study." Unpublished report. Written under ROCAP/AID Contract No. 596-0000-c-00-2004-00 (1982). 


\section{EL SALVADOR}

CONTENTS

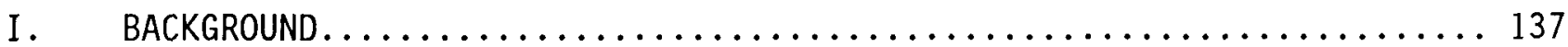

A. Political Situation/Government Structure.................. 137

B. Population Trends....................................... 137

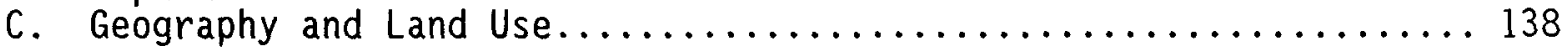

D. Cultural Aspects............................................. 140

E. Natural Hazards.................................... 140

II. ECONOMIC SITUATION OVERVIEW............................... 141

A. Basic Characteristics............................... 141

B. Gross Domestic Product (GDP) by Sector................... 141

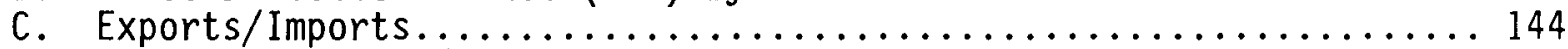

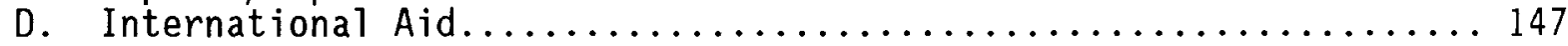

E. Role of Government................................ 149

F. Employment.................................... 150

G. Welfare and Income Distribution........................ 150

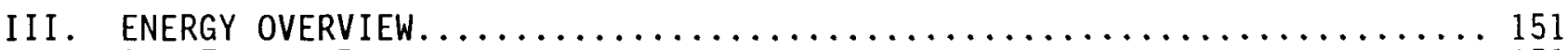

A. Energy Resources........................................ 151

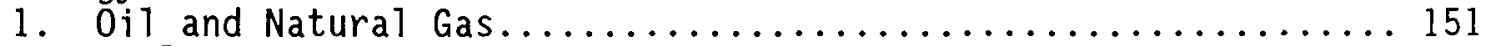

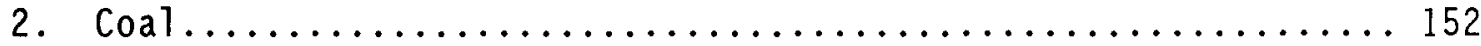

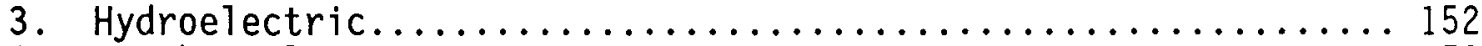

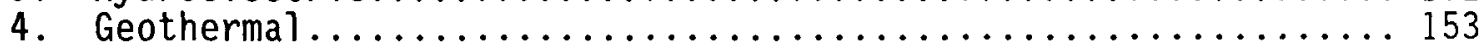

5. Fuel wood and Biomass Resources........................ 154

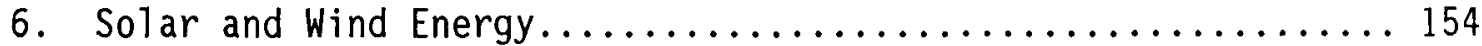

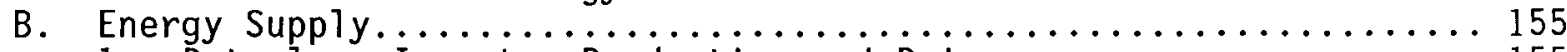

1. Petroleum Imports, Production and Prices................. 155

a. Production, Imports, and Exports.................. 155

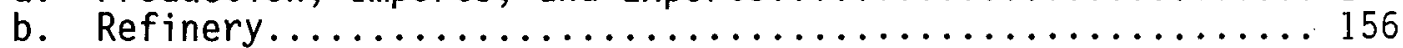

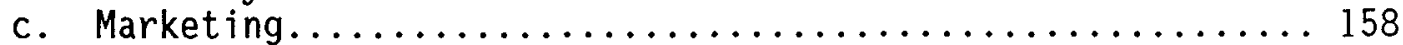

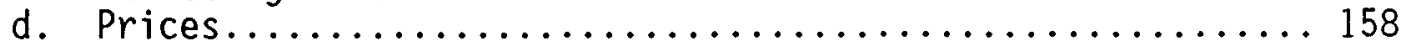

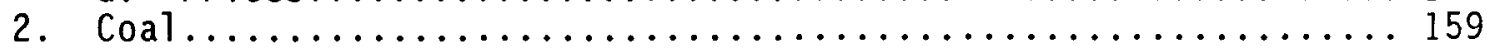

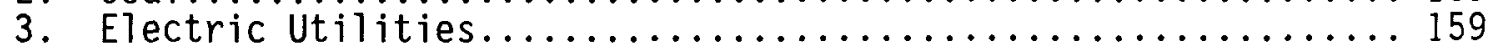

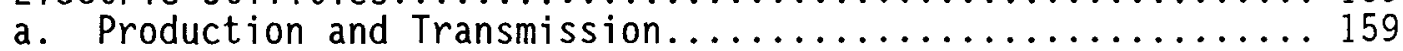

b. Distribution................................ 161

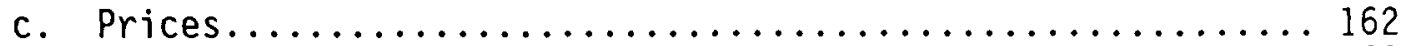

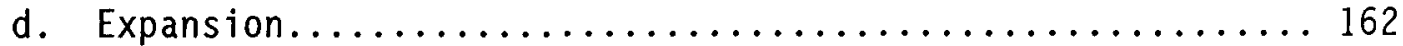

4. Noncommercial Energy................................. 164

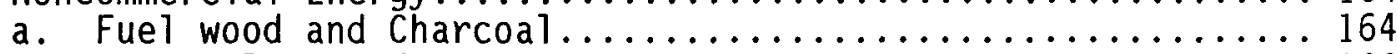

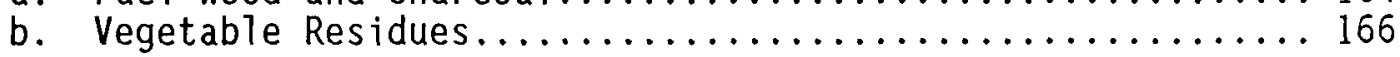




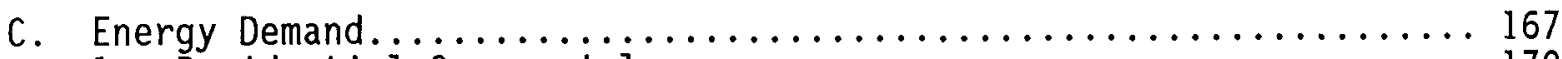

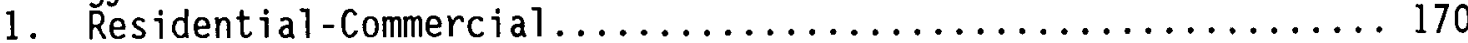

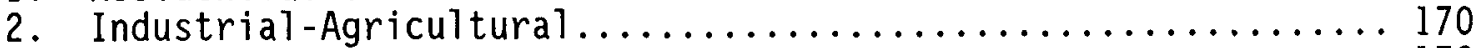

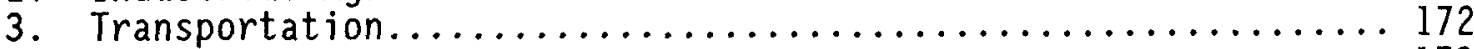

D. Energy Planning and Management........................... 173

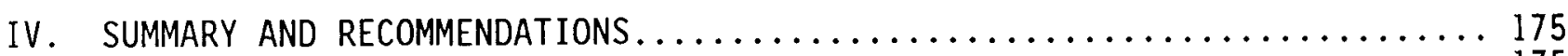

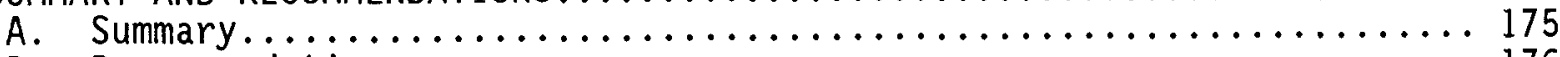

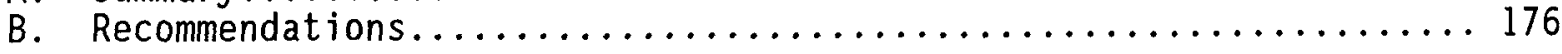

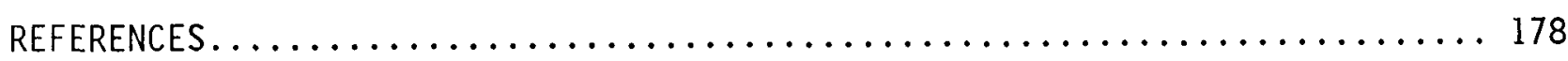


1. El Salvador: Land Use Distribution......................... 139

2. El Salvador: Gross Domestic Product.......................... 142

3. El Salvador: Gross Domestic Product Growth Rates................... 143

4. El Salvador: Sectorial Contributions to Gross Domestic Product (percentage of tota 1 ........................... 143

5. El Salvador: Exports and Imports............................ 145

6. El Salvador: Growth Rates for Exports and Imports................. 145

7. El Salvador: Exports and Imports (percentage of total) ........... 146

8. El Salvador: External Public Indebtedness....................... 148

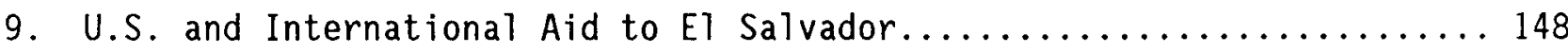

10. El Salvador: Potential Rio Lempa Hydroelectric Generation Stations.... 152

11. El Salvador: Petroleum Imports by Product, $1970-1984 \ldots \ldots \ldots \ldots \ldots \ldots 156$

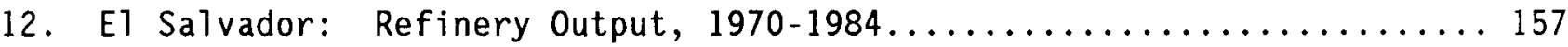

13. El Salvador: Total Supply of Petroleum Products................. 158

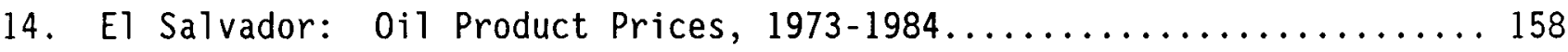

15. El Salvador: Installed Electric Generating Capacity............... 160

16. El Salvador: Price of Electricity by Sector.................... 163

17. El Salvador: Generation System Expansion Program.................. 164

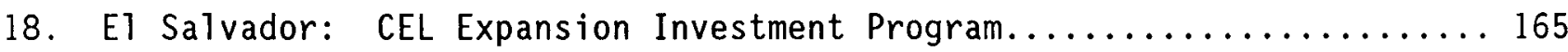

19. El Salvador: 1984 Energy Consumption (thousands of BEP) $\ldots \ldots \ldots \ldots \ldots 168$

20. El Salvador: 1984 Energy Consumption (percentage of total).......... 168

21. El Salvador: 1984 Energy Consumption (percentage of fuel use

by sector)............................... 169

22. El Salvador: Compounded Annual Average Growth Rate for Energy Consumption, by Sector and Selected Years.................. 169 
1. El Salvador: Population, urban and rural, $1960-2000 \ldots \ldots \ldots \ldots \ldots \ldots 137$

2. El Salvador: GDP by major sector......................... 142

3. El Salvador: Total exports over time by product................. 144

4. El Salvador: Total exports, total imports, and 011 imports.......... 147

5. El Salvador: Labor force by sector for $1983 \ldots \ldots \ldots \ldots \ldots \ldots \ldots \ldots \ldots 15$

6. El Salvador: Map of hydro and geothermal resources............... 153

7. El Salvador: Energy flow diagram for $1984 \ldots \ldots \ldots \ldots \ldots \ldots \ldots \ldots \ldots \ldots \ldots$

8. El Salvador: 0il imports as a percentage of imports, exports, and GDP. 157

9. El Salvador: Map of CEL generation and transmission system.......... 161

10. El Salvador: Map of electrical distribution service areas.......... 162 


\section{BACKGROUND}

\section{A. Political Situation/Government Structure}

El Salvador was ruled by military leaders from the 1930s through the early 1980s. The 1960s were a period of rapid economic growth. In the 1970s, political, social, and economic factors combined to slow development. Following a military coup d'etat in 1979 , there was a return to civilian rule. This civilian government is carrying out programs of land reform and economic development. However, the sluggish world economy and the continued social problems in the country hamper these efforts. ${ }^{1}$

\section{B. Population Trends}

In 1980 the estimated population was about $4.8 \mathrm{million}$, increasing to 5.2 million in 1983, and 5.4 million in 1984 , the second largest population in Central America. Figure 1 shows population growth trends. The birth rate is high, but steadily decreased during the 1980 s from 37 per 1000 inhabitants in 1980 to just over 30 in 1983. During the same period the mortality rate also decreased from 7.90 to 6.90 per 1000 inhabitants. ${ }^{2}$ These figures suggest a rapid population increase. However, the official population growth-rate estimates have ranged between 1.77 and 1.29 percent per year for the 1980-83 period, and 1.27 percent for 1984 . Because no census has been taken since 1971, some analysts argue that the actual growth rate may be even lower owing to outward migration of Salvadoran citizens.

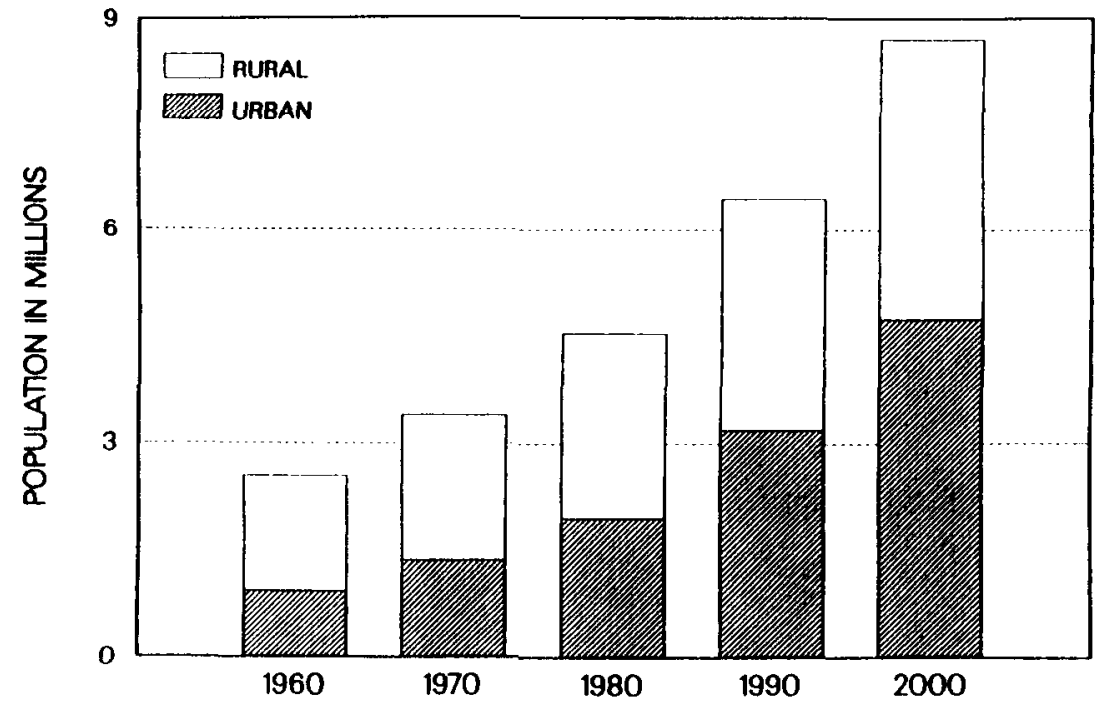

SOURCES: WORLD BANX. UNIVERSTYY OF CALIFORNIA LATIN AMERICAN CENIER

Fig. 1. El Salvador: Population, urban and rural, 1960-2000 (projections for 1990 and 2000). 
Over the past four decades, economic pressures contributed to the outward migration of Salvadorans; earlier, the migration was mainly made up of farmers, but now it includes businessmen and skilled workers. According to the U.S. Census Bureau, there were only 94,000 Salvadorans in the United States legally and illegally in 1980. However, it is estimated that as many as 500,000 Salvadorans may be here today. 2

In 1968, the population density was 403 per square mile - - the most densely populated mainland nation in the Western Hemisphere. Using 1984 population estimates, population density was over 654 per square mile. The country is the second smallest mainland nation in the Americas and has no sizeable areas of unsettled 7 and.

The age profile is typical of a developing country, being predominantly young and rural. In 1961, 44.4 percent of the population was under fifteen years of age, and only 5.5 percent was over sixty. Twenty-four years later, in $1984,47.1$ percent was estimated to be under 15 years of age, with approximately the same 5.5 percent being over 60 . This population composition puts great strain on already burdened and scarce national resources, with a relatively small proportion of people working to support the economically inactive young people.

\section{Geography and Land Use}

El Salvador is located on the southern slopes of the Central American Cordillera in the isthmus between Mexico and Panama. Roughly rectangular in shape, it has a total area of some 8,260 square miles, the size of Massachusetts, averaging 60 miles in width and extending 160 miles in maximum length. Its varied terrain ranges from tropical lowlands on the Pacific coastal plain to arid semidesert in the mountainous region of the north.

El Salvador's high population density has led to the occupation of all usable land, and the country is faced with the difficult task of accommodating an expanding population with no new area available.

According to the data shown in Table 1 , there has been an increase in agricultural use and a decrease in cattle ranching. Deforestation occurred from the advance of the urban areas upon the vegetated areas. More recent data are not available.

Some 30 percent of the country's land area is under cultivation. This extensive activity over the years has significantly altered the character of the vegetation, and much of the original natural cover has been destroyed. There are areas where harmful farming practices, such as slash-and-burn techniques, 
TABLE 1

EL SALVADOR: LAND USE DISTRIBUTION

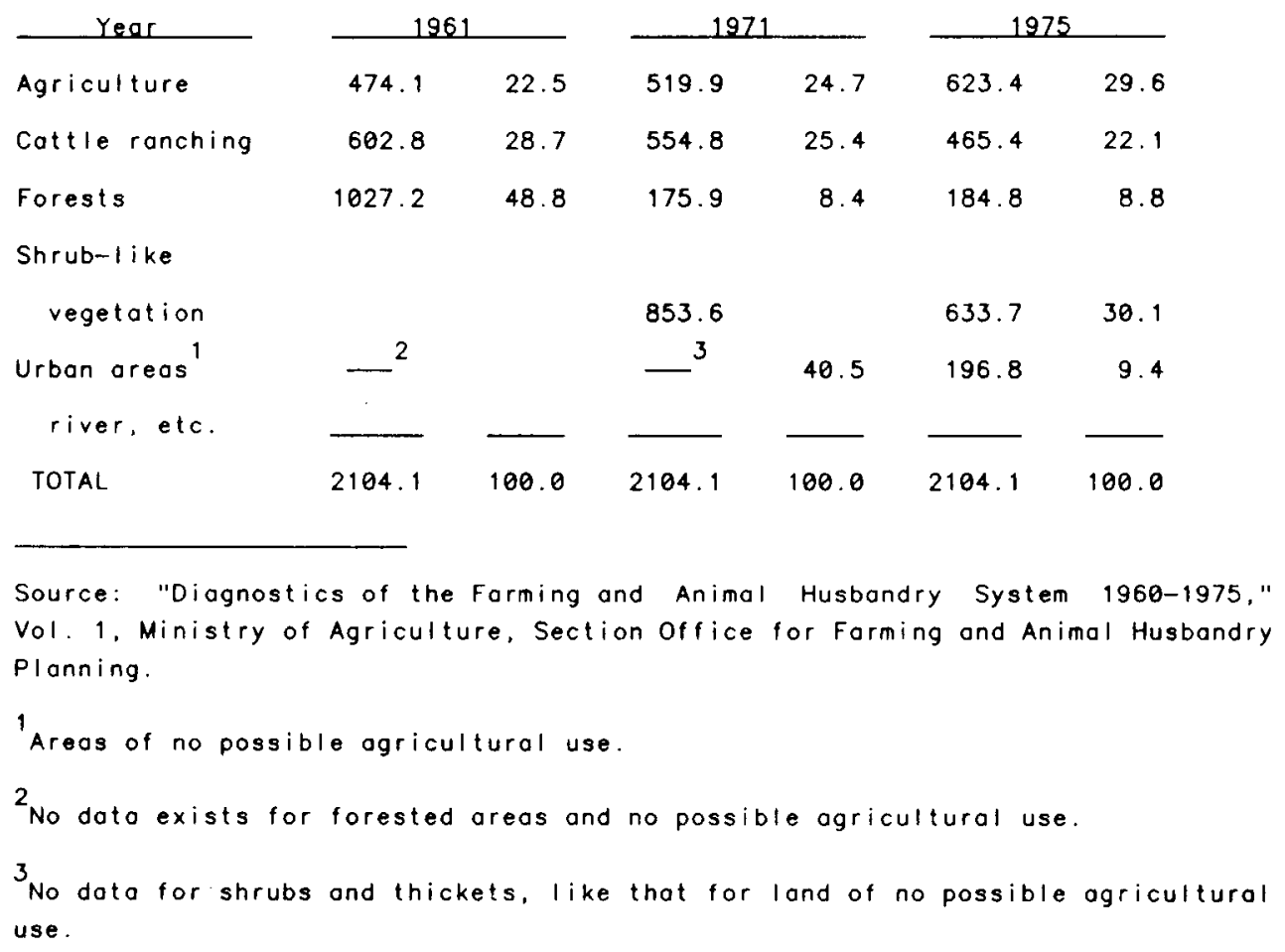

have resulted in considerable soil erosion, requiring extensive rehabilitation. In fact the erosion problem has greatly increased in recent years as farmers have cultivated the steep mountain slopes. Currently, public television advertisement encourages better harvesting practices for the forest products.

Although much of the original forest 1 and has been destroyed, about 8.8 percent of the country is still covered with forest and woodland, and the rest supports a great variety of vegetation. There are dogwood, mahogany, cedar, walnut, and rubber trees. Numerous tropical fruits and medicinal plants and a variety of other trees and bushes occur. Both the northern and southern mountains are covered with temperate grassland, and remnants of deciduous oak and pine forests remain. The central plateau area is mostly subtropical grassland interspersed with small deciduous trees or bushes. The coastal plain and lower southern mountain slopes are mostly savanna and broadleaf forest. A mixture of hard-and softwood trees provides the bulk of the energy supply in El Salvador at this time.

The uneven distribution of land has been a growing problem for a number of years and has become more acute as the number of rural workers has increased. A 
1967 survey showed that 1,800 property owners owned half of the nation's productive 1 and, whereas over 86,000 owners own the other half. It was estimated that over 100,000 small farmers and agricultural wage laborers lived on less than 1 hectare $(2.47$ acres) of 1 and each.

Recently, the Government began agrarian reform and by December 1983 had distributed 300,000 hectares of 1 and to 80,000 farmers (representing indirectly 500,000 people). Then the expropriation of properties ranging in size from 100 to 500 hectares was halted. In December of 1983 a new constitution set a maximum size of 245 hectares for agricultural property to be owned by any individual or corporate body.

\section{Cultural Aspects}

From the time of arrival of the Spaniards there was much intermarriage with the indigenous population. African slaves were imported to work as miners and agricultural laborers. After the various forced-labor and slavery systems were abolished, the process of acculturation proceeded even more rapidly than before, and racial lines became progressively blurred. Cultural distinctions came to be made onty between Indian and Ladino.

Spanish is the official language and is spoken by virtually all the inhabitants. It is the language of the government, schools, newspapers, and radio. Most of the Indians, particularly those who are most acculturated, are monolingual in Spanish. Salvadoran social patterns differ from those of neighboring countries. There are no Indians who speak only their own language.

Distinctions between an urban and a rural way of life cut through the social structure. As in many countries wealth and education are the principal determinants of social structure. About 80 percent of the total population of the country is Catholic.

Economic activity is generally responsive to changes in technology. For example, most farmers are willing to implement advice of the extension agent concerning modern farming practices. The El Salvadorans generally place a great deal of emphasis on the work ethic. ${ }^{3}$

E. Natural Hazards

Because of the country's small size and compact physical structure, climatic conditions are relatively uniform in its three regions, with no pronounced extremes distinguishing one from another. Temperatures vary generally with altitude, with maximum heat and humidity along the coastal lowlands, whereas the central plateau has a temperate climate bordering on the semitropical. Coolest temperatures are found in the northern mountains. 
Owing to its small size and location, the country is fortunate with respect to the weather hazards of winds and hurricanes that sometimes affect surrounding areas of Latin America. Although it occasionally suffers from fringe effects of tropical storms, for the most part it is out of the direct path of the more serious disturbances. The Gulf of Mexico hurricanes that periodically batter lower Mexico and the Caribbean usually miss El Salvador, as do the Pacific hurricanes.

The land is frequently shaken by earthquakes, some of which cause extensive damage. The capital city was completely destroyed by an earthquake in 1854 , and in 1919 it was struck by another, which did extensive damage, but mostly to surrounding farmlands. Since that time, earthquake activity has been relatively minor, although a fairly serious tremor in 1965 again caused limited destruction in San Salvador. ${ }^{3}$ A minor tremor occurred in November 1985 .

\section{ECONOMIC SITUATION OVERVIEW}

A. Basic Characteristics

In the 1980 s economic activity continued to be overshadowed by the events of the civil conflict. Destruction of the economic infrastructure continues, especially that of the energy sector and transportation. These circumstances have adverse effects on productive activity. However, the economic recession that had been advancing since 1979 slowed in 1983, and economic growth continued to improve through 1984. After falling 21 percent between 1979 and 1982 , the real gross domestic product (GDP) stopped moving downward in 1983. Even though a large part of the population emigrated, the per capita GDP diminished by over one-third between 1978 and 1983. The improvement in the economic situation during 1983 and 1984 resulted from the improving world economics and from assistance received from the United States. Inflation in consumer prices doubled in 1985 from 11.2 percent to 22 percent, the highest rate in the region.

B. Gross Domestic Product (GDP) by Sector

Agriculture is the largest sector in the El Salvadoran economy, contributing approximately 25 percent of the GDP in 1984 (see Fig. 2 and Tables 2 through 4). Other major sectors are manufacturing, 17 percent; trade, 16.8 percent; and public administration/defense, 12.7 percent. Output of each of these sectors except public administration/defense declined during the early 1980s. In

* San Salvador was struck by a major earthquake in 0ctober 1986, which caused extensive damage. 


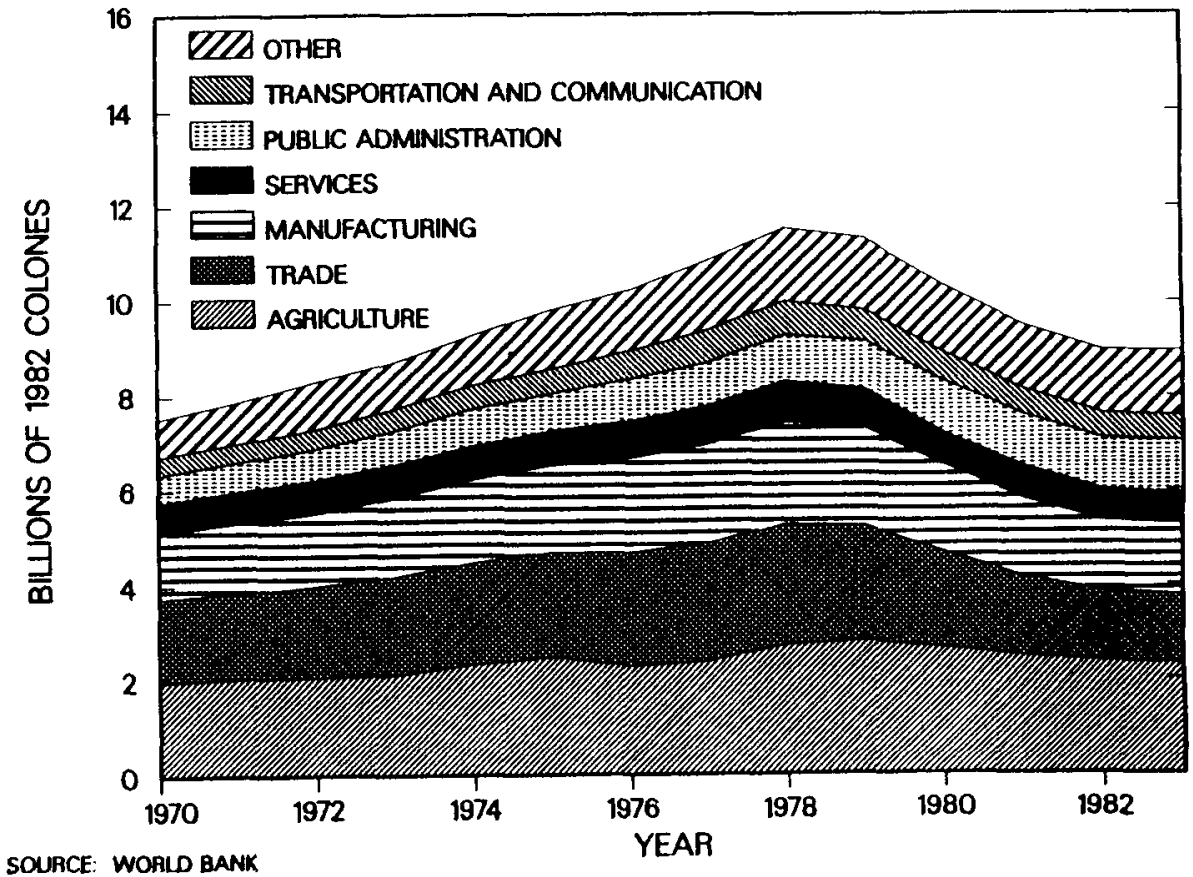

Fig. 2. El Salvador: GDP by major sector.

TABLE 2

EL SALVADOR: GROSS DOMESTIC PRODUCT

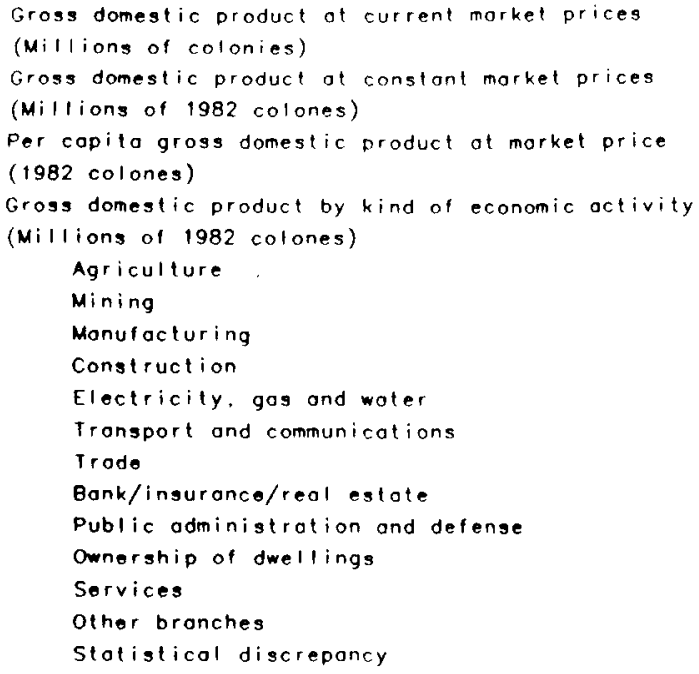

Source: The World Bank. "World Tobles. The Third Edition, Volume I - Economic Dota in Volume 11 - Social Dato," Washington, D.C., 1984. Additional information provided September 1986 
TABLE 3

EL SALVADOR: GROSS DOMESTIC PRODUCT GROWTH RATES

(percentage based on 1982 colones)

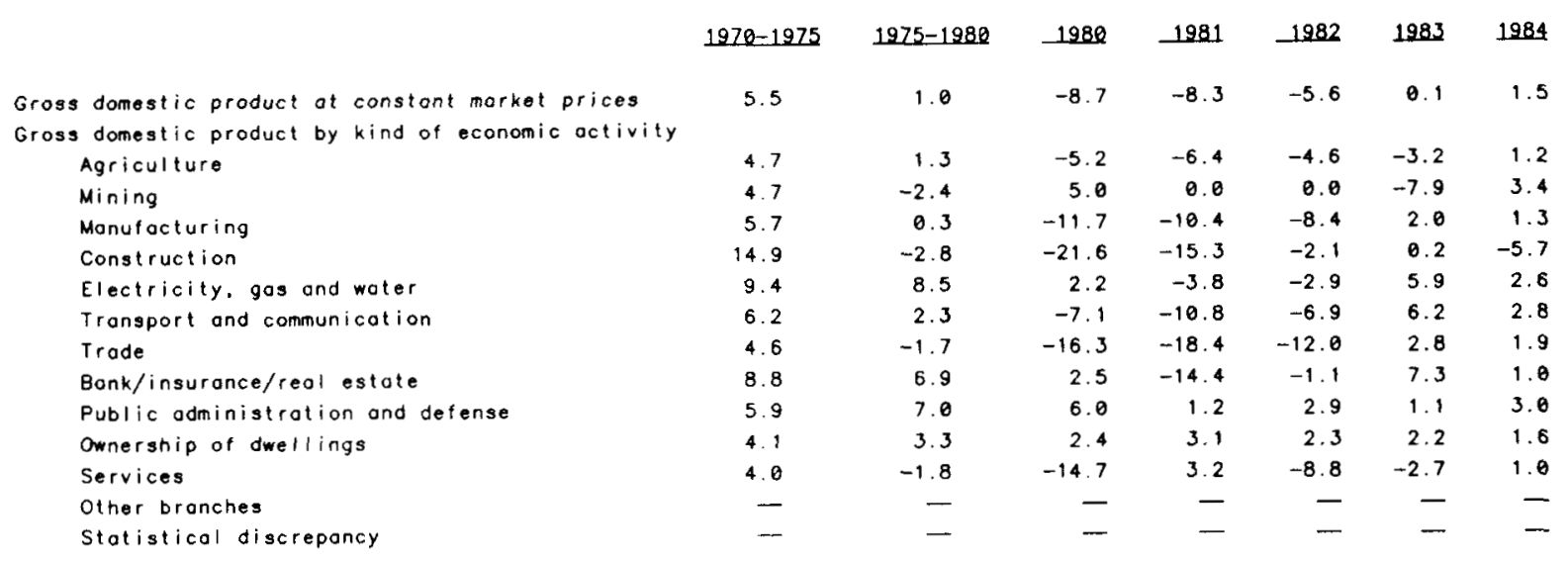

TABLE 4

EL SALVADOR: SECTORIAL CONTRIBUTION TO GROSS DOMESTIC PRODUCT

(percentoge based on 1982 colones)

\begin{tabular}{|c|c|c|c|c|c|c|c|}
\hline & 1970 & 1975 & 1980 & 1981 & -1982 & 1983 & 1984 \\
\hline \multicolumn{8}{|c|}{ Gross domestic product by kind of economic activity } \\
\hline Agriculture & 26.2 & 25.2 & 25.6 & 26.1 & 26.4 & 25.3 & 25.3 \\
\hline Mining & 0.1 & 0.1 & 0.1 & 0.1 & 0.1 & 0. 1 & 0.1 \\
\hline Monufacturing & 18.3 & 18.5 & 17.8 & 17.4 & 16.9 & 17.1 & 17.1 \\
\hline Construction & 2.7 & 4.1 & 3.4 & 3.1 & 3.2 & 3.2 & 3.0 \\
\hline Electricity, gos ond woter & 1.9 & 2.3 & 3.2 & 3.4 & 3.5 & 3.7 & 3.7 \\
\hline Transport and communicotion & 5.3 & 5.5 & 5.9 & 5.7 & 5.7 & 6.0 & 6.0 \\
\hline Trade & 23.6 & 22.7 & 19.8 & 17.6 & 16.4 & 16.8 & 16.8 \\
\hline Bank/insurance/real estate & 2.1 & 2.5 & 3.3 & 3.1 & 3.2 & 3.4 & 3.4 \\
\hline Public administration and defense & 7.6 & 7.8 & 10.4 & 11.5 & 12.5 & 12.5 & 12.7 \\
\hline Ownership of dwellings & 3.8 & 3.5 & 4.0 & 4.4 & 4.8 & 4.9 & 4.9 \\
\hline Services & 8.3 & 7.7 & 6.7 & 7.5 & 7.3 & 7.0 & 7.0 \\
\hline Other branches & - & - & - & - & 一 & 一 & - \\
\hline
\end{tabular}

1984, output of all sectors except construction increased slightly, resulting in an increase of 1.5 percent in GDP.

The agricultural sector has been affected by changes in the productive structure introduced by the agrarian reform and the by civil conflict, which has caused uncertainty and the abandonment of some productive units. In 1984, the value added for agriculture reversed its downward slide that had begun in 1980 . The production of sugar cane, cotton, and basic grains increased, as did that of coffee, albeit to a lesser extent; poultry production also rose moderately, but the output of the livestock, forestry, fishing and beekeeping subsectors all dropped. 
Manufacturing accounts for about 17 percent of GDP in El Salvador, a proportion that was increasing for many years but declined between 1980-1982. The drop in the industrial production reflected the impact of the closing of 102 factories between 1979 and 1982, the decline in domestic demand, and the stagnation of the Central American Common Market (CACM). 4

Over the past several decades, many programs have been implemented to promote economic development to increase per capita incomes and the standard of living within El Salvador. Most of these programs have recognized industrializaton and birth control to be basic steps required in meeting these goals.

\section{Exports/Imports}

El Salvador's economy has long depended on a few agriculture commodities for export, mainly coffee, sugar, and cotton. These commodities have experienced wide price fluctuations in the world market. In recent years they have faced a declining export price and have earned less foreign revenue. Indeed, export earnings declined in 4 of the last 5 years, experiencing a 33 percent overall reduction from the 1980 total of $\$ 1.1$ billion to the 1984 total of $\$ 717$ million (see Fig. 3 and Tables 5 and 6 ). This reduced inflow of foreign exchange has led to difficulties in the purchase of important imports such as capital goods and petroleum.

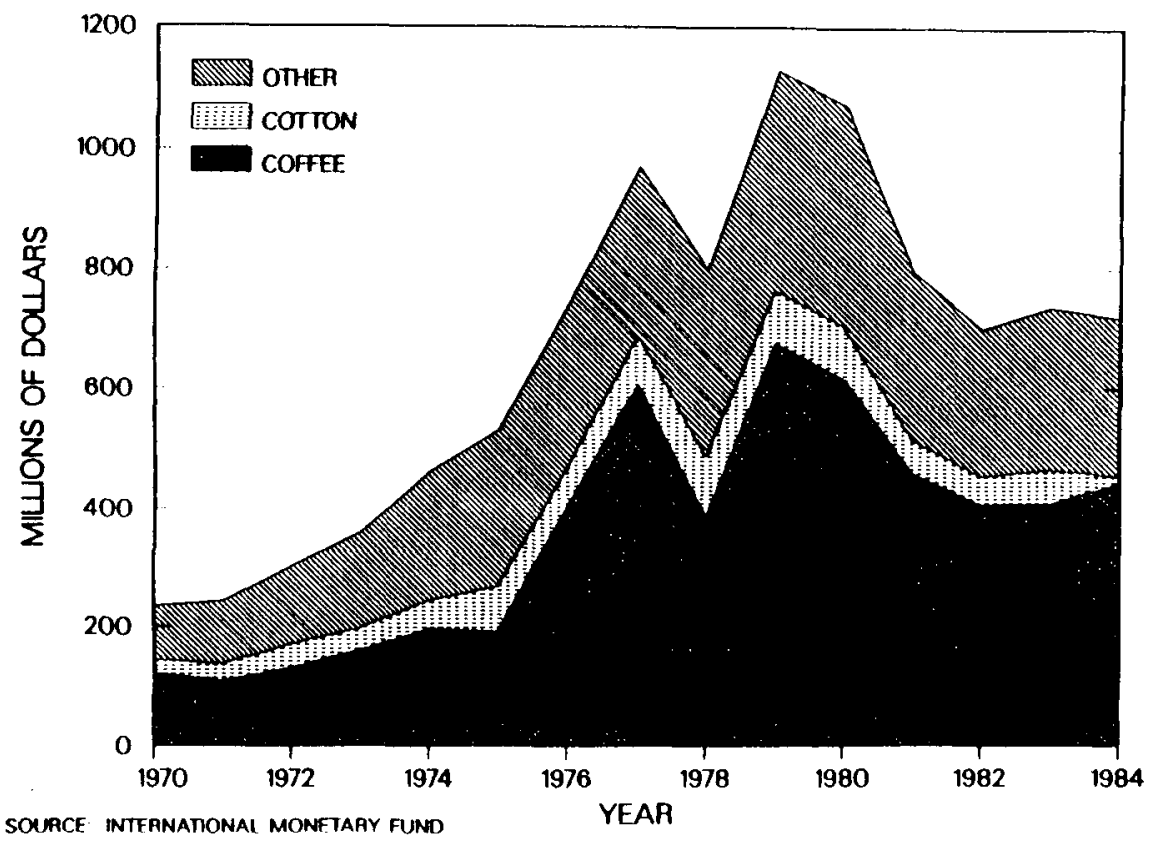

Fig. 3. El Salvador: Total exports over time by product. 
TABLE 5

EL SALVADOR: EXPORTS AND IMPORTS

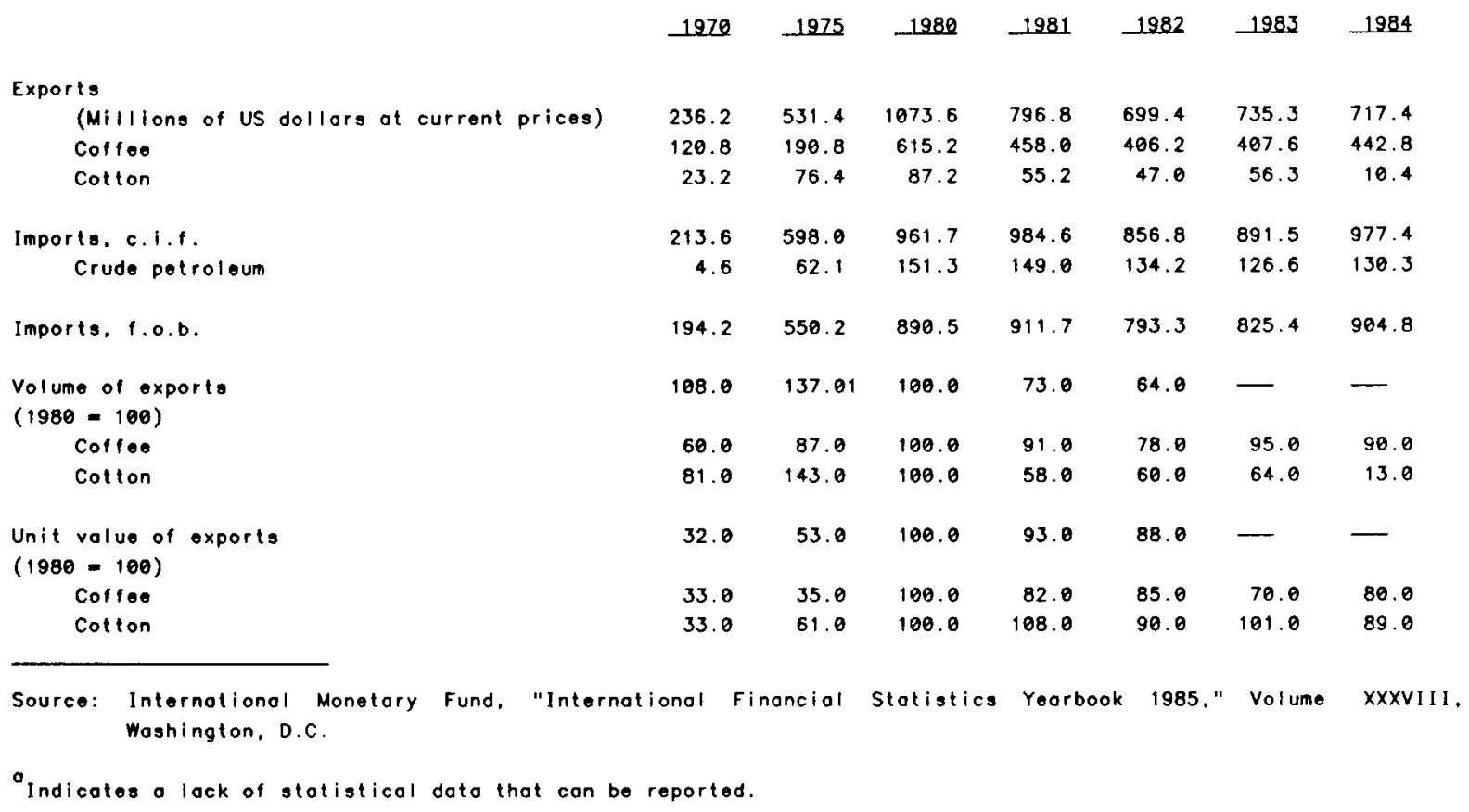

TABLE 6

EL SALVADOR: GROWTH RATES FOR EXPORTS AND IMPORTS

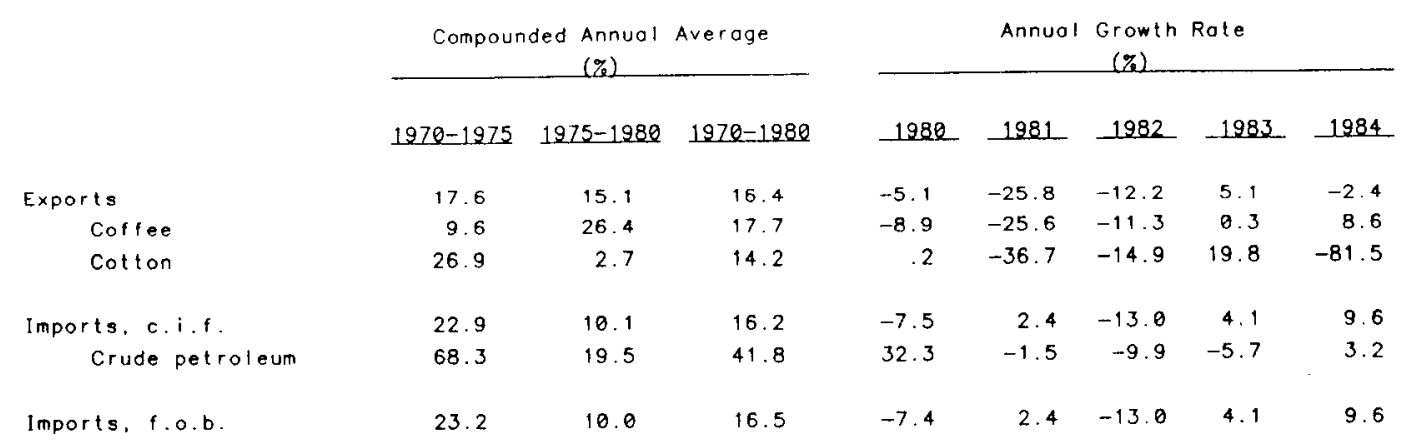

In 1984 the value of coffee shipments was $\$ 442.8$ million, which accounted for almost 62 percent of the total value of exports (Table 7). This was the first significant increase in coffee earnings since the decline began in 1981; the increase was precipitated by a partial recovery in world coffee prices. Overall, earnings from this product decreased a total of 28 percent from 1980 to 1984 . 
TABLE 7

EL SALVADOR: EXPORTS AND IMPORTS

(percentage of total)

\begin{tabular}{|c|c|c|c|c|c|c|c|}
\hline & 1970 & 1975 & 1980 & 1981 & 1982 & 1983 & 1984 \\
\hline Exports & 100.0 & 100.0 & 100.0 & 100.0 & 100.0 & 100.0 & 100.0 \\
\hline Coffee & 51.1 & 35.9 & 57.3 & 57.5 & 58.1 & 55.4 & 61.7 \\
\hline Cotton & 9.8 & 14.4 & 8.1 & 6.9 & 6.7 & 7.7 & 1.5 \\
\hline Other & 39.1 & 49.7 & 34.6 & 35.6 & 35.2 & 36.9 & 36.8 \\
\hline $\begin{array}{l}\text { Imports, c.l.t. } \\
\text { Crude petroleum }\end{array}$ & 2.2 & 10.4 & 15.7 & 15.1 & 15.7 & 14.2 & 13.3 \\
\hline
\end{tabular}

The volume of sugar exports in 1983 showed a substantial recovery over that of 1982; it rose by 36 percent owing to the larger area planted to cane. In addition, sugar prices were 25 percent higher. As a result, the value of sugar exports rose from $\$ 40$ million in 1982 to $\$ 67$ million in 1983 . The government has encouraged additional sugar cane production, some of which is processed into alcohol for export.

The 1983 total cotton export earnings of $\$ 56.3$ million was caused by an increase in both cotton price and export volume over the 1982 total. However, price and volume rapidly declined during $1984--$ the $\$ 10$ million total for that year represents an 82 percent reduction from 1983. Consequent1y, cotton's share of the export revenue declined from 7.7 percent to 1.5 percent.

Exports to the CACM, primarily finished goods including agro-industrial products, remained depressed throughout the $1980 \mathrm{~s}$. The value of these products in 1983 was $\$ 168$ million compared with $\$ 174$ million in 1982 .

In 1983 imports increased 4.1 percent relative to the preceding year and 9.6 percent in 1984. Approximately 60 percent consisted of production inputs, including 13.3 percent for oil for refining; 29 percent of consumer goods; and the remainder, of capital goods. The dollar value of $0 i 1$ imports declined from 1980 through 1983 but rose 3.2 percent in 1984. The decline in the early 1980's was primarily owing to the country's recession. In addition, food imports during this period were lower because basic grain production was strong, partly as a result of the success of the food self-sufficiency program.

$0 i 1$ imports as a share of total imports increased between 1978 and 1980, as a result of increased world $0 i 1$ prices, then slightly declined between 1980 and 1983 (see Fig. 4). The total cost of $0 i 1$ imports has rapidly escalated over the past 15 years owing to both increased prices and increased volume. For example, 


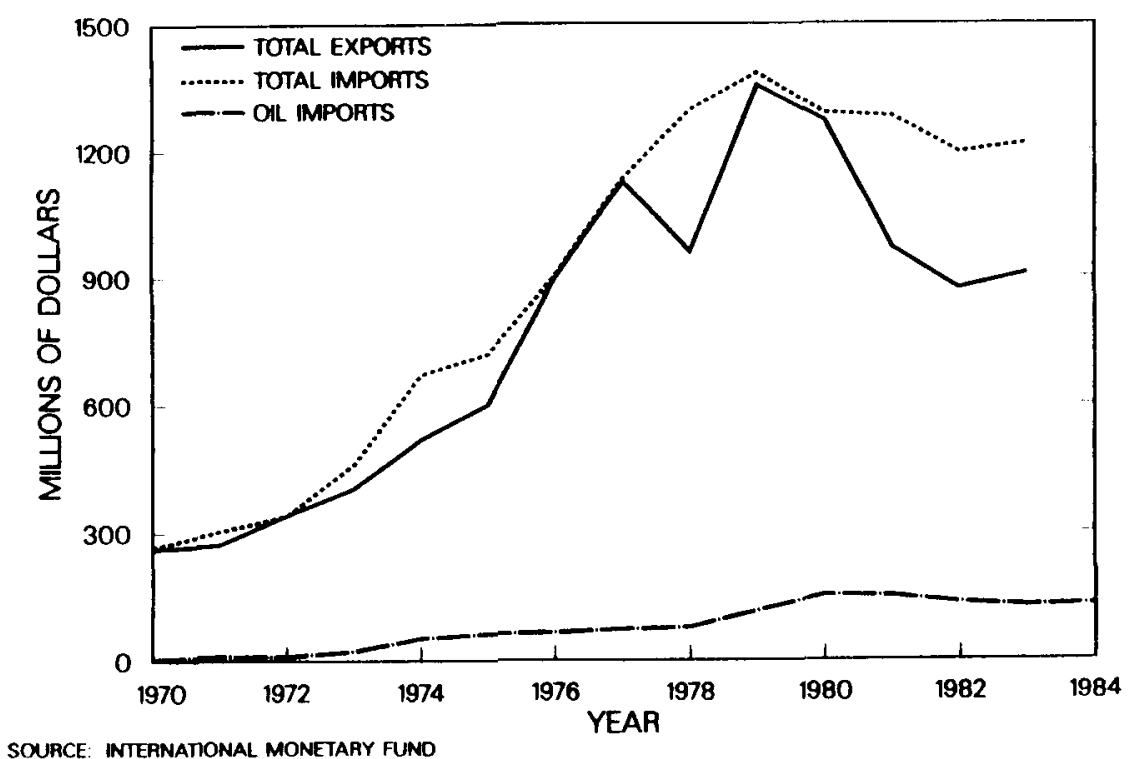

Fig. 4. El Salvador: Total exports, total imports, and oil imports.

oil imports in 1970 were $\$ 4.6$ million--less than 2 percent of El Salvador's export revenues. However, by 1980 the oil import cost was $\$ 151.3 \mathrm{million}$ and more than 14 percent of export revenue. Then, because of a decrease in world oil prices and a slight reduction in import volume, the 1984 cost of petroleum imports decreased to $\$ 130$ million. Still, as a portion of the country's export revenue in 1984, oil expenditures were over 18 percent of export revenue.

\section{International Aid}

The disbursed external public debt of El Salvador--how much the government owes to foreign creditors, chiefly the United States--reached $\$ 1.4$ billion in 1984, up from $\$ 509$ million in 1980 (see Table 8). In 1980 El Salvador's debt service obligations of $\$ 41.3$ million equaled 3.8 percent of export earnings. By 1984 , this percentage had risen to 27 percent.

In 1984, the external public debt grew by almost 30 percent over the previous year to $\$ 1390$ million. Although the service of that debt has been rising in recent years, the Inter-American Development Bank (IDB) feels it does not yet constitute a problem. The current account worsened in 1984 but was still far above its low in 1981.

Economic assistance to El Salvador has increased rapidly in the 1980s, reflecting the growing U.S. concern over economic and political instability. The 1984 assistance levels reached $\$ 412.5$ million in El Salvador (see Table 9), making it the fifth 1 argest recipient of U.S. economic assistance in the world. 
TABLE 8

EL SALVADOR: EXTERNAL PUBLIC INDEBTEDNESS

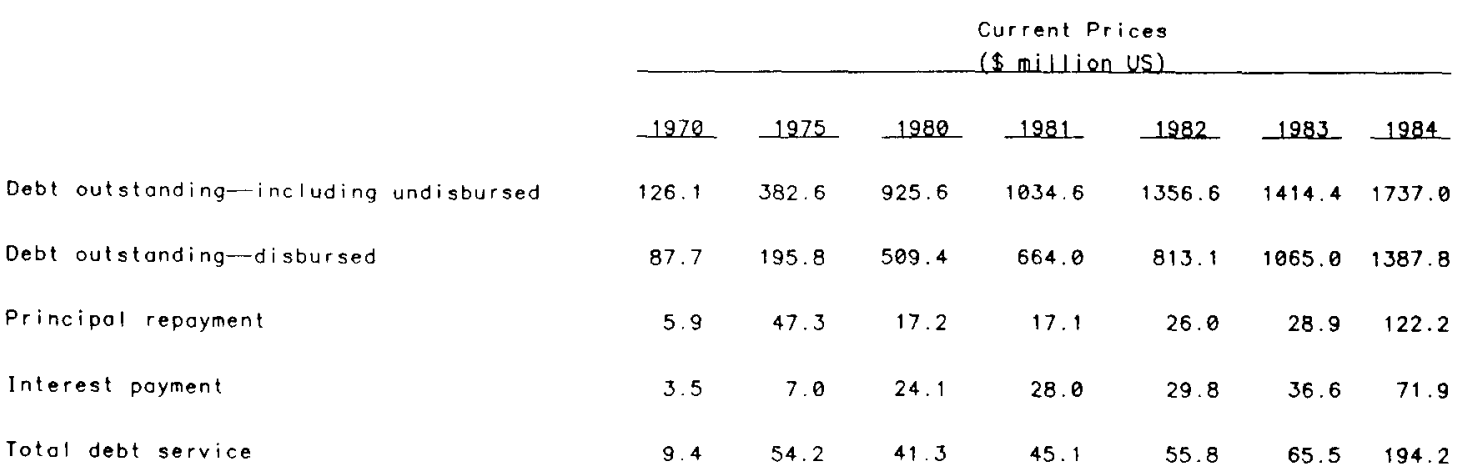

Source: The World Bank. "World Tables, The Third Edition, Volume I - Economic Data ond Volume Il - Social Data," Woshingtan, D.C.. 1984 . Additional informotion provided September 1985 ond September 1986.

TABLE 9

US AND INTERNATIONAL AID TO EL SALVADOR

(\$million US)

\begin{tabular}{|c|c|c|c|c|c|c|}
\hline & $1962-1979$ & 1980 & 1981 & 1982 & 1983 & 1984 \\
\hline Totol U.S. economic ossistance & 185.6 & 58.3 & 114.0 & 182.2 & 245.6 & 215.9 \\
\hline Loans $\quad$.. & 93.8 & 40.4 & 80.0 & 63.8 & 86.6 & 81.2 \\
\hline Grants & 91.8 & 17.9 & 34.0 & 118.4 & 159.0 & 134.7 \\
\hline Grants as a percentage of total economic assistance & $49.5 \%$ & $320.7 \%$ & $29.8 \%$ & $65.0 \%$ & $64.7 \%$ & $62.4 \%$ \\
\hline Total U.S. military assistance & 16.5 & 5.9 & 35.5 & 82.0 & 81.3 & 196.6 \\
\hline Loans & 3.5 & 5.7 & 10.0 & 16.5 & 46.5 & 18.5 \\
\hline Gronts & 13.0 & 0. 2 & 25.5 & 65.5 & 34.8 & 178.1 \\
\hline Grants as a percent of total military assistance & $78.8 \%$ & $3.4 \%$ & $71.8 \%$ & $79.9 \%$ & $42.8 \%$ & $90.6 \%$ \\
\hline Total U.S. Economic and Militory ossistance & 202.1 & 64.2 & 149.5 & 264.2 & 326.9 & 412.5 \\
\hline Loans & 97.3 & 46.1 & 90.0 & 80.3 & 133.1 & 99.7 \\
\hline Grants & 104.8 & 18.1 & 59.5 & 183.9 & 193.8 & 312.8 \\
\hline Military assistonce as a percentage of total assistance & $8.2 \%$ & $9.2 \%$ & $23.7 \%$ & $31.0 \%$ & $24.9 \%$ & $47.7 \%$ \\
\hline Total assistance from international organizotions & 503.4 & 48.9 & 40.5 & 112.8 & 53.3 & 114.3 \\
\hline IBRD & 180.7 & - & - & - & - & - \\
\hline IFC & 0.9 & - & - & - & - & - \\
\hline IDA & 25.0 & - & - & - & - & - \\
\hline $\operatorname{IDB}$ & 272.3 & 48.5 & 40.4 & 112.4 & 52.9 & 114.0 \\
\hline UNDP & 18.4 & 0.4 & 0.1 & 0.4 & 0.4 & - \\
\hline other UN & 5.6 & - & - & - & - & 0.3 \\
\hline
\end{tabular}

Source: Reference 5 
The El Salvadoran economic assistance total for the 2-year period 1984 and 1985 was $\$ 740$ million.

U.S. economic assistance to El Salvador ( $\$ 215.9$ million in 1984) is intended to provide balance-of-payments support, achieve specific development and humanitarian goals, and encourage social and economic changes. For 1983 and 1984 approximately two-thirds of this assistance was grants and one-third was loans. The Agency for International Development (AID) is responsible for administering economic assistance programs and has field missions in El Salvador. The majority of assistance made available in fiscal year 1984 and 1985 regular and supplemental appropriations was designed to provide short-term, balance-ofpayments relief. By using cash transfers, AID is able to provide such assistance quickly to help meet the immediate needs for foreign exchange. According to AID officials, the demand for dollars to purchase imports far exceeds the available supply of dollars in El Salvador. Industry is operating at reduced capacity in part because of a shortage of imported raw materials and spare parts, and this situation has constrained production and employment. AID projects in El Salvador do not emphasize institution-strengthening and training but rather the country's immediate need to repair damage to its physical infrastructure and to restore funding for social services that have been curtailed by armed conflict. For example, helicopters and spare parts needed to repair the electrical grid have been provided under this program.

Military assistance has been an increasing share of the U.S. total assistance package to El Salvador. In 1980, it was only 9.2 percent of total assistance but grew to almost 48 percent by 1984 .

E. Role of Government

The government deficit is large and growing. The nation is faced with extraordinary expenditures, in part because civil unrest is destroying part of the economy. Labor demands in the public sector have already exceeded the capacity of the government to increase salaries. An austerity program announced by the government calls for a 10 percent reduction in expenditures and for not filling government positions that become vacant. ${ }^{6}$

Perhaps the major economic policy change by the government has been in the area of the foreign currency exchange rate. The current exchange rate overvalues the El Salvadoran currency. This stimulates imports by setting artificially low prices and lowers demand for exports by setting artificially high prices.

E1 Salvador's currency, the colon, is officially valued at 2.5 per dollar, but in August 1985, could be purchased on the black market at a rate of slightly 
more than 6 per dollar. El Salvador has established a second legal exchange rate, referred to as the parallel exchange rate of 4.80 to 4.85 colones per dollar for a portion of its imports and exports, which more closely reflects the market value of its currency. The official exchange rate is used throughout the remainder of this report to convert colones into US dollars.

According to AID, the government of El Salvador has enacted some measures to increase profitability of traditional exports and to address fiscal problems in conjunction with US balance-of-payments assistance. For example, the government decided to exchange a portion of shrimp and cotton export proceeds at the parallel exchange rate and required that about $\$ 75$ million of imports be purchased at the parallel exchange rate rather than the official rate. As of March 1985, 42 percent of both imports and exports were transacted at the parallel rate. This represents an important exchange rate adjustment but is less than the full unification of exchange rates. El Salvador had indicated that it would undertake a more comprehensive economic program by the end of $1985 .^{5}$

F. Employment

It is estimated that over 30 percent of the population is unemployed. Combined unemployment and underemployment may exceed 50 percent. In addition, about 10 percent of the population has been displaced from their homes by the violence in the countryside. The unemployment situation is not expected to improve in the near future: as stated earlier, over 47 percent of the population is under fifteen years of age. In the near future, as these children enter the work force, the unemployment rate may well mushroom. Figure 5 shows the percentage of the labor force employed by each sector.

G. Welfare and Income Distribution

Between 1978 and 1984, El Salvador's economic output dropped by 25 percent each year, and population grew by 2.8 percent each year. As a result, the real standard of living in El Salvador fell by one-third. Estimated per capita income is $\$ 700-$-more than for Honduras but less than for other Central American countries. Income distribtuion is such that 8 percent of the population earns over one-half of the country's income and 61 percent receives 20 percent. The government has few resources available for programs to maintain living standard$s$, promote social services, and deal with humanitarian problems because of the high expense associated with maintaining the military and repairing the damage to infrastructure caused by the armed conflict. 


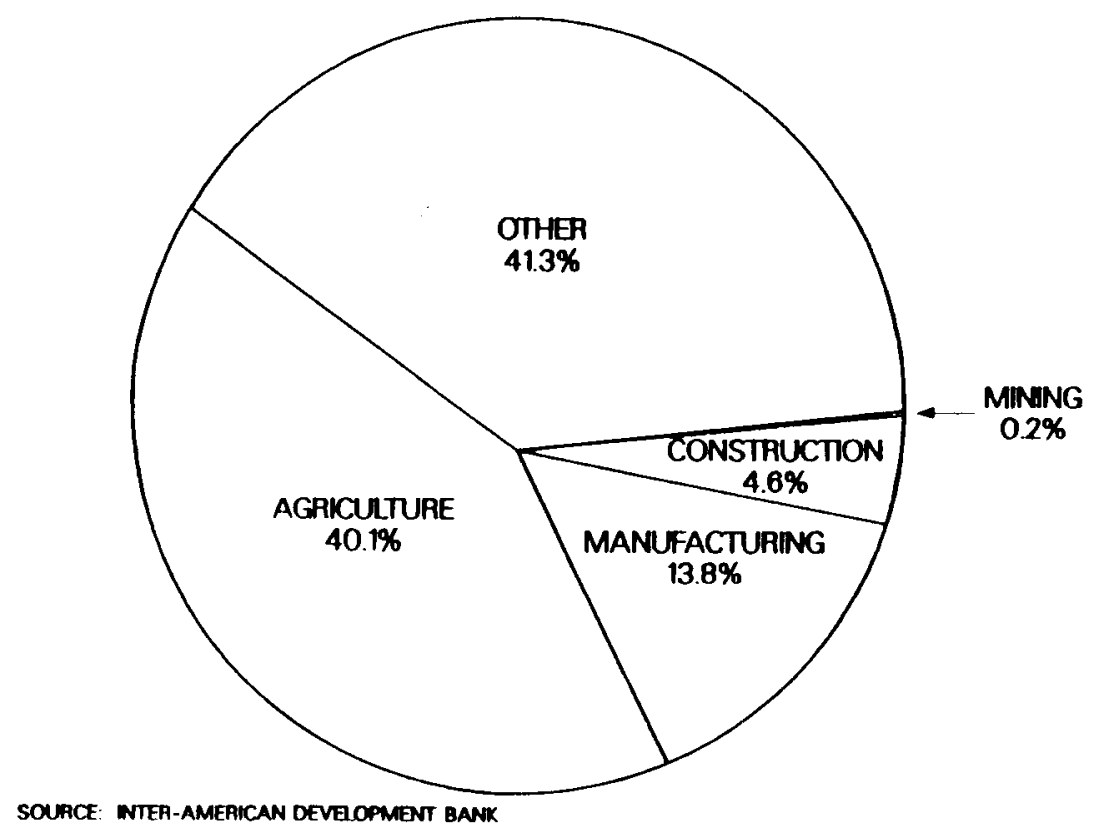

Fig. 5. El Salvador: Labor force by sector for 1983.

\section{ENERGY OVERVIEW}

\section{A. Energy Resources}

1. $0 i 1$ and Natural Gas. No exploration activity was reported between 1977 and 1982. The last efforts were reported in 1976 when Arpel (Latin American National 0il Companies Aid Group) and Ecopetrol of Colombia assisted in an evaluation of the Pacific offshore areas. This effort was sponsored by the United Nations and the government of El Salvador. Prior to that, in the fall of 1974, companies were invited to seek qualification to bid for offshore acreage. The companies had 150 days from November 14, 1974, to finalize negotiations. The single company (unidentified) that had agreed to accept the minimum requirements for lease purchase withdrew when a government commission was preparing to negotiate. No wells for hydrocarbons have ever been drilled in the country, and a11 petroleum is imported. ${ }^{7}$

The national utility and energy authority, Comision Ejecutiva Hidroelectrica del Rio Lempa (CEL), evaluated various means of conducting oil exploration with the help of consultants. CEL has chosen to allow exploration by private companies on leases obtained through international public bidding. The Energy Superintendent of CEL recently called for bids on offshore tracts. Promising reponses were obtained and are being evaluated. Any exploration will 
be carried out in the name of CEL. Onshore leasing is also being considered by CEL. ${ }^{8}$

2. Coal. CEL executed several preliminary studies with OLADE and a German geological group. They discovered several deposits, but of negligible commercial amounts.

Very young lignite beds are known to exist in the following departments of El Salvador: Santa Ana, Cuscatlan, Cabanas, San Miguel, Morazan, and La Union.

3. Hydroelectric. The largest hydroelectric resource in the country is the Rio Lempa. Studies conclude that between the discharge of the Lago de Guija and Puente Cuscatlan (a bridge on the Panamerican Highway), nine generating stations are feasible. Four of these are already on line and represent 30.5 percent of the estimated resource potential. The additional five potential hydroelectric stations and their generating capacities are shown in Table 10.

Additional, private service firms that are connected to the national electric system have hydroelectric resources with potential output of $422.6 \mathrm{MW}$. This constitutes 26 percent of the country's total hydroelectric resource of approximately $1630 \mathrm{MW}$. Approximately two-thirds of this potential resource, or $955 \mathrm{MW}$, is associated with the Rio Lempa. ${ }^{8}$

TABLE 10

EL SALVADOR: POTENTIAL RIO

LEMPA HYDROELECTRIC GENERATION STATIONS

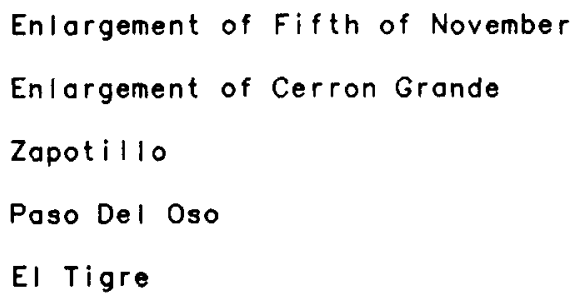

Enlargement of Cerron Grande

Zapoti 110

Paso Del Oso

El Tigre

Source: Reference 8 .

\section{$120 \mathrm{MN}$ \\ $135 \mathrm{MW}$ \\ $120 \mathrm{MW}$ \\ $40 \mathrm{NW}$ \\ $540 \mathrm{MH}$}

955 MW TOTAL Additional

Information provided by Guillermo Selva T., Instituto Centroamericano de Administracion de Empresas, December 1985. 
The only feasible short-term hydroelectric project alternatives are on the Rio Lempa. According to results of previous studies, the small hydroelectric projects identified on other rivers of the country are not now economically attractive for CEL. Therefore, for the near term, the economically exploitable additional hydroelectric potential for the country is considered to be 955 MW.

4. Geothermal. The entire territory of El Salvador lies within the Central American volcanic axis. Many surface manifestations of geothermal activity occur in the country; in addition to four active volcanoes, there are many fumarole and geyser fields with steam jets and hot springs.

CEL's Superintendent of Geothermal Resources performed a geothermal reconnaissance exploration of the country and identified 24 resource areas. The highest temperature encountered was $250^{\circ} \mathrm{C}$. The geothermal resource potential of El Salvador lies between a minimum of $270 \mathrm{MW}$ and a maximum of $4140 \mathrm{MW}$. The average potential is approximately $1080 \mathrm{MW}$. Of the areas investigated thus far, only four have potential for electricity generation. They are Berlin, Chinameca, San Vicente, and Chipilapa (Fig. 6). El Salvador is already

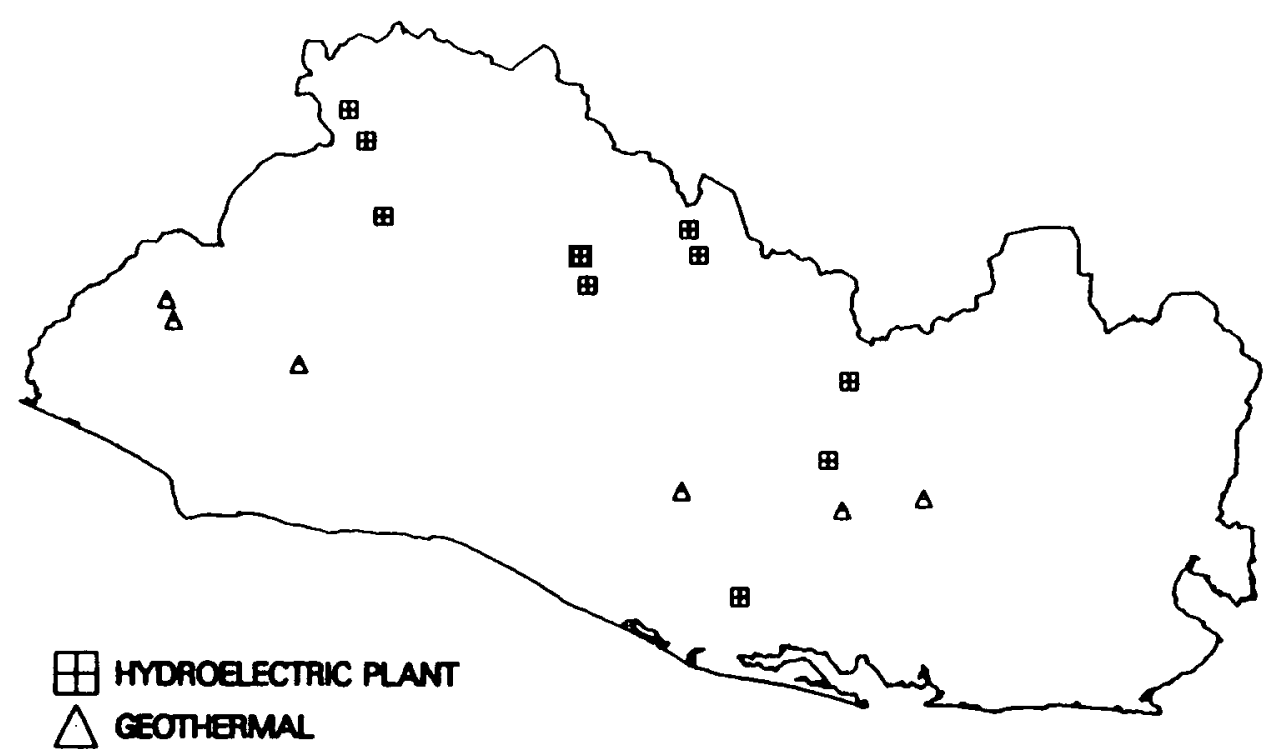

SOURCE: REFERENCE 8.

Fig. 6. El Salvador: Map of hydro and geothermal resources.

\footnotetext{
$\star$

Information provided by Guillermo Selva T., Instituto Centroamericano de Administracion de Empresas, December 1985.
} 
producing electricity from a fifth field, Ahuachapan, which has an installed generating capacity of $95 \mathrm{MW}$. Installation of up to $500 \mathrm{MW}$ of geotherma 1 capacity in 55 MW units was considered technically feasible by CEL in the year 2000. CEL's present expansion plans call for the installation of $200 \mathrm{MW}$ of geothermal electricity capacity by $2000 .^{8}$ The geothermal fields in the west of the country, Ahuachapan and Chipilapa, are strategically important because they are less vulnerable to sabotage

5. Fuel wood and Biomass. An alcohol plant, which has a daily production of 60,000 liters, is currently in operation. The production of this plant is exported to earn hard currency. The alcohol may be mixed with gasoline to decrease oil imports. The alcohol $\mathrm{plant}$ is the responsibility of INAZUCAR, the state sugar agency. The bidding process for construction of a second plant with a capacity of 120,000 liters per day is under way. Also, the agricultural industry has received special support to promote plantings of sugar cane to supply these fuel alcohol production plants. Alcohol produced in this new plant will also be exported. Therefore, no effect is expected on the internal supply of gasoline.

Fuel wood resources in El Salvador are not well defined, and the country has perhaps the most potential among Central American countries for a serious fuel-wood crisis in the near future. Because of the civil conflict in parts of the country, a ground survey of forest resources is infeasible. CEL is considering construction of a forest map from satellite imagery of the country. As in most of the other Central American countries, coffee shade trees, coffee plants, lumber mills, and shrub forests are important sources of fuel wood. These are discussed in the supply section of this document.

6. Solar and Wind Energy. An evaluation of solar and wind resources has been done, 8 and the following information was provided: "Average annual daily solar radiation varies between 13.88 and 19.15 megajoules per square meter $\left(\mathrm{MJ} / \mathrm{m}^{2}\right)$, annual solar energy values totaling between $1407 \mathrm{kWh} / \mathrm{m}^{2}\left(5066 \mathrm{MJ} / \mathrm{m}^{2}\right)$ and $1942 \mathrm{kWh} / \mathrm{m}^{2}\left(6960 \mathrm{MJ} / \mathrm{m}^{2}\right)$. The majority of the meteorological stations studied have levels of available solar energy above $1610 \mathrm{kWh} / \mathrm{m}^{2}\left(5800 \mathrm{MJ} / \mathrm{m}^{2}\right) . "$ More than $500 \mathrm{kWh} / \mathrm{m}^{2}$ is required for electricity generation; therefore, solar may have widespread application for El Salvador.

* Information provided by Guillermo Selva T., Instituto Centroamericano de Administracion de Empresas, December 1985. 
Regarding wind energy, the study found that "Wind energy potential in the majority of the meteorological stations is modest compared to what is required for electricity generation." CEL does not have any special metering stations and has used information collected from normal meteorological stations. 8

The studies described above provided rough theoretical estimates of solar and wind energy potential, and they are preliminary. In the short and medium term, CEL considers development of wind and solar resources uneconomical.

B. Energy Supply

This section describes the sources of supply, method of distribution, and prices for each type of energy used in El Salvador. Figure 7 displays the energy flow diagram for El Salvador. This is a good overview of the energy supply (left side), the conversion and flow of fuels (center), and the final consumption (right side).

1. Petroleum Imports, Production and Prices.

a. Production, Imports, and Exports. As stated earlier, El Salvador does not have any proven $0 i 1$ deposits; therefore, all petroleum for domestic use is imported.

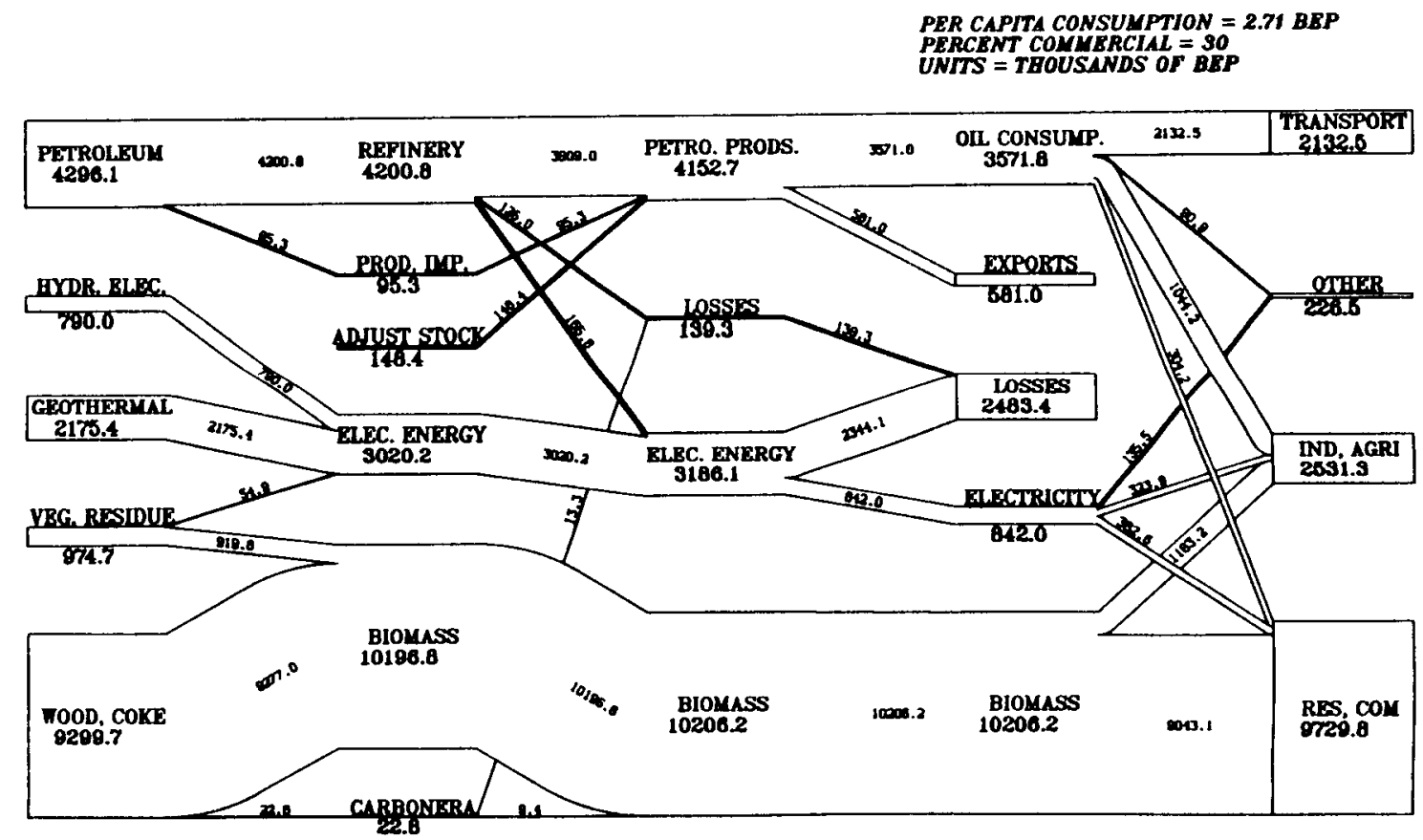

SOURCE: REFERENCE 8.

Fig. 7. El Salvador: Energy flow diagram for 1984. 
Imported petroleum from Venezuela and Mexico is paid for through credit with a 30-day expiration period that is granted by the San Jose Pact. Under this agreement, loans are to be used in economic development projects, with preference given to the energy sector.

As shown in Table 11, crude petroleum imports more than doubled between 1970 and 1971, compensating for the decline in import of refined products. 0i1 imports steadily increased through 1978. Between 1979 and 1982, imports decreased, but have recently begun to increase again. Foreign oil purchases require a substantial amount of foreign exchange--in 1983, the value of oil imports represented about 14 percent of that for total exports for the year (see Fig. 8). However, in terms of GDP, the percentage was only about 3 percent.

El Salvador exports a small amount of fuel oil and other products. This is a result of excess output from the refinery for these products.

b. Refinery. The country's single refinery [Refineria de Acajuta S. A. (RASA)] the property of ESSO (65 percent) and She11 (35 percent). The refinery has a daily processing capability of 17,000 barrels of topping, 3000 barrels of reforming, 2000 barrels of vacuum distillation, 3500 barrels of naptha, and 5000 barrels of distillates (see Table 12). Crude petroleum purchases comprised 62 percent of the total cost of refined products; the remaining 38 percent is refining costs. As part of the IDB/CEL project, there is work being done on a simulation model for petroleum imports and refining. The percentage of capacity

TABLE 11

EL SALVADOR: PETROLEUM IMPORTS BY PROOUCT 1970-1984

\begin{tabular}{|c|c|c|c|c|c|c|c|c|c|c|c|c|c|c|c|}
\hline & 1970 & 1271 & 1972 & 1973 & 1974 & 1975 & 1976 & 1977 & 1978 & 1979 & 1980 & 1981 & 1982 & 1983 & 1984 \\
\hline \multicolumn{16}{|l|}{ Primary Energy } \\
\hline Potroloum & 1618 & 3358 & 3348 & 4713 & 4370 & 5004 & 5137 & 5269 & 5517 & 5133 & 4588 & 4471 & 3909 & 4436 & 4419 \\
\hline \multicolumn{16}{|c|}{ (Unit: Teracalorios) } \\
\hline & 1970 & 1971 & 1972 & 1973 & 1974 & 1975 & 1926 & 1977 & 1978 & 1979 & 1980 & 1981 & 1982 & 1983 & 1984 \\
\hline LPG & 74 & 11 & 11 & 一 & 4 & $\overrightarrow{s t}$ & $\overrightarrow{3}$ & $\begin{array}{r}4 \\
53\end{array}$ & 48 & 21 & 28 & 30 & 40 & 118 & 54 \\
\hline Gasoline & 604 & 59 & 171 & 106 & 59 & 61 & 43 & 53 & 81 & 63 & 88 & 38 & 143 & 118 & 54 \\
\hline \multicolumn{11}{|l|}{ Kerosene * jet } & 19 & - & 32 & 32 & 20 \\
\hline $\begin{array}{l}\text { fuel } \\
\text { Diesel oil }\end{array}$ & $\begin{array}{l}299 \\
758\end{array}$ & - & $\begin{array}{r}66 \\
205\end{array}$ & $\overline{67}$ & - & $\overline{123}$ & - & 43 & - & 102 & - & - & 28 & 69 & - \\
\hline Fuel oil & 840 & 40 & 385 & - & 一 & 283 & 386 & 518 & 193 & - & - & - & - & - & 一 \\
\hline \multicolumn{16}{|l|}{ Non-energy } \\
\hline products & 134 & 123 & 157 & 51 & 66 & 61 & 77 & 76 & 82 & 84 & 44 & 48 & 66 & 69 & 47 \\
\hline Cool and coke & 2.4 & 2.2 & 2.8 & 2.5 & 3.0 & 4.2 & 3.7 & 5.3 & 5.5 & 5.9 & 5.9 & 5.9 & 5.9 & 4.0 & 3.2 \\
\hline
\end{tabular}




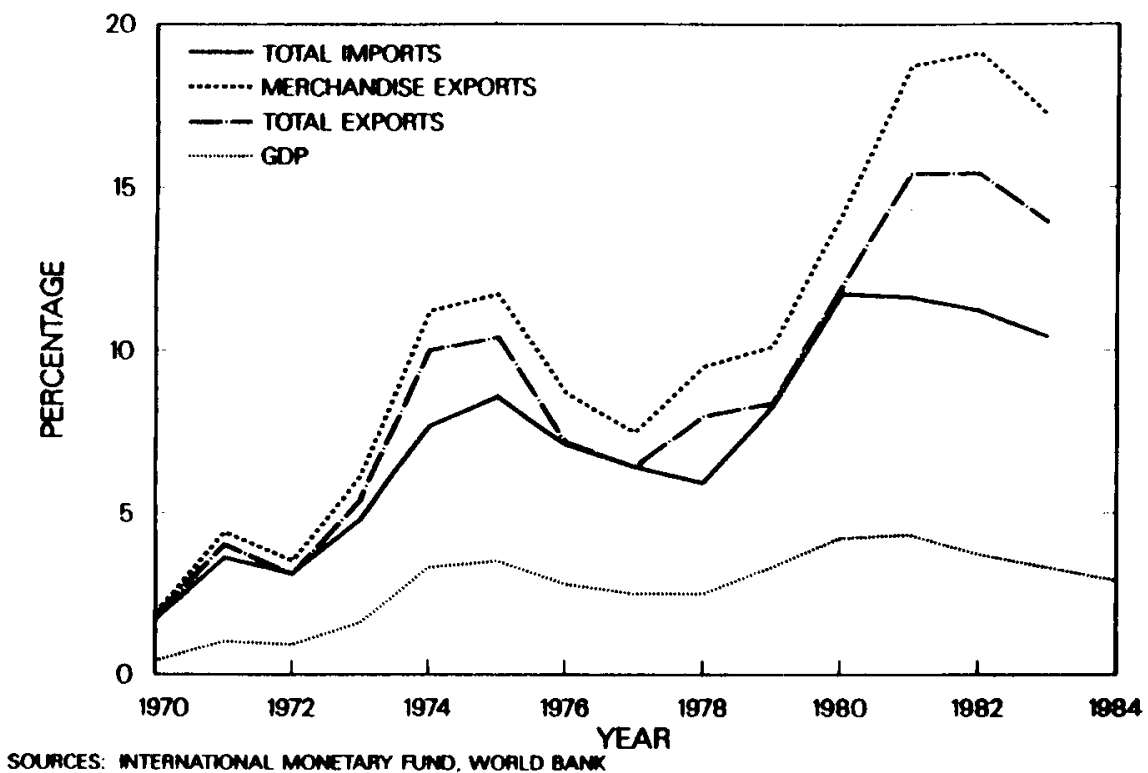

Fig. 8. El Salvador: $0 \mathrm{il}$ imports as a percentage of imports, exports, and GDP.

TABLE 12

EL SALVADOR: REFINERY OUTPUT 1970 - 1984

(thousands of barrels)

Preducts
LPG
Kerosene/turbo fuel
Super gosoline
Regular gasoline
Diesel oil
Fuel oil
Asphalt

LPG
Kerosene/turbo fuel
Super gosoline
Regular gasoline
Dlesel oil
Fuel oll
Asphalt

\begin{tabular}{|c|c|c|c|c|c|c|}
\hline 1970 & 1971 & 1972 & 1973 & 1974 & 1975 & 1976 \\
\hline 51.1 & 175.6 & 210.3 & 228.4 & 185.3 & 217.6 & 253.6 \\
\hline 162.6 & 339.8 & 327.9 & 384.1 & 348.7 & 353.9 & 368.0 \\
\hline 147.9 & 410.5 & 443.1 & 565.0 & 479.5 & 601.0 & 715.9 \\
\hline 156.7 & 372.9 & 357.2 & 353.6 & 395.2 & 385.0 & 421.5 \\
\hline 319.6 & 952.6 & 846.5 & 1160.9 & 1207.4 & 1510.1 & 1468.4 \\
\hline 402.4 & 990.7 & 1161.2 & 1440.1 & 1609.5 & 1587.7 & 1643.6 \\
\hline- & - & - & 125.9 & 134.2 & 154.3 & 154.0 \\
\hline 1978 & 1979 & 1980 & 1981 & 1982 & 1983 & 1984 \\
\hline 294.2 & 315.1 & 289.5 & 263.3 & 254.4 & 287.0 & 304.4 \\
\hline 383.0 & 390.6 & 338.0 & 300.3 & 278.5 & 276.6 & 343.5 \\
\hline 892.3 & 883.4 & 709.8 & 648.8 & 611.0 & 713.8 & 780.3 \\
\hline 343.7 & 419.4 & 384.2 & 330.0 & 293.8 & 289.0 & 299.4 \\
\hline 685.7 & 735.4 & 1434.9 & 1348.8 & 1268.8 & 1336.8 & 1336.8 \\
\hline 1411.7 & 306.7 & 1253.8 & 1266.3 & 1194.5 & 1220.0 & 1304.3 \\
\hline 163.1 & 134.8 & 108.0 & 92.7 & 93.3 & 98.1 & 64 \\
\hline
\end{tabular}

Source: Reference 8 . 
utilization for the refinery was 65 percent in $1982 .^{*}$ Net supply of petroleum products is shown in Table 13 .

c. Marketing. The Ministry of Economics sets the prices of petroleum products, employing the Caribbean parity system for the determination of refinery prices. To these prices are added transport costs, company and distributor profit margins, taxes, and subsidies before reaching the final sale price to the public. The government has little control of the oil market beyond the setting of prices because the distribution system (from the refinery to the retail gasoline stations) is privately owned.

d. Prices. There are no regional differences in petroleum product prices. The nominal price of these products for 1973-1984 are shown in Table 14 . In

TABLE 13

EL SALVADOR: TOTAL SUPPLY OF PETROLEUM PRODUCTS

(thousands of barrel equivalents of petroleum)

\begin{tabular}{|c|c|c|c|c|c|c|c|c|c|}
\hline & 1970 & 1977 & 1978 & 1979 & 1980 & 1981 & 1982 & 1983 & 1984 \\
\hline Liquified gos & 89.1 & 223.8 & 298.8 & 322.3 & 277.4 & 244.4 & 237.2 & 249.8 & 278.5 \\
\hline Gasoline & 655.9 & 1019.7 & 1074.7 & 1118.2 & 961.5 & 833.8 & 843.4 & 905.8 & 928.9 \\
\hline Kerosene and jet fuel & 343.7 & 325.6 & 337.7 & 353.8 & 302.8 & 264.9 & 267.1 & 265.4 & 316.2 \\
\hline Diesel oil & 802.7 & 1451.2 & 1551.6 & 1666.3 & 1320.6 & 1243.2 & 1187.8 & 1278.0 & 1232.0 \\
\hline Fuel oil & 963.5 & 1662.9 & 1301.1 & 1086.7 & 863.6 & 885.7 & 947.2 & 817.3 & 777.3 \\
\hline Totol & 2854.9 & 4683.2 & 4563.9 & 4547.3 & 3725.9 & 3472.0 & 3482.7 & 3516.3 & 3532.9 \\
\hline
\end{tabular}

Source: Country Energy Bolances

TABLE 14

EL SALVADOR: OIL PRODUCT PRICES

(colones per gollon, colones per pound for propane gos)

Premium gasoline

Regular gasoline

Kerosene

Diesel oil

Diesel oil (public transport)

Fuel oil

Liquid propane gas

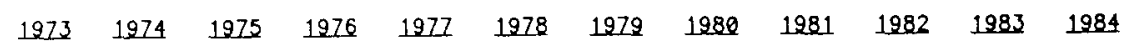

$\begin{array}{llllllllllll}1.50 & 2.12 & 2.28 & 2.28 & 2.58 & 2.58 & 4.37 & 5.09 & 6.41 & 6.41 & 6.41 & 6.41\end{array}$

$\begin{array}{llllllllllll}1.41 & 1.98 & 2.15 & 2.15 & 2.44 & 2.44 & 3.97 & 4.92 & 6.23 & 6.23 & 6.23 & 6.23\end{array}$

$\begin{array}{llllllllllll}0.59 & 1.15 & 1.20 & 1.20 & 1.25 & 1.25 & 2.00 & 2.60 & 3.94 & 3.94 & 3.94 & 3.94\end{array}$

$\begin{array}{llllllllllll}0.70 & 1.20 & 1.20 & 1.20 & 1.20 & 1.20 & 2.25 & 3.16 & 4.25 & 4.25 & 4.25 & 4.25\end{array}$

$\begin{array}{llllllllllll}0.70 & 1.00 & 1.00 & 1.00 & 1.00 & 1.00 & 1.00 & 1.00 & 1.30 & 1.30 & 1.30 & 1.30\end{array}$

$\begin{array}{llllllllllll}0.45 & 0.69 & 0.71 & 0.71 & 0.86 & 0.86 & 0.86 & 1.29 & 1.79 & 1.95 & 1.95 & 1.95\end{array}$

$\begin{array}{lllllllllll}0.16 & 0.16 & 0.16 & 0.16 & 0.16 & 0.19 & 0.27 & 0.31 & 0.31 & 0.31 & 0.31\end{array}$

Source: Reference 8 .

Information provided by Guillermo Selva T., Instituto Centroamericano de Administracion de Empresas, December 1985. 
1984 premium gasoline sold for 6.41 colones per gallon ( $\$ 2.56$ US). Note that there has been no change in 011 product prices since 1981 except for fuel oil, which increased. Between 1978 and 1981 the price of all oil products except diesel fuel for public transportation increased rapidly. For example, the price of regular gasoline rose by 155 percent and that of diesel oil for general use by 254 percent. During this period, according to the implicit GDP deflator provided by the World Bank, average prices for the total economy rose 63 percent.

Diesel fuel for public transportation rose by only 30 percent to 1.30 colones per gallon. The price for general-use diesel oil was more than three times higher: 4.25 colones per gallon. In effect, the reduced real cost of diesel fuel for public transportation is an indirect subsidy to the public transportation system. This became a generally accepted practice for many countries during the 1970s to encourage the use of public transportation rather than less energy efficient private automobiles.

2. Coal. Coal and coke are a very small portion of El Salvador's total energy supply, and both are to be used primarily as fuel in metal foundries.

3. Electrical Utilities

a. Production and Transmission. The development of Rio Lempa started in 1954 with the installation of the Fifth-of-November power plant and has continued with the installation of Guajoya in 1963, Cerron Grande in 1977, one unit of the Fifteenth-of-September plant in 1983 and another one in 1984. These three hydrostations represent 412 MW of installed capacity and 1952 GWh of average annual generation. ${ }^{8}$

Over the past 10 years the production of electricity in El Salvador has moved increasingly to generation from hydroelectric and geothermal resources (see Table 15). In 1975, 50 percent (127 MW) was produced by hydroelectric and geothermal and the remaining 50 percent (128.2 MW) by thermoelectric. In 1975, the Ahuachapan geothermal station came on line with $30 \mathrm{MW}$, increased to $60 \mathrm{MW}$ the following year, and then to $95 \mathrm{MW}$ in 1980. In 1977, an additional $135 \mathrm{MW}$ of hydroelectric power at Cerron Grande came on line, followed in 1983 by Central Fifteenth of September with 90 MW. For 1984, CEL reported that 93.8 percent of the electrical energy was generated using indigenous resources: 62 percent of the total production was hydroelectric and 32 percent was geothermal. The remaining 6.2 percent was for thermal generation using imported petroleum.

Whereas the country has been successful in reducing the percentage of thermal capacity, the absolute amount has remained constant over the past 10 years. This is mainly because of sabotage of the transmission lines. The 
TABLE 15

EL SALVADOR: INSTALLEO ELECTRIC GENERATING CAPACITY

(MW)

\begin{tabular}{|c|c|c|c|c|c|}
\hline & Hedre & Geethermal & Steam & Gas Iurbines & Iotal \\
\hline 1970 & 97.0 & 一 & 63.0 & 6.6 & 166.6 \\
\hline 1971 & 97.0 & - & 63.0 & 6.6 & 166.6 \\
\hline 1972 & 97.0 & 一 & 63.0 & 39.6 & 199.6 \\
\hline 1973 & 97.0 & - & 63.0 & 60.5 & 220.5 \\
\hline 1974 & 97.0 & - & 63.0 & 60.5 & 220.5 \\
\hline 1975 & 97.0 & 30.0 & 63.0 & 60.5 & 250.5 \\
\hline 1976 & 97.0 & 60.0 & 63.0 & 60.5 & 280.5 \\
\hline 1977 & 232.0 & 60.0 & 63.0 & 60.5 & 415.5 \\
\hline 1978 & 232.0 & 60.0 & 63.0 & 60.5 & 415.5 \\
\hline 1979 & 232.0 & 60.0 & 63.0 & 60.5 & 415.5 \\
\hline 1980 & 232.0 & 95.0 & 63.0 & 60.5 & 450.5 \\
\hline 1981 & 232.0 & 95.0 & 63.0 & 60.0 & 450.5 \\
\hline 1982 & 232.0 & 95.0 & 63.0 & 60.5 & 450.5 \\
\hline 1983 & 310.3 & 95.0 & 63.0 & 60.5 & 528.8 \\
\hline 1984 & 388.0 & 95.0 & 63.0 & 85.8 & 631.8 \\
\hline
\end{tabular}

generation and transmission system is shown in Fig. 9. CEL has had to generate electricity with the thermal plants to supply those areas of the country that would normally be supplied with either hydroelectric or geothermal-generated electricity. If the system could run at full capacity, the current electrical requirements for the country could be supplied by domestic resources, with little or no bunker $C$ or diesel imports. For example, CEL estimated that 41 percent more hydroelectric energy could have been produced by the generation capacity had the transmission system remained intact. Even though there was an excess of water available for generation, it was discharged through spillways because the transmission system was incapable of moving the electricity to the consumers. 8 Additionally, CEL reports that in 198430 percent of the total geothermal energy extracted from the ground was not taken advantage of and was discharged as steam into the atmosphere or water into the gutter. ${ }^{8} \mathrm{Also}$, there has been a decline in energy generated at Ahuachapan owing to problems of the reservoir (subsidence of soil has been detected close to the site). Because it is a shallow reservoir and the rate of production has been higher than the refill rate, some of the wells showed a decrease in the delivered power, and CEL had to reduce the generation of electricity. They have taken several measures, 


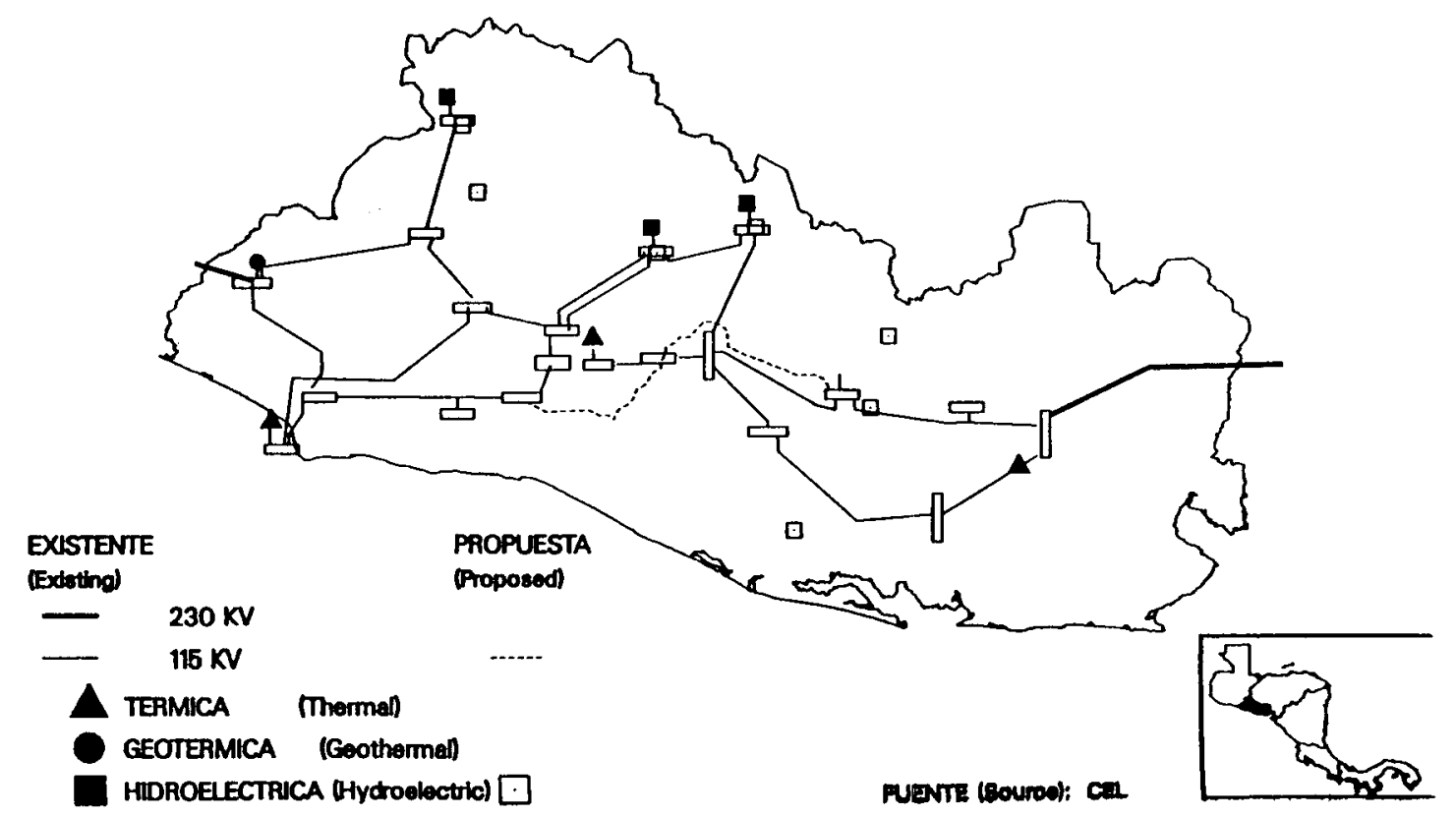

Fig. 9. El Salvador: Map of CEL generation and transmission system.

including stopping reinjection, and it seems the reservoir has shown minor signals of improvement, but for the last several years the power plant had been operating at lower than normal capacity. Los Alamos is working with CEL to develop a program to evaluate and solve the Ahuachapan problems.

b. Distribution. CEL generates over 95 percent of the electric energy of El Salvador, but there are nine distribution companies. The distribution companies are listed below, and Fig. 10 shows the area they service.

CEL: Comision Ejecutiva Hidroelectria del Rio Lempa

CAESS: Compania de Alumbrado Electrico de San Salvador, S.A.

CLESA: Compania de Luz Electrica de Santa Ana, S.A.

CLES: Compania de Luz Electrica de Sonsonate, S.A.

CLEA: Compania de Luz Electrica de Ahauchapan, S.A.

CECSA: Compania Electrica de Cucumcayan, S.A.

DEUSEM: Distribuidora Electrica de Usulutan, Sociedad de Economia Mixta

DESSEM: Distribuidora Electrica de Sensuntepeque Sociedad de Economia Mixta

HSDM Co: Hidroelectrica Sociedad de Matheu y cia. de C.V.

In 1982 these distribution companies produced 10.6 MW of hydroelectric energy and purchased the balance of their needs from CEL. According to the electricity $1 \mathrm{aw}$, the franchise for CAESS, which is the largest electric distribution company, and other electric companies, will expire in 1986. CEL will take over 


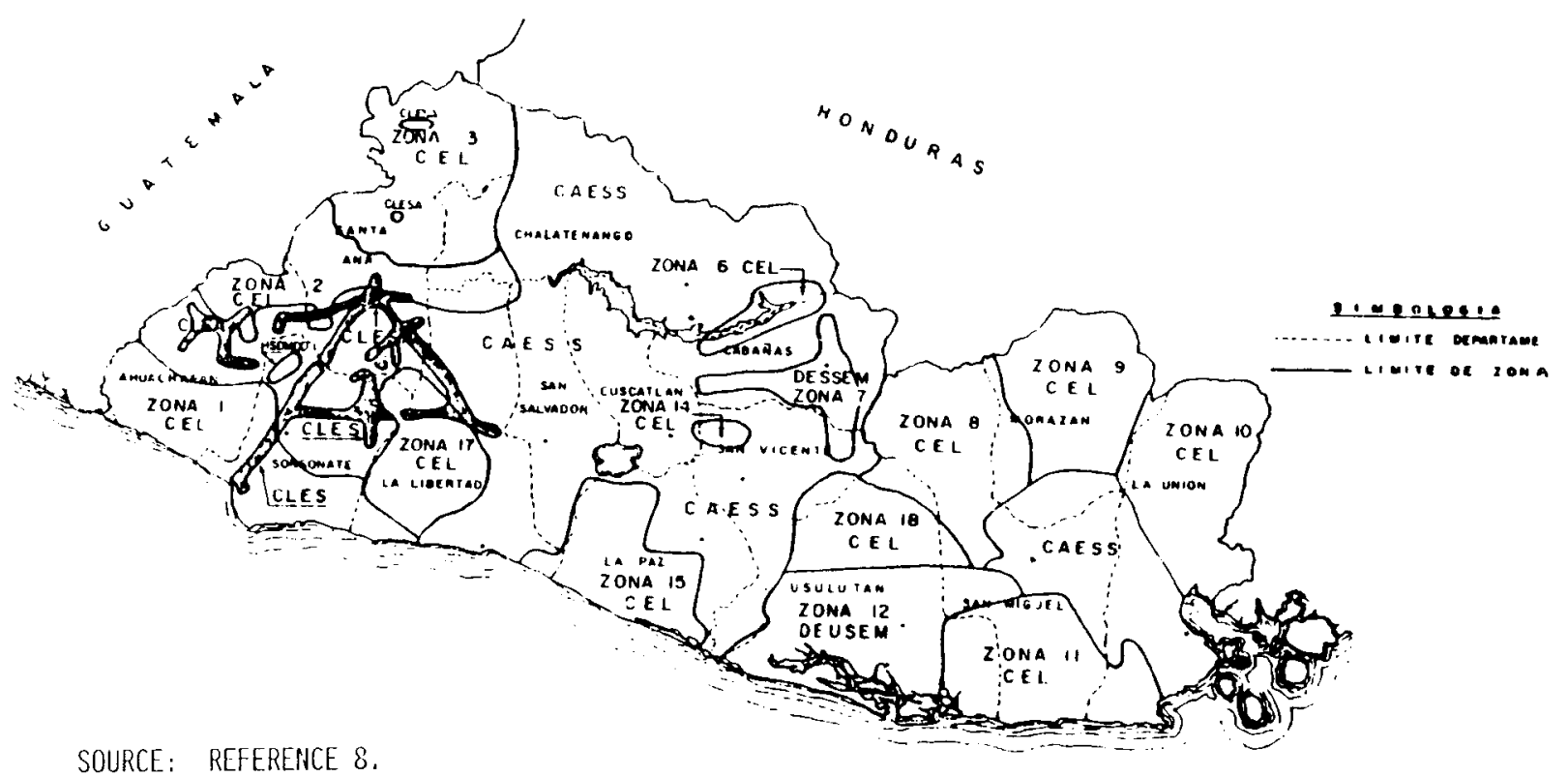

Fig. 10. El Salvador: Map of electrical distribution service areas.

these distribution companies at that time. Because of the impending expirations of their concessions, the distribution companies have cancelled all investments in new transmission lines. A bottleneck and unsatisfied demand has resulted.

Since 1945, CEL has had sole responsibility for production, transmission, and distribution of electricity in rural areas. The 1982 estimates stated that only 8 percent of the rural population had electric service. CEL is seeking financing to extend the rural grid.

c. Prices. Compared to electrical prices in some regions of the United States, rates are relatively cheap in El Salvador. This is primarily because of the preponderance of inexpensive hydroelectric production. Rates increased in 1984 after remaining almost constant since 1979 (see Table 16). In 1984, commercial rates were the highest at 0.187 colones $/ \mathrm{kWh}(\$ 0.075 / \mathrm{kWh}$ at the official exchange rate), and government rates were the lowest at 0.136 colones $/ \mathrm{kWh}$ $(\$ 0.054 / \mathrm{kWh})$. Between 1978 and 1983 the price of electricity in each of the economic sectors actually decreased in constant-value terms. For example, residential rates rose by only 8.8 percent whereas prices in general (as measured by the GDP deflator) increased by 63 percent.

d. Expansion. At the present time, the identified hydroelectric resources of the country include (a) the Rio Lempa hydroelectric potential, estimated to have an additional 992 MW of exploitable capacity and (b) the hydroelectric potential of small projects on Rio Pax, Rio Jiboa, Rio Grande de 


\begin{tabular}{|c|c|c|c|c|}
\hline & Residential & Commercial & Industrigl & $\begin{array}{l}\text { Government } \\
\text { and } \\
\text { Municioal }\end{array}$ \\
\hline 1973 & 073 & .887 & .063 & $.070^{\circ}$ \\
\hline 1974 & .083 & .099 & .074 & $.075^{\circ}$ \\
\hline 1975 & .095 & .112 & .088 & $.884^{\circ}$ \\
\hline 1976 & .122 & .131 & .108 & $.101^{\circ}$ \\
\hline 1977 & .131 & .125 & .129 & .097 \\
\hline 1978 & .114 & .134 & .108 & .098 \\
\hline 1979 & .117 & .142 & .117 & .105 \\
\hline 1980 & .125 & .156 & .134 & .120 \\
\hline 1981 & .124 & .158 & .135 & .121 \\
\hline 1982 & .124 & .157 & .135 & .129 \\
\hline 1983 & .124 & .156 & .134 & .120 \\
\hline 1984 & .155 & .187 & .166 & .136 \\
\hline
\end{tabular}

San Miguel and Rio Goascoran estimated in 1982 to have 227.4 MW of maximum exploitable capacity. With respect to the geothermal potential, CEL's Superintendent of Geothermal Studies conservatively estimated that an additional 240-MW capacity can be exploited by the year 2000. The vulnerability of the electrical transmission grid would be reduced if the geothermal production sites were developed in the western part of the country, which is more secure. The total of indigenous resources is thus $1439 \mathrm{MW}$ including the proposed El Tigre hydroelectric power plant, whose damming would flood Honduran territory.

CEL has recently completed a capacity expansion plan that evaluates power generated using hydroelectric, geotherma1, and imported coal through the year 2000. In the short term, only indigenous hydroelectric and geothermal resources were considered for generation expansion. CEL expects that in the long run other fuels like natural gas can be included in future programs.

The expansion plan is shown in Table 17; it shows that CEL's main objective is to develop El Salvador's hydroelectric and geothermal resources.

The complete development of the Rio Lempa represents the installation of a total capacity of $1404 \mathrm{MW}$ and an average annual generation of $4552 \mathrm{GWh}$. This development would take advantage of all economical resources of the Rio Lempa utilizing 363 meters of waterfall and flow regulations by stationary damming in Zapotillo, Cerron Grande, and EI Tigre. ${ }^{8}$ The development recommended by HARZA 
TABLE 17

EL SALVADOR: GENERATION SYSTEM EXPANSION PROGRAM

\begin{tabular}{|c|c|c|c|}
\hline Year & Additional Propesel & $\begin{array}{l}\text { Additionol } \\
\text { (Min) }\end{array}$ & $\begin{array}{l}\text { Cumulat ive } \\
\text { (Mai) }\end{array}$ \\
\hline 1985 & Present & & 631.8 \\
\hline 1986 & Two goothermol mobile units ot Borlin & 10 & 641.8 \\
\hline 1988 & Two geothermal mobile units ot Chipilopo & 10 & 651.8 \\
\hline 1989 & Retirement gos unit & -6.6 & 645.2 \\
\hline 1991 & Two units ot 5 de Noviembre plont (hydro) & 120 & 765.2 \\
\hline 1992 & One geothermol Unit (BerIIn) & 55 & 820.2 \\
\hline & Retirement of two goothermal mobile units & -10 & 810.2 \\
\hline 1993 & One goothermal unit (Chipilopa) & 55 & 865.2 \\
\hline 1994 & One geothermal unit (San Vicente) & 55 & 920.2 \\
\hline 1995 & One geothermal unit (Chinameca) & 55 & 975.2 \\
\hline & One unit ot Cerron Grande plont (nydro) & 67.5 & 1042.7 \\
\hline 1996 & One coal-fired steam unit & 50 & 1692.7 \\
\hline 1997 & El tigre power plant (hydro) & 270 & 1362.7 \\
\hline 1999 & One cool-fired steam unit & 100 & 1462.7 \\
\hline 2000 & One cool-fired stoam unit & 100 & 1562.7 \\
\hline
\end{tabular}

and SOGREAH includes the construction of Zapotillo, Paso del 0so, San Marcos, and El Tigre, the expansion of the Fifth of November and Cerron Grande Projects, and the retirement of the Guajoya power plants. ${ }^{8}$ CEL has planned an investment program for these new projects (see Table 18). Approximately two-thirds of the total cost is expected to come from foreign investments.

As shown above and in the resource section, El Salvador has the resources, interest, and plans to develop a large amount of electrical generation capacity. With this development and government assistance, some rural citizens could switch from firewood to more efficient electrical stoves. This would help reduce the deforestation that is presently occurring.

4. Noncommercial Energy

a. Fuel wood and Charcoal. By far the most important energy source in El Salvador is noncommercial energy, most of which is fuel wood. As stated before, precise evaluation of these resources is not available. Because of the civil conflict, the needed survey of consumption in the rural areas has not been done. CEL currently estimates the fuel-wood supply by using an estimated consumption adjusted for population increases, plus an estimated consumption by the artisan industry and charcoal producers. Therefore, the reported fuel-wood supply is a rough estimate of what has been consumed within a specific year. 
TABLE 18

EL SALVADOR: CEL EXPANSION INVESTMENT PROGRAM

(Millions of US $\$$ )

$\begin{array}{rrrr}\text { Yegr } & \text { Lecol Investment } & \text { Eereign_Investment } & \text { Iotal } \\ 1985 & 0.5 & 5.8 & 6.3 \\ 1986 & 1.0 & 2.0 & 3.0 \\ 1987 & 5.4 & 15.7 & 21.1 \\ 1988 & 17.8 & 37.2 & 55.0 \\ 1989 & 36.7 & 76.1 & 112.8 \\ 1990 & 38.1 & 76.2 & 114.3 \\ 1991 & 33.1 & 64.6 & 97.7 \\ 1992 & 31.8 & 63.7 & 95.5 \\ 1993 & 41.7 & 92.0 & 133.7 \\ 1994 & 67.0 & 155.1 & 222.1 \\ 1995 & 57.1 & 130.3 & 187.4 \\ 1996 & 26.9 & 62.2 & 89.1 \\ 1997 & 26.1 & 59.4 & 85.5 \\ 1998 & 24.1 & 54.8 & 78.9 \\ 1999 & 7.2 & 16.3 & 23.5 \\ 101 \mathrm{AL} & 414.5 & 911.4 & 1325.9 \\ & & & \end{array}$

Source: CEL

The supply of fuel wood comes from harvested lumber from the forest, shrub forestry, and coffee shade-tree trimmings. INCAE states that rough estimates indicate that approximately 34 percent of the harvested forest woods is industrially processed and the remainder is used as fuel wood.

The shrub forests are the natural supply of fuel wood for rural consumers. However, in recent years the resource potential of shrub forestry is decreasing owing to other uses of 1 and (for example, cattle and urban development). The estimated amount of fuel wood obtained from this source varies between 4 and 5 cubic meters per hectare per year. CEL estimates this source contributed approximately 1.7 million tons in 1980 , but because of deforestation the supply has diminished each year. ${ }^{8}$

CEL estimated that trimmings from coffee shade trees provides approximately 1.2 million tons of fuel wood per year, depending upon the size of area planted with coffee. As with shrub forestry, declines are foreseen in the coffee shadetree supply of fuel wood. ${ }^{8}$ Coffee has traditionally been grown under shade; however, new varieties do not require shade trees. The sun-resistant coffee variety known as Pacas was introduced several years ago. It has a higher production rate than the commonly used Arabigo variety; however, it needs much more attention and use of pesticides and fertilizers. Because of the depressed 
economic situation of the country and the higher operating costs, the new variety accounts for only 1 percent of coffee plants. It is anticipated that it will remain at that level in future years. * Hence, in the short run, the fuelwood resource from coffee shade trees may be secure. However, as the economy improves and use of the Pacas variety expands, this supply source is expected to decrease.

According to CEL's officials who are now working on a fuel-wood project in the west part of the country that is funded by the Organization of American States (OAS), political, social, and economic conditions are at present having a much more important impact on fuel-wood supply than the introduction of sunresistant coffee varieties. Many of the plantations now owned by cooperatives have extended tree trimmings to every 3 or more years from the usual 1 year. In several cases, tree trimming has not been made at all. Therefore, while the resources exist, it may not be legally available to the consumer. Furthermore, internal migration caused by political unrest is leading to new urban- and semiurban developments that compete heavily for the use of fuel wood. These general conditions were identified in the western part of the country and are considered representative of the entire country.

The above supply sources are not able to cover the increasing demand. In 1982, it was estimated that the fuel-wood deficit was more than 1 million tons.

To counter these negative trends, a national reforestation program has been implemented. The program is carried out through planting projects on farms created by agrarian reform. The average size of these farms is 70 hectares. overall, price increases are expected in the future as a result of the decrease in fuel-wood supply. 8

CEL does not have an exact quantification for charcoal since it is a noncommercial fuel. Three tons of wood are required to produce 1 ton of charcoal, an average approximate yield of 33 percent in weight. Charcoal is used mainly for domestic and restaurant cooking. 8

b. Vegetable Residues. In recent years vegetable residues experienced an absolute increase in production and a larger consumption than hydroelectric energy. This situation can be improved upon still, if this product is predried before being used.

Information provided by Guillermo Selva T., Instituto Centroamericano de Administracion de Empresas, December 1985. 
Sugar-cane bagasse, coffee pulp, and coffee husks are included in the category of vegetable residues. Bagasse is used in the sugar industry to generate steam for the sugar refining plants, and coffee husks are used for the same purpose in the coffee industry.

C. Energy Demand

This section describes the consumption of each type of energy--which sectors of the economy use what type of fuel and the growth trends in consumption. An overview of how demand has changed over time is first presented, followed by detail on each sector.

CEL provides energy balance information for the following four sectors (1) residential-commercial, (2) industrial-agriculture, (3) transportation, and (4) other. During the 1980s, the residential-commercial sector consumed about 67 percent of the energy supplied, while industry and agriculture consumed about 17 percent (see Tables 19 through 21). The transportation sector is the third largest consumer and comprised just under 15 percent of final consumption. The remaining 1 to 2 percent of consumption is in a category entitled "other net consumption."

Since 1970, the relative consumption decreased in the residential and commercial sectors and increased in the transportation and industry/agriculture sectors. However, all sectors consumed more energy during the $1980 \mathrm{~s}$ than they did in 1970. The compounded average annual growth rate of energy use in the entire economy from 1970 to 1984 was 2.3 percent (see Table 22). Total energy consumption had grown at an almost 5 percent rate between 1970 and 1978, peaked in 1979, and then dropped 13 percent in 1980. The 1980 drop was mainly because of the world oil price increases and the beginnings of an international recession. In 1981, El Salvador's energy consumption decreased slightly from the 1980 consumption 1 eve1, but in 1982 it began to increase again. The 1984 consumption of 14.6 million barrels equivalent petroleum (BEP) was approximately equal to the 1977 consumption level, but still below the 1979 level, which peaked at 15.9 mi11ion BEP.

As with many other less-developed countries, the El Salvadoran economy is still heavily dependent upon traditional energy sources. In 1984, firewood, vegetable residues, and charcoal comprised about 70 percent ( 10 million BEP) of the total energy used in the country (see Table 20).

Possibly because of El Salvador's severe economic recession and the high world price for $0 i 1$, the portion of energy consumption supplied by vegetable residues increased during the $1980 \mathrm{~s}$. In the $1970 \mathrm{~s}$, almost no energy came from vegetable residues, but this edged up to roughly 6 percent in 1984 . Most 
TABLE 19

EL SALVADOR: 1984 ENERGY CONSUMPTION

(thousands of barrel equivalents of petroleum)

Energy Ixpe
Fuelwood
Vegetable residue
Electricity
Petroleum derivatives
Liquid gas
Gasoline
Kerosene/jet fuel
Diesel oil
Fuel oil
Subtotal
Non-Energy
Coal and coke
Charcoal
Total Consumption

Residential/

Commercial Iranspert

9034

0

383

190

0
115

0

8

304

8

0

9

9730
Industrial/

Agriculture

241

920

324

90

0
942

190

1001

0

2132

0

0

0

2132
0

18
228

228

708

1044

0

2

0

2531
Total Consumption Qther

$\begin{array}{rr}0 & 9275 \\ 0 & 920 \\ 136 & 842\end{array}$

Source: Country Energy Balance.

TABLE 20

EL SALVADOR: 1984 ENERGY CONSUMPTION (percentage of total)

Energy Tyre
Fuelwood
Vegetable residue
Electricity
Petroleum derivatives
Liquid gas
Gosoline
Kerosene/jet fuel
Diesel oil
Fuel oil
Subtotal
Non-Energy
Cool and coke
Charcoal
Total Consumption

Residentiol/
Cemmerciel

Iranspert
Industrial/

Agriculture
Total Consumption

Qther By Energy. Ixpe

Source: Reference 8 .

Note: Total may not add to 100 due to rounding. 
TABLE 21

EL SALVADOR: 1984 ENERGY CONSUMPTION

(percentoge of fuel use by sector)

\begin{tabular}{|c|c|c|c|c|c|}
\hline Enerax Iype & $\begin{array}{l}\text { Residential/ } \\
\text { Commercial }\end{array}$ & Iranspert & $\begin{array}{l}\text { Industriol/ } \\
\text { Agriculture }\end{array}$ & Qther & $\begin{array}{l}\text { Total Consumption } \\
\text { By Eneray Type }\end{array}$ \\
\hline Fue I wood & 97 & $\theta$ & 3 & 0 & 100 \\
\hline Vegetable residue & 0 & 0 & 100 & 0 & 100 \\
\hline Electricity & 45 & $\theta$ & 39 & 16 & 100 \\
\hline \multicolumn{6}{|l|}{ Petroleum derivotives } \\
\hline Liquid gos & 67 & 0 & 32 & 1 & 100 \\
\hline Gosoline & 0 & 100 & $\theta$ & 0 & 100 \\
\hline Kerosene/jet fuel & 35 & 59 & 6 & $\theta$ & 100 \\
\hline Diesel oil & 0 & 81 & 19 & $\theta$ & 100 \\
\hline Fuel oil & 0 & 0 & 98 & 2 & 100 \\
\hline Subtotal & 9 & 61 & 30 & 0 & 100 \\
\hline Non-Energy & $\theta$ & 0 & 0 & 100 & 100 \\
\hline Cool and coke & 0 & $\theta$ & 100 & 0 & 100 \\
\hline Charcool & 100 & $\theta$ & 0 & $\theta$ & 100 \\
\hline Total Consumption & 67 & 15 & 17 & 1 & 100 \\
\hline Source: Reference 8 . & & & & & \\
\hline
\end{tabular}

TABLE 22

EL SALVADOR: COMPOUNDED ANNUAL AVERAGE GROWTH RATE FOR ENERGY CONSUMPTION, BY SECTOR ANO SELECTED YEARS

$\begin{array}{lcccrr}\text { Iime Peried } & \begin{array}{c}\text { Residential } \\ \text { and commercial }\end{array} & \text { Iranspert } & \begin{array}{c}\text { Industriol } \\ \text { gnd Agrieulture }\end{array} & \begin{array}{r}\text { Qther } \\ \text { Ietal }\end{array} \\ 1970-1978 & 3.07 & 9.09 & 8.84 & 7.06 & 4.96 \\ 1978-1984 & 0.28 & -2.51 & -3.34 & -8.25 & -1.01 \\ 1980-1984 & 1.56 & 1.68 & -0.51 & 1.70 & 1.20 \\ 1970-1984 & 1.85 & 3.94 & 3.44 & .21 & 2.35\end{array}$

vegetable residue is consumed in industries that process agriculture commodities. This fuel substitution displays the capability of the El Salvadoran economy to adjust somewhat to the high world price of $0 i 1$.

As stated earlier, it has been estimated that the fuel-wood deficit in 1982 was more than 1 million tons. As consumption increases and the supply decreases owning to deforestation plus less trimmings from coffee shade trees, the deficiencies will likely increase. 
In 1984 petroleum products provided 24 percent of the total energy consumed in El Salvador. This percentage has steadily declined during the $1980 \mathrm{~s}$.

The remaining energy consumption of 5 to 6 percent is provided by electricity. The share of total energy consumption supplied by electricity has been slowly increasing over the past decade and may well provide a larger share of energy use in the future.

1. Residential-Commercial. For El Salvador the residential-commercial sector consumes by far the largest portion of energy. Within this sector, fuelwood is the dominant source of that energy, providing about 97 percent of the total energy consumption in 1984. CEL reported that over 3 million people consume this fuel in El Salvador, using approximately 3 kilograms per day of wood per person. As in other developing countries, the inefficient use of wood in food preparation is a fundamental cause of the high consumption. Food is often cooked over open fires with much heat loss, and efficiency is less than 10 percent in some cases. 8

The other types of energy consumed in this sector are electricity, which comprised about 4 percent of the 1984 total, and kerosene and liquid gas, which together comprised about 3 percent (see Table 19). Electricity and 1iquid gas are potential growth fuels for this sector because they are possible substitues for fuel-wood use in cooking. Indeed, from 1970 to 1984 the consumption of these two fuels almost tripled, and as fuel wood becomes more scarce and the government encourages substitution of other fuels, the use of electricity and liquid gas should continue to grow.

Overal1, after growing at an average annual rate of 3.1 percent between 1970 and 1978, the growth of energy use in this sector slowed to only 0.3 percent per year during 1978 to 1984 (see Table 22).

2. Industrial-Agricultural. The industrial-agricultural sector comprised a little more than 17 percent of the total energy consumption in the country in 1984 (see Table 21). Of this, 36 percent was vegetable residues, 10 percent was fuel wood, 41 percent was petroleum derivatives, and 13 percent was electricity. The industrial-agricultural use of fuel wood in absolute terms has remained roughly level since 1970. However, the use of vegetable residues has almost doubled, but is still well below its peak use in 1978. The 1984 electricity consumption is more than double the 1970 consumption 1evel, but as with vegetable residues, it is less than the 1978 consumption level.

In 1970, petroleum derivatives constituted almost 46 percent of this sector's energy use, by 1978 it increased to over 48 percent, but now it has decreased to 41 percent. Both substitution and conservation has contributed to 
the reduced use of each of the petroleum derivatives except diesel oil, the consumption of which has slightly increased since 1970. About 6 percent of electricity production is fueled by petroleum products and is required to service areas when transmission lines are downed as a result of the civil conflict. A peaceful settlement of the armed conflict would immediately conserve the oil imports currently used by these generators.

Industrial users of firewood are brickmakers, lime kilns, salt producers, pottery shops, bakeries, and charcoal kilns. The total fuel-wood consumption for the brick, lime, and salt industries does not exceed 3.5 percent of domestic energy consumption although these industries are considered high wood consumers. CEL reported that interviews with brickmakers were conducted to estimate total wood consumption in kilograms of wood consumed per brick made, the amount of bricks that are fired, and how many firings each brickmaker does per year. The resulting estimate was that a total of 47.1 million kilograms of firewood was consumed each year by this industry. Possibly with an expanded hydroelectric generating capacity, these 400 brickmaking businesses could be converted to electric kilns rather than firewood. A study is needed to determine the economics of this fuel switching, which may become economically feasible as the price of firewood increases.

Almost all the lime kilns are located in the department of Santa Ana, specifically in Metapan; this area was also surveyed by CEL. The survey encompassed approximately half of the lime kilns in the country. The average annual consumption of fuel wood is 145,329 kilograms of wood per oven. As with brickmakers, the lime kilns can also be converted to electricity.

Salt can be dried by the sun or by wood-burning ovens. A CEL survey was done for the eastern part of the country where almost all the salt producers use wood in their ovens. More than 10 businesses were surveyed to obtain the following information. The sea water is evaporated in shallow pots sitting on wood-burning ovens. One cart of wood is used to produce each pot of salt. The use of firewood began to decrease in the late 1970 s as the price of wood began to increase. Solar drying has been used as an economical substitute, and its use is expected to expand throughout the salt industry.

Pottery shops have also been high users of firewood in the recent past. Pottery shops are concentrated in the departments of Cabanas, Cuscatlan, San Miguel, and Morazan. This artisan activity is disappearing as more products are made of plastic. Data on the number of shops and production of clay objects was not available, so wood consumption could not be determined. 
3. Transportation. The transportation sector has been greatly affected by the civil conflict. At times the rural roads have been under the complete control of the rebels. The impacts of the conflict are also felt in the cities. A December 1985 Associated Press news report stated "Rebels have burned an estimated 900 buses since 1979 as a part of an economic sabotage campaign that has cost an estimated $\$ 1$ billion in direct damages. 9 These impacts, along with the military energy requirements, affect transportation fuel requirements. However, at this time, no estimates of the impacts are available.

In 1984, the transportation sector consumed almost 15 percent $(2.1$ million BEP) of the country's total energy (see Table 21). This percentage steadily increased from 11.7 percent in 1970 to 16.0 percent (2.5 million BEP) in 1978 but has since decreased to the 14 to 15 percent range. A 11 of this energy was a form of imported petroleum and for 1984 included diesel (47 percent), gasoline (44 percent), and kerosene and jet fuel (9 percent). Until 1984, a small share of the transportation energy requirements was supplied by fuel oil, but this share has since been eliminated.

Between 1970 and 1978 , the annual rate of increase for transportation energy was 9.1 percent, the highest growth rate for the three sectors for which El Salvador tabulates energy data. Then in 1980, owing to the recession and a sharp increase in world oil prices, transportation energy consumption decreased sharply by 540,000 BEP--a 21 percent decrease from the 1979 consumption level. At the same time, total energy consumption decreased only 12 percent; hence, the transportation sector's share of total energy consumption dropped from approximately 16 percent to 14.3 percent. This drop was expected and similar to what other countries experienced during this period, because transportation sectors are heavily dependent on petroleum and therefore are more directly impacted by the increased world oil prices.

Another small decrease in transportation energy consumption followed in 1981, but since then consumption has begun to increase each year. The 1982 increase of 3.7 percent in consumption actually preceded the economic recovery by 1 year. In 1984 the increase over the preceding year was 6.1 percent, mostly owing to increasing economic recovery and a softening of the world oil price. As a consequence of these high growth rates, transportation energy has again become a growing share of total energy consumed in El Salvador.

In 1984, transportation consumed approximately 61 percent of all the petroleum in the country (see Table 21). Conservation of oil or substitution of other energy sources in the transport sector is essential if oil imports are to be reduced. CEL is aware of this, and a study on conservation will be completed. However, preliminary data for 1984 indicate that private transportation 172 
consumes 68.4 percent $(747,302$ barrels) of gasoline and 7 percent $(83,842$ barrels) of diesel. The public transportation system, which includes taxies, pickups, and buses, consumes 14 percent $(151,467$ barrels) of gasoline and 55 percent $(644,154$ barrels) of diesel. Cargo trucks consume 18 percent $(194,332$ barrels) of gasoline and 38 percent $(438,637$ barrels) of diesel. In sum, private automobiles consume over two-thirds of the gasoline, whereas public transportation and trucking consume almost 93 percent of the diesel.

At this time, complete information is not available on the age, size, or fuel use of automobiles in the public or private sector. However, CEL has recently received a consultant's study on this topic and is analyzing the results. CEL reports there are no incentives to promote the use of public transportation rather than private automobiles. However, diesel fuel for bus transportation is highly subsidized, which is an indirect subsidy of public transportation.

There is a mandatory vehicle safety inspection program as a registration requisite for vehicles. These are annual inspections conducted by the General Directorate of Transit (Direccion General de Transit). 8 There are no maintenance requirements to improve fuel efficiency.

Heavy cargo is transported by truck or railroad, but data are not available to permit a determination of the percentage transported by each mode. Over the past 10 years the use of trucks has substituted for some rail transportation. 8 D. Energy Planning and Management

Since 1945, CEL has been responsible for the production, transmission and distribution of electricity, having sole responsibility in rural areas. The CEL Electrical Planning Division was established in 1974 as a requirement by the World Bank (WB) for the Cerron Grande project.

At the end of 1978 CEL created the Energy Division, whose initial tasks were related to the preparation of the National Energy Balances as a first step for the development of plans and energy policies. In 1979, the Nonconventional Resources Department was created within the Energy Division, with responsibilities for the research activities in solar and biogas energy resources.

In 1980, the Government modified the 1 aw pertaining to CEL in order to assign to CEL all responsibilities related to the energy sector in El Salvador. To comply with these new responsibilities, the Hydrocarbons Department was formed within the Energy Division. This was done in order to promote and control the exploration and development of hydrocarbon reservoirs as well as the transport of $0 i 1$ by pipelines and to oversee the imported crude oil and derivatives to satisfy the needs of the country. 
Also a Global Planning Division for overall energy planning was established within the Energy Division, and it is separate from the existing planning division for the electrical sector. The Electrical Planning Division provides information to the Global PIanning Division for integration into a national energy planning model. CEL's present electrical expansion plan came out in March 1985 and is being reviewed. Also CEL participated in the PIECA project to standardize energy balances for 1970 through 1984 using the OLADE format. CEL has produced their first energy plan entitled "Alternatives De Desarrollo Energetico, Plan Preliminar Periodo 1985-2000."

In order to improve their planning capabilities, CEL requested and received assistance from IDB. In the IDB/CEL project there were two phases: (1) compiling and generating information needed for integrated energy planning, and (2) analysis leading to an energy plan to be completed by May or June of 1986 . Phase 1 needed several energy consumption surveys, and some have been done, specifically those for the industrial, commercial, and transport sectors. In addition, a survey of urban consumption is almost completed, and one for the public sector is just beginning. The political situation has stopped the rural residential survey; therefore, little is known of firewood consumption.

The IDB/CEL Project was assisted by a consultant, who formulated the sectorial demand models. Two preliminary documents have been completed to describe the models. The consultant worked directly with the planning staff of CEL so that now CEL has preliminary demand models for each sector, which can be corrected and adapted as additional information becomes available from hired consultants. The models of the agriculture and rural residential sectors are incomplete because of a lack of critical information. CEL plans to integrate its demand, supply, and macroeconomic models to develop a national energy plan. However, current funding will not cover all energy planning needs. For example, al though some transport surveys are done, additional surveys are required. The transportation sector lacks historical data, and this deficiency will affect the ability to develop and calibrate models.

The models use Lotus 1-2-3 on IBM microcomputers including PCs, XTs, and ATs. CEL has 11 PCS in Global Planning Department, along with a mix of IBM XTs and ATs for a total of 29 microcomputers. CEL chose Lotus 1-2-3 because of versatility and ease of use. Each sector analyst manipulates his or her own sectorial data. Interconnection of microcomputers to a central unit (IBM 4330) is planned. Also, for several years CEL has used WASP III for electrical planning in the Electrical Planning Division and wishes to interconnect it to the system. This division received no funding for computers through the IDB project 
(the funding went to the Global Energy Planning Division). The Electrical Planning Division needs two IBM XTs with 256K RAM as well as software and training. 8

CEL has funding for energy audit personnel, but not for the needed equipment. They have tried to borrow or rent the equipment, with no success. For planning purposes, CEL needs results quickly, so they are going to do audits based on survey results and refine the data as equipment becomes available. In order to obtain information on fuel-wood resources, CEL is considering the possibility of producing a vegetation map from LANDSAT data.

\section{SUMMARY AND RECOMMENDATIONS}

A. Summary

El Salvador's principle energy resources are hydroelectric and geothermal energy. Estimates place the additional potential hydroelectric capacity of the country's major river (Rio Lempa) at $955 \mathrm{MW}$; some $412 \mathrm{MW}$ of capacity is currently installed. Geothermal electricity generation capacity has been estimated to be at least $240 \mathrm{MW}$ beyond the $95 \mathrm{MW}$ that have already been developed.

The dominant source of energy supply is fuel wood, which comprises about 65 percent of the total supply. The second largest source is imported petroleum; it makes up about 25 percent of total energy supply. Electricity and biomass (such as residual vegetable matter) constitute the remaining 10 percent.

The residential-commercial sector in El Salvador consumes more energy than al1 the other sectors combined. In 1984, its consumption constituted about 67 percent of the total consumption, whereas the industrial and transport sectors made up only about 16 percent each.

This report has elucidated several key energy problems facing El Salvador. They are (1) energy vulnerability, (2) fuel-wood shortages and continued high consumption, and (3) the decline in electicity production of the Ahuachapan geothermal project.

El Salvador's internal conflict has caused heavy losses to the energy infrastructure, particularly in the electrical grid. Power lines are periodically knocked down, causing blackouts or brownouts in the urban areas. Although the country has significant hydroelectric resources, most are located in, or would have power lines which cross, areas under rebel influence. Consequently, development of these resources will not be feasible until a stable national transmission grid can be maintained. At present the power outages force CEL to use thermal electric generation, which is more costly than hydroelectric power both in terms of cost per kilowatt hour and because of the use of foreign oil. 
A serious fuel-wood crisis is developing in El Salvador. The country is the most densely populated mainland nation in the Western Hemisphere--the 1984 density was estimated to be 579 persons per square mile. This, coupled with the continued rapid population growth and the flight to the cities caused by the internal conflict, has precipitated fuel-wood shortages in both urban and rural areas. At the present time, only about 8 percent of the rural population is served by electricty, so electric stove cooking is not a feasible alternative in the rural regions unless an expansion of the grid is undertaken.

The development of the El Salvador energy sector and the economy in general is hindered by a lack of foreign exchange that is necessary for the purchase of important capital goods. $0 i 1$ import purchases currently represent about 14 percent of the value of total exports, and the service on external debt is equal to about 4 percent of GDP. (In Costa Rica, where there is a more pronounced foreign exchange problem, debt service is 20 percent of GDP.) However, military spending and repair of the infrastructure currently diverts money from more development-oriented pursuits such as grid expansion.

A final energy problem facing El Salvador is the steady decline in field pressure of the Ahuachapan geothermal site and the subsequent decline in electricity production. The site is now generating about $42 \mathrm{MW}$, equal to half of its rated capacity of $95 \mathrm{MW}$. Technical studies are necessary to determine the causes and the possible solutions to the problem.

\section{B. Recommendations}

El Salvador's energy problems are among the most severe in the region. The energy problems are unique because they stem from the armed conflict and the resulting energy vulnerability of the electricity grid and transportation system. The full capacity of the hydroelectric and geothermal power stations cannot be used because of the inability of the grid system to transmit the electricity. The public transportation system has suffered because many buses have been destroyed in the continuing conflict. Potentially, the country could have the most serious fuel-wood problem in the region, but fuel-wood consumption in rural areas cannot even be quantified because of the danger of conducting a survey in many rural areas. On the positive side, El Salvador has one of the

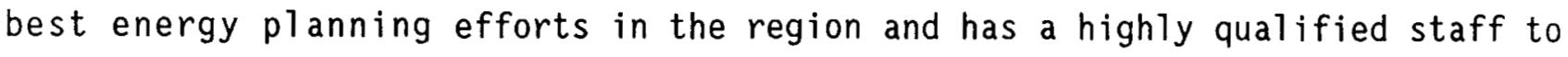
deal with the country's unique problems. The recommendations to AID for assistance to El Salvador are strongly influenced and limited by the options available to improve the energy situation under the present circumstances. 
The recommendations are the following:

Continue assistance to CEL for repair of power lines.

AID has al ready contributed a substantial amount of assistance to help alleviate serious energy problems in the region.

- Assist CEL in addressing production declines from the Ahuachapan geothermal field and in the development of other geothermal fields in the west of the country.

The Ahuachapan and Chipilapa geothermal sites are located in the western part of the country and are less vulnerable to attack. However, serious production declines have occurred at Ahuachapan. It is recommended that AID support assistance to log wells, improve the reservoir model with the data obtained from well logging, and design an optimal reinjection plan for the waste geothermal fluids. Reinjection at optimal locations should increase reservoir pressure in the field and help to restore production. In addition, technical and planning assistance is needed to help site new production wells at the Ahuachapan and Chipilapa geothermal fields.

- Provide support to CEL in definition of the country's fuel-wood resources and in the formulation of policies to address fuel-wood problems.

El Salvadoran planners cannot quantify fuel-wood resources and consumption because of lack of access to many areas of the country. Construction of a forest map may be possible from LANDSAT or aerial photos. CEL will need financial assistance to purchase the necessary equipment to interpret the imagery and to train technicians in its use. Alternatively, such a map could be produced by experts in the US and given to CEL. The technical and economic feasibility of this option needs to be further evaluated before a strong recommendation can be made. Because the country faces a potentially severe fuel-wood shortage, policies necessary to encourage fuel-wood substitution should be identified and evaluated.

- Assist CEL in the formulation of policies to improve the efficiency of energy use by industry.

CEL has aggregate information on energy consumption by industry but needs help on energy audits to obtain more detailed information. The resulting data would be used to formulate policies to improve efficiency of energy use by industry. El Salvador has well-trained industrial ists who may be very amenable to adopting changes or new technologies that will improve operating efficiencies. Thus, the potential for more efficient energy use in industry is greater than in some of the other countries. However, some industrialists may need financial assistance for recommended investments. 
- Provide assistance to CEL for follow-on planning work to complement the activities of the IDB.

A large energy-planning assistance project funded by the IDB has recently ended in El Salvador. Although CEL is a strong energy-planning organization, it is anticipated that projects will be identified that could benefit from technical assistance. One such project is an integrated study of energy prices in the country. As in other countries, artificial pricing policies may encourage inefficient use of energy. A study to determine relative and absolute prices is needed.

\section{REFERENCES}

1. "Jorge I. Dominguez and Marc Lindenberg, "Central America: Current Crisis and Future Prospects," Foreign Policy Assoc. Headline Series No. 271 (1984).

2. "Economic Indicators 1980-84," Central Reserve Bank of El Salvador, p. 2.

3. Howard I. Blutstein, Elinor C. Betters, John Cobb, Jr., Jonathan A. Leonard, and Charles M. Townsend, El Salvador - A Country Study, (The American University, Washington, DC, 1979).

4. Economic and Social Progress in Latin America, Economic Integration - 1984 Report (InterAmerican Development Bank, Washington, DC) pp. 292-297.

5. Providing Effective Economic Assistance to ET Salvador and Honduras, (General Accounting Office, USA, July 3, 1985) pp. 27-29.

6. "El Salvador in Perspective," El Salvador News Gazette, August 13-19, 1985.

7. AAPG Bulletin, El Salvador section, October 1976-1980, 1982, and November 1981 .

8. Eric Casamiquela, "Response to LANL Questionnaire," unpublished report, Comision Ejecutiva Del Rio Lempa, San Salvador, El Salvador, September 1985.

9. "Salvador Seeks Aid from U.S. Cities," Albuquerque Journal, December 4, 1985. 


\section{GUATEMALA}

\section{CONTENTS}

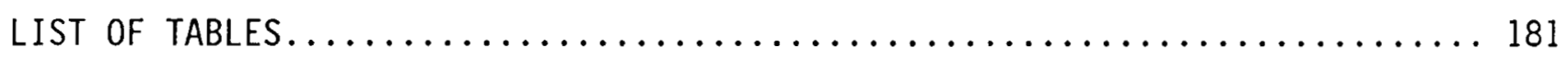

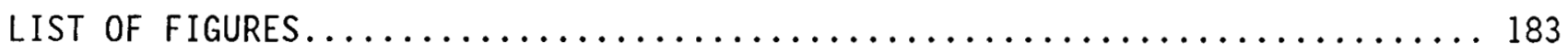

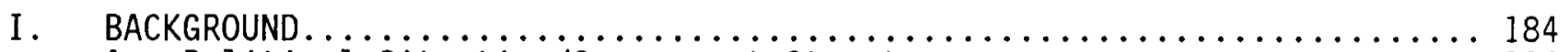

A. Political Situation/Government Structure.......................... 184

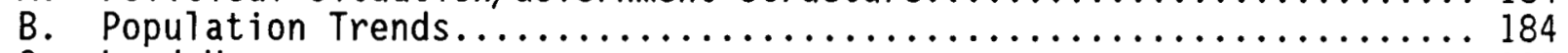

C. Land Use............................................... 185

D. Cultural Aspects....................................... 185

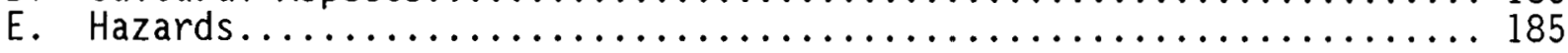

II. ECONOMIC SITUATION OVERVIEW................................ 186

A. Basic Characteristics of the Economy......................... 186

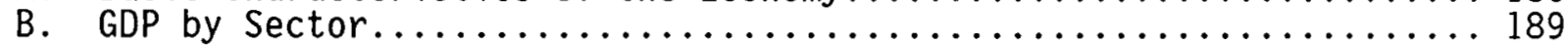

C. External Sector................................................. 190

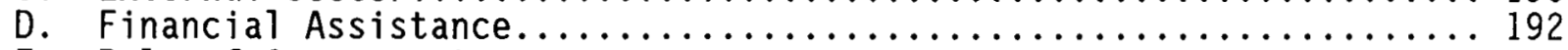

E. Role of Government........................................... 195

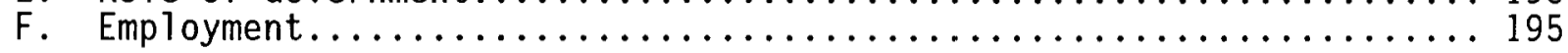

III. ENERGY OVERVIEW........................................ 196

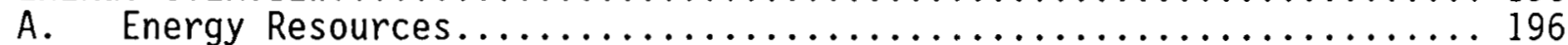

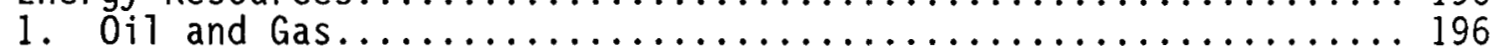

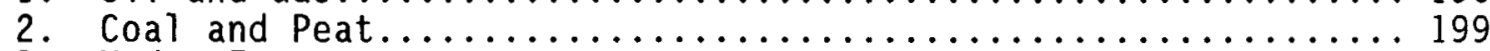

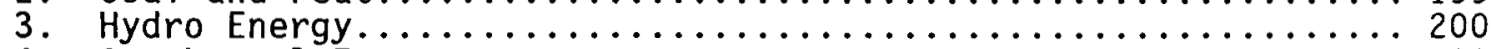

4. Geothermal Energy............................................. 200

5. Fuel wood and Other Biomass.............................. 203

6. Other Resources.................................... 203

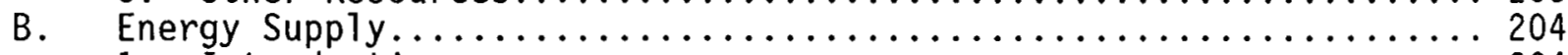

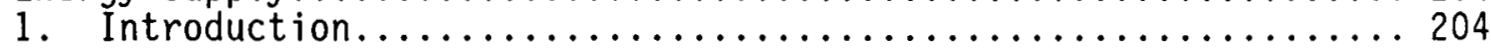

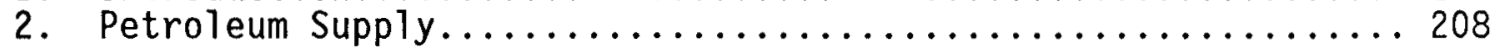

a. 0 il Product Prices............................. 210

b. $0 i\rceil$ Refining................................... 212

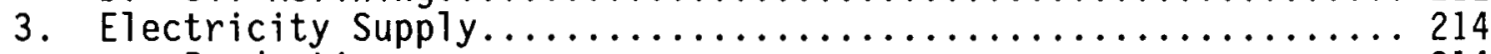

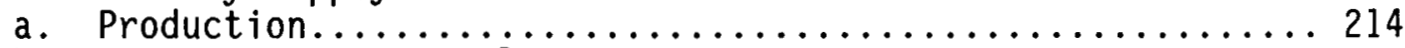

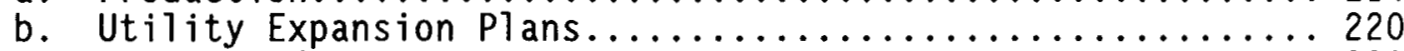

c. Prices and Costs............................... 221

4. Noncommercial Energy Supply......................... 223

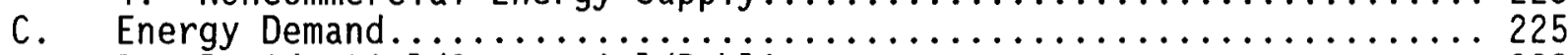

1. Residential/Commercial/Pubi ic ........................... 228

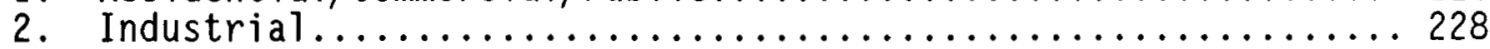

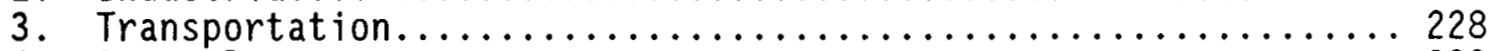

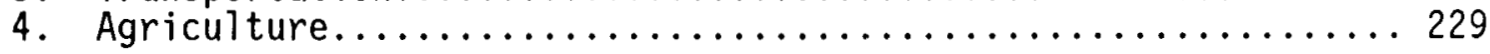




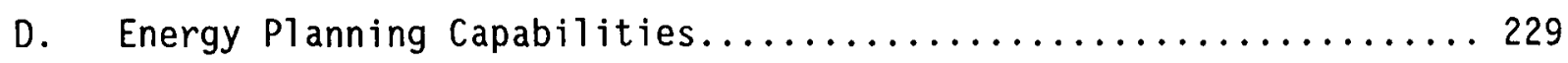

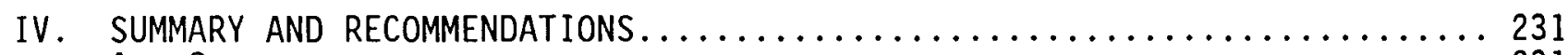

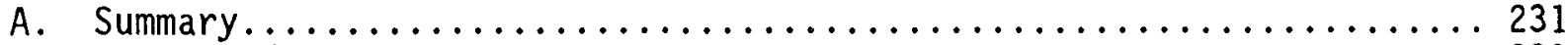

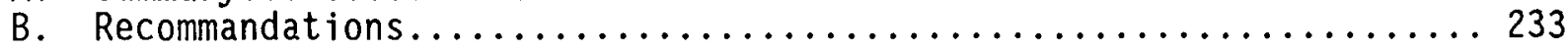

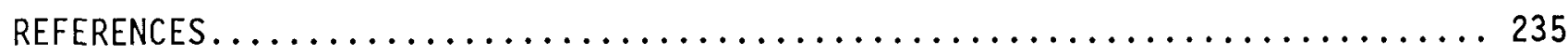




\section{LIST OF TABLES}

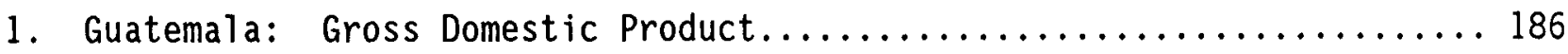

2. Guatemala: Exports and Imports (percentage of total) ............ 187

3. Guatema1a: Gross Domestic Product Growth Rates................... 188

4. Guatemala: Sectorial Contribution to Gross Domestic Product......... 188

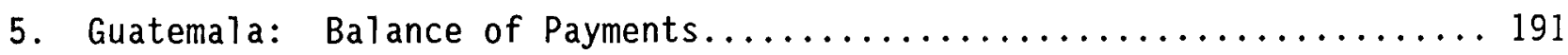

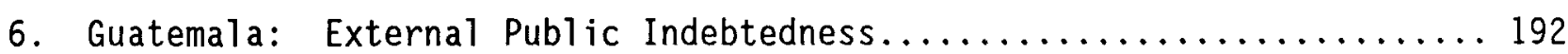

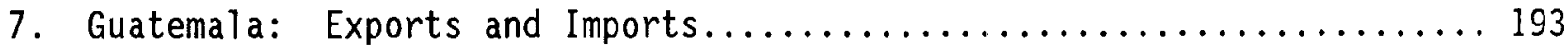

8. Guatema1a: Growth Rates for Exports and Imports................... 194

9. U.S. and International Aid to Guatemala......................... 195

10. Guatemala: Crude 0il Production Statistics..................... 197

11. Guatemala: Production Volume of Natural Gas..................... 200

12. Guatemala: Economically Recoverable Hydroelectric Energy Through

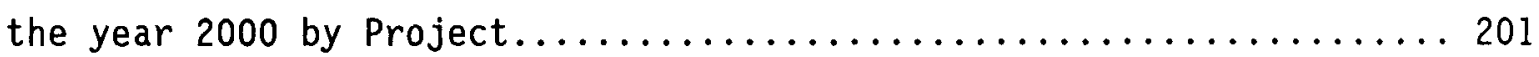

13. Guatemala: Wind Energy Potential and Statistics at Selected Sites.... 204

14. Guatema7a: Energy Supply to Final Demand..................... 206

15. Guatemala: Average Annual Compounded Growth Rates for Energy Supply... 207

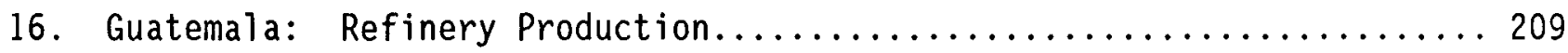

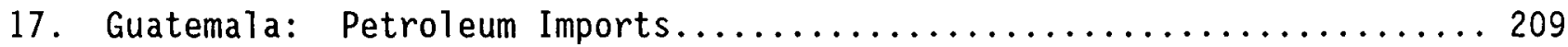

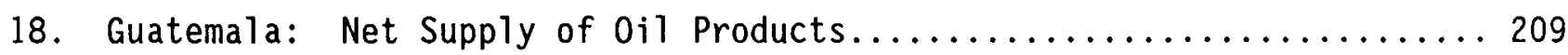

19. Guatema1a: Percentage of Petroleum Imports by Product............ 210

20. Guatemala: Percentage of Total 0il Products Supplied by Refinery..... 210

21. Guatema1a: 0i1 Product Prices in Guatemala City.................. 211

22. Guatemala: Installed Refinery Production Capacity by Product for 1983. 212

23. Guatemala: Percentage of Total Refinery Production by Product....... 213

24. Guatemala: Installed Electric Generating Capacity............... 215

25. Guatemala: Installed Capacity of Plants in Service, $1983 \ldots \ldots \ldots \ldots .216$

26. Guatemala: Cost of Capacity and Energy at Recently Completed

and $\mathrm{Planned}$ Electricity Projects......................... 217

27. Guatema1a: INDE Investment Program, 1987-1993............... 218

28. Guatemala: EEGSA Investment Program, 1987-1993................ 219

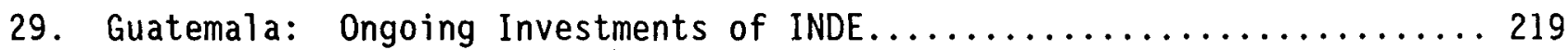

30. Guatemala: Distribution Grid Constructed in $1983 \ldots \ldots \ldots \ldots \ldots \ldots . \ldots 220$

31. Guatemala: Electricity Generation (Interconnected System).......... 221

32. Guatemala: Fuels Consumed for Electrical Generation.............. 222

33. Guatemala: Number of Customers in the Interconnected System......... 222 
34. Guatemala: Price of Electricity by Sector................... 224

35. Guatemala: Cost of 0 il Used by INDE and EEGSA, 1983 and $1984 \ldots \ldots \ldots 224$

36. Guatemala: Wood Supplied to Final Demand.................... 225

37. Guatemala: Compounded Annual Average Growth Rates for Energy Consumption, by Sector and Selected Years.................. 226

38. Guatema1a: 1984 Energy Consumption (thousands of BEP)........... 226

39. Guatemala: 1984 Energy Consumption (percentage of total) ......... 227

40. Guatemala: 1984 Energy Consumption (percentage of fuel

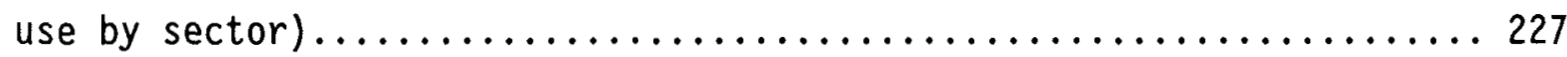




\section{LIST OF FIGURES}

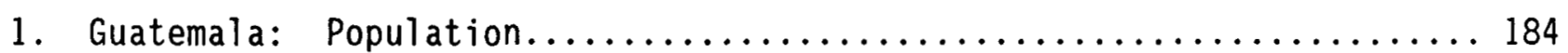

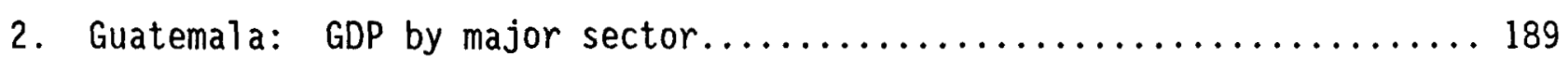

3. Guatemala: Labor force by sector for $1980 \ldots \ldots \ldots \ldots \ldots \ldots \ldots \ldots . \ldots \ldots$

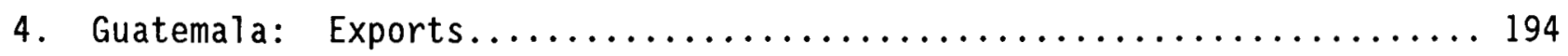

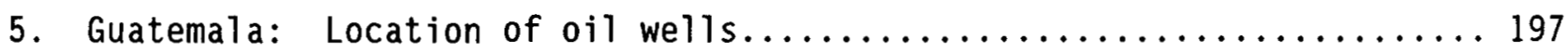

6. Guatemala: Location of geothermal sites..................... 202

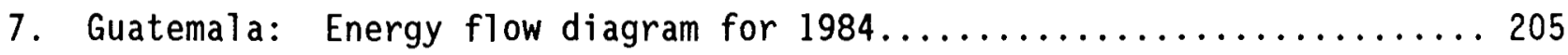

8. Guatema7a: Energy supply by fuel type..................... 206

9. Guatemala: Installed electric generating capacity............... 215

10. Guatemala: Organizational Chart of the Ministry of Energy and Mines... 230 


\section{BACKGROUND}

\section{A. Political Situation/Government Structure}

Guatemala recently elected and installed its first constitution in over 30 years. The new civilian government faces many political and economic challenges. The country is just beginning to recover from the worldwide economic recession of the early 1980s. The new administration is implementing social and economic programs in an effort to stimulate growth.

\section{B. Population Trends}

Population statistics for Guatemala are relatively scarce, so identifying growth and trends is difficult. The average annual population growth rate for the $1970 \mathrm{~s}$ and $1980 \mathrm{~s}$ is estimated to have been about 2.5 percent. The projected population for 1983 was about 7.6 million (see Fig. 1), the largest in Central Amercia. Children are highly valued among Guatemalans and birth control is used by less than 20 percent of child-bearing-age women. On average, there are 3.4 1 ive births per woman 15 to 45 years of age. ${ }^{1}$

Urban migration was significant during the 1950 s and 1960 s but has begun to slacken in recent years. The reasons for this movement out of rural areas are typical: dwindling land inheritance among the Indians, lack of employment, severe poverty, and few opportunities to increase the standard of living. In general, Latins are more likely to move to urban areas than Indians, and women are more likely to migrate than men. The lowest income groups live in the

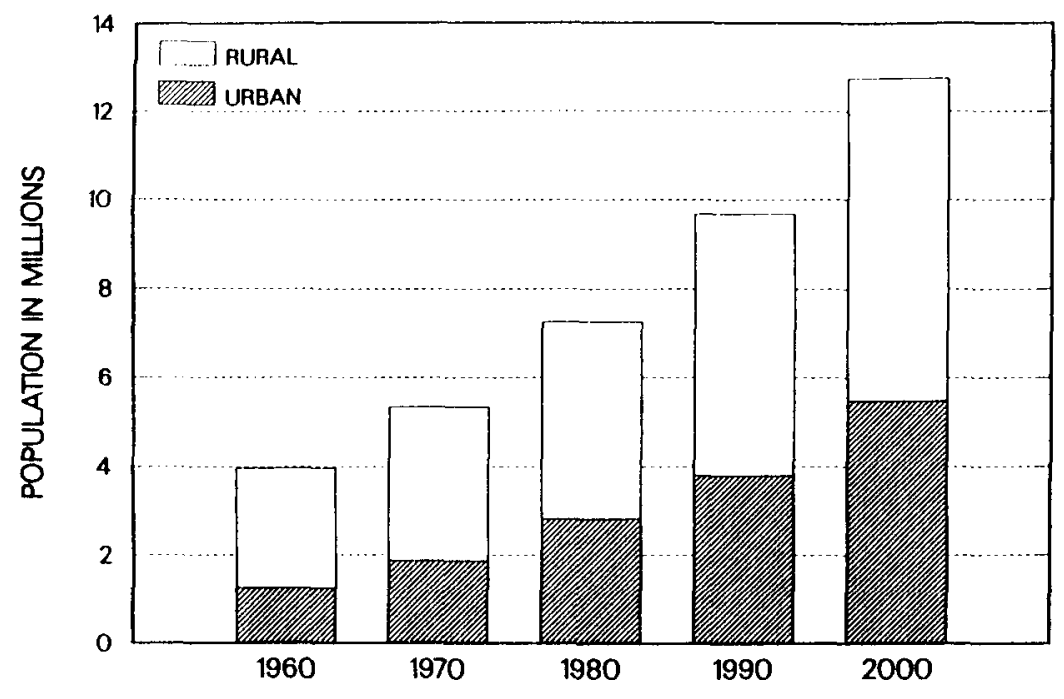

SOURCES: WORLD BANK. UNIVEASTTY OF CAUIFORNIA LATN AMERICAN CENTER

Fig. 1. Guatemala: Population. (Population is projected for 1990 and 2000.) 
western highlands, where 70 percent of the Indians live; Latins comprise about 80 percent of the urban population. 1

Health care is minimal, especially in the rural areas where the child mortality rate is high. Indeed, about 80 percent of the doctors 1 ive in Guatemala City, where only 20 percent of the population resides. This contributes to the low 1 ife expectancy of rural Indians--about 10 to 15 years less than Latins.

c. Land Use

Guatemala has a varied geography that ranges from the hot, humid lowlands of Peten, to the cold highlands (which has peaks of up to 4,200 meters). Because of the range in climate, nearly all Western Hemisphere crops can be grown. The Pacific coastal plains are very fertile, and a wide variety of export crops such as coffee, cotton, sugar, and bananas are grown there using modern agricultural methods.

The slopes between the Pacific plains and the highlands are covered with broadleaf forests and volcanic soils that are excellent for coffee growing. The Caribbean coastal lands and valleys are also characterized by dense forests, but the soil there is mainly calcareous. The valleys run inland from the Caribbean coast and are key transportation routes for the country.

\section{Cultural Aspects}

Guatemala is the only Central American country with a substantial remnant of the indigenous Indian culture; descendents of the ancient Maya represent about 60 percent of the total population. The Latin and Indian cultures do not mix easily and few Indians have become successful in the Latin-dominated culture.

It is estimated that about 40 percent of the rural labor force was 1 andless during the $1970 \mathrm{~s}$. This contributed to the massive influx of rural poor to the cities and the subsequent urban housing shortages and growth of shanty towns.

E. Hazards

Guatemala is located where five major tectonic plates meet and thus is subject to periodic earthquakes, some of which are severe. The old capital city of Antigua was destroyed by earthquakes in 1717 and 1773, and the second largest city, Quezaltenango, was heavily damaged in 1902, as was much of Guatemala City in 1918. The most recent severe quake occurred in 1976 and caused substantial damage. An estimated 30,000 people were killed, 77,000 were injured, and one million were left homeless (about 20 percent of the population). Other hazards are the monsoonal wind that blows in from the Pacific during the rainy season and Caribbean hurricaines that often cause damage to crops and existing infrastructure. The possibility of volcanic eruptions pose another threat to limited population areas in Guatemala. 


\section{ECONOMIC SITUATION OVERVIEW}

\section{A. Basic Characteristics of the Economy}

Guatemala is still in a relatively early stage of economic development; its GDP in 1984 was just over 9350 million quetzales (see Table 1). At the official exchange rate of one quetzal per dollar, this represents a per capita income equivalent to \$1146 US. However, a parallel exchange market has been established in which 2.5 to 3.0 quetzales equal one dollar. (The rate has varied considerably during the past year.) In the parallel market, the per capita income is equivalent to only $\$ 382$ US. Neither dollar figure is truly representative of the purchasing power of the per capita income in Guatemala because the market basket is composed of a mixture of imported and domestic goods; i.e., the standard of living decreased by less than a factor of three when the parallel exchange rate increased from 1 to 3 quetzales per dollar. The prices of some imported goods, such as oil products, have risen sharply owing to the devaluation in the parallel market. Increases in the price of some imported goods fuel inflation in the country and may lead to price increases in domestic goods as well. The dollar figures reported by the Inter-American Development Bank (IDB) are used in the overview section of this report, and the

TABLE 1

GUATEMALA: GROSS DOMESTIC PRODUCT

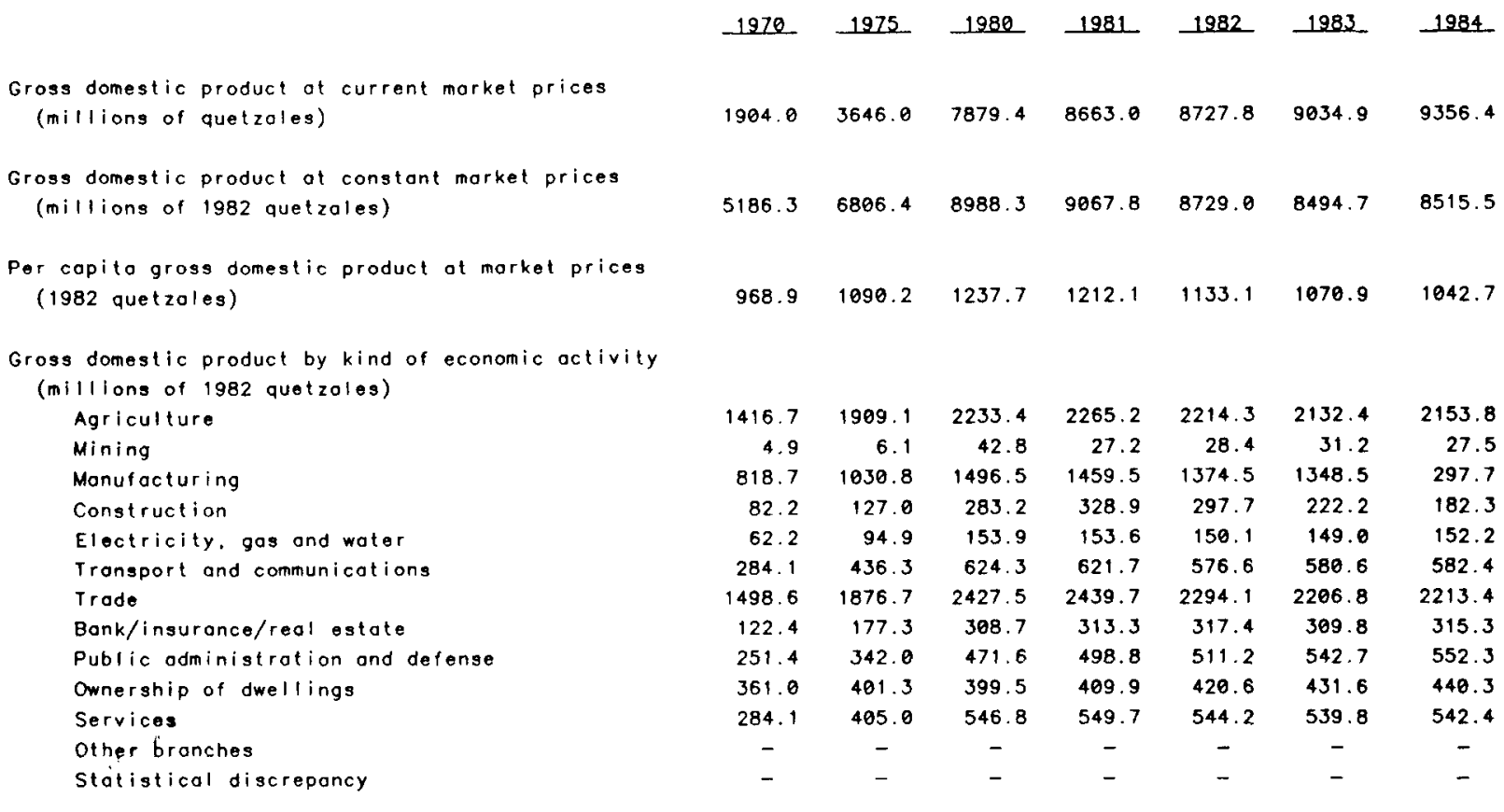

Source: World Bank. 
IDB continued to use a rate of 1 quetzal per dollar through 1984. The International Monetary Fund (IMF) continues to report a market exchange rate of 1 to 1 through 1986. The country's highly skewed income distribution means that the per capita income does not provide a very clear picture of the economic well-being of the average citizen. In early 1983, President Rios Montt said that about 3 million people--40 percent of the population--had annual incomes of less than $\$ 200$ US and another 2.5 million earned less than $\$ 450$ US. $^{1}$

The Guatemalan economy is heavily dependent on a few export commodities-coffee and sugar constituted about 40 percent of total export earnings in 1984 (see Table 2). In addition, the country strongly depends on the rest of the world for oil and consumer/capital goods. Thus, the internal economic situation is largely determined by external markets and the terms of trade.

Favorable world markets for Guatemala's major export commodities led to an average annual economic growth of about 5.6 percent during the 1970 s (see Table 3). Although the terms of trade began declining in the 1970s, initially the economy did not suffer much because the rebuilding after the 1976 earthquake provided substantial stimulation to domestic demand. However, after this boom ended in 1978, the economy began slowing owing to competitive foreign markets, increased military opposition within the country, and the oil price hike of 1979. Real GDP actually declined 3.7 percent in 1982 after a very slow 0.9 percent growth the previous year (see Table 3 ).

The sectorial split of GDP has not changed much since 1970, as shown in Table 4 and Fig. 2. The only clear trend appears to be the slight decline in importance of agriculture, which went from 27.3 percent of GDP in 1970 to 25.3 percent in 1984. Trade's share of GDP has also declined about 3 percent in

\begin{tabular}{|c|c|c|c|c|c|c|}
\hline \multicolumn{4}{|c|}{$\begin{array}{l}\text { GUATEMALA: EXPORTS AND IMPORT } \\
\text { (percentoge of tolol) }\end{array}$} & \multirow[b]{2}{*}{1982} & \multirow[b]{2}{*}{1983} & \multirow[b]{2}{*}{1984} \\
\hline 1970 & 1975 & 1980 & 1981 & & & \\
\hline 100.0 & 100.0 & 100.0 & 100.0 & 100.0 & 100.0 & 100 \\
\hline 34.4 & 25.9 & 29.9 & 23.6 & 30.7 & 29.5 & 32.4 \\
\hline 2.9 & 18.0 & 4.5 & 6.8 & 2.3 & 10.7 & 6.3 \\
\hline 9.1 & 11.8 & 10.7 & 10.4 & 6.8 & 4.2 & 6.7 \\
\hline 7.2 & 5.4 & 5.3 & 6.3 & 9.5 & 6.0 & 5.0 \\
\hline 4.3 & 2.6 & 1.9 & 2.3 & 1.3 & 1.3 & 1.1 \\
\hline 42.1 & 36.3 & 47.7 & 50.6 & 49.4 & 48.3 & 48.5 \\
\hline- & 9.5 & 9.2 & 11.5 & 10.9 & 17.4 & 11.7 \\
\hline
\end{tabular}


TABLE 3

GUATAMALA: GROSS DOMESTIC PRODUCT GROWTH RATES

(percentage based on 1982 quetzoles)

$\begin{array}{rrrrrrr}1970-1975 & 1975-1980 & 1980 & 1981 & 1982 & 1983 & 1984 \\ 5.6 & 5.7 & 3.7 & 0.9 & -3.7 & -2.7 & 0.2 \\ & & & & & & \\ 6.1 & 3.2 & 1.6 & 1.4 & -2.2 & -3.7 & 1.0 \\ 4.5 & 47.6 & 71.9 & -36.4 & 4.4 & 9.9 & -11.9 \\ 4.7 & 7.7 & 5.7 & -2.5 & -5.8 & -1.9 & 0.4 \\ 9.1 & 17.4 & 3.7 & 16.1 & -9.5 & -25.4 & -18.0 \\ 8.8 & 10.2 & 2.3 & -0.2 & -2.3 & -0.7 & 2.1 \\ 9.0 & 7.4 & 8.2 & -0.4 & -7.3 & 0.7 & 0.3 \\ 4.6 & 5.3 & 1.7 & 0.5 & -6.0 & -3.8 & 0.3 \\ 7.7 & 11.7 & 4.5 & 1.5 & 1.3 & -2.4 & 1.8 \\ 6.3 & 6.6 & 10.6 & 5.8 & 2.5 & 6.2 & 1.8 \\ 2.1 & -0.1 & 3.0 & 2.6 & 2.6 & 2.6 & 2.0 \\ 7.3 & 6.2 & 3.7 & 0.5 & -1.0 & -0.8 & 0.5 \\ - & - & - & - & - & - & - \\ - & - & - & - & - & - & -\end{array}$

Source: World Bank.

TABLE 4

GUATAMALA: SECTORIAL CONTRIBUTION TO GROSS DOMESTIC PRODUCT (percentoge bosed on 1982 quetzoies)

\begin{tabular}{|c|c|c|c|c|c|c|c|}
\hline & 1970 & 1975 & 1980 & 1981 & 1982 & 1983 & 1984 \\
\hline \multicolumn{8}{|c|}{ Gross domestic product by kind of economic activity } \\
\hline Agriculture & 27.3 & 28.0 & 24.8 & 25.0 & 25.4 & 25.1 & 25.3 \\
\hline Mining & 0.1 & 0.1 & 0.5 & $\theta .3$ & 0.3 & 0.4 & 0.3 \\
\hline Manufacturing & 15.8 & 15.1 & 16.6 & 16.1 & 15.7 & 15.9 & 15.9 \\
\hline Construction & 1.6 & 1.9 & 3.2 & 3.6 & 3.4 & 2.6 & 2.1 \\
\hline Electricity, gas and water & 1.2 & 1.4 & 1.7 & 1.7 & 1.7 & 1.8 & 1.8 \\
\hline Transport and communications & 5.5 & 6.4 & 6.9 & 6.9 & 6.6 & 6.8 & 6.8 \\
\hline Trode & 28.9 & 27.6 & 27.0 & 26.9 & 26.3 & 26.0 & 26.0 \\
\hline Bonk/insurance/real estate & 2,4 & 2.6 & 3.4 & 3.5 & 3.6 & 3.6 & 3.7 \\
\hline Public odministration and defense & 4.8 & 5.0 & 5.2 & 5.5 & 5.9 & 6.4 & 6.5 \\
\hline Ownership of dwellings & 7.0 & 5.9 & 4.4 & 4.5 & 4.8 & 5.1 & 5.2 \\
\hline Services & 5.5 & 6.0 & 6.1 & 6.1 & 6.2 & 6.4 & 6.4 \\
\hline Other branches & - & - & - & - & - & - & - \\
\hline Statistical discrepancy & - & - & - & - & - & - & - \\
\hline
\end{tabular}

Source: World Bank 


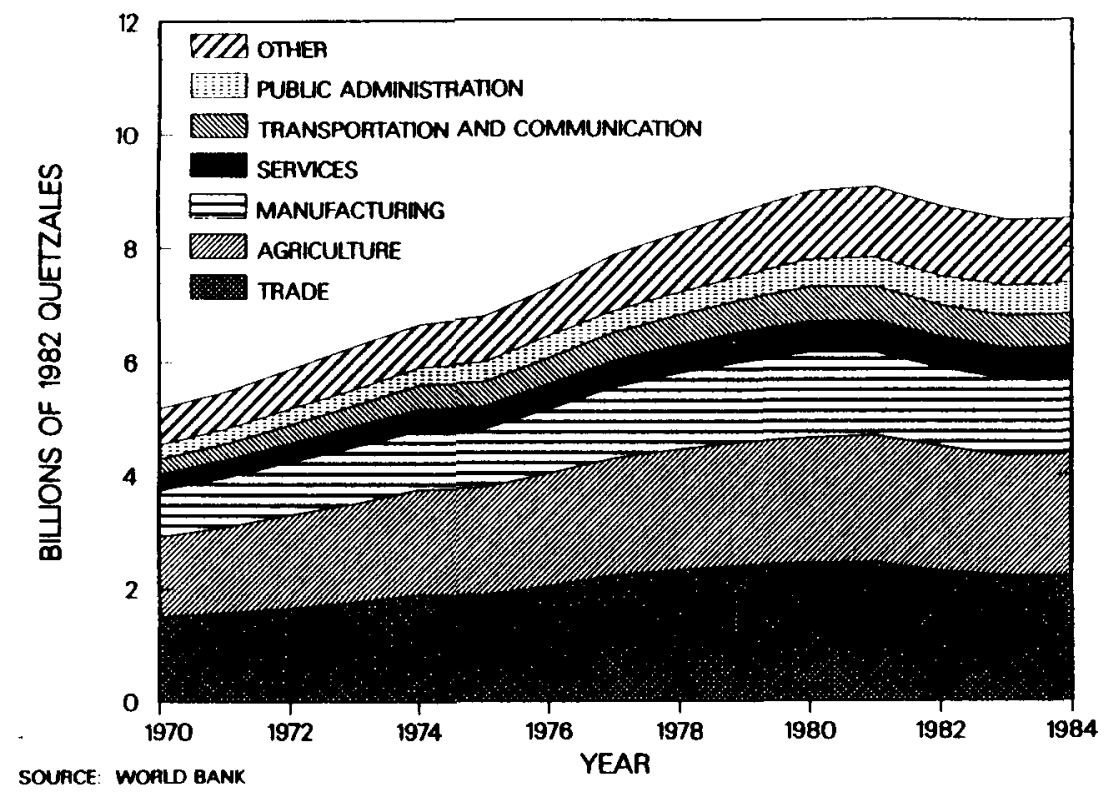

Fig. 2. Guatemala: GDP by major sector.

that same time period. The key growth sectors are construction, transport and communication, and public administration and defense.

\section{B. GDP by Sector}

Guatemala is basically an agrarian society. Although in 1984 about onequarter of the GDP was generated through farming, this sector employed over onehalf of the labor force (see Fig. 3). A few large estates producing export commodities comprise most of the output value, and the subsistence plots are often too small to support a family. From 1970 to 1975 , the agriculture sector grew at an average of 6.1 percent annually, but the growth slowed to only 3.2 percent during the subsequent five years and was even lower in the 1980 s. During the recession ${ }^{2}$ the sector declined by 2.2 percent in 1982 and 3.7 percent in 1983 (see Table 3).

The manufacturing sector comprised about one-sixth of GDP in 1984 (see Table 4) and consisted mainly of small handicraft shops and a few large producers that made up the bulk of the value of output. Consumer goods such as food products and beverages are the dominant output.

Guatemala's manufacturers fared well while the Central American Common Market was operating, and even after it collapsed, industrial growth remained high. The decade of the 1970s saw manufacturing growing at an annual average of 6.2 percent, and the rate actually increased in the latter five years: 7.7 percent from 1975 to 1980 versus 4.7 percent from 1970 to 1975 (see Table 3). 


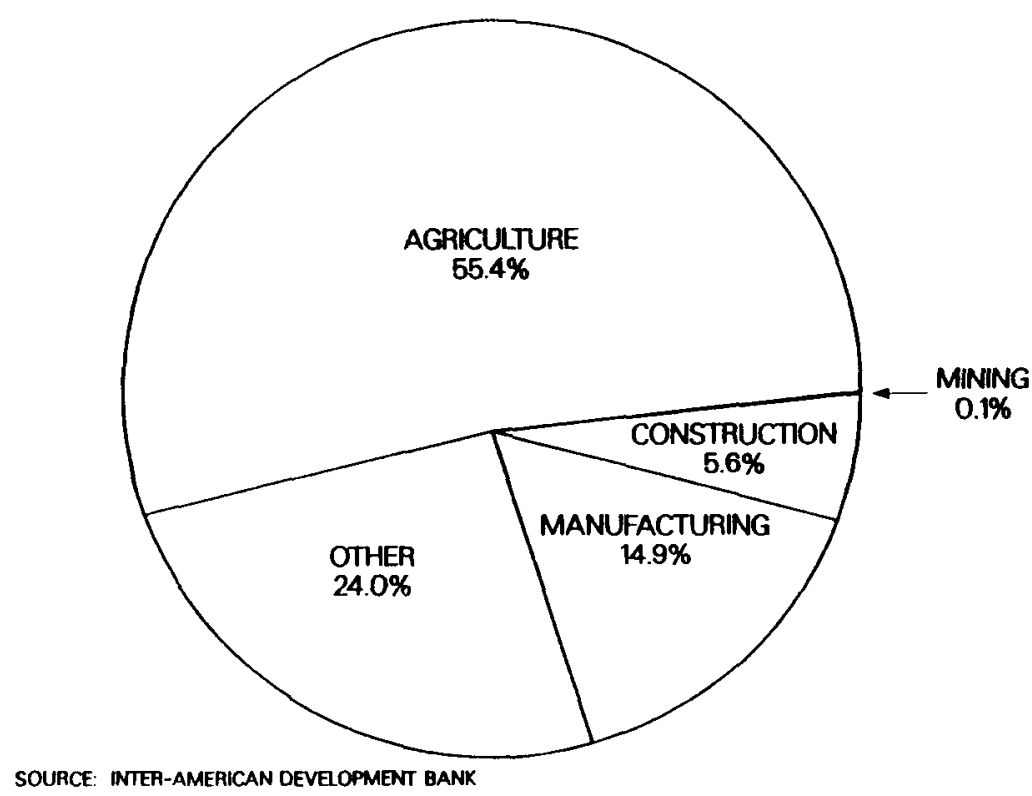

Fig. 3. Guatemala: Labor force by sector for 1980.

Although it was one of the fastest growing sectors in 1980, manufacturing led the recession with a decline of 2.5 percent and 5.8 percent in 1981 and 1982 , respectively.

The construction sector is volatile and pro-cyclical, as is the case in most economies. It comprised approximately 2.6 percent of GDP in 1983 and had annual growth rates in the 1980 s ranging from 16.1 percent in 1981 to -25.4 percent in 1983. The decline during 1982 and 1983 is most likely owing to the severe credit crisis within the country.

The trade sector is characterized by mainly small shops in the urban areas and comprises about one-fourth of GDP. Public administration and defense is a relatively small proportion of GDP, on 1 y 6.5 percent in 1984 . This is about half of what occurs in the other Central American countries and generally demonstrates the Guatemalan government's laissez faire policy.

\section{External Sector}

During the $1980 \mathrm{~s}$, Guatemala suffered severe international trade and finance crises: The prices of its export commodities fell to the lowest level since World War II, and import prices continued to rise. Consequently, the current account deficit rose alarmingly--to about $\$ 570 \mathrm{million}$ US in 1981 and $\$ 380 \mathrm{mil}$ 1 ion US in 1984 (see Table 5). In addition, the net foreign reserves of the country were exhausted by the end of $1981 .^{3}$ 
TABLE 5

GUATEMALA: BALANCE OF PAYMENTS

( $\$$ million US)

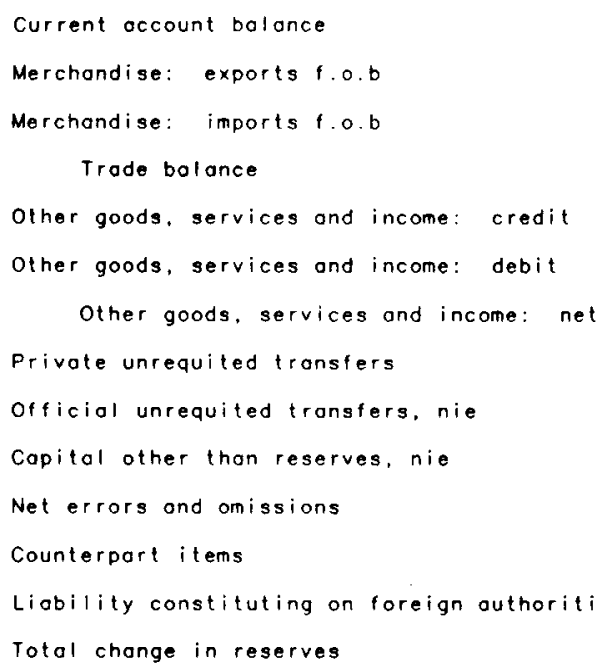

\begin{tabular}{|c|c|c|c|c|c|c|}
\hline 1970 & 1975 & 1980 & 1981 & 1982 & 1983 & 1984 \\
\hline-7.9 & -65.7 & -163.3 & -572.7 & -399.1 & -223.9 & -377.4 \\
\hline 297.1 & 640.9 & 1519.8 & 1291.3 & 1170.4 & 1091.7 & 1132.2 \\
\hline-266.6 & -672.4 & -1472.6 & -1540.0 & $-1284 \cdot 3$ & -1856.0 & -1182.2 \\
\hline 30.5 & -31.4 & 47.2 & -248.7 & -113.9 & 35.7 & -50.0 \\
\hline 56.6 & 156.5 & 314.2 & 234.6 & 141.8 & 113.3 & 129.0 \\
\hline-112.5 & -268.6 & -634.5 & -649.5 & -489.7 & -403.5 & -485.1 \\
\hline-55.9 & -112.1 & -320.3 & -414.9 & -347.9 & -290.2 & -356.1 \\
\hline 17.4 & 78.3 & 108.6 & 89.5 & 61.9 & 29.8 & 28.0 \\
\hline 0.1 & -0.5 & 1.2 & 1.4 & 0.8 & 0.8 & 0.7 \\
\hline 27.1 & 180.5 & -76.5 & 267.1 & 378.7 & 270.6 & $-{ }^{\circ}$ \\
\hline-3.8 & -10.7 & -18.1 & 4.3 & -18.0 & -37.1 & 12.9 \\
\hline-0.8 & -1.7 & 5.4 & 0.4 & 5.5 & 5.5 & 一 \\
\hline${ }^{b}$ & $--^{b}$ & ${ }^{b}$ & $ـ^{b}$ & $-^{b}$ & 41.4 & -6.0 \\
\hline
\end{tabular}

Source: International Monetary Fund.

Indicotes a lock of statistical data that can be reported.

bindicotes that a figure is zero or less than half of a significant digit or that data cannot exist.

Note: The minus sign indicotes a debit.

Because of a crisis in the international capital markets, it was very costly for the country to arrange for additional external financing. The total disbursed external debt outstanding increased by 69 percent in 1982 alone, and debt service more than doubled to $\$ 102.5$ million US in the same year (see Table 6). By 1983, total debt service was $\$ 140.6 \mathrm{million}$ US, about 12 percent of total export earnings. In October 1981 Guatemala entered into an agreement with the IMF to reduce government spending. Furthermore, in 1982, the combination of the external credit shortage, lack of liquid reserves, and the foreign trade deficit forced the country to impose emergency regulations to reduce the outflow of foreign exchange. As a result, the public budget deficit decreased from 8.6 percent of GDP in 1981 to 5.7 percent in $1982 .^{3}$

Export earnings, after rising an average of 18 percent a year through the 1970s, dropped over 19 percent in 1981 and another 7 percent in the following year to $\$ 1,167.5$ million US (see Tables 7 and 8 and Fig. 4). The goods that led this decline were coffee and cotton. The 36 percent decrease in coffee exports in 1981 was particularly devastating because coffee exports are the primary 
TABLE 6

GUATAMALA: EXTERNAL PUBLIC INDEBTEDNESS

\begin{tabular}{|c|c|c|c|c|c|c|c|}
\hline & \multicolumn{7}{|c|}{$\begin{array}{l}\text { Current Prices } \\
\text { (\$million US) }\end{array}$} \\
\hline & 1970 & 1975 & 1980 & 1981 & -1982 & 1983 & 1984 \\
\hline Debt outstanding-including undisbursed & 175.8 & 281.9 & 882.3 & 1041.1 & 1548.1 & 1833.9 & 1987.3 \\
\hline Debt outstanding-disbursed & 106.3 & 164.1 & 560.6 & 684.1 & 1156.6 & 1495.3 & 1513.9 \\
\hline Principol repoyment & 20.0 & 6.9 & 33.3 & 20.2 & 43.6 & 64.9 & 111.5 \\
\hline Interest poyment & 6.2 & 6.4 & 31.3 & 29.8 & 58.9 & 75.7 & 84.5 \\
\hline Total debt service & 26.3 & 13.3 & 64.6 & 50.0 & 102.5 & 140.6 & 196.0 \\
\hline
\end{tabular}

foreign exchange earner for the country, equaling 30 percent of total exports in 1980 (see Table 2). Cotton earnings experienced an unprecedented decline during the early 1980s, dropping from $\$ 166$ million US in 1980 to only $\$ 50$ million US in 1983, an average decrease of 33 percent a year. Exports began to recover in 1983 and experienced a 2 percent growth over the 1982 value, but they declined again in 1984.

The value of imports reached a peak of about $\$ 1.7$ billion US in 1981 , then declined by one-third over the next two years as the austerity measures enacted by the government in 1982 took effect (see Table 7). The value of oil purchases fluctuated from about $\$ 150$ million US to $\$ 200$ million US during the early $1980 \mathrm{~s}$ and equaled about 13 percent of total export earnings in 1984 . Thus, petroleum imports and debt service together absorb about 30 percent of the total foreign exchange earnings from exports.

\section{Financial Assistance}

Guatemala receives aid in the form of 10 ans and grants from the United States and international agencies such as the IDB and UNDP. Table 9 details the amount and type of assistance from each source.

Aid to Guatemala from the United States is mainly economic. Military aid was terminated in 1977. The economic assistance comes from the AID and Food for Peace programs, which together accounted for an annual average of $\$ 5.5$ million US during the 1962 to 1980 period and $\$ 20.3$ million US in 1984 .

Guatemala has received a substantial amount of aid from international organizations in the form of loan authorizations. The average amount authorized annually over the 18 years prior to 1980 was $\$ 38$ million US, and it rose to 
TABLE 7

GUATEMALA: EXPORTS AND IMPORTS

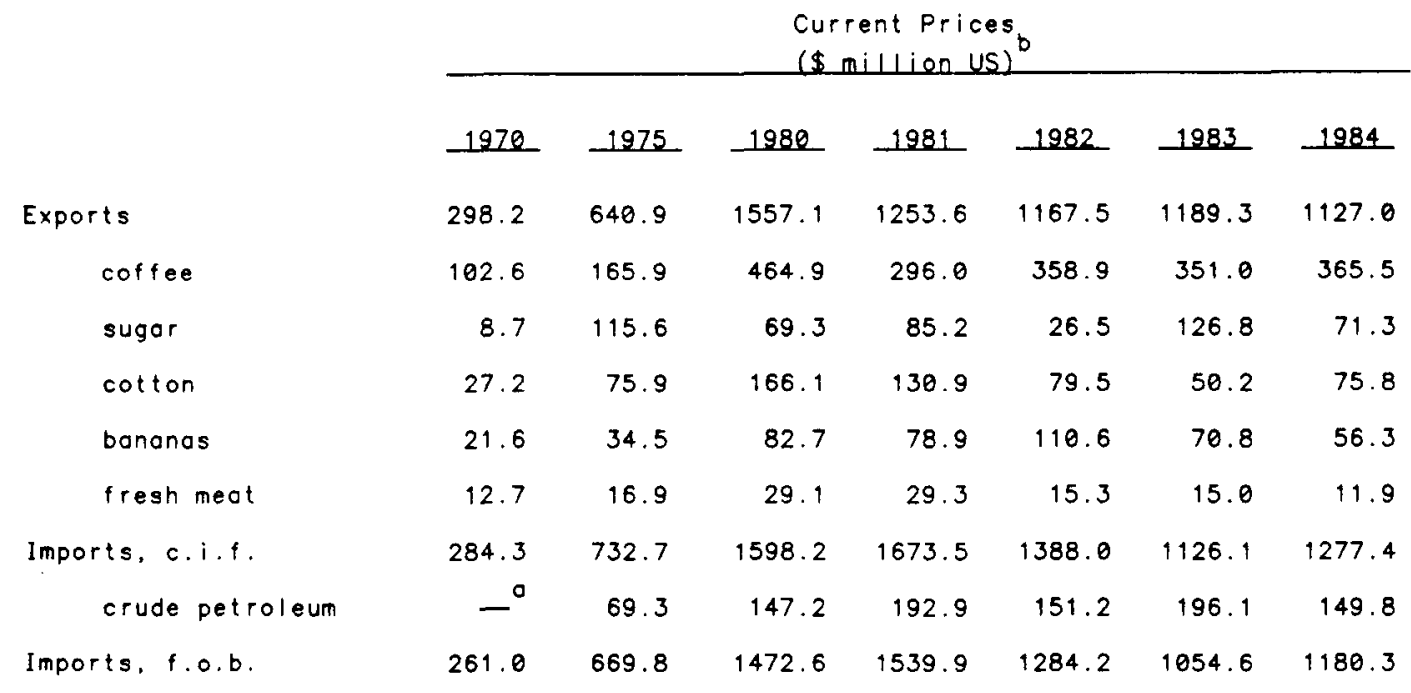

Volume of Exports

$\begin{array}{lrrrrrrr}\text { coffee } & 74.0 & 106.0 & 100.0 & 86.0 & 110.0 & 107.0 & 102.0 \\ \text { sugar } & 27.0 & 96.0 & 100.0 & 94.0 & 60.0 & 210.0 & 132.0 \\ \text { cotton } & 43.0 & 80.0 & 100.0 & 70.0 & 53.0 & 28.0 & 39.0 \\ \text { banonas } & 50.0 & 60.0 & 100.0 & 89.0 & 134.0 & 75.0 & 69.0 \\ \text { fresh meat } & 108.0 & 111.0 & 100.0 & 117.0 & 65.0 & 76.0 & 77.0\end{array}$

Unit Value of Exports

$\begin{array}{lrrrrrrr}\text { coffee } & 29.0 & 33.0 & 100.0 & 74.0 & 70.0 & 70.0 & 76.0 \\ \text { coffee (wholesale) } & 34.0 & 48.0 & 100.0 & 77.0 & 83.0 & 85.0 & 94.0 \\ \text { sugar } & 47.0 & 174.0 & 100.0 & 131.0 & 64.0 & 87.0 & \text { - }^{\circ} \\ \text { cotton } & 38.0 & 57.0 & 100.0 & 113.0 & 91.0 & 107.0 & 111.0 \\ \text { banonas } & 52.0 & 69.0 & 100.0 & 107.0 & 100.0 & 114.0 & 99.0 \\ \text { fresh meot } & 40.0 & 53.0 & 100.0 & 86.0 & 80.0 & 68.0 & 57.0\end{array}$

Source: International Monetary Fund.

Indicates o lock of statistical dota thot can be reported.

Exchonge rote "ae" reported by IMF used to convert quetzeles to dollors. (1 quetzel equals 1 dollor). 
TABLE 8

GUATEMALA: GROWTH RATES FOR EXPORTS ANO IMPORTS

Compounded Annual Average (\%)

$1970-1975$ $1975-1980$

$1970-1980$

Exports

coffee

sugar

cotton

bonanos

fresh meat

Imports, c.i.f

petroleum

Imports, f.o.b.
16.5

19.4

18.0

10.0

22. 9

16.3

24.1

$-9.7$

23.1

22.8

17.0

19.8

9.8

19.1

11.5

14.4

5.9

20.9

- a

20.7
16. 9

16.3

17.1
Annual Growth Rate

(\%)

$\begin{array}{lllll}1980 & 1981 \quad 1982 \quad 1983 \quad 1984\end{array}$

$\begin{array}{lllll}22.6 & -19.5 & -6.9 & 1.9 \quad-0\end{array}$

$\begin{array}{lllll}7.3 & -36.3 & 21.3 & -2.2 & 2.8\end{array}$

$\begin{array}{lllll}29.5 & 22.9 & -68.9 & 378.5 & -43.8\end{array}$

$\begin{array}{lllll}-13.7 & -21.2 & -39.3 & -36.9 & 44.2\end{array}$

$\begin{array}{llll}72.3 & -4.6 & 40.2 & -36.0\end{array}$

$\begin{array}{llllll}-29.7 & 0.7 & -47.8 & -2.0 & -15.3\end{array}$

$\begin{array}{lllll}5.9 & 4.7 & -17.1 & -18.9 & 13.4\end{array}$

$\begin{array}{lllll}33.0 & 31.0 & 21.6 & 26.7 & -23.6\end{array}$

$\begin{array}{lllll}5.6 & 4.6 & -16.6 & -17.9 & 11.9\end{array}$

andicates a lack of stotistical data that can be reported.

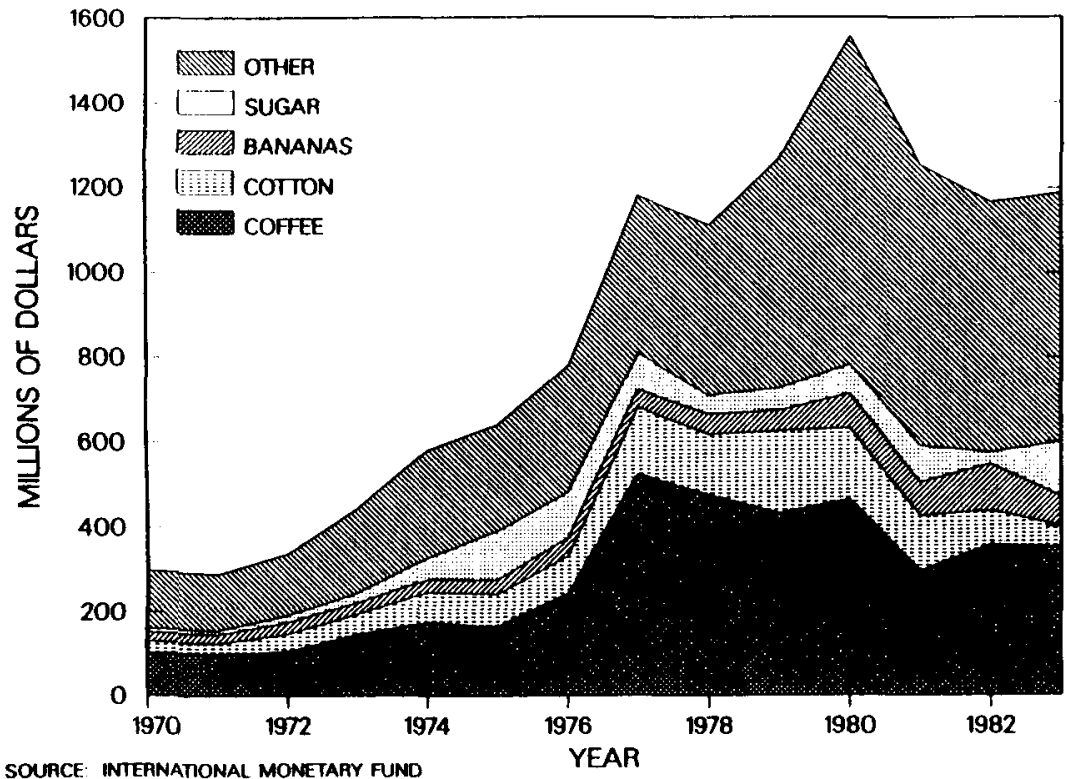

Fig. 4. Guatemala: Exports. 
( $\$$ millions US)

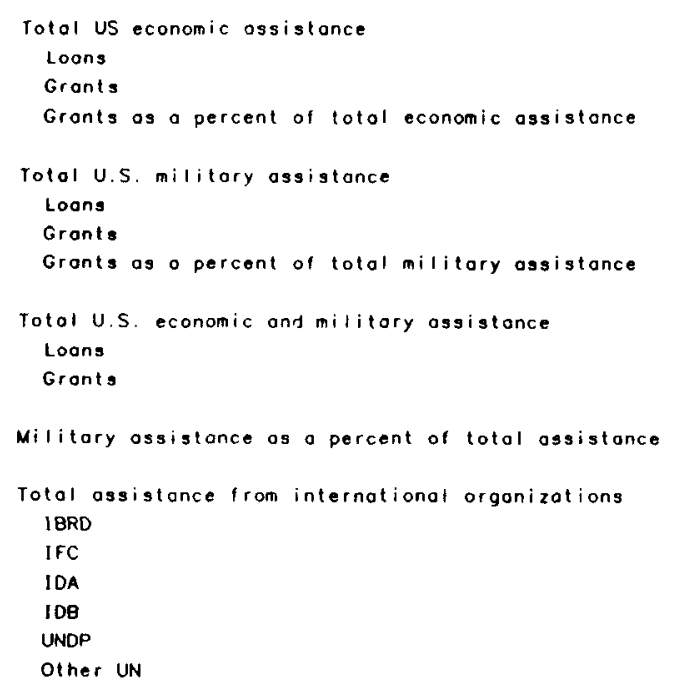

\begin{tabular}{|c|c|c|c|c|c|c|}
\hline $1962-1979$ & -1980 & 1981 & 1982. & 1983 & & 1984 \\
\hline 293.9 & 13.0 & 19.0 & 15.5 & 29.7 & & 20.3 \\
\hline 143.1 & 5.0 & 5.6 & 3.0 & 17.5 & & 6.7 \\
\hline 150.8 & 8.0 & 13.4 & 12.5 & 12.2 & & 13.6 \\
\hline $51.3 \%$ & $61.5 \%$ & $70.5 \%$ & $80.6 \%$ & 41.17 & & $67.0 \%$ \\
\hline 40.2 & - & - & - & - & & - \\
\hline 10.8 & - & - & - & - & & - \\
\hline 29.4 & - & - & - & - & & - \\
\hline $73.1 \%$ & - & - & - & - & & - \\
\hline 334.1 & 13.0 & 19.0 & 15.5 & 29.7 & & 20.3 \\
\hline 153.9 & 5.0 & 5.6 & 3.0 & 17.5 & & 6.7 \\
\hline 180.2 & 8.0 & 13.4 & 12.5 & 12.2 & & 13.6 \\
\hline 12.87 & - & - & - & - & & - \\
\hline 597.7 & 86.9 & 26.5 & 45.9 & 102.4 & & 134.5 \\
\hline 242.3 & 17.0 & - & - & 18.5 & & 50.0 \\
\hline 18.0 & - & - & - & - & - & - \\
\hline \multicolumn{7}{|c|}{ Category not applicable for Guatemola } \\
\hline 315.9 & 66.0 & 25.5 & 42.5 & 83.3 & & 84.5 \\
\hline 14.7 & 2.8 & 1.0 & 0.9 & 0.6 & & - \\
\hline 6.8 & 1.1 & - & 2.5 & - & & - \\
\hline
\end{tabular}

Source: US Agency for International Devolopment.

$\$ 134.5$ million US in 1984 . IDB has been the most active agency in providing assistance to Guatemala in the early 1980s.

E. Role of Government

The Guatemalan government generally does not interfere with the economy. Public administration and defense comprise a relatively small share of GDP--only 6.5 percent in 1984. Also, Guatemala's external public debt of $\$ 1.5$ billion US in 1984 (equaling about 15 percent of GDP) is small by developing country standards.

The country has one of the lowest tax bases in Latin America. "In the mid1970s, tax revenues were less than 9 percent of GDP, compared with 13 percent in the rest of Central America and over 15 percent in other parts of Latin America." 2

Because of the importance of energy to the economy, the government is active in the regulation of energy supply and prices. The national utility handles the vast majority of electricity production and distribution, and the Ministry of Energy and Mines is in charge of energy planning and price regulation. More detail on these functions is given in later sections.

\section{F. Employment}

Since 1950 the labor force in Guatemala has doubled, from about 1 million to 2 million persons. It grew an average of 2.9 percent a year from 1973 to 
1980. 1 More than half of the labor force is employed in the agricultural sector. Manufacturing is the second largest employer with 15 percent of the 1 abor force (Fig. 3).

\section{ENERGY OVERVIEW}

\section{A. Energy Resources}

1. $0 i 1$ and Gas. Guatemala is the only Central American country in the region with proven and productive petroleum resources. As of November 1985, proven reserves were 41.98 million barrels, probable reserves were 18.28 million barrels, and possible reserves were 11 million barrels. Serious exploration activities commenced in the 1ate 1950s, but it was not until 1974 that discovery of a significant oil field occurred. Large-scale oil exploitation began in 1980 and increased gradually until 1984. However, the years 1984 and 1985 saw a significant drop in annual output. Table 10 contains production statistics for the years 1974 through 1985. During the last two years daily production has averaged between 3,000 and $5,000 \mathrm{bbl/day}$. Estimates for 1986 indicate the potential for a 30 percent increase in production capacity, possibly from 4000 to $6500 \mathrm{bbl} /$ day or more.

Table 10 also contains statistics on the disposition of the oil production. Exports make up the largest portion each year and were about 75 percent in 1984 . Internal sales have been to the Guatemala Electric Company (EEGSA) for use in several of their thermal generating units. In the future Guatemala hopes to increase its domestic crude production and exports; the latter will be facilitated by EEGSA's decreasing use of crude for power generation. A large hydroelectric project on the Chixoy river resumed operation in 1986 and much of the current thermal generation will be displaced by its production.

Guatemala currently has eleven producing wells in four fields: Caribe--two wells; Chinaja 0este--three wells; Rubelsanto--five wells; and San Diego--one wel1. Chinaja Oeste and Rubelsanto are located along the northern border of Alta Verapaz Department, and Caribe and San Diego lie just north of the other fields in the Peten Department (see Fig. 5). A fifth field (Yalpemech), located in the north of the Alta Verapaz Department, is slated to begin production in late 1986. In addition, one well that had been previously abandoned is currently being reworked by Hispanoil--the local operator of all production wells-and is expected to come on 1 ine in 1987.

The crude produced from the Guatemalan $0 i 1$ fields is relatively heavy, with average American Petroleum Institute (API) ratings of $27.2^{\circ}$ for Rubelsanto, $31.2^{0}$ for Chinaja Oeste, $21.5^{\circ}$ for Caribe and $34.1^{\circ}$ for San Diego. The API ratings from the newer wells expected to come on line in late 1986 average $34^{\circ}$ 
TABLE 10

GUATEMALA: CRUDE OIL PRODUCTION STATISTICS

(thousands of barrels)

$\begin{array}{lcccc}\text { Yejr } & \begin{array}{c}\text { National } \\ \text { Preduction }\end{array} & \text { Experts } & \text { Zexports } & \begin{array}{c}\text { Internol } \\ \text { Sales }\end{array} \\ 1974 & 2.4 & - & - & - \\ 1975 & 27.1 & - & - & - \\ 1976 & 86.0 & - & - & 15.2 \\ 1977 & 49.2 & - & - & 32.1 \\ 1978 & 220.7 & - & - & 215.2 \\ 1979 & 571.4 & - & 53 & 568.7 \\ 1980 & 1467.4 & 781.6 & 44 & 755.2 \\ 1981 & 1493.4 & 661.6 & 67 & 773.4 \\ 1982 & 2292.1 & 1546.0 & 87 & 345.7 \\ 1983 & 2549.4 & 2206.3 & 74 & 481.1 \\ 1984 & 1715.2 & 1262.9 & 43 & 571.9 \\ 1985 & 1068.1 & 458.3 & -3\end{array}$

Source: Ministry of Energy and Mines, Guatemala.

a Sales to electric power production.

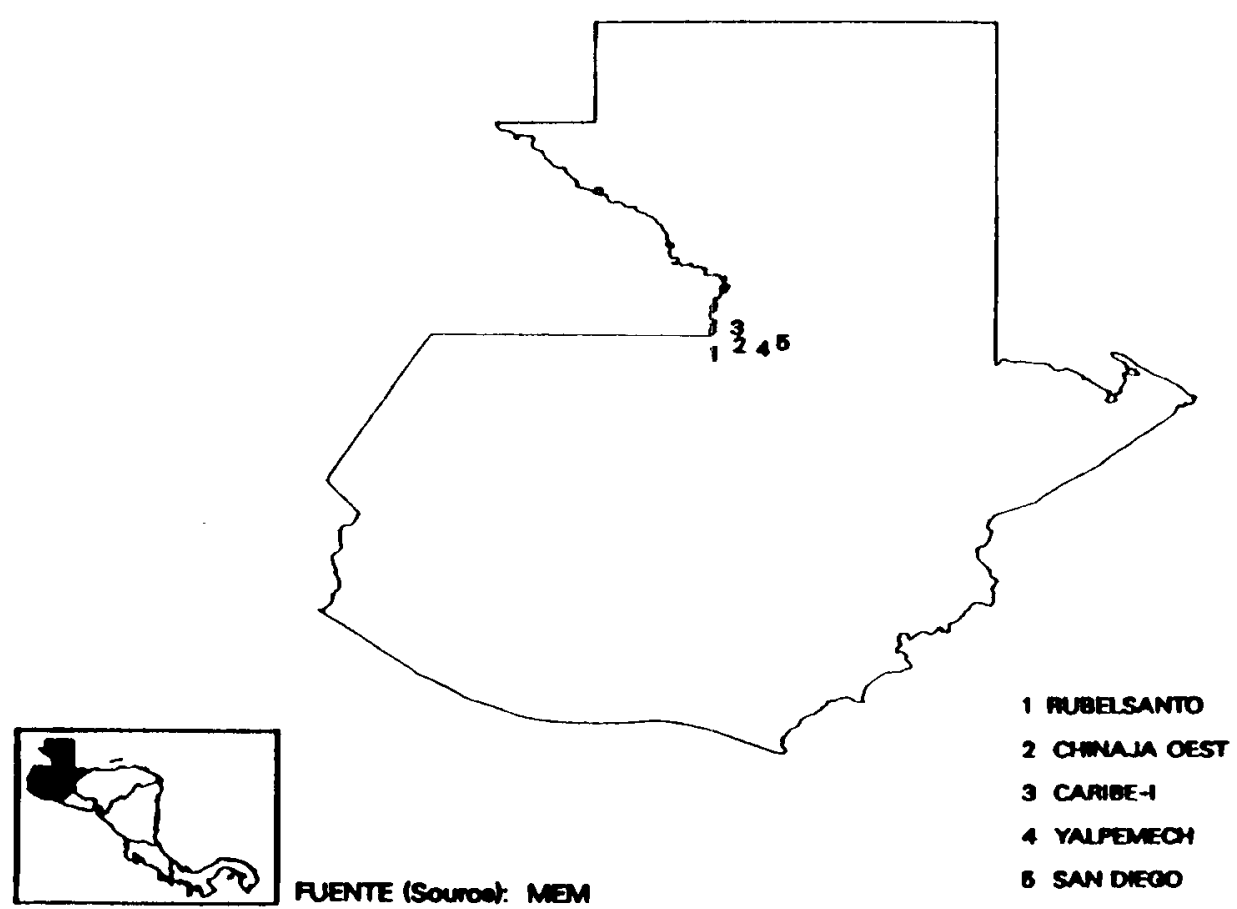

Fig. 5. Guatemala: Location of oil wells. 
for Yalpemech and only $16^{\circ}$ for the northwest Peten we11. The average API rating for Guatemalan oil exported from Santo Thomas, the Caribbean port on the East Coast of Guatemala (just north of Puerto Barrios), is currently $25.6^{\circ}$ today.

The oil is processed at the production site to remove sulfur and then transported by a pipeline running east from the Alta Verapaz producing fields to Santo Thomas. Delivery of crude to several thermal plants for power production is made by trucks. New production from the Alta Verapaz fields and Caribe in Peten will also rely on the Rubelsanto Santo Thomas pipeline for crude oil transport. However, production from the northwest Peten field will be trucked south to the processing $\mathrm{plant}$ and then transported by the Rubelsanto Santo Thomas pipeline. Alternative transportation routes and methods are being examined, with two options receiving careful attention: a truck/barge/pipeline route west and then south of the northwest Peten field to the existing Santo Thomas pipeline (taking advantage of river transportation) and a pipeline south to the existing Santo Thomas pipeline. Both the economic and technical feasibilities are being addressed.

Production in the present four operating fields is from fracture type reservoirs. This type of formation results in rapid depletion of the reservoirs, with depletion rates as high as 50 percent a year. The drop in total production since 1983 is owing principally to reservoir depletions at existing wells and lack of investment in replacement wells. However, production in the northwest Peten field will be from a more traditional type of reservoir where depletion rates should be significantly lower.

Official estimates of recoverable reserves have not changed since 1980. Approximately $18 \mathrm{million}$ barrels of crude was estimated as commercially recoverable from the Alta Verapaz and Peten operating fields. To date, a total of 11 million barrels has been produced (more than one-half of the estimated reserves), leaving less than 7 million barrels to be commercially recovered. At the present rate of production, these commercially known reserves will be exhausted in another 4 to 5 years. Reserves in the northwest Peten field could exceed 4 million barrels of crude oil--albeit heavier and less valuable.

There has been limited activity in the secondary recovery of oil. Pumps are now being added to or planned for most of the production wells. There are two water injection wells (one in Rubelsanto and the other in Chinaja Oeste), but the area of coverage may be too great to see greatly improved results. Additional water injection, when operating, has the potential to boost recovery rates and, ultimately, quantities.

Several off-shore exploration wells were also completed in Guatemala: one in the Pacific Ocean off the west coast and two in the Caribbean north-northwest 
of Puerto Barrios. Several on-shore wells were also drilled in the same vicinities. No oil-bearing formation was discovered on the Pacific Coast, but some hydrocarbon presence was detected in almost all of the wells. Discussions have recently begun again about additional exploration activity in the Manibique area, although the wells were abandoned in 1976.

In August 1985, a new contract was signed between Guatemala and Exxon. The exploration contract covers a large area--300,000 hectares. Additional concession items agreed to by Exxon include the drilling of a minimum number of exploratory wells, the laying of over $500 \mathrm{~km}$ of seismic lines, and the expenditure of over $\$ 30$ million US during the first exploratory phase. The company has a set schedule ( 3 years) under which to conduct its exploration activities, and the acreage must be returned to Guatemala if production does not commence within 6 years. In addition, the total of the effective tax, royalty rates, and production sharing after expenses are repaid can approach 50 percent. The Exxon contract is the first major one under the new 1983 Guatemala hydrocarbon $1 \mathrm{aw}$. With Exxon's recent signing and the continuing discussions between the government and at least two additional large oil interests, increased exploration activity is anticipated over the next several years. Other concessionaires have included Amoco Guatemala Petroleum Co., Basic Resources International (Bahamas), Ltd., and Hispanica de Petroleos, S.A. (Hispanoi1).

Natural gas is also produced in Guatemala, although the actual quantities developed have been limited. The Peten South basin contains 30.9 million cubic feet of proven gas reserves comprising 16.4 million in the Rubelsanto field, 14 million in the Chinaja Oeste field, and 0.5 million in the Caribe field. All the natural gas produced to date has been "associated gas," that is, gas produced as part of oil production. Of the total gas produced, a portion has been utilized in the oil processing plant and the remainder has been flared to the atmosphere. There were plans in the late 1970s to capture this natural gas, either through liquification or direct transport via pipeline. However, those plans have not been realized. Indications are that considerably more gas must be produced before the transport to potential markets is economically justified. A processing plant would also be needed because the natural gas now produced is considered sour and not directly usable by most markets. Table 11 contains production statistics for 1976 to 1984.

2. Coal and Peat. There are no known high-quality coal deposits in Guatemala. Reconnaissance studies have indicated, however, lignite deposits and the presence of some peat in the Izabal Department. Quantities and qualities of these potential energy resources have not been completely estimated. 
TABLE 11

GUATEMALA: PRODUCTION VOLUME OF NATURAL GAS

$\begin{array}{cc}\text { Year } & \text { Production } \\ 1975 & \\ 1976 & 2,165.0 \\ 1977 & 198.0 \\ 1978 & 3,708.7 \\ 1979 & 5,672.8 \\ 1980 & 16,540.8 \\ 1981 & 14,587.9 \\ 1982 & 31,069.3 \\ 1983 & 31,664.2 \\ 1984 & 17.766 .1 \\ 1985 & 12,393.4\end{array}$

Source: Ministry of Energy and Mines, Guatemala.

Note: A portion of the natural gas is utilized in the operotion of the oil processing plant; the remainder is flared to the atmosphere.

3. Hydro Energy. Guatemala is favored with climate and terrain that give rise to a large hydroelectric resource potential. Hydroelectric resources were evaluated between 1974 and 1976 by the National Institute of Electrification (Instituto Nacional de Electrificacion--INDE) with the cooperation of the West German government. Estimates based on theoretical yield, total water flows, and vertical drops in principal rivers indicate a 12,000-MW potential. However, the economically developable capacity is believed to be 5900 MW. INDE has conducted several studies that identify specific sites and capacities. Table 12 contains a list of sites and sizes of plants that they believe to be the most economically feasible. Other sites have been identified as also feasible but more costly to develop.

With the recent costly experience with the faulty pressure tunnel at the Pueblo Viejo Project (also called "Chixoy"), large hydroelectric development projects (Chulac, Xalala) have been deferred temporarily. The decrease in expected demand now calls for smaller hydroelectric sites to be developed first along with geothermal energy at Zunil and Amatitlan.

4. Geothermal Energy. Systematic mapping of geothermal areas was begun in the early 1970s by the Direccion General de Mineria y Hidrocarburos [DGMH, a predecessor to the present Ministerio de Energia y Minas (MEM)]. Of the 10 or more areas that appeared to have steam fields, only 3 have received any 
TABLE 12

GUATEMALA: ECONOMICALLY RECOVERABLE HYDROELECTRIC ENERGY THROUGH THE YEAR 2000 BY PROJECT

(MW)

\begin{tabular}{|c|c|c|c|c|}
\hline Name of Project & River & $\begin{array}{l}\text { Instal led } \\
\text { Capacity }\end{array}$ & $\begin{array}{l}\text { Firm } \\
\text { Capocity }\end{array}$ & $\begin{array}{l}\text { First Year } \\
\text { of operations }\end{array}$ \\
\hline Jurum Marinala & Michatoya & 60 & 40 & 1970 \\
\hline Los Esclavos & Los Esclavos & 14 & 13 & 1966 \\
\hline \multicolumn{5}{|c|}{ Ortras plantas on } \\
\hline existencia & Vorios & 28 & 16 & $1927-54$ \\
\hline Aguacapa & Maria Linda & 90 & 88 & 1981 \\
\hline Pueblo Viejo & Chixoy & 300 & 270 & 1986 \\
\hline Chuloc & Cahabon & 441 & 313 & \\
\hline Xalala & Chixoy Interior & 348 & 227 & \\
\hline Serchil & Chixoy & 109 & 101 & \\
\hline El Cormen & Los Esclaros & 113 & 91 & \\
\hline Chacehila & Dulce & 36 & 28 & \\
\hline San Luis & Xalbal & 43 & 35 & \\
\hline El Arco & Ixcon & 112 & 22 & \\
\hline Tzucanca & $1 \times \operatorname{con}$ & 66 & 14 & \\
\hline Sumalito & Xolbal & 44 & 6 & \\
\hline Semuc & Cahobon & 120 & 18 & \\
\hline Sauce & Dulce & 139 & 118 & \\
\hline Chicoc & Cahabon & 200 & 40 & \\
\hline San Juan & Ixcon & 105 & 77 & \\
\hline Agua Caliente & Aguacapa & 49 & 45 & \\
\hline Polzojel & Chicox & 54 & 37 & \\
\hline \multicolumn{5}{|l|}{ Polochic y } \\
\hline Matonzas & Polochic & 123 & 99 & \\
\hline El Capon & Chixoy Interior & 123 & 113 & \\
\hline Estrella Pol & xalbal & 147 & 21 & \\
\hline Quixabaj & Ixcan & 24 & 5 & \\
\hline Alta Vista & Xalbal & 55 & 9 & \\
\hline Monte Cristo & Ixcan & 29 & 17 & \\
\hline Jocotales & Chixoy & 52 & 45 & \\
\hline Los Topezcos & Chixoy & 84 & 69 & \\
\hline La Campana & Ixcon & 31 & 23 & \\
\hline San Ramon & Ixcon & 40 & 24 & \\
\hline Camotan & Gronde de Zocapa & 143 & 133 & \\
\hline Sala & Suchiate & 10 & 2 & \\
\hline Pompeyo & Suchiate & 40 & 11 & \\
\hline Virginia & Suchiate & 57 & 13 & \\
\hline Son Jose & Cabuj-Xula & 85 & 18 & \\
\hline Sisimite & Motagua & 72 & 58 & \\
\hline El Chapayal & De la Posion & 57 & 41 & \\
\hline TOTAL & & 3,643 & 2.300 & \\
\hline
\end{tabular}

Source: Notional Institute of Electrificotion (INDE). 
significant exploration to date (see Fig. 6). Detailed investigations were carried out at the Moyuta field, $25 \mathrm{~km}$ across the border from the geothermal project Ahuachapan in El Salvador. Shallow test wells produced encouraging temperatures, but deeper wells evidenced lower permeability, only moderate temperatures (less than $200^{\circ} \mathrm{C}$ ), and low temperature gradients. It also appeared that the geology differed from that of the Ahuachapan area, and consequently the exploration activity was abandoned in the mid 1970s.

Two other sites, Zunil and Amatitlan, continue to see exploration activity. INDE, in cooperation with geothermal experts from Japan, has intensively explored Zunil. There are 11 exploratory wells and 61 arge commercial wells at Zunil, 4 of which are producing. IDB is funding a $\$ 58$ million project for the development of this geothermal site, which includes the installation of a 15-MW power plant and feasibility studies of Zunil II and Amatitlan. Fifteen additional production wells are $\mathrm{planned}$ to ensure continuous steam flow for the project. There have been estimates of $50 \mathrm{MW}$ or more of geothermal electricity potential at Zunil, but this figure is uncertain at this time. The project at Zunil has so far been designed only to generate electricity, but cogeneration and thermal production may also be possibilities. Studies are being conducted to evaluate this potential.

The site at Amatitian has also shown promise for geothermal development, though to date only shallow exploration wells have been completed. Preliminary evaluations place the potential electricity generation capacity at about 100 MW. A request for bids has been sent out for three more exploratory wells to confirm

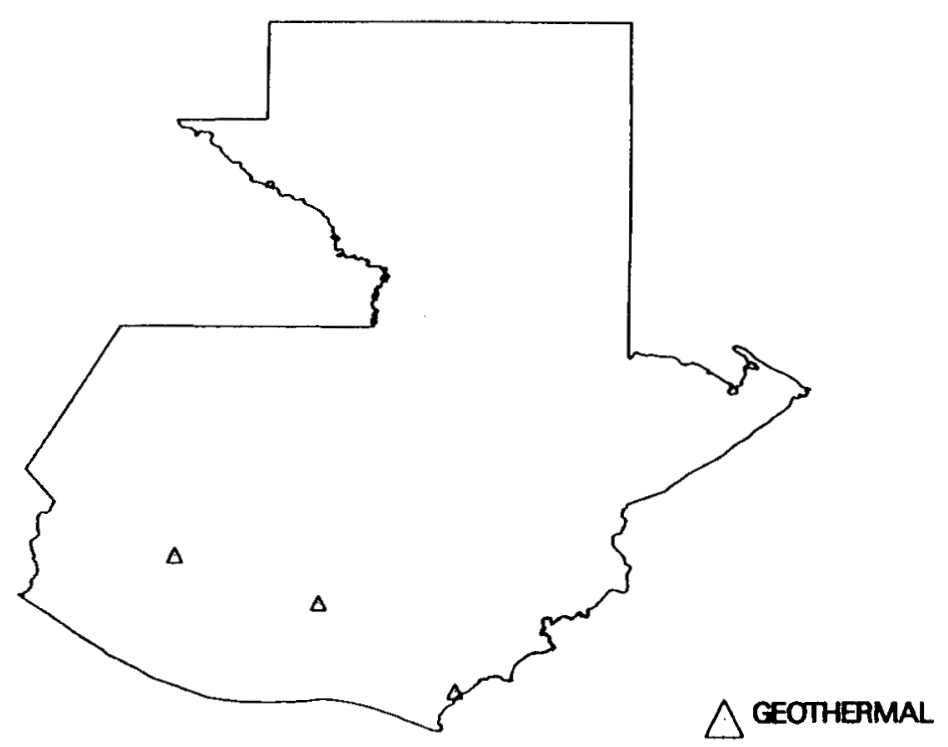

Fig. 6. Guatemala: Location of geothermal sites. 
a high-temperature area that has been selected for potential development. After these are completed, the drilling of three production-size wells is planned.

Evaluation of direct-heat applications of geothermal energy is also currently underway at INDE with assistance from Los Alamos. Both the Zunil and Amatitlan sites are being studied, and a demonstration project at Zunil is being planned for construction in 1986.

5. Fuel Wood and Other Biomass. In Guatemala, 72 percent of the national territory is forested. In 1977, it was estimated that $43,750 \mathrm{~km}^{2}$ or 40 percent of the total land area of the country was covered by coniferous forest $(8,098$ $\mathrm{km}^{2}$ ) and latifoliates $\left(35,625 \mathrm{~km}^{2}\right) .{ }^{4}$ If the rate of deforestation--on the order of 900 square kilometers per year--is taken into account, this forested area has decreased appreciably by 1986 .

The cutting of trees for fuel wood is the largest contributor to deforestation. In 1984, 11 million cubic meters of wood were consumed for energy purposes while the sawmill industry consumed 0.15 million cubic meters.

The high fuel-wood consumption is owing to the fact that for 97 percent of rural households and 52 percent of urban households, fuel wood is the only energy resource utilized for meal preparation.

After fuel wood, bagasse is the biomass resource most used in Guatemala; its use is well known in the sugar mills where bagasse provides almost all of the energy used in the industrial processing of sugar. In the future, bagasse will be even more important in the country if it is used in electricity cogeneration.

6. Other Resources. Other resources that have not been developed within Guatemala are wind and solar energy. However, there exists a growing knowledge of their potential and importance for the future. A series of studies have been initiated to evaluate not only the potential in all of the country but also the better sites for its development. This evaluation is done with a network of stations that collect solar radiation and wind velocity information. This network was established in 1970 under the Central American Isthmus Hydrological Program.

The base data for evaluating the wind potential has been collected since the beginning of the 1970s. The winds are sufficiently strong in Guatemala during the dry season--the months of December to March. The winds along the Pacific coast show a different pattern from those of the Caribbean coast, and the winds near Puerto Barrios are considerable. Table 13 gives the results of the evaluation of wind potential.

The wind resource as well as the solar resource has been promoted by the Ministry of Energy and Mines. The Directorate of New and Renewable Energy 
TABLE 13

GUATEMALA: WIND ENERGY POTENTIAL AND STATISTICS AT SELECTED SITES

\begin{tabular}{|c|c|c|c|c|c|}
\hline $\begin{array}{l}\text { Stotion } \\
\mathrm{Ne}\end{array}$ & $\begin{array}{l}\text { Names of } \\
\text { Station }\end{array}$ & $\begin{array}{l}\text { Velocity } \\
\text { in } \mathrm{m} / \mathrm{sec}\end{array}$ & $\begin{array}{c}\text { Potent jal } \\
\mathrm{m} / \mathrm{m}^{2} \\
\end{array}$ & $\begin{array}{l}\text { Energy } \\
\text { kwh/m }\end{array}$ & $\begin{array}{l}\text { Weibull } \\
\text { KFacter }\end{array}$ \\
\hline 1 & Coban P.H.C. & 1.09 & 11 & 96.36 & 0.73 \\
\hline 2 & Panzos P.H.C. & 0.50 & 5 & 43.8 & 0.52 \\
\hline 3 & Esquipulas P.H.C. & 2.01 & 29 & 254.04 & 1.06 \\
\hline 4 & Observatorio Nac. & 3.47 & 83 & 727.08 & 1.36 \\
\hline 5 & Montufar P.H.C. & 0.54 & 5 & 43.8 & 0.52 \\
\hline 6 & Son Pedro Mactun & 0.23 & 2 & 17.52 & 0.33 \\
\hline 7 & Labor Ovalle & 2.00 & 29 & 254.04 & 1.03 \\
\hline 8 & Los Esclaros & 0.75 & 8 & 70.08 & 0.65 \\
\hline 9 & La Frogua & 2.30 & 35 & 306.6 & 1.11 \\
\hline 10 & Huehuetenango & 2.13 & 30 & 262.8 & 1.06 \\
\hline 11 & Cerro La Laguna & 1.50 & 17 & 148.92 & 0.89 \\
\hline 12 & Lo Providencia & 0.52 & 5 & 43.8 & 0.52 \\
\hline 13 & La Navidad & 1.50 & 17 & 148.92 & 0.89 \\
\hline 14 & San Cristobal & 1.10 & 11 & 96.36 & 0.76 \\
\hline 15 & Chirresquiche & 0.72 & 7 & 61.32 & 0.61 \\
\hline 16 & Las Pacayos & 0.55 & 6 & 52.56 & 0.52 \\
\hline
\end{tabular}

Source: Ministry of Energy and Mines, Guatemala.

Sources of the Ministry has a multifaceted program: identification of the resource, development of the technology, and pilot programs. Wind is considered principally as a future source of electricity. It may complement as well as substitute for small generating energy stations in isolated areas, reducing the consumption of fuel and promoting energy use in rural areas where the installation of transmission lines is too costly. Another use for wind energy is, for example, irrigation with pumps. Also there is emphasis on a more integral use of its potential.

\section{B. Energy Supply}

1. Introduction. Data from energy balances prepared by Guatemala indicate a reliance on four primary sources and three secondary sources of energy supply to meet all but a small portion of internal energy demands. The primary sources are wood, animal and agricultural wastes, crude petroleum, and hydroelectric resources; the secondary sources are petroleum products, electricity, and charcoal. For purposes of the summary discussion below, we aggregate several sources to arrive at two primary sources--wood and bagasse from sugar, the 
latter being the only reported resource under the broader category of animal and agricultural wastes and two secondary sources--oil products and electricity. Charcoal represents less than 0.3 percent and has therefore been ignored. Data reporting and availability makes this type of supply aggregation necessary. An energy flow diagram for 1984 is shown in Fig. 7.

Table 14 and Fig. 8 reports the energy supplied from 1970 to 1984 to meet Guatemala's energy demand. Note that the energy supply statistics are viewed from the perspective of final consumption. No inefficiencies (in final consumption) are included in these energy statistics.

There has been a fairly steady increase in total energy supplied for final consumption. In only two years between 1970 and 1984, 1973 and 1981, was there a decrease from the preceding year. In 1979 a significant jump occurred, but this is owing to the increase in estimated fuel-wood consumption which occurred in the same year; in all other remaining years, modest increases are noted. The rate of growth in total supply was generally higher in the 1970 s than in the 1980s.

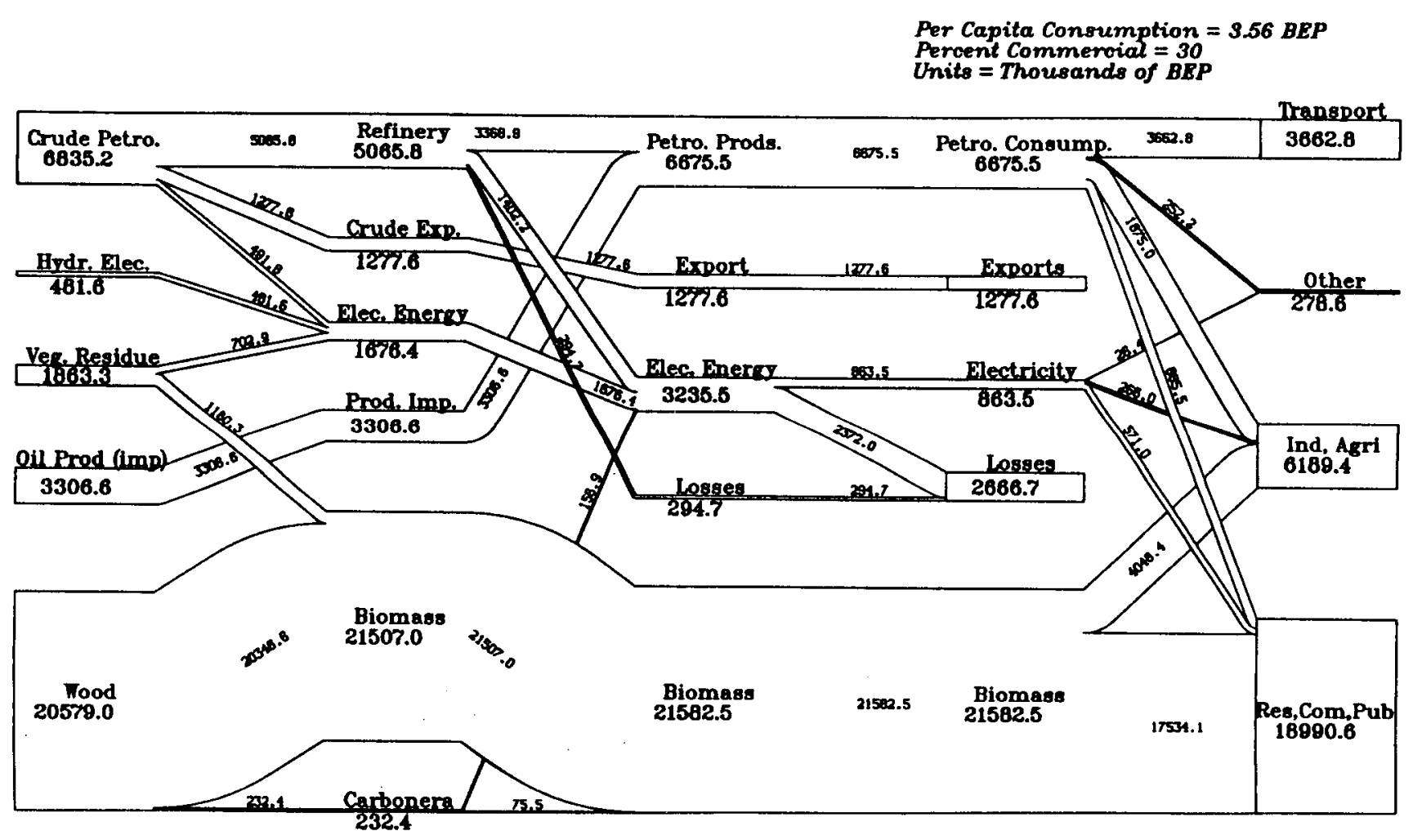

SOURCE: MINISTRY OF ENERGY AND MINES, GUATEMALA.

Fig. 7. Guatemala: Energy flow diagram for 1984. 
TABLE 14

$$
\begin{aligned}
& \text { GUATEMALA: ENERGY SUPPLY TO FINAL DEMAND } \\
& \text { (thousonds of barrol equivalents of petroleum) }
\end{aligned}
$$

\begin{tabular}{|c|c|c|c|c|c|c|c|c|c|}
\hline Source & 1970 & 1977 & 1978 & 1979 & 1980 & 1981 & 1982. & 1983 & 1984 \\
\hline Wood & 11,743 & 13.553 & 13.832 & 17.629 & 18,464 & 18,919 & 19.381 & 19,857 & 20.348 \\
\hline Bagasse & 491 & 1.532 & 1,224 & 1,004 & 880 & 1.041 & 1.217 & 1.048 & 1.165 \\
\hline 0il products & 4,508 & 6.714 & 7.249 & 7,066 & 6,795 & 5,783 & 6,040 & 6.011 & 6,077 \\
\hline Eloctricity & 337 & 777 & 850 & 1.121 & 1,165 & 865 & 828 & 821 & 836 \\
\hline Total & 17.079 & 22,554 & 23,155 & 26,820 & 27,304 & 26,608 & 27,466 & 27.737 & 28,426 \\
\hline
\end{tabular}

Source: Ministry of Enorgy and Mines, Guatemala.

ancludes some direct use of crude oil in the lote 1970s and early 1980s.

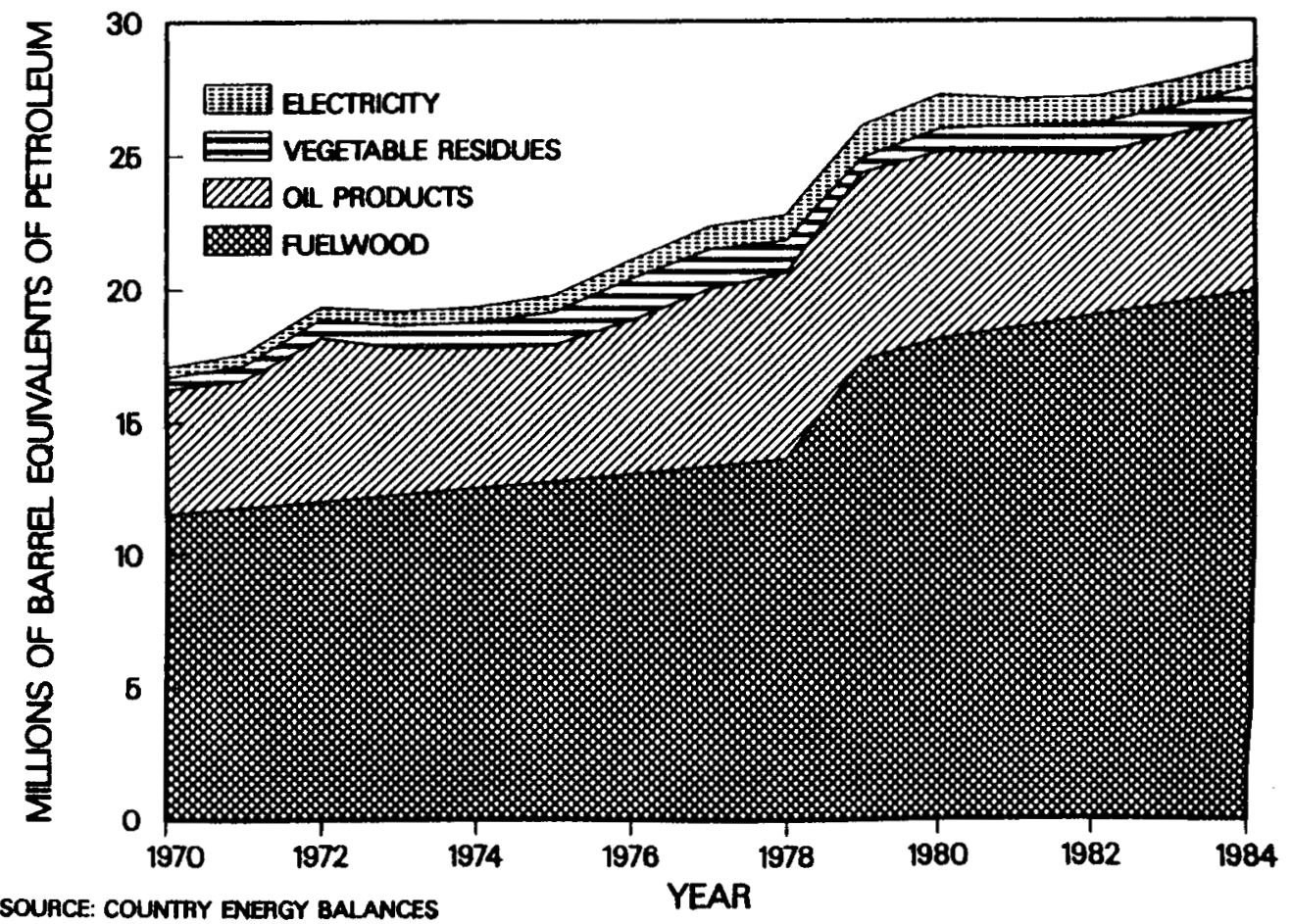

Fig. 8. Guatemala: Energy supply by fuel type. 
A different pattern is evident, however, for individual supply sources. There was a continuous increase in wood supplied from 1970 to 1984 . However, for bagasse, the other primary source, there were substantial increases from year to year until 1976. From 1976 to 1980 supply of this resource declined, in part because of the decline in the market for sugar itself. Bagasse supply has increased during the last four years, but the total supplied still remains below that of 1976. Electricity supply, based principally on rapid increases of thermal conversion, increased steadily until 1980. From 1980 to 1984 the supply of electricity has decreased a total of 8 percent, and the mix of generation has changed from predominantly thermal conversion to one that relies on hydroelectric generation. The supply of oil and its products has fluctuated somewhat more than the supply of the other three sources. Increases were noted from 1970 to 1972, followed by a period of decreases until 1977 when oil supply to final consumption once again increased for several years. From 1982 to 1984 the supply has remained relatively constant at 6 million BEP per year.

The average annual growth rates over three time periods for the energy supply sources are reported in Table 15. The recession of the early 1980s caused the supply of bagasse, oil products, and electricity to decline over the 1978 to 1984 period. In contrast, during the economic growth years of 1970 to 1978 the three energy sources grew at a rapid pace: 12.1 percent for bagasse, 6.1 percent for 011 products, and 12.2 percent for electricity. The fuel-wood growth rate for 1978 to 1984 is artificially high because of the upward adjustment in the supply and demand figures that occurred in 1979. Since fuel wood is the

TABLE 15

GUATEMALA: AVERAGE ANNUAL COMPOUNDED GROWTH RATES FOR ENERGY SUPPLY

(percentage)

\begin{tabular}{|c|c|c|c|}
\hline \multirow[b]{2}{*}{ Source } & \multicolumn{3}{|c|}{ Year } \\
\hline & $70-84$ & $70-78$ & $78-84$ \\
\hline Wood & 4.0 & 2.1 & 6.6 \\
\hline Bagasse & 6.4 & 12.1 & -0.8 \\
\hline Oil \& Products & 2.2 & 6.1 & -2.9 \\
\hline Electricity & 6.7 & 12.2 & -0.3 \\
\hline Total & 3.7 & 3.9 & 3.5 \\
\hline
\end{tabular}

Source: Ministry of Energy and Mines, Guatemala. 
dominant energy source, the total energy supply growth rate for 1970 to 1984 and 1978 to 1984 are biased as well. The following sections discuss in more detail each principal supply source.

2. Petroleum Supply. Petroleum and its products have constituted between 20 and 30 percent of the total supply, with the 7 ast four years averaging 22 percent. If only commercial energy is considered, petroleum products make up approximately 86 percent of that total. This percentage share has ranged from a high of 90 percent in the early 1970s to a low of about 80 percent in 1981 .

Most of Guatemala's crude production is exported, although some has been consumed directly as internal sales. All petroleum products that are consumed in Guatemala must be imported either as the products themselves or as crude to the local refinery. $0 i l$ supply statistics are contained in three tables for the years 1970 and 1977-1984. The first table, Table 16, contains statistics on annual production from the refinery. Table 17 contains annual imports of $0 i 1$ products, and Table 18 summarizes the total oil products supplied from year to year.

The products produced in the refinery are (1) propane and butane; (2) gasoline--both regular and premium, unleaded is not produced; (3) kerosene and jet fuel; (4) diese1; (5) fuel oil or bunker C; and (6) refinery gases, which are used internally in the refining process (see Table 16). Production from the refinery has varied over time, both as to total product quantity and to relative mix of product supplied. In the supply of gasoline, the refinery has generally favored the production of regular-grade fuel, with this trend more noticeable whenever the price difference between premium and regular was increased.

Since 1982 the total supply of gasoline has exceeded that of fuel oil, and this is expected to continue as Guatemala substitutes additional hydroelectric resources for heavy oil-burning thermal electric units.

The individual product shares of total petroleum imports are summarized in Table 19. Because this source of supply is used to match requirements (demand) with available supplies (production from the refinery), there is considerable fluctuation in product mix. Over the last 4 years the relative shares have been fairly stable. Since 1981, gasoline and diesel oil imports together have comprised more than two-thirds of imports. The third largest product import was propane/butane, which constituted about one-fifth of total imports in 1984 .

The proportion of total supplies met by refinery production is shown in Table 20. In the early 1970s and again over the last 4 years, over 90 percent of total fuel oil supplies were produced at the refinery, leaving less than 10 percent that needed to be imported. Since 1978, there has been about an even split between imported supplies and locally produced diesel fuel. The 
TABLE 16

GUATEMALA: REFINERY PRODUCTION

(thousands of barrels)

\begin{tabular}{|c|c|c|c|c|c|c|c|c|c|}
\hline & 1970 & 1972 & 1978 & 1979 & 1980 & 1981 & 1982 & 1983 & 1984 \\
\hline Propone/butane & 102.9 & 43.3 & 51.3 & 30.7 & 19.3 & 22.3 & 24.5 & 31.6 & 57.9 \\
\hline Gasoline & 1390.2 & 1111.4 & 1225.2 & 1125.7 & 919.2 & 922.7 & 844.8 & 882.7 & 1623.4 \\
\hline Kerosene/jet fuel & 623.1 & 497.8 & 564.5 & 630.8 & 536.1 & 482.2 & 418.7 & 464.3 & 480.6 \\
\hline Diesel & 1469.1 & 1473.6 & 1885.7 & 1875.6 & 1750.5 & 1602.1 & 1475.5 & 1444.3 & 1680.5 \\
\hline Fuel oil & 1419.9 & 2009.3 & 2160.2 & 2032.0 & 2069.7 & 2210.6 & 1626.6 & 1385.0 & 1665.0 \\
\hline Other (refinery gases) & 44.2 & 41.6 & 48.7 & 46.6 & 21.6 & 36.8 & 54.4 & 53.7 & 57.8 \\
\hline Total & 5049.4 & 5198.3 & 5958.4 & 5767.4 & 5380.6 & 5344.9 & 4507.6 & 4304.9 & 5008.9 \\
\hline
\end{tabular}

Source: Ministry of Energy and Mines, Guatemalo.

TABLE 17

GUATEMALA: PETROLEUM IMPORTS

(thousands of barrels)

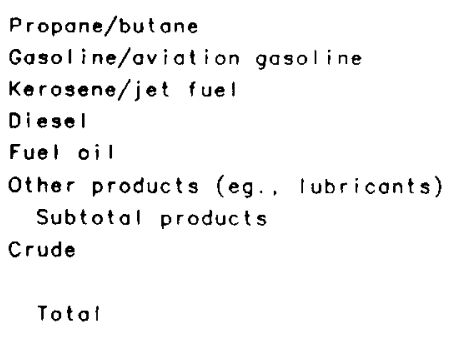

\begin{tabular}{|c|c|c|c|c|c|c|c|c|}
\hline 1970 & 1977 & 1978 & 1979 & 1980 & 1981 & 1982 & 1983 & 1984 \\
\hline 133.7 & 418.7 & 467.3 & 571.1 & 600.0 & 598.5 & 560.0 & 633.1 & 669.4 \\
\hline 113.8 & 1277.2 & 1387.0 & 1597.1 & 1319.3 & 1119.8 & 1125.6 & 1111.1 & 1049.8 \\
\hline 98.8 & 158.6 & 162.6 & 160.4 & 186.0 & 305.2 & 304.6 & 205.5 & 241.8 \\
\hline 7.3 & 1765.8 & 1702.0 & 1809.2 & 1883.2 & 1674.7 & 1598.3 & 1324.0 & 1386.5 \\
\hline 26.9 & 729.5 & 522.5 & 1239.7 & 1165.2 & 131.4 & 147.7 & 139.5 & 0.0 \\
\hline 0.0 & 0.0 & 280.7 & 301.0 & 2154.4 & 225.2 & 195.8 & 166.2 & 207.7 \\
\hline 380.5 & 4713.1 & 4522.1 & 5678.5 & 5370.7 & 4054.8 & 3932.0 & 3579.4 & 3555.2 \\
\hline 5246.0 & 5291.2 & 5829.4 & 5723.5 & 5443.4 & 5324.4 & 4341,4 & 4376.3 & 5331.3 \\
\hline 5626.5 & 10004.3 & 10351.5 & 11402.0 & 10814.1 & 9379.2 & 8273.4 & 7955.7 & 8886.5 \\
\hline
\end{tabular}

Source: Ministry of Energy and Mines, Guatemola.

TABLE 18

GUATEMALA: NET SUPPLY OF OIL PRODUCTS

(thousands of barrels)

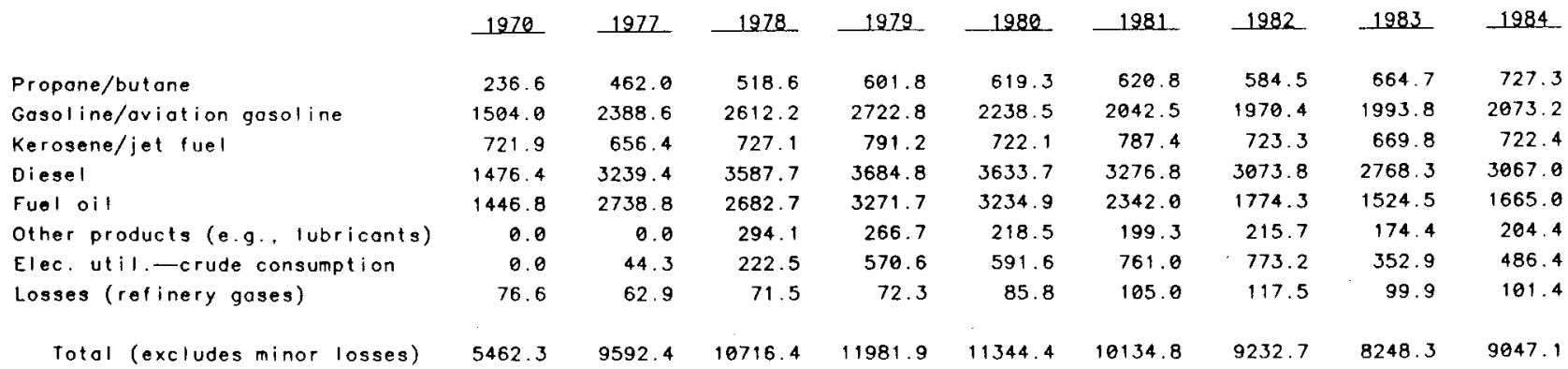

SOURCE: Ministry of Energy and Mines, Guatemalo.

Note: Small quantity of liquid gas exports not included; their inclusion will diminish net supply slightly. 
TABLE 19

GUATEMALA: PERCENTAGE OF PETROLEUM IMPORTS BY PRODUCT

Propane/butane

Gosoline

Kerosene/jet fuel

Diesel

Fuel oil

other (refinery gases)

$\begin{array}{rr}1970 & 1977 \\ 35 & 9 \\ 30 & 27 \\ 26 & 3 \\ 2 & 37 \\ 7 & 15 \\ 0 & 0\end{array}$

1978
10
31
4
38
12
6

1979

1980
11
25
3
35
22
40
100

1981
15
28
8
41
3
6
100

1982

$1983 \quad 1984$

Totol

100

100

100

100

100

100

$\begin{array}{rrr}14 & 18 & 19 \\ 29 & 31 & 30 \\ 8 & 6 & 7 \\ 41 & 37 & 39 \\ 4 & 4 & 0 \\ 5 & 5 & 6\end{array}$

Note: Total may not sum to 100 owing to rounding

TABLE 20

GUATEMALA: PERCENTAGE OF TOTAL OIL PRODUCTS SUPPLIED BY REFINERY

\begin{tabular}{|c|c|c|c|c|c|c|c|c|c|}
\hline & 1970 & 1977 & 1978 & 1979 & 1980 & 1981 & 1.982 & 1983 & 1984 \\
\hline Propane/butane & 43 & 9 & 10 & 5 & 3 & 4 & 4 & 5 & 8 \\
\hline Gosoline/oviotion gasoline & 92 & 47 & 47 & 41 & 41 & 45 & 43 & 44 & 49 \\
\hline Diesel & 100 & 45 & 53 & 51 & 48 & 49 & 48 & 52 & 55 \\
\hline Fuel oil & 98 & 73 & 81 & 62 & 64 & 94 & 92 & 91 & 100 \\
\hline
\end{tabular}

proportion of gasoline supplied at the refinery is again approaching 50 percent after falling below that level in 1977. In addition, approximately two-thirds of the total kerosene and jet fuel supplied comes from the local refinery. Only propane/butane of the five principal petroleum products must be extensively imported: imports were at least 90 percent of total supplies in the years since 1977.

Total products supplied in 1984 were just over the 9-million-barrel level. Product imports exceeded 3.5 million barrels, while refinery products total a little over 5 million barrels. Crude imports exceeded product imports by just under 2 million barrels.

a. 0 il Product Prices. Petroleum product prices in Guatemala are set by the government. The variation in the prices across the country are associated with transportation cost differences. Table 21 presents a history of prices by principal product in Guatemala City.

Several important points should be noted about these product prices. First, the prices are stated in the local currency--quetzales (Q) per gallon (pounds for propane/butane). The official exchange rate was $1 Q=\$ 1$ US until 
TABLE 21

GUATEMALA: OIL PRODUCT PRICES IN GUATEMALA CITY
(quetzoles per galion. quetzoles per 100 pounds for liquid propone gos)

\begin{tabular}{|c|c|c|c|c|c|c|}
\hline Year & Eremium Gaseline & Reqular Gasoline & Kecosene & Diesel & Evel oil & Liquid Propane Gas \\
\hline 1975 & 0.868 & 0.828 & 0.555 & 0.545 & 0.322 & 16.50 \\
\hline 1976 & 0.868 & - & 0.555 & 0.545 & 0.322 & 16.50 \\
\hline 1977 & 0.978 & 0.935 & 0.550 & 0.564 & 0.348 & 17.85 \\
\hline 1978 & 0.978 & - & 0.550 & 0.564 & 0.348 & 17.85 \\
\hline 1979 & 1.600 & 1.550 & 0.760 & 0.770 & 0.566 & 20.40 \\
\hline 1980 & 2.000 & 1.910 & 0.900 & 1.030 & 0.640 & 20.40 \\
\hline 1981 & 2.09 & 2.04 & 1.12 & 1.24 & 1.01 & 20.40 \\
\hline 1982 & 2.07 & 1.90 & 1.12 & 1.20 & 0.848 & 20.30 \\
\hline 1983 & 2.07 & 1.90 & 1.09 & 1.17 & 0.720 & 20.30 \\
\hline 1984 & 2.07 & - & 1.09 & 1.17 & 0.729 & 20.30 \\
\hline 1985 & 3.10 & 2.90 & - & - & - & \\
\hline
\end{tabular}

the fall of 1984. A floating exchange rate replaced the fixed rate at that time and the current exchange has varied between 2.5 to $4 \mathrm{Q}$ per $\$ 1$ US.

Second, the price of gasoline has been considerably higher than that of fuel 0 il, diese1, and kerosene. In effect, these fuels have been subsidized by the Guatemalan government. Bunker $C$ (fuel oil) is used for electric power production as well as for some industrial thermal applications. Diesel oil is used in both commercial transportation and in power generation, and kerosene is used by the commercial sector.

Third, the nominal price of gasoline has remained fairly constant since 1980. It was not until August 1, 1985, that the price increased drastically. From the fall of 1984, when the quetzal was effectively devalued, to the present, gasoline has been priced at less than cost. The price differential between premium and regular gasoline has reflected both differences in refining costs and shifts in demand; many private vehicles can use either fuel interchangeably with performance and mileage improvements noted for premium use.

Fourth, diesel oil prices are substantially below those of gasoline as a means to support the commercial (and public) transportation sectors that are heavily diesel powered; in 1982, regular gasoline was priced about 60 percent higher than diesel. However, the large price differential has also encouraged a dramatic shift toward diesel-powered vehicles within the private sector. An August 1, 1985 50-percent increase in gasoline prices and the continued subsidization of the other product prices will further this shift. 
Fifth, the price for fuel oil was decreased in the 1980s to encourage its use in industry at the expense of industrial diesel consumption. By 1983, fuel $0 i 1$ was about 40 percent cheaper than diesel 011 , Q0.715 versus Q1.17, respectively. There were two rationales for this price adjustment. First, diesel is a more flexible fuel than fuel oil, and its ability to displace gasoline in the transport sector made it very valuable to the economy. Second, Guatemala can rely on the local Texaco refinery to produce enough fuel oil to satisfy the economy's needs, whereas substantial amounts of diesel oil must be imported at high prices.

b. 0il Refining. Two refineries exist in Guatemala although only one is currently in operation. The Refineria Texas Petroleum Company (TEXPET) is 10cated in the south of the country, 40 kilometers from Puerto San Jose, and receives input via a pipeline to the port. The refinery contains an atmospheric distillation unit, a hydro-desulphurizer, and a catalytic reformer. TEXPET has a capacity of 17,500 barrels per day of spiked crude $0 i 1$ ( $\left.35^{\circ} \mathrm{API}\right)$. The product mix is shown in Table 22. The product mix depends of course on the nature of the refining process, but it has varied to some degree over the years depending on whether a significant amount of fuel oil was required for thermal electricity generation. When it became apparent that the Chixoy hydroelectric plant would not be in full operation in 1983, the refinery had to continue to produce more fuel oil until Chixoy could be recommissioned in 1986. The refinery has operated since 1965, and its products supply about 50 percent of domestic demand

TABLE 22

GUATEMALA: INSTALLED REFINERY PRODUCTION CAPACITY BY PRODUCT FOR 1983 (barrels per day)

Preduct
Maximum capacity
Gas and GLP
Kerosene and turbo jet fuel
Gasoline
Diesel
Fuel oil

Lexos Petreleum_compony

17,600

200

1,950

3,450

5,800

6,200

Source: Ministry of Energy and Mines, Guatemala. 
for petroleum products. The economic feasibility of continued operation will be evaluated.*

TEXPET acquires crude petroleum feed from Mexico and Venezuela according to terins of the San Jose Accord. Two types of crude are shipped from each country: Ismos (1ight crude) and Mayan (heavy crude) from Mexico, and Lago Medio (base medium crude) and reconstituted crude that is a mixture of some initial distilled products from Venezuela. Depending upon the required product mix from the refinery and on product price information, instructions are issued monthly to Venezuela as to the exact mix of reconstituted crude. In the Spring of 1985 the following prices per barrel were paid for Venezuelan oil: Lago Medio $\left(32^{\circ}\right.$ API), $\$ 28.35$; heavy and light napthas, $\$ 31.08$; kerosene and stove $011, \$ 30.66$; and gasoil, $\$ 30.87$. The Mexican crude varies in price and average API depending upon the mix of Mayan and Ismos crudes, and recently the price has dropped somewhat owing to a larger proportion of less expensive Mayan crude being used.

Table 23 contains information on the relative shares of each product in total refinery production. Although there have been some product shifts through time, the mix has been fairly stable since 1978. Fuel oil's share reached a peak of 41 percent in 1981 and then declined to its present 33 percent. Gasoline and diesel were the principal products whose shares increased during the 1981 to 1984 period. In 1984, an essentially equal share of fuel oil and

TABLE 23

GUATEMALA: PERCENTAGE OF TOTAL REFINERY PRODUCTION BY PRODUCT

Propane/butane

Gasoline

Kerosene/jet fuel

Diesel

Fuel oil

other (refinery goses)

Total

$\begin{array}{rrrrrr}1970 & 1977 & 1978 & 1979 & 1980 \\ 2 & 1 & 1 & 1 & 0 \\ 28 & 21 & 21 & 20 & 17 \\ 12 & 10 & 9 & 11 & 10 \\ 29 & 28 & 32 & 33 & 33 \\ 28 & 39 & 36 & 35 & 38 \\ 1 & 1 & 1 & 1 & 0 \\ 100 & 100 & 100 & 100 & 100\end{array}$

1981
0
17
9
30
41
1
100

1982
1
19
9
33
36
1
100

1983
1
21
11
34
32
1

1984

1

20

34

33

100

Note: Total may not sum to 100 owing to rounding.

* Information provided by Rolando Yon Siu, Ministerio de Energia y Minas, Guatema1a, May 1986. 
diese1--33 percent--was produced at the refinery. Gasolines, premium and regular, made up another 20 percent of refined products, and kerosene and jet fuel comprised the bulk of the remaining 13 percent. Kerosene continued to exceed jet fuel supplied by an approximate $60 / 40$ ratio.

The other refinery, Refineria Guatemala California, Inc. (Guatcal), operated from 1963 through 1975 and had a maximum capacity of 12,000 barrels per day. It is located in the north of the country at Santo Tomas de Castilla, and it serves at present as storage capacity for imported oil products.

oil products are distributed within the country via trucks. The feasibility of a pipeline will be considered by the government in the future.

There are four major distributors of $0 i 1$ products in Guatemala. In addition to TEXACO (TEXACO Guatemala, Inc.) which distributes not only its own refined products but also some imported products, there are ESSO Central America, S.A., Guatemala SHELL Compania Distribuidora, and Compania Petrolera CHEVRON, which import products for distribution. There are also several companies that serve as prime distributors for liquid gases (propane and butane) and other petroleum refined products such as lubricants.

3. Electricity Supply. INDE is charged by 1 aw to supply electricity to the country. Much of the country's electricity, particularly around Guatemala City, is distributed and sold by EEGSA. In addition, there are 10 municipal utilities in Guatemala and a few private producers that generate electricity for their own use. In 1984 , EEGSA made 81 percent of the sales to final consumers, INDE, 13 percent, and municipal utilities, 6 percent. As of 1986, INDE reports to the Minister of Energy and Mines. EEGSA is 92-percent owned by INDE and the general public owns the remainder. 5

a. Production. In 1986, if the Chixoy plant is assigned a capacity of 300 MW, total electric generating capacity in the country will be $838 \mathrm{MW}$. Of this total, 59 percent is hydroelectric and 41 percent is thermal. (Although $300 \mathrm{MW}$ is Chixoy's plate capacity, its effective net capacity is expected to be less than this amount.) The ownership of the capacity is as follows: INDE, 79.3 percent; EEGSA, 11.5 percent; municipal utilities, 0.3 percent; and private industry, 8.2 percent. Similar data for recent years are shown in Figure 9 and Table 24. A description of the publicly owned generating facilities occurs in Table 25.

In 1981, three hydroelectric plants were under construction: Chixoy (300 MW), Chulac (440 MW), and Santa Maria II (68 MW). Chixoy came on stream in 1983 but had to be closed during 1984-85 for tunnel repair. Electricity demand slumped in the early 1980s, and as a result, INDE revised its demand estimates and expansion plans. The Chulac and Santa Maria II plants were originally 


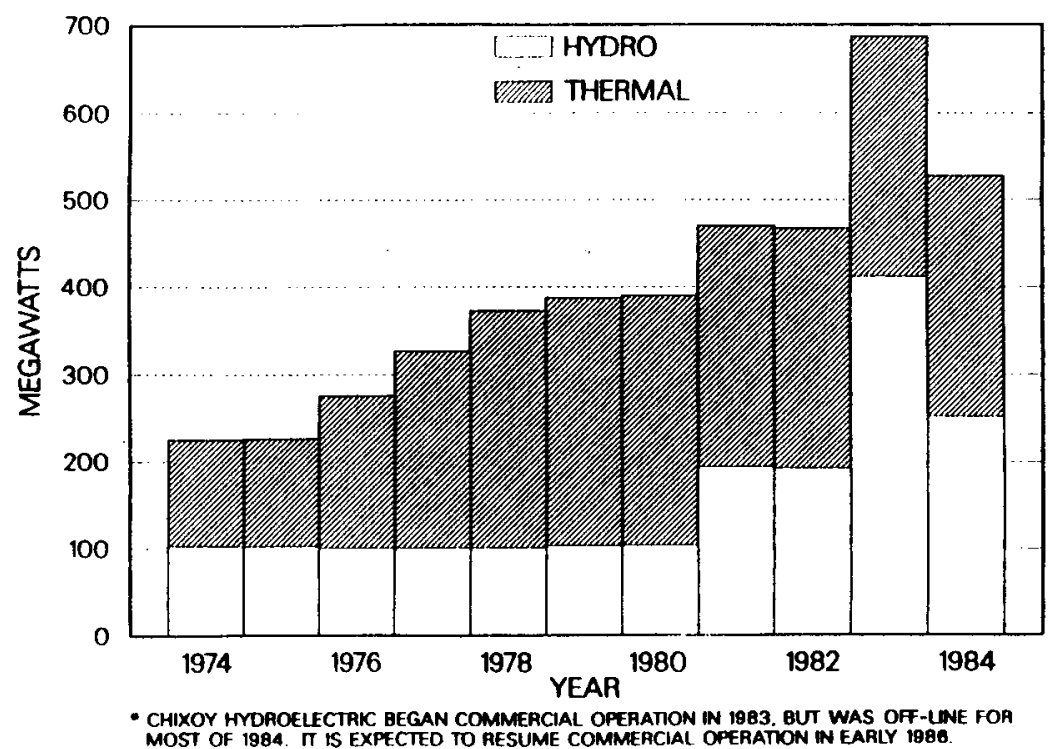

SOURCE: MINISTRY OF ENERGY AND MINES, GUATEMALA.

Fig. 9. Guatemala: Installed electric generating capacity.

TABLE 24

GUATEMALA: INSTALLED ELECTRIC GENERATING CAPACITY

(MW)

\begin{tabular}{|c|c|c|c|c|c|}
\hline & Hydre & $\begin{array}{l}\text { Percentage } \\
\text { of Iotal }\end{array}$ & Ihermal & $\begin{array}{l}\text { Percentage } \\
\text { of Letal }\end{array}$ & Total \\
\hline 1974 & 102.9 & 46 & 122.8 & 54 & 225.7 \\
\hline 1975 & 102.9 & 45 & 123.9 & 55 & 226.8 \\
\hline 1976 & 101.0 & 36 & 175.5 & 64 & 276.5 \\
\hline 1977 & 100.9 & 31 & 225.8 & 69 & 326.7 \\
\hline 1978 & 100.9 & 27 & 272.1 & 73 & 373.0 \\
\hline 1979 & 103.0 & 26 & 284.9 & 74 & 387.9 \\
\hline 1980 & 103.4 & 26 & 287.1 & 74 & 390.5 \\
\hline 1981 & 193.8 & 41 & 276.4 & 59 & 470.2 \\
\hline 1982 & 192.4 & 41 & 274.9 & 59 & 467.3 \\
\hline $1983^{\circ}$ & 412.2 & 60 & 274.7 & 40 & 686.9 \\
\hline 1984 & 252.4 & 48 & 274.7 & 52 & 527.1 \\
\hline
\end{tabular}

Source: National Institute of Electrificotion (INDE).

'The Chixoy hydroelectric project began commercial operation in 1983 but was off line for most of 1984. It is expected to resume commercial operation in eorly 1986 . 
TABLE 25

GUATEMALA

INSTALLED CAPACITY OF PLANTS IN SERVICE, 1983

\begin{tabular}{|c|c|c|c|c|}
\hline System & $\begin{array}{l}\text { No. of } \\
\text { Units }\end{array}$ & $\begin{array}{l}\text { Capocity } \\
(\mathrm{kW})\end{array}$ & $\begin{array}{c}\text { Dote of } \\
\text { Insted }\end{array}$ & Department \\
\hline Netional Interconnected & & 664,320 & & \\
\hline Hydre & & 407,720 & & \\
\hline Chixoy & 5 & 300,000 & 1983 & Alto Verapaz \\
\hline Aguocapa & 3 & 60,000 & $02-82$ & Sonta Roso \\
\hline Jurun Marinala & 3 & 60.000 & $02-70$ & Escuintla \\
\hline Esclavos & 2 & 13,500 & $88-66$ & Santa Rosa \\
\hline El Salto & 2 & 5,500 & $07-54$ & Escuintla \\
\hline Son Luis & 2 & 5,000 & $10-27$ & Escuintla \\
\hline Polin & 3 & 1.820 & $09-27$ & Escuintla \\
\hline Rio Hondo & 2 & 2,400 & $02-62$ & Zocopo \\
\hline Santa Maria & 3 & 6,520 & $86-66$ & Quezaltenango \\
\hline El Porvenir & 1 & 2,280 & $09-68$ & Son Marcos \\
\hline Chichaic & 2 & 700 & $07-79$ & Alta Verapaz \\
\hline \multicolumn{5}{|l|}{ Ihermal } \\
\hline Steam & & 116,000 & & \\
\hline Escuintla Vopor I & 1 & 33,000 & $85-72$ & Escuintlo \\
\hline Escuintla Vopor II & 1 & 53.000 & $04-77$ & Escuintla \\
\hline Laguna Vapor (EEGSA) & 4 & 30,000 & 1961 & Guatemala \\
\hline Gas Turbine & & 134,400 & & \\
\hline Escuintla Gos 1 y 2 & 2 & 25.000 & $05-68$ & Escuintlo \\
\hline Escuintla Gas 3 y 4 & 2 & 50,000 & $08-76$ & Escuintla \\
\hline Laguno Gas 1 (EEGSA) & 1 & 12,500 & 1964 & Guatemala \\
\hline Laguno Gas 2 y 3 (EEGSA) & 2 & 46,900 & - & Guatemala \\
\hline Diesel & & 6,200 & & \\
\hline San Felipe & 1 & 1.200 & $05-65$ & Retalhules \\
\hline La Castellano (EEGSA) & 5 & 5,000 & 1956 & Guatemala \\
\hline \multicolumn{5}{|l|}{ SELF PRODUCERS } \\
\hline \multicolumn{5}{|l|}{ Atlantico } \\
\hline Diese1 & & 11,925 & & \\
\hline Puerto Borrios & 10 & 9,620 & 1977 & Izobal \\
\hline Livingston & 6 & 550 & 1975 & I zabal \\
\hline El Estor & 4 & 855 & $99-81$ & Izobal \\
\hline \multicolumn{5}{|l|}{ Peten } \\
\hline Diesel & & 3,785 & & \\
\hline Melchor de Mencos & 4 & 350 & $09-76$ & Peten \\
\hline Santo Eleno & 9 & 2.950 & 1978 & Peten \\
\hline Poptun & 3 & 485 & $12-80$ & Peten \\
\hline \multicolumn{5}{|l|}{ Alto Veropez } \\
\hline Diesel & & 350 & & \\
\hline Sebol & 4 & 350 & $04-80$ & Alta Verapaz \\
\hline
\end{tabular}


scheduled to be commissioned in 1984 and 1988, respectively. In 1982, INDE stopped construction activities on the latter two plants owing to the slump in demand. Currently, electricity demand is expected to increase at a rate of 4.7 percent per year from 1984-88 and 6.6 percent per year from 1989-93.5

With the recent repair and reopening of Chixoy, present capacity is sufficient to satisfy demand through 1991, when the Zunil I geothermal project (15 MW) is expected to be completed. The next new project is required to be on line in 1993. With assistance from the IDB and the World Bank, INDE will evaluate the feasibility of their potential projects and select one for construction in 1988. Santa Maria II is considered economic and will probably come on stream in 1993. A second geothermal plant, Zunil II ( $55 \mathrm{MW}$ ), will be evaluated also. Large hydroelectric plants (e.g., Chulac) are not expected to be included in the near-term expansion plans because they are not currently economic. The costs of some recent projects are shown in Table $26 .{ }^{5}$ Past investment and planned investment are contained in Tables 27 through 29.

TABLE 26

GUATEMALA: COST OF CAPACITY AND ENERGY AT RECENTLY COMPLETED AND PLANNED ELECTRICITY PROJECTS

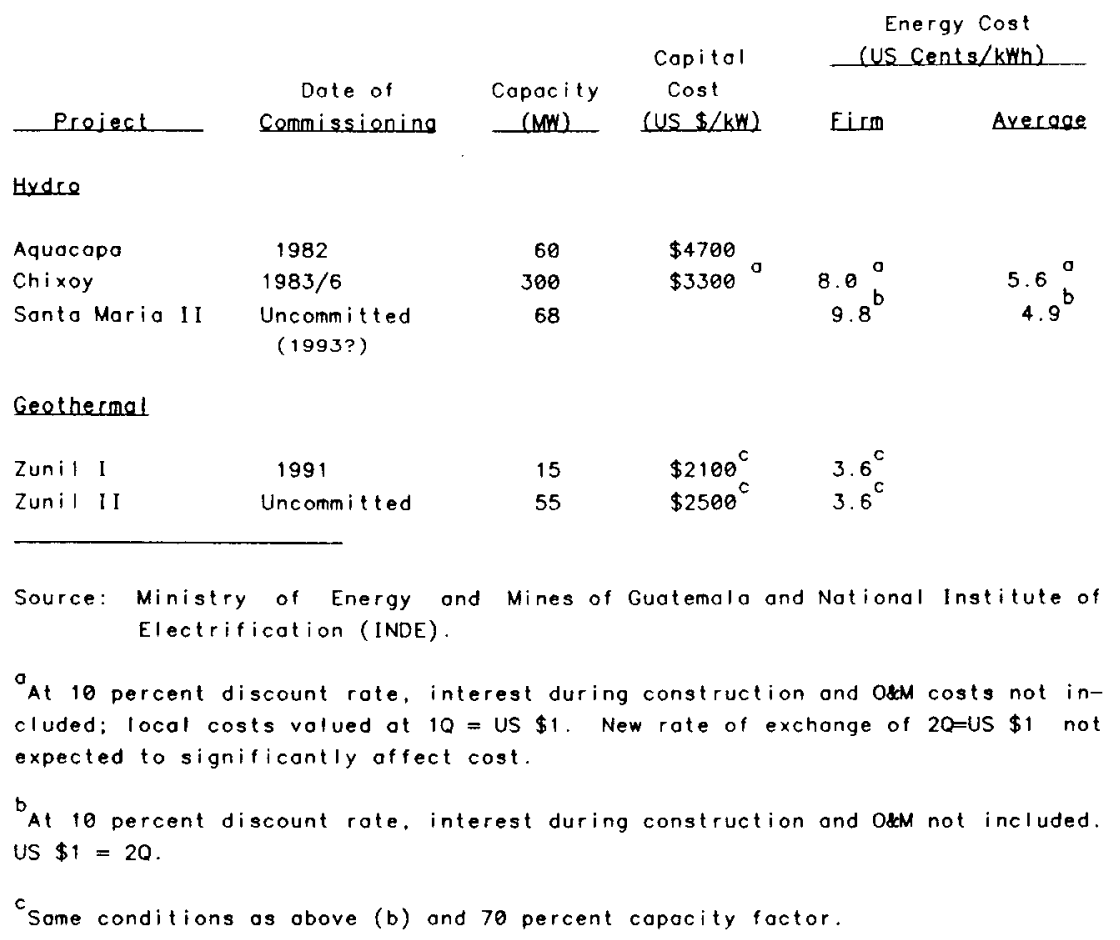


TABLE 27

GUATEMALA: INDE INVESTMENT PROGRAM 1987-1993

(Thousands of 1985 Dollars)

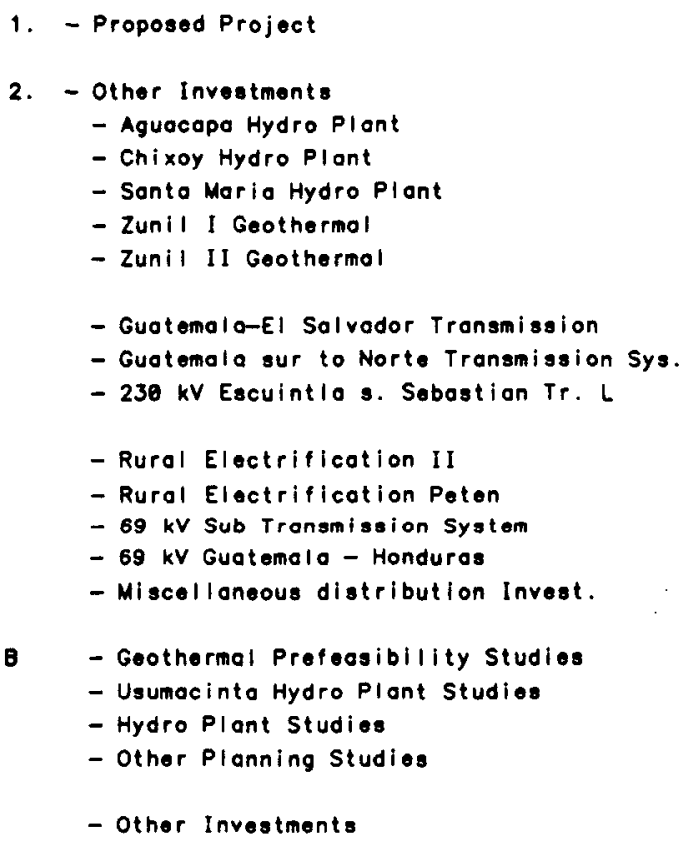

\begin{tabular}{|c|c|c|c|c|c|c|c|}
\hline 1987 & 1988 & 1989 & 1990 & 1991 & 1992 & 1993 & $\begin{array}{l}\text { Total } \\
87-93\end{array}$ \\
\hline 11380 & 10400 & 8520 & 6480 & 5070 & 0 & 0 & 41850 \\
\hline 2000 & 0 & 0 & 0 & $\theta$ & 0 & 0 & 2000 \\
\hline 0 & 0 & 0 & 0 & 0 & 0 & 0 & 0 \\
\hline 0 & 0 & 0 & 36000 & 48000 & 36000 & 0 & 120000 \\
\hline 6500 & 9179 & 10647 & 4073 & $\theta$ & 0 & 0 & 30394 \\
\hline 0 & 0 & $\theta$ & 0 & $\theta$ & 0 & 69600 & 69000 \\
\hline 235 & 0 & 0 & 0 & 0 & 0 & 0 & 235 \\
\hline 0 & 0 & 0 & 0 & $\theta$ & 0 & 0 & 0 \\
\hline 5655 & 5655 & 0 & 6 & 0 & 0 & $\theta$ & 11310 \\
\hline 0 & $\theta$ & 0 & 0 & 0 & 0 & $\theta$ & 0 \\
\hline 800 & 1100 & 1300 & 1500 & 1700 & 4000 & 0 & 10400 \\
\hline 4440 & 8646 & 5416 & 3395 & 1887 & 630 & 600 & 25014 \\
\hline 0 & 0 & 0 & 0 & 0 & 0 & 0 & 0 \\
\hline 350 & 400 & 400 & 400 & 400 & 400 & 400 & 2750 \\
\hline 2010 & 10066 & 1200 & $\theta$ & 0 & $\theta$ & 0 & 14004 \\
\hline 2241 & 767 & 1000 & 4000 & 7000 & 6000 & 6000 & 27000 \\
\hline 3047 & 1837 & 683 & 175 & $\theta$ & 0 & 0 & 5742 \\
\hline 5260 & 5740 & 5300 & 3000 & 3800 & 3800 & 3800 & 31440 \\
\hline 1700 & 1900 & 1900 & 1900 & 190 & 0 & 0 & 7590 \\
\hline 34986 & 45290 & 27841 & 55243 & 62977 & 50830 & 79880 & 156967 \\
\hline 46366 & 55690 & 36361 & 61723 & 68047 & 50830 & 79860 & 398817 \\
\hline 7820 & 7920 & 5950 & 4290 & 3369 & 0 & 0 & 29340 \\
\hline 3560 & 2480 & 250 & 2190 & 1710 & 0 & 0 & 12510 \\
\hline & & & & & & & 0 \\
\hline 19817 & 31038 & 14004 & 28458 & 35889 & 27744 & 48300 & 205330 \\
\hline 16344 & 14252 & 93757 & 26785 & 27688 & 23086 & 31500 & 152812 \\
\hline
\end{tabular}

Source: Ministry of Energy and Mines, Guotemala.

OFigures may not add up becouse they have been rounded off. 
IABLE 28

GUAIEMALA: EECSA INVESTMENI PROGRAM 1987-1993

(Thousonds of 1985 Dollars)

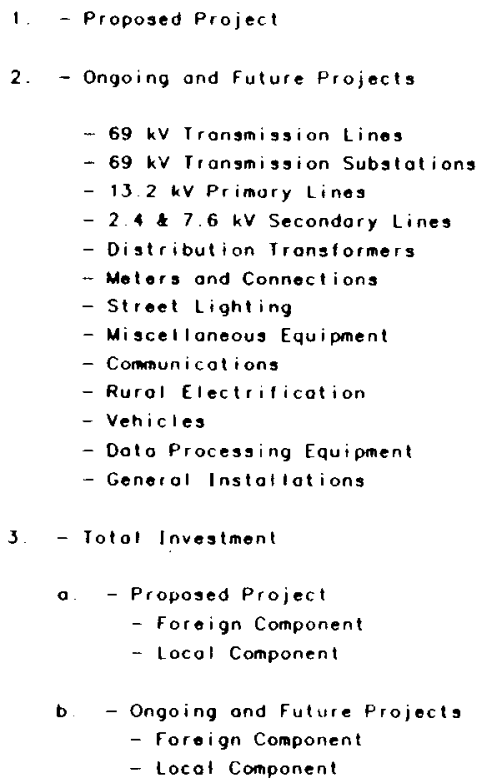

Projects

\begin{tabular}{|c|c|c|c|c|c|c|c|}
\hline .1987 & -1988 & 1989 & -1990 & 1991 & 1992 & -1993 & $\begin{array}{r}\text { Totol } \\
87-93\end{array}$ \\
\hline 4310 & 6390 & 8470 & 7410 & 6490 & 4960 & 1050 & 39080 \\
\hline 1881 & 2553 & 1527 & 1259 & 503 & 4158 & 6434 & 18315 \\
\hline - & 0 & 0 & 0 & $\theta$ & 285 & 0 & 285 \\
\hline 0 & 0 & 0 & $\theta$ & $\theta$ & 184 & $\theta$ & 184 \\
\hline 0 & 0 & 0 & $\theta$ & 0 & 653 & 1719 & 1872 \\
\hline 0 & 0 & 0 & $\theta$ & 0 & 354 & 743 & 1097 \\
\hline 0 & 0 & 0 & $\theta$ & 0 & 350 & 717 & 1075 \\
\hline 0 & D & D & $\theta$ & $\theta$ & 397 & 760 & 1157 \\
\hline 0 & - & $\theta$ & 0 & $\theta$ & 374 & 736 & 1110 \\
\hline 0 & 0 & $\theta$ & $\theta$ & $\theta$ & 136 & 274 & 410 \\
\hline 0 & 0 & $\theta$ & 0 & 0 & 105 & 0 & 185 \\
\hline 0 & - & 0 & 0 & 0 & 600 & 1200 & 1800 \\
\hline 402 & 614 & 356 & 507 & 401 & 615 & 735 & 3710 \\
\hline 109 & 669 & 971 & 322 & 52 & 57 & 0 & 2175 \\
\hline 1370 & 1270 & 200 & 350 & 50 & 50 & 50 & 3340 \\
\hline 6191 & 8943 & 9997 & 8669 & 6993 & 9118 & 7484 & 57395 \\
\hline 2580 & 3840 & 5200 & 4520 & 3900 & 7480 & 630 & 78650 \\
\hline 1730 & 2550 & 3270 & 2890 & 2590 & 1980 & 420 & 15430 \\
\hline 509 & 1253 & 1331 & 883 & 451 & 2631 & 3863 & 10921 \\
\hline 1372 & 1300 & 196 & 376 & 52 & 1527 & 2571 & 7394 \\
\hline
\end{tabular}

Source: Ministry of Energy and Minos, Guotemalo.

"Figures may not odd up becouse they have been rounded of"

TABLE 29

GUATEMALA: ONGOING INVESTMENTS OF INDE (amount of money invested in ooch yeor in selocted projocts) (thousands of quatzales)

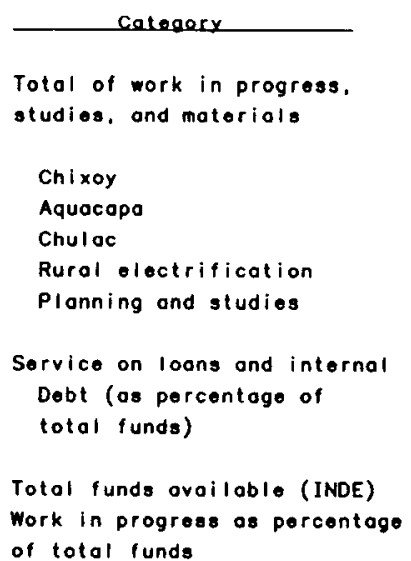

of total funds

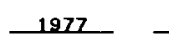

$38,126.0$

37.596 .1
2.340 .2
-
1.742 .9
3.077 .6
$(3.1 \%)$

97.420 .6

39.17
1978

$103,073.5$

69.901 .0

$38,509.0$

273.0

4.646 .0

$3,658.0$
192

$144,141.7$$$
78,047 .
$$$$
48.262 \text {. }
$$$$
355.0
$$

8.842 .0

$9,842$.

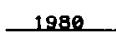

186.125 .0

117.478 .2

46.495 .0

646.0

203.0

9.189 .0

$6,756.0$

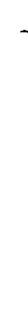

$160,164.3$

5.781 .0

31.372 .0

6.540 .

$9,536.0$

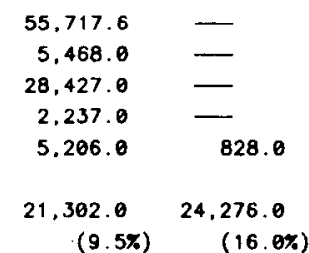

(4.5\%)

(9.5\%)

Sourco: Notional Institute of Electrification (INDE).

- preliminary 
INDE is expanding the transmission and distribution grid into currently unelectrified areas. In 1983, $159 \mathrm{~km}$ of high-voltage transmission line (230 kv) was added to the Central System, and a total of $331 \mathrm{~km}$ of lower voltage wire was installed in the other systems. To get the electricity into the households, the distribution network has also been expanded (see Table 30). The Occidental System, located in the southwest highlands of the country, received about 75 percent of the new distribution 1 ines in 1983 (over $100 \mathrm{~km}$ ) at a cost of over Q1 million. This region is characterized by extreme poverty, and should be greatly benefitted by the availability of electricity. The total cost of the 1983 grid expansion effort was about Q1.5 million.

The investment in new grid lines is part of the rural electrification project begun by INDE in 1980 . Its goals are to electrifiy 186 communities by the end of 1985 and obtain 70,000 additional users (both residential and commercial) in rural areas. It is estimated that this project will require a total of $321 \mathrm{~km}$ of new transmission 1 ines and over $600 \mathrm{~km}$ of grid distribution wire. ${ }^{6}$ The annual investment in this project peaked in 1982 , when $\$ 6.5$ million US was spent (see Table 29). Spending on rural electrification in Peten is expected to total $\$ 10.4 \mathrm{milli}$ ion between 1987 and $1993 .^{5}$

b. Utility Expansion Plans. Total production of electricity has increased at an average compounded rate of 6.3 percent annually during the 1970 to 1984 period, from 604 GWh to 1,415 GWh (see Table 31). As with all of the Central American countries, Guatemala has attempted to diversify its electricity production away from foreign $0 i l$ by increasing its use of hydropower. In 1974,

TABLE 30

GUATEMALA: DISTRIBUTION GRID CONSTRUCTED IN 1983

\begin{tabular}{|c|c|c|}
\hline Regional System & Iotalengen & Investment (0) \\
\hline Occidental system & 108.4 & $1,018,580$ \\
\hline Oriental system & 20.2 & 241,917 \\
\hline Norcentral system & 14.0 & 200,000 \\
\hline Atlantico system & 2.6 & 15,027 \\
\hline Total, all systems & 145.2 & $1,475,524$ \\
\hline
\end{tabular}


TABLE 31

GUATEMALA: ELECTRICITY GENERATION (INTERCONNECTED SYSTEM)

(GWh)

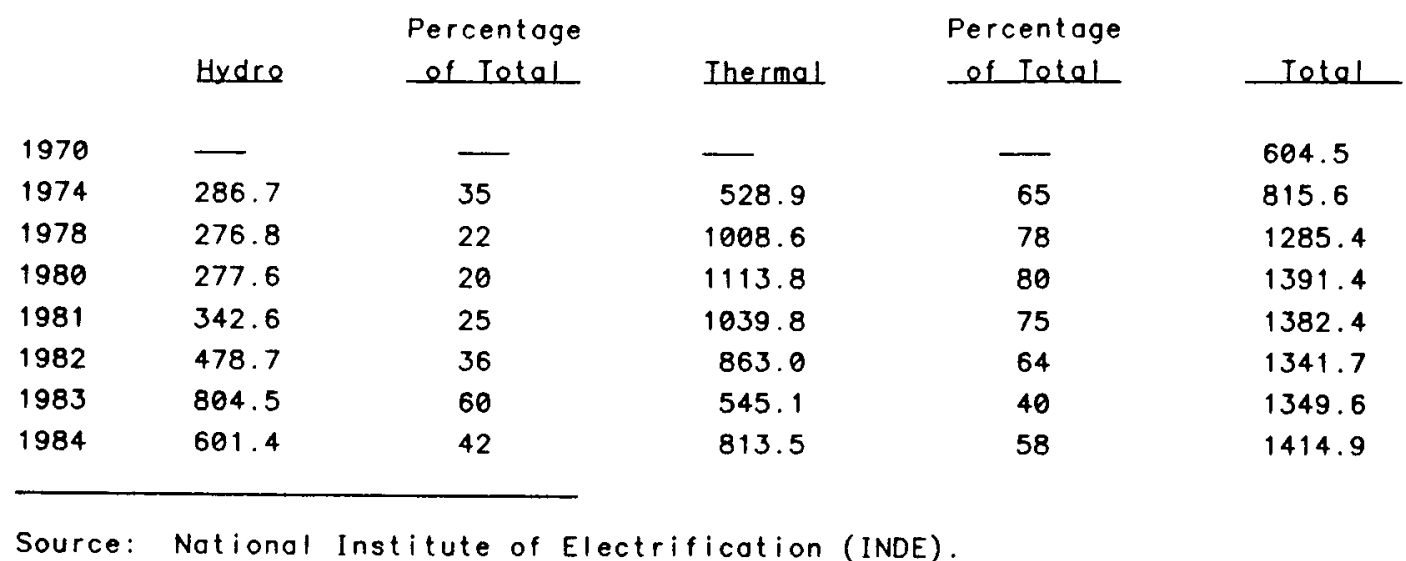

hydroelectric power comprised only 35 percent of the net generated electricity. ("Net generation" is equal to gross generation minus internal consumption). In addition, because electricity production continued to grow and hydro capacity actually decreased during the late 1970s and early 1980s, this percentage actually decreased to about 22 percent. The percentage from hydropower did not again reach 35 percent until 1982. The addition of the Aquacapa plant in 1982 and the large Chixoy project in 1983 brought the proportion generated from hydropower back up to about 60 percent in 1983. In this year the total consumption of oil for electricity generation was only 1.3 million barrels, less than half the 2.8 million in 1980 (see Table 32). Unfortunately, because of problems with the long pressure tunnel in the Chixoy plant, the plant had to be shut down for repairs during much of 1984 and 1985. As a consequence, thermal generators had to fulfill the unsatisfied demand, and thermal electricity generation once again contributed more than half of the total in 1984 (see Table 30). Because Chixoy recently came on line substantial oil import reductions have occurred.

INDE had about 416,000 customers connected to the national grid in 1983 (see Table 33). This represents an average annual increase in the number of customers of 10.3 percent over the 1974 total of 172,175 . The two sectors with the fastest rate of user growth are residential and commercial, with 10.2 and 11.2 percent, respectively.

c. Prices and Costs. INDE's electricity prices to the final user are quite high relative to those of other Central American electric utilities. The 
TABLE 32

GUATEMALA: FUELS CONSUMED FOR ELECTRICAL GENERATION

(thousonds of barrel equivalents of petroleum)

\begin{tabular}{|c|c|c|c|c|c|c|c|}
\hline & & Vegetable & Crude & & Diesel \& & & \\
\hline & & Residues & Petreleum & Hydre & Gasoil & Euel oil & Iotal Petreleun \\
\hline 1978 & public service & - & - & 187.2 & 302.4 & 468.0 & 770.4 \\
\hline & Self producers & 79.2 & - & - & - & - & $\theta$ \\
\hline 1978 & public service & - & 23.0 & 214.6 & 1.112 .4 & $1,149.4$ & $2,584.8$ \\
\hline & Self producers & 617.0 & - & 5.0 & 43.2 & 222.5 & 265.7 \\
\hline 1979 & public service & - & 361.4 & 213.1 & 959.0 & 1.468 .1 & $2,788.5$ \\
\hline & Self producers & 568.1 & - & $\longrightarrow$ & 51.8 & 456.5 & 568.3 \\
\hline 1980 & public service & - & 373.7 & 220.3 & 763.2 & 1.681 .9 & 2.818 .8 \\
\hline & Self producers & 666.0 & - & - & 12.2 & 505.4 & 517.6 \\
\hline 1981 & public servico & - & 418.3 & 271.4 & 524.9 & 1.728 .0 & 2.671 .2 \\
\hline & Self producers & 684.0 & - & - & 15.1 & - & 15.1 \\
\hline 1982 & public service & - & 535.7 & 378.0 & 344.2 & 1.283 .0 & $2,162.9$ \\
\hline & Self producers & 799.2 & - & - & 12.2 & - & 12.2 \\
\hline 1983 & public service & - & 308.2 & 630.0 & 275.8 & 757.4 & 1.341 .4 \\
\hline & Solf producers & 689.0 & - & - & 10.1 & - & 10.1 \\
\hline 1984 & public service & - & 483.1 & 473.0 & 416.9 & 949.7 & 1.849 .7 \\
\hline & Self producers & 690.5 & - & - & 10.8 & - & 10.8 \\
\hline
\end{tabular}

Source: Ministry of Energy and Mines, Guotemala.

TABLE 33

GUATEMALA: NUMBER OF CUSTOMERS IN THE INTERCONNECTED SYSTEM

\begin{tabular}{|c|c|c|c|c|c|c|c|c|c|c|}
\hline & 1974 & 1975 & 1976 & 1972 & 1978 & 1979 & 1980 & 1981 & 1982 & 1983 \\
\hline Residentiol & 144.013 & 176,764 & 188,314 & 209,305 & 233,420 & 252.925 & 270,981 & 292,180 & 320.379 & 344,990 \\
\hline Commercial & 24,629 & 30.305 & 34,052 & 39,087 & 45.682 & 50.858 & 54.641 & 58.428 & 61,384 & 64,319 \\
\hline Industriol & 1.081 & 1.307 & 1.452 & 1.570 & 1,721 & 1.586 & 1.544 & 1.568 & 1.686 & 1.718 \\
\hline Public & 2,452 & 3.264 & 3.357 & 3.283 & 3,705 & 3,954 & 4.087 & 4.359 & 4.678 & 4.913 \\
\hline Total & 172,175 & 211,640 & 227.185 & 253,245 & 284,528 & 309.323 & 331,253 & 356.535 & 388,127 & 415,940 \\
\hline
\end{tabular}

Source: National Institute of Electrification (INDE). 
average price per kilowatt hour in 1984 was $\$ 0.144$ US (see Table 34), whereas the average for three of the other four countries in this study was about $\$ 0.08$ US (Honduras is lacking electricity price data, see Overview, Sec. III B.3). The $\$ 0.144$ US per kWh reflects an exchange rate of $1 Q=\$ 1$ US. In a recent World Bank study of the power sector, 5 a one-to-one rate was still being used by the Bank to translate electricity prices into dollars. During the 10-year period from 1974 to 1984, INDE's price for electricity rose on average 12.8 percent per year, substantially faster than Guatemala's prices in general (as shown by implicit GDP deflator's increase of 8.8 percent annually for the same period). 7 Electricity prices to industry have risen faster than those to the other sectors, with a 17 percent average annual growth during the 1974 to 1984 period.

Because INDE has depended to a large extent on $0 i 1$ for electricity generation, its costs per kilowatt hour were relatively high. In 1983 the average cost per kilowatt hour from thermal units was 8.43 cents, but because of the decline in world oil prices, by 1984 the cost dropped to only 7.39 cents per KWh (see Table 35). Depending on world supply and demand conditions for the respective oil products, the relative operating cost of the various types of thermal generators can change substantially. For example, in 1983 diesel generation was 46 percent more expensive per kilowatt hour than fuel oil (10.72 cents for diesel versus 7.35 cents for fuel oil), while in 1984 it was 85 percent more expensive (9.6 cents for diesel versus only 5.2 cents for fuel oil). In 1984 , some Q56 million worth of crude and oil products were purchased by INDE for thermal generation (see Table 35).

4. Noncommercial Energy Supply. The supply of wood to both residential and industrial sectors has steadily grown. Between 80 and 90 percent of wood supplies go to support needs of the residential population, principally for cooking fuel, the remainder to support industrial activities. Charcoal has also been a significant energy source in Guatemala, although supplies of charcoal have declined. Table 36 presents summary statistics on wood supplied in Guatemala from 1970 to 1984. Supply estimates are based, in part, on a per capita consumption of wood estimate. Although the total population dependent upon wood supplies has grown every year, the proportion of population dependent on wood has dropped from 85 percent in 1960 to just over 77 percent in 1984 .

Supplies of wood are projected to become tighter in the future as resources near the population centers are depleted. In addition, wood demand will continue to increase as the population grows and industry expands its consumption of this resource. Wood is the only energy source available to most of the 
TABLE 34

GUATEMALA: PRICE OF ELECTRICITY BY SECTOR

(quetzales/kWh)

\begin{tabular}{|c|c|c|c|c|c|}
\hline & Residential & Conmerciol & Industrial & $\begin{array}{l}\text { Government } \\
\text { and } \\
\text { Municipal }\end{array}$ & Average \\
\hline 1974 & .047 & .052 & .038 & .036 & .043 \\
\hline 1975 & .060 & .055 & .044 & .042 & .050 \\
\hline 1976 & .063 & .061 & .048 & .048 & .055 \\
\hline 1977 & .066 & .062 & .051 & .049 & .057 \\
\hline 1978 & .075 & .071 & .058 & .057 & .065 \\
\hline 1979 & .088 & .089 & .078 & .068 & .081 \\
\hline 1980 & .117 & .120 & .112 & .094 & .111 \\
\hline 1981 & .139 & .142 & .134 & .114 & .132 \\
\hline 1982 & .124 & .144 & .140 & .115 & .131 \\
\hline 1983 & .121 & .143 & .138 & .113 & .129 \\
\hline 1984 & .140 & .123 & .182 & .131 & .144 \\
\hline
\end{tabular}

Source: National Institute of Electrificotion (INDE).

TABLE 35

GUATEMALA: COST OF OIL USED BY INDE AND EEGSA, 1983 AND 1984

\begin{tabular}{|c|c|c|c|c|}
\hline Total cost (thous. Q) & $25,025.1$ & 17.157 .0 & 14,370 & 56.552 .1 \\
\hline Price per barrel (Q) & 28.14 & 40.81 & 29.56 & 31.49 \\
\hline Yield, kWh/barrel & & & & \\
\hline (INDE only) & 538.0 & 426.7 & - & 482.16 \\
\hline $\begin{array}{l}\text { Cost per kWh (c) } 1983 \\
\text { (INDE only) }\end{array}$ & 7.35 & 10.72 & - & 9.04 \\
\hline $\begin{array}{l}\text { Cost per kWh }(k) \\
\text { (INDE only) }\end{array}$ & 5.19 & 9.60 & - & 7.39 \\
\hline
\end{tabular}

Source: Notional Institute of Electrification (INDE). 
TABLE 36

GUATEMALA: WOOO SUPPLIED TO FINAL DEMAND

(thousands of barrel oquivalents of petroloum)
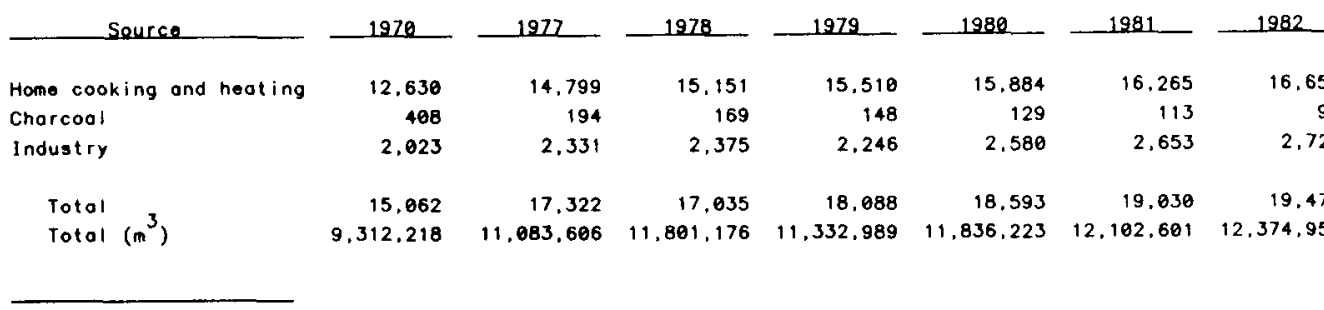

18,593

$\begin{array}{rrr}19.477 & 19.944 & 20.421\end{array}$

Source: Miniatry of Energy and Mines. Guatemala.

people living in Guatemala's rural areas and most of it is harvested individually or in small cooperative efforts.

The supply of bagasse from sugar operations has depended on the sugar production and harvests. In 1970, bagasse supply was estimated at about 0.5 million BEP. Steady increases were seen until 1976, when 1.6 million BEP were supplied, almost entirely to industry. Since 1976 the supplies have fluctuated somewhat with about 1.2 million BEP being estimated for 1984 . If alternative uses for sugar are found, such as for an ingredient for ethanol production, then bagasse supplies should see an increase in the coming years.

c. Energy Demand

Total energy demand in Guatemala has grown fairly steadily, increasing at a compounded average annual rate of 3.7 percent throughout the 1970 to 1984 period (see Table 37). Demand growth occurred in all sectors from 1970 until 1978, but demand declined in the transportation and industrial sectors during the 1978 to 1984 period. Only the residential/commercial/public sector continued its increase to the present, and its average annual growth rate of 4.3 percent over the 1970 to 1984 period was the highest of all sectors. The decline in the transportation sector was continuous since 1979, while there was more fluctuation in industrial demand from 1979 to 1984. Three tables are provided for use in the following discussion. Table 38 reports the actual 1984 energy consumption for each sector by fuel type, and Tables 39 and 40 show the percentage shares of the sectors and fuels.

At the outset it should be noted that fuel wood is extremely important to the Guatemalan economy. Sixty-seven percent of total energy consumed in 1984 came from this single source (see Table 39). Electricity makes up only 3 percent of the total consumption and oil products, 24 percent. 
TABLE 37

GUATEMALA: COMPOUNDED ANNUAL AVERAGE GROWTH RATES FOR ENERGY CONSUMPTION, BY SECTOR AND SELECTED YEARS (percentages)

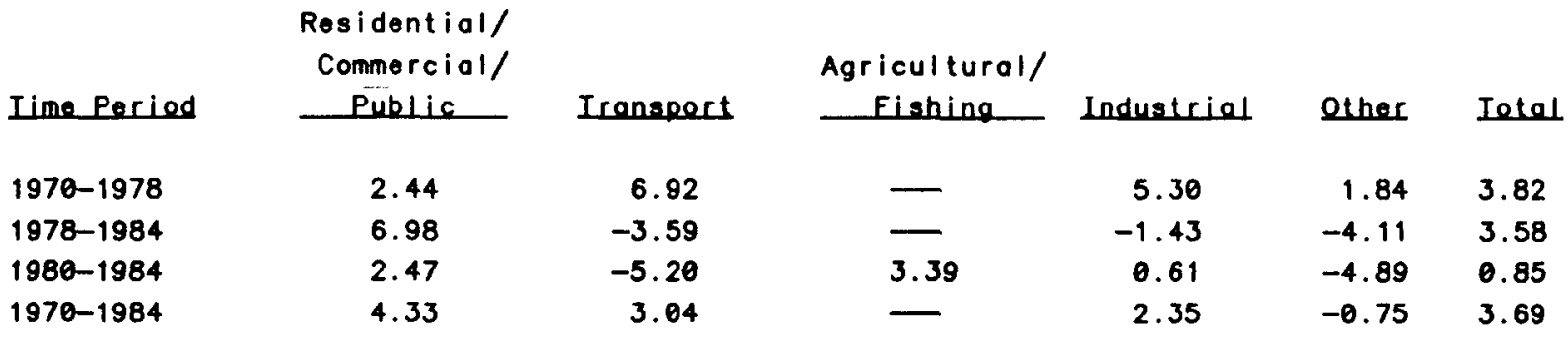

Source: Ministry of Energy and Mines, Guatemala.

TABLE 38

GUATEMALA: 1984 ENERGY CONSUMPTION

(thousands of barrol equivalonts of polroloum)

\begin{tabular}{|c|c|c|c|c|c|c|}
\hline Enerax Iype & $\begin{array}{l}\text { Residential/ } \\
\text { Commercial/ } \\
\text { Public }\end{array}$ & Iranspert & $\begin{array}{c}\text { Agriculture/ } \\
\text { Fishing }\end{array}$ & Industrial & Qther & $\begin{array}{l}\text { Total Consumption } \\
\text { By Eneray Iype }\end{array}$ \\
\hline Fuel wood & 17,487 & 0 & 0 & 1.116 & 0 & 18.603 \\
\hline Vegetable/animal residue & 0 & $\theta$ & 0 & 1.140 & 0 & 1.140 \\
\hline Eloctricity & 561 & 0 & 2 & 259 & 26 & 848 \\
\hline \multicolumn{7}{|l|}{ Petroloum derivatives } \\
\hline Liquid gas & 429 & 10 & 26 & 52 & 0 & 517 \\
\hline Gosoline/naphthas & 0 & 1.782 & 36 & 36 & 1 & 1,855 \\
\hline Kerosene/jet fuel & 387 & 226 & 13 & 45 & 6 & 672 \\
\hline Dlesel/gasoll & 53 & 1.806 & 266 & 531 & 8 & 2.664 \\
\hline Fuel oll & 0 & 0 & 0 & 779 & 58 & 837 \\
\hline Refinery gos & 0 & 0 & 0 & 0 & 73 & 73 \\
\hline Subtotal & 870 & 3.824 & 341 & 1,444 & 140 & 6.618 \\
\hline Non-Energy & 0 & 0 & 0 & 0 & 160 & 160 \\
\hline Chorcool & 503 & 0 & 0 & 0 & 0 & 503 \\
\hline Total Consumption & 19,421 & 3,824 & 343 & 3.959 & 325 & 27,871 \\
\hline
\end{tabular}

Source: Ministry of Energy and Mines. Guatemolo. 
TABLE 39

GUATEMALA: 1984 ENERGY CONSUMPTION

(percentoge of totol)

\begin{tabular}{|c|c|c|c|c|c|c|}
\hline \multirow[b]{2}{*}{ Eneroy Iype } & \multicolumn{6}{|l|}{ Residential/ } \\
\hline & $\begin{array}{l}\text { Commercial/ } \\
\text { Puble }\end{array}$ & Ironsport & $\begin{array}{c}\text { Agriculture/ } \\
\text { Fishing }\end{array}$ & Industrial & Other & $\begin{array}{l}\text { Total Consumption } \\
\text { By Eneray Type }\end{array}$ \\
\hline Fuel wood & 63 & $\theta$ & $\theta$ & 4 & 0 & 67 \\
\hline Vegetable/animal residue & 0 & 0 & 0 & 4 & 0 & 4 \\
\hline Electricity & 2 & 0 & 6 & 1 & 0 & 3 \\
\hline \multicolumn{7}{|l|}{ Petroleum derivatives } \\
\hline Gosol Ine/nophthas & 6 & 6 & 0 & 0 & 0 & 7 \\
\hline Kerosene/jet fuel & 1 & 1 & 0 & 0 & 0 & 2 \\
\hline Dlesel/gosoil & 0 & 6 & 1 & 2 & 0 & 10 \\
\hline Fuel oil & 0 & $\theta$ & 0 & 3 & $\theta$ & 3 \\
\hline Refinery gas & 0 & 0 & 0 & 0 & 0 & 0 \\
\hline Subtotal & 3 & 14 & 1 & 5 & 1 & 24 \\
\hline Non-Energy & 0 & 0 & 0 & 0 & 1 & 1 \\
\hline Total Consumption & 70 & 14 & 1 & 14 & 1 & 100 \\
\hline
\end{tabular}

Note: Total may not add to 100 owing to rounding.

TABLE 40

GUATEMALA: 1984 ENERGY CONSUMPTION

(percentage of fuel use by sector)

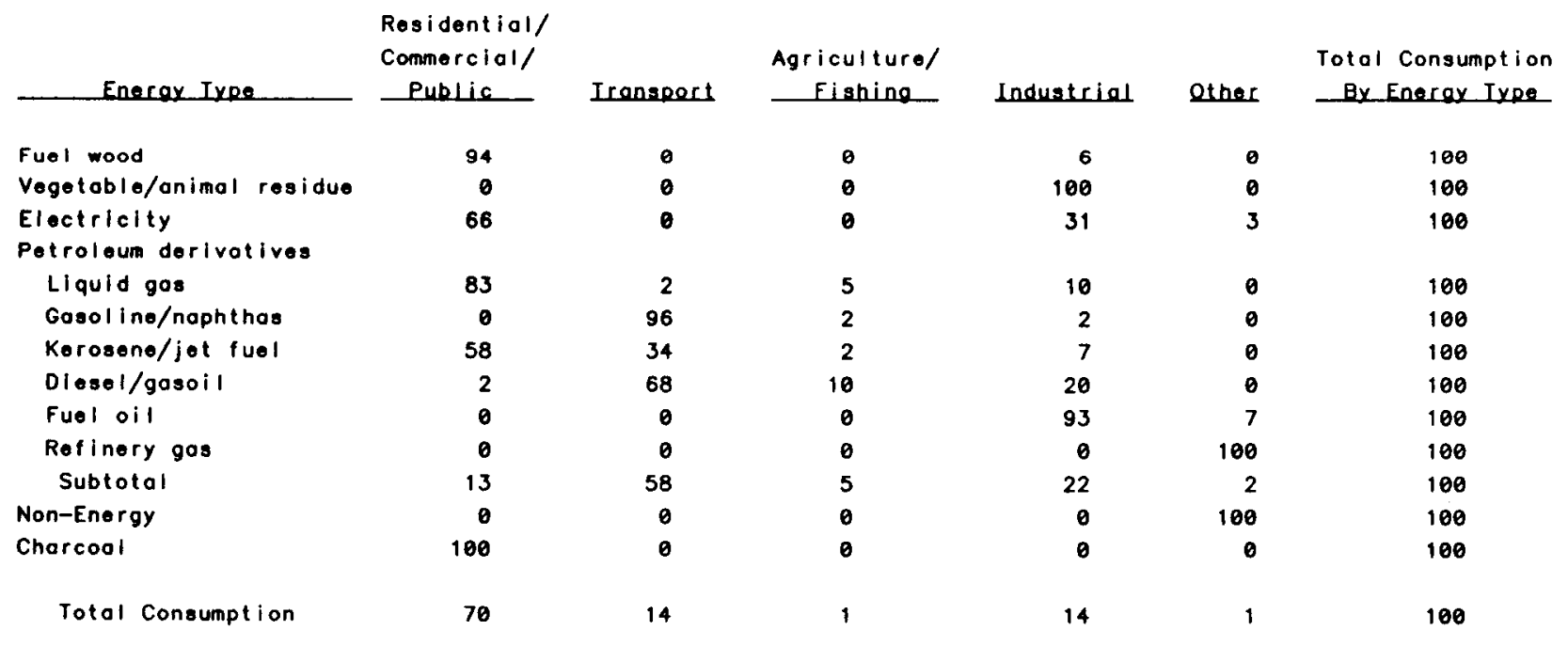

Note: Totols moy not sum to 100 owing to rounding. 
1. Residential/Commercial/Public. Fuel wood is by far the most important energy source in these sectors. Out of the $19 \mathrm{million}$ BEP consumed by the combined residential/commercial/public sectors in 1984, some 17.5 million BEP of it was fuel wood (see Table 38). This means that fuel wood supplied about 90 percent of the needs in the combined sector. The remaining requirements are fulfilled by oil products (mainly kerosene and liquid gas) and electricity. (Although because of data limitations we cannot assign individual sectorial demands, oil and electricity use occurs principally in the commercial and public portions of the combined sector.) As a whole, the three sectors together comprised over two-thirds of the total energy consumption in the country during 1984 (see Table 39).

Growth of wood consumption generally follows population growth, since it is the fuel of choice for cooking and heating for most Guatemalans. The actual use of wood for home heating and cooking is uncertain because the demand is based on an estimated use-factor per person day. Nevertheless, one can be certain that the expected future shortages and price increases of fuel wood will have serious ramifications for the standard of living for the average Guatemalan. A survey of fuel-wood consumption is currently being completed.

2. Industrial. Since industrial growth and decline is closely dependent on the health of the economy in general, the energy demand of this sector is quite variable. Strong economic growth during the 1970 s caused this sector's energy use to increase at an average rate of 5.3 percent per year (see Table 37). However, the following 6 years were more difficult for industry, and energy consumption declined by about 1.4 percent annually.

Guatemalan industry consumes a significant amount of traditional fuels. Indeed, out of a total energy consumption of 4 million BEP in 1984, some 2.2 million BEP (or 57 percent) of it was fuel wood and vegetable/animal residue (see Table 38 ). 0 il products made up another 36 percent of the total, and electricity represented less than 7 percent.

As shown in Table 39, industry comprised less than one-sixth of the country's total energy consumption in 1984.

3. Transportation. Demand for transportation fuels is almost exclusively for gasoline and diesel--the 1984 consumption of 3.8 million BEP was equally split between these two fuels (see Table 38). Demand grew at a fast and steady rate during the 1970s, averaging about 7 percent a year over the 1970 to 1978 period (see Table 37). The second world oil price hike in late 1979 and the recession of the 1980s interacted to cause transportation oil demand to decrease substantially during the 1980s: it fell an average of 5.2 percent a year from 1980 to 1984 . 
Transportation made up about 14 percent of total consumption of energy in the country in 1984 and over half of $0 i 1$ product use (see Tables 39 and 40). About 95 percent of all gasoline consumption occurs in this sector, as does 68 percent of diesel use. Throughout the 1980s, the government's oil pricing policies (which generally underprice diesel relative to gasoline) have encouraged a shift toward diesel-powered vehicles. The recent 50 percent gasoline price increase will add impetus to this trend.

4. Agriculture. Agricultural energy demand has been accounted for as separate from industrial sector demand only since 1979. From 1979 to 1983 the demand averaged 293,000 BEP, most of which was demand for diesel fuel. In 1984, demand increased to 343,000 BEP, with diesel comprising 78 percent of the total. Agriculture includes both traditional working of the land and the harvesting of forest products. Even though the agricultural sector produces 25 percent of the GDP and employs some 55 percent of the labor force, it consumes only about 1 percent of the total energy used in the country. This disparity is typical of developing countries that rely on traditional labor-intensive farming techniques.

\section{Energy Planning Capabilities}

The Ministry of Energy and Mines (Ministerio de Energia y Minas--MEM) is the principal government organization responsible for overall energy planning, coordination, and policy in the country. The national electric utility, Instituto Nacional de Electrification (INDE), has primary responsibility for the supply, transport, and distribution of electricity within Guatemala and for many other issues related to electricity such as development of Guatemala's geothermal potential. The Secretaria General Consejo Nacional de Planificacion Economica (SEGEPLAN)--an agency for economic planning--has primary definition of global economic policy, especially as it relates to financing of energy projects.

MEM is a relatively new government organization, being less than four years 01d. However, directorates of MEM do have a long history, having been in existtence in some form for more than 20 years. The present organizational structure of MEM is as portrayed in Fig. 10. There are five Directorates, along with some support departments and the National Petroleum Commission. The Department of Energy and Mineral Planning (Departmento de Planificacion Energetica y Minera), hereinafter called the "Planning Department," is responsible for overall energy planning but depends upon input and assistance from all of MEM. Two directorates, Hydrocarbons and New and Renewable Energy, work very closely with the Planning Department. Both directorates provide much of the basic data and some analytical support to the Planning Department's activities. 


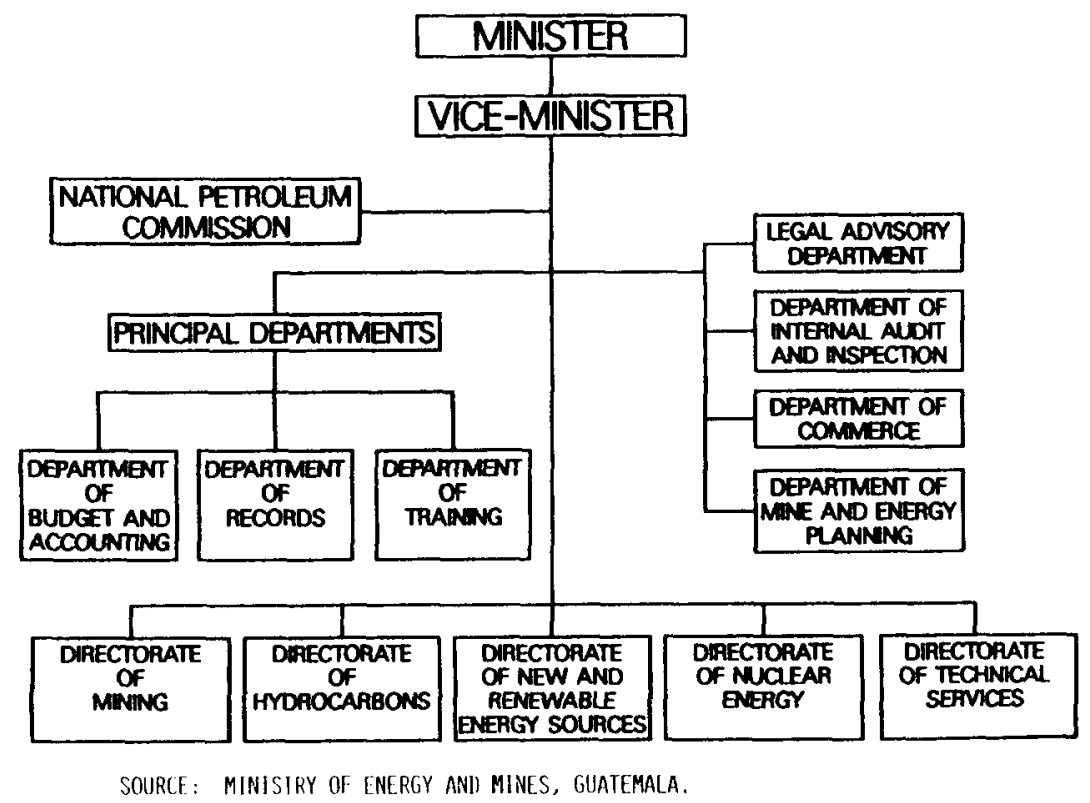

Fig. 10. Guatemala: Organizational chart of the Ministry of Energy and Mines (MEM).

The New and Renewable Energy Directorate (Direccion General de Fuentes Nuevas y Renovables de Energia) was created in August 1983 by 1 aw as a logical response to the global energy problems in Guatemala, the two chief concerns being the high and inefficient consumption of fuel wood and the dependence on imported fossil fuels. The Directorate is organized into two principal departments: a Research Department that addresses energy consumption issues such as conservation and potential energy savings, and a Development Department that examines alternative sources of energy supply. The Development Department is composed of four major sections, each focusing on a different supply technology: (1) geothermal, (2) firewood and charcoal, (3) biomass and animal energy, and (4) solar, wind, and small-scale hydro energy. Many of the objectives and tasks of this Directorate overlap with those of the Planning Department. Energy use analysis as well as coordination of national programs, projects, and studies promoting increased use of new and renewable energy technologies constitute the two most important areas of activities of the Development Department.

The General Directorate of Hydrocarbons (Direccion General de Hidrocarburos) has a long history of involvement with petroleum development and use of derivatives. Three principal Departments within the Directorate are responsible for differing facets of control of petroleum in Guatemala. The Departments are (1) petroleum development, (2) transformation and distribution, and (3) prices and data compilation. A number of sections addressing more 230 
specific topics are organized under each Department. Of the more than 300 MEM employees, a large fraction are assigned to Hydrocarbons--both because of historical reasons and because of the importance of petroleum to Guatemala.

As with other Central American countries, the professional staff faces difficult tasks in the energy planning and policy areas. Problems are large, resources are limited, and the staff is stretched very thin. However, portions of the staff have experience in energy issues and are dedicated to helping reduce Guatemala's energy problems.

Guatemala was the only country covered in this report that did not participate in the PEICA project (described in the overview section). Guatemala did formulate energy balances in the OLADE format, however. Guatemala has been the recent beneficiary of a UNDP-sponsored energy planning assistance project. The first phase ends in June 1986 and a second phase has been proposed. Under the first phase, some surveys of energy consumption were carried out, and a detailed report analyzing Guatemala's energy situation is in preparation. The second phase will include the development of an energy-planning model for the microcomputer.

\section{SUMMARY AND RECOMMENDATIONS}

A. Summary

Like the other Central American countries, Guatemala has experienced a serious economic recession in the early 1980s, and recovery is still uncertain. GDP, expressed in constant 1982 quetzales, grew at over 5 percent per year in the $1970 \mathrm{~s}$ but declined in the early $1980 \mathrm{~s}$ and has yet to reattain its 1980 level. Real per capita income declined by almost 15 percent between 1980 and 1984. The sectoral composition of Guatemala's GDP has been remarkably constant since 1970, with trade, agriculture, and manufacturing accounting for approximately two-thirds of GDP.

The government plays a smaller role in Guatemala's economy than it does in some of the other Central American governments. To combat disequilibrium in the external sector, the government established a parallel exchange rate in November 1984. In the wake of the devaluation, some prices to consumers have increased significantly, particularly petroleum product prices. Guatemala's external public debt is relatively small by developing country standards, although it is rising. A significant portion of the debt was incurred to finance the construction of Chixoy, a large hydroelectric power project that opened in 1983.

The temporary closure of Chixoy for repairs to its pressure tunnel during 1984 and 1985 posed one of the most serious energy problems for Guatemala. Guatemala experienced power shortages and had to spend large, unplanned amounts 
of foreign exchange to purchase fuel for oil-burning power plants during this period. With Chixoy back on line in 1986, it is expected that this problem will be alleviated.

Guatemala is favorably endowed with energy resources. It is the only Central American country with proven $0 i 1$ reserves, and the country produced 3,000 to 5,000 barrels per day during the past two years. Potential for peat deposits exists along the Caribbean coast, and some lignite deposits are known, but little coal and peat exploration has been conducted in the country. Hydroelectric potential is large, but revisions in electricity demand estimates and the high cost of large hydroelectric power plant construction will deter exploitation of this resource in the near future. With Guatemala's volcanic history, the country possesses considerable geothermal energy potential. One site, Zunil, is being developed with assistance from the IDB, and another, Amatitlan, is under investigation.

Guatemala's fuel-wood situation is less critical than that of some of the other Central American countries, but since fuel wood is the main source of energy, the fuel-wood resources merit close monitoring and proper management.

Wind and solar energy measurement networks exist in the country, and the Ministry of Energy and Mines is interested in development of these resources.

As of 1984, fuel wood supplied over 70 percent of Guatemala's final energy demand, petroleum products supplied less than 22 percent, electricity, 3 percent, and vegetable residues, 4 percent. Fuel wood is generally gathered by individual users. A new fuel-wood survey in the late 1970 s resulted in a large upward revision in estimates of Guatemala's fuel-wood consumption. The crude oil that Guatemala produces is exported, with the exception of a small portion that was used in the past by INDE to generate electricity until chixoy resumed operation. Imported crude oil is refined domestically, and petroleum products are imported as well to meet final demand. Domestically refined products generally have met about half of product requirements in recent years. Electricity supply grew through the early 1980s, with the replacement of thermal generating capacity with hydroelectric capacity. Total supply was interrupted by the temporary closure of Chixoy for repairs in 1984 and 1985. The next scheculed capacity increment will be a 15-MW geothermal plant at Zunil, scheduled to come on stream in 1991. The main vegetable residue used in the country, sugar cane bagasse, mainly supplies Guatemala's large sugar industry.

Between 1970 and 1984, Guatemala's total energy consumption has increased at a rate of 3.7 percent per year. However, this statistic is influenced by the large upward revision in fuel-wood consumption in 1979. The recession of the early 1980 s and troubles with electricity shortages have strongly affected 
demand in the transport, industrial, and "other" sector, where energy consumption decreased or remained nearly constant. In 1984, the combined residential, commercial and public sector consumed 70 percent of total energy; industry, 14 percent; transport, 14 percent; agriculture and fishing, 1 percent; and other, 1 percent.

Guatemala has significant energy problems and is assembling a capable group of planners in the Ministry of Energy and Mines to deal with these problems. The country needs continued support in this effort.

\section{B. Recommendations}

Several energy problems face Guatemala today: the most serious of which is the high cost of oil imports. Recent currency devaluations have made the purchase of foreign oil very expensive; in mid-1985, 20 percent of the national gold reserves were spent to import 0i1. Also in 1985, long queues occurred at gasoline stations because of periodic shortages, and the government increased gasoline prices by 50 percent.

INDE's debt significantly increased with the construction of chixoy. The high reliance on fuel wood in the country is leading to severe deforestation in some highly populated regions. As this problem grows, wood prices will increase, shortages may develop, and soil erosion may lead to watershed degradation and the potential for siltation of hydroelectric dams.

In view of these energy problems, it is recommended that AID consider the following projects for Guatemala.

- Complement assistance provided by IDB to develop geothermal energy.

Geothermal energy is a strong candidate for direct substitution for imported oil in both electricity production and industrial uses. INDE has already completed a general reconnaissance of the country and chosen two sites with excellent prospects. A direct-heat end-use demonstration project is recommended for the Zunil site during 1986. A thorough analysis of geothermal energy's applicability for direct heat should be undertaken when the results of the demonstration become available.

- Assist MEM in the development of a data management system for the energy sector.

As part of the Los Alamos/AID project, an information system called SICAPE (Central American Information System for Energy Planning) has been transferred to MEM, and training in its use has been provided. The transfered system has macroeconomic as well as energy balance information on an annual basis. This is an adequate start for MEM's data management needs. However, currently there is a need for an expanded system that would include detailed data on the oil industry and energy prices, among other things. The goal of MEM is to utilize their Hewlett-Packard 3000 minicomputer for a ministry-wide data system. Unfortunately, at the present time 
the machine is not operating ( $i t$ lacks software and a maintenance agreement). Because SICAPE is already functioning, the MEM has people trained in its use; its methodology could be expanded to fulfill the immediate data management needs while the HP is being readied for the more comprehensive task. A benefit of SICAPE is that it can be modified by people who are not programmers, thereby freeing the programmers to work on the HP 3000 problems.

The first step in the expansion of SICAPE is to upgrade the existing IBM microcomputers at MEM so that they have adequate memory and storage capacity to handle the SICAPE programs and the additional data. This upgrading requires the installation of a memory card and a 20 -megabyte hard disk. The next step would be to assist the MEM staff in implementing the SICAPE methodology for the new data. Given the training that several people have already received, this last step should not require a large effort.

- Assist INDE in the evaluation of coal, peat, biomass, wind, and solar resources.

The availability and applications of these energy resources have yet to be thoroughly examined. AID assistance for a reconnaissance of coal is recommended, since it can be readily substituted for foreign oil and fuel wood.

As a sugar production nation, Guatemala has the option of producing alcohol to be used as a supplement to gasoline. A study of the desirability of this option is recommended, and data from Costa Rica's experience may be applicable for Guatemala. Given bagasse's high content of fiber, an analysis would be useful of the relative merits of using this vegetable residue as an input to the construction of fiber boxes or as a fuel.

Some work on the supply of wind and solar energies in Guatemala has already been completed. However, an examination of the feasibility of various end uses and the development costs, along with the construction of pilot projects, is needed before an informed decision can be made as to the future development of these resources.

- Provide support for energy demand and supply analysis.

Current1y, MEM planners are working on an energy demand model with the assistance of the UNDP. This project is expected to be completed at the end of 1986. Additional assistance may be needed for the full implementation of the model in the planning process. Modification of the macroeconomic scenario analys is developed by Los Alamos for Costa Rica may be useful to the planners at MEM as we11. Also recommended is the development of a methodology for the evaluation of energy projects to provide an adequate and rational supply of energy for the country.

- Assist MEM in the development of a national program to promote rational energy use and energy conservation. 
AID support is recommended for the examination of the current energy pricing policy and how it could be used more effectively to encourage efficient energy use. Emphasis should be given to the current supply problems in the transport sector.

\section{REFERENCES}

1. Guatemala: A Country Study, R. F. Nyrop, ed. (U.S. Government Printing Office, Washington, D.C., 1983).

2. Ibid, p. 92.

3. United Nations, "Economic Survey of Latin America and the Caribbean, 1982," Vol. 1, Economic Commission for Latin America and the Caribbean, United Nations Publication, November 1984.

4. W. Mittak, "Guatemalan National Reforestation Study, "United Nations Development Program report (1977), p. 52.

5. "Staff Appraisal Report, Guatemala, Fifth Power Project, " a report by the Regional Projects Department of Latin America and the Caribbean Regional Office of the World Bank (January 1986).

6. Informe Financiero y Estadistico: 1974 - 1983, a report by INDE, Guatemala City, Guatemala; Informe Financiero y Estadistico: 1984, a preliminary INDE report.

7. World Bank, EPD Data Bank, Comparative Analysis and Data Division, September 1986. 



\section{HONDURAS}

\section{CONTENTS}

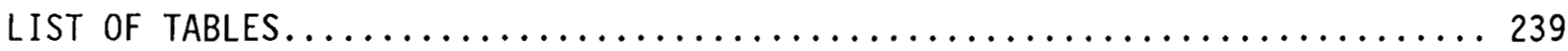

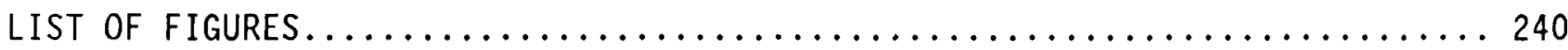

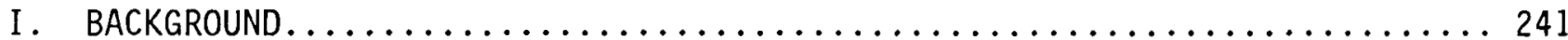

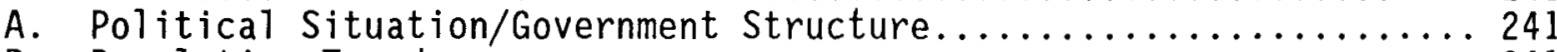

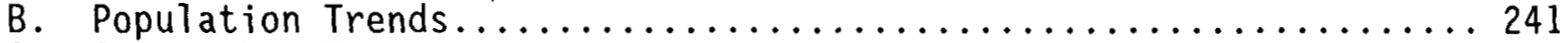

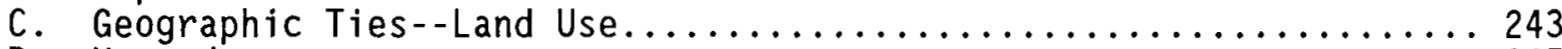

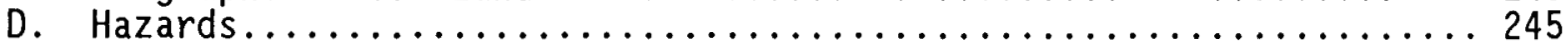

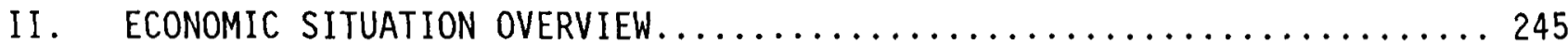

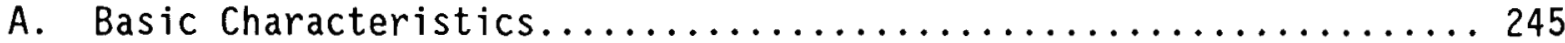

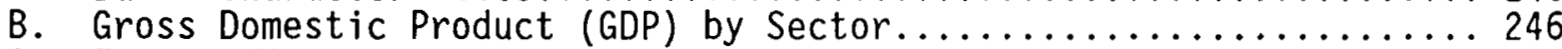

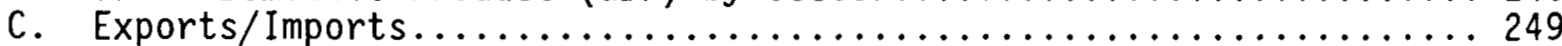

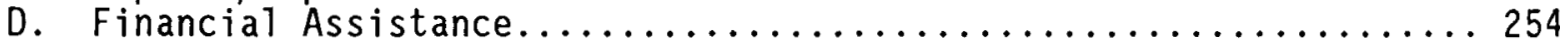

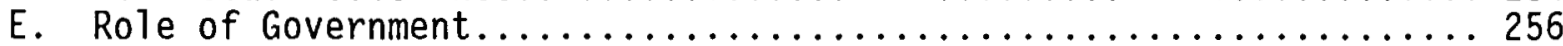

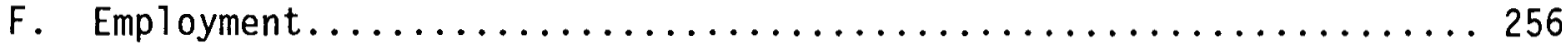

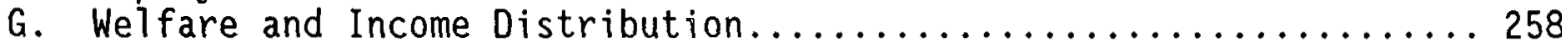

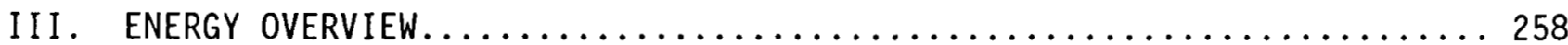

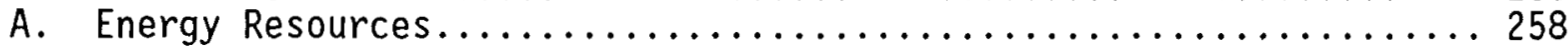

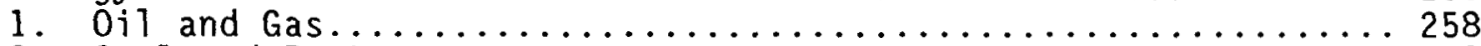

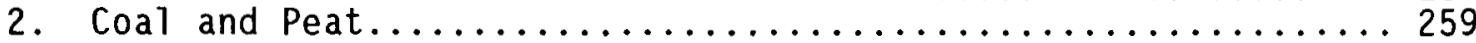

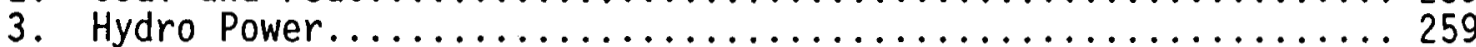

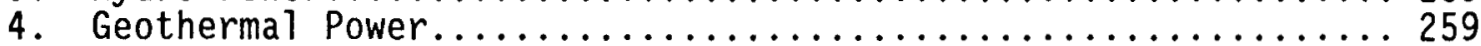

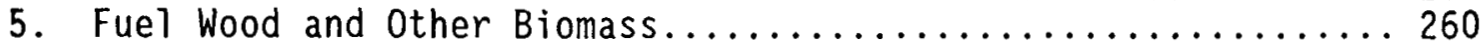

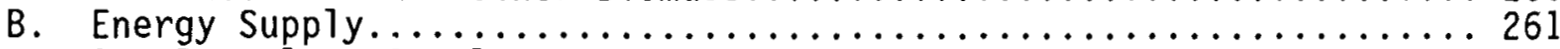

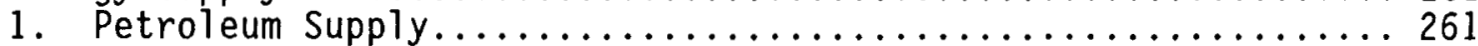

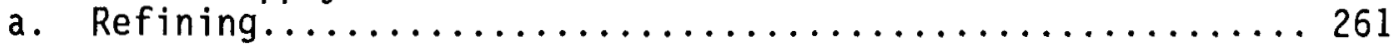

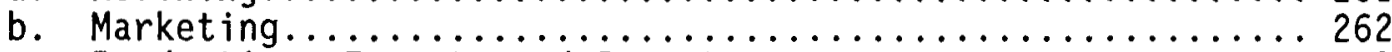

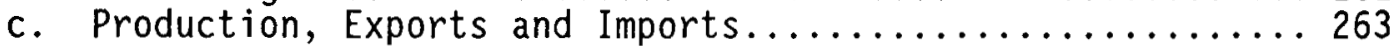

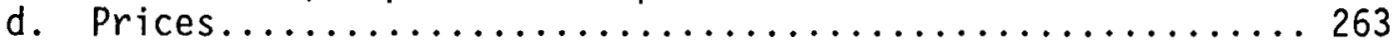

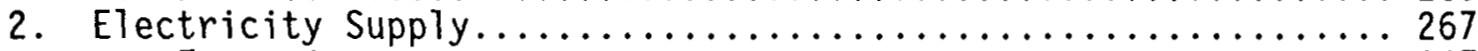

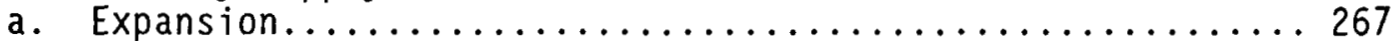

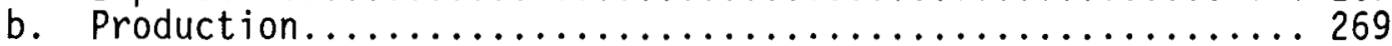

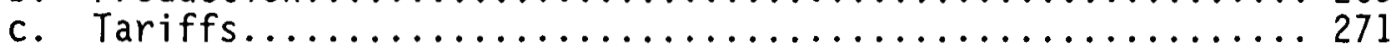

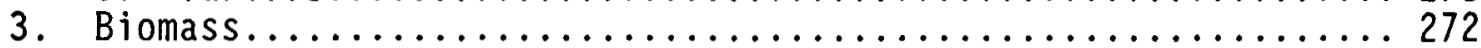

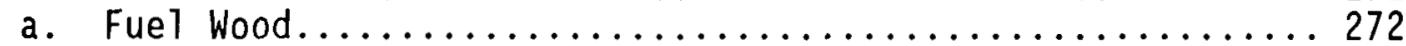

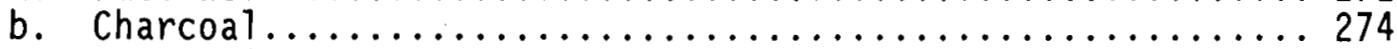

c. Residual Vegetable Matter: Bagasse and Sawdust......... 274

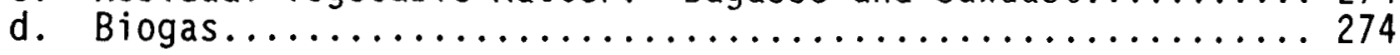




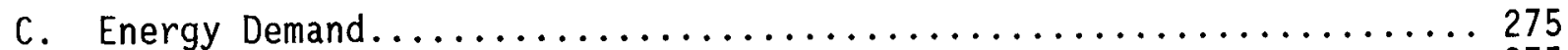

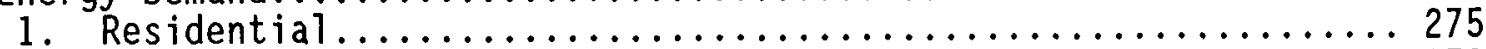

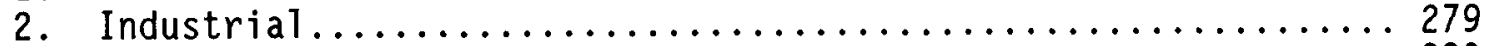

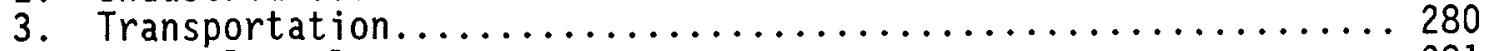

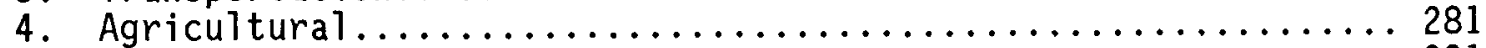

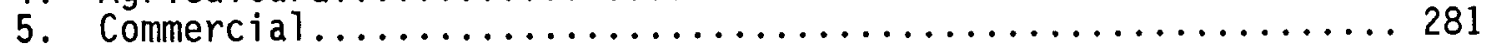

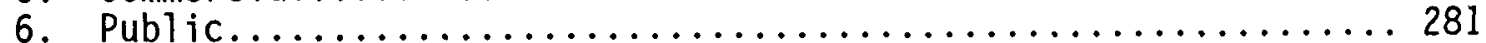

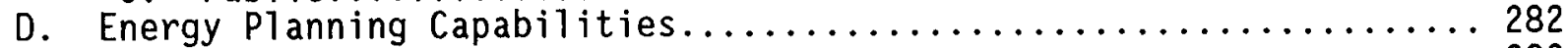

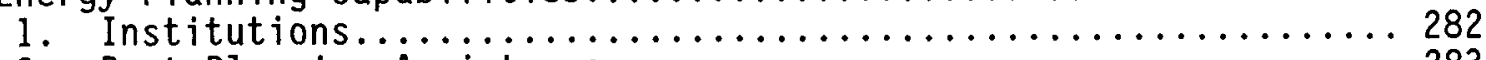

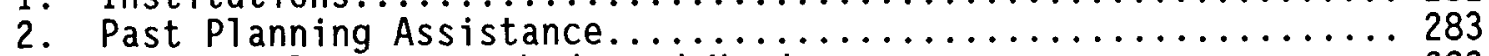

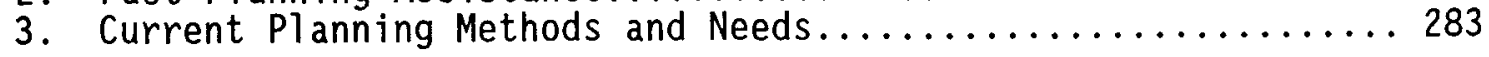

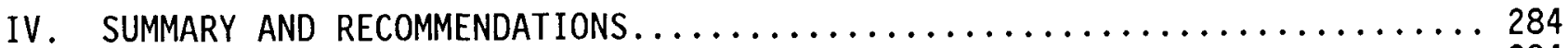

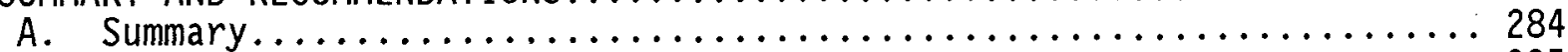

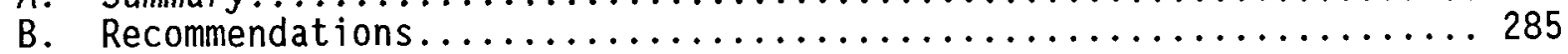

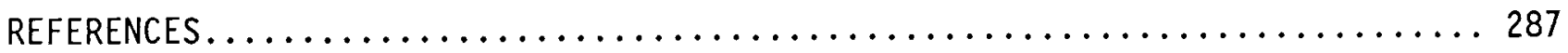




\section{LIST OF TABLES}

1. Honduras: Population and Projections (Urban and Rural) $\ldots \ldots \ldots \ldots \ldots 242$

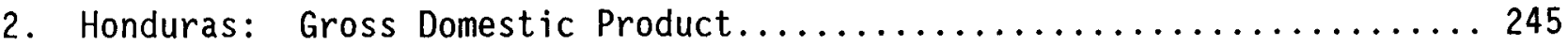

3. Honduras: Sectorial Contribution to Gross Domestic Product.......... 247

4. Honduras: Gross Domestic Product Growth Rates.................... 248

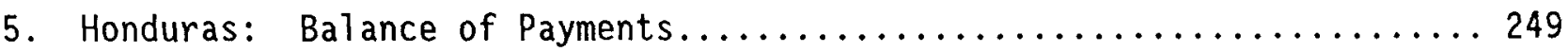

6. Honduras: External Public Indebtness......................... 250

7. Honduras: Exports and Imports (percentage of total) ............. 251

8. Honduras: Growth Rates for Exports and Imports................. 252

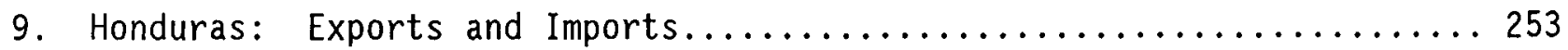

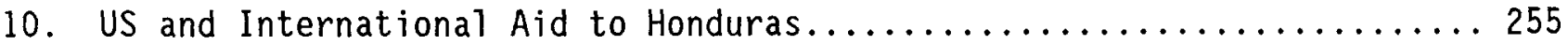

11. Honduras: Employed Labor Force, by Sector.................... 257

12. Honduras: Potential Hydroelectric Projects...................... 259

13. Honduras: Production of Petroleum Derivatives by Domestic Refinery.... 264

14. Honduras: Imports of Crude and Derivatives.................... 264

15. Honduras: Percentage Breakdown of Refinery Production............... 264

16. Honduras: Exports of Petroleum Derivatives.................... 265

17. Honduras: Crude $0 i 1$ Imports by Country of Origin................. 265

18. Honduras: Percentage of $0 i 1$ Products Refined Domestically........... 265

19. Honduras: $0 i 1$ Import Costs Relative to Other Variables.............. 266

20. Honduras: Average 011 Product Prices for Selected Years............ 267

21. Honduras: Maximum $0 i 1$ Product Price......................... 268

22. Honduras: Summary of Investments of ENEE..................... 269

23. Honduras: ENEE Investments for "Special Project" for Integrated

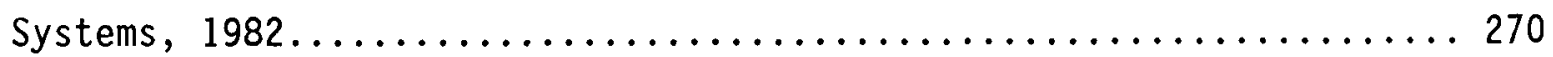

24. Honduras: Electric Generation........................... 271

25. Honduras: Average Electricity Prices...................... 272

26. Honduras: Supply of Alternative Energy..................... 273

27. Honduras: 1984 Energy Consumption (thousands of BEP) $\ldots \ldots \ldots \ldots \ldots 276$

28. Honduras: 1984 Energy Consumption (percentage of total) .......... 276

29. Honduras: 1984 Energy Consumption (percentage of fuel use by sector).. 277

30. Honduras: 1984 Energy Consumption by Sector.................. 277

31. Honduras: 1970 Energy Consumption by Sector................... 278

32. Honduras: 1978 Energy Consumption by Sector................. 278

33. Honduras: Compounded Annual Average Growth Rates for Energy

Consumption, by Sector and Selected Years................. 279 


\section{LIST OF FIGURES}

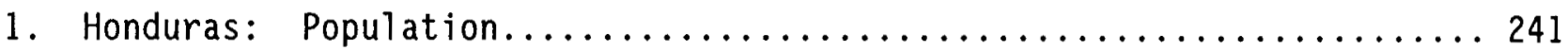

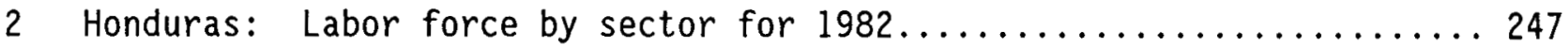

3. Honduras: Gross domestic product by major sector................ 248

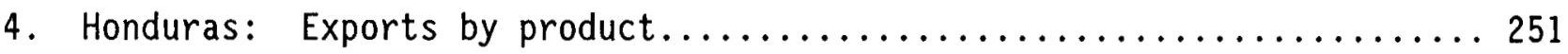

5. Honduras: Location of geothermal resources.................... 260

6. Honduras: Energy supply by fue type...................... 262

7. Honduras: Installed electric generating capacity................ 268

8. Honduras: Location of transmission grid....................... 270

9. Honduras: Energy flow diagram for $1984 \ldots \ldots \ldots \ldots \ldots \ldots \ldots \ldots . \ldots . \ldots . \ldots 28$ 


\section{BACKGROUND}

A. Political Situation/Government Structure

Prior to 1982, Honduras had been led by military administrations for over 20 years. In 1981, a civilian government was elected. A second civilian administration was installed in early 1986. As in other developing countries, Honduras is struggling to overcome the problems caused by the oil shocks of the 1970 s and the worldwide recession of the early 1980s. In addition, Honduras has to contend with an influx of refugees resulting from the strife in the region. ${ }^{1}$

B. Population Trends

Honduras has the fastest growing population in Central America. The growth rate has been over 3 percent per year since 1960, and was nearly 3.5 percent in 1975. In addition, estimates for the future show that there is no slowdown in sight; the population is expected to grow at over 3 percent per year through the year 2000 (see Fig. 1)..$^{1}$ As a consequence the population of Honduras is becoming younger, placing a burden on the economy to provide education and health care for the young, as well as to provide future employment opportunities.

The rural/urban breakdown has been steadily declining as people have migrated toward the cities (see Table 1). The leading factors in this migration have been the increasing pressures of population, land, and poverty in the rural

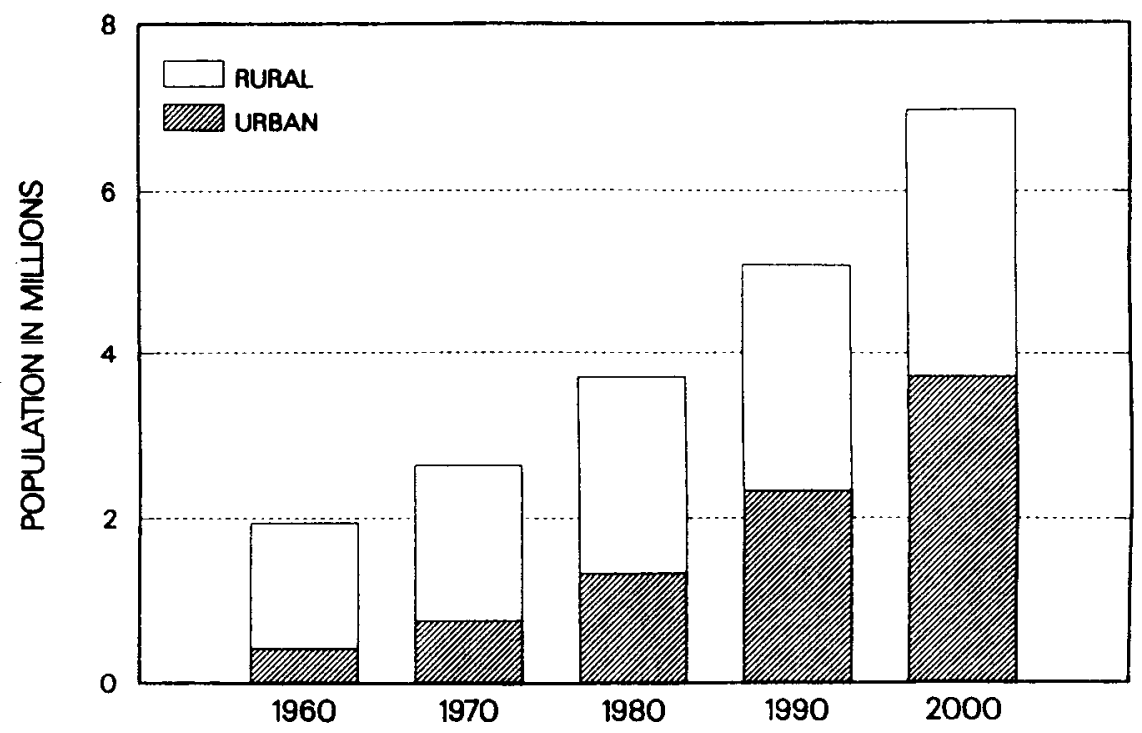

SOURCES: WORLD BANK. UNIVEASTYY OF CAUFOANIA LATNN AMERICAN CENTER

Fig. 1. Honduras: Population. (Population is projected for 1990 and 2000). 
TABLE 1

HONDURAS: POPULATION AND PROJECTIONS

(urban and rural)

\begin{tabular}{lrrrrrr} 
& \multicolumn{2}{c}{$\begin{array}{c}\text { Absolute Numbers } \\
\text { (in theusands) }\end{array}$} & \multicolumn{2}{c}{$\begin{array}{c}\text { Percentage of } \\
\text { Iotal Population }\end{array}$} \\
\cline { 2 - 4 } Year & Rural & Urban & Iotal & Rural & Urban \\
1950 & 1,188 & 181 & 1,369 & 87 & 13 \\
1960 & 1,566 & 319 & 1,885 & 83 & 17 \\
1970 & 2,211 & 686 & 2,897 & 76 & 24 \\
1980 & 2,659 & 935 & 3,594 & 74 & 26 \\
1990 & 3,529 & 1,468 & 4,997 & 71 & 29 \\
2000 & 4,631 & 2,250 & 6,881 & 67 & 33 \\
& & & & &
\end{tabular}

areas. Also, the lack of job and social opportunities for the young have encouraged many to try life in the cities. Male migrants generally go to areas of agricultural development such as the north coast, whereas the females seek work as domestics in middle- and upper-income households in the cities.

The two large cities in Honduras, Tegucigalpa and San Pedro Sula are absorbing much of the internal migration and are expected to contain over 70 percent of all the urban population by the year 2000.1

The population is quite homogeneous, and about 90 percent are of mixed race or mestizo. The minorities are generally concentrated in the north coast region and consist of the Black Caribs, the Miskito Indians, and the Bay Islanders. Because of the influence of English and American businesses, English is quite widely spoken in the region.

The Miskito Indians are a racially mixed population of Indians, Negroes, and Europeans and have a language of their own. These people have lived for numerous generations on the border of Nicaragua and Honduras. Because of political differences, refugees have swelled the Miskito population in Honduras.

The quality of health care and education is of concern to the government, which operates compulsory primary schools, the number of which have steadily increased through the 1960s and 1970s. Primary enrollment is estimated at about 90 percent, although the percentage is most likely lower within the rural interior. 1 
Honduras has made a concerted effort to improve health through vaccinations, water purification, and sewage disposal. Although significant progress has been made, diseases such as measles, malaria, and whooping cough continue to cause early deaths and low productivity.

C. Geographic Ties--Land Use

Honduras is the second 1 argest country in Central America (Nicaragua is largest), with 112,088 square kilometers of 1 and. About 80 percent of the total 1 and area is mountainous terrain, ranging from 300 to 3,000 meters in altitude. About 70 percent of the population lives in the mountainous interior, which is the traditional heartland of the country. This area is characterized by a relatively cool and dry climate, with most of the towns located in the prominent valleys.

Land ownership is relatively concentrated in Honduras for long-standing socio-economic and political reasons. Much prime agricultural land has been converted into pastureland for cattle or plantations for cotton. Indeed, total cattle production in Honduras more than tripled between 1960 and 1980 .

It is estimated that over 80 percent of the interior $(60$ percent of the entire country) has slopes of more than 40 percent. Such land is unsuitable for agriculture and does not even provide decent pasture. Honduras has a relatively low population density, and the amount of arable land is very small. Thus, agriculture is not foreseen as a growth area for the country.

Many of the rural people have quite small hillside plots or, if landless, work as part-time day laborers, earning the equivalent of $\$ 65$ to $\$ 195$ US annually. It has been estimated that in the early 1970s, 87 percent of the country was malarial and that the work-force output was reduced 25 to 30 percent simply because of poor health. ${ }^{1}$ Traditional slash and burn techniques and use of simple tools such as the digging stick contribute to erosion and loss of soil fertility. Further, the lack of efficient cooking stoves and fuels other than wood has led to deforestation.

The north coast is very rainy and humid, has many rivers and savannas, and represents 13 percent of the national 1 and area, with about 20 percent of the population living there in 1980. Fruit companies affiliated with the United States have substantial influence in this region as the principle crop is bananas. The employees of the companies are generally well cared for, but as modernization occurs on the plantations, many of the workers are being displaced.

The Honduran Forestry Development Corporation (Corporacion Hondurena de Desarrol10 Forestal--COHDEFOR) is in charge of regulating and preserving the national forests. Current law relating to forests allows a person to gain title 
to national land if improvements are made and the person uses the land for 10 years. However, the country people rarely obtain legal title to such land because the soil will not support 10 years of continuous farming. Therefore, a farmer will generally clear the land, farm it for a few years, then sell his "improvements" to a cattle rancher who uses the land for pasture. A rural person can also raise money by collecting firewood for sale in the urban areas. These two activities lead directly to the deforestation problem in Honduras ${ }^{2}$ and will require further regulation by COHDEFOR.

COHDEFOR regulates the cutting of timber for lumber or sawdust, but the cutting permits are difficult for the rural people to acquire, and they have little incentive to protect the forest for future timber gains. This leads to a conflict between the timber companies and the local small farmers. To maximize timber profits, the trees must be allowed to grow to a significant size, and regeneration of the forest is important. From the country person's perspective, in clearing the land the best strategy is to remove the trees before they get large. Thus, deforestation is most rapid in regions where both timber companies are active and population pressure exists. 2

Forest fires are also a significant problem in Honduras; they claim about 45,000 hectares of trees annually. ${ }^{1}$ Again, the present 1 and tenure system provides the local people with incentive for fires to help clear the 1 and and little incentive to protect the forest.

The Honduran government is aware of the deforestation problem and is currently looking for ways of altering the incentive structure. Consideration is given to plans to promote commercial activities for the rural people, such as making charcoal for steam generation or selling clippings from thinning operations. But this also involves implementing policies to encourage industry to convert to wood-or charcoal-burning boilers. Such a conversion will be difficult given the current slow growth of the economy and the low price of fuel oil, the key substitute for wood in many operations. A system of rural cooperatives, each responsible for a particular geographic region, has been suggested as a way to implement commercial opportunities in the forest.

Eliminating or even reducing the deforestation problem will be difficult for the following reasons. First, the government lacks the necessary resources to design, implement, and carry out a comprehensive forestry policy. Second, it will be very difficult to alter the rural people's long-standing agricultural habits. Finally, the deforestation problem is expected to increase as the population expands and farmers are forced to clear the pine forests. Pine forest 1 and is less productive than that of the more fertile wide-leaf forests, so it will only support subsistence farming and that for fewer seasons. 2 


\section{Hazards}

Honduras has the natural hazard of hurricanes. The most noteworthy is Hurricane Fifi which struck Honduras in 1974 and caused an estimated damage of $\$ 200$ million US, devastating 70 percent of the banana crop and 25 percent of the cotton and sugar-cane crops for that year.

\section{ECONOMIC SITUATION OVERVIEW}

\section{A. Basic Characteristics}

Honduras has one of the lowest per capita gross domestic products of all Latin America. Honduras faces several obstacles to economic progress. First, it lacks abundant natural resources such as arable land. Second, its economy currently depends on only a few commodity exports (for example, bananas and coffee) that suffer from volatile price swings. Finally, as a result of the worldwide recession and declining export prices (see Table 2) the financial and economic situation of Honduras has deteriorated during the 1980s. Indeed, real

TABLE 2

HONDURAS: GROSS DOMESIIC PRODUCT

\begin{tabular}{|c|c|c|c|c|c|c|c|}
\hline & 1970 & 1975 & 1980 & 1981 & 1982 & 1983 & 1984 \\
\hline \multicolumn{8}{|c|}{ Gross domestic product at current market prices } \\
\hline (millions of lempiros) & 1446.0 & 2212.0 & 4976.0 & 5293.0 & 5582.0 & 5891.0 & 6375.0 \\
\hline \multicolumn{8}{|c|}{ Gross domastic product at current factor cost } \\
\hline (millions of lompiros) & 1306.0 & 1992.5 & 4432.0 & 4691.0 & 5018.0 & 5273.0 & 5672.0 \\
\hline \multicolumn{8}{|c|}{ Gross domestic product at constant morket prices } \\
\hline (millione of 1982 lempiras) & 3590.4 & 3971.2 & 5616.8 & 5682.1 & 5581.4 & 5554.2 & 5709.3 \\
\hline \multicolumn{8}{|c|}{ Gross domostic product at constant foctor cost } \\
\hline (millions of 1982 lempiras) & 3245.0 & 3577.0 & 5002.0 & 5035.0 & 5021.0 & 4969.0 & 5092.0 \\
\hline \multicolumn{8}{|c|}{ Per capita gross domestic product at morket prices } \\
\hline (1982 lempiros) & 670.7 & 636.1 & 773.5 & 759.5 & 724.5 & 700.2 & 699.1 \\
\hline \multicolumn{8}{|c|}{$\begin{array}{l}\text { Gross domestic product by kind of economic octivity } \\
\text { (millions of } 1982 \text { lampiras) }\end{array}$} \\
\hline Agriculture & 1101.6 & 1028.2 & 1466.1 & 1490.6 & 1501.4 & 1542.2 & 1593.9 \\
\hline Mining & 70.7 & 89.8 & 103.4 & 97.9 & 106.1 & 106.1 & 114.2 \\
\hline Manufacturing & 462.4 & 530.4 & 802.4 & 805.1 & 758.9 & 729.6 & 745.3 \\
\hline Construction & 119.7 & 141.4 & 209.4 & 193.1 & 201.3 & 204.0 & 212.2 \\
\hline Eloctricity, gas and wotor & 35.4 & 46.2 & 92.5 & 100.6 & 97.9 & 97.9 & 100.6 \\
\hline Transport and communicotions & 255.7 & 340.0 & 326.4 & 340.0 & 342.7 & 334.6 & 345.4 \\
\hline Trade & 416.2 & 399.8 & 641.9 & 631.6 & 620.2 & 598.4 & 617.4 \\
\hline Bank/insuronco/rool ostate & 81.7 & 125.1 & 201.3 & 198.6 & 187.7 & 185.0 & 187.7 \\
\hline Public odministration and defense & 114.2 & 133.3 & 233.9 & 244.8 & 253.0 & 253.0 & 255.7 \\
\hline Ownorship of dwollings & 225.8 & 285.6 & 389.0 & 386.2 & 386.2 & 383.2 & 383.5 \\
\hline Sorvicos & 361.8 & 457.0 & 535.8 & 546.7 & 565.8 & 535.8 & 535.8 \\
\hline Other branches & - & - & - & - & - & - & - \\
\hline Stotistical discrepancy & - & - & - & - & - & - & - \\
\hline
\end{tabular}

Source: World Bank. 
per capita gross domestic product (GDP) declined over 11 percent from 1980 to 1983 (see Table 2). Unemployment in 1983 was at least 20 percent, and the underemployment rate was near 60 percent. 1 In this section, we examine the current macroeconomic situation in the country, giving special attention to the very important foreign sector.

B. Gross Domestic Product (GDP) by Sector

In Honduras, agriculture contributes about 30 percent of GDP and is the largest single productive sector in the country, employing over half of the labor force (see Fig. 2). The manufacturing sector ranks second and contributes about 15 percent of GDP, and transport and communications is a close third with 12 percent (see Table 3). Between 1970 and 1980, relatively strong economic growth stimulated the development of industry so that manufacturing's share of GDP rose from 14 to 16 percent while agricultural's portion declined from 34 to 29 percent. However, even this slight trend was reversed with the demise of the Central American Common Market (CACM) and the deep recession of the early 1980 s. These figures may be deceptive, however, because much of the country's manufacturing sector is involved with processing agricultural products. Thus, agriculture is still the dominant sector in the economy and will likely remain so for the foreseeable future.

From 1970 to 1984, the real rate of growth of GDP in Honduras averaged 3.4 percent annually, and population grew more than 3 percent each year. Thus, per capita economic growth was extremely low over the last 14 years. The Honduran economy experienced a short boom period during the second half of the 1970s, when real GDP grew at a 7.2 percent annual rate (see Table 4 and Fig. 3 ). However, growth fel1 to 1.2 percent in 1981 and was negative in both 1982 and 1983. This decrease coupled with continued rapid population growth created severe hardships. The economy began to pick up again in 1984 , but the 2.8 percent growth in that year was still below the historical average.

The economic decline of the early 1980s was led by the trade and manufacturing sectors, as the world recession continued to hamper international demand for Honduran products. Fortunately, the agricultural sector continued growing throughout the recession, thus preventing food shortages and subsequent price rises.

The Honduran economy has experienced an increase in inflation during the $1970 \mathrm{~s}$ because of the rapid run-up in the price of imported oil and government deficit spending. The average annual rate of change in consumer prices during the 1960s was only 2.2 percent. But during the 1970s, inflation increased to an average of 8 percent per year, and by the 1980s, inflation averaged 12 percent. ${ }^{3}$ Thus, Honduras is having a progressively harder time holding inflation in check, 


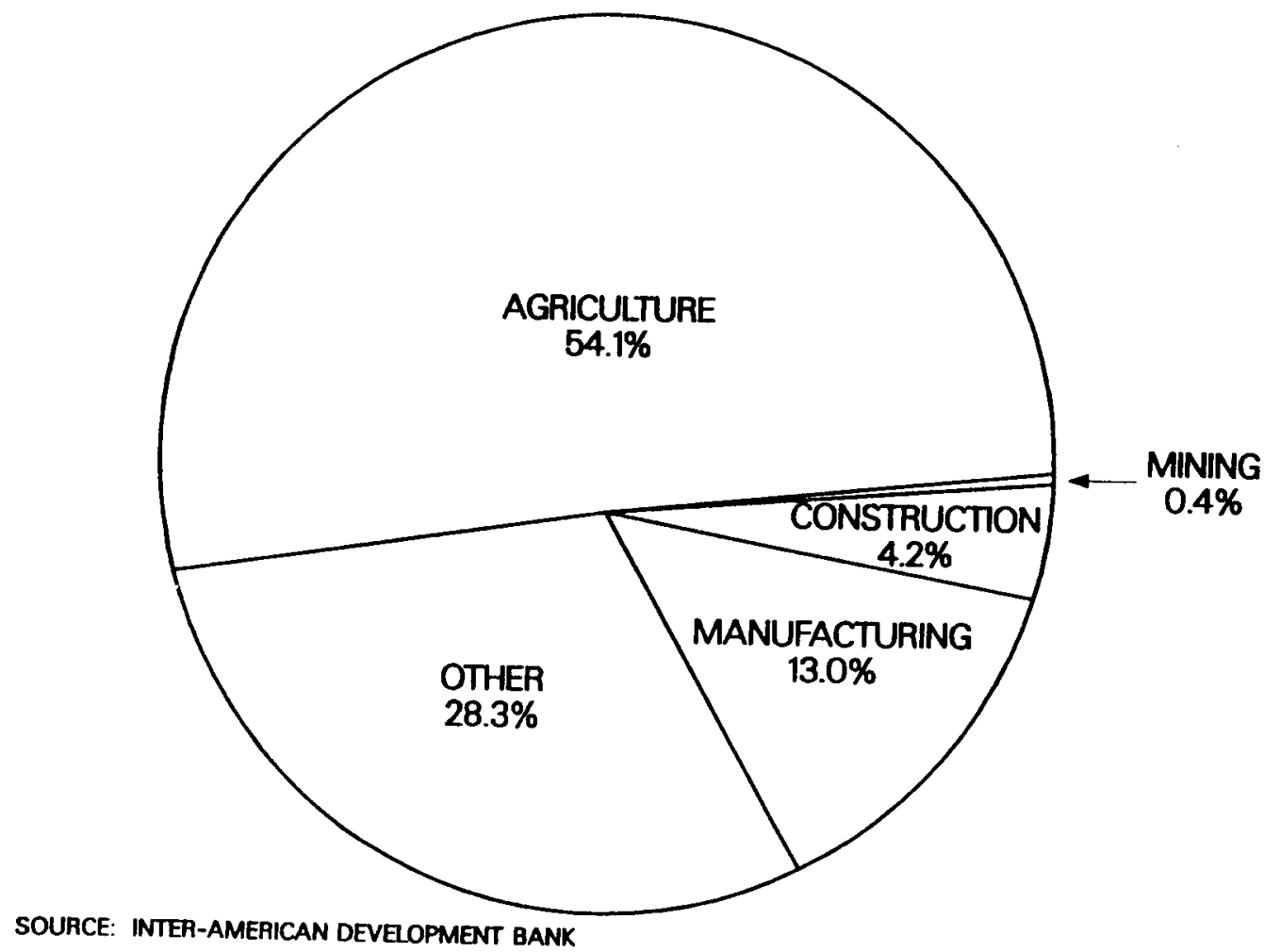

Fig. 2. Honduras: Labor force by sector for 1982.

TABLE 3

HONDURAS: SECTORIAL CONTRIBUTION TO GROSS DOMESTIC PRODUCT

(percentage based on 1982 lempiras)

$\begin{array}{lllllll}1970 & 1975 & 1980 & 1981 & 1982 & 1983 & 1984\end{array}$

Gross domestic product by kind of oconomic activity

Agriculture

$\begin{array}{lllllll}33.9 & 28.7 & 29.3 & 29.6 & 29.9 & 31.0 & 31.3\end{array}$

Mining

Manuf acturing

Construction

2.2

$2.5 \quad 2.1$

1.9

2.1

2.1

2.2

14.2

$\begin{array}{lll}14.8 & 16.0 \quad 16.0\end{array}$

15.1

14.7

14.6

Electricity, gos and water

$3.7 \quad 4.0 \quad 4.2$

4.04 .1

4.2

$\begin{array}{lllllll}1.1 & 1.3 & 1.8 & 2.0 & 1.9 & 2.0 & 2.0\end{array}$

Transport and communications

$7.9 \quad 9.5$

6.5

6.8

6.86 .7

6.8

Trode

Bank/insurance/real estate

$\begin{array}{lll}12.8 & 11.2 \quad 12.8\end{array}$

12.5

$2.5 \quad 3.5$

4.0

3.9

$12.4 \quad 12.0$

12.1

Public adminietration and defense

3.53 .7

4.7

4.9

3.7

3.7

3.7

$7.0 \quad 8.0$

7.8

Services

11.

Other branches

Statistical discrepancy 
TABLE 4

HONDURAS: GROSS DOMESTIC PRODUCT GROWTH RATES

(porcentoge based on 1982 lempiras)

\begin{tabular}{|c|c|c|c|c|c|c|c|c|}
\hline & & $1970-1975$ & $1975-1980$ & 1980 & 1981 & 1982 & 1983 & 1984 \\
\hline Gross & Somestic product ot constont market pricos & 2.0 & 7.2 & 5.0 & 1.2 & -1.8 & -0.5 & 2.8 \\
\hline Grose & - domestic product at constant factor cost & 2.0 & 6.9 & 7.2 & 0.7 & -0.3 & -1.0 & 2.5 \\
\hline \multicolumn{9}{|c|}{ Gross domestic product by kind of oconomic activity } \\
\hline & Agricuiture & -1.4 & 7.4 & 6.7 & 1.7 & 0.7 & 2.7 & 3.4 \\
\hline & Mining & 4.9 & 2.9 & 31.1 & -5.3 & 8.4 & 0.0 & 7.6 \\
\hline & Manufacturing & 2.8 & 8.6 & 5.0 & 0.3 & -5.7 & -3.9 & 2.2 \\
\hline & Construction & 3.4 & B. 2 & 13.2 & -7.8 & 4.2 & 1.3 & 4.0 \\
\hline & Eloctricity, gas and wator & 5.5 & 14.9 & 62.0 & 8. 8 & -2.7 & 0.0 & 2.8 \\
\hline & Transport and communicotions & 5.9 & -0.8 & -26.4 & 4.2 & 0.8 & -2.4 & 3.2 \\
\hline & Trado & -0.8 & 9.9 & 21.6 & -1.7 & -1.7 & -3.5 & 3.2 \\
\hline & Bonk/insurance/rool ostate & 8.9 & 10.0 & 15.6 & -1.3 & -5.5 & -1.4 & 1.5 \\
\hline & Public administration and defense & 3.1 & 11.9 & 21.1 & 4.7 & 3.3 & 0.0 & 1.1 \\
\hline & Ownership of dwellings & 4.8 & 6.4 & 12.6 & -0.7 & 0.0 & -0.7 & 0.0 \\
\hline & Services & 4.8 & 3.2 & 2.1 & 2.0 & 3.5 & -5.3 & 0.0 \\
\hline & Other branches & - & - & - & - & - & - & - \\
\hline & Statistical discroponcy & - & - & - & - & - & - & - \\
\hline
\end{tabular}

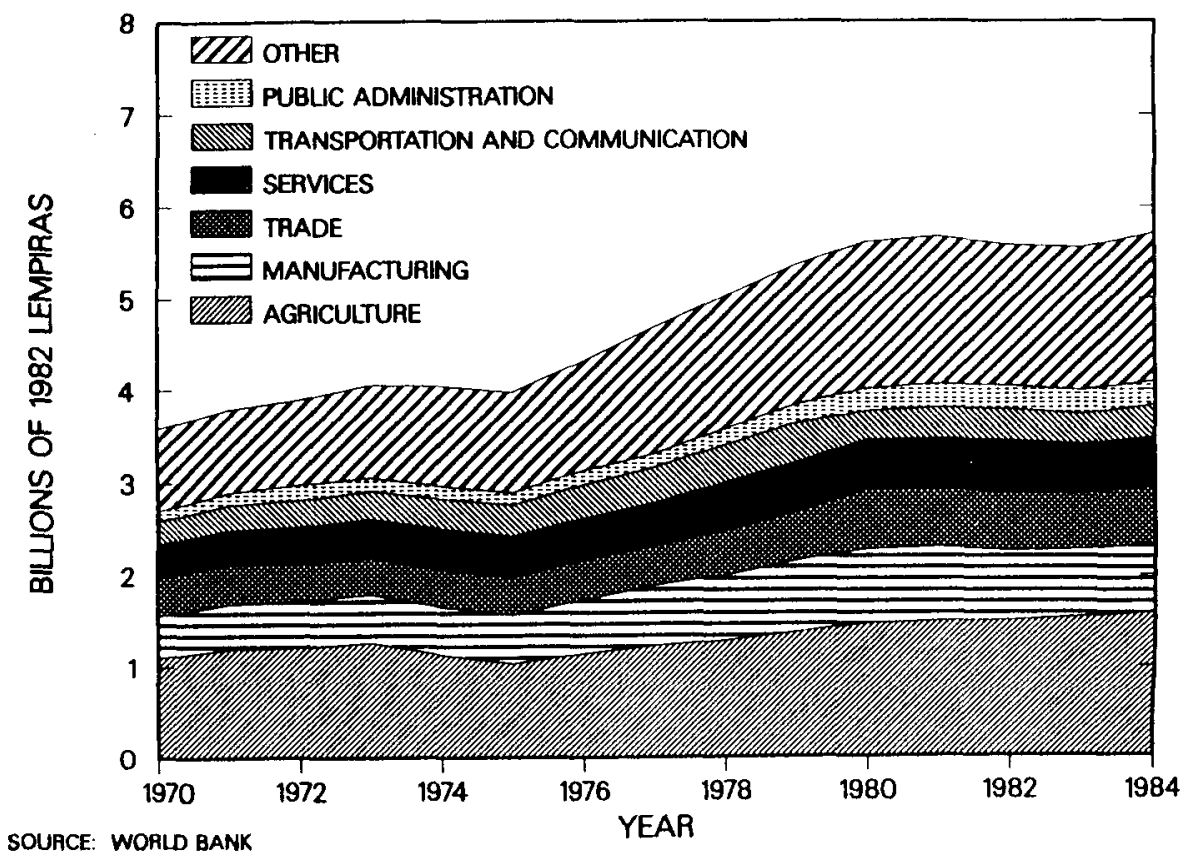

Fig. 3. Honduras: Gross domestic product by major sector. 
although the inflation rate appeared to be moderating in 1984 and is still low by Latin American standards.

\title{
C. Exports/Imports
}

Honduras, along with the other Central American countries, has experienced difficulties in avoiding balance of payments deficits during the $1980 \mathrm{~s}$. The combination of reduced foreign demand for its exports and rapidly increasing external debt service to finance debt related to oil imports and hydoelectric construction caused the current account deficit to increase from $\$ 112.1$ million US in 1975 to $\$ 316.8$ million US in 1980 (see Table 5). This induced the government to enact restrictive economic policies to 1 imit imports. During 1982 , Honduras experienced difficulty in obtaining adequate external financing and had to enter negotiations with its creditors to restructure some of its debt. Further financing was not forthcoming, however, and the country has had to utilize its international reserves to cover the international deficits. ${ }^{4}$

The disbursed external debt has risen dramatically since 1970 (see Table 6). It increased an average of 27 percent a year from 1970 to 1980 and

\author{
TABLE 5 \\ HONDURAS: BaLANCE OF PAYMENTS \\ (\$ million US)
}

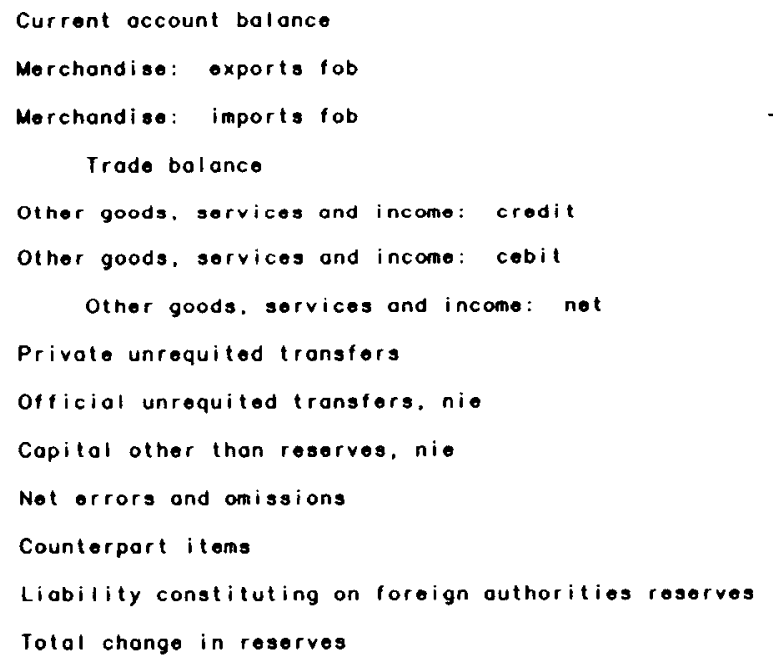


TABLE 6

HONDURAS: EXIERNAL PUBLIC INDEBTEONESS

Debt outstanding-including undisbursod

Debt outstanding-disbursod

Principol ropoyment

Interest poyment

Totol debt service

\begin{tabular}{lrrrrrrr}
\multicolumn{8}{c}{$\begin{array}{c}\text { Curront Pricos } \\
\text { (Smillion US) }\end{array}$} \\
\hline 1970 & 1975 & 1980 & 1981 & 1982 & 198.3 & 1984 \\
143.9 & 448.8 & 1709.8 & 1968.5 & 2031.8 & 2313.5 & 2502.1 \\
96.1 & 264.0 & 981.0 & 1227.7 & 1374.9 & 1570.3 & 1840.7 \\
3.1 & 6.4 & 39.3 & 37.8 & 50.8 & 37.6 & 54.7 \\
2.5 & 10.2 & 58.9 & 77.5 & 96.9 & 83.1 & 80.0 \\
5.6 & 16.6 & 98.2 & 115.3 & 147.7 & 120.7 & 134.7
\end{tabular}

Source: World Bank.

an average of 17 percent each year during the 1980s. Total debt service has also risen, from only $\$ 5.6$ million US in 1970 to a peak of $\$ 147.7$ million US in 1982, equal to about 5 percent of GDP in that year. Compared with other Latin American countries, this figure is actually quite low. After rescheduling the debt in 1982, debt service declined to $\$ 134.7 \mathrm{mil1}$ ion US by 1984 .

In Honduras, over 50 percent of export earnings come from only two products, bananas and coffee (see Table 7 and Fig. 4). These two products have been dominant throughout the $1970 \mathrm{~s}$ and $1980 \mathrm{~s}$ and are expected to remain so into the future. Over the 1970 to 1984 period, wood and chilled meat have declined in importance, while the export earnings shares of shellfish and zinc have increased. (The latter two products are included in the "other" category in Table 7.)

The total value of exports declined markedly during 1981 and 1982, mainly because of reductions in sales of coffee and meat. Fortunately, Honduras' two main crops show an increase for 1984: 8.4 percent for bananas and 11.9 percent for coffee (see Table 8). Continued growth in the export sector is critical if Honduras is to be able to resume economic expansion.

The value of imports came to $\$ 896$ million US in 1984 , reflecting a 28 percent increase over the low 1982 total (see Tables 8 and 9). The situation was just the opposite in 1981 and 1982, when imports declined over 30 percent from the 1980 figure. This situation was in part owing to the institution of measures to reduce imports in the face of declining export foreign exchange earnings: in addition to discouraging the purchase of imported luxuries, 
TABLE 7

HONDURAS: EXPORTS AND IMPORTS

(percentage of total)

\section{Exports}

banonos

coffoo

wood

frozon beof

sugor

other

Imports, c.i.f.

$\begin{array}{rrrrrrr}1970 & 1975 & 1980 & 1981 & 1982 & 1983 & 1984 \\ 100.0 & 100.0 & 100.0 & 100.0 & 100.0 & 100.0 & 100.0 \\ 41.6 & 20.3 & 27.5 & 28.1 & 33.1 & 30.4 & 29.9 \\ 14.2 & 18.8 & 24.6 & 22.7 & 23.2 & 22.6 & 23.0 \\ 8.9 & 12.7 & 4.4 & 5.7 & 6.8 & 6.0 & 4.6 \\ 5.4 & 6.0 & 7.3 & 6.1 & 5.1 & 4.6 & 3.4 \\ -0 & 2.3 & 2.2 & 6.1 & 3.4 & 4.2 & 3.4 \\ 29.9 & 39.9 & 34.0 & 31.3 & 28.4 & 32.2 & 35.7\end{array}$

a
15.6

17.0

17.0

23.9

20.6

21.2

andicates a lack of statistical data that can be reported.

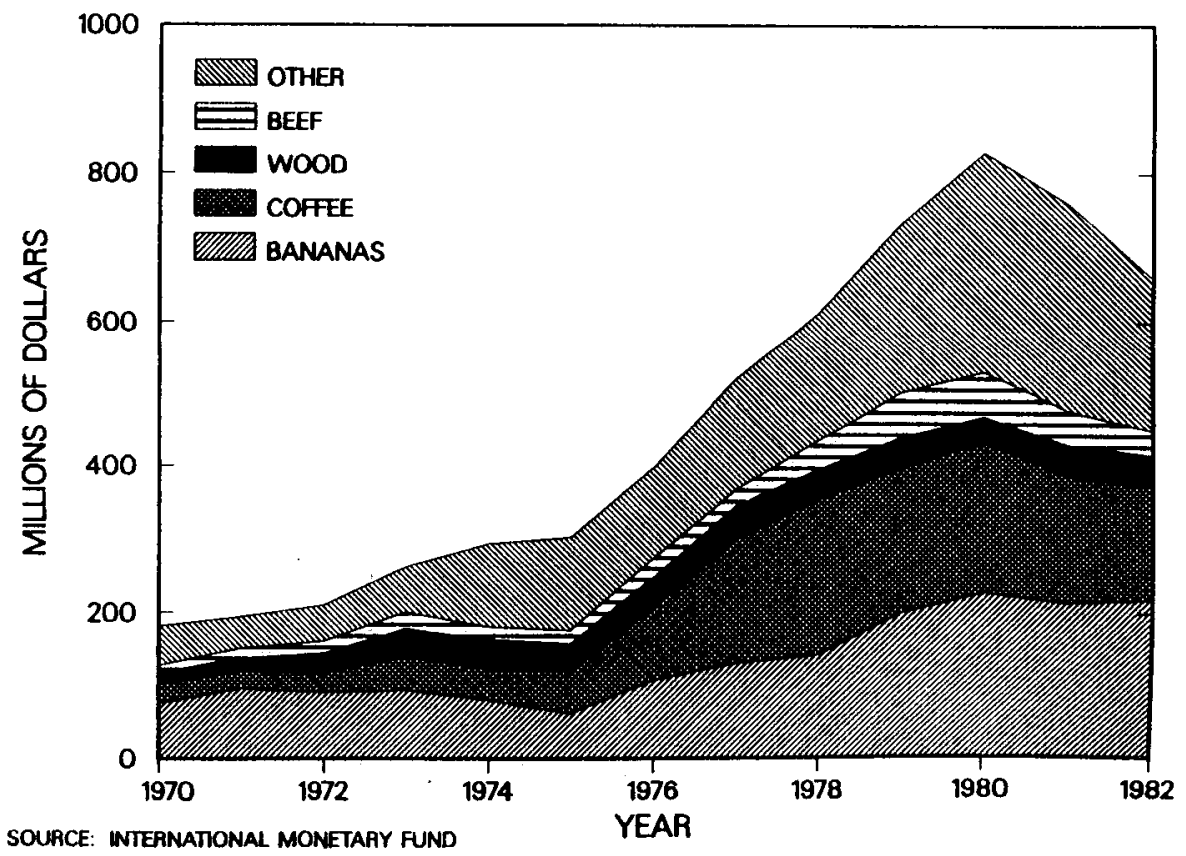

Fig. 4. Honduras: Exports by product. 
TABLE 8

HONDURAS: GROWTH RATES FOR EXPORTS AND IMPORTS

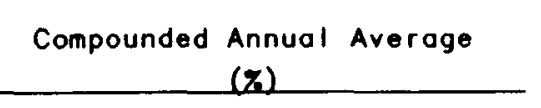

$1970-1975 \quad 1975-1980 \quad 1970-1980$

\section{Exports}

bonanas

coffoe

wood

frozen beef

sugar

Imports, c.i.f.

petroleum

Imports, f.o.b.

$\begin{array}{rrr}10.8 & 22.3 & 16.4 \\ -4.0 & 30.0 & 11.7 \\ 17.1 & 29.1 & 23.0 \\ 18.9 & -1.2 & 8.4 \\ 13.3 & 27.1 & 20.0 \\ -^{\circ} & 21.8 & -0 \\ 12.9 & 20.1 & 16.4 \\ -0 & 22.1 & -0 \\ 13.1 & 20.0 & 16.5\end{array}$

Annual Growth Rote (z)

$1980 \quad 1981 \quad 1982 \quad 1983 \quad 1984$

$\begin{array}{lllll}13.1 & -8.3 & -13.3 & 1.8 & 10.3\end{array}$

$\begin{array}{lllll}14.1 & -6.2 & 2.1 & -6.9 & 8.4\end{array}$

$\begin{array}{lllll}3.7 & -15.3 & -11.5 & -1.3 & 11.9\end{array}$

$\begin{array}{lllll}-14.0 & 19.3 & 3.5 & -11.1 & -15.0\end{array}$

$\begin{array}{lllll}0.0 & -23.5 & -27.5 & -8.8 & -19.4\end{array}$

$\begin{array}{lllll}107.9 & 151.9 & -52.1 & 27.3 & -10.7\end{array}$

$\begin{array}{lllll}22.1 & -5.9 & -26.2 & 14.7 & 13.4\end{array}$

$\begin{array}{lllll}51.6 & -5.4 & 3.3 & -0.6 & 14.4\end{array}$

$22.1-5.9-26.2 \quad-0$

Indicates a lack of statistical data that can be reported. 
TABLE 9

HONDURAS: EXPORTS AND IMPORTS

\section{Exporta \\ banonas \\ coffeo \\ wood \\ frozen beef \\ sugar \\ Imports, c.l.f. \\ potroloum \\ Imports, f.o.b.}

\begin{tabular}{|c|c|c|c|c|c|c|}
\hline 1970 & 1975 & 1980 & 1981 & 1982 & $1983^{\circ}$ & $1984^{a}$ \\
\hline 181.4 & 303.2 & 829.4 & 760.8 & 659.5 & 667.0 & 736.0 \\
\hline 75.4 & 61.5 & 228.0 & 213.8 & 218.3 & 203.0 & 220.0 \\
\hline 25.8 & 56.9 & 204.1 & 172.9 & 153.1 & 151.0 & 169.0 \\
\hline 16.2 & 38.5 & 36.2 & 43.2 & 44.7 & 40.0 & 34.0 \\
\hline 9.8 & 18.3 & 60.8 & 46.5 & 33.7 & 31.0 & 25.0 \\
\hline$-^{b}$ & 6.9 & 18.5 & 46.6 & 22.3 & 28.0 & 25.0 \\
\hline 220.7 & 404.3 & 1008.7 & 949.1 & 700.5 & 804.0 & 896.0 \\
\hline - b & 63.1 & 171.0 & 161.7 & 167.1 & 166.0 & 190.0 \\
\hline 199.2 & 368.6 & 917.0 & 862.8 & 636.8 & $-b$ & $-b$ \\
\hline
\end{tabular}

Indexes

$(1980=109)$

\begin{tabular}{|c|c|c|c|c|c|c|}
\hline 75.0 & 68.0 & 100.0 & 105.0 & 94.0 & $-^{b}$ & $-^{b}$ \\
\hline 86.0 & 42.0 & 100.0 & 89.0 & 94.0 & $-b$ & -b \\
\hline 45.0 & 86.0 & 100.0 & 120.0 & 101.0 & - $^{b}$ & - b \\
\hline 43.0 & 58.0 & 100.0 & 83.0 & 56.0 & - & -b \\
\hline$-b$ & 17.0 & 100.0 & 194.0 & 96.0 & $-^{b}$ & $-^{b}$ \\
\hline 137.0 & 169.0 & 100.0 & 107.0 & 112.0 & - & $--^{b}$ \\
\hline 34.0 & 56.0 & 100.0 & 92.0 & 92.0 & $-\mathrm{b}$ & - $^{b}$ \\
\hline 39.0 & 64.0 & 100.0 & 105.0 & 102.0 & $\square^{b}$ & -0 \\
\hline 44.0 & 86.0 & 100.0 & 107.0 & 100.0 & 114.0 & 99.8 \\
\hline 28.0 & 32.0 & $100.0^{-}$ & 71.0 & 74.0 & & $-^{b}$ \\
\hline 33.0 & 63.0 & 100.0 & 111.0 & 114.0 & & $-{ }^{\mathbf{b}}$ \\
\hline 37.0 & 51.0 & 100.0 & 92.0 & 99.0 & - & $-^{b}$ \\
\hline
\end{tabular}

Source: International Monetary Fund.

Bank of Honduras dato.

bIndicates a lock of statistical data that can be reported. 
the government enacted a surcharge of 20 percent on all imports except essential goods such as petroleum and agricultural products. The substantial reduction in the imports of consumer and intermediate goods in 1982 contributed to the weakness of the trade and manufacturing sectors and thus to that of the general economy.

\section{Financial Assistance}

Honduras receives grants and loans from various sources including the United States and multilateral financing institutions such as the World Bank (WB). Table 10 provides details on economic and military aid from the United States and loan authorizations from the International Bank for Reconstruction and Development (IBRD), Inter-American Development Bank (IDB), and the United Nations Development Program (UNDP).

Economic aid from the United States is focused in three programs. The Agency for International Development (AID) provides the largest portion (about 75 percent of total economic aid in 1984) and the Food for Peace and Peace Corp programs contribute the remainder.

Over the 1962 through 1980 period, Honduras received an average of $\$ 15.8$ million US in economic aid from the United States annually. During the economic crisis of the 1980s, the aid was increased rapidly to a peak of $\$ 106$ million US in 1983. In addition, because of the problems Honduras was facing with its external financing, the proportion of grants in the programs, as opposed to loans, increased from an average of 40 percent during 1962 to 1979 to almost 60 percent in 1984 .

The US military aid also rapidly increased as the political and social climate in the countries surrounding Honduras deteriorated. From an average of $\$ 1.6$ million US annually during 1962 to 1979 , such aid increased to $\$ 77.4 \mathrm{mil}$ lion US for 1984 alone. Note also that grants are increasingly being used; in fact, all of the military aid in 1984 is of this form. In addition, the military aid segment has become a larger part of the total United States aid package to Honduras: during the 1962 to 1979 period, military aid was only about 10 percent of the total; now it comprises 45 percent.

In order to stimulate economic growth, all less-developed countries, including Honduras, need investment funds. The international banking system and the multilateral financial aid organizations such as the World Bank provide authorization loans to facilitate this growth process. Loan authorizations are basically a line of credit available to the country if it desires a loan. Therefore, the whole amount of the authorization is not necessarily dispersed, al though during the 1980s, Honduras had great need for funds, requiring more than was authorized. The international organizations responded to this need by 
TABLE 10

US AND INTERNATIONAL AID TO HONDURAS

( $\$$ million US)

\begin{tabular}{|c|c|c|c|c|c|c|}
\hline & $1962-1979$ & 1989 & 1981 & 1982 & 1983 & 1984 \\
\hline Total US economic ossistance & 248.7 & 53.1 & 36.4 & 80.7 & 106.0 & 95.0 \\
\hline Loons & 149.8 & 40.6 & 23.8 & 61.5 & 45.0 & 38.3 \\
\hline Gronts & 98.9 & 12.5 & 12.6 & 19.2 & 61.0 & 56.7 \\
\hline Grants as a percent of total economic ossistance & $39.8 x$ & $23.5 x$ & $34.6 x$ & $23.8 x$ & $57.5 \pi$ & $59.7 \pi$ \\
\hline Total U.S. military ossistance & 27.2 & 3.9 & 8.9 & 31.3 & 48.3 & 77.4 \\
\hline Loans & 12.5 & 3.5 & 8.4 & 19.0 & 9.0 & - \\
\hline Grants & 14.7 & 0.4 & 0.5 & 12.3 & 39.3 & 77.4 \\
\hline Gronts as a percent of total military aseistance & $54.0 x$ & 10.35 & $5.6 \%$ & $39.3 \%$ & 81.47 & $100.0 \%$ \\
\hline Totol U.S. economic ond military assistance & 275.9 & 57.0 & 45.3 & 112.0 & 154.3 & 172.4 \\
\hline Loons & 162.3 & 44.1 & 32.2 & 86.5 & 54.0 & 38.3 \\
\hline Gronts & 113.6 & 12.9 & 13.1 & 31.5 & 100.3 & 134.1 \\
\hline Military ossistance os a percent of total assistance & 9.97 & 6. $8 \%$ & $19.6 \%$ & $27.9 \%$ & $31.3 \%$ & 44.97 \\
\hline Total ossistance from internotional orgonizations & 681.6 & 224.0 & 35.5 & 37.0 & 89.6 & 154.3 \\
\hline IBRO & 232.9 & 128.0 & 28.0 & 30.0 & 45.0 & 19.6 \\
\hline IFC & 10.4 & - & - & - & - & - \\
\hline IDA & 49.2 & 25.0 & - & - & - & - \\
\hline IDB & 366.2 & 71.0 & 7.5 & - & 42.2 & 134.1 \\
\hline UNDP & 17.4 & $\bullet$ & - & 7.0 & 2.4 & - \\
\hline othor UN & 5.5 & - & - & - & - & 0.6 \\
\hline
\end{tabular}

Source: Urited Statos Agoncy for International Development.

- Los8 than $\$ 50,000$ 
offering $\$ 89.6$ million US and $\$ 154.3$ million US in 1983 and 1984 , respectively. This represents a substantial increase over the $\$ 37 \mathrm{mi} 11$ ion US offered in 1982 . E. Role of Government

Before 1950, the Honduran government had little involvement with the economy; in 1952, government expenditures were equal to only 8.4 percent of GDP. During the 1950 s and 1960 s some institutions were established to deal with issues of housing, social security, agricultural development, and so on. During this time, more emphasis was placed on the expansion of the country's infrastructure. However, the government remained a small segment of the economy even in the late 1960s: its share of GDP was only 11.2 percent in 1967.

The governments of the $1970 \mathrm{~s}$ began to take a more active role in the economy. They stressed economic development through agrarian reform, forestry development, and industrialization in general. In order to deal more effectively with foreign banana companies, the Honduran Banana Corporation (Corporacion Hondurena del Banano--COHBANA) was established. Another new institution, the National Investment Corporation (Corporacion Nacional de Inversiones-CONADI), began stimulating private sector investment through the use of loans, loan guarantees, and equity holdings. To stimulate the forestry industry, the government formed the Honduran Forestry Development Corporation (Corporacion Hondurena de Desarrollo Forestal--COHDEFOR). In addition to all of this, infrastructure investment was rapidly increased for such expensive projects as the El Cajon hydroelectric plant and road building. Taxes were raised to help pay for the increased government involvement. Unfortunately, these activities were not as successful as was hoped. For example, the El Cajon project ended up costing twice as much for one-half the capacity as originally planned.

An important negative economic effect of the above activities is that Honduras has accumulated a significant external debt (about 1.5 billion US in 1983) and has experienced budget deficits of at least 6 percent of GDP each year since 1975. Even with World Bank pressure to get its finances in order, the financial and economic crisis experienced in 1982 made it difficult to reduce the deficit. Indeed, the deficit was equal to about 7 percent of GDP in $1983 .{ }^{1}$ F. Employment

The economically active population of Honduras was about $1.1 \mathrm{million}$ persons in the early 1980s. As shown in Table 11 the agriculture sector employs the largest portion of these people--about 59 percent. In 1950, that percentage was about 80 percent, so the society has experienced a substantial cultural shift away from the rural life. 
TABLE 11

HONDURAS: EMPLOYED LABOR FORCE, BY SECTOR

1971 and 1981

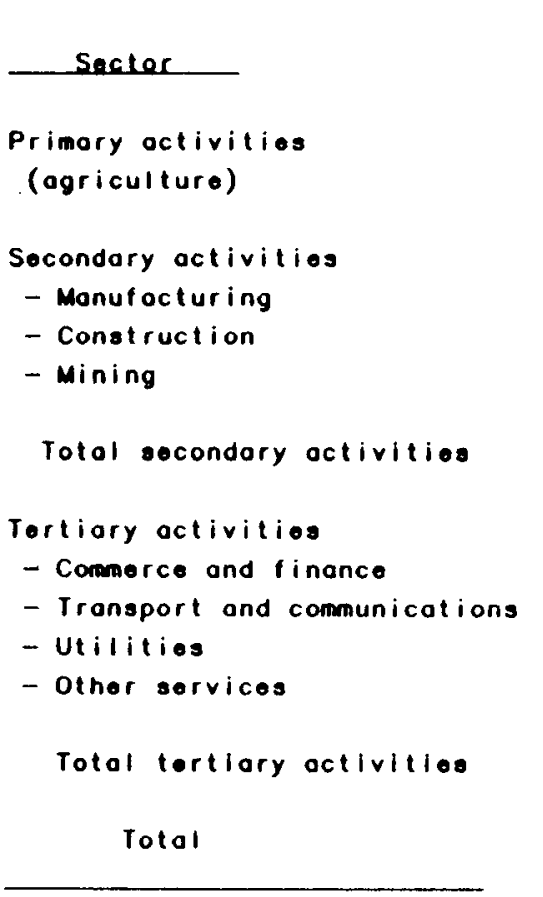

1971

Ihousonds Percentoge

502.5

62.8

87.2

25.6

2.4

115.2

68.0

20. 0

2.4

92.9

182. 4

800. 1
10.9

3. 2

Q. 3

14.4

8. 5

2.5

0.3

11.5

22.8

100.0
1981 Ihousonds Percentage

593.2

58.7

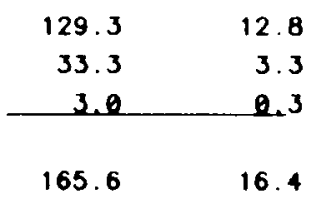

$92.8 \quad 9.2$

$30.3 \quad 3.0$

$5.0 \quad 0.5$

\begin{tabular}{ll}
$123.3 \quad 12.2$ \\
\hline
\end{tabular}

$251.4 \quad 24.9$

$1.010 .2 \quad 100.0$

Source: Reference 1 .

During 1971 to 1981 , the 3.1-percent average annual growth rate in the 1 abor force outstripped the 2.4 -percent annual growth rate in jobs. The agricultural sector experienced the slowest growth, averaging only a 1.7 -percent average increase in jobs per year. Although manufacturing jobs expanded at a 4-percent annual rate, it still remained a relatively small employment sector. The category of "Other Services" is ill-defined but includes many of the jobs that the migrating rural people take--i.e., jobs such as street vendors or domestics.

The rapid population rise in Honduras implies the need for expansion of employment opportunities in the future. Unfortunately, the outlook remains grim. The recent recession severely dampened the economy, and many firms were forced to close. It will take several years simply for the economy to recover what jobs were lost; meanwhile, the labor force and unemployment will continue to grow.

The unemployment rate has been extremely high in Honduras during the 1980s. Open unemployment was estimated to be between 20 and 30 percent of the labor force. In addition, 35 to 45 percent were underemployed. ${ }^{1}$ Agriculture contains 
the highest proportion of underemployed persons, and seasonal crop patterns lead to peaks of unemployment during February, March, and September.

G. Welfare and Income Distribution

The Honduran government spends about 25 percent of its total expenditures on social needs such as education and health care. The Honduran Social Security Institute (Instituto Hondureno de Seguro Social--IHSS) has made significant progress, but it is not yet a formidable force in the economy, and most people do not receive any form of aid from the government. The Center for Industrial Development (Centro de Desarrollo Industrial--CDI) currently has a small rural technology program to help the rural people construct simple tools to facilitate farming.

Because the country is very rugged, it is quite expensive to run electric power lines to remote areas; consequently, many rural villages have yet to receive electricity. Most villages do have running water, but sewers are rare.

\section{ENERGY OVERVIEW}

\section{A. Energy Resources}

1. 0 il and Gas. Responsibility for petroleum exploration and production rests with the General Directorate of Mines and Hydrocarbons (Direccion General de Minas e Hidrocarburos--DGMH) of the Secretariat of Natural Resources. A new Petroleum Exploration Law was approved by Congress in late 1984 to provide the basis for contracts between the Government and national or international oil companies. The World Bank, through a $\$ 3$ million loan to create incentives for petroleum exploration, provided technical assistance for the drafting of the law as well as for training personnel and organizing information that already exists.

Petroleum exploration in Honduras dates back to 1916, but most of the exploratory efforts took place during the last 25 years. In 1961 several oil companies became active in Honduras. They conducted geological surveys, air and surface magnetic surveys, as well as gravity and seismic surveys. A total of 19 wells have been drilled, and there are over 30 thousand kilometers of seismic reflection 7 ines providing data as well as other relevant information that are now being organized and consolidated with World Bank support.

Honduras' prospective petroleum exploration areas are located both onshore and offshore. About $36,000 \mathrm{~km}^{2}$ of sedimentary basins exist inland, both in the Caribbean coast as well as in the Comayagua Valley, where natural gas deposits have been detected. The areas with highest potential lie offshore, with over $100,000 \mathrm{~km}^{2}$ located in deep water (over 200 meters in depth) and $53,000 \mathrm{~km}^{2}$ on the continental shelf. 
The new Petroleum Exploration Law will likely promote a new round of interest on the part of petroleum companies because it sets the framework for risk contracts as well as provides attractive conditions for potential bidders.

2. Coal and Peat. Currently, nothing is being done with coal--no exploration and no exploitation. Past exploration efforts have revealed that Honduras has several areas with mesozoic coal deposits of at least 2 meters in thickness, but analyses of mining feasibility have yet to be made. The country has not been explored for peat, but there is potential for peat resources in some regions of the country.

3. Hydro Power. Results of a recent study of hydroelectric potential in Honduras are shown in Table 12. The total potential of the possible projects is approximately $1700 \mathrm{MW}$. Dam types, line storage capacity, average annual energy, and costs have been estimated for these projects.

4. Geothermal Power. A geothermal reconnaissance is being carried out by an Italian team funded by the United Nations Development Project. Geoscientists from Los Alamos National Laboratory (LANL) and the United States Geological Survey (USGS) are currently working with the Honduran electric utility (ENEE) on an exploration project in Honduras to ascertain the extent of geothermal resources. The project is designed to be ongoing, with training and support to facilitate within-country expertise and surveying capabilities. After two survey trips to the region, some recommendations have been made as to what geographic areas are suitable for further exploration and drilling.

TABLE 12

HONDURAS: POTENTIAL HYDROELECTRIC PROJECTS

\begin{tabular}{|c|c|c|c|}
\hline $\begin{array}{l}\text { Project } \\
\text { Nome }\end{array}$ & River & 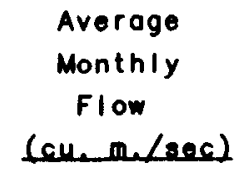 & Capacity (Mil) \\
\hline Los Llanitas & Ulua & 82.65 & 150 \\
\hline Cerro Malin & Uluo & 197.38 & 230 \\
\hline Lo Foligrano & Utuo & 207.90 & 236 \\
\hline Noranjito & Jicotuyo & 76.20 & 72 \\
\hline Remol ino & Comayogua & 140.58 & 125 \\
\hline Cayotano & Potuca & 152.82 & 118 \\
\hline Valencio & Patuca & 237.67 & 344 \\
\hline Roity & Potuca & 408.20 & $250-403$ \\
\hline sico-2 & Sico & 99.96 & 122 \\
\hline Sico-1 & Sico & 108.89 & $85-156$ \\
\hline
\end{tabular}

SOURCE: National Company of Electric Energy (ENEE). 
Six hot springs sites have so far been reconnoitered: samples were drawn and analyzed, and the following preliminary ranking of potential geothermal sites was made. Out of the six sites explored, three appear to have the necessary attributes to warrant further exploration and drilling. They are San Ignacio, Platanares, and Azacualpa (see Fig. 5). Platanares has the hottest subsurface water, with estimated temperatures of between 200 degrees $C$ and 235 degrees $C$. The San Ignacio site is characterized by boiling water and a subsurface temperature of approximately 185 degrees $C$. The large flow of water indicates a potential for substantial electricity capacity. Azacualpa has water between $180^{\circ} \mathrm{C}$ and 187 degrees $C$ in temperature and probably would produce about the same amount of electricity as San Ignacio. Besides producing electricity, these sites may also be useful in direct-heat applications.

The other three sites that were recently explored are the Sambo Creek area, the Pavana area, and the El 01 ivar-Laguna Agua Caliente area. These three sites have hot water but were not deemed as top choices for further exploration.

5. Fuel Wood and Other Biomass. Honduras is blessed with a climate that is very conducive to the growth of forests. Most of its land was originally covered with both pine and wide-leaf trees, and in 1965 it was estimated that 7 million hectares (about 63 percent of the total land area) were still covered by forests. ${ }^{5}$ Some 39 percent of these forests was composed of pine trees, and

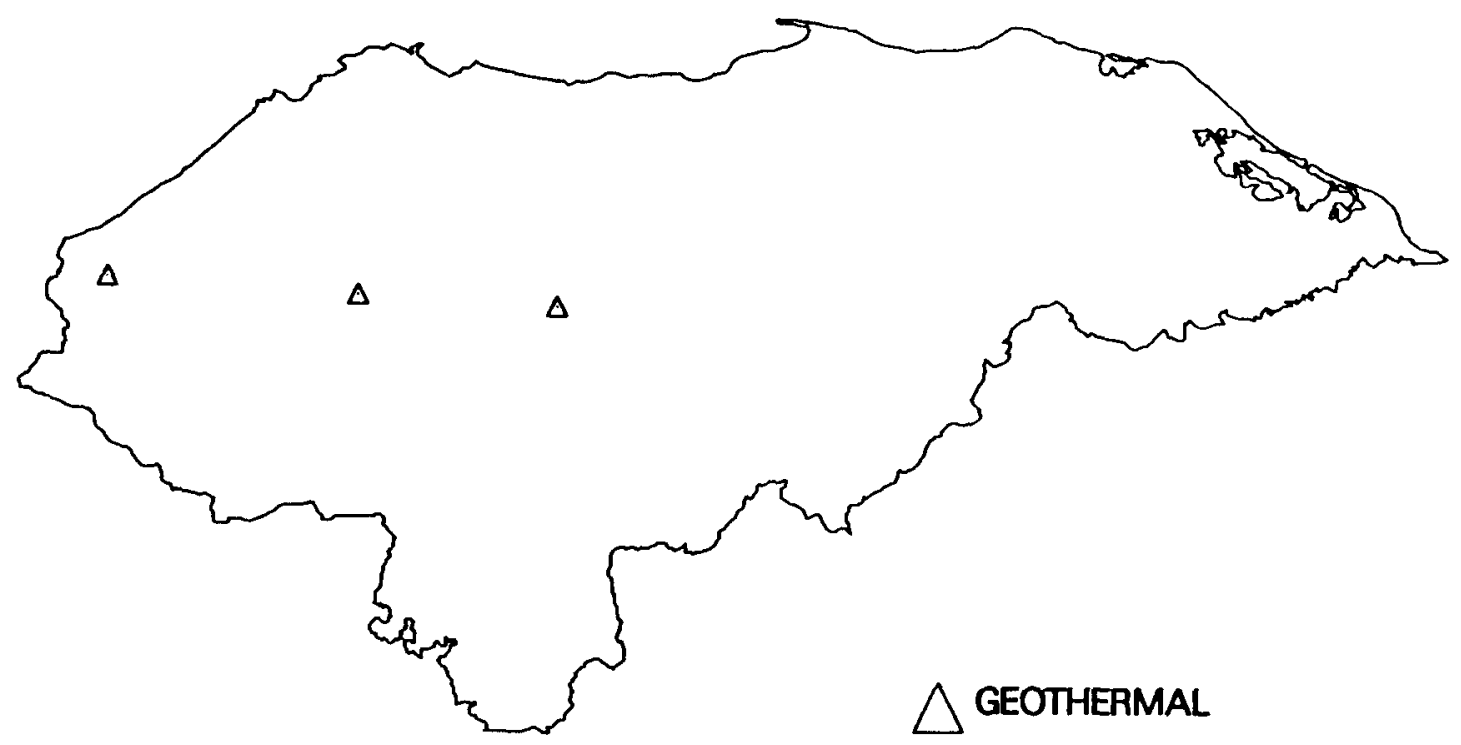

SOURCE: LANL/ENEE,

Fig. 5. Honduras: Location of geothermal resources. 
the remainder was wide-leaf trees. By 1980, because of rapid cutting of timber for lumber, sawdust, and firewood, Honduras had only 3.7 million hectares of forest remaining. ${ }^{2}$ The pine/wide-leaf split had changed to 51/49 from the $39 / 61$ in 1965, and in terms of total 1and mass, only 33 percent was forest covered.

In 1965 deforestation was evident in the south and west of the country. These two areas are quite different in terms of land use: subsistence agriculture is prevalent along the El Salvador border, whereas commercial agriculture, such as cattle and cotton, is more common in the south. However, both types of agriculture have led to the rapid depletion of the forests.

Recently, the large forested area of the northeast has become the key area in the campaign by COHDEFOR to protect the national forests; however, that area has also come under increased population and deforestation pressure in the past few years.

Clearly, Honduras has suffered a rapid decline in its forestry resource. The Food and Agriculture Organization of the United Nations estimates that the rate of deforestation was about 2.4 percent annually during the 1976 to 1980 period. 2

As of March, 1984, the resources of eight forest districts had been inventoried. The districts are the following: Comayagus, Francisco Morazan, Yoro, El Paraiso, Nor-Occidental, Corocito, La Mosquitia, and the Reserva Forestal 01 ancho. The area of these districts covers 44.5 percent of the country. Approximately half of the area inventoried was covered by forests. The categorization of forests by type was 57 percent coniferous, 10 percent mixed, and 33 percent latifoliates.

B. Energy Supply

Honduras' energy needs are largely supplied by traditional sources, mainly fuel wood. Fuel wood, along with charcoal and other biomass, provided about 75 percent of all energy in 1970 and 65 percent in 1983 (see Fig. 6). On the other hand, oil supplied about 30 percent in 1983 and electricity, only 4 percent. 6 This section describes the sources of supply, method of distribution, and prices for each type of energy used in Honduras.

\section{Petroleum Supply}

a. Refining. Honduras' oil refinery is owned by Texaco and is located at Puerto Cortez. Although its capacity is rated at 14,000 barrels per day, it cannot supply the correct mix of products for the country and often runs at less than full capacity. (It was originally designed to export bunker oil to Panama, but the market collapsed in 1976 and shows little chance for recovery.) Indeed, during 1984 some 3 million barrels passed through the refinery, representing only about 60 percent of its capacity. As is true for all of the central 


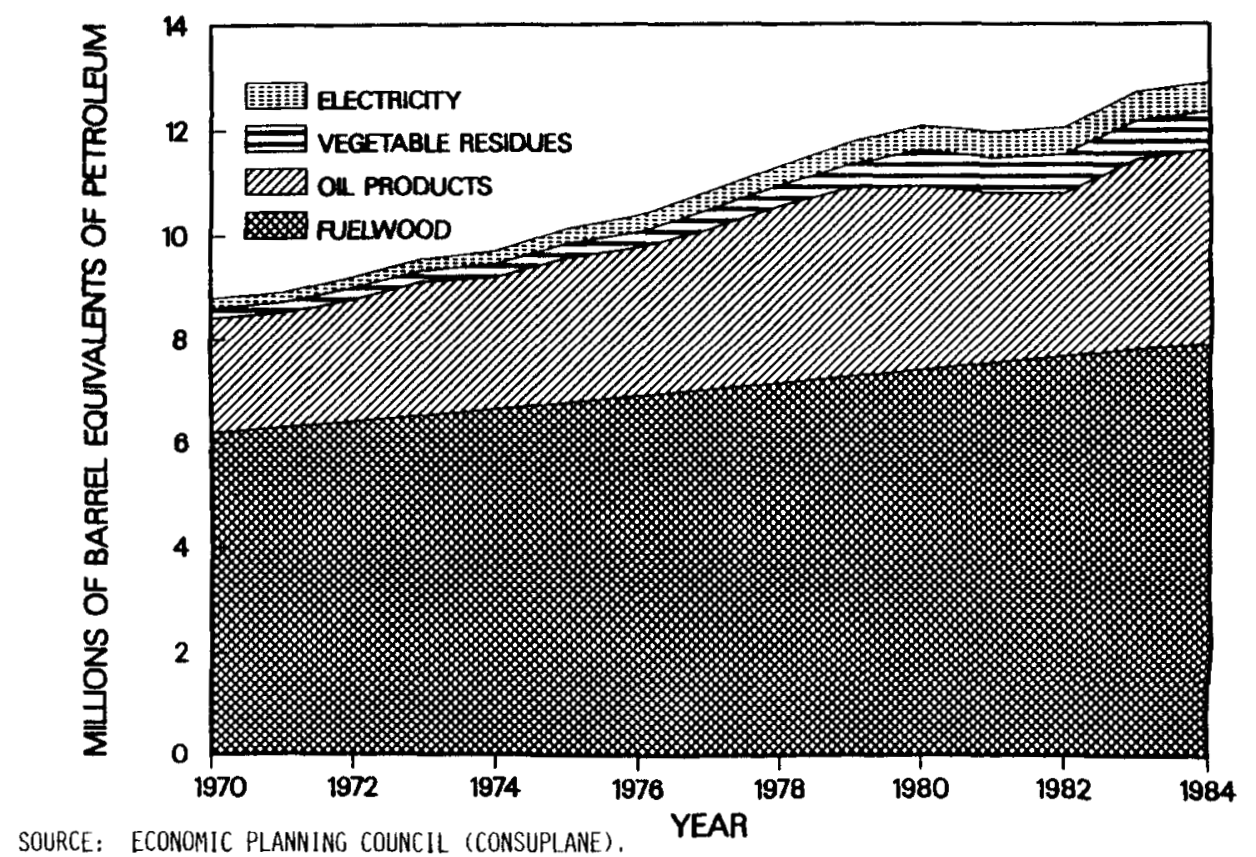

Fig. 6. Honduras: Energy supply by fuel type.

American oil refineries, the Honduran refinery handles only basic refining processes and consequently produces too much heavy $0 i 1$ relative to the lighter distillates. It is for this reason that Honduras must import products.

b. Marketing. Up until 1973, the oil market in Honduras was free of government restrictions, and prices were determined by supply and demand. Since then, however, the Ministry of Economics has regulated prices and thus influenced the refinery's profit margin. The government purchases crude oil from Venezuela and Mexico under the San Jose Agreement, then sells it to the refinery. Prices within the country are fixed according to geographic zones to take account of different transport costs. Honduras has no oil pipeline, and a11 internal oil movements are made by tank truck.

Since 1979, the prices of kerosene, bunker $C$ (fuel oil), and diesel fuel have been subsidized out of revenues from gasoline taxes. This subsidy has caused the demand for diesel fuel to increase as people switched to dieselburning cars and trucks. The Ministry regulates diesel fuel use by individuals by exacting a sales tax of 130 percent on a new car.

The production mix for the refinery is evaluated each quarter to see if any adjustments are needed to keep supply in line with demand. The goal is to utilize the refinery as much as possible to limit both imports from abroad and the export of excess bunker $C$ fuel oil. Thus, the oil product mix is determined main1y by market forces. 
c. Production, Exports, and Imports. Table 13 reports the refinery's production of oil distillates, and it is clear that the total output declined substantially since 1970 as Honduras imported progressively larger amounts of the lighter distillates (see Table 14). In 1982 the refinery's output decreased to only 668,300 barrels, about a third of the previous year's production. This decrease was because crude purchases from Mexico were stopped and instead derivatives were purchased from Trinidad and Tobago. The refinery's product mix has also evolved away from fuel $0 i 1$ and toward diesel fuel: in 1970, the refinery produced 31 percent diesel and 45 percent fue 1 oil, whereas in 1983, the combined production was 42 percent diesel and only 33 percent fuel oil. Since 1970 the production of the other three products (liquified gas, gasoline, and kerosene) has remained at about one-quarter of the total production (see Table 15).

During the early 1970s, the refinery's output was high enough to permit the export of several products, the most important being fuel oil. Table 16 shows that in 1970, substantial amounts of diesel fuel and gasoline were also sold abroad. However, as both world oil prices and the oil needs of the country increased, more of the refinery's output was used at home. Indeed, exports of petroleum products other than fuel oil had ceased by 1978, and even fuel oil has declined in importance as a foreign exchange earner.

Honduras has imported an increasing share of necessary distillates over time and appears to be depending on its own refinery less and less; the amount of crude imported for domestic refining in 1983 was less than half of the amount purchased in 1970 (see Table 14). In addition, during the 1980s lighter crude from Venezuela and Arabia was partially substituted for the harder-to-refine Mayan oil from Mexico (see Table 17).

The percentage of oil products that are refined domestically has declined for all products except fuel oil as shown in Table 18. For example, in 1983, Honduras imported over 1.2 million barrels of diesel fuel and only refined about 44 percent of its needs domestically. This pattern compares with purchases of only 71,200 barrels of diesel oil in 1970, when the refinery produced over 95 percent of domestic diesel needs.

The cost of oil imports has rapidly escalated as a result of both increased price and increased volume. In 1972, before the first oil price run-up, the petroleum import cost was only $\$ 18.5$ million US, which was equal to 8.8 percent of export earnings for the year (see Table 19). By 1984, however, the oil bill had risen to $\$ 167$ million US and was equivalent to over 25 percent of export earnings and 21 percent of total imports. 
TABLE 13

HONDURAS: PRODUCTION OF PETROLEUM DERIVATIVES BY DOMESTIC REFINERY

(thousands of barrels)

\begin{tabular}{|c|c|c|c|c|c|c|c|c|}
\hline & 1970 & 1972 & 1978 & 1979 & 1989 & 1981 & 1982 & 1983 \\
\hline Liquified gos & 50.8 & 60.3 & 50.4 & 38.6 & 31.5 & 26.8 & 4.4 & 18.7 \\
\hline Gavoline & 890.0 & 684.3 & 751.4 & 723.9 & 678.6 & 302.8 & 85.5 & 318.1 \\
\hline Kerosene & 276.6 & 340.8 & 405.0 & 455.0 & 465.0 & 215.2 & 72.8 & 237.6 \\
\hline Diesel oil & 1568.0 & 1364.5 & 1253.2 & 1396.1 & 1478.7 & 658.1 & 303.7 & 955.8 \\
\hline Fuel oil & 2284.6 & 816.9 & 659.4 & 785.2 & 923.7 & 660.1 & 201.9 & 768.4 \\
\hline Total & 5870.0 & 3266.8 & 3119.4 & 3398.8 & 3577.5 & 1863.0 & 668.3 & 2298.6 \\
\hline
\end{tabular}

Source: Economic Plonning Council (CONSUPLANE).

TABLE 14

HONDURAS: IMPORTS OF CRUDE AND DERIVATIVES

(thousands of borrels)

\begin{tabular}{|c|c|c|c|c|c|c|c|c|}
\hline & 1970 & 1972 & 1978 & -1979 & 1980 & 1981 & 1982 & -1983 \\
\hline Liquified gos & $\theta$ & 52.1 & 59.2 & 78.3 & 84.6 & 86.5 & 92.6 & 86.1 \\
\hline Gasoline & 92.8 & 154.4 & 140.4 & 172.4 & 167.6 & 500.2 & 694.2 & 512.0 \\
\hline Kerosene & 0 & 52.6 & 68.4 & 49.8 & 29.5 & 249.5 & 367.7 & 312.8 \\
\hline Diesel oil & 71.2 & 478.8 & 503.3 & 400.5 & 382.9 & 1091.2 & 1595.1 & 1201.3 \\
\hline Fuel oil & 0 & $\theta$ & $\theta$ & 0 & $\boldsymbol{\theta}$ & 120.9 & 440.1 & 0 \\
\hline Crude oll & 5255.2 & 3475.1 & 3150.7 & 3558.9 & 3697.5 & 1739.1 & 716.2 & 2389.7 \\
\hline
\end{tabular}

Source: Economic Planning Council (CONSUPLANE).

TABLE 15

HONDURAS: PERCENTAGE BREAKDOWN OF REFINERY PRODUCTION

\begin{tabular}{|c|c|c|c|c|c|c|}
\hline & 1970 & 1977 & 1980 & 1981 & 1982 & 1983 \\
\hline Liquified gos & 1.0 & 1.8 & 0.9 & 1.4 & 0.6 & 0.8 \\
\hline Gasoline & 17.6 & 20.9 & 19.0 & 16.2 & 12.8 & 13.7 \\
\hline Kerosene & 5.4 & 10.4 & 13.0 & 11.6 & 10.9 & 10.3 \\
\hline Diesel oil & 31.0 & 41.8 & 41.3 & 35.3 & 45.4 & 41.6 \\
\hline Fuel oil & 45.0 & 25.0 & 25.8 & 35.4 & 30.2 & 33.4 \\
\hline Total & 100.0 & 100.0 & 100.0 & 100.0 & 100.0 & 100.0 \\
\hline
\end{tabular}


TABLE 16

HONDURAS: EXPORTS OF PETROLEUM DERIVATIVES

(thousands of barrols)

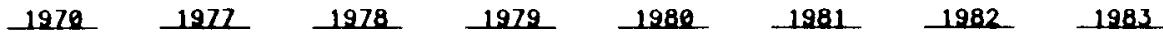

\begin{tabular}{|c|c|c|c|c|c|c|c|c|}
\hline Liquified gos & 1.2 & 6 & $\theta$ & 0 & 0 & $\theta$ & 0 & 0 \\
\hline Gosol ine & 281.7 & 0 & $\boldsymbol{0}$ & 0 & 0 & 0 & $\theta$ & e \\
\hline Kerosene & 0.7 & $\boldsymbol{\theta}$ & 0 & 0 & $\theta$ & $\theta$ & 0 & \\
\hline Diesel oil & 598.9 & $\theta$ & 3.7 & 0 & 0 & 0 & $\theta$ & \\
\hline Fuel oil & 1736.1 & 50.6 & 0 & 18.4 & 150.7 & 65.2 & 0 & 123.6 \\
\hline
\end{tabular}

Source: Economic Planning Council (CONSUPLANE).

TABLE 17

HONDURAS: CRUDE OIL IMPORTS BY COUNTRY OF ORIGIN

(volume and value)

\begin{tabular}{|c|c|c|c|c|c|c|c|c|}
\hline \multirow[b]{2}{*}{ Country $/$ Comperny } & \multicolumn{2}{|c|}{1981} & \multicolumn{2}{|c|}{1982} & \multicolumn{2}{|c|}{1983} & \multicolumn{2}{|c|}{1984} \\
\hline & MALE. & M.Lpe. & M.Pls. & Mabea. & M.BLE. & Mupe. & M.R日 & Mules. \\
\hline Venezuela/Texaco & $\begin{array}{c}888.8 \\
(528)\end{array}$ & 65.786 .4 & $\begin{array}{l}704.1 \\
(100 \pi)\end{array}$ & 52.039 .30 & $\begin{array}{c}2.023 .9 \\
(86 x)\end{array}$ & 129.555 .0 & $\begin{array}{c}2.257 .0 \\
(68 \pi)\end{array}$ & 139.043 .0 \\
\hline Moxico/Toxaco & $\begin{array}{l}188.0 \\
(11 \pi)\end{array}$ & 14.347 .0 & - & - & $\begin{array}{l}324.2 \\
(14 \pi)\end{array}$ & $\begin{array}{l}19.767 .4 \\
(32 x)\end{array}$ & 1.046 .2 & 61.297 .0 \\
\hline Arabian Light/Toxaco & $\begin{array}{l}632.5 \\
(37 x)\end{array}$ & 40.480 .4 & - & - & - & 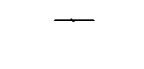 & - & - \\
\hline Total & $\begin{array}{r}1.709 .3 \\
(100 x)\end{array}$ & 120.613 .8 & $\begin{array}{l}704.1 \\
(100 x)\end{array}$ & $52,039.30$ & $\begin{array}{r}2.348 .1 \\
(100 x)\end{array}$ & $149,322.4$ & $\begin{array}{r}3.303 .2 \\
(100 \pi)\end{array}$ & 200.340 .0 \\
\hline
\end{tabular}

Source: Ministry of Economics

TABLE 18

HONDURAS: PERCENTAGE OF OIL PRODUCTS REF INED DOMESTICALLY

(porcentage of total)

Liquified gos

Gasoline

Kerosene

Diesel oil

Fuel oil
1970

100.0

90.6

100.0

95. 6

100.0

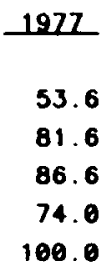

53.6

81.6

74.0

100.0

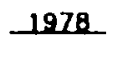

46.0

84. 2

85.6

71.3

100.0

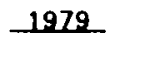

33.0

80.8

90.1

77.7

100.0

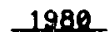

27.1

80.2

94.0

79.4

100.0
1981

1982

1983

23.7

37.7

46.3

4.5

11.0

17.9

37.6

84.5

16.5

38.3

43.2

16.0

44.3

100.0 
TABLE 19

HONOURAS: OIL IMPORT COSTS RELATIVE TO OTHER VARIABLES

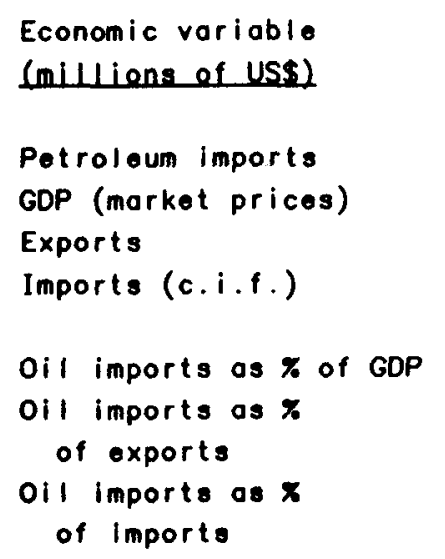

$\begin{array}{rr}1972 & 1977 \\ & \\ 18.5 & 70.3 \\ 841.5 & 1660.5 \\ 209.5 & 518.6 \\ 192.8 & 579.4\end{array}$

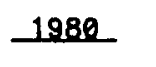

1981

1982

1983

1984

171.0

161.6

167.0

166.0

190.0

2488.0

2646.0

2791.0

2945.0

3187.0

829.4

760.8

659.5

667.0

736.0

1008.7

949.1

700.5

804.0

896.0

2.2

4.2

6.9

6.1

6.0

5.6

6.0

8.8

13.6

20.6

21.2

25.3

24.9

25.8

9.6

12.1

16.9

17.0

23.8

20.6

21.2

Source: World Bank and International Monetory Fund.

d. Prices. The Petroleum Management Commission (Comision Administradora de Petroleo--CAP) was created by Decree No. 94 of May 1983 to control directly and exclusively the purchases of crude $0 i 1$ and refined petroleum products as well as to control the sale of the products to the refinery.

CAP's goals are to guarantee an adequate supply of crude and refined products to the Honduran economy, to negotiate purchase prices for these products, and to determine resale prices to the refinery. At the same time, CAP is directed to review periodically the global market conditions and to adjust prices accordingly.

CAP is structured as an independent commission with membership of the Secretaries of State, Commerce, Economics, and Finance, and the President of the Central Bank of Honduras. In addition to this board, CAP has a technical committee made up of representatives from each of the Secretariats and the Central Bank. A coordinator for this Technical Committee is the only full-time member of CAP.

Sales prices to the consumer are set by the Economic Cabinet (part of the Cabinet composed of the Secretaries of Finance, Commerce and Economics, and CONSUPLANE, among others) under recommendation by CAP and another agency, the Comision del Articulo 91, a separate commission set up to control prices of a 11 basic goods. Table 20 reports major oil product prices for selected years. The prices for regular gasoline, diesel fuel, and fuel oil all more than doubled between 1975 and 1981. Since then, even though world oil prices have fallen, the prices have remained constant. For several years Honduras has taxed gasoline 
TABLE 20

HONDURAS: AVERAGE OIL PRODUCT PRICES FOR SELECTED YEARS

(US dollars per gallon)

$\begin{array}{llllll} & 1975 & & 1978 & 1981 & 1984 \\ & & & & \\ \text { Gasoline (regular) } & 0.93 & 1.05 & 1.96 & 1.96 \\ \text { Diesel oil } & 0.52 & & 0.54 & 1.21 & 1.22 \\ \text { Fuel oil } & 0.26 & 0.30 & 0.66 & 0.66\end{array}$

Source: Ministry of Economics.

sales at a much higher rate than that for other products. A regional report by RECOPE (the Costa Rican national petroleum company) estimates the 1984 taxes to be 19 cents per gallon for gasoline, 2.5 cents per gallon for diesel, and only 0.7 cents per gallon for kerosene. 7 This has led to a shift toward dieselpowered vehicles for agriculture and basic transportation.

Because of differences in transport costs, the maximum prices for disti1lates are adjusted to account for different geographic zones of sale (see Table 21). Deliveries in the area in and around the location of the refinery. Zone 1 , are permitted a price increase of only $\$ 0.0125$ US a gallon for diesel and $\$ 0.0175$ US for all other products. Sales in the most distant area of cone 7, such as those in the department of Choluteca, have a price premium of about 10 cents per galion.

\section{Electricity Supply}

The national electric utility of Honduras (Empresa Nacional de Energia Electrica--ENEE) was nationalized in 1957. It is responsible for the provision of electricity to the country and the construction and maintenance of production and transmission facilities.

a. Expansion. Since the oil price increases of 1973 and 1979, ENEE has made a concerted effort to diversify its production away from diesel and fueloil generators and toward hydroelectric plants. Figure 7 shows the installed capacity of thermal versus hydroelectric generating capacity from 1970 to 1985. The two most recent projects are the El Nispero hydroelectric plant, with 22.5 MW of capacity, and the large El Cajon dam. The El Cajon hydroelectric project cost a total of $\$ 774.5$ million US (equal to about half of the disbursed external debt in 1983) and currently has 292 MW operating. In addition, El Cajon is designed to allow the expansion, if necessary, of another $292 \mathrm{MW}$ in the future. ENEE plans to add $25 \mathrm{MW}$ of capacity in 1992 and must decide whether it will be 
TABLE 21

HONDURAS: MAXIMUM OIL PRODUCT PRICE

(Differentials by Zone, 1983)

(US dollars per galion)

\begin{tabular}{|c|c|c|c|c|c|c|c|}
\hline \multirow{2}{*}{$\begin{array}{l}\text { Type of } \\
\text { Evel }\end{array}$} & \multicolumn{7}{|c|}{ Zone } \\
\hline & 1 & 2 & 3 & 4 & 5 & 6 & .7 \\
\hline Diesel & 0.0125 & 0.0228 & 0.0366 & 0.0528 & 0.065 & 0.0872 & 0.0964 \\
\hline Other products & 0.0175 & 0.0278 & 0.0416 & 0.0578 & 0.07 & 0.0922 & 0.1014 \\
\hline
\end{tabular}

Source: Ministry of Economics.

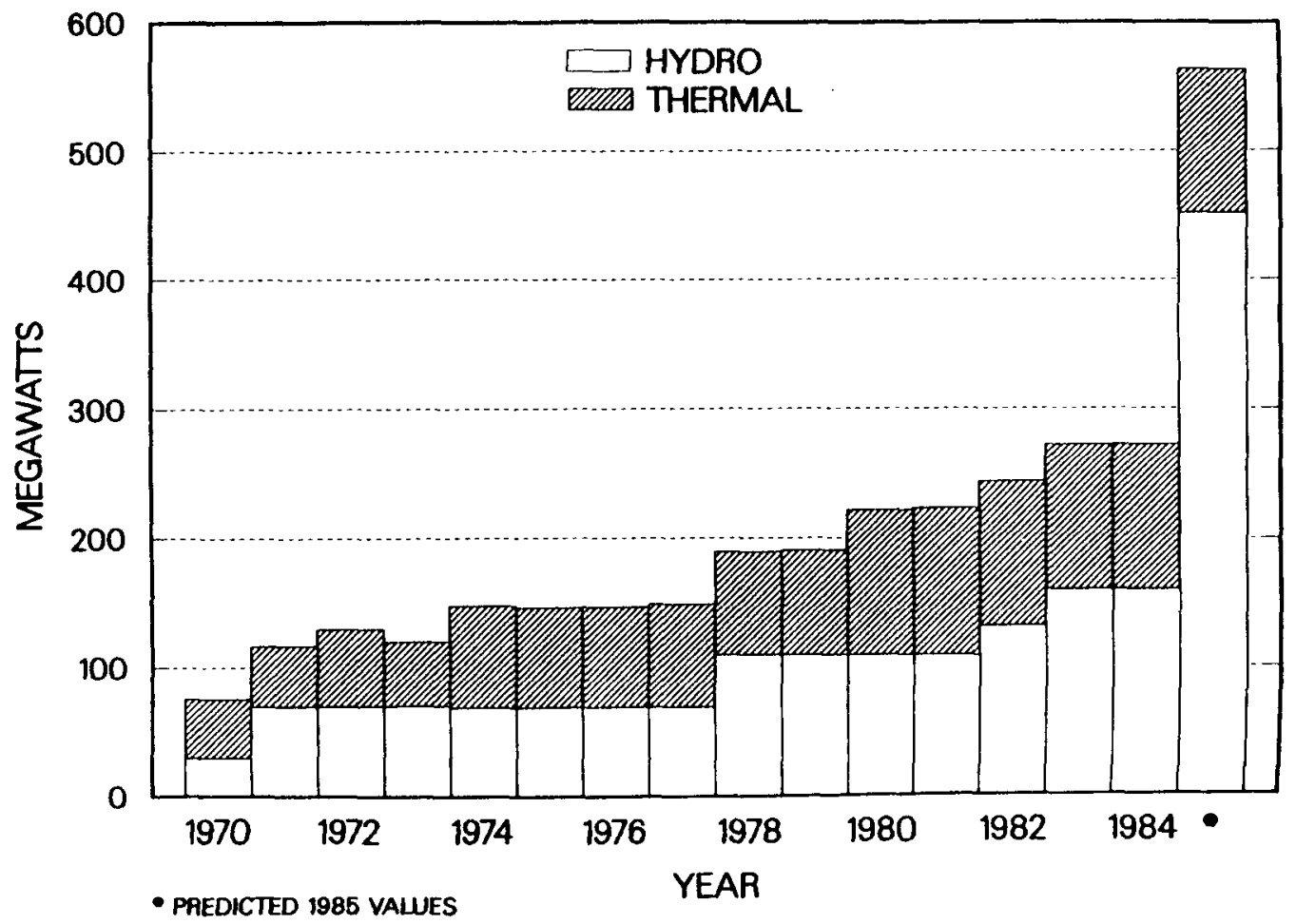

SOURCE: ENEE

Fig. 7. Honduras: Installed electric generating capacity. 
supplied by oil or geothermal energy in the late 1980s. Currently, ENEE is receiving assistance from Los Alamos and the UNDP in the evaluation of geothermal generation potential in Honduras. Table 22 reports ENEE's expansion investments for 1970 to 1984, and Table 23 provides a breakdown on investments in special projects in 1982 .

ENEE also has some plans for transmission grid expansion, specifically a line to link Juticalpa and Tegucigalpa, and Tegucigalpa and Danli. In addition, a 69-kV line is planned to pass through Santa Rosa on its way to Copan (see Fig. 8). Since grid expansion is very expensive in the mountainous areas of Honduras, ENEE has few plans for rural electrification.

b. Production. The production of electricity in Honduras has changed from a relatively heavy reliance on thermal generation in the early $1970 \mathrm{~s}$ to a commitment to hydroelectric power in the 1980s. Table 24 reports that in 1970 the percentage of total generation from hydroelectric sources was 54 percent, whereas in 1983 it was 81 percent.

In the 1980s, a lack of sufficient generation capacity to cover demand caused ENEE to purchase power from Costa Rica. Electricity imports were a very sma11 proportion of total generation from 1980 through 1982 , but they rose to 12.7 percent in 1983 .

Although precise generation numbers are unavailable for 1985, the addition of the El Cajon plant to the grid has caused the hydroelectric portion to reach

TABLE 22

HONDURAS: SUMMARY OF INVESTMENTS OF ENEE (thousands of lempiras)

$\begin{array}{lrl}\text { Year } & 000 & \text { Lps } \\ 1970 & 23 & 431 \\ 1971 & 10 & 737 \\ 1972 & 11 & 030 \\ 1973 & 28 & 579 \\ 1974 & 21 & 888 \\ 1975 & 23 & 095 \\ 1976 & 39 & 710 \\ 1977 & 52 & 877 \\ 1978 & 49 & 483 \\ 1979 & 65 & 632 \\ 1980 & 152 & 756 \\ 1981 & 224 & 510 \\ 1982 & 230 & 517 \\ 1983 & 331 & 153 \\ 1984 & 463 & 778\end{array}$

Source: National Company of Electric Energy (ENEE). 
TABLE 23

HONDURAS: ENEE INVESTMENTS FOR "SPECIAL PROJECTS"

FOR INTEGRATED SYSTEMS, 1982

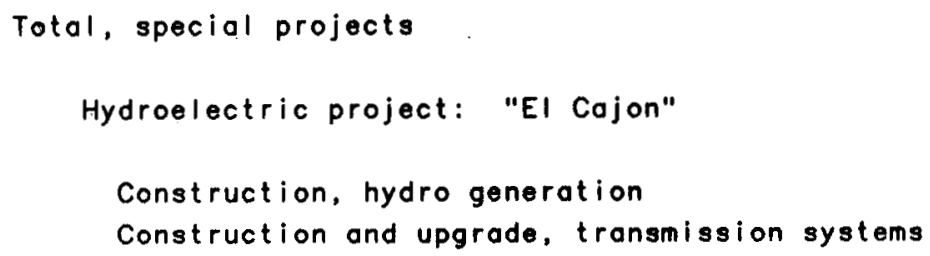

Source: National Company of Electric Energy (ENEE).

$$
\begin{gathered}
\text { Thousands } \\
\frac{\text { of Les }}{212.507}
\end{gathered}
$$

172.648

172,082 566

24.939

13,751

1,168

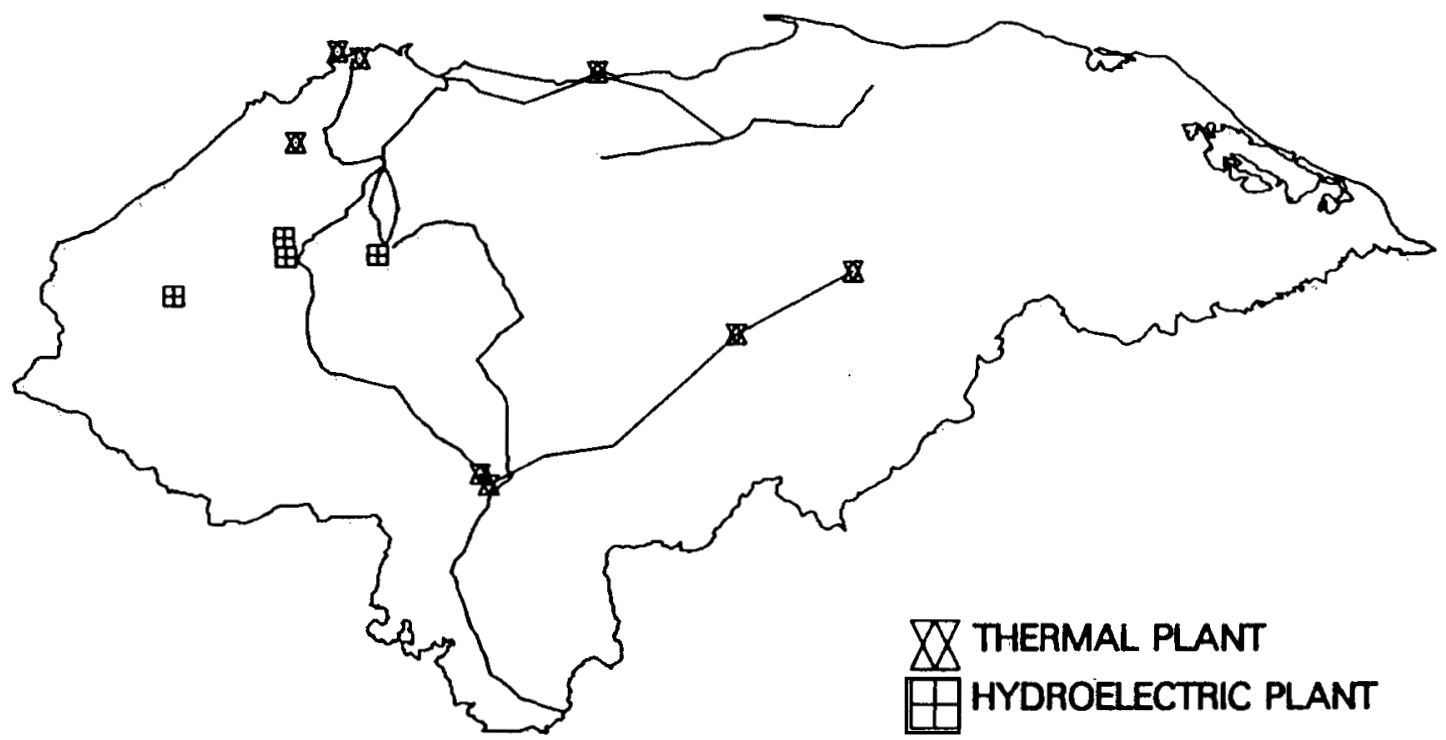

SOURCE: NATIONAL COMPANY OF ELECTRIC ENERGY (ENEE),

Fig. 8. Honduras: Location of transmission grid. 
HONDURAS: ELECTRIC GENERATION

(GWh)

\begin{tabular}{|c|c|c|c|c|c|}
\hline & Hydre & $\begin{array}{c}\text { As Percentage } \\
\text { of Total }\end{array}$ & Ihermal & $\begin{array}{c}\text { As Percentage } \\
\text { of Lotal }\end{array}$ & Iotol \\
\hline 1970 & 196.8 & 54 & 164.7 & 46 & 361.5 \\
\hline 1971 & 242.6 & 62 & 148.5 & 38 & 391.1 \\
\hline 1972 & 305.4 & 72 & 117.1 & 28 & 422.5 \\
\hline 1973 & 360.8 & 74 & 125.7 & 26 & 486.5 \\
\hline 1974 & 401.4 & 77 & 117.5 & 23 & 518.9 \\
\hline 1975 & 421.1 & 74 & 144.7 & 26 & 565.8 \\
\hline 1976 & 432.8 & 71 & 178.6 & 29 & 611.4 \\
\hline 1977 & 471.0 & 68 & 217.1 & 32 & 688.1 \\
\hline 1978 & 649.2 & 86 & 110.0 & 14 & 759.2 \\
\hline 1979 & 743.5 & 87 & 107.3 & 13 & 850.8 \\
\hline 1980 & 784.6 & 84 & 146.8 & 16 & 931.4 \\
\hline 1981 & 822.9 & 81 & 189.7 & 19 & 1012.6 \\
\hline 1982 & 848.6 & 79 & 222.2 & 21 & 1070.8 \\
\hline 1983 & 833.2 & 81 & 192.4 & 19 & 1025.6 \\
\hline
\end{tabular}

Source: Economic Planning Council (CONSUPLANE).

99 percent of total generation during the last half of the year. Also, ENEE no longer needs to purchase electricity from Costa Rica. Currently, the only time thermal plants are used is when there is a significant drop in the hydroelectric production because of maintenance.

Currently, Honduras has significant excess capacity, equal to about $350 \mathrm{MW}$. This estimate assumes that all thermal plants continue to be functional; that is, no decommissioning takes place. To the extent that such plants are removed from the grid, the excess will be be reduced accordingly. In the section on demand below, we will discuss the long-term electricity demand prospects for Honduras.

c. Tariffs. Although the World Bank has recommended that ENEE use marginal price criteria for the setting of electricity tariffs, such criteria have not yet been implemented because ENEE would need to change the accounting system for the country. Currently tariffs are set based on two criteria: the ability of the user to pay and the need to cover costs. Consequently, underdeveloped regions generally pay lower amounts.

Table 25 contains electricity prices over time for Honduras. Data are available from 1970 to 1984 for only two groups of users, commercial and industrial. The electric rates to these groups more than doubled over the period, 
TABLE 25

HONDURAS: AVERAGE ELECTRICITY PRICES

(hundredths lempiras/kWh)

\begin{tabular}{|c|c|c|c|c|c|c|}
\hline Year. & Commerciol & Industrial & Residential & $\begin{array}{l}\text { Large } \\
\text { Users }\end{array}$ & $\begin{array}{l}\text { Gov. and } \\
\text { Munic. }\end{array}$ & $\begin{array}{l}\text { Public } \\
\text { Lighting }\end{array}$ \\
\hline 1970 & 9.7 & 8.1 & & & & \\
\hline 1971 & 9.6 & 8.0 & & & & \\
\hline 1972 & 9.8 & 7.8 & & & & \\
\hline 1973 & 9.6 & 7.8 & & & & \\
\hline 1974 & 9.5 & 7.6 & & & & \\
\hline 1975 & 10.8 & 9.8 & & & & \\
\hline 1976 & 10.7 & 9.4 & & & & \\
\hline 1977 & 10.7 & 9.6 & & & & \\
\hline 1978 & 11.4 & 10.0 & & & & \\
\hline 1979 & 12.7 & 11.5 & & & & \\
\hline 1980 & 15.1 & 12.3 & & & & \\
\hline 1981 & 16.1 & 12.4 & & & & \\
\hline 1982 & 16.5 & 15.5 & 16.4 & 12.4 & 15.8 & 8.3 \\
\hline 1983 & 19.5 & 17.2 & 18.4 & 13.7 & 16.9 & 7.4 \\
\hline 1984 & 21.2 & 18.0 & 20.0 & 14.9 & 18.6 & 7.5 \\
\hline
\end{tabular}

Source: National Company of Electric Energy (ENEE).

reaching 0.21 lempiras and 0.18 lempiras in 1984 for commercial and industrial users, respectively. Other electricity users pay similar prices except for large users and public lighting, which are charged lower rates.

\section{Biomass}

a. Fuel Wood. By far the most important biomass energy source in Honduras is fuel wood. The amount supplied to the final consumer is at least nine times as high as the second largest biomass energy, residual vegetable matter (see Table 26). Fuel-wood use has grown at slightly less than 2 percent each year since 1970, more slowly than population growth.

Where possible, fuel wood is gathered by individual users. The market for fuel wood is most developed in and around the two main cities, Tegucigalpa and San Pedro Sula. For the market, the wood is cut, dried, and stacked by people in the countryside, often as a sideline to other farming tasks. Fuel wood comes from several sources: from farms, from national forest 1 and that is being cleared, from sawmills in the area, or from timber tracts used specifically for fuel-wood production. The producers sell the wood to middlemen, who truck it to the urban areas for resale. Some middlemen specialize in deliveries to industrial users whereas others sell fuel wood in small lots (or even individual pieces) in shops or on the city streets. Grocers often sell wood by the piece. 2 
TABLE 26

HONDURAS: SUPPLY OF ALTERNATIVE ENERGY

(thousonds of BEP)

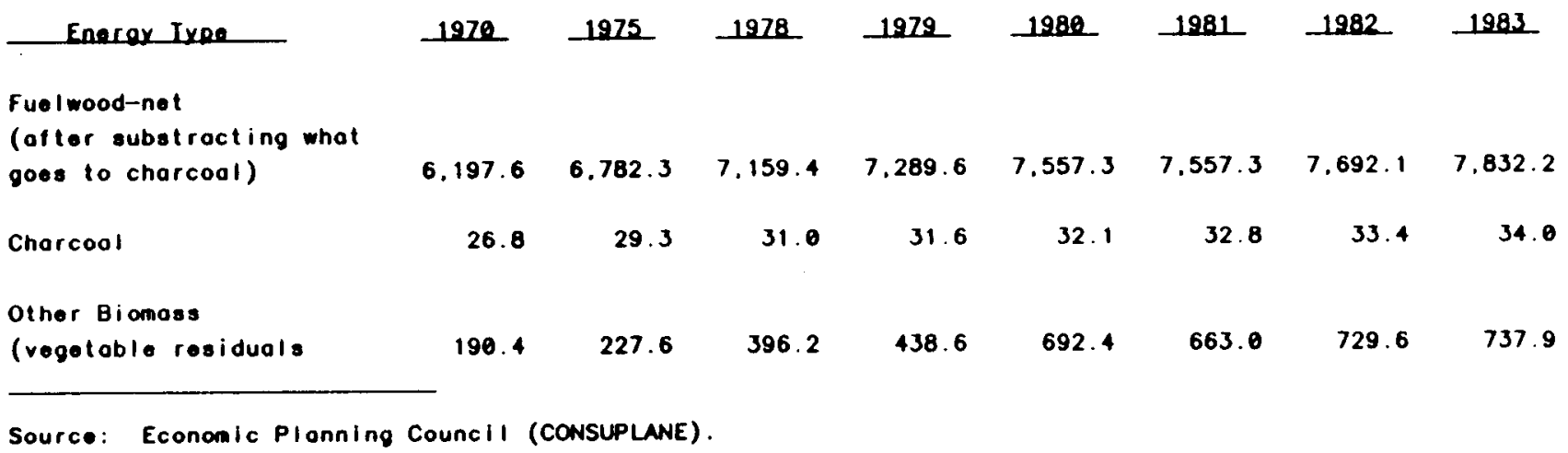

The markets in Tegucigalpa and San Pedro Sula are somewhat different. Tegucigalpa's market is more formal, with many middlemen trucking wood exclusively. The fuel-wood production around the capital is regulated through agri-forestry cooperatives. The Tegucigalpa market has only two types of wood: oak and pine. 2

In contrast, the San Pedro Sula market has over 10 types of wood, and the distribution is generally carried out by truckers who also handle other agricultural products. The supply comes from several sawmills in the region as well as from local farms and forésts.

The prices of fuel wood vary widely by type of wood and the proximity to the large cities. In Tegucigalpa, a 60-piece truckload of oak cost between 7 and 10 lempiras in 1982, the price of pine is usually 1 or 2 lempiras less than that of oak. Fuel-wood prices in Tegucigalpa have been rising: recent surveys indicate they have doubled in the past 5 years. In San Pedro Sula, a load of 100 pieces costs about 20 lempiras for pine and 23 lempiras for oak. By contrast, in 1971, the same amount of these woods cost 4 lempiras and 4.5 lempiras, respectively. ${ }^{2}$

Rising fuel-wood prices are expected to continue as good wood sources near the urban areas are depleted. As described in the land use section, rapid deforestation has occurred in many regions of the country. As long as population growth continues, localized fuel-wood shortages and price increases will occur. 
b. Charcoal. This product has a higher value-to-weight ratio than fuel wood; therefore, it can be more easily transported. Its supply is taxed and regulated by COHDEFOR, but a black market exists. As shown in Table 26, the amount of charcoal produced is quite small, and its growth has kept pace with that of fuel wood, about 2 percent a year.

The main producers of charcoal are independent country people who consider its production to be quite risky. Charcoal arrives in San Pedro Sula from sources as far away as Yojoa Lake, about 60 kilometers distant. Major sources for Tegucigalpa are Valle de Angeles and Lepaterique, about 35 kilometers away. ${ }^{2}$

Many of the country people deliver the charcoal to the cities by donkey and sell it themselves there. Others sell it to middlemen, who arrange for transport and sell through fixed sites in the city markets. The transportation of charcoal is largely clandestine. In Tegucigalpa, the majority of charcoal flows through the San Isidro market in Comayaguela to the other areas of the city.

Units of sale in San Pedro Sula consist of the large cement bag size, which weighs about 7 pounds and cost between 2.4 and 2.5 lempiras in 1982, and the 2 pound bag, which cost 0.50 lempiras. In Tegucigalpa, there are four units of sale. The "matate" is a net bag that costs 8 lempiras, and the "load" is carried on a donkey and equals two matates. The load price ran between 14 and 20 lempiras in 1982. Then there are smaller units of sale--the gallon can costing 1.5 lempiras and the plastic bag costing 0.50 lempiras. These prices seem to have increased at about the same rate as those of fuel wood, about 200 to 300 percent since $1974 .^{2}$

c. Residual Vegetable Matter: Bagasse and Sawdust. The use of these energies is concentrated within the facilities which produce them. Although significant amounts of bagasse are burned by sugar processing plants, not much sawdust is being used currently. In addition to drying wood, sawdust can be used to generate electricity. The annual production of vegetable residuals has increased dramatically as the increased oil prices put pressure on processing plants to make use of whatever fuels are available (see Table 26). Note the rapid increase that occurred after the second oil price hike, from 440 BEP in 1979 to 690 BEP in 1980 , a 58 percent rise. Over the 1970 to 1984 period, residual vegetable fuel production rose an average of 10 percent a year.

d. Biogas. Since 1978 the National University and the Ministry of Natural Resources have coordinated a biogas project in Honduras. With OLADE and United Nations assistance, some 36 biodigesters have been constructed, with capacities ranging from $10 \mathrm{~m}^{3}$ to $25 \mathrm{~m}^{3}$. The goals of the program are to encourage the 
adaptation of the agricultural waste digester on farms and cattle ranches to provide fertilizer and biogas.

C. Energy Demand

This section describes the consumption of each type of energy: which sectors of the economy use what type of fuel, the growth trends in consumption, etc. Tables 27, 28, 29 and 30 describe the consumption of energy in 1984, and Tables 31 and 32 report sectorial consumption for 1970 and 1978, respectively.

In Honduras, the residential sector consumes about 60 percent of the total energy supplied, whereas industry consumes only about 23 percent (see Table 28). The transport sector is the third largest consumer and comprised about 13 percent of the final consumption in 1984. The remaining four sectors--commercial, public, agriculture, and other are very small energy consumers and use about 1.5 percent of the energy each. Since 1970, the relative consumption declined in agriculture (from 6 percent to a negligible amount) and residential (from 66 to 59 percent) and increased in the other four sectors--transport, commercial, public, and industry. However, all sectors have grown and consume more energy now than they did in the past, and the average growth rate for total energy consumption from 1970 to 1984 is about 3 percent (see Table 33). In the years 1970 to 1978, energy consumption grew at a 3.2 percent rate, then the average rate over the next 5 years dropped to only 2.2 percent because of the $0 i 1$ price rise and international recession.

The Honduran economy is still quite dependent upon traditional energy sources. In 1984, fue 1 wood and biomass contributed 67 percent of the total energy used in the country, whereas petroleum products equaled 29 percent (see Table 28). There has been a movement away from fuel wood since 1970, and it is al so noteworthy that the efforts of Honduras to utilize so-called waste products have succeeded to the point where, in 1984, vegetable residue comprised 6 percent of final energy consumption (up from 2.2 percent in 1970). Electricity use in Honduras is small; it contributed only 4 percent of total consumption in 1984.

1. Residential. As previously mentioned, the residential sector consumes by far the largest proportion of energy. And within the sector, fuel wood is the dominant source of energy (see Table 30), which gives rise to the difficult deforestation problem in the countryside. Even though the government is aware of the problem and has instituted programs to solve it, changing the traditions of the country people is a challenging undertaking. Indeed, over the last 13 years, there has been little change in the types of fuels used in households. 
TABLE 27

HONDURAS: 1984 ENERGY CONSUMPTION

(thousanda of borrel equivalents of polroleun)

Total Conaumption

Enerax Ixpe
Fuelwood
Vegeloble residue
Electricity
Petroleun derivotivos
Liquid gas
Gosoline
Relinery gos
Kerosene
Dienel oil
Fuel oil
Subtotal
Coke
Charcool

conaceial

Public Icanapors

Aariaullure

Laduntrial ether

Bx Enecar Irpe

Totol Consumption 7,62

$\begin{array}{rr}213 & 0 \\ 0 & 0 \\ 168 & 87 \\ 51 & \\ 0 & 4 \\ 0 & 6 \\ 189 & 0 \\ 0 & 31 \\ 0 & 24 \\ 240 & 0 \\ 0 & 67 \\ 0 & 0 \\ & 35\end{array}$

$\begin{array}{rl}0 & 0 \\ 0 & 0 \\ 40 & 0\end{array}$

0
34

715
726
233

7.928

726

561

$\begin{array}{rrr}4 & 0 & 0 \\ 6 & 30 & 606 \\ 6 & 0 & 0 \\ 31 & 23 & 149 \\ 24 & 110 & 967 \\ 0 & 7 & 0 \\ 67 & 171 & 1.722 \\ 0 & 0 & 0 \\ 35 & 0 & 0\end{array}$

2
1
0
0
11
5
20
0
0

26
60

6

0

732

520

1.337

1

6
0

83

706

35

392

1.864

609

3. 668

1

35

$\begin{array}{lll}189 & 211 & 1.722\end{array}$

$53 \quad 5.012$

130

12.939

Source: Economic Planning Council (CONSUPLANE).

TABLE 28

HONDURAS: 1984 ENERGY CONSUNPIION

(porcentage of total)

Iotal Consumption

Enacor Ixpa

Bealdentlat comarsial Publis

Ironapert Agricultuse Induatrial gthes

Fuelwood
Vegeloble reeidue
Electricity
Potroleu derlvollves
Liquid gas
Gosoline
Refinery gas
Kerosene
Diesel oil
fuel oll
Subtotal:
Coke
Chorcool

$\begin{array}{rr}56 & \\ 0 & \\ 1 & \\ 0 & \\ 0 & \\ 0 & \\ 1 & 0 \\ 0 & \\ 0 & 0 \\ 2 & \\ 0 & \end{array}$

Totol Consunption

59

0
1
1
0
0
0
0
0
1
0
0

0
0
0
0
0
0
0
1
0
1
0
0

0
0
0
0
5
0
1
7
0
13
0
0

0
0
0
0
0
0
0
0
0
0
0

Note: Total may not add to 108 due to rounding 
TABLE 29

HONOURAS: 1984 ENERGY CONSUMPTION

(percentage of luel une by sector)

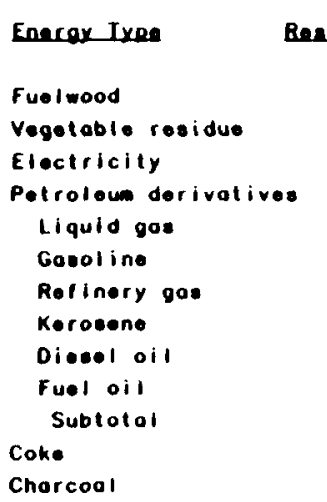

Totol Consumption
Renidential

Comacalal
Eublic

$\begin{array}{rr}91 & 0 \\ 0 & 0 \\ 30 & 16 \\ 61 & 5 \\ 0 & 1 \\ 0 & 0 \\ 48 & 0 \\ 0 & 1 \\ 0 & 0 \\ 7 & 2 \\ 0 & 0 \\ 0 & 100\end{array}$

1

$\begin{array}{rr}0 & 0 \\ 0 & 0 \\ 7 & 0 \\ 0 & 0 \\ 4 & 86 \\ 0 & 0 \\ 6 & 30 \\ 6 & 52 \\ 1 & 0 \\ 5 & 47 \\ 0 & 0 \\ 0 & 0\end{array}$

2
Lronaport

13

\section{Aacianltura}

Induatcial

Qther

Tolol Consumption

Ex Enerax Ixpe.

Note: Totale moy not add to 100 due $t_{0}$ rounding.

$\begin{array}{rr}0 & 9 \\ 0 & 100 \\ 6 & 42 \\ 2 & 31 \\ 0 & 8 \\ 0 & 0 \\ 0 & 0 \\ 1 & 39 \\ 1 & 85 \\ 1 & 36 \\ 0 & 100 \\ 0 & 6\end{array}$

○

23

TABLE 30

HONDURAS: 1984 ENERGY CONSUMPTION BY SECTOR

(percentages)

Eneray Ixpe

Residential

\section{Public}

19
0
46

Vegetable residue

Electricity

95

Petroleum derivalives

Liquid gas
Gosoline
Refinery gas
Kerosene
Diesel oil
Fuel oil
Subtotal
Total consumption

2

1
0
0
2
0
0
3
100

Note: Totol may not

$\begin{array}{rr}0 & 100 \\ 0 & 100 \\ 0 & 100 \\ 0 & 100 \\ 0 & 100 \\ 100 & 100 \\ 0 & 100 \\ 1 & 100 \\ 13 & 100 \\ 4 & 100 \\ 0 & 100 \\ 0 & 100\end{array}$

100

1
100
100
100
100
100
100
100
100
100
100
100
100 
TABLE 31

HONDURAS: 1970 ENERGY CONSUMPTION BY SECTOR

(Porcontagos)

Eneray Iype

Residential Comercial

Public

Iranspers

Industrial sariaulture

Other

Fuel wood and charcoal

Vegetable residue

Electricity

Potroleum distillates

Liquid gas

Gosoline

Refinery gas

Kerosene

Diesel oil

Fuel oil

Subtotal

Total consumption

\section{6}

0

1

0

0

3

0

0

3

100
32

0

35

$\begin{array}{rrr}2 & 0 & 0 \\ 21 & 27 & 52 \\ 0 & 0 & 0 \\ 4 & 14 & 4 \\ 6 & 45 & 44 \\ 0 & 5 & 0 \\ 33 & 91 & 100 \\ 100 & 100 & 100\end{array}$

-

0

0

0

52

0

4

44

100

100
52

17

9

6

3

0

0

20

0

23

100

$\begin{array}{ll}0 & 0 \\ 0 & 0 \\ 4 & 0\end{array}$

\section{0}

40

- 24

00

130

$79 \quad 76$

96

100

Source: Economic Planning Council (CONSUPLANE).

Note: Totals may not odd to 100 due to roundings.

TABLE 32

HONOURAS: 1978 ENERGY CONSUMPIION BY SECTOR

(Porcentagos)

\section{Eneray Ixpe}

Fuel wood and charcoal Vegetable/animal residue Electricity

Petroloum derivatives
Liquid gos
Gosoline
Korosene
Dlesel oll
Fuel oil
Subtotal
Total consumption

Residential Commercial Public Iranspert saciculture Industrial

$\begin{array}{rrrrrr}94 & 24 & 0 & 0 & 0 & 29 \\ 0 & 0 & 0 & 0 & 0 & 17 \\ 1 & 42 & 9 & 0 & 12 & 8 \\ 1 & & & & & \\ 0 & 14 & 12 & 44 & 0 & 0 \\ 4 & 4 & 8 & 8 & 13 & 2 \\ 0 & 14 & 65 & 47 & 0 & 0 \\ 0 & 0 & 5 & 0 & 74 & 22 \\ 5 & 34 & 91 & 100 & 2 & 21 \\ 100 & 100 & 100 & 100 & 88 & 46 \\ & & & 0 & 100 & 100\end{array}$


TABLE 33

HONDURAS: COMPOUNDED ANNUAL AVERAGE GROWTH RATES FOR ENERGY CONSUNPTION, BY SECTOR AND SELECTED YEARS (percentages)

\begin{tabular}{|c|c|c|c|c|c|c|c|c|}
\hline Iime Peried & Lلمنيمesident & Commercial & Public & Iranspert & Aacicullure & Industrial & Qther & Iotel \\
\hline $1970-1978$ & 2.1 & 5.4 & 11.0 & 5.4 & -13.9 & 9.3 & 1.7 & 3.2 \\
\hline $1978-1984$ & 1.7 & 6.6 & -2.7 & 3.8 & -16.9 & 4.4 & -7.2 & 2.2 \\
\hline $1980-1984$ & 1.5 & 6.9 & -5.0 & 5.1 & -25.3 & 2.0 & -6.4 & 1.6 \\
\hline $1970-1984$ & 1.9 & 5.9 & 4.9 & 4.7 & -15.2 & 7.1 & -2.2 & 2.8 \\
\hline
\end{tabular}

- Figures do not reflect real trends in agricultural sector.

In Honduras, fully 75 percent of the total population uses fuel wood for cooking, and although this percentage is declining over time, the absolute number of people who cook with wood continues to increase, owing to population growth. 2

It is estimated that 4.5 million cubic meters of fuel wood are consumed each year, which, in per capita terms, works out to about 2.75 kilograms daily. The majority of families collect their own fuel wood, and only about 30 percent rely exclusively on purchased wood. For those who collect their own wood, the average daily time required for this activity is estimated at about 1.1 hours. For families that purchase fuel wood, the average annual cost per family in 1982 was between 122 and 322 lempiras, which represented 12 and 33 percent of the annual income of an agricultural day laborer. ${ }^{2}$

Besides fuel wood, the only other fuels used by households in Honduras are electricity and kerosene, which together account for only 5 percent of consumption (an insignificant amount of cooking is done with liquid gas). Overall, the energy use in this sector has grown at a 1.9 percent annual rate since 1970, with only a slight slowdown during the economic decline of the early 1980 s (see Table 33).

2. Industrial. The Honduran industrial sector used about 23 percent of the total energy consumption in the country in 1984 (see Table 28). Of this energy, 48 percent was from fuel wood and vegetable residues and 44 percent was from petroleum products (see Table 30). Industry uses about 30 percent of the petroleum products consumed in the country and is the largest user of electricity (see Table 29). 
Industrial fuel-wood consumption in the cities is concentrated in the bakeries and in brick and tile making. In the rural areas, the largest industrial use is for processing salt (using mainly mangrove trees), lime, coffee, and tobacco. Charcoal is mainly used in food vendor cooking in the cities. The energy furnished by biomass consists largely of that from bagasse, which produces energy at sugar plantations. 2

It appears that industry has had some success in substituting biomass for fuel wood. The percentage of industrial energy coming from fuel wood versus vegetable residues in 1978 was 29 percent to 17 percent, but in 1984 it was 24 percent to 24 percent. This could imply that recycling of wastes has begun to displace a portion of fuel-wood use, thereby helping to preserve forests. An alternative interpretation is that the recession of the early $1980 \mathrm{~s}$ affected fuel-wood-using industries (for example, cement) more severely than those using vegetable residues (for example, sugar). There is some evidence of this occurring, but industry-specific data would be necessary before a definitive statement could be made.

Concerning industrial oil use since 1978, the use of fuel oil has declined in absolute as well as percentage terms, with the use of diesel fuel rising to fill the gap (see Tables 30 and 32). Given the excess supply of fuel oil and its low price relative to other fuels, this substitution seems counterintuitive. As in the case of fuel wood and vegetable residuals, the phenomenon may be explained by the fact that the recession affected the fuel oil-using companies more heavily than those using diesel fuel. One should not place too much emphasis on fuel-share shifts during periods of economic recession, especially in small countries like Honduras, because the temporary shutdown of only one large fuel oil-using factory may significantly alter the fuel share-statistics. However, the oil price rise, the severe recession, and foreign exchange problems of the 1980s did cause the relative total energy share of oil products in general to decrease from 46 percent in 1978 to about 40 percent in 1984 .

Overall, the industrial sector has experienced a decrease in the relative use of fuel wood and oil products and an increase in the use of vegetable residues and electricity. However, one would expect that as the economy and industry develop, petroleum and electricity use would increase at the expense of the more traditional energies. The overall energy consumption trend between 1970 and 1984 has been an increase of about 7 percent per year. The sector's 1984 energy consumption was almost triple the 1970 level.

3. Transportation. This sector has experienced rapid and steady growth in energy consumption--approximately doubling in the 14 years since 1970 . Table 33 shows that even after the oil price increases during the late 1970s, consumption 
continued to grow at over 5 percent a year through 1984 . National investment in the road network along with the increased number of vehicles have encouraged this phenomenon, and as further economic development occurs, this sector will continue to grow, both in size and in energy consumption.

The transport sector gets all of its energy from petroleum products; it used about half of all the oil produced and imported to Honduras in 1984 (see Table 29). The government subsidy and tax program on fuels has caused consumers to switch away from gasoline and toward diesel fuel. The relative share of gasoline has steadily declined from over half the total in 1970 to about a third in 1984, whereas diesel's share has increased over the same period.

4. Agricultural. The agricultural sector consumes a negligible portion of the country's energy, and its consumption has been relatively stable from 1971 to 1983. The national energy balances show large drops in energy use from 1970 to 1971 and from 1983 to 1984 , but these drops were caused by changes in the definition of the category, not by structural changes.

Agriculture's energy use is concentrated in the petroleum products (36 percent) and in electricity. The fact that agriculture consumes about 5 percent of the petroleum supply in the country while producing 30 percent of the GDP demonstrates the traditional nature of Honduran farming. As in the transport sector, fuel taxes have encouraged a steady shift away from equipment powered by gasoline engines toward diesel-engines over the 1970 to 1984 period.

5. Commercial. Commerce, another small energy-using sector, has had a relative decrease in charcoal use since 1970, with electricity being the substitute. As Honduras becomes more urbanized and more modern forms of commerce take over, the percentage of electricity used in the sector will continue to increase.

6. Public. The public sector of Honduras consumed about 2 percent of the total energy supplied in the country in 1984. The use of government vehicles causes oil products to be the dominant fuel source in the sector (81 percent in 1984), with electricity being a distant second with 19 percent. As government spending has increased, this sector has become a larger portion of the economy. Indeed, its energy consumption more than doubled in the 1970 to 1984 period, with an average annual growth rate of 4.9 percent (see Table 33 ). It appears that the financial hardships of the late 1970 s and early $1980 \mathrm{~s}$ caused the government to slow down on its projects, since public energy consumption actually fell during the 1978 to 1984 period.

The supply and demand for energy in 1984 are summarized in the flow diagram (Fig. 9). 


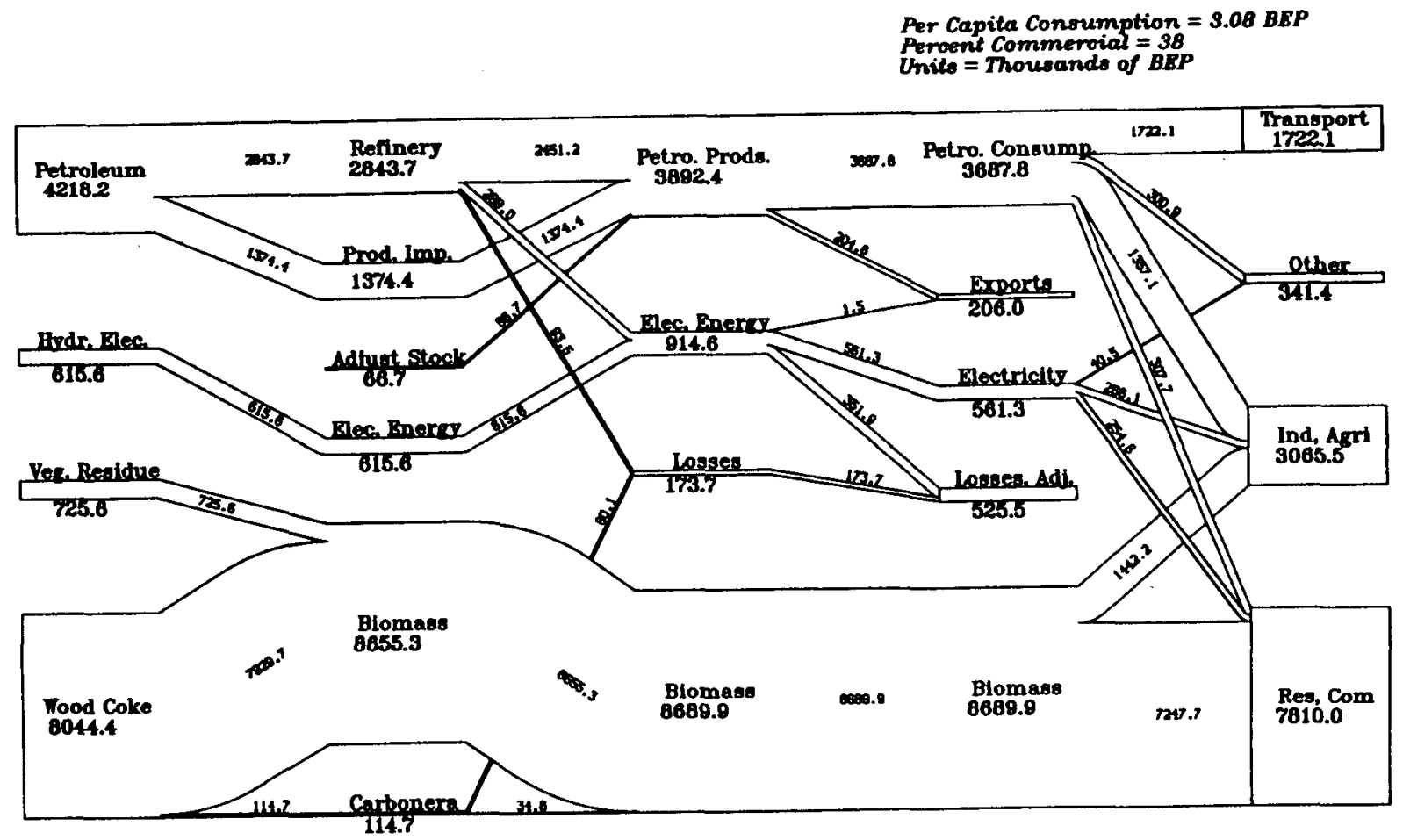

SOURCE: ECONONIC PLANNING COLNCIL (CONSUPLANE).

Fig. 9. Honduras: Energy flow diagram for 1984.

\section{Energy Planning Capabilities}

Honduras has several institutions that participate to some extent in energy planning and/or pricing. The responsibilities, abilities, and interrelationships of these agencies are discussed in this section.

1. Institutions. The official government body for energy and economic planning is the Economic Planning Council (Consejo Superior de Planificacion Economica--CONSUPLANE). It is responsible for compiling all relevant data and projections into the five-year national plan. As a repository for energy and economic data, CONSUPLANE also is able to complete analyses of economic trends and forecasts.

The Central Bank of Honduras (Banco de Honduras) is involved with compilation and analysis of macroeconomic data such as GDP and foreign trade indicators. Its forecasts of economic growth, inflation, and other key variables are used in the energy demand forecasts of other institutions in the country.

ENEE analyzes electricity demand, supply, and price, and uses investment planning models to optimize the expansion of electricity production and distribution. Consequently, ENEE has capable economists, statisticians, engineers, and computer personnel to work on planning efforts. 
The General Directorate of Mining and Hydrocarbons (Diriccion General de Minas $E$ Hidrocarburos--DGMH) is responsible for hydrocarbon resource data and handles all oil exploration contracts with private companies. In the past few years, DGMH received OLADE support to consolidate the institutional framework for national energy planning.

All of the above organizations are assigned to work together to disseminate relevant data throughout the Honduran economy and to international institutions. Important information is $\mathrm{planned}$ to flow to CONSUPLANE for incorporation into the national plan and for analysis. Improvement of communication among the agencies will improve energy-planning effectiveness.

2. Past Planning Assistance. Energy planning efforts started in Honduras in the late 1970 s as a result of the UNDP-sponsored Energy Program of the Central American Isthmus (PEICA). A small national group was set up at CONSUPLANE and a UNDP advisor was assigned to work with the group.

As in the rest of the Central American countries, an important initial task was the elaboration of the national energy balances. End-use surveys were conducted in the household sector to quantify firewood utilization as well as other noncommercial energy sources. Additional efforts were necessary to collect data on utilization of petroleum products owing to the fact that the distributors have to be surveyed independently and sometimes do not keep the disaggregated records necessary to identify final users. This is still an important shortcoming of energy planning efforts, since it is difficult to estimate, for example, the percentage of diesel utilized in transportation versus consumption for electricity generation in isolated areas. With the support of OLADE, CONSUPLANE carried out a survey of industrial energy utilization to update the 1975 industrial census.

The CONSUPLANE group, the staff of which has remained relatively constant during the past years, publishes the energy balances, which still remain the primary sources of information in the sector and is now involved in industrial conservation and substitution efforts.

3. Current Planning Methods and Needs. Currently no publications are available that describe demand forecasting methodology at CONSUPLANE. The method used for a recent forecast was as follows. First, commercial energy was correlated with GDP. A time series of 1970 to 1983 was used, and an energy/GDP elasticity of 1.06 was found. A Central Bank forecast of 3.2 percent annual GDP growth was then used to predict energy demand. The GDP growth implied energy demand would grow at 3.39 percent a year. Total forecasted commercial energy demand was then split into the various sectors of the economy, and fuel shares were estimated for each sector based on current share breakdowns. Noncommercial 
energy is more closely tied with the residential sector then to industry. Therefore, in the second stage of the forecasting process, fuel-wood demand was correlated with population. Demand was then extrapolated based on the increase in the number of households. This result was adjusted downward somewhat to take account of the substitution of the use of kerosene and liquid propane gas for fuel wood as people migrate to the cities.

CONSUPLANE has requested assistance in the development and implementation of an information system that can organize their energy data for easy production of reports for dissemination. Also, they would like to design an energy planning methodology that would include models for forecasting energy demand and for measuring the economic impacts of alternative governmental energy policies. Los Alamos has helped in these areas during 1986 with the transfer of an IBM microcomputer and a computerized data base and data management software. Training in the use of these tools, along with model design assistance was also provided.

\section{SUMMARY AND RECOMMENDATIONS}

A. Summary

One of the largest changes to hit the Honduran economy was the rapid increase of oil prices in the 1970s. This shock was unanticipated by the country and led to a run-up in its oil import bi11, which in turn contributed to an increase in balance of payments deficits.

In response, Honduras has made a concerted effort to diversify its fuel use away from foreign oil and toward indigenous resources. The outstanding case of this is electricity generation. Since 1980, ENEE has invested an average of $\$ 140$ million US per year mainly on hydroelectric plants and grid expansion. One project, El Cajon, increased the country's foreign debt by more than one-third. ENEE's efforts have resulted in a reduction in the amount of oil used for electricity generation; in 1970 (before the first OPEC oil price hike) about 45 percent of electricity was produced using 011 , whereas in 1985 , the percentage had dropped to less than 1 percent. Also, Honduras purchased inexpensive hydroelectric power from Costa Rica from late 1983 until the El Cajon plant came on line in 1985 to cover its capacity needs.

Thus, $0 i 1$ for electricity generation used to be one of the largest consuming sectors in the country, but Honduras has effectively eliminated oil from this activity for the time being. To provide for future increases in electricity demand, exploration is currently being done on the possibility of geothermal development. Honduras has numerous sites with such potential, and development will further contribute to the limiting of oil imports. Overall, 
for the foreseeable future large quantities of ail will no longer be necessary in the production of electricity.

As is true in most countries, the transport sector is the single largest consumer of oil products in Honduras; in 1983 it consumed about half of the oil supply. Unfortunately, less expensive alternative fuels for vehicles have yet to be discovered, so fuel substitution is not a real solution for this sector. Honduras has used a policy of tax and subsidies on the prices of oil products for the past several years and this has caused a switch toward diesel oil use in transportation and agriculture. Because diesel engines are generally more efficient than gasoline engines, this policy has served to reduce oil consumption below what it otherwise would have been. In addition, a 130 percent tax on the retail price of new cars discourages private vehicles and stimulates the use of public transportation.

These tax and subsidy policies have definitely had an effect on fuel consumption. Diesel fuel use, as a percentage of total energy consumed in the transport sector, has risen from 44 percent in 1970 to 56 percent in 1984. During the same time, gasoline use has diminished from 52 to 35 percent. But overal1, economic development will most likely lead to more, not less, oil consumption in this sector.

The use of fuel wood has changed little in the past decade and it continues to be the largest source of energy in Honduras. Coupled with the fact that population growth in Honduras continues to be one of the highest in Latin America, this means that deforestation of the countryside looms as a very serious problem for the future. Not only will the cooking fuel for most of the population become scarce, damage to important watersheds and agricultural areas is a likely possibility. The government is attempting to regulate the sale of fuel wood in the capital city.

New ideas on recycling wastes has led to a moderate increase in the use of biomass in industry. Although its use has displaced some oil and wood, biomass remains only a small segment of the total energy consumed. However, biomass use may be an essential component in efforts to provide incentives for the rural population to utilize the forests more efficiently.

B. Recommendations

The most important energy problems facing Honduras are (1) the amount of foreign exchange required for foreign oil, (2) the high consumption of fuel wood, and (3) a lack of adequate energy planning facilities. The rapid oil price increase during the 1970 s induced Honduras to move toward hydroelectric capacity and away from thermal generation. This effort paid off: currently almost 99 percent of electricity is produced with hydroelectric power. However, 
oil consumption in the transport and industrial sectors continues to cause a drain on the country's foreign exchange balance. The largest source of energy in Honduras is fuel wood. Concern about deforestation in the EI Cajon watershed has led to calls for tree-planting programs. A very high population growth coupled with the current lack of alternative cooking fuels for the rural areas implies that increased deforestation will occur. Energy planning has not received as much support from international agencies in Honduras as in other Central American countries. Consequently, Honduras lacks the computers and data necessary to complete national energy plans.

In view of the above energy concerns, it is recommended that AID consider the following programs for Honduras.

o Assist ENEE with the develoment of geothermal and hydroelectric resources.

As the economy continues to grow and develop, additional electricity production capacity will need to be constructed. Because it has become clear that building large-scale hydroelectric plants places a heavy financial burden on small countries such as Honduras, lower capitalcost-per-project alternatives such as geothermal and minihydroelectric plants should be considered. A thorough reconnaissance of these resources is needed soon so they can be available to fill the predicted electricity supply shortfall in the 1990s.

- Provide support to Honduras for the evaluation of peat, coal, and biomass resources.

Biodigestors for fertilizer and biogas have received some attention in Honduras, and more support in this area is warranted.

- Encourage and support the development of a national fuel-wood program.

Detailed studies are necessary to find methods of changing the incentive structure to encourage the maintenance and replanting of forests. Because of the historic and cultural barriers to change in this area, solutions to the deforestation problem will have to be long-term in nature. In addition to encouraging the use of more efficient cooking stoves, the program should examine the feasibility of widespread substitution of alternative energies such as biogas and solar for fuelwood use in the residential sector.

- Provide support to Honduras for the evaluation of alternative energy pricing policies.

Both absolute and relative energy prices have large influences on consumption patterns. It is recommended that an analysis be completed to 
determine a pricing policy that would encourage the efficient use of energy without hindering economic growth.

- Provide assistance for institutional strengthening at CONSUPLANE.

As the institution in charge of national energy planning, CONSUPLANE needs support in the form of additional staff, computer equipment and software, and training in energy modeling. In addition, better communication and coordination among the energy institutions should be encouraged by AID.

- Support data collection and computerization.

A further requirement for successful energy planning and demand management is adequate data. Honduras still lacks critical information on energy consumption in the residential and transport sectors. Given that deforestation and the foreign exchange expense of $0 i 1$ are the two key energy problems facing the country today, it would be valuable to fill such data voids expeditiously.

\section{REFERENCES}

1. Honduras: A Country Study, James D. Rudolph, ed., (U.S. Government Printing Office, Washington, D.C., 1984).

2. Jeffrey J. Jones and Perez G. Alfonso, "Diagnostico Socio-Economico Sobre el Consumo y Produccion de Lena en Honduras," Report by Centro Agronomico Tropical de Investigacion y Ensenanza, Turialba, Costa Rica, 1982.

3. World Bank, EPD Data Bank, Comparative Analysis and Data Division, September 1986.

4. United Nations, "Economic Survey of Latin America and the Caribbean, 1982," Vol. 1, Economic Commission for Latin America and the Caribbean, United Nations Publication, November 1984.

5. United Nations Development Program (UNDP), Pine Forest Survey Project Map (1965).

6. "International Financial Statistics Yearbook 1985," Vol. XXXVIII, Bureau of Statistics, International Monetary Fund (IMF).

7. RECOPE, "RECOPE y el Desarrollo Energetico en Costa Rica," San Jose, Costa Rica (June 1984). 



\section{PANAMA}

\section{CONTENTS}

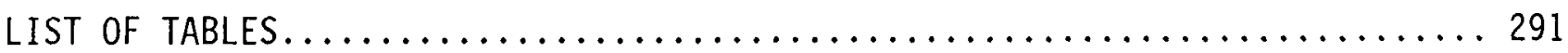

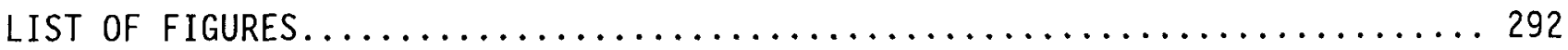

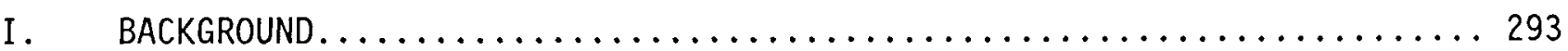

A. Political Situation/Government Structure.................. 293

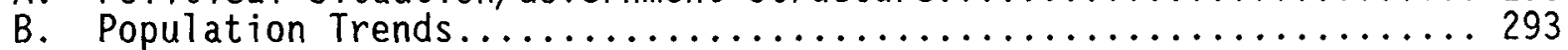

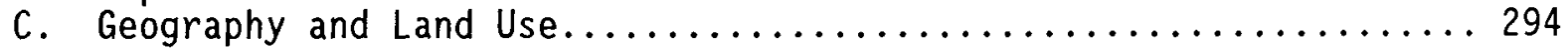

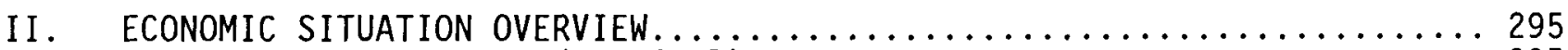

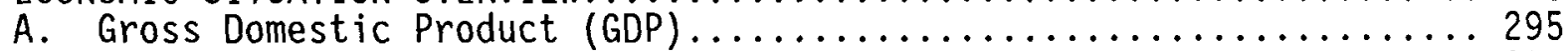

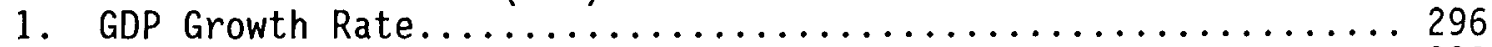

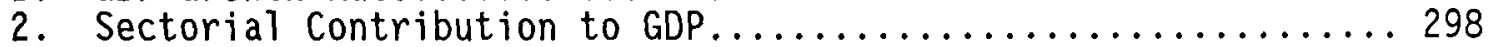

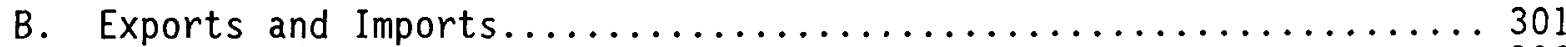

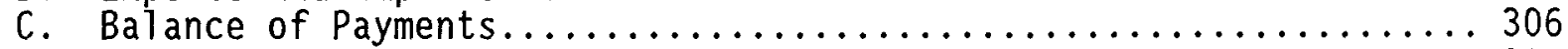

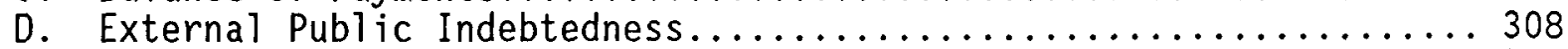

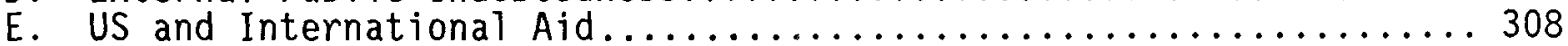

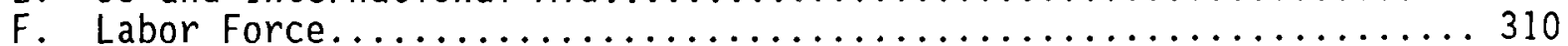

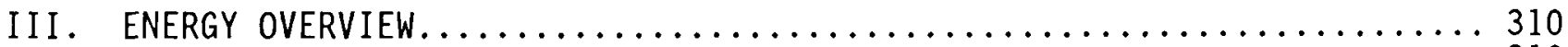

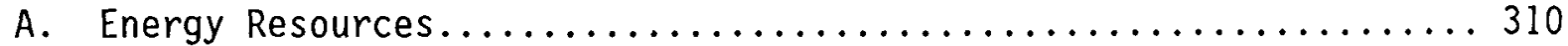

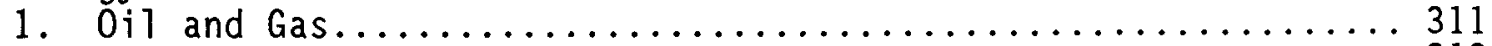

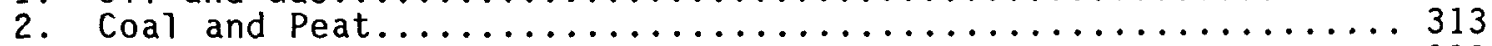

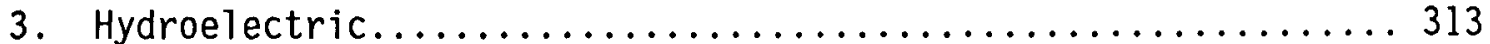

a. Medium-Capacity Hydroelectric.................. 313

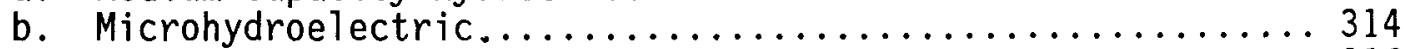

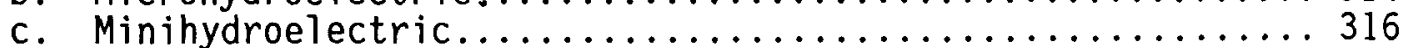

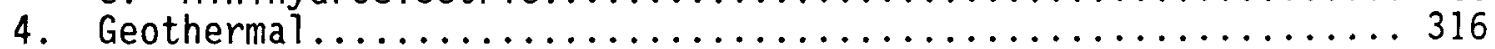

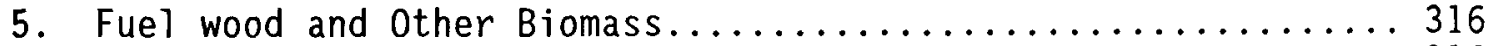

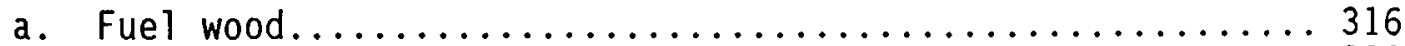

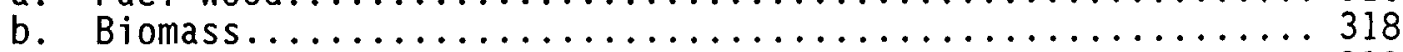

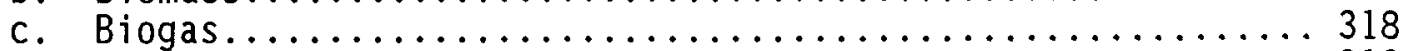

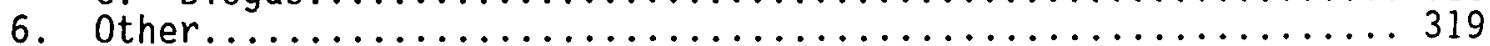

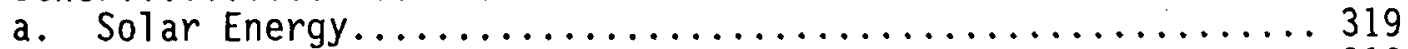

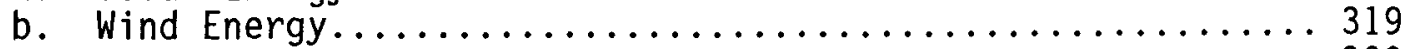

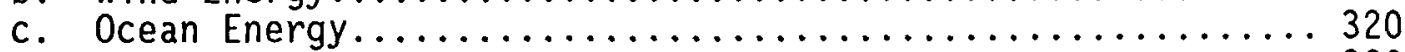

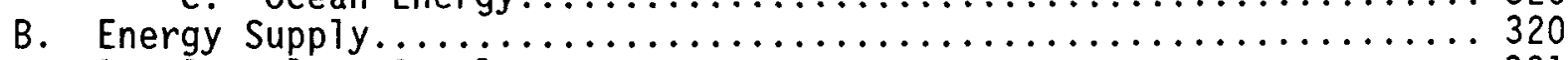

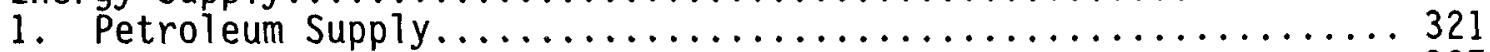

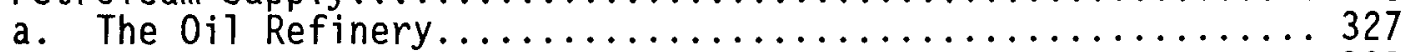

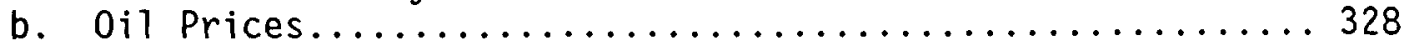

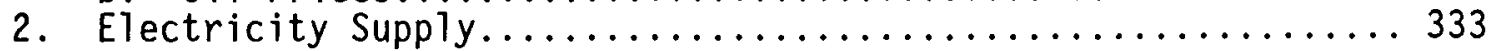




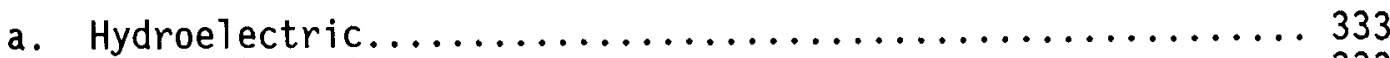

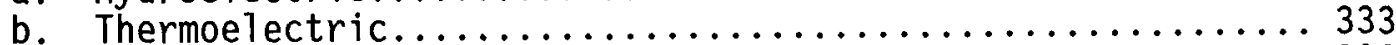

c. Electricity Generation by Fuel Type................ 338

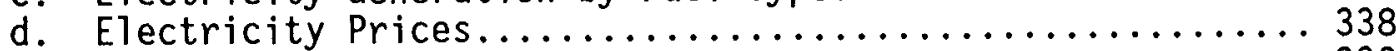

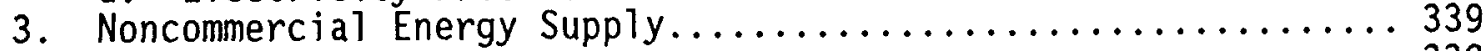

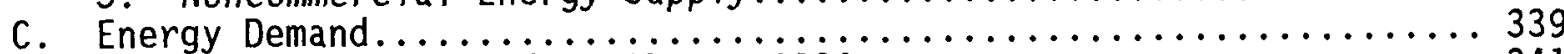

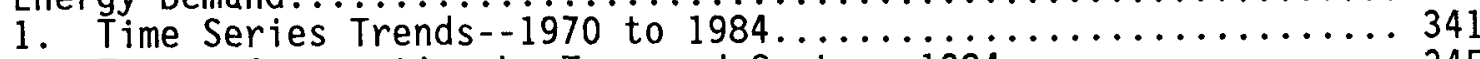

2. Energy Consumption by Type and Sector--1984............ 345

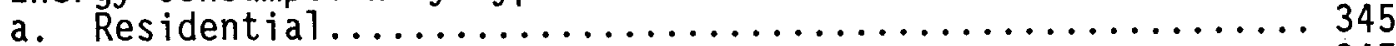

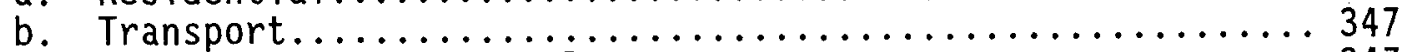

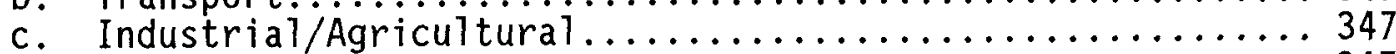

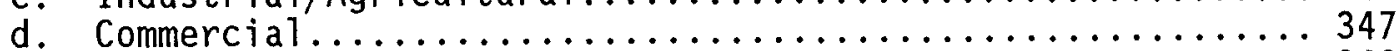

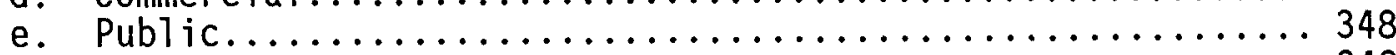

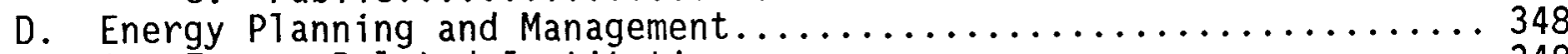

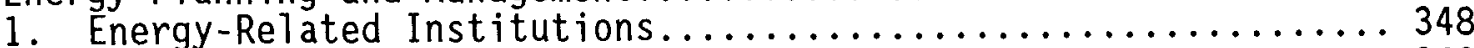

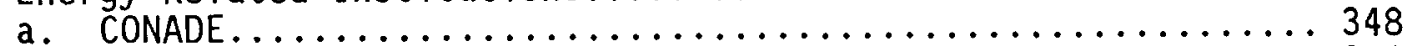

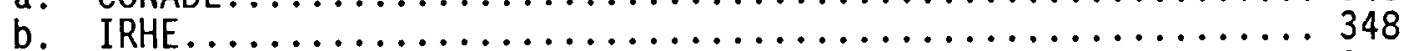

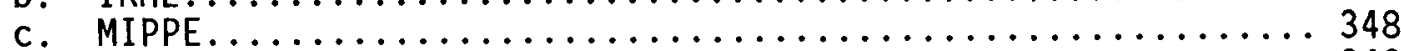

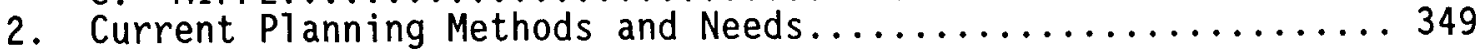

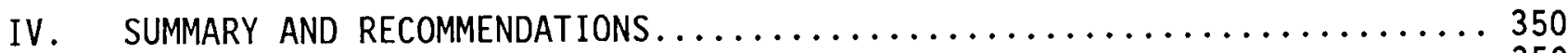

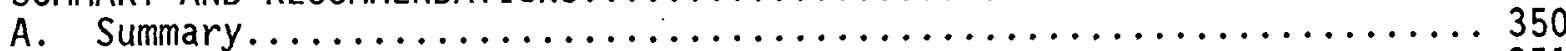

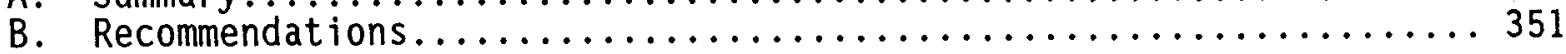

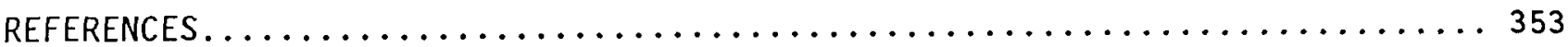

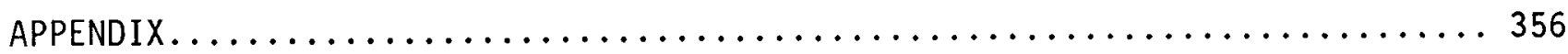


1. Panama: Gross Domestic Product........................... 296

2. Panama: Gross Domestic Product Growth Rates.................... 297

3. Panama: Sectorial Contribution to Gross Domestic Product.......... 299

4. Panama: Exports and Imports......................... 302

5. Panama: Growth Rates for Exports and Imports................. 304

6. Panama: Exports and Imports (percentage of total) ............. 304

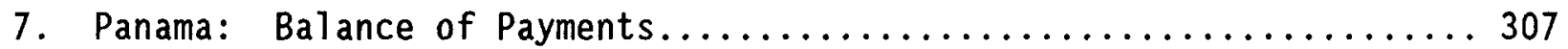

8. Panama: External Public Indebtedness.................... 309

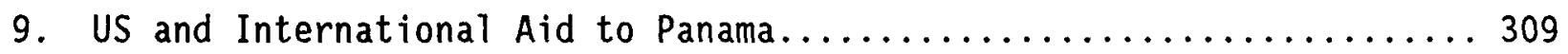

10. Panama: Hydroelectric Projects of Medium Capacity.............. 314

11. Panama: Principal Projects of Microhydroelectric Units.......... 315

12. Panama: Summary of Usable Biomass Potential.................. 318

13. Panama: Annual Biogas Production from Readily Collectible Wastes.... 318

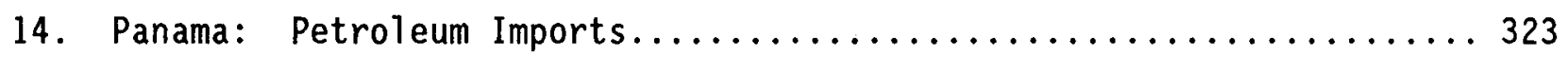

15. Panama: Production, Importation, and Exportation of Petroleum

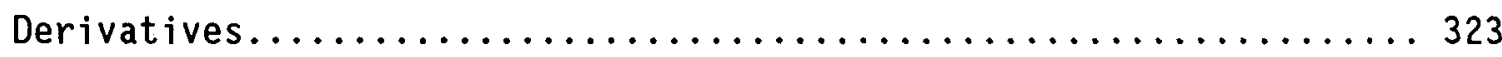

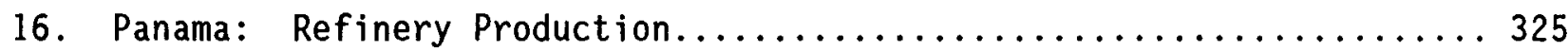

17. Panama: 0il Products Imported as a Percentage of $0 i 1$ Products

Supplied......................................... 325

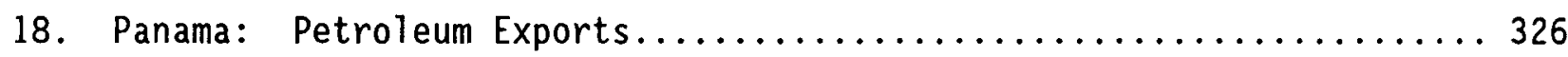

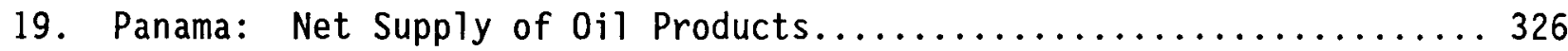

20. Panama: Value of Imported Crude Petroleum..................... 328

21. Panama: 0il Product Prices; Percentage Change in 011 Product Prices. 330

22. Panama: Installed Electric Generating Capacity............... 334

23. Panama: Electric Generation............................. 334

24. Panama: Characteristics of Existing Hydroelectric Projects....... 335

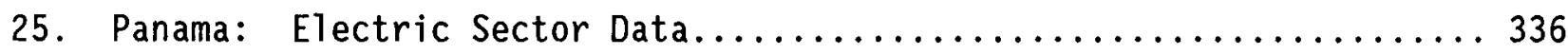

26. Panama: Comparison of Capacity Expansion Plans................ 336

27. Panama: Characteristics of Existing Thermal Generation Facilities... 337

28. Panama: Percentage of Total Fuels Consumed for Electricity

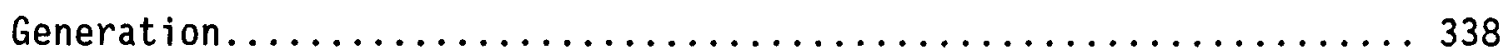

29. Panama: Electricity Prices; Percentage Change in Electricity Prices. 340

30. Panama: 1984 Energy Consumption (thousands of BEP) ............ 341

31. Panama: Compounded Annual Average Growth Rates for Energy

Consumption, by Sector and Selected Years.................. 342

32. Panama: 1984 Energy Consumption (percentage of tota 1).......... 346

33. Panama: 1984 Energy Consumption (percentage of fuel use by sector).. 346 


\section{LIST OF FIGURES}

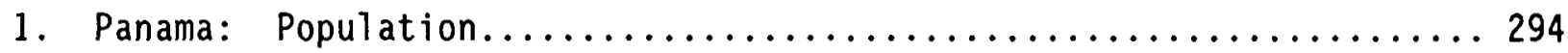

2. Panama: Gross domestic product by major sector................ 299

3. Panama: Merchandise exports............................. 302

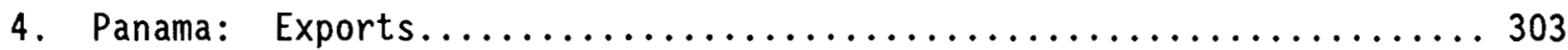

5. Panama: Total exports, total imports, and oil imports........... 303

6. Panama: Imports.......................................... 305

7. Panama: $0 i 1$ imports as a percentage of imports, exports, and GDP... 306

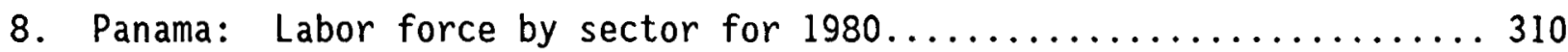

9. Panama: 1975 acreage holdings and well locations of prior years.... 312

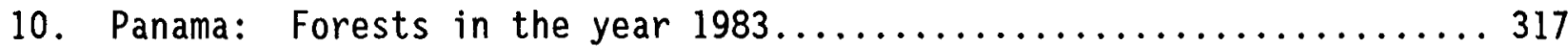

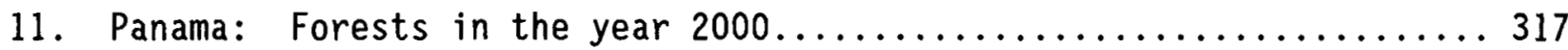

12. Panama: Energy flow diagram for Panama $1984 \ldots \ldots \ldots \ldots \ldots \ldots \ldots \ldots . \ldots \ldots 22$

13. Panama: Energy supply by fuel type...................... 322

14. Panama: Petroleum derivative price structure................. 332

15. Panama: Production and transmission of electrical energy......... 335

16. Panama: Energy consumption by sector for $1970-1984 \ldots \ldots \ldots \ldots \ldots \ldots . \ldots 342$

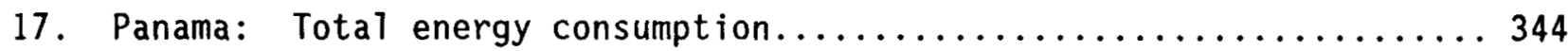




\section{BACKGROUND}

\section{A. Political Situation/Government Structure}

The constitutional framework of Panama allows for three branches of government--the executive, the legislative, and the judiciary. But, as is the case throughout most of Latin America, constitutional power in Panama is heavily concentrated in the executive office. After the october 1968 coup d'etat, Brigadier General Omar Torrijos Herrera, Commander in Chief of the National Guard, headed the government until 1978. The constitution of 1972 had delegated legislative and executive power to Torrijos for six years. After this period, the government instituted an electoral process that culminated in direct election of the president and vice president.

One outstanding achievement of the Torrijos' regime during the seventies was the successful negotiation of the 1977 Panama Canal treaties with the United States. The new treaties went into effect on October 1, 1979 transferring legal jurisdiction over the Canal Zone to Panama and providing for Panama's assumption of control over canal operations at the end of the century. More detail concerning the two treaties is given at the beginning of the energy supply section of this report.

During the 1978 National Assembly election, Aristides Royo was elected president for a six year term to end in 1984. Torrijos retained his position as commander in chief of the National Guard and maintained considerable influence in foreign and domestic affairs. In 1981, General Torrijos died in a plane crash; President Royo resigned in 1982. Ricardo de la Espriella (former Vice President) became constitutional President, but the National Guard (renamed Defense Forces in 1983) retained a position of importance.

In 1984, Nicolas Ardito Barletta (former World Bank Vice President) was elected in the first direct elections since 1968. Barletta enacted strict austerity measures in an attempt to reduce the 3.8 billion dollar foreign debt. After one year in office, Barletta resigned, and Vice President Eric Arturo Delvalle was elevated to the Presidency. ${ }^{1-5}$

\section{B. Population Trends}

Panama currently has a population of about 2 million (Fig. 1) and is the least populated country in Central America. " The last census was in 1980 and more recent figures for population are estimates. In 1970, Panama's population was $1.5 \mathrm{million}$, and by 1980 the population had increased to 1.8 million--a 25

Information provided by David Cieslikowski, Comparative Analysis and Data Division, World Bank, September 1985. 


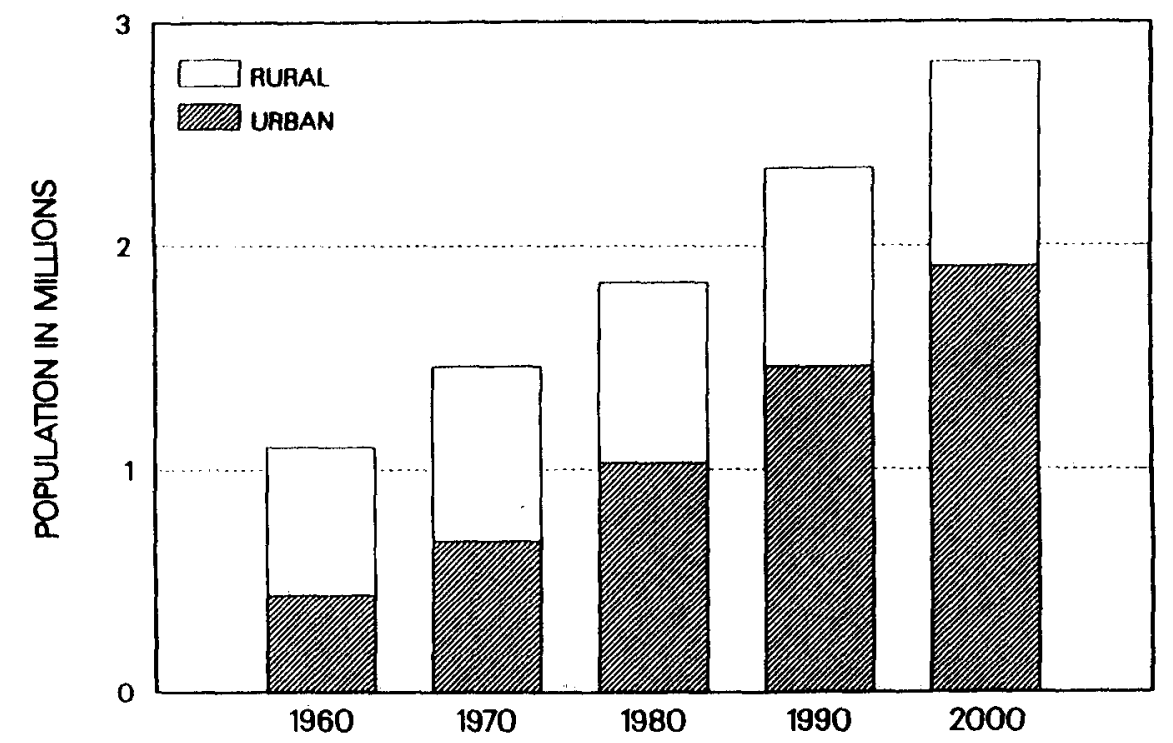

SOURCES: WORLD BANK. UNIVERSTYY OF CALFOANIA LATIN AMERICAN CENTER

Fig. 1. Panama: Population. (Population is projected for 1990 and 2000.)

percent increase. Between 1980 and 1985, population increased by an additional 11 percent. This growth in population is owing to natural births and to very heavy immigration from surrounding countries, the Orient, Europe, and the United States.

Panama is the commercial center of the region. It is the most urbanized country in Central America, which explains why it has the lowest consumption of fuel wood in Central America. In 1970, 48 percent of Panama's population was urban dwellers. In 1985, it was estimated that 58 percent of Panama's population was urban dwellers. " Most of the rural population lives west of the Canal Zone. $^{2}$

\section{Geography and Land Use}

Panama occupies the southeastern end of the isthmus forming the 1 and connection between North and South America and comprises 77,082 square kilometers of territory. The long axis of the country runs east to west with the Gulf of Mexico and the Caribbean Sea bordering the northern coast and the Pacific Ocean bordering the southern coast. The dominant feature of the country's landform is the central spine of mountains, called the Cordillera Central, which forms the

* Information provided by Moja Diddi, Comparative Analysis and Data Division, World Bank, September 1985. 
Continental Divide. The eastern regions of the country are covered almost entirely with heavy tropical forests, and rainfall is heavy but seasonal. ${ }^{1,2}$

Although Panama lies within the humid Neotropics, it does not possess large extensions of fertile soils because the rainfall of the tropics tends to leach the soil of its nutrients. Thus, tropical soils do not lend themselves to intensive agriculture. According to land capability studies realized by the Panamanian government with the assistance of the Agency for International Development, 23.9 percent of Panama's lands are arable. Approximately half of these arable lands are at best of marginal utility for intensive agriculture, and they require great care and management in order to remain productive. ${ }^{6}$ Nine percent of the agricultural land is fallow, 4 percent is crop, and 11 percent is pasture. ${ }^{3}$ The main agricultural products are rice, bananas, sugar, corn, red meat, and shrimp; Panama is largely self-sufficient in foods, except wheat.

As is the case for other Central American countries, deforestation has occurred at a rapid rate since the mid-nineteenth century. It has been estimated that 83 percent of Panama was covered in forest in 1850, decreasing to 60 percent in 1947, 52 percent in 1974, and 37 percent in 1984. The rapid population growth that Panama has experienced since the mid-nineteenth century has contributed, in part, to this rapid deforestation. Panama's population has increased from 0.13 million in 1851 , to 0.62 million in 1940 , and to 2 million in 1984. Between 50,000 and 70,000 hectares of forest are felled annually, and this figure is much higher during extended dry seasons, as was the case in 19821983 when an estimated 100,000 hectares were destroyed. "Of particular concern to Panama is the deforestation that has taken place in the watershed of the Panama Canal. The operation of the Canal depends on the existence of forests that provide a stable water regime. Approximately 60 percent of the 326,000 hectares of this vital watershed are deforested." 6

\section{ECONOMIC SITUATION OVERVIEW}

A. Gross Domestic Product (GDP)

GDP at current prices was 1021 million balboas in 1970 (the Panamanian balboa has the same value as the US dollar) (Table 1). Between 1980 and 1983, GDP increased steadily from 3559 to 4379 million balboas, declining in 1984 to 4112 million balboas. In real terms, GDP was 2281 million balboas in 1970 , reaching a high of 4303 mitlion balloas in 1983. During 1970, Panama had a population of 1.464 million and a real per capita GDP of 1558 balboas. By 1983 , Panama's 
TABLE 1

PANAMA: GROSS DOMESTIC PRODUCT

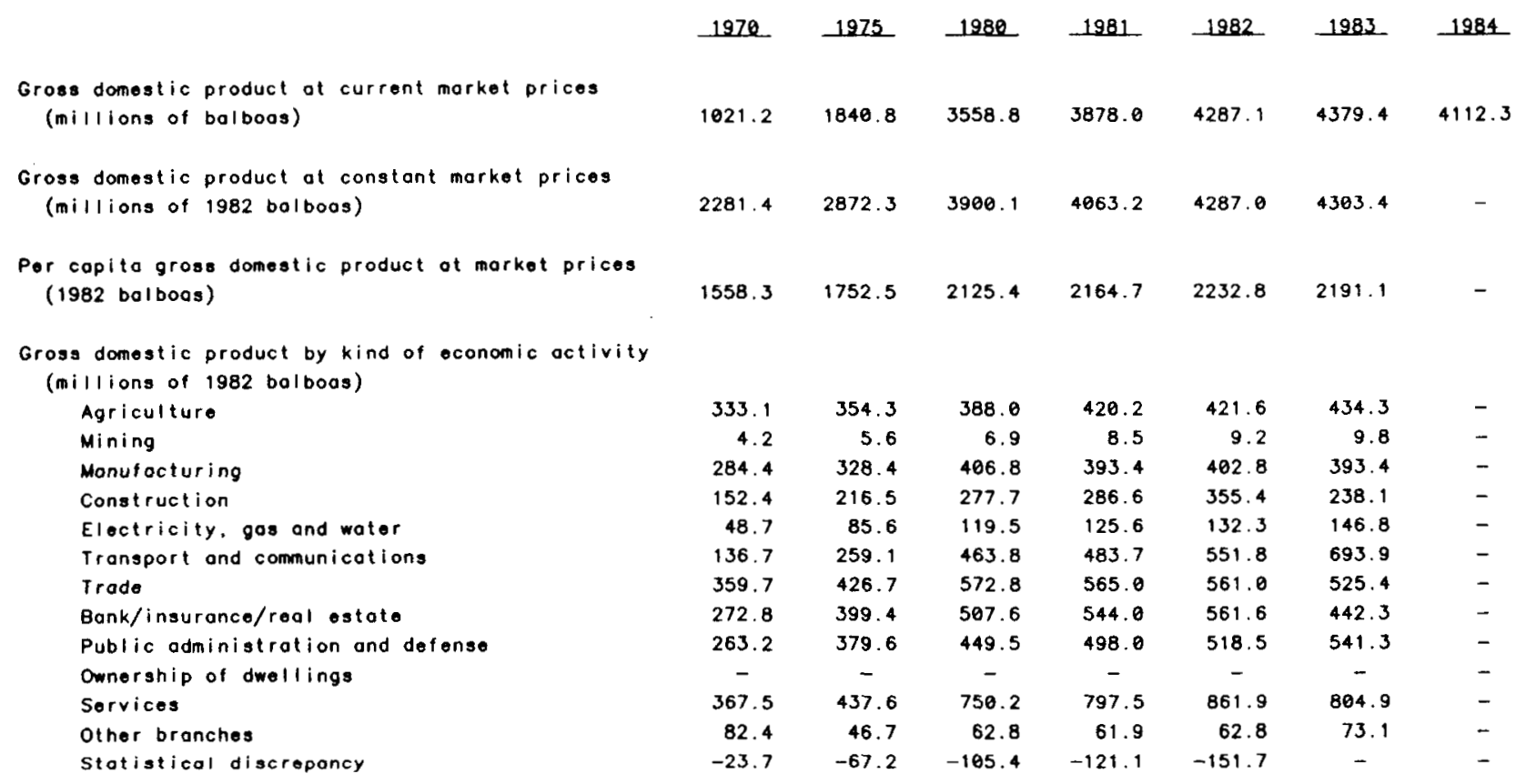

Source: World Bank.

population was 1.964 million, and real GDP was 2191 balboas. Population increased by 34 percent, and real per capita GDP increased by 41 percent during the 1970 to 1983 period. In 1983 the dominant sectors contributing to GDP were services ( 805 million balboas), transport and communications (694 million balboas), public administration and defense (541 million balboas), and trade (525 million balboas). These same sectors have been the main contributors to GDP since 1970 .

1. GDP Growth Rate. During the periods of 1970 to 1975 and 1975 to 1980, real GDP grew at an average annual rate of about 5 percent and 6 percent, respectively (Table 2) with much of the growth occurring in 1970 to 1973 and 1978 to 1980. During 1974 to 1977, GDP growth averaged on $7 y$ about 1.7 percent annualiy. This period of economic stagnation was the result of several international and domestic factors. International factors included (1) the energy crisis and the associated sharply rising world petroleum prices, (2) international inflation and recession that adversely affected the canal and related activities, and (3) disagreements among banana exporters about an export tax on bananas. Domestic actions included government policies enacted during the late 1960s, which discouraged private investment in the 1970s. ${ }^{1}$ 
TABLE 2

PANAMA: GROSS DOMESTIC PRODUCT GROWTH RATES

(percentage based on 1982 balboas)

\begin{tabular}{|c|c|c|c|c|c|c|c|}
\hline & $1970-1975$ & $1975-1980$ & 1980 & 1981 & 1982 & 1983 & 1984 \\
\hline Gross domestic product at constant morket prices & 4.7 & 6.3 & 15.1 & 4.2 & 5.5 & 0.4 & - \\
\hline \multicolumn{8}{|l|}{ Gross domestic product by kind of oconomic activity } \\
\hline Agriculture & 1.2 & 1.8 & -4.1 & 8.3 & 6.3 & 3.0 & - \\
\hline Mining & 5.9 & 4.3 & 27.8 & 23.2 & 8.2 & 6.5 & - \\
\hline Manufacturing & 2.9 & 4.4 & 5.9 & -3.3 & 2.4 & -2.3 & - \\
\hline Construction & 7.3 & 5.1 & 21.4 & 3.2 & 24.0 & -33.0 & - \\
\hline Electricity, gos and water & 11.9 & 6.9 & 2.0 & 5.1 & 5.3 & 11.0 & - \\
\hline Transport ond communications & 13.6 & 12.3 & 33.6 & 4.3 & 14.1 & 25.8 & - \\
\hline Trade & 3.5 & 6.1 & 6.4 & -1.4 & -0.7 & -6.3 & - \\
\hline Bank/insurance/roal estate & 7.9 & 4.9 & 1.9 & 7.2 & 3.2 & -21.2 & - \\
\hline Public odmintstration and defense & 7.6 & 3.4 & 2.4 & 10.8 & 4.1 & 4.4 & - \\
\hline Ownership of dwellings & - & - & - & - & - & - & - \\
\hline Services & 3.6 & 11.4 & 52.3 & 6.3 & 8. 1 & -6.6 & - \\
\hline Other branches & -10.7 & 6.1 & 6.8 & -1.4 & 1.5 & 16.4 & - \\
\hline
\end{tabular}

The 1978 to 1980 period marked a period of substantial increase in real growth of about 8.1 percent, reflecting the improved political environment after ratification of the 1977 Panama Canal Treaty. "In addition, the government took steps to improve public finances by restricting current and capital expenditures, raising taxes, and halting the creation of new state enterprises. Private enterprise was encouraged through export, investment, and employment incentives and through a resurgence of regional trade." 7 Specifically, the large real growth rate of 15.1 percent in 1980 was mainly attributed to the inclusion in the national accounts of entrepreneurial activities carried out in the former Canal Zone.

This short term economic growth continued into 1981 and 1982 (fueled by increased private sector investment). In particular, two factors were mainly responsible for the increased private investment over these years: "(1) the construction of the trans-Isthmian oil pipeline (promoted by a private transnational company) that began in 1981 and was completed in october 1982, and (2) the enlargement and modernization of the urban infrastructure in Panama City." 8 During 1983 and 1984, Panama's economy was affected by the international recession as real growth dropped. During these two years, Panama experienced a slowdown in tourism and canal shipping traffic that adversely affected commercial activity.

The fastest growing sectors during the 1970 s were transport and communications, electricity, gas and water (hydroelectric development began in the mid1970s), and bank/insurance/real estate (Table 2). Agriculture was the least 
dynamic sector. During 1980, the service sector registered one of the largest growth rates of 52 percent, mainly owing to the incorporation of activities carried out in the former Canal Zone. Other sectors registering large growth rates during 1980 were transport/communications, mining, and construction. Electricity generation programs were intensified during 1980, and negotiations continued for the electrical interconnection with Costa Rica. The interconnection of the electricity networks of Panama and Costa Rica is intended "to rationalize and make greater use of the electricity potential of these two countries, thereby helping also to cut down on the amount of foreign currency devoted by them to fuel imports." 9 During 1981, the least dynamic sectors were manufacturing ( 3 percent decline) and trade ( 1 percent decline). For both of these sectors, the drop in growth rates was mainly attributed to the slowdown of transport operations through the Canal and the resulting drop in output of the oil refinery. ${ }^{9}$ The largest growth rates occurred in the mining sector, the public administration and defense sector, and the bank/insurance/real estate sector. During 1982, the construction sector registered the largest growth rate, 24 percent. Two projects were mainly responsible for this large growth-(1) the Fortuna hydroelectric power station (the first stage was completed during the year), and (2) the trans-Isthmian pipeline (which began in 1981 and was completed in October 1982). ${ }^{8}$ Trade registered a decline in growth of -0.7 percent owing to the international recession and the resulting decline in canalrelated activities. During 1983, transport and communications registered the highest growth rate, 26 percent. Several sectors showed rather 1 arge drops in growth rates during the year: construction (owing mostly to the completion of the inter-ocean pipeline), bank/insurance/real estate, trade, services, and manufacturing.

2. Sectorial Contribution to GDP. The service sector of Panama's economy (including services, transport and communications, trade and finance, public administration and defense, and other branches) has consistently dominated and increased its contribution to GDP over the years since 1950. Several factors that contribute to the service sector domination of the economy include "(1) Panama's geographic location and the Panama Canal, (2) modern infrastructure, and (3) an educated population trained in commercial activity." ${ }^{1}$ The services sector of the economy has grown from 66 percent of GDP in 1950 to 72 percent of GDP in 1980, with much of the growth occurring during the 1970 s (Table 3 and Fig. 2). "The principal stimulus was in banking--particularly offshore banking transactions in the 1970s--and transportation, communications and storage." The bank/insurance/real estate and trade sectors have been the main thrust to 
TABLE 3

PANAMA: SECTORIAL CONTRIBUTION TO GROSS DOMESTIC PROOUCT

(percentage bosed on 1982 balboos)

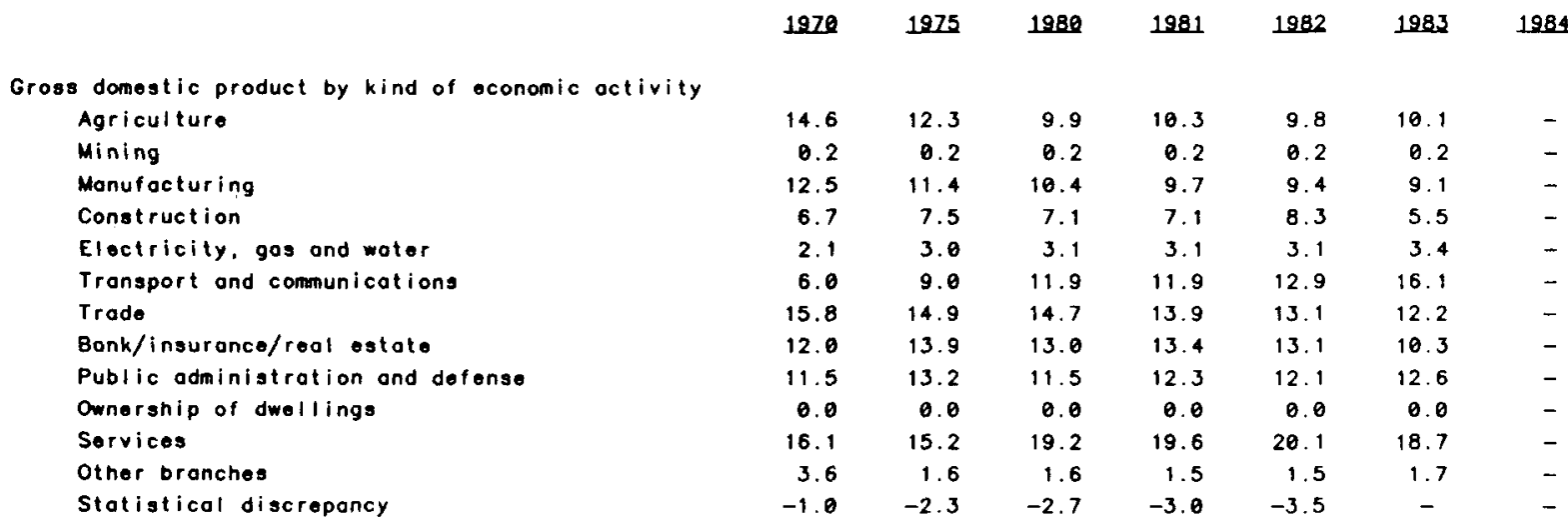

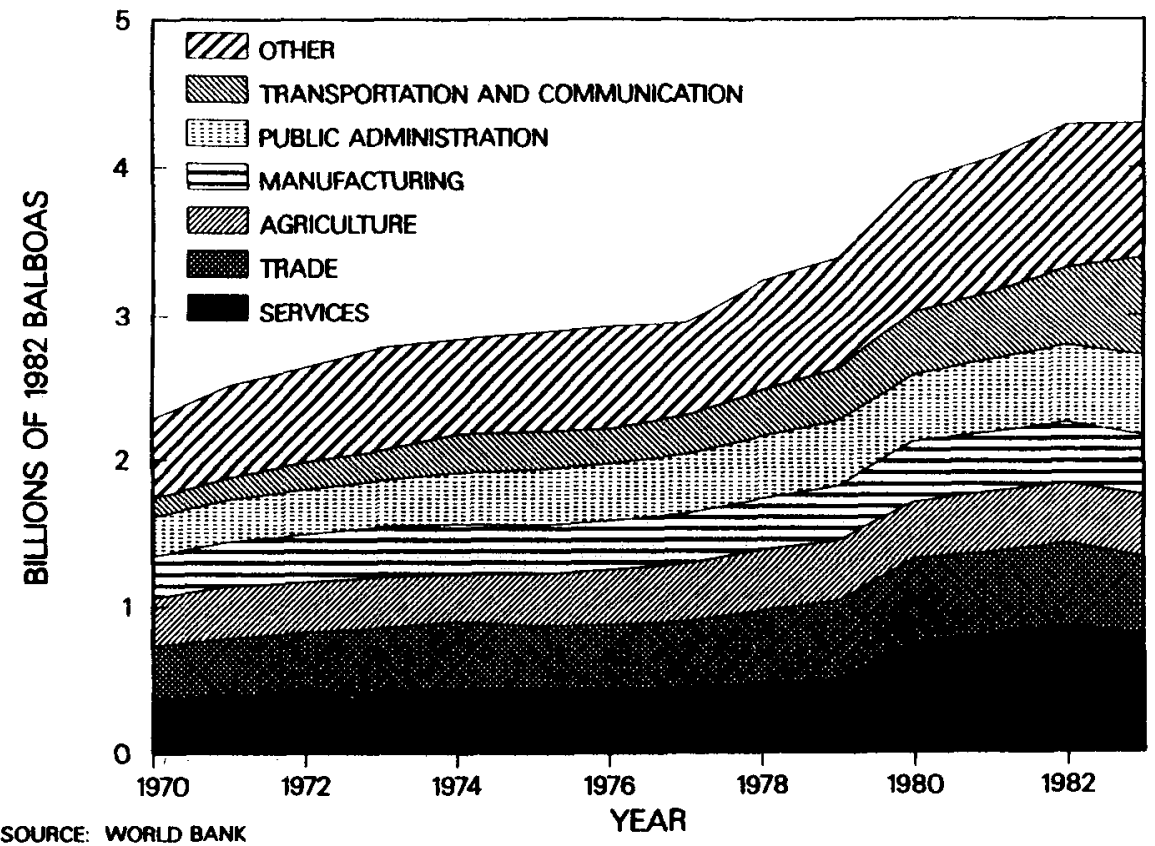

Fig. 2: Panama: Gross domestic product by major sector. 
the service sector's growth. Transport and communications also increased. "Transportation increased rapidly along with expansion of the road network and monetization of the rural economy; substantial investments were made to keep the communications system up to international standards for the extensive foreign business; and storage and warehousing grew rapidly in response to the economy's own needs and particularly to the foreign business conducted in the Colon Free Zone." 1 Between 1980 and 1983, the services sector declined slightly owing to the international recession.

The industrial sector of Panama's economy (including mining, manufacturing and electricity, gas and water) has progressed moderately during the past four decades, increasing from 8 percent of GDP in 1950 to 14 percent of GDP in 1980 . Mining's share of GDP remained relatively constant between 1950 and 1980 . Manufacturing's share of GDP rose from 7 percent in 1950 to 10 percent in 1980. Earlier expansion "was based primarily on import substitution, but the easy possibilities had largely been exhausted by 1970. Growth slackened in the $1970 \mathrm{~s}$ because an export orientation was required." 1 A further constraint to industrial growth during the 1970 s was "the lack of natural resources, particularly energy. "1 Until hydroelectric development had begun during the mid-1970s, Panama relied heavily on imported oil for commercial energy. Electricity, gas, and water's share of GDP rose from 1 percent in 1950 to 3 percent in 1980. Generally, the industrial sector of the economy decreased between 1980 and 1983 owing mainly to manufacturing.

Agriculture's share of GDP has consistently decreased in the past four decades. Between 1950 and 1977 agrarian reform brought considerable change in rural areas, but reform was reflected more in social and economic conditions than in output. Although the agricultural sector has been the main source of employment over the years (e.g., 34 percent of the labor force in 1980) and has been the main supplier of export commodities (e.g., over 56 percent in 1984), the presence of the canal and related trade and finance activities has dominated economic activity in Panama over the years. General7y, between 1980 and 1983 , agriculture's share of GDP increased only slightly. 1

Construction's share of GDP has consistently increased during the past four decades, from 4 percent of GDP in 1950 to 7 percent of GDP in 1980. Expansion of this sector also aided in the expansion of the industrial sector (through acquisitions of construction materials and furniture) and had an impact on employment and imports. During the early 1970s, Panama experienced a construction boom, but it collapsed in 1974; after that the Panamanian government "sought to reinvigorate the economy by creating a building program for relatively inexpensive housing. Part of the United States aid proposed in 
conjunction with the Panama Canal Treaty included the financing of public housing projects to meet a social need, to stimulate other economic sectors, and to create jobs for the large number of urban unemployed, especially in colon." 1 Between 1980 and 1983, construction's share of GDP decreased slightly.

B. Exports and Imports

Panama's major export items comprise mainly a few products--bananas, shrimp, sugar, and refined petroleum (Fig. 3); whereas, import items are varied and consist of such items as crude petroleum, fuels and lubricants, machinery and transport equipment, manufactured articles, chemical and pharmaceuticals, animal and vegetable oils, beverages and tobacco, and food products. 1 The value of export commodities has always been less than that of import items (Table 4 ). This is partially explained by the fact that Panama is mainly an exporter of services as exemplified in the balance of payments (see Sec. II.C) where exports of other goods, services and income (credit) has always been greater in value than merchandise exports (Fig. 4). Fig. 5 shows Panama's total imports, total exports, and oil imports for 1970-1984 in millions of dollars.

The total value of exports increased between 1970 and 1980 mainly owing to sugar, shrimp and refined petroleum (Table 4). The value of bananas declined slightly between 1970 and 1980. The growth rate for exports during the decade was 13 percent, with the largest growths occurring for sugar (30 percent), shrimp (16 percent), and refined petroleum (14 percent) (Table 5). Together, these three commodities accounted for about 33 percent of exports (Table 6). Although sugar accounted for only 5 percent of exports, it registered the largest growth rate during the 1970s. In 1980 alone, sugar export grew by 152 percent. During the 1970s, the Panamanian government "encouraged the rapid growth of the sugar industry because it provided employment, a cash crop for farmers, and later substantial foreign exchange earnings. During the early 1970 s the government also began building sugar mills to process the expanding cane production." I Bananas, Panama's main export commodity, accounted for 57 percent of exports in 1970 but experienced a decline in export growth during the decade. Two factors caused this decline: (1) the "banana war" during the early 1970 s in which there were disagreements among banana exporters about an export tax on bananas, and (2) "during the same period, Panama was considering taking over United Brands' plantations. The effect was to reduce banana acreage and production between 1970 and 1976."1

Between 1980 and 1984, the total value of exports generally declined mainly owing to the decline in the export of refined petroleum and sugar. overa11, the growth rate for exports dropped from 19 percent in 1980 to -14 percent in 1984. Refined petroleum exhibited the largest decline in growth 


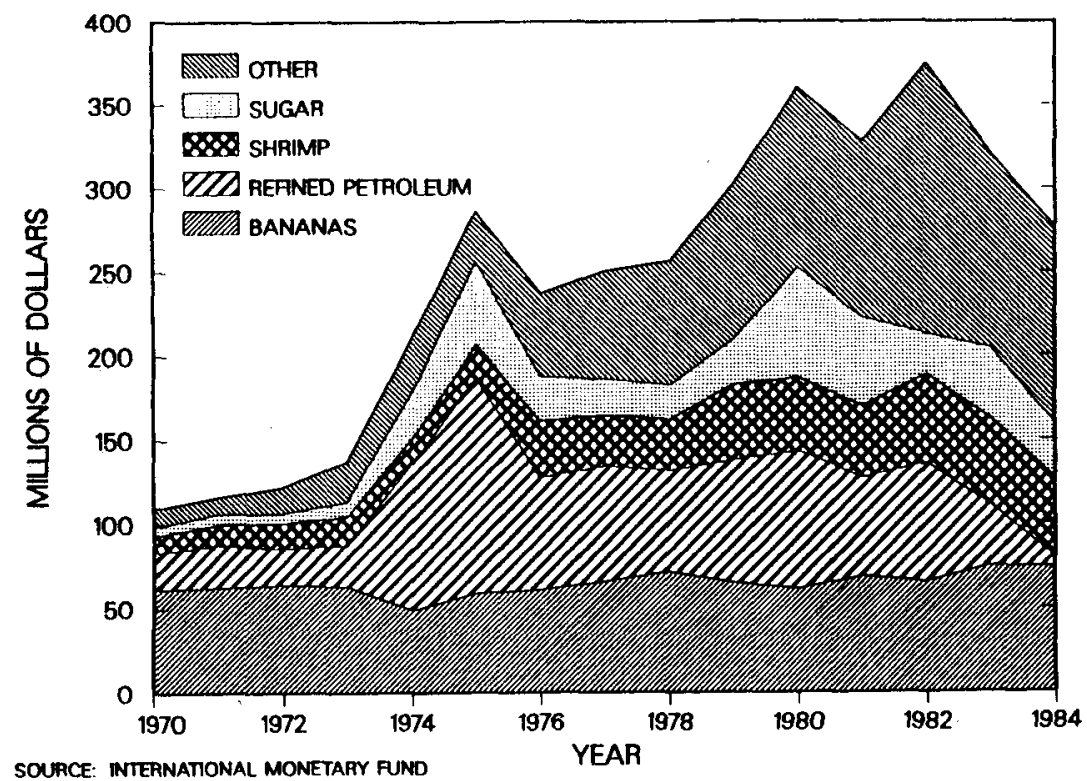

Fig. 3. Panama: Merchandise exports.

TABLE 4

PAMAMA: EXPORTS AND IMPORTS

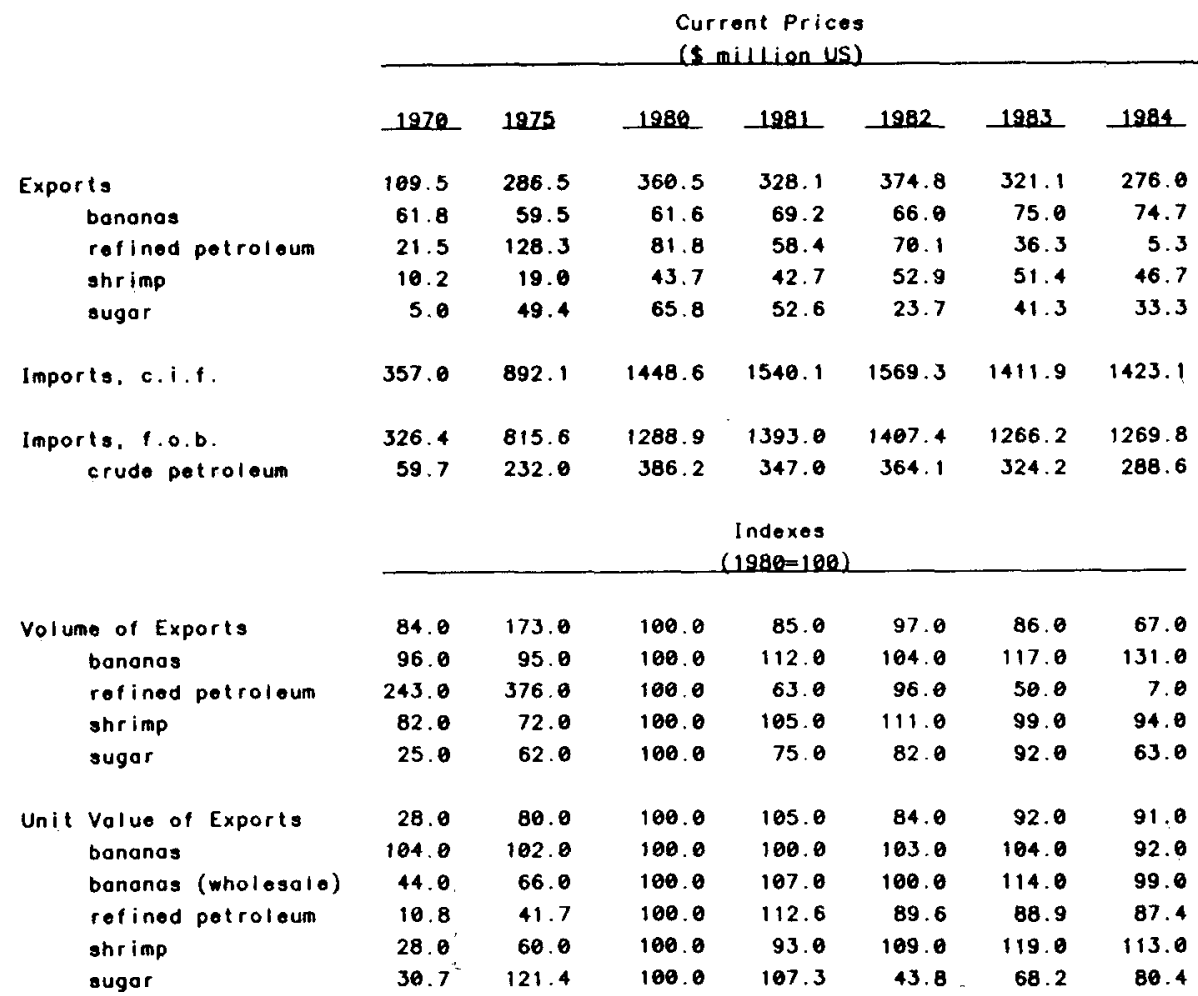

Source: Internotional Monotary Fund. 


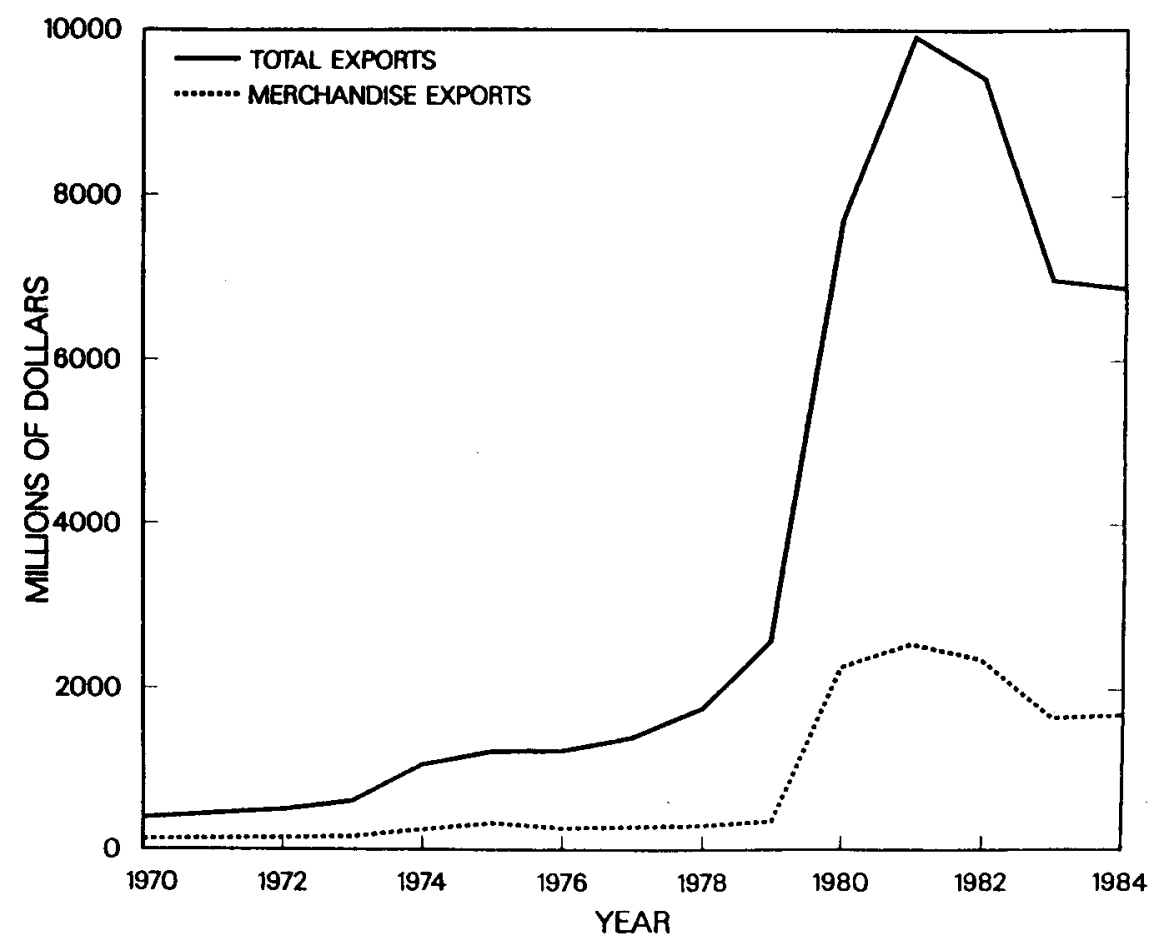

SOURCE: INIERNATIONAL MONETAAY FUND

Fig. 4. Panama: Exports.

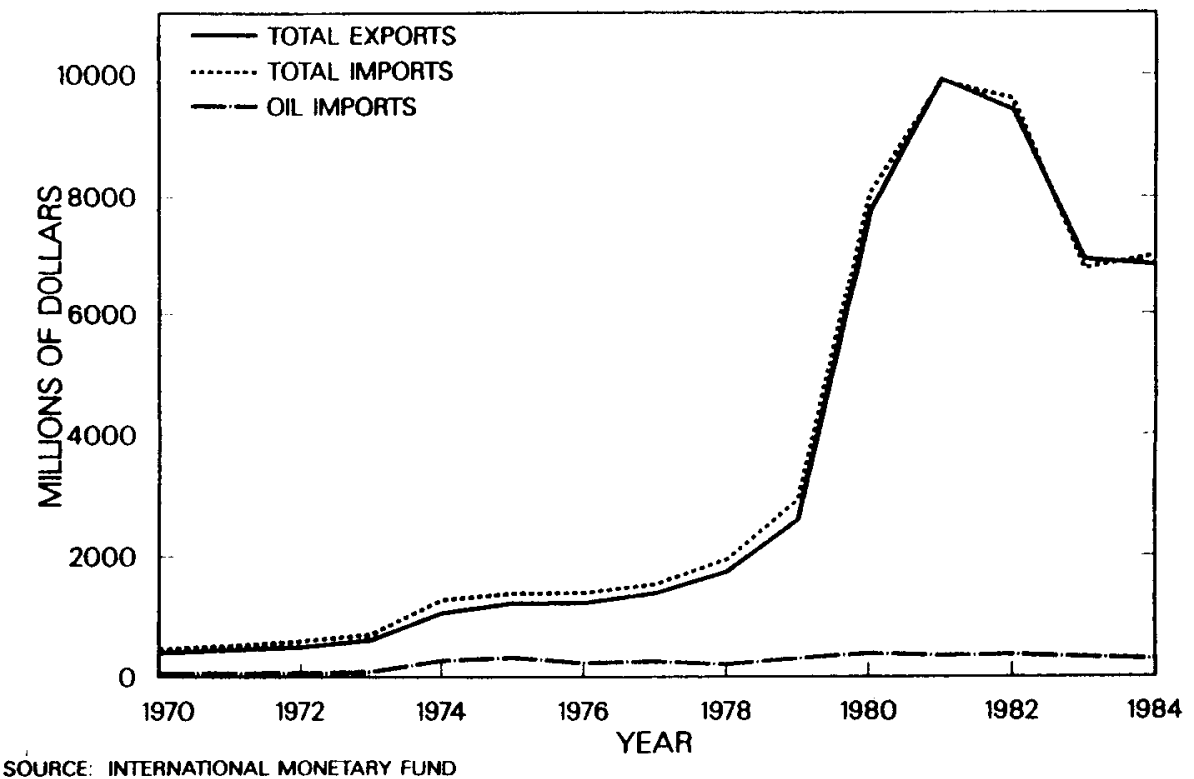

Fig. 5. Panama: Total exports, total imports, and oil imports. 
TABLE 5

PANAMA: GROWTH RATES FOR EXPORTS AND IMPORTS

\begin{tabular}{|c|c|c|c|c|c|c|c|c|}
\hline & \multicolumn{3}{|c|}{ Compounded Annuol Average } & \multicolumn{5}{|c|}{ Annual Growth Rate } \\
\hline & $1970=1975$ & $1975-1980$ & $1970-1980$ & 1980 & 1981 & 1982 & 198.3 & 1984 \\
\hline Exports & 21.2 & 4.7 & 12.7 & 19.0 & -9.0 & 14.2 & -14.3 & -14.0 \\
\hline bananas & -0.8 & 0.7 & 0.0 & -6.3 & 12.4 & -4.6 & 13.7 & -0.5 \\
\hline refined petroleum & 43.0 & -8.6 & 14.3 & 13.0 & -28.6 & 19.9 & -48.2 & -85.5 \\
\hline shrimp & 13.3 & 18.1 & 15.7 & -2.9 & -2.2 & 23.7 & -2.8 & -9.2 \\
\hline sugar & 58.1 & 5.9 & 29.5 & 151.9 & -20.1 & -55.0 & 74.5 & -19.4 \\
\hline Imports, c.i.f. & 20.1 & 10.2 & 15.0 & 22.4 & 6.3 & 1.9 & -10.0 & 0.8 \\
\hline Imports, f.o.b. & 20.1 & 9.6 & 14.7 & 21.3 & 8.1 & 1.0 & -10.0 & 0.3 \\
\hline crude potroleum & 31.2 & 10.7 & 20.5 & 28.0 & -10.2 & 4.9 & -10.9 & -11.0 \\
\hline
\end{tabular}

TABLE 6

PANAMA: EXPORTS AND IMPORTS

(percentage of total)

Exports

bananas

refined petroleum

shrimp

sugar

other

Imports, f.o.b.

crude petroleum

18.3

28.5

30.0

24.9

25.9

25.6

22.7

during the 1980s with value dropping from $\$ 82$ million US in 1980 to only $\$ 5$ million US in 1984. Such a dramatic decline has been attributed to two factors: (1) a drop in world hydrocarbon prices, and (2) a decrease in demand for fuels by ships in transit owing to an international recession during the period. This decline can be observed in Table 4 in the volume and unit value figures, as the volume of refined petroleum has decreased much more rapidly than has the unit value between 1980 and 1984. For the most part, the export of sugar also declined during this period, from $\$ 66$ million US in 1980 to $\$ 33$ million US in 1984. Growth rates for sugar fluctuated during the 1980s. The volatile growth 
rates during the early 1980 s may be the result of Panama's vulnerability to export quotas (as Panama is a member of the International Sugar Agreement), of the international prices of sugar, and of the tax on sugar imports imposed by the US. ${ }^{1}$ The value of bananas increased slightly during the 1980 to 1984 period, from $\$ 62$ to $75 \mathrm{million}$ US. Growth rates fluctuated slightly during the $1980 \mathrm{~s}$. During the 1980 to 1984 period, volume generally increased while value slightly decreased (Table 4). Bananas as a percentage of exports increased over the period, from 17 percent in 1980 to 27 percent in 1984. The value of shrimp. increased significantly during the period, from $\$ 10$ to 47 million US, and its share of total exports increased consistently. As observed in Table 4, although volume of shrimp generally decreased during the 1980s, unit value consistently increased.

The total value of imports, f.o.b., increased from $\$ 326$ million US in 1970 to $\$ 1270$ million US in 1980 (Table 4). Panama experienced a higher average growth rate of 15 percent for imports during the 1970 s than for exports (13 percent) (Table 5 and Fig. 6). Between 1980 and 1984, growth rates for imports generally increased. Crude petroleum imports increased in value from $\$ 60 \mathrm{mil}$ lion US in 1970 to $\$ 386$ million US in 1980. Thereafter, crude petroleum

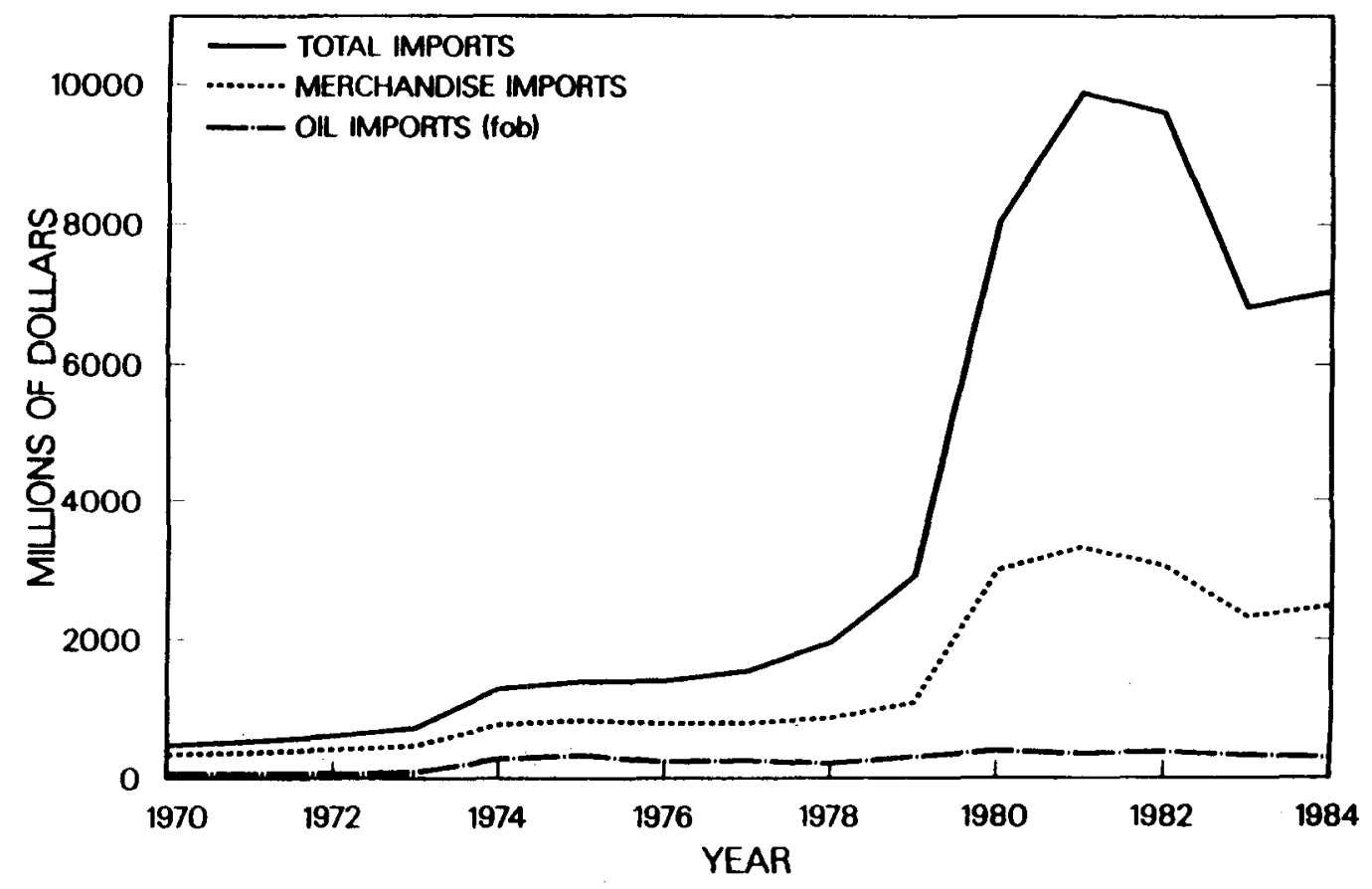

SOURCE: INTERNATIONAL MONETARY FUND

Fig. 6. Panama: Imports. 
imports decreased in value, for the most part to $\$ 289$ million US in 1984. Although the value and growth rates of crude petroleum imports generally decreased during the eighties, crude petroleum accounted for about 15 percent of merchandise imports during the period (Fig. 7). Crude petroleum imports as a percent of merchandise exports (including refined petroleum) was about 46 percent in 1970, decreasing during the 1980 s to 17 percent in 1984 . As a percentage of GDP (in current dollars), crude petroleum imports were 6 percent in 1970, 11 percent in 1980, and 7 percent in 1984.

\section{Balance of Payments}

"Panama's balance of payments is less critical than in most developing countries because of its monetary system and foreign banking. The country has no short-term transfer problem because of the extensive use of United States dollars. Capital flows and particularly changes in the banking system's foreign assets are less dependent on the current account of the balance of payments than they are in other countries; these items responded partially to the government's fiscal situation and partially to conditions affecting international banking." 1

The balance of payments (Table 7) shows the importance of services as an export item for Panama. For a 17 years between 1970 and 1984 , the category "other goods, services and income: net" has always been positive, indicating

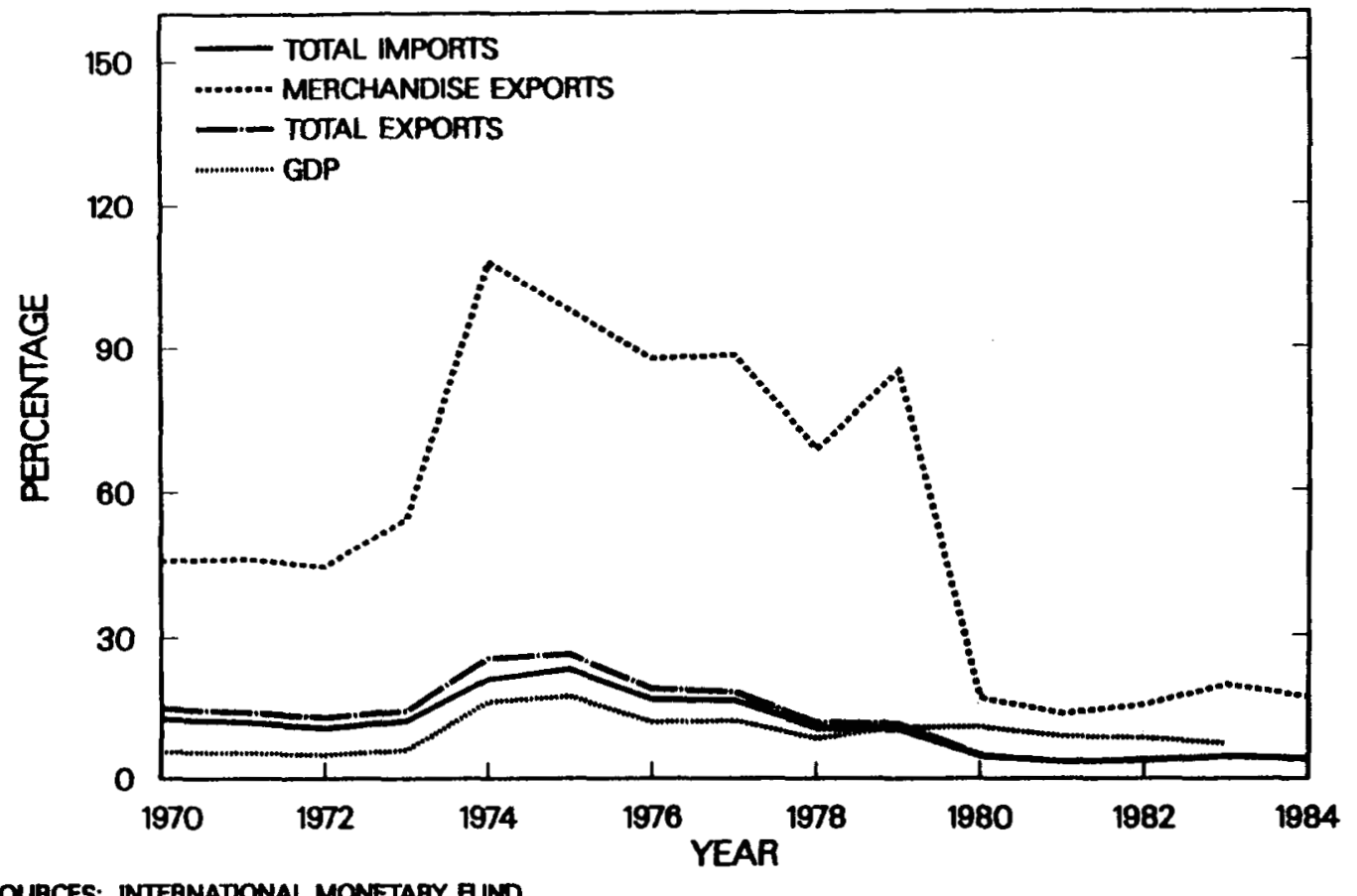

SOUACES: INTERNATIONAL MONETARY FUND.

Fig. 7. Panama: $0 i 1$ imports as a percentage of imports, exports, and GDP. 
TABLE 7

PANAMA: gaLANCE OF PAMMENTS

(\$ million US)

Current occount balonce

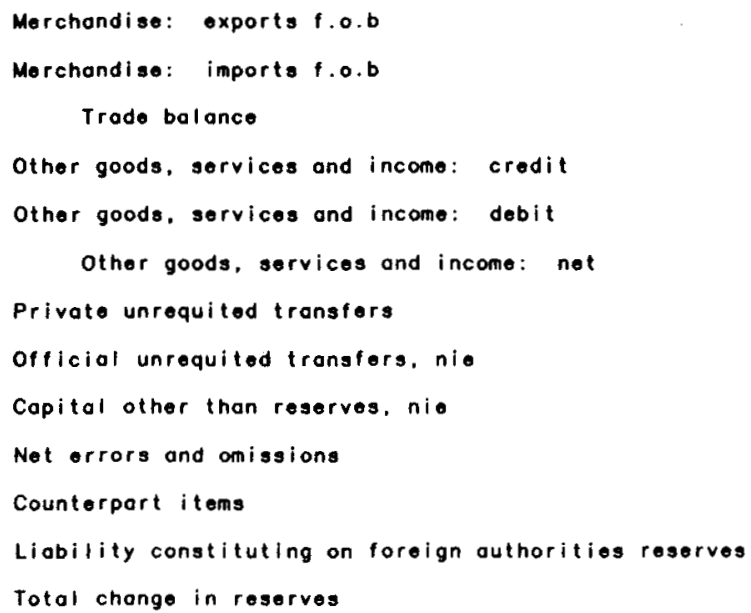

Source: Internotional Monetary Fund.

Note: The minus sign indicates a debit.

Indicotes a lack of statistical dato that can be reported.

bIndicates that a figuro is zero or less than half of o significont digit or that data cannot oxist

that Panama has always exported more services than it has received. In fact, exports of "other goods, services and income" has accounted for 67 percent of total exports in 1970 and 76 percent in 1984. Again, this is attributed to the canal and related activities (including foreign banking).

At the same time, Panama has consistently had an unfavorable trade balance from 1970 through 1984, as its merchandise exports have been less than its merchandise imports. Partially, this can be attributed to the rising international prices, especially for crude oil which has accounted for about one-quarter of Panama's commodity imports. This has been the main cause of deficits in the current account balance during years when "other goods, services and income" credits have not been high enough to offset the unfavorable trade balance. Such was the case during 1970, 1980, 1982, and 1984. After taking into account "capital other than reserves," "net errors and omission," and "counterpart items," the "total change in reserves" was $\$ 69$ million US in 1984. 


\section{External Public Indebtedness}

"Panama has become one of the world's foremost debtors; in 1982, Panama paid a higher fraction of GDP for debt service than any other country in the world. For the near future, managing and controling the public debt will dominate all other aspects of economic policy as well as, perhaps, the future growth of the entire economy." 7 Table 8 gives Panama's external public indebtedness for 1970, 1975, and 1980 through 1984. Panama's total public-debt-toGDP ratio was 28 percent in 1970, 80 percent in 1980, and 87 percent in 1984 . During 1983, Panama's total public debt had reached its highest value of 88 percent of GDP "as compared with 39 percent in the Western Hemisphere countries and 36 percent for the Net $0 i 1$ Importers. "10 "It is a widespread view that Panama's debt crisis is mainly accounted for by two factors: first, the rapid build-up of external debt in the mid to late 1970s, owing to the financing of capital expenditures, largely by the public enterprises; second, the unexpected rise in nominal and real interest rates on the international capital market in the late 1970s and early 1980s." 10

\section{E. US and International Aid}

Table 9 gives US and international aid figures. Between 1962 and 1979, total US economic assistance was $\$ 381$ million US, 40 percent of which were grants. In 1984, US economic aid was $\$ 12$ million US (58.3 percent grants).

Total military assistance between 1962 and 1979 was $\$ 15$ million US, 76 percent of which were grants. During 1980 and 1981 US military assistance was only $\$ 3$ and 4 million US, respectively. Between 1982 and 1984 US military assistance increased from $\$ 5.4$ to $\$ 13.5$ million US. Military assistance as a percent of total assistance (economic and military combined) has increased substantially over the years. Between 1962 and 1979, only 4 percent of total assistance was attributed to military assistance. Between 1980 and 1984, military assistance as a percent of total assistance increased to 53 percent. Such a large increase in military aid in recent years can be attributed to agreements made in the Panama Canal Treaty negotiations, when the US agreed to "provide $\$ 50 \mathrm{million}$ US in credits under the Foreign Military Sales program. The credits were to be spread over the first ten years of the treaty period." 1

Total assistance from international organizations was $\$ 573$ million US between 1962 and 1979. Total assistance was $\$ 82.6 \mathrm{million}$ US for 1984 . International organizations that assisted Panama during these years were the International Bank for Reconstruction and Development (IBRD), the International Finance Corporation (IFC), the Inter-American Development Bank (IDB), the United Nations Development Program (UNDP), and other United Nations Programs. 
TABLE 8

PANAMA: EXTERNAL PUBLIC INDEBTEDNESS

\begin{tabular}{|c|c|c|c|c|c|c|c|}
\hline & \multicolumn{7}{|c|}{$\begin{array}{l}\text { Curront Pricos } \\
(\$ \text { milien US) }\end{array}$} \\
\hline & 1970 & 1975 & 1980 & 1981 & 1982 & 1983 & 1984 \\
\hline Debt outstanding-including undisbursed & 296.4 & 1124.1 & 2848.7 & 3143.5 & 3402.9 & 3853.1 & 3566.6 \\
\hline Debt outstanding-digbursed & 193.9 & 770.7 & 2265.9 & 2379.0 & 2821.9 & 2986.2 & 3090.8 \\
\hline Principol repoyment & 23.6 & 31.2 & 213.8 & 215.9 & 282.3 & 188.1 & 231.0 \\
\hline Intorest payment & 6.9 & 41.2 & 251.5 & 279.4 & 331.6 & 283.3 & 288.0 \\
\hline Total debt service & 30.5 & 72.4 & 465.3 & 493.3 & 613.9 & 471.5 & 519.1 \\
\hline
\end{tabular}

Source: World Bank.

TABLE 9

US ANO INTERNATIONAL AID TO PANAMA

( $\$$ million US)

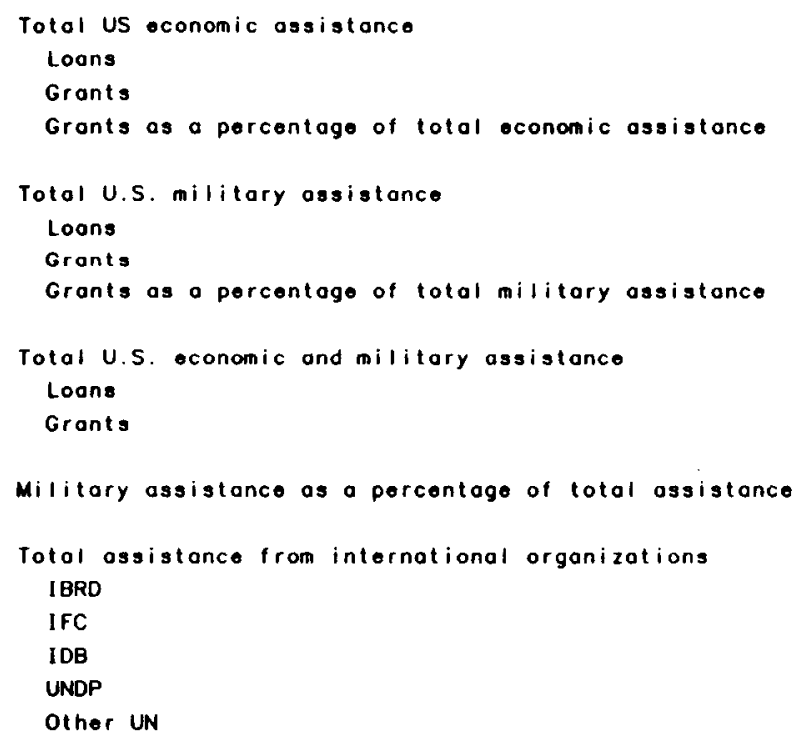

\begin{tabular}{|c|c|c|c|c|c|}
\hline $1962-1979$ & 1980 & 1981 & 1982 & 1983 & 1984 \\
\hline 381.4 & 2.0 & 10.6 & 13.0 & 7.4 & 12.0 \\
\hline 230.4 & - & 6.4 & 8.1 & 3.8 & 5.0 \\
\hline 151.0 & 2.0 & 4.2 & 4.9 & 3.6 & 7.0 \\
\hline $39.6 \%$ & $100.0 \%$ & $39.6 \%$ & 37.77 & $48.6 \%$ & 58.37 \\
\hline 14.7 & 0.3 & 0.4 & 5.4 & 5.5 & 13.5 \\
\hline 3.5 & - & - & 5.0 & 5.0 & 5.0 \\
\hline 11.2 & 0.3 & 0.4 & 0.4 & 0. 5 & 8.5 \\
\hline $76.2 \pi$ & $100.0 \%$ & 100.07 & $7.4 \%$ & 9.17 & 63.07 \\
\hline 396.1 & 2.3 & 11.0 & 18.4 & 12.9 & 25.5 \\
\hline 233.9 & - & 6.4 & 13.1 & 8.8 & 10.0 \\
\hline 162.2 & 2.3 & 4.6 & 5.3 & 4. 1 & 15.5 \\
\hline $3.7 \%$ & $13.0 \%$ & $3.6 \%$ & 29.37 & $42.6 \%$ & $52.9 \%$ \\
\hline 573.4 & 149.9 & 74.5 & 126.9 & 137.7 & 82.6 \\
\hline 243.7 & 58.0 & 45.5 & 24.4 & 85.0 & 74.2 \\
\hline 8. 3 & - & - & - & - & - \\
\hline 296.9 & 91.4 & 28.5 & 99.0 & 52.0 & 8.4 \\
\hline 20.6 & 0.5 & 0.5 & $3: 5$ & 0.6 & - \\
\hline 3.9 & - & - & - & 0.1 & - \\
\hline
\end{tabular}

Source: Agency for Internotional Development. 


\section{F. Labor Force}

Between 1970 and 1974, unemployment fell from 7.1 percent to 5.8 percent. Thereafter, for the remainder of the seventies, unemployment generaliy rose from 5.8 percent in 1974 to 8.8 percent in 1979. Between 1970 and 1980, Panama's population increased almost 33 percent. This rapid growth meant a growing labor force that required jobs. "The service sector was the most important source of new jobs for the expanding labor force. Productive employment in services expanded substantially because of the growing sophistication of wholesale and retail trade, expansion of banking, and increased warehousing, transportation, and communications. Government employment also grew considerably in the 1970s." 1 Figure 8 shows the labor force by sector for 1980 . During that year, agriculture accounted for 34 percent of the labor force, manufacturing for 11 percent, construction for 7 percent, and mining for 1 percent. Other sectors accounted for 49 percent of the labor force in 1980 .

\section{ENERGY OVERVIEW}

\section{A. Energy Resources}

Studies of Panama's conventional energy resources indicate that there are at present no known or commercially exploitable resources of petroleum or fissionable fuels. 11 Therefore Panama is looking toward renewable energy sources in order to decrease oil dependence. Panama's stated energy policy is directed

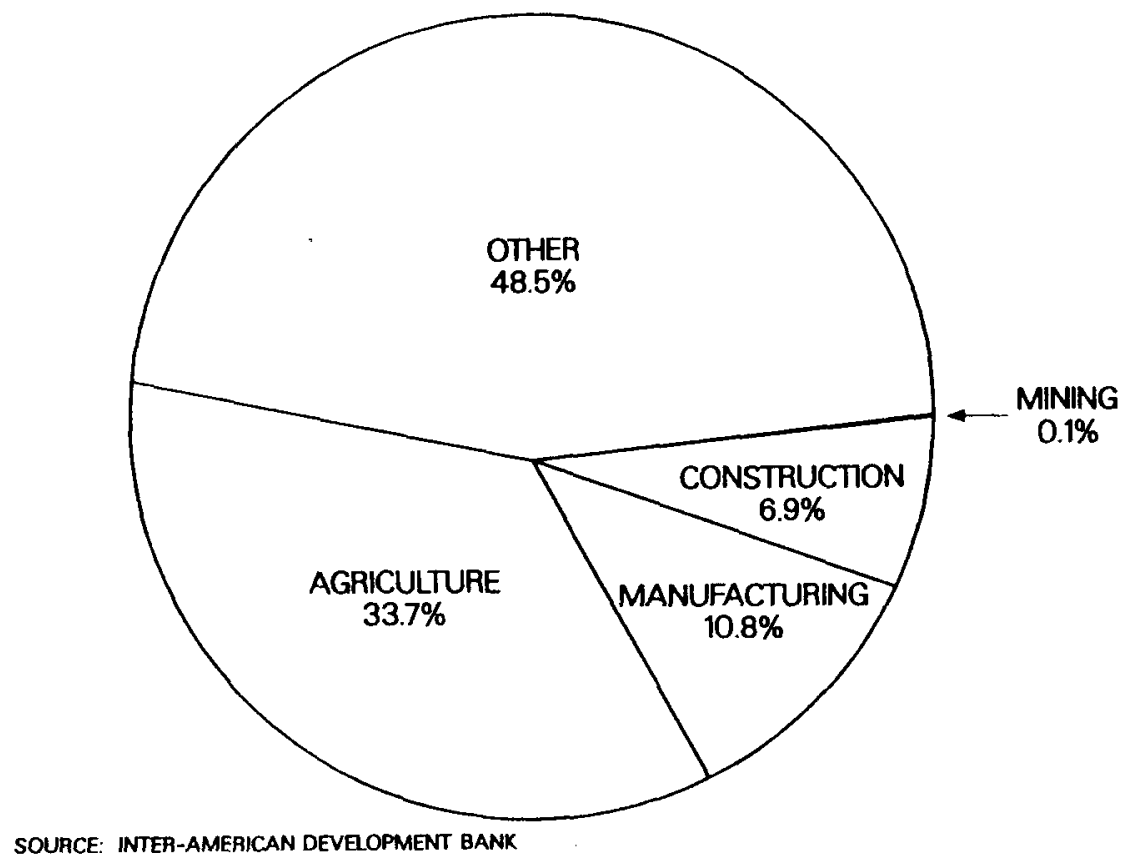

Fig. 8. Panama: Labor force by sector for 1980. 
toward "developing indigenous energy sources to reduce to a minimum petroleum dependence." 12 The Section of Alternate Energy and Conservation ${ }^{*}$ has among its functions the investigation, evaluation and selection of energy alternatives and technological innovations; and, in addition, carries out studies and energy activities that would take advantage of the renewable energy sources at a national level. In 1980, a preliminary study was begun on the development of renewable energy sources. 11 This study was carried out jointly by IRHE, CONADE, the Institute for Energy Conversion of the University of Delaware, and the Center for Environmental and Energy Studies of the University of Puerto Rico. USAID provided the bulk of the funding for the project. The project covered two activities: (1) surveying information and defining strategies for the development of the renewable sources of energy at a national level, and (2) constructing a demonstration project for renewable sources. The survey covered the energy areas of microhydroelectrics, minihydroelectrics, geothermal, biomass, biogas, solar, wind, and ocean. Key findings of the study are summarized in those sections below, as well as resources of $0 i 1$ and gas and coal and peat.

1. $0 i l$ and Gas. Some petroleum exploration has taken place in Panama. As of 1975, 28 exploratory wells had been drilled in onshore and offshore Panama, with a depth total of $39,829 \mathrm{~m}$ (Fig. 9). Depths of the individual wells ranged from 250 to $3230 \mathrm{~m}$. Since 1975, private leaseholding in Panama has gradually increased and culminated in the drilling of two exploratory wells in 1978, adding up to a total of four holes being drilled in the period 1975 through 1978 . Private activity has since declined. The Panamanian government, through the Bureau of Mines, has also been active in petroleum exploration. The government received a loan of $\$ 6$ million in 1981 from the World Bank to reevaluate the hydrocarbon potential of the country. The government's work is currently under way. Panama has no oil reserves. Exploration activity from 1975 through 1981 is summarized below.

The major areas of interest have been the offshore Caribbean and parts of the Darien and Panama departments in southeastern Panama. The main private companies involved have been Texaco, Amerada, and Sossa, a domestic company. On the offshore Caribbean, Panama Exploration, a subsidiary of Texaco, conducted brief seismic surveys in 1975, 1976, and 1978. In 1978, Panama Exploration and

*

The Section of Alternate Energy and Conservation is a part of the Technical Secretary of Comision National de Energia (CONADE) with jurisdiction in the Department of Energy and Tariffs of the The Instituto de Recursos Hidraulicos $y$ Electrification (IHRE). 


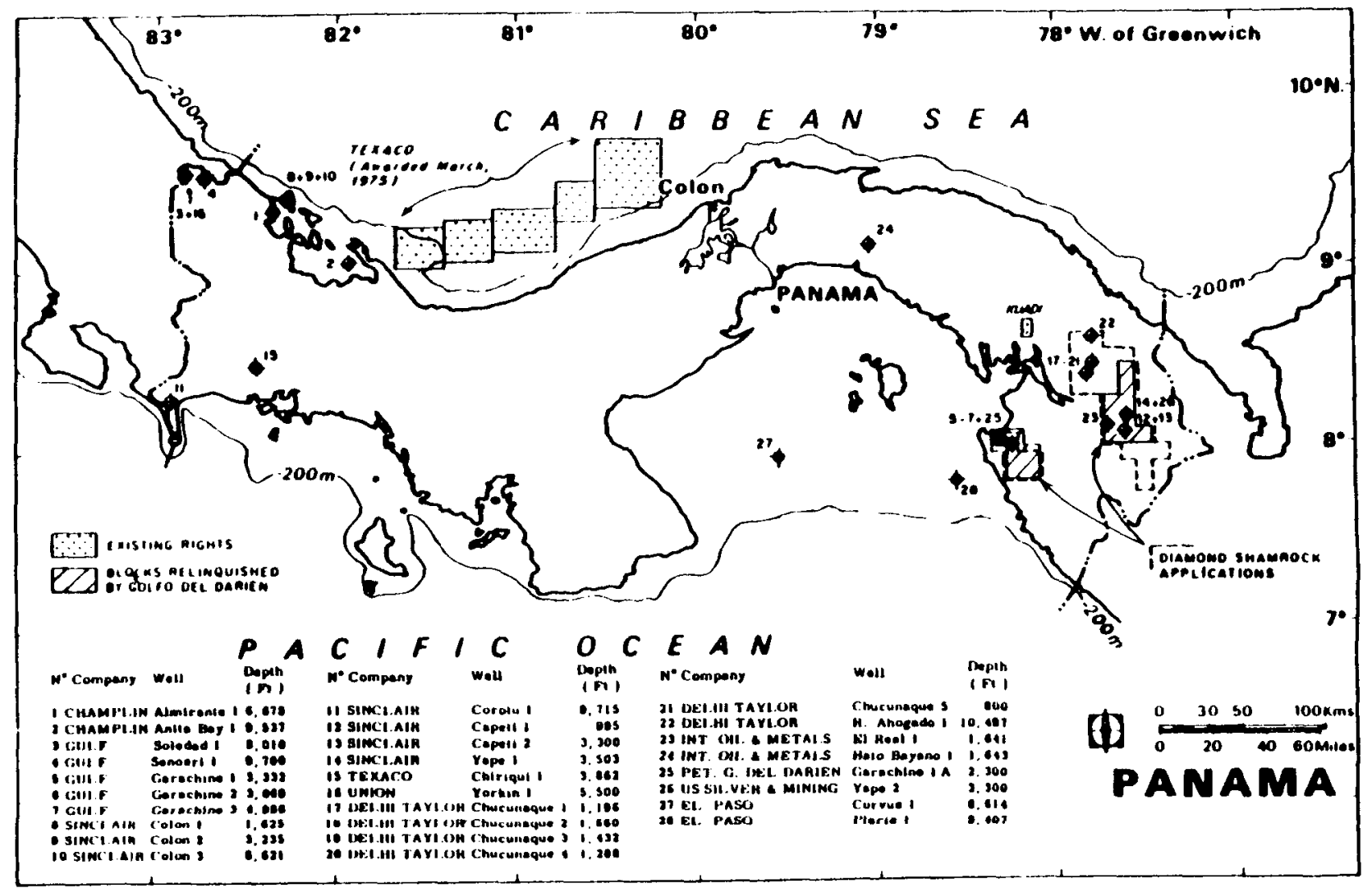

SOURCE: INTERNATIONAL MONETARY FUND

Fig. 9. Panama: Locations of 28 exploratory oil wells drilled and Tand rights for future activity.

Amerada Hess joint-ventured in a wildcat well $55 \mathrm{~km}$ northwest of Colon City, encountering gas indications at $2,038 \mathrm{~m}$. This well was abandoned. Amerada and Texaco discontinued exploration in Panama after that year.

The other major private activity has been carried out by Sossa with some financing from Tacoma Mining, a subsidiary of Tacoma Resources of Vancouver. In 1978, Sossa/Tacoma drilled a 1,001-m-deep wildcat well, Canazas 1, onshore at 9 degrees $02^{\prime} \mathrm{N}, 78$ degrees $21^{\prime} \mathrm{W}$. The dry well was abandoned in 1979. Sossa drilled a second well on the same formation in 1981, Canazas 2, which was also dry. As of 1981, Sossa had plans to drill up to eight wells in the Darien area between 1982 and 1984. As of 1981, Sosa was the only company with holdings in Panama.

Before the government commenced the reevaluation of petroleum resources funded by the World Bank in 1981, it had drilled a stratigraphic test well near Tonosi in the Azuero Peninsula in 1977, encountering shows of heavy $0 i 1$. 
2. Coal and Peat. IRHE ${ }^{*}$ is very interested in studying the possibility of coal deposits in Panama, and they have conducted preliminary investigations of a few sites. A geologic formation with coal occurrences extends from costa Rica into Panama, and the Panamanian deposit looks even more promising than that of Costa Rica.

IRHE feels that the Darien region has sizable peat resources. Electricity costs $\$ 0.25 \mathrm{kWh}$ in that region. Diesel fuel and firewood are primarily used, and peat could be a good substitute for these two fuels. Preliminary investigations in Panama by LANL scientists indicated that significant peat deposits (occupying $40 \mathrm{sq} . \mathrm{km}$ and $3 \mathrm{in}$. thick) and other exploitable deposits are probable in the Bocos del Toro region.

3. Hydroelectric. Hydroelectric generation began in Panama in the mid1970s. IRHE has estimated potential hydroelectric sites at $2500 \mathrm{MW}$. At present existing hydroelectric projects total $557 \mathrm{MW}$ (nameplate capacity). These include Yeguada and Chiriqui (in 1968, $11 \mathrm{MW}$ ), La Estrella (in 1978, 43 MW), Los Valles (in 1979, $47 \mathrm{MW}$ ), Bayano (in 1976, $156 \mathrm{MW}$ ) and Fortuna (in 1984, $300 \mathrm{MW}$ ). From a total of $840 \mathrm{MW}$ of installed electric capacity in 1984, hydroelectric capacity accounted for about 66 percent. The average annual energy generated by these existing plants is 1984 was $2210 \mathrm{GWh}$, and about 68 percent of this annual generation was hydro-generated. A new hydroelectric project--the Rio Esti (located at Norte de Gualaca, Chiriqui Provance)--is now under consideration.

Two alternatives for the project include either an 88-MW, installed capacity, station (with annual generation of $525 \mathrm{GWh}$ ) or a 114-MW capacity station (with annual generation of $642 \mathrm{GWh})$. With the establishment of a policy to satisfy the demand for electricity with hydroelectric energy, a 1 arge portion of investment has been designated to the importation of equipment and material for generation, transmission, and distribution. Hydroelectric sources are typically located some distance from consumption centers, and Panama lacks the heavy local industry to satisfy the demand for equipment and material needed for generation, transmission, and distribution of electrical energy. 12

a. Medium-Capacity Hydroelectric. Table 10 shows 15 medium capacity (10 to $100 \mathrm{MW}$ ) hydroelectric projects that are at present being considered for

* Information provided by IRHE to LANL, July 1985.

** Information provided by IRHE, "Projecto Hidroelectric Rio Esti," July 1985. 
TABLE 10

PANAMA: HYDROELECTRIC PROJECTS OF MEDIUM CAPACITY

Sites Ideatified
1. Chico y Trancado
2. Piedras
3. Gotu Arriba
4. La Soledod
5. Calovebora I
6. Calovebora II
7. Son Pablo I
8. San Pablo II
9. Liano Nopo
10. Rio Rey
11. Son Lorenzo
12. Baru
13. Caizan
14. Canazas
15. Cobre

15. Cobre
Estimated Installed

Capocity

Rixer
Chagres
Rio Piedros
Gatu
Sta. Mario
Calovebora
Colovebora
Son Pabio
San Pablo
Tabasora
Rio Rey
Fonseca
Chiriqui
Viejo
Chiriqui
Viejo
Canazos
Cobre
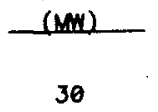

10

35

40

45

30

20

25

25
35

15

20

90

60

30

10
Proxince

Panamo

Colon

Veroguas

Veraguas

Veroguas

Veroguas

Veraguas

Veraguas

Chiriqui

Chiriqui

Chiriqui

Chiriqui

Chiriqui

Veraguas

Veraguas

Source: Institute of Hydro Resources and Electrification. Panama.

development. ${ }^{*}$ of the 15 projects, consultants will choose the ten best, do a reconnaissance to choose the best three for prefeasibility, and finally choose the best two for a feasibility study. The whole process should take about 26 months.

b. Microhydroelectric. The microhydroelectrics represent an alternative for electrification of remote areas in Panama. Two hundred possible sites have been identified, and 40 of those have the requirements for the implementation of a microhydroelectric project (Table 11). At a national level, it is estimated IRHE could obtain at least 10.5 MW of electric power with this type of installation. IRHE has constructed, with AID support, two microhydroelectic units with

$\star$

Information provided by IHRE, "Projectos Hidroelectricos de Mediana Capacidad," July 1985.

$* *$

Information provided by Ramon Argote, CONADE, July 1985. 
TABLE 11

PANAMA: PRINCIPAL PROJECTS OF MICROHYOROELECTRIC UNIT

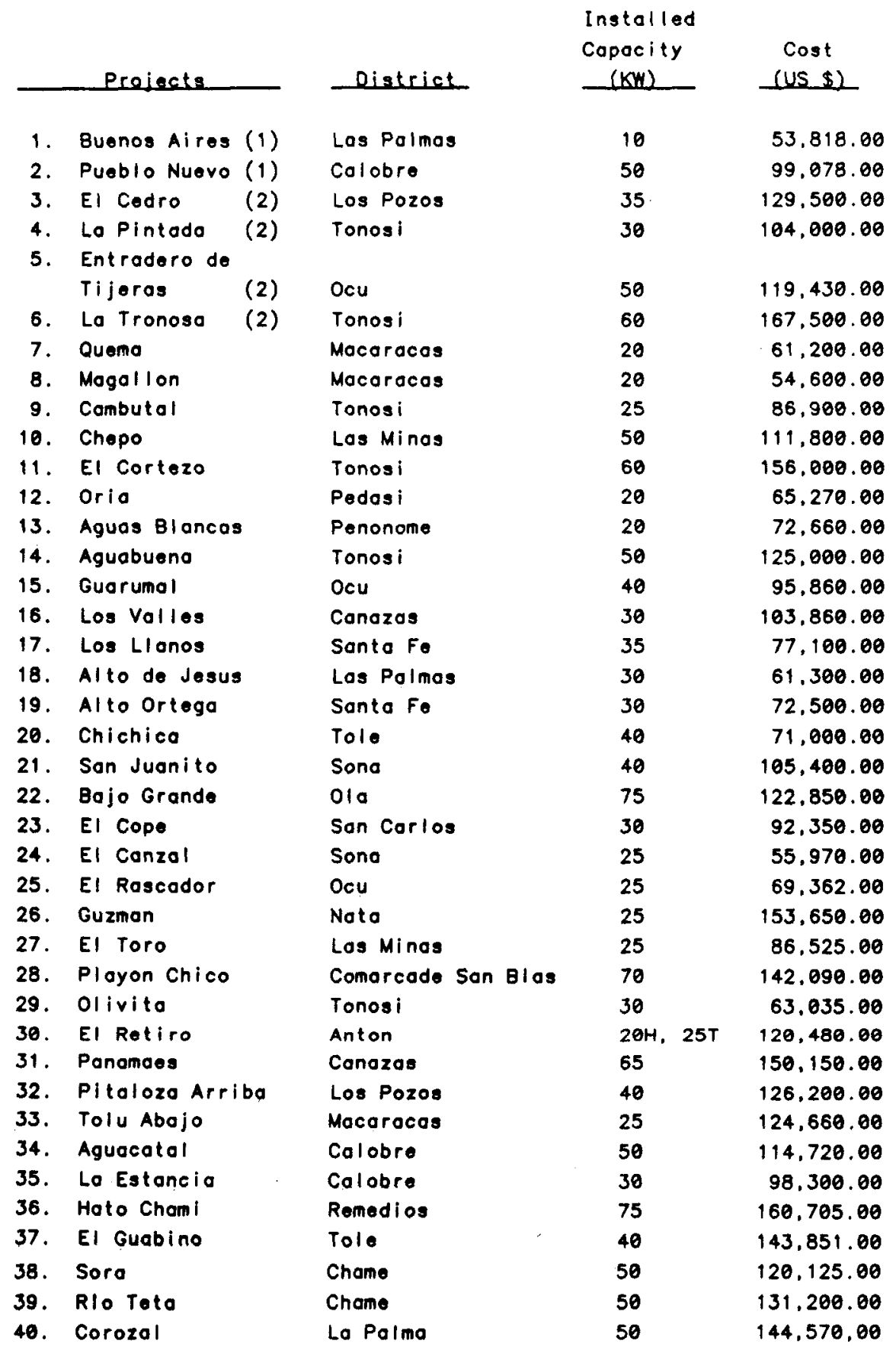

(1) Constructed

(2) Under construction

$H=$ hydroelectric

$T=$ thermoelectric

Source: Institute of Hydro Resources and Electrification, Ponama. 
an installed capacity of 10 and $50 \mathrm{~kW}$, respectively; and four microhydroelectric units with capacities of $30,35,50$, and $60 \mathrm{~kW}$ were under construction at the end of 1983 .

c. Minihydroelectric. With respect to minihydroelectrics, it is estimated that the potential capacity can reach $25 \mathrm{MW}$. At the end of 1983, IRHE was carrying out a pilot program. It has already constructed 2 minihydroelectric units of 350 and $250 \mathrm{~kW}$, respectively; and three minihydroelectric projects with capacities of 500,300 , and $200 \mathrm{~kW}$ are being studied.

4. Geothermal. Studies to determine the geothermal potential in Panama are in their first stages. Preliminary investigations have been carried out in the area of Cerro Pando and Cerro Colorado in the province of Chiriqui and the valley in Cocle. The IDB-sponsored Geothermal Advisory Panel for Panama feels that El Valle de Anton has the most promise for exploitable geothermal energy. ${ }^{11}$

In 1981, when IRHE was assigned the responsibility for the Geothermal Exploration Project, it requested the cooperation of OLADE to establish an exploration program, with the purpose of evaluating the available information, carrying out some investigations to reorient the project, and establishing an exploration program according to the local geological conditions. The analysis and evaluation of the preliminary investigations together with the new geovulcanological investigations carried out by OLADE and the Geothermic Italian Consulting Organization established the presence of large volcanic activity in the western part of the chiriqui Province. The results, obtained from the reevaluation of these geothermal possibilities in the Baru-Colorado Region, made IRHE consider that geothermal energy could play an important role in the energy development of the country. CONADE considers it necessary to (1) establish a systematic recognition program of the main geothermal zones in order to structure study programs of the most important areas, and (2) prepare a prefeasibility study of the geothermal complex Baru-Colorado. The preliminary evaluation carried out with OLADE's help has resulted in an estimated geothermal energy potential of approximately $400 \mathrm{MW}$.

\section{Fuel Wood and 0ther Biomass}

a. Fuel Wood. Figures 10 and 11 show the forests of Panama as they existed in 1983 and estimates of the forests by 2000 based on the actual rate of deforestation. It has been estimated that 83 percent of Panama was covered by forests in 1850, decreasing to 60 percent in 1987, 52 percent in 1974, and 37 percent in 1984. The explosive population growth that Panama has experienced

Information provided by Guillermo Selva, INCAE, November 1985. 


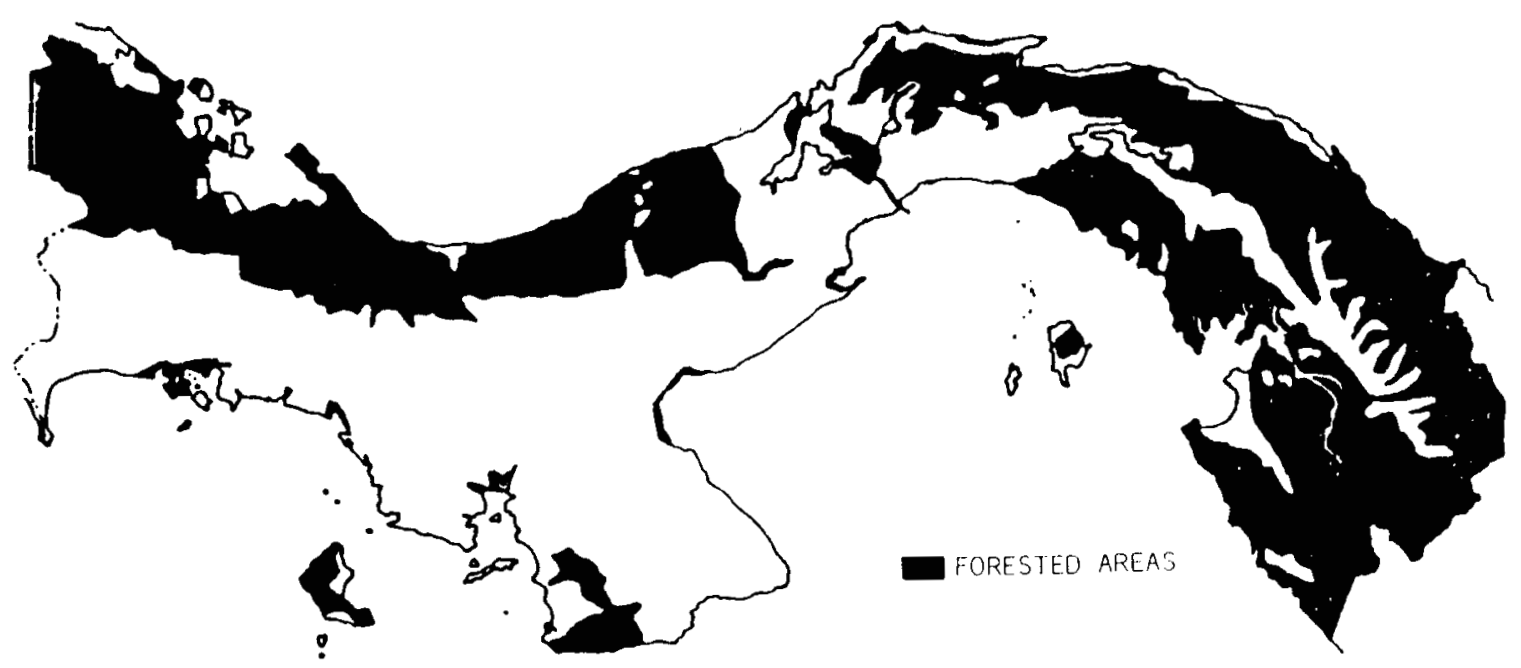

SOURCE: COMMITTEE ON SCIENCE AND TECHNOLOGY, U.S. CONGRESS.

Fig. 10. Panama: Forests in the year 1983.

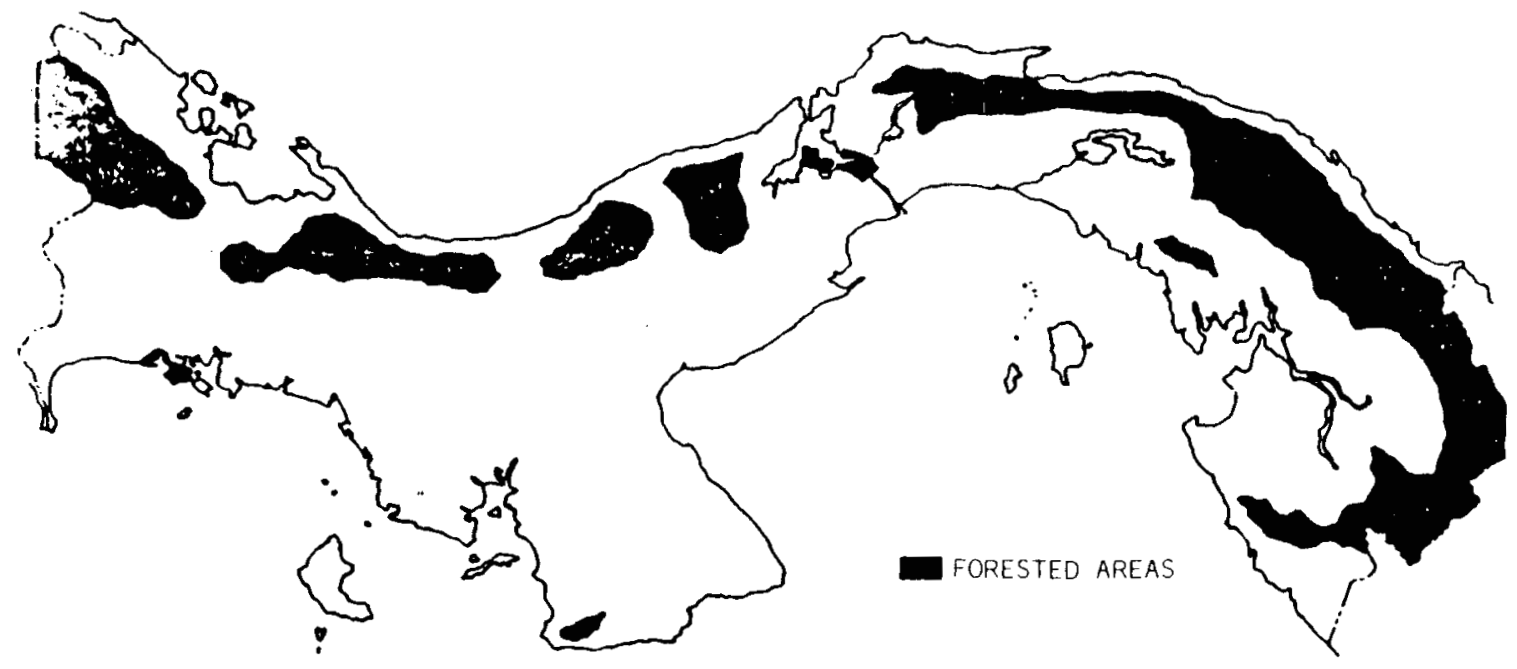

SOURCE: COMMITTEE ON SCIENCE AND TECHNOLOGY, U.S. CONGRESS.

Fig. 11. Panama: Forests in the year 2000 (estimate based on actual rate of deforestation). 
since the mid-nineteenth century has contributed, in part, to this rapid deforestation. Between 50,000 and 70,000 hectares of forest are felled annual1y, and this figure is much higher during extended dry seasons as was the case in 1982-1983 when an estimated 100,000 hectares were destroyed. George E. I11ueca states that "Of particular concern to Panama is the deforestation that has taken place in the watershed of the Panama Canal. The operation of the Canal depends on the existence of forests which provide a stable water regime. Approximately. 60 percent of the 326,000 hectares of this vital watershed are deforested. " 6

b. Biomass. Panama has a standing biomass equivalent of approximately 4.7 million Tcals, with an annual growth rate of 4,827 Tcals (Table 12).

c. Biogas. The resources that can be used for the generation of biogas are estimated between 900 and 1,800 Tcal (Table 13). The greatest potential resources for biogas production are animal residues and agroindustrial wastes.

TABLE 12

PANAMA: SUMMARY OF USABLE BIOMASS POTENTIAL

\begin{tabular}{|c|c|}
\hline Seurce & Icals \\
\hline Stonding biomoss & $4,703,517$ \\
\hline Forest wastes & 370 \\
\hline \multicolumn{2}{|l|}{ Centralized wastes } \\
\hline (garbage, agri-industry waste, etc.) & 7,540 \\
\hline Totals & 4.711 .427 \\
\hline
\end{tabular}

TABLE 13

PANAMA: ANNUAL BIOGAS PRODUCTION FROM READILY COLLECTIBLE WASTES

\begin{tabular}{|c|c|c|c|c|c|c|}
\hline Resource & $10^{6} m^{3}$ & & Biogas/ & Ical & & Equivalent \\
\hline Animal residues & 34.1 & - & 132.3 & 180.5 & - & 698.5 \\
\hline Plant residues & 11.3 & & & 59.8 & & \\
\hline Agro-industrial wastes & 103.1 & - & 181.4 & 545.6 & - & 960.0 \\
\hline Government & 20.5 & - & 34.5 & 108.5 & - & 182.6 \\
\hline Totals & 169.0 & - & 348.2 & 894.4 & - & 1841.1 \\
\hline
\end{tabular}

Source: Institute of Energy Conversion. Univ. of Delaware. 
According to the University of Delaware study, biogas appears to be one of the most promising near-term renewable energy resources for Panama. ${ }^{11}$

6. Other

a. Solar Energy. The resources for solar energy vary from region to region and include seasonal variations. Panama has an annual average of $2,100 \mathrm{~h}$ of insolation with levels of radiation between $193 \mathrm{~W} / \mathrm{m}^{2}$ and $500 \mathrm{~W} / \mathrm{m}^{2}$. It was found that almost everywhere in the country the minimum level of radiation is approximately $193 \mathrm{~W} / \mathrm{m}^{2}$. The portion of the report focusing on the application of thermal technology consisted of detailed reports on 16 site visits. The principal activity undertaken in these site visits was examination of the sites for prospective application of solar-thermal technology and energy conservation. As one indication of the potential contribution that solar-thermal technology could make to Panama, it was concluded that if 30 percent of the petroleum derivative consumption at these 16 sites were to be replaced by solar energy, annual savings of over 1.6 million gallons of diesel fuel, over 102,000 gallons of bunker 011 , and over 12,000 gallons of LPG could be realized. 11

Solar energy in Panama has the greatest potential in the areas of water heating and grain drying, because, as a result of the high cloudiness incidence, direct radiation is limited to the dry season, just four months a year. The use of water heating has a limited market in the residential sector, but there are possibilities to use photovoltaic panels for communication applications in relation to a remote communication system powered with a 360-watt photovoltaic unit. The extension of the use of photovoltaic cells will depend not only on how fast the production cost on photovoltaic electricity decreases but also on improvements of efficiency of the equipment.

b. Wind Energy. In terms of wind energy, analysis of existing surface and upper-air wind data indicated that several regions in Panama might successfully produce usable wind-generated electricity. Particularly, the area on the Caribbean coast between Colon and Portobello appears promising during the dry season. A second area along the eastern end of the Central Cordillera mountain range also appears promising.

However, the analyzed information has to be complemented with a windmeasuring program at a regional level because few data are in existence. In spite of the lack of information, IRHE considers wind energy as a promising resource for isolated villages in the high lands of Panama. As a first step,

Information provided by Guillermo Selva, INCAE, November 1985. 
IRHE has initiated the installation of four small wind-energy conversion systems at isolated sites where there is no electric service.

c. Ocean Energy. The ocean energy assessment, which focused primarily on the potential for current and tide motion as a source of energy, concluded that very little possibility for such energy exists in Panama. Tide changes and current velocities on the Atlantic side are too small to permit significant energy yields. Whereas significant tide changes exist on the Pacific side, suitable sites would either interfere with fisheries and spawning grounds and navigational routes to the Panama Canal, or would be prohibitively costly. Panama is in the appropriate ocean zones for use of the ocean thermal energy conversion (OTEC) technology if this should be proven feasible and cost-effective in the future. 11

\section{B. Energy Supply}

The two Canal treaties are briefly described in the following passage. "The first concerns the administration, maintenance and defense of the canal and the transfer of ownership to Panama by the year 2000. Panama has taken on the responsibility for the public and medical services, utilities, and retail commissaries in the zone as well as police duties. It is also gradually taking control of some 70 percent of the lands and waters of the Canal Zone. The second treaty concerns the neutrality of the waterway after 2000."12

All energy-related statistics exclude the Canal Zone between 1970 and 1980 . Energy balances for the Canal Zone for these years appear in Appendix A. In 1981, IRHE officially began to include electric energy consumption from two provinces of the Canal Zone--Ancon and Cristobal (which account for about 2 percent of Panama's estimated population). These two provinces accounted for 6 percent of Canal Zone electric consumption and 1.9 percent of Panama's electric consumption in 1980. By 1984, these two provinces accounted for 2.4 percent of Panama's electricity consumption.

Gross energy supply is the primary energy supplied to the country. For Panama, this includes crude petroleum, fuel wood, vegetable residue, and hydraulic energy. In 1984, crude petroleum supplied about 75 percent of gross energy supply, whereas fuel wood supplied about 14 percent, vegetable residue, 6 percent, and hydraulic energy, 5 percent. In 1970, crude petroleum supplied about 92 percent, fuel wood, 7 percent, vegetable residue, 0.9 , and hydraulic energy, 0.2 percent. Thus, since 1970, gross energy supply has generally shifted away from petroleum toward fuel wood, vegetable residue, and hydraulic

$\star$

Information provided by Guillermo Selva, INCAE, November 1985. 
energy. ${ }^{13,14}$ However, the apparent decline of petroleum's share of primary energy supply is misleading because in 1970 more of the crude 011 was imported to refine for re-export. By 1984, the amount of crude 0 il imported for this purpose had decreased significantly.

Net supply is energy consumed in its final form. Thus, net supply is "net" of (1) petroleum losses during the refining process, (2) petroleum consumed to generate electricity, (3) exportation of petroleum derivatives, and (4) losses associated with transformation of fuel wood into charcoal. Net supply for final Panamanian consumption includes (1) refined petroleum products such as refinery gas, 1 iquid gas, distributed gas (produced from fuel oil and gasoline), gasoline, kerosene and jet fuel, diesel oil, fuel oil, and nonenergy products; (2) biomass products such as fuel wood, vegetable residue, and charcoal (produced from fuel wood); and (3) electricity (produced from fuel oil, diesel oil, and hydraulic energy). Figure 12 shows gross and net energy supply for Panama for 1984. In 1984, petroleum products supplied about 54 percent of net energy supply--including refinery gas (4 percent), liquid gas ( 4 percent), gasoline (17 percent), kerosene and jet fuel (1 percent), diesel oil (18 percent), fuel oil ( 9 percent), and nonenergy items (1 percent) (Fig. 13). Electricity supplied 14 percent and biomass supplied 32 percent--including fue wood (25 percent), vegetable residue ( 7 percent) and charcoal ( 0.03 percent). During 1970, petroleum products supplied about 55 percent, biomass, 37 percent, and electricity, 8 percent of net energy supply. Thus, since 1970, there has been an increase in electricity generation, a decrease in the share of energy supplied by biomass, and petroleum use has only slightly decreased. ${ }^{13,14}$

1. Petroleum Supply. In 1984, petroleum products consisted of a little over one-half of the energy supplied in Panama. Panama has no domestic oil production and must import all of its crude for refining as well as some refined products (Table 14). Owing to the increasing crude prices since 1973-74, a decline in the Caribbean market for refined petroleum exports, and Panama's economic condition in recent years (heavy indebtedness), crude oil imports have generally decreased in recent years from a high of 31 million barrels in 1975 to 11 million barrels in 1984--a decrease of about 65 percent. Crude $0 i 1$ is imported from Ecuador, Mexico, and Venezuela under the conditions outlined in the San Jose Accord. ${ }^{15}$ Refined petroleum imports have also generally decreased from a high of 3 million barrels in 1976 to about 1 million barrels in 1984--a decrease of 67 percent.

Most of the petroleum products consumed in Panama or exported are refined domestically (Table 15). During 1978 and 1979, 99 percent of petroleum derivatives were refined domestically; whereas during the 1980 to 1984 time 


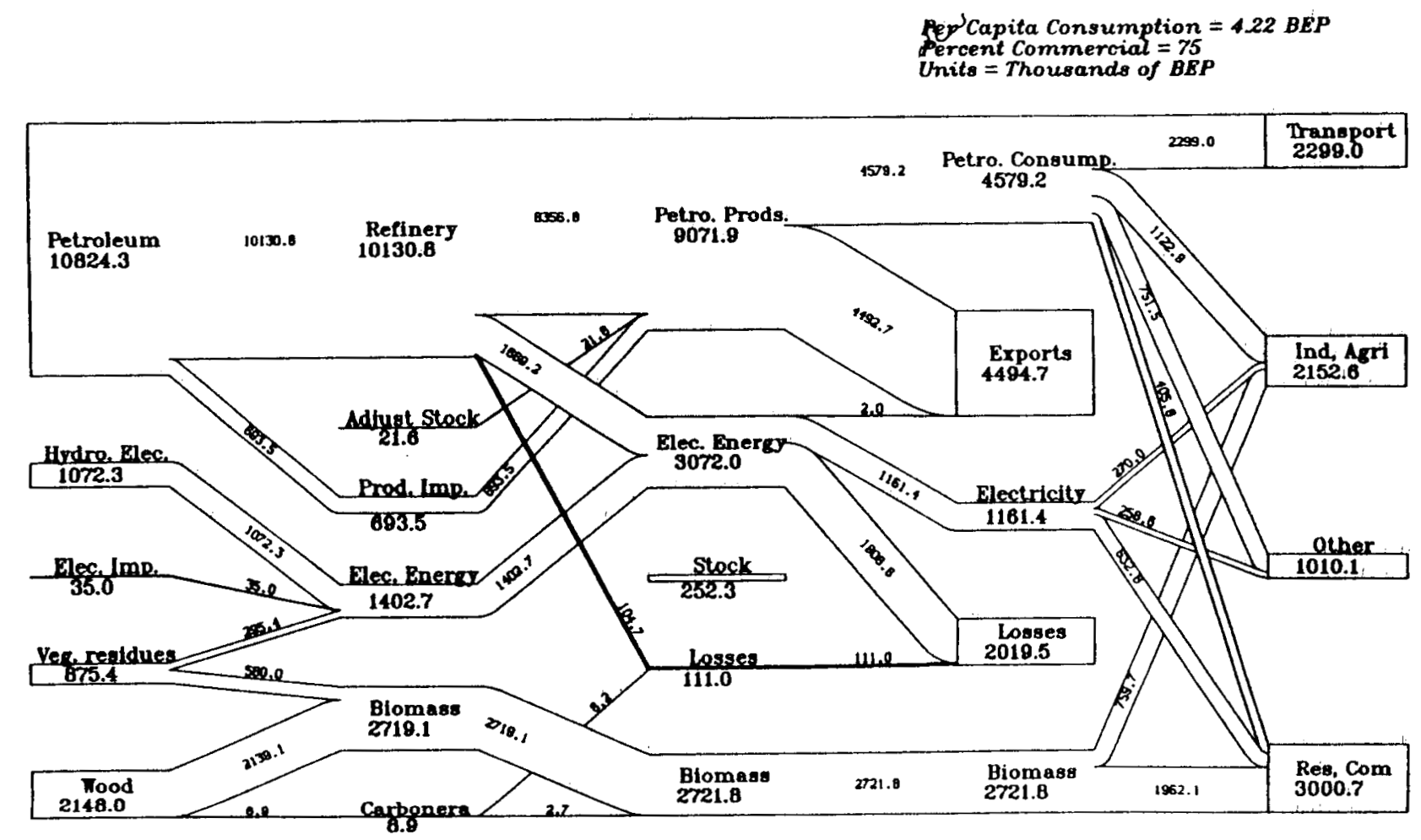

SOURCE: NATIONAL COMNISSION OF ENERGY (CONADE).

Fig. 12. Panama: Energy flow diagram for 1984.
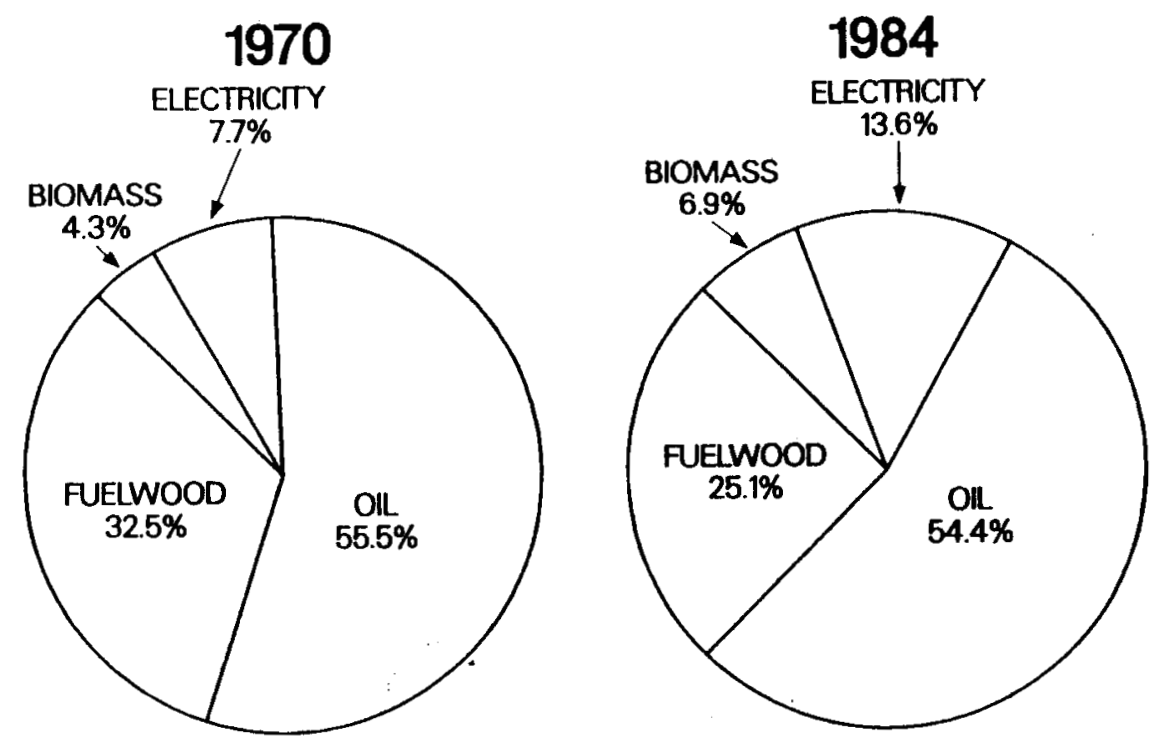

SOURCE: NAIIONAL COMMISSION OF ENERGY (CONADE),

Fig. 13. Panama: Energy supply by fuel type. 
PANAMA: PETROLEUM IMPORTS

(thousands of barrets)

\begin{tabular}{|c|c|c|c|c|c|c|c|c|c|}
\hline & 1970 & 1977 & 1978 & 1979 & 1980 & 1981 & 1982 & 1983 & 1984 \\
\hline Crude oil & 26.920 .0 & $21,167.8$ & $17,259.6$ & 16.066 .9 & $14,298.8$ & $11,035.9$ & $12,135.0$ & $12,150.1$ & 10.872 .7 \\
\hline Liquid gas & 12.1 & 93.7 & 161.8 & 221.4 & 239.1 & 367.9 & 390.0 & 326.8 & 434.0 \\
\hline Gasoline & 4.0 & 67.3 & 0.0 & 0.0 & 154.2 & 470.6 & 76.1 & 100.7 & 198.7 \\
\hline Kerosene and jet fuel & 3.6 & 29.0 & 19.9 & 0.0 & 0.0 & 118.5 & 54.7 & 29.5 & 0.0 \\
\hline Diesel oil & 0.0 & 92.5 & 0.0 & 0.0 & 0.0 & 522.4 & 86.1 & 566.4 & 295.6 \\
\hline Fuel oil & 706.2 & 18.8 & 0.0 & 0.0 & 99.7 & 12.0 & 0.0 & 0.0 & 0.0 \\
\hline Nonenergy & 105.1 & 0.0 & 0.0 & 0.0 & 46.7 & 0.0 & 0.0 & 0.0 & 0.0 \\
\hline Total. & 27.751 .0 & $21,469.1$ & $17,441.3$ & 16.288 .3 & $14,838.5$ & $12,527.3$ & $012,741.9$ & $13,173.5$ & $11,801.0$ \\
\hline
\end{tabular}

Source: National Commission of Energy (CONADE).

Note: Data originally in Teracalories.

TABLE 15

PANAMA: PRODUCTION, IMPORTATION AND EXPORTATION OF PETROLEUM DERIVATIVES (percentages)

\section{Percentage of}

Demestic Consumption

$\begin{array}{lrrrrrrrr}\text { Domestically refined } & 97 & 99 & 99 & 97 & 89 & 96 & 93 & 93 \\ \text { Imported } & 3 & 1 & 1 & 3 & 11 & 4 & 7 & 7\end{array}$

Percentage of

5

(2)


period, this percentage decreased somewhat. Table 16 gives refinery production in thousands of barrels for 1970 and 1977 to 1984. In 1984, fuel oil comprised 48 percent, diesel oil, 25 percent, gasoline, 14 percent, kerosene and jet fuel, 7 percent and other products (refinery gas, liquid gas, and nonenergy items), 6 percent of total petroleum products produced. This product mix is similar to that of 1970 when fuel oil comprised 49 percent, diesel 011,21 percent, gasoline, 13 percent, kerosene and jet fuel, 11 percent, and other products, 6 percent of total petroleum products produced.

As observed in Table 17, Panama imports very 1 ittle refined oil products, although slightly more oil products have been imported since 1981. 0il products imported during 1970 were mainly liquid gas, "fuel $0 i 1$, and nonenergy items. Between 1981 and 1984, oil product imports included liquid gas, gasoline, kerosene and jet fuel, and diesel oil.

Panama is a big exporter of refined petroleum products. In 1970, 85 percent of the petroleum products produced in the refinery were exported (Table 15). On average, between 1978 and 1981, this figure decreased to about 57 percent and has generally been decreasing in recent years to about 45 percent in 1984. Petroleum products are typically exported to neighboring countries or sold as bunker and aviation fuel to ships and aircraft. The downward trend of petroleum product exports in recent years reflects a decrease in traffic through the Canal, depressed world demand for petroleum, and the relatively high price of Panamanian refined oil products. Table 18 gives petroleum product exports in thousands of barrels for 1970 and 1977 to 1984. Fuel oil (bunker for ships) has consistentiy been the 1 argest petroleum export product over the years. ${ }^{15}$ Panama has recently signed a contract to sell bunker fuel to Ecuador at a price equal to marginal cost. ${ }^{*}$ Other export items include diesel oil, kerosene and jet fuel, gasoline, and nonenergy products.

Table 19 gives the net supply of oil products in thousands of barrels for 1970 and 1977 to 1984 . These figures represent the supply of oil products after taking into account the refinery production, imports, exports, variations in stock and adjustments. Generally, the net supply of oil products for Panama has decreased about 10 percent between 1977 (7672 thousand barrels) and 1984 (6924 thousand barrels). The supply of fuel oil has decreased 30 percent as greater use of hydroelectric energy lessened the need for this product. Gasoline supply has decreased 13 percent as diesel was substituted in the transportation sector

\footnotetext{
* Information provided by Ramon Argote of CONADE, July 1985.
} 
TABLE 16

PANAMA: REFINERY PRODUCTION

(thousands of barrels)

\begin{tabular}{|c|c|c|c|c|c|c|c|c|c|}
\hline & 1970 & 1977 & 1978 & 1979 & 1980 & 1981 & 1982 & 1983 & 1984 \\
\hline Refinery gas & 551.1 & 388.2 & 332.1 & 346.9 & 321.2 & 213.2 & 213.5 & 285.8 & 264.3 \\
\hline Liquid gos & 231.5 & 355.4 & 312.0 & 272.1 & 255.9 & 143.9 & 148.2 & 180.0 & 167.5 \\
\hline Distributed gos & 409.4 & 26.5 & 29.5 & 24.8 & 14.1 & 0.0 & 0.0 & 0.0 & 0.0 \\
\hline Gasoline & $3,442.3$ & $2,915.1$ & $2,592.4$ & 2.370 .9 & $2,011.5$ & $1,429.2$ & $1,692.8$ & 1.721 .6 & $1,537.2$ \\
\hline Kerosene and jet fuel & 2.763 .6 & $1,827.5$ & $1,228.5$ & 1.342 .9 & 1.049 .5 & 695.9 & 794.2 & 631.2 & 704.1 \\
\hline Diesel oil & $5,640.3$ & $4,389.3$ & 4.569 .1 & 4.173 .5 & $3,339.6$ & $2,563.4$ & $2,724.9$ & 3.021 .2 & $2,684.6$ \\
\hline Fuel oil & $12,911.8$ & 10.530 .9 & 7.888 .6 & 7.178 .8 & $6,669.9$ & 5.354 .6 & 6.255 .5 & 5.889 .7 & 5.167 .5 \\
\hline Nonenergy & 350.4 & 45.4 & 90.6 & 46.1 & 5.7 & 55.7 & 92.7 & 60.9 & 142.5 \\
\hline Total & $26,300.4$ & 20.478 .3 & $17,042.8$ & $15,756.0$ & 13.667 .4 & 10.455 .1 & 11.921 .8 & 11.790 .1 & $10,667.7$ \\
\hline
\end{tabular}

Source: National Commission of Energy (CONADE).

Note: Data originaily in telecalories.

TABLE 17

PANAMA: OIL PRODUCTS IMPORTED AS A PERCENTAGE OF OIL PRODUCTS SUPPLIED

\begin{tabular}{|c|c|c|c|c|c|c|c|c|}
\hline 1970 & 977 & 1978 & 1979 & 1980 & 1981 & 1982 & 1983 & 1984 \\
\hline 5 & 21 & 34 & 45 & 48 & 72 & 72 & 64 & 72 \\
\hline 0.1 & 2 & 0 & $\theta$ & 7 & 25 & 4 & 23 & 11 \\
\hline 0.1 & 2 & 2 & $\theta$ & 0 & 15 & 6 & 4 & 0 \\
\hline 0 & 2 & 0 & 0 & 0 & 17 & 3 & 16 & 10 \\
\hline 5 & 0.2 & $\theta$ & 0 & 2 & 0.2 & 0 & 0 & 0 \\
\hline 23 & 0 & 0 & 0 & 89 & 0 & 0 & 0 & 0 \\
\hline 3 & 2 & 1 & 1 & 4 & 14 & 5 & 11 & 7 \\
\hline
\end{tabular}


PANAMA: PETROLEUM EXPORTS

(thousonds of barrels)

\begin{tabular}{|c|c|c|c|c|c|c|c|c|c|}
\hline & 1970 & 1977 & 1978 & 1979 & -1980 & 1981 & 1982 & 1983 & 1984 \\
\hline Gosoline & $2,475.6$ & 754.6 & 582.9 & 378.0 & 328.3 & 115.9 & 25.8 & 21.1 & 15.7 \\
\hline Kerosene and jet fuel & 1.738 .4 & 1.865 .7 & 1.148 .5 & 1.233 .5 & 1.019 .0 & 816.0 & 723.1 & 570.1 & 582.6 \\
\hline Diesel oil & 4.716 .1 & $2,635.3$ & $2,689.6$ & $2,297.1$ & 1.599 .6 & 1.389 .8 & 1.052 .1 & 814.9 & 691.7 \\
\hline Fuel oil & $12,805.7$ & $7,702.8$ & $6,071.7$ & $3,436.7$ & 4.775 .9 & 3.796 .6 & 3.825 .2 & $2,849.4$ & $3,337.2$ \\
\hline Nonenergy & 352.7 & 0.0 & 0.0 & 0.0 & 0.0 & 0.0 & 0.0 & 3.3 & 0.0 \\
\hline Total & $22,088.5$ & 12.958 .4 & 10.492 .7 & 7.345 .3 & 7.722 .8 & $6,118.3$ & $5,626.2$ & $4,258.8$ & $4,627.2$ \\
\hline
\end{tabular}

Source: National Commission of Energy (CONADE).

TABLE 19

PANAMA: NET SUPPLY OF OIL PROOUCTS

(thousands of barrels)

\begin{tabular}{|c|c|c|c|c|c|c|c|c|}
\hline 1970 & 1977 & 1978 & 1979 & 1980 & 1981 & -1982 & 1983 & 1984 \\
\hline 551.1 & 388.2 & 332.1 & 346.9 & 321.2 & 213.2 & 213.5 & 285.8 & 264.3 \\
\hline 228.3 & 450.7 & 476.0 & 484.8 & 500.4 & 511.8 & 527.9 & 544.9 & 591.0 \\
\hline 340.2 & 27.8 & 24.8 & 20.9 & 10.7 & 0.0 & 0.0 & 0.0 & 0.0 \\
\hline $1,460.1$ & $2,025.3$ & 2.126 .4 & $1,988.4$ & 1.907 .1 & $1,784.8$ & 1.750 .1 & 1.738 .2 & 1.761 .1 \\
\hline 146.7 & 102.8 & 75.3 & 69.4 & 59.5 & 62.6 & 59.2 & 53.5 & 52.3 \\
\hline 727.1 & $1,845.6$ & 1.893 .5 & $1,880.6$ & $1,833.0$ & 1.859 .1 & 1.919 .2 & 2.718 .8 & 2.238 .2 \\
\hline $2,308.8$ & $2,758.2$ & 2.356 .3 & $2,821.0$ & 2.396 .6 & 1.806 .4 & 2.652 .3 & $2,782.0$ & $1,938.6$ \\
\hline 85.3 & 73.6 & 64.7 & 62.5 & 59.1 & 56.7 & 76.1 & 73.1 & 78.5 \\
\hline 5.847 .6 & 7.672 .2 & 7.349 .1 & 7.674 .5 & 7.087 .6 & 6.294 .6 & $7,198.3$ & $8,196.3$ & 6.924 .0 \\
\hline
\end{tabular}

Source: National Commission of Energy (CONADE).

Note: Doto originally in telocolories. 
(diesel supply increased 21 percent). Liquid gas supply has increased 31 percent during the 1977-1984 period as this oil product replaced some fuel-wood usage.

a. The 0il Refinery. Since 1962, the Texaco refinery--Refineria Panama, S.A. (REFPAN), has had a contract with Panama which states that oil bought by the refinery is not considered "imported." In effect, the refinery is considered to be a duty-free zone and can buy oil, refine it, and then export it without paying import duties. $0 i 1$ used for distribution to Panama evidently must have a duty paid on it. Thus, the refinery has to account only for oil actually sold within the country, which gives rise to a joint-production problem. That is, even though the $0 i 1$ is a homogeneous product when it first arrives at the refinery, it is treated differently depending upon where or how it is sold. It is very difficult to regulate such a product because capital costs, investments, etc. are spread over both regulated and unregulated products.

The refinery is a large one by Central American standards with a 100,000 bbl/day capacity. It was built to handle the refining needs of the Caribbean basin. When it opened in 1964, only 10,000 to $12,000 \mathrm{bbl} /$ day were designated for consumption in Panama, whereas about 25,000 bbl/day are now designated for Panamanian consumption. The refinery's contract guaranteed that it would serve Panama's needs first and would receive a "fair profit" on those sales only. The refinery's economic situation deteriorated in the 1970 s as the Caribbean market declined. * Several Caribbean countries installed competitive refineries and this, coupled with the recession of the 1980 s, caused the Panamanian refinery to lose money. In order for the Panamanian government to guarantee a profit to the refinery, the signing of the "Coral Gables Agreement" took place in 1981, socalled because it was negotiated at Texaco's headquarters in Florida. The agreement guarantees a 10 to 15 percent profit to the refinery.

A recent CONADE study ${ }^{16}$ compared the prices of products bought from REFPAN with those that could be bought from other Caribbean refineries. The major result is that by continuing to buy petroleum products from REFPAN, Panama spends an extra $\$ 20$ million each year. This study also examined possible solutions to this financial problem. One solution is simply to close the refinery. Another solution is to modify the refinery in order that a more useful mix of products be produced (e.g., instead of 50 percent fuel $0 i 1$, produce on 1 y 20 percent). Texaco does not want to make the necessary $\$ 30-60$ million investment to improve cracking capabilities. In addition, because the current 40,000

* Information provided by Ramon Argote of CONADE, July 1985. 
bb1/day output is too small to be efficient with cracking technology, an agreement with other Central American nations to purchase from Panama would have to be obtained.

The Department of Hydrocarbons within the Ministry of Commerce and Industry (Ministerio de Comercia e Industria--MICI) mainly has data on the refinery and on sales of oil products. The overall functions of MICI include (1) maintaining a communications link between the government and the commercial and industrial sectors, (2) managing contracts for import/export companies, (3) writing the hydrocarbon 1 aw to regulate mineral and oil exploration, and (4) regulating imports of oil through the San Jose Agreement and maintaining refinery statistics.

b. Oil Prices. Panama's oil bill in 1984 was $\$ 289$ million US, constituting 7 percent of GDP, 4 percent of total exports and of total imports (including merchandise exports and merchandise imports as well as other goods, services and income), and 17 percent of merchandise exports (Table 20). Not only have crude petroleum imports generally decreased between 1978 and 1984 from 17 to $11 \mathrm{mil}$ lion barrels ( Table 14), but the percent of exports required to pay the oil import bill has also decreased from 12 percent in 1978 to 4 percent in 1984 (Table 20).

TABLE 20

PANAMA: VALUE OF IMPORTED CRUDE PETROLEUM

\begin{tabular}{|c|c|c|c|c|c|c|c|c|}
\hline & 1970 & 1978 & 1979 & 1980 & 1981 & 1982 & 1983 & 1984 \\
\hline $\begin{array}{l}\text { Crude petroleum imports } \\
\text { (millions of US } \$ \text { ot current dollars) }\end{array}$ & 59.7 & 208.1 & 301.8 & 386.2 & 347.0 & 364.1 & 324.2 & 288.6 \\
\hline $\begin{array}{l}\text { Crude petroleum imports os a } \\
\text { percentage of total imports }\end{array}$ & 12.9 & 10.7 & 10.4 & 4.8 & 3.5 & 3.8 & 4.7 & 4.1 \\
\hline $\begin{array}{l}\text { Crude petroleum imports os a } \\
\text { percentage of total exports }\end{array}$ & 15.2 & 11.9 & 11.7 & 5.0 & 3.5 & 3.9 & 4.6 & 4.2 \\
\hline $\begin{array}{l}\text { Crude petroleum imports os } 0 \\
\text { percentage of merchondise exports }\end{array}$ & 45.9 & 68.5 & 84.8 & $17.0^{\circ}$ & 13.7 & 15.5 & 19.7 & 17.1 \\
\hline $\begin{array}{l}\text { Crude petroleum imports as o } \\
\text { percentoge of GDP }\end{array}$ & 5.8 & 7.0 & 9.8 & 10.9 & 9.4 & 9.3 & 8.3 & 7.4 \\
\hline
\end{tabular}

Souce: International Monetary Fund and World Bank.

'Canal zone activities included in the national accounts in 1980 . Merchandise oxports increased from 356 to $2267 \mathrm{milli}$ ion US dollors between 1979 and 1980.

* Information provided by Ramon Argote of CONADE, July 1985. 
Between 1973 and 1975, owing to the increase in world oil prices, most 0 il product prices almost doubled and the price of fuel oil tripled. When OPEC raised prices sharply again in 1979, Panamanian 0 il product prices also increased sharply. In real terms, prices increased by approximately 30 to 60 percent between 1978 and 1979, and then by another 15 to 30 percent between 1979 and 1980 (Table 21). In current balboas, prices have remained constant or declined slightly since 1982. In real terms, this translates into an effective decrease in prices since 1982 .

As in other Central American countries, a large price differential between gasoline and diesel favors the use of diesel. In 1985, regular and premium gasoline were 61 and 71 percent, respectively, more expensive than diesel. In order to foster the use of liquid propane gas, its real price has increased little since 1970 .

Prior to the energy crisis of 1973, the Office of Price Regulation (Oficina de Regulacion de Precios) was in charge of setting petroleum product prices. In 1974, the National Commission of Prices for Hydrocarbons (Comision Nacional de Precios de Hidrocarburos) was created, in ad-hoc form, to assess the price policies for petroleum and its derivatives for the Executive Branch. In 1980, MICI formally created the Commission of Petroleum Prices (Comision de Precios de Petroleo) to respond to requests for price changes by REFPAN and the Executive branch. The Comision reviews these price modifications proposed by REFPAN for MICI. The Commission of Petroleum Prices is composed of representatives from each ministry involved in energy--MICI, Ministry of Planning and Economic Policy (Ministerio de Planificacion y Politica Economica--MIPPE), the Ministry of Finance and Treasury, the Controller General's Office, the Office of Price Regulation, and IRHE/CONADE. The Commission of Petroleum Prices is involved exclusively in the study of variations of the costs of shipping and of crude oil that the refinery imports as well as transfer costs for local sales. These studies are based on international information and information supplied by the refinery. The Office of Price Regulation (Oficina de Regulacion de Precios) is an independent price regulation office, which is part of the Commission of Petroleum Prices. The executive director is the Minister of commerce. This office prepares the legal documents on petroleum prices that are signed by the President of the republic. 17

The San Jose Agreement states that the government can only buy oil from Venezuela and Mexico. Although cheaper oil is sometimes available on the spot market, special loan provisions provide an incentive to continue abiding by the agreement. The government (through MICI) sells the oil to Texaco to be refined 
TABLE 21

PANAMA: OIL PRODUCT PRICES

(current bolboos or dollars per gallon)

\begin{tabular}{|c|c|c|c|c|c|c|c|c|c|c|}
\hline & 1970 & 1977 & 1978 & 1979 & 1980 & 1981 & 1982 & 198.3 & 1984 & 1985 \\
\hline Premium gosoline & 0.35 & 1.1 & 1.1 & 1.56 & 2,17 & 2.32 & 2.32 & 2.28 & 2.28 & 2.28 \\
\hline Regular gasoline & 0.323 & 1.0 & 1.0 & 1.45 & 2.04 & 2.18 & 2.18 & 2.14 & 2.14 & 2.14 \\
\hline Diosel & 0.135 & 0.55 & 0.55 & 0.89 & 1.26 & 1.4 & 1.4 & 1.33 & 1.33 & 1.33 \\
\hline Fuel oil & 0.07 & 0.39 & 0.39 & 0.64 & 0.82 & 0.9262 & o. 9262 & 0.8459 & 0.8459 & 0.8459 \\
\hline Kerosene & 0.21 & 0.5 & 0.5 & 0.9 & 1.16 & 1.3 & 1.3 & 1.2 & 1.2 & 1.2 \\
\hline LPG & 2.15 & 4.0 & 4.0 & 4.66 & 5.9 & 5.54 & 5.54 & 5.04 & 5.04 & 5.04 \\
\hline
\end{tabular}

Note: Balboas per 25 pounds for liquid propane gos.

REAL OIL PRODUCT PRICES

( 1982 bolboas per galion)

\begin{tabular}{|c|c|c|c|c|c|c|c|c|c|}
\hline & 1970 & 1977 & 1978 & 1979 & 1980 & 1981 & 1982 & 1983 & $1984^{\circ}$ \\
\hline Premium gasoline & 0.78 & 1.57 & 1.45 & 1.89 & 2.38 & 2.43 & 2.32 & 2.24 & \\
\hline Regulor gasoline & 0.72 & 1.43 & 1.32 & 1.75 & 2.24 & 2.29 & 2.18 & 2.10 & \\
\hline Dlesel & 0.30 & 0.79 & 0.72 & 1.07 & 1.38 & 1.47 & 1.40 & 1.30 & \\
\hline Fuel oil & 0.16 & 0.56 & 0.51 & 0.77 & 0.90 & 0.97 & 0.93 & 0.83 & \\
\hline Kerosene & 0.47 & 0.71 & 0.66 & 1.08 & 1.27 & 1.37 & 1.30 & 1.18 & \\
\hline LPG & 4.78 & 5.71 & 5.26 & 5.61 & 6.48 & 5.83 & 5.54 & 4.94 & \\
\hline
\end{tabular}

Note: Bolboos per 25 pounds for liquid gos.

Not available.

PERCENTAGE CHANGE IN OIL PRODUCT PRICES

(current)

$1970-1977$

$1977-1978 \quad 1978-1979$

1979-1989

$1980-1981$

1981-1982

$1982-1983$

$1983-1984$

$1984-1985$

$\begin{array}{lrr}\text { Promium gasoline } & 214.3 & 0.0 \\ \text { Regular gasoline } & 209.6 & 0.0 \\ \text { Diesel } & 307.4 & 0.0 \\ \text { Fuel oil } & 457.1 & 0.0 \\ \text { Kerosene } & 138.1 & 0.0 \\ \text { LPG } & 86.0 & 0.8\end{array}$

41.8
45.0
61.8
64.1
80.0
16.5

39.1
40.7
41.6
28.1
28.9
26.6

6.9
6.9
11.1
13.0
12.1
-6.1

0.0
0.0
0.0
0.0
0.0
0.0

$-1.7$

$-1.8$

$-5.0$

$-8.7$

$-7.7$

$-9.0$

0.0
0.0
0.0
0.0
0.0
0.0

0.0

0.0

0.0

0.0

0.0

0.0

PERCENTAGe CHANGE IN OIL PROOUCT PRICES

(real)

$1970-1977$

\begin{abstract}
$1977-1978$
\end{abstract}

$1978-19$
29.8
32.8
48.2
50.3
64.8
6.7

$\begin{array}{rr}100.7 & -7.3 \\ 99.0 & -7.9 \\ 161.9 & -7.9 \\ 258.2 & -7.9 \\ 53.1 & -7.9 \\ 19.6 & -7.9\end{array}$

$1979-1989$

$1988-1981$

$1981-1982$

$1982-1983$

Premium gosoline
Regulor gosoline
Diesel
Fuel oil
Kerosene
LPG

Source: National Commiasion of Energy (CONADE). 
and distributed or exported. Imports of already-refined products are taxed in order to protect the refinery. The regulatory task of MICI is complicated by the lack of accurate data on the cost structure of REFPAN and the jointproduction problem previously mentioned.

The price structure of the main derivative fuels--gasoline, diesel, bunker and 1 iquid gas--begin with the "Ex-refinery" price, which differs according to the type of derivative. This price can be defined as the sum of the weighted cost of imported crude, the shipping cost and insurance, the costs of refining and sales from the plant, and the import tax (taxed at 0.01 balboa for each barrel of 42 gallons of crude or semiprocessed crude that REFPAN imports). Other items are added to the "Ex-refinery" price, depending on the type of fuel and the mechanisms of fiscal policy:

\section{(1) The "Over" Costs}

These are the additional charges such as increases in the price of crude retroactively fixed by provider countries or increases in the price of crude incurred by delays in fixing new prices. The refinery is compensated for these additional charges.

(2) Taxes

This refers to the fiscal pressure on derivative prices and includes the so-called Special Taxes and the Indirect Tax. Special Taxes were created by Cabinet Decrees and refer to (a) Inflation Adjustment, (b) Transportation and Supply Fund created in 1981, and (c) Compensation Fund, conceived to be utilized in situations of unbalanced subsidies. The Indirect Tax includes the tax on consumption plus the import tax.

\section{(3) Subsidies}

These are transfers that the state makes, with the socio-economic end of favoring the consumers of some sectors (i.e. residential, industrial, or transportation). In the case of petroleum derivatives, the prices of some derivatives (bunker, diesel, and bunker C) are lowered, while others are increased. MICI makes recommendations on oil product taxes (subsidies) to the President of the republic. If approved at the top level, the final taxes are decided jointly by MICI and the Ministry of Planning. The basic process is as follows: First, fuel costs are determined. Then, decisions are made as to which fuel should be subsidized at the expense of others. Taxes are generally based on octane level, with the higher octanes being taxed at a higher rate and bunker having no tax. LPG is subsidized because it is used for cooking. The taxes and subsidies are designed to break even. 
The corresponding sum of the above described items give the FOB-refinery price at which REFPAN sells the product in its plant. To the FOB-refinery price are added the margins for sales of the transporter, distributor, and concessioner, which include the cost of the activity plus a utility, in order to establish the price to the consumer. ${ }^{25}$ See Fig. 14.

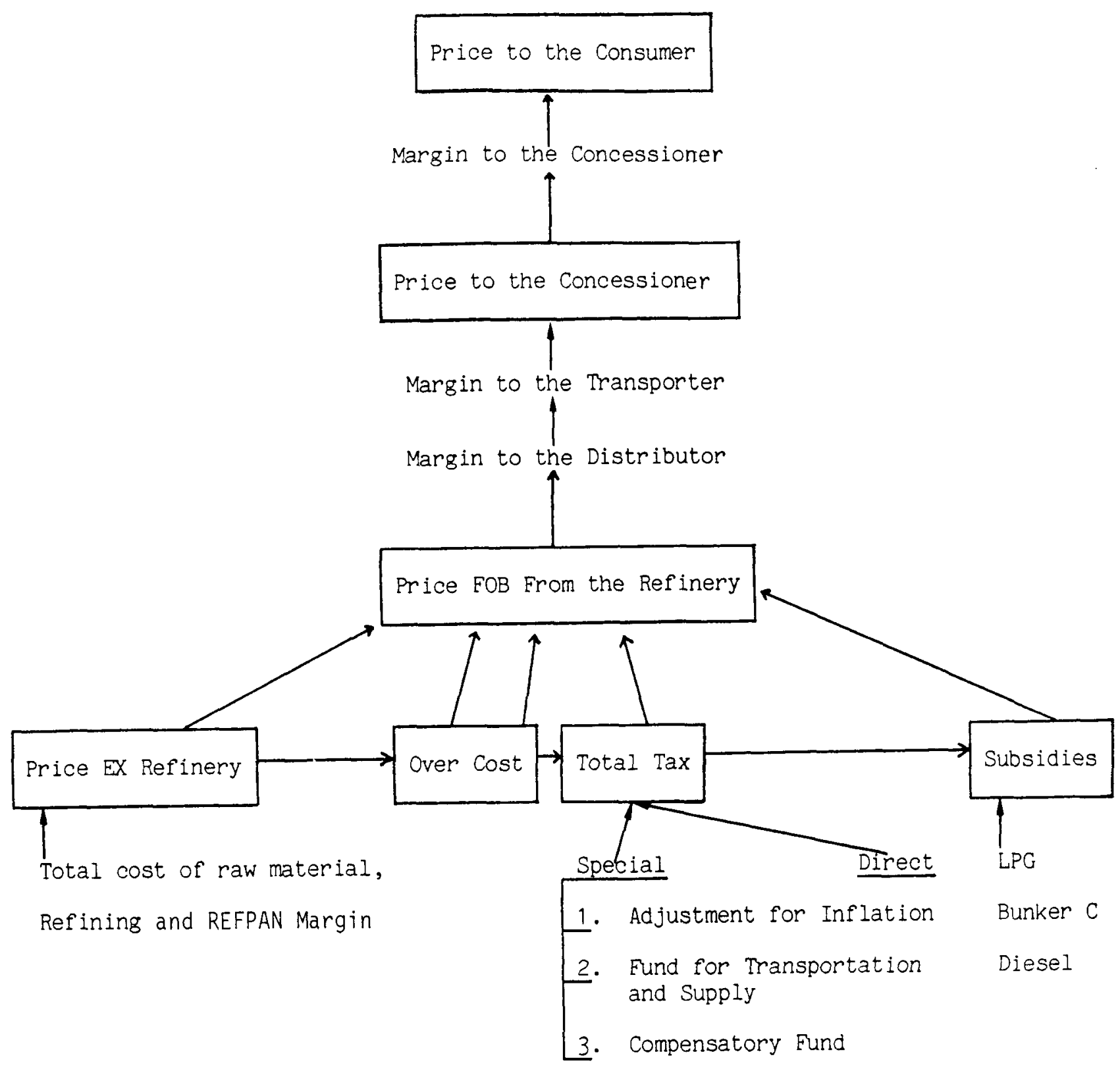

Source: National Commission of Energy (CONADE).

Fig. 14. Panama: Petroleum derivative price structure. 
As mentioned previously, the Office of Price Regulation is the agency in charge of preparing and overseeing the corresponding Resolution as well as informing the public of the fixed prices. The Technical Commission for Prices of Products from Petroleum Derivatives (Comision Tecnica de Precios de los Productos Derivados de Petroleo) was created in 1979 in order to fix the EXrefinery prices as well as the different fuels controlled by the State. This ad-hoc commission is composed of representatives of the Ministry of the Treasury, the Office of Price Regulation, the Ministry of Planning and Economic Policy, IRHE, and the Ministry of Commerce and Industry. This commission complies with the requests of REFPAN. ${ }^{17}$

2. Electricity Supply. In 1984, Panama had an installed capacity of 840 MW (Table 22) and electric generation of 2,210 GWh (Table 23). Of the total installed capacity, two-thirds was hydroelectric and the remainder was thermoelectric. Figure 15 shows the production (thermoelectric and hydroelectric generation plants) and transmission of electrical energy in Panama.

a. Hydroelectric. In an effort to reduce dependence on petroleum imports, Panama has had vigorous hydroelectric development since the early 1970s (Table 22). For example, in 1970 about 11 percent of total generating capacity was hydroelectric, and in 1975 this figure was only 6 percent. During that time period, only two projects--Yeguada ( $7 \mathrm{MW}$ ) and Chiriqui (4 MW), were in commercial operation. By 1976, about one-third of total capacity was hydroelectric as the first large hydroelectric project, Bayano (156 MW) came on 1 ine. As other hydroelectric projects began commercial operation--La Estrella (in 1978, 43 MW), Los Valles (in 1979, $47 \mathrm{MW}$ ), and Fortuna (in 1984, $300 \mathrm{MW}$ )--hydroelectric grew to about two-thirds of total capacity by 1984 . Table 24 gives the characteris tics of these hydroelectric projects. Hydroelectric generation accounted for one-tenth of total generation in 1970. By 1984, hydroelectric generation accounted for two-thirds of total generation. IRHE projects that by 1990 , fourfifths of total capacity will be hydroelectric and will account for all of the average annual electricity generation in Panama (Table 25). Table 26 gives the hydroelectric expansion plans (by project name) proposed by IRHE for the time period 1984 to 2000.

b. Thermoelectric. As mentioned previously, 36 percent of total installed capacity is thermoelectric--19 percent steam, 10 percent gas turbine, and 7 percent diese1. Whereas, in 1970,89 percent of total installed capacity was thermoelectric. Table 27 lists the characteristics of existing thermoelectric generation facilities. The most recent thermoelectric plant began commercial 
TABLE 22

PANAMA: INSTALLED ELECTRIC GENERATING CAPACITY

(MN)

Hydre Diesel Steam Iotol

$\begin{array}{rrrrr}1970 & 6.0 & 8.3 & 40.0 & 54.3 \\ 1971 & 6.0 & 8.1 & 40.0 & 54.1 \\ 1972 & 6.0 & 45.0 & 149.0 & 200.0 \\ 1973 & 16.1 & 79.9 & 149.0 & 245.1 \\ 1974 & 16.1 & 80.5 & 188.4 & 285.0 \\ 1975 & 16.1 & 81.3 & 182.9 & 280.3 \\ 1976 & 166.1 & 107.5 & 182.9 & 456.5 \\ 1977 & 166.1 & 107.4 & 182.9 & 456.4 \\ 1978 & 187.1 & 111.1 & 182.9 & 481.1 \\ 1979 & 256.1 & 164.5 & 175.2 & 535.7 \\ 1980 & 251.2 & 100.8 & 175.2 & 527.2 \\ 1981 & 251.2 & 99.7 & 175.2 & 526.0 \\ 1982 & 251.2 & 96.9 & 174.0 & 522.0 \\ 1983 & 251.2 & 137.9 & 155.5 & 544.6 \\ 1984 & 551.2 & 133.0 & 155.5 & 839.7\end{array}$

Source: National Commission of Energy (CONADE).

TABLE 23

PANAMA: ELECTRIC GENERATION (GWh)

\begin{tabular}{lrrr} 
& Hydre & Ihermel & Tetal \\
\cline { 2 - 4 } 1970 & & & \\
1971 & 83.7 & 754.3 & 838.1 \\
1972 & 82.9 & 815.8 & 898.7 \\
1973 & 82.9 & 924.5 & 1007.4 \\
1974 & 101.8 & 1077.1 & 1178.1 \\
1975 & 105.5 & 1093.1 & 1198.5 \\
1976 & 97.5 & 1153.6 & 1251.1 \\
1977 & 138.3 & 1269.9 & 1408.2 \\
1978 & 341.4 & 1145.1 & 1486.5 \\
1979 & 718.9 & 782.8 & 1501.7 \\
1980 & 803.2 & 972.1 & 1775.2 \\
1981 & 963.5 & 848.2 & 1811.7 \\
1982 & 1334.2 & 563.1 & 1897.2 \\
1983 & 1074.3 & 1013.8 & 2088.1 \\
1984 & 865.7 & 1372.5 & 2238.2 \\
& 1491.5 & 719.1 & 2210.6
\end{tabular}

Source: National Commission of Energy. 


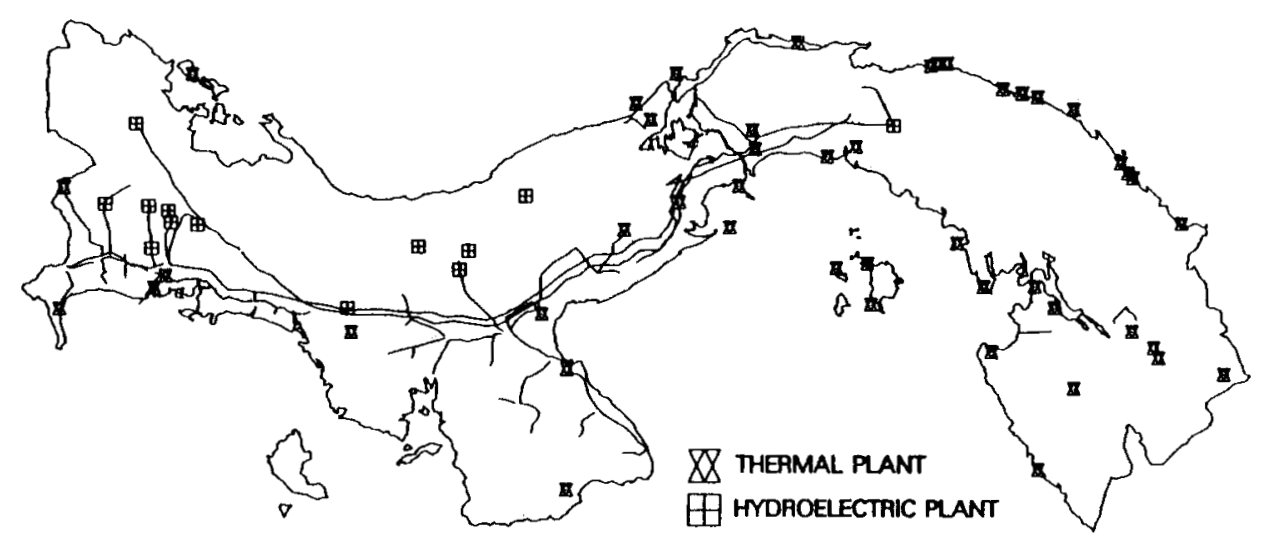

SOURCE: INSTITUTE OF HYDRO RESOLRCES AND ELECTRIFICATION.

Fig. 15. Panama: Production and transmission of electrical energy.

TABLE 24

PANAMA: CHARACTERISTICS OF EXISTING HYOROELECTRIC PROJECTS

\begin{tabular}{|c|c|c|c|c|c|c|}
\hline \multirow[b]{2}{*}{ Item. } & \multirow[b]{2}{*}{ Unit } & \multicolumn{5}{|c|}{ Project } \\
\hline & & $\begin{array}{l}\text { Yoguado and } \\
\text { chiriqui }\end{array}$ & $\begin{array}{l}\text { Lo } \\
\text { Estrello }\end{array}$ & $\begin{array}{l}\text { Los } \\
\text { xalles }\end{array}$ & Baxane & Eortung \\
\hline Drainage aroo & $\mathrm{km}^{2}$ & - & 109 & 159 & 3652 & 155 \\
\hline \multirow[t]{2}{*}{ Mean annual flow } & $m^{3} / s$ & - & 11.2 & 15.1 & 176.1 & 26.6 \\
\hline & (MCM) & - & (353) & $(475)$ & $(5560)$ & $(84 \theta)$ \\
\hline Mean annual spill & $\mathrm{m}^{3} / \mathrm{s}$ & - & 1.9 & 1.5 & 5.4 & 0.7 \\
\hline Total reservoir volume & $\mathrm{mm}^{3}$ & - & 0.15 & 0.015 & 4020 & 161.0 \\
\hline Live reservole volume & $\mathrm{mm}^{3}$ & - & 0.15 & $0: 015$ & 2580 & 157.0 \\
\hline Live volume/MAF & $m^{3}$ & 一 & 0.04 & $0: 003$ & 46 & 19 \\
\hline \multicolumn{7}{|l|}{ Reservoir full supply } \\
\hline lovel & m & - & 380.0 & 295.0 & 62.3 & 1050.0 \\
\hline Minimum operating lovol & $\mathrm{m}$ & - & & 295.6 & 49.0 & 999.0 \\
\hline Tollwater elevation & $m$ & 一 & & & 8.1 & 232.0 \\
\hline Rated hoodloss & m & - & & & 1.0 & 20.0 \\
\hline Net hood & $m$ & - & 345.0 & 270.0 & 53.2 & $788: 0$ \\
\hline Nomeplote copocity & MW & $11^{\circ}$ & 43 & 47 & 156 & 300 \\
\hline Firm copocity & 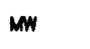 & 3 & 22 & 15 & 106 & 272 \\
\hline Number of units & & - & 2 & 2 & 2 & 3 \\
\hline Nominal efficioncy & x & 88 & 88 & 88 & 88 & \\
\hline Averago annual energy & Gwh & 56 & 243 & 279 & 688 & 1543 \\
\hline Capacity factor & & 58 & 65 & 68 & 50 & 59 \\
\hline
\end{tabular}

Sourco: Institute of Hydro Resources and Electrification

Made up of 7 MW at Yoguado ond 4 MW at Chiriqui hydro.

bosed on overage onnual energy. 
TABLE 25

PANAMA: ELECTRIC SECTOR DATA

\begin{tabular}{|c|c|c|c|c|c|c|}
\hline & 1970 & $\%$ & 1980 & 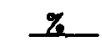 & 1990 & $\%$ \\
\hline Installed capacity (GW) & 54.3 & & 527.2 & & $1,080.6$ & \\
\hline Hydroelectric & 6.0 & (11) & 251.2 & $(48)$ & 851.0 & (79) \\
\hline Thermoelectric & 48.3 & (89) & 276.0 & $(52)$ & 229.6 & (21) \\
\hline Production of energy (GWh) & 276.9 & & 1.811 .6 & & 3.376 .0 & \\
\hline Hydroelectric & 35.6 & $(13)$ & 963.5 & (53) & 3.376 .0 & $(100)$ \\
\hline Thermoelectric & 241.3 & (87) & 848.1 & (47) & - & - \\
\hline Sales of energy (GWh) & 254.0 & & 1.473 .0 & & 2.819 .2 & \\
\hline Hydroelectric & 33.0 & & 780.7 & & 2.819 .2 & \\
\hline Thermoelectric & 221.0 & & 692.3 & & - & \\
\hline Number of $\mathrm{clients}$ & 21.837 & & 234,234 & & 352,780 & \\
\hline Residential & 19,398 & & 207.380 & & 313,455 & \\
\hline Commercial & 1,748 & & 21,894 & & 29.420 & \\
\hline Industrial & 98 & & 855 & & 1.042 & \\
\hline Government & 593 & & 4.105 & & 8.863 & \\
\hline
\end{tabular}

Source: Institute of Hydro Resources and Electrification.

TABLE 26

PANAMA: COMPARISON OF CAPACITY EXPANSION PLANS

\begin{tabular}{|c|c|c|c|c|}
\hline \multirow[b]{2}{*}{ Year } & \multirow[b]{2}{*}{ Project } & \multirow[b]{2}{*}{$\begin{array}{l}\text { Potential } \\
(\mathrm{MN}) \\
\end{array}$} & \multicolumn{2}{|c|}{ Maximum Substitutien Plan } \\
\hline & & & Project & $\begin{array}{l}\text { Potentiol } \\
\text { (MN) }\end{array}$ \\
\hline 1984 & Fortuna & 300 & Fortuna & 300 \\
\hline 1989 & & & Changuinola I & 300 \\
\hline 1990 & Bayano 3 & 75 & Bayano 3 & 75 \\
\hline 1991 & Changuinola I & 300 & & \\
\hline 1992 & & & Boyabo 4 & 75 \\
\hline 1993 & & & Teribe 1 & 237 \\
\hline 1996 & & & Tobasara & 214 \\
\hline 1997 & Teribe I & 237 & Changuinola II & 306 \\
\hline 1999 & Tabasara & 214 & Teribe II & 76 \\
\hline 2000 & & & Changuinola III & 102 \\
\hline
\end{tabular}

Source: Institute of Hydro Resources and Electrification. 
TABLE 27

PANAMA: CHARACTERISTICS OF EXISTING THERMAL GENERATION FACILITIES

\begin{tabular}{|c|c|c|c|c|c|c|c|c|c|c|}
\hline Plant Name & Iroe & $\begin{array}{c}\text { Started } \\
\text { epecatien }\end{array}$ & Reticement & $\begin{array}{l}\text { No. of Units } \\
\text { and Installed } \\
\text { Capacity }\end{array}$ & $\begin{array}{l}\text { Maximum } \\
\text { Output } \\
\text { (IMI) }\end{array}$ & $\begin{array}{l}\text { Minimum } \\
\text { Output } \\
\text { (MN) }\end{array}$ & $\begin{array}{l}\text { Forced } \\
\text { Outage } \\
\text { Rote } \\
(x)\end{array}$ & $\begin{array}{c}\text { Scheduled } \\
\text { Maintenance } \\
(d / \$) \\
\end{array}$ & $\frac{\text { Avo }}{A^{a}}$ & $\frac{\operatorname{lity}^{6}}{\mathrm{~B}^{\mathrm{b}}}$ \\
\hline $\begin{array}{l}\text { Bahia Las Minas } \\
1 \text { (BLMI) }\end{array}$ & Steam & 1964 & & $1 \times 22.0$ & 22.0 & 12.0 & 10 & $35 / 10$ & 80 & 80 \\
\hline $\begin{array}{l}\text { Bahia Las Minas } \\
2,3,4 \text { (BLMR) }\end{array}$ & Steam & $69,72,74$ & & $3 \times 40.0$ & 112.5 & 48.0 & 12 & $35 / 10$ & 78 & 78 \\
\hline $\begin{array}{l}\text { San Francisco } \\
3 \text { (SFN3) }\end{array}$ & Steam & 55 & $11.0 \mathrm{MW}-87$ & $1 \times 14$ & 11.0 & 5.0 & 8 & $28 / 8$ & 84 & 84 \\
\hline $\begin{array}{l}\text { San Francisco } \\
4 \text { (SFGT) }\end{array}$ & $\begin{array}{l}\text { Gas } \\
\text { turbine }\end{array}$ & 64 & 12 & $2 \times 12$ & 22.0 & 0.0 & 12 & $56 / 15$ & 73 & 30 \\
\hline $\begin{array}{l}\text { San Francisco } \\
\text { Pielstick (PIEL) }\end{array}$ & $\begin{array}{l}\text { Gas } \\
\text { turbine }\end{array}$ & 76 & & $4 \times 7$ & 24.0 & 0.0 & 16 & $28 / 8$ & 76 & 76 \\
\hline $\begin{array}{l}\text { Chiriqul Diesels } \\
\text { (CHOL) }\end{array}$ & Diesel & $\begin{array}{l}72.72 \\
69.61\end{array}$ & $4.2 \mathrm{MW}-95$ & $14 \times V^{c}$ & 13.4 & 0.0 & 12 & $56 / 15$ & 73 & 73 \\
\hline $\begin{array}{l}\text { G.M. Diesels } \\
\text { (GMDL) }\end{array}$ & Diesel & 75 & $9.6 \mathrm{MN}-95$ & $11 \times 2.5$ & 20.0 & 0.0 & 12 & $56 / 15$ & 73 & 73 \\
\hline $\begin{array}{l}\text { Avenida Sur } \\
\text { (ASUR) }\end{array}$ & Steom & 58 & $5.0 \mathrm{MN}-85$ & $1 \times 5.0$ & 5.0 & 4.0 & 12 & $28 / 8$ & 80 & 80 \\
\hline $\begin{array}{l}\text { Now gas } \\
\text { turbine (O.T.) }\end{array}$ & $\begin{array}{l}\text { Gos } \\
\text { turbine }\end{array}$ & 84 & & $2 \times 18.0$ & 36.0 & 0.0 & 7 & $14 / 4$ & 89 & 30 \\
\hline Totol & & & & & 265.9 & & & & & \\
\hline
\end{tabular}

Source: Instilute of Hydro Resources and Electrification.

ane hundred percent minus FOR and scheduled maintenance.

bame os A but limited to 30 percent for gas turbines during normal operation.

Enits ranging in size from $0.55 \mathrm{~kW}$ to $2.40 \mathrm{~mW}$. 
operation in 1984 (Now Gas Turbine, $36 \mathrm{MW}$ ). Prior to this, the gas turbine plant San Francisco Pleistick (28 MW) came on line in 1976. Diesel and gas turbine plants consume diesel fuel and steam plants consume fuel oil to produce electricity. The use of vegetable residue--mainly cane bagasse--is basically for steam generation. According to IRHE's future plans, installed thermal capacity will decrease (as some plants are retired) from 312 MW in 1984 to 230 MW in 1990 and will generate no electricity by 1990 (Table 25).

c. Electricity Generation by Fuel Type. Table 28 shows how the composition of fuels (in thousands of barrels equivalent of petroleum) used to generate electricity has evolved and how hydraulic energy has displaced diesel and fuel oil for electricity generation. In 1970, the percentage of fuels used to generate electricity was 80 percent fuel 0i1, 16 percent diese1, 4 percent hydro, and 3 percent vegetable residue. By 1984 , these percentages had changed considerably--38 percent fuel 011,35 percent hydro, 17 percent diesel, and 10 percent vegetable residue.

d. Electricity Prices. Panama and Honduras are the only two countries in the region in which households pay higher prices than other sectors for their electricity. Panama and Guatemala have the highest electricity prices in the region. In dollar terms, Panama's prices to the residential and commercial sectors are triple those of neighboring costa Rica. However, the reader is

TABLE 28

PANAMA: PERCENTAGE OF TOTAL FUELS CONSUMEO FOR ELECTRICITY GENERATION

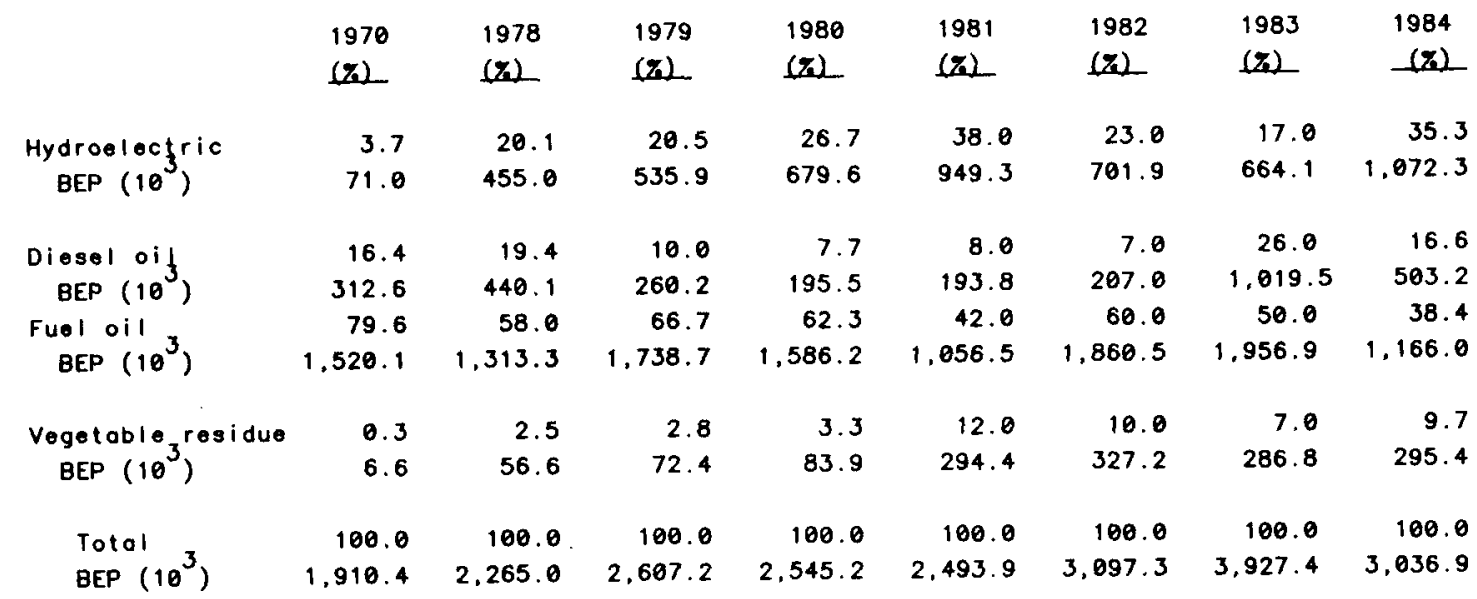

Source: National Commission of Energy (CONADE). 
cautioned that the conversion to dollars is not an entirely effective means of comparison because of devaluation or over-valuation of currencies.

Because of Panama's heavy reliance on oil-fired electricity generation in the past, electricity prices have increased sharply with the major oil price increases of 1973 and 1979. Real electricity price increases after the $19790 i 1$ price increase were lower than the oil product price increases, being 12 percent for electricity between 1979 and 1980, compared to 15 to 30 percent for 011 products (see Table 21 and 29). However, whereas real 011 product prices stabilized and decreased after 1981, electricity prices have continued to increase gradual1y. Still, 1983 real electricity prices are less than 30 percent higher than 1978 prices, while regular gasoline, for example, was 60 percent more expensive. The real price of liquid propane gas, a substitute for electricity in cooking, has actually decreased by 6 percent between 1978 and 1983. Electricity prices are expected to decrease with Fortuna on 1 ine as the utility passes savings in fuel costs on to the consumer.

In Panama, residential customers pay higher electricity prices than commercial, industrial, and government customers. By 1984, the price differential had decreased to only 15 percent, whereas in 1970, households paid two-thirds more for their electricity than industry did.

Electricity rates are regulated differently than oil prices. CONADE makes price recommendations to IRHE based on demand and supply forecasts. IRHE then makes its own recommendations to the President of the republic, who then can approve or disapprove them.

3. Noncommercial Energy Supply. Noncommercial energy supply in Panama mainly consists of fuel wood and vegetable residue (charcoal supply is insignificant). As mentioned previously, noncommercial energy supply accounted for about 32 percent of total net supply in 1984. Of this fuel wood accounted for 25 percent and vegetable residue, 7 percent. The supply of noncommercial energy has decreased since 1970, when it accounted for 37 percent of total supply (33 percent fuel wood and 4 percent vegetable residue). ${ }^{13,14}$ As mentioned in the background section of this report, Panama has the lowest consumption of fuel wood in Central America because it is the most urbanized country and LPG substitution is greater.

\section{Energy Demand}

This section gives an overview of energy consumption by sector as well as energy consumption by fuel type for 1970 to 1984 . Also, detailed discussions are given for energy consumption by sector and fuel type for 1984, the most recent year that data is available from the energy balances. Sectors that are 
TABLE 29

PANAMA: ELECTRICITY PRICES

(current balboas per kWh)

Total

Residential

Commercial

Industrial

Government
1970

$\begin{array}{ll}0.0282 & 0.0705 \\ 0.0386 & 0.0753 \\ 0.0302 & 0.0679 \\ 0.0233 & 0.0668 \\ 0.0269 & 0.070\end{array}$

1978

0.0742

0.0789

0.0723

0.0694

0.0724
1979

0.079

0.0836

o. 078

อ. 0742

b. 0763
1880

0.0976

0. 1061

0.0953

ค. 0899

0.0934
1981

0.1063

0.1144

0. 1052

0.0979

0.1012
1982

1983

$0.1152 \quad 0.1268$

อ. 1271

อ. 1142

o. 1054

0. 1062 b. 1268
b. 1383

0.126

o. 1169

0.1177
1984

D. 1272

0.1371

- .1273

0.1188

0.0159
1985

0. 1206

0. 1338

อ. 1237

0. 116

o. 1183

ELECTRICITY PRICES

(1982 balboos per kWh)

\begin{tabular}{|c|c|c|c|c|c|c|c|c|c|}
\hline 1970 & 1977 & 1978 & 1979 & 1980 & 1981. & 1982 & 1983 & 1984 & 1985 \\
\hline 0.0630 & 0.1006 & 0.0981 & D. 0956 & 0.1670 & 0.1114 & 0.1152 & 0.1246 & - & - \\
\hline 0.0858 & 0.1076 & 0.1038 & 0.1007 & 0.1166 & 0.1204 & 0.1271 & 0.1356 & - & - \\
\hline 0.0671 & 0.0970 & 0.0951 & 0.0940 & 0.1047 & 0.1107 & o. 1142 & 0. 1235 & - & - \\
\hline 0.0518 & 0.0954 & 0.0913 & 0.0894 & 0.0988 & 0.1031 & 0.1054 & 0.1146 & - & - \\
\hline 0.0598 & 0.1001 & 0.0953 & 0.0919 & 0.1026 & 0.1065 & D. 1062 & 0.1154 & - & - \\
\hline
\end{tabular}

PERCENTAGE CHANGE IN ELECTRICITY PRICES

$$
\text { (curront) }
$$

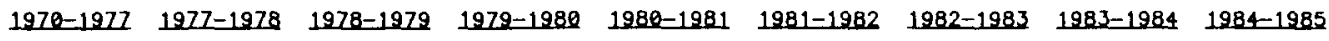

\begin{tabular}{|c|c|c|c|c|c|c|c|c|c|}
\hline Total & 150.0 & 5.2 & 6.5 & 23.5 & 8.9 & 8.4 & 10.1 & 0.3 & -5.2 \\
\hline Residential & 95.1 & 4.8 & 6.0 & 26.9 & 7.8 & 11.1 & 8.8 & -0.9 & -2.4 \\
\hline Commerciol & 124.8 & 6.5 & 7.9 & 22.2 & 10.4 & 8.6 & 10.3 & 1.0 & -2.8 \\
\hline Industrial & 186.7 & 3.9 & 6.9 & 21.2 & 8.9 & 7.7 & 10.9 & 1.6 & -2.4 \\
\hline Government & 160.6 & 3.3 & 5.4 & 22.4 & 8.4 & 4.9 & 10.8 & -10.0 & 11.7 \\
\hline
\end{tabular}

PERCENTAGE Change IN ELECTRICITY PRICES

$(r \circ a 1)$

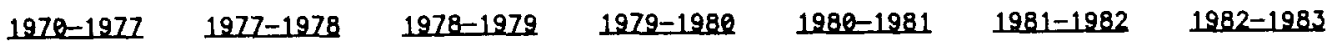

$\begin{array}{lllllrr}\text { Total } & 59.6 & -2.5 & -2.6 & 12.0 & 4.1 & 3.4 \\ \text { Residential } & 25.4 & -3.5 & -3.0 & 15.8 & 3.3 & 5.5 \\ \text { Commercial } & 44.5 & -1.9 & -1.2 & 11.4 & 5.7 & 3.1 \\ \text { Industrial } & 84.3 & -4.3 & -2.1 & 10.5 & 4.3 & 2.3 \\ \text { Government } & 67.5 & -4.9 & -3.5 & 11.7 & 3.8 & -0.3\end{array}$

Source: IRHE/CONADE. 
discussed include residential, commercial, transport, public and other (losses and nonenergy). Fuel types are fuel wood, vegetable residue, electricity, refinery gas, liquid gas, gasoline, kerosene and jet fuel, diesel oil, fuel oil, nonenergy, and charcoal. The type of fuels used in each sector remained about the same throughout the 1970 to 1984 period. Therefore, although Table 30 represents 1984 data, it gives an indication of the types of fuels used in each sector throughout the period.

Previous to 1980 , residential and commercial sectors were combined in the energy balances. Between 1980 and 1984, these sectors were separated. Therefore, for the overview discussion of the 1970 to 1984 time series, residential and commercial sectors have been combined; but for the detailed discussions of 1984, the residential and commercial sectors have been separated to allow for more depth in analyzing the most recent year.

1. Time Series Trends--1970 to 1984 . Figure 16 gives energy consumption by sector for 1970 to 1984, and Table 31 gives compounded annual average growth rates for energy consumption by sector for selected time periods. During the period, the residential/commercial sector consumed the largest quantity of energy--about 30 to 35 percent (Fig. 16). The commercial sector includes commercial activities such as wholesale and retail stores, hotels, restaurants, laundries, etc. ${ }^{18}$ The transport sector was the second largest consumer of energy--about 25 to 30 percent. The industrial/agriculture sector (the third

TABLE 30

PANAMA: 1984 ENERGY CONSUMPTION
(thousonds of barrel equivalents of potroloum)

\begin{tabular}{|c|c|c|c|c|c|c|c|}
\hline Enerax Ixpe & Residential & Commercial & Iransport & $\begin{array}{l}\text { Industrial/ } \\
\text { Agriculture }\end{array}$ & Public & Other & $\begin{array}{l}\text { Total Consumption } \\
\text { By Enecay Type }\end{array}$ \\
\hline Fuel wood & 1959 & & & 180 & & & 2139 \\
\hline Vegetoble residue & & & & 580 & & & 580 \\
\hline Eloctricity & 301 & 332 & & 270 & 209 & 49 & 1161 \\
\hline \multicolumn{8}{|l|}{ Petroleum derivatives } \\
\hline Refinery gos & & & & & & 332 & 332 \\
\hline Liquid gas & 247 & 85 & & 42 & & 2 & 376 \\
\hline Gasol ine & & & 1439 & & & 1 & 1440 \\
\hline Kerosene and jet fuel & 31 & 1 & 13 & 4 & & & 49 \\
\hline Diesel oil & & 37 & 847 & 668 & & 14 & 1566 \\
\hline Fuel oil & & 4 & & 409 & & 330 & 743 \\
\hline $\begin{array}{c}\text { Total potroloum } \\
\text { derivatives }\end{array}$ & 278 & 126 & 2299 & 1123 & & 679 & 4506 \\
\hline Nonenergy & & & & & & 73 & 73 \\
\hline Charcool & & 3 & & & & & 3 \\
\hline $\begin{array}{c}\text { Total sectoriol } \\
\text { consumption }\end{array}$ & 2538 & 461 & 2299 & 2153 & 209 & 801 & 8462 \\
\hline
\end{tabular}

Source: Notional Commission of Energy Inter-American Development Bank.

Note: Dota originally in teracalories. 


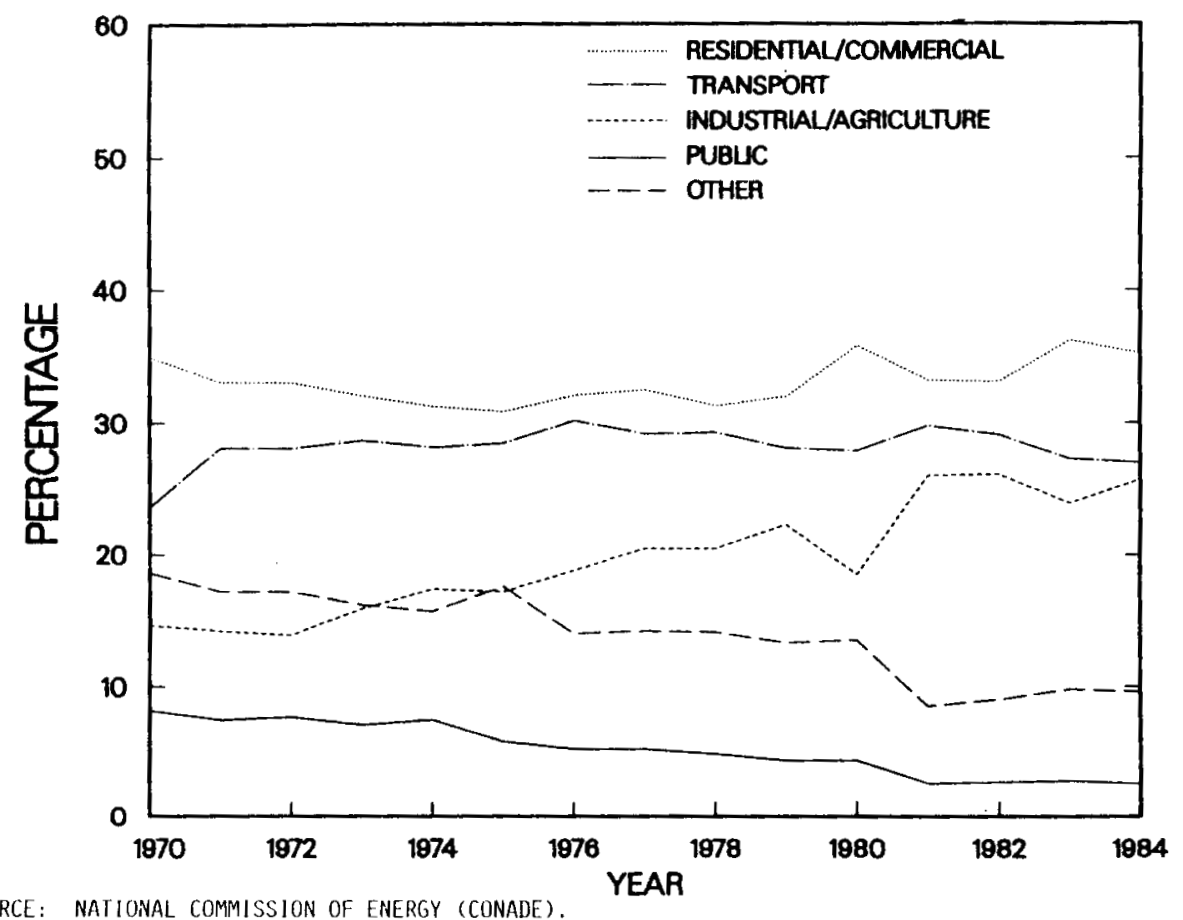

SOURCE: NATIONAL COMMISSION OF ENERGY (CONADE).

Fig. 16. Panama: Energy consumption by sector for 1970-1984 (percentages).

TABLE 31

PANAMA: COMPOUNDED ANNUAL AVERAGE GROWTH RATES FOR ENERGY CONSUMPTION, BY SECTOR AND SELECTED YEARS (percentages)

$\begin{array}{lcccccc}\text { Lime Peried } & \begin{array}{c}\text { Residentiol/ } \\ \text { cemmercial }\end{array} & \text { Iranspert } & \begin{array}{c}\text { Industrial/ } \\ \text { Agricultural }\end{array} & \text { Public } & \text { Other } & \text { Ietal } \\ 1970-1978 & 2.2 & 7.8 & 8.6 & 14.0 & -0.2 & 4.6 \\ 1978-1984 & 1.3 & -1.6 & 2.8 & 6.6 & -4.1 & 0.3 \\ 1980-1984 & 1.5 & 0.4 & 0.2 & 3.9 & -1.8 & 0.6 \\ 1970-1984 & 1.8 & 3.7 & 5.7 & 10.8 & -1.9 & 2.7\end{array}$

largest consumer of energy) increased consumption from about 15 percent in 1970 to about 25 percent in $1984--$ the 1 argest growth of all sectors. Included in this sector are agriculture, forestry, hunting, fishing, and manufacturing. ${ }^{18}$ The "other" sector (which includes losses and nonenergy items) decreased energy consumption from about 20 to 10 percent during the period. The public sector 
also decreased consumption from about 8 to 2 percent during the period. This sector includes electricity consumption in public and municipal buildings and public lighting. ${ }^{18}$ The national consumption of energy grew at a compounded annual average growth rate of 2.7 percent between 1970 and 1984 (Table 31). Again, the sector with the most rapid growth during the period was industrial/agriculture at an average rate of 5.7 percent per year. The 1970 to 1984 growth rates were highly affected by the 1973 and 1979 increases in 011 prices and the international recession which soon followed. For example, before 1978, the national consumption of energy grew at 4.6 percent per year, but during the 1978 to 1984 time period, national energy consumption grew at only 0.3 percent per year. After the oil price increases, domestic energy prices increased sharply.

Figure 17 gives total energy consumption by fuel type for 1970 to 1984 . Panama, more than any other Central American country, has been quite dependent on petroleum derivatives as a fuel type throughout the period. Petroleum derivatives--1iquid gas, gasoline, kerosene and jet fuel, diesel 011 , and fuel oil (refinery gas is not included since it is only consumed in the refinery)-accounted for about 58 percent of total fuels consumed in 1970 and about 54 percent in 1984. This continuing reliance on petroleum derivatives is owing to Panama's involvement in commercial activities related to the Canal, especially in the area of transportation (the second largest consumer of energy in Panama and the 1 argest consumer of petroleum derivatives). Indigenous energy sources such as fuel wood, charcoal, and vegetable residue have accounted for about 34 percent of total fuels in 1970 and about 32 percent in 1984.

Major changes that have occurred during the 1970 to 1984 time period for petroleum derivatives include the following: ${ }^{18}$

(1) Diesel consumption increased substantially because the fast-growing industrial sector is a heavy user of the fuel. Also, the subsidy on the price of diesel has encouraged the substitution of diesel for gasoline in the transport sector.

(2) The fall in consumption of fuel oil between 1979 and 1980 is owing to (a) a considerable reduction in use by cement companies (resulting from a more efficient manufacturing process), which are the main consumers of this derivative, (b) a real increase in fuel oil prices of 50 percent in 1979 and 17 percent in 1980, and (c) a reduction in fue 1 oil usage for electricity generation as increasingly more hydroelectric capacity has come on 1 ine in recent years (for further details, see below). 


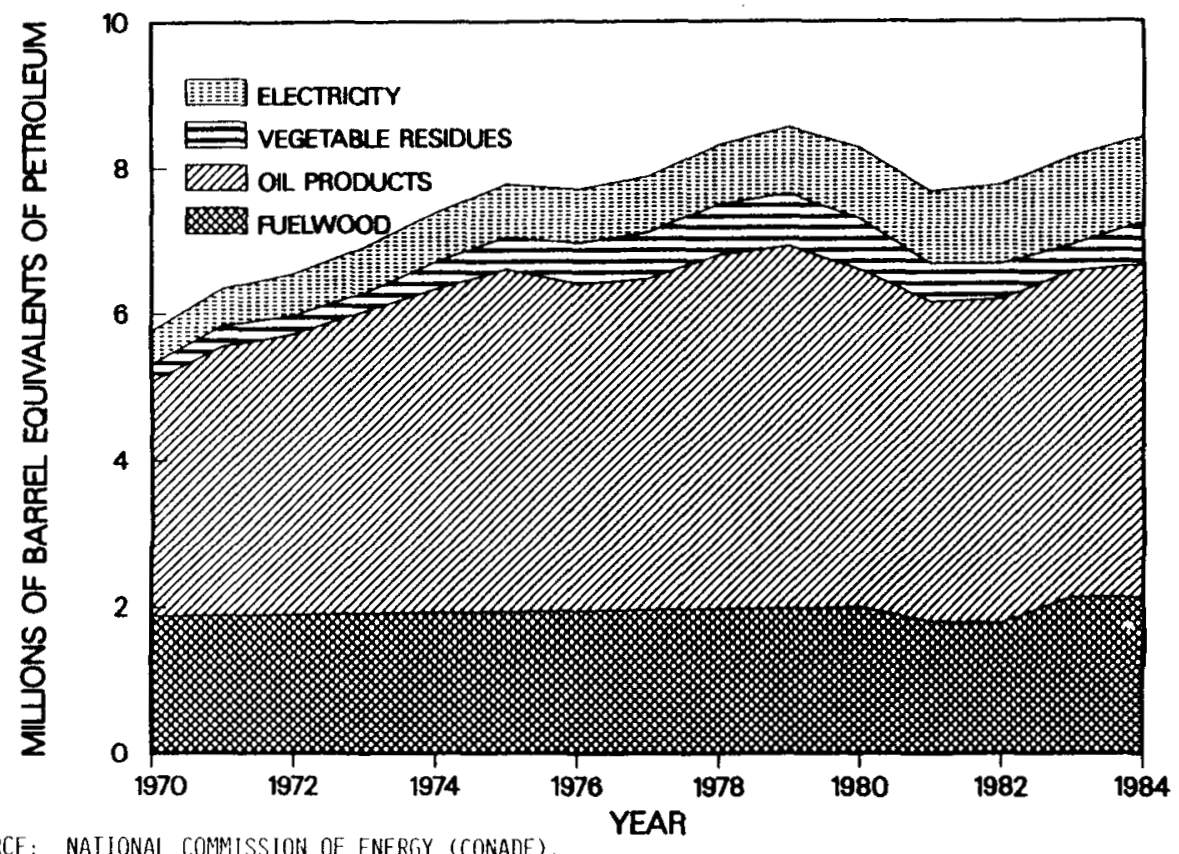

SOURCE: NATIONAL COMMISSION OF ENERGY (CONADE).

Fig. 17. Panama: Total energy consumption.

(3) Gasoline consumption has decreased over the period owing to the increased use of more efficient cars for transport and to some substitution of diesel for gasoline that is fostered by large price differentials.

(4) LPG consumption has increased over the period as it has replaced a large portion of kerosene for cooking and lighting. Real price increases for LPG have been far lower than they were for the other oil products, especially kerosene.

Fuel wood (mainly used in the residential sector) accounted for about 27 percent of total fuels consumed in 1970 and about 22 percent in 1980 . Fuel wood maintained a steady decrease in usage from its 1970 value until 1979, mainly because of the increased use of LPG and the migration of the rural population to urban areas (urban population as a percent of total population was 48 percent in 1970 and 56 percent in 1985).

Fuel-wood useage began to increase between 1979 and 1983 as LPG prices dramatically increased from $\$ 4.00$ for 25 lbs in 1978 to $\$ 4.66$ in 1979 , and $\$ 5.90$ in 1980. Also, in real terms the kerosene price almost doubled between 1978 and 1980. Between 1983 and 1984, fuel-wood usage decreased somewhat as LPG prices decreased to $\$ 5.04$ for 25 1bs. Although the extent of fuel-wood use is not as 
great in Panama as it is in other Central American countries, wood use and wood quality in Panama are very important. In 1970, about 55 percent of the country's total households used this fuel for cooking, and by 1980 , this figure was 36 percent. For the rural population, especially those of low incomes, the free use of wood is imperative, given that the available income does not permit the individual to obtain fuel that is more efficient and costly (such as LPG).

In the rural areas, wood consumption is specifically affected by the marked deforestation, meaning that each time wood is needed, the inhabitants of the area have to dedicate more time to obtaining wood or are obligated to dedicate a high percentage of their income to purchase commercial fuels. In families where there is sufficient income to purchase commercial energies and there is a cost similarity between wood and LPG, LPG is favored because it is easy to use and wood stoves are not energy efficient. These factors have influenced the energy consumption structure for cooking over the years.

2. Energy Consumption by Type and Sector--1984. Tables 30,32 and 33 give energy consumption by type and sector for 1984 . Table 30 gives this information in thousands of barrels equivalent of petroleum (BEP) and Tables 32 and 33 give this information in percentages. Fuels consumed during 1984 totaled 8,522 thousand BEP. Overa11, the fuel types accounting for the largest consumption were residential firewood--1959 thousand BEP (23 percent of the tota1), gasoline consumption in the transport sector--1439 thousand BEP (17.9 percent of the total), and diesel oil consumption also in the transport sector--847 thousand BEP ( 10.0 percent of the total). However, petroleum derivatives accounted for 53 percent of all fuels consumed in 1984, and half of that was used in the transport sector alone (see Table 32).

a. Residential. The residential sector corisumes the largest proportion of energy--30 percent (Table 33). Energy sources consumed in this sector are fuel wood, electricity, liquid gas, and kerosene. Of the total fuels consumed in this sector, fuel wood accounts for about 77 percent, electricity for about 12 percent, LPG for about 10 percent and kerosene for only about 1 percent. In the rural areas, fundamental energy needs are mainly provided by the noncommercial energy source--wood, used for cooking; while in the urban areas, the principal energy sources consumed are commercial--mainly electricity and LPG, for cooking and air conditioning. Of the electricity consumed in the residential sector, about 52 percent is used for refrigeration, about 30 percent for electrical appliances, and about 28 percent for cooking, lighting, air conditioning, and hot water heating. 18 
TABLE 32

PANAMA: 1984 ENERGY CONSUMPIION (percentage of total)

\begin{tabular}{|c|c|c|c|c|c|c|c|}
\hline Enerax Ixpe & Residentilel & Commeraial & Ironspert & $\begin{array}{l}\text { Industrial/ } \\
\text { Agriculture }\end{array}$ & Public & other & $\begin{array}{l}\text { Totol Consumption } \\
\text { By Eneray Ixpe }\end{array}$ \\
\hline Fuel wood & 23.0 & & & 2.1 & & & 25.1 \\
\hline Vegetoble residue & & & & 6.8 & & & 6.8 \\
\hline Eloctricity & 3.5 & 3.9 & & 3.2 & 2.5 & 0.6 & 13.6 \\
\hline \multicolumn{8}{|l|}{ Petroloum and derivatives } \\
\hline Rofinery gos & & & & & & 3.8 & 3.8 \\
\hline Liquid gas & 2.9 & 1.0 & & 0.5 & & 0.02 & 4.4 \\
\hline Gasoline & & & 17.0 & & & 0.01 & 17.0 \\
\hline Kerosene and jet fuel & 0.4 & & 0.2 & & & & 0. 6 \\
\hline Diesel oil & & 0.4 & 10.0 & 7.9 & & 0.02 & 18.3 \\
\hline Fuel oil & & & & 4.8 & & 3.9 & 8.7 \\
\hline $\begin{array}{c}\text { Total petroleum } \\
\text { derivatives }\end{array}$ & 3.3 & 1.5 & 27.2 & 13.3 & & 8.0 & $\overline{53.2}$ \\
\hline Nonenergy & & & & & & 0.9 & $\overline{0.9}$ \\
\hline Charcoal & & 0.03 & & & & & 0.03 \\
\hline $\begin{array}{c}\text { Total soctorial } \\
\text { consumption }\end{array}$ & 30.0 & 5.4 & 27.2 & 25.4 & 2.5 & 9.5 & 100.0 \\
\hline
\end{tabular}

Note: Total does not sum to 100 due to rounding.

TABLE 33

PANAMA: 1984 ENERGY CONSUMPTION

(percentoge of fuel use by soctor)

\begin{tabular}{|c|c|c|c|c|c|c|c|}
\hline & & Camoral & Tranenort & Industriol/ & Public & Other & Total Consumption \\
\hline Fuel wood & 91.6 & & & 8.4 & & . & 100.0 \\
\hline vegetable reaidue & & & & 100.0 & & & 100.0 \\
\hline Electricity & 25.9 & 28.6 & & 23.2 & 18.0 & 4.2 & 100.0 \\
\hline \multicolumn{8}{|l|}{ Potroloum derivatives } \\
\hline Refinery gas & & & & & & 100.0 & 100.0 \\
\hline Liquid gas & 65.7 & 22.6 & & 11.1 & & 0.5 & 100.0 \\
\hline Gasolino & & & 99.9 & & & 0.1 & 100.0 \\
\hline Kerosene and jet fuel & 63.3 & 2.0 & 26.5 & 8. 2 & & & 100.0 \\
\hline Diesel oil & & 2.4 & 54.1 & 42.7 & & 0.8 & 100.0 \\
\hline Fuel oll & & 0.5 & & 55.0 & & 44.4 & 100.0 \\
\hline $\begin{array}{l}\text { Total petroleum } \\
\text { derivatives }\end{array}$ & 6.2 & 2.8 & 51.0 & 24.9 & & 15.1 & 100.0 \\
\hline Nonenergy & & & & & & 100.0 & 100.0 \\
\hline Chorcoal & & 100.0 & & & & & 100.0 \\
\hline $\begin{array}{c}\text { Total sactorial } \\
\text { consumption }\end{array}$ & 30.0 & 5.4 & 27.2 & 25.4 & 2.5 & 9.5 & 100.0 \\
\hline
\end{tabular}

Note: Total does not sum to 100 due to rounding. 
b. Transport. The transport sector was the second largest consumer of energy in 1984--27 percent of total energy consumption (Table 33). All fuels consumed in this sector are petroleum derivatives-gasoline, kerosene and jet fuel, and diesel oil. Of the total fuels consumed in this sector, gasoline accounts for about 63 percent, diesel oil for about 37 percent and kerosene and jet fuel for only 0.6 percent. In 1 and transport of passengers, the principal fuels used are gasoline and diesel. In the transport of cargo, the same fuels are used. Private maritime includes all private yachts, boats and vessels, and the fuel consumed is gasoline. Commercial maritime consists of small business boats and shrimp boats that consume diesel $011 .{ }^{18}$

c. Industrial/Agricultural. The industrial/agriculture sector was the third largest consumer of energy in 1984--26 percent of total energy consumption (Table 33). Energy sources consumed in this sector are fuel wood, vegetable residue, electricity, liquid gas, kerosene, diesel oil, and fuel oil. Of the total fuels consumed in this sector, petroleum derivatives account for 53 percent, vegetable residue for about 27 percent, electricity for about 12 percent, and fuel wood for about 8 percent. The major requirements of energy for this sector are tied to the generation of steam, electricity, and certain productive processes. The branch of food, beverage, and tobacco products is characterized by its strong consumption of diesel, fuel $0 i 1$, kerosene, electricity and vegetable residues (in sugar mills). The branch of textiles, clothing, and leather industries is characterized by consumption of petroleum derivatives. The wood and wood product industries (including furniture manufacturing) recorded substantial consumption of diesel and electricity and a small consumption of fuel oil. Paper and paper product manufacturing (including printing and publishing companies) consume fuel $0 i 1$ and electricity. The manufacturing of chemical substances (chemical products derived from petroleum and coal) is an energy-intensive branch and records strong consumption of diesel oil and electricity. The manufacturing of nonmetallic products consumes fuel $0 i 1$ and diesel. For the basic metal industries, the principal energy sources are diesel and fuel oil. Fuel wood consumption in this sector is attributed to bakeries and sweet shops, sugar mills, coffee processing, saw mills, alcohol factories, ceramic shops, and brick-making businesses. 18

d. Commercial. The commercial sector consumed 5.5 percent of total energy consumption in 1984 (Table 33). Energy sources consumed in this sector include electricity, liquid gas, diesel oil, kerosene, fuel oil, and charcoal. Of the total fuels consumed in this sector, electricity accounted for about 71 percent (virtually 50 percent of the electricity consumed in this sector is used for air 
conditioning), petroleum derivatives accounted for about 28 percent, and charcoal for only about 1 percent (not shown in table). As mentioned previously, this sector includes commercial activities such as wholesale and retail stores, hotels, restaurants, laundries, etc. The principal energy consumed in the majority of commercial establishments is electricity, mostly used for air conditioning. During the past several years, the number of retail establishments has increased and in many cases, their doors are left open, and they have no installed thermostats. Thus energy for air conditioning has increased considerably. The principal energies consumed in hotels are electrical energy and LPG, with some use of fuel oil and diesel oil for the production of steam and hot water. Electricity and LPG satisfy the cooking needs, lighting, heating of water and refrigeration for restaurants. Services such as hospital, schools, social clubs, etc., primarily use LPG, fuel 0i1, diesel and electricity. 12

e. Public. The public sector consumed the least amount of energy of all sectors in 1984--2.5 percent (Table 33). Electricity is the principal energy consumed in the sector, and its destination is lighting, air conditioning, and office equipment in public and municipal buildings.

\section{Energy Planning and Management}

\section{Energy-Related Institutions}

Panama has several institutions that participate in energy planning: CONADE, IRHE, and MIPPE.

a. CONADE. CONADE is Panama's national energy board and has the responsibility to recommend energy-related policies and practices to the President and ministers. CONADE collects and manipulates energy data and does analyses in the energy field. The board consists of persons from various institutions--Minister of Commerce and Industry, Minister of Agricultural Development, Minister of Planning and Economic Policy, Director of IRHE, and persons from the private sector-representatives from two universities and three citizens appointed by the Executive Branch. The Director of IRHE is chairman of the commission. There also exists a Technical Secretariat of CONADE composed of five working groups: (1) Economy of Energy; (2) Planning; (3) Alternative Energy and Conservation; (4) Programming and Coordination; and (5) Administration.

b. IRHE. IRHE is Panama's national electric company and has sole responsibility for the production, transmission, and distribution of electricity within Panama. The company was organized in 1960 and expanded in 1972 with its nationalization.

c. MIPPE. MIPPE has the mandate for economy-wide planning. The five sections of MIPPE include (1) Public Credit, (2) Economic and Social Planning, (3) 
Budget Office, (4) Institutional Development, and (5) Regional Planning and coordination. They are responsible for administering the national budget. MIPPE has three rural development programs that deal with the economic-social development of specific areas that are the poorest in the country.

\section{Current Planning Methods and Needs.}

CONADE has a capable staff of computer programmers, economists, and engineers. A project funded by the World Bank was recently completed that had three major components: (1) analysis of the costs, prices, and substitution of fuels in Panama, (2) data base construction, and (3) a planning-strategies analysis. Although significant work was begun in these areas, follow-on is required to complete these activities. For example, the information system transferred did not run on the CONADE computers. To fill this void, as part of the Los Alamos/AID energy development project, an IBM PC-XT and data base system was transferred to CONADE. Training and additional assistance were also provided.

During 1986, CONADE completed an ambitious project to prepare a prelimenary national energy plan. The plan utilized an energy-demand model, a refinery simulation, and macroeconomic scenarios to provide forecasts of the energy situation in the future. The demand model runs on the IBM PC-XT using software transferred as part of the Los Alamos/AID project.

The demand model uses a methodology similar to that of a French $p 1$ anning model called "MEDEE." Basically, energy consumption is estimated on a sectorby-sector basis using energy-use coefficients and statistical relationships. The model is very flexible and can be expanded as new, more disaggregated, data become available. Because it uses integrated spread-sheets, it is also easy to understand.

Currently, CONADE is improving the energy plan by constructing scenarios for the future. A model to test and confirm the consistency of these scenarios is needed. Also, to improve the accuracy and detail of the energy forecasts, additional data surveys must be undertaken. The transport sector is a top priority for surveys. As CONADE's experience grows, it hopefully will play a more integral role in planning for the future of the country. Further institutional assistance is needed, however, to insure that this hope becomes a reality. 


\section{SUMMARY AND RECOMMENDATIONS}

A. Summary

Three main energy problems that Panama faces include (1) a large dependence on oil products, (2) high electricity rates, and (3) the potential for fuel-wood shortages in some areas of the country.

As in other Central American countries, the rapid rise in oil prices during 1973 and 1979 has substantially increased Panama's 0 il import bill. In 1984, petroleum products supplied about 54 percent of net energy in Panama. Areas of large oil consumption in Panama are transportation and electricity generation. A large price differential between gasoline and diesel favors the use of the heavier distillate, diesel. For example, in 1985 regular and premium gasoline were 65 percent and 71 percent, respectively, more expensive than diesel. Other than encouraging the use of heavier distillates, there is little that Panama can do because a less expensive fuel substitution is currently not available, at least for the transport sector.

In areas where substitution is possible, Panama is making an effort to develop indigenous resources in order to be less dependent on oil imports. One area where this is occurring is in electricity generation. In 1970, thermoelectric generation accounted for 90 percent of total electricity generation. Because of Panama's heavy reliance on oil-fired electricity generation in the past, electricity prices have increased sharply with the major price increases of 1973 and 1979. In an effort to reduce dependence on petroleum imports, Panama began hydroelectric development in the early 1970s. By 1984, thermoelectric generation accounted for only 33 percent of total electricity generation. During the transition from thermoelectric to hydroelectric generation, IRHE has experienced both cost overruns on projects and operating inefficiencies. Thus, electric rates are at present about 13 to 15 cents per kilowatt-hour. In a continuing effort to reduce 0 il dependence and as an alternative for electrification in rural areas, Panama has begun micro-and minihydroelectric power plant construction.

At present, Panama has the lowest consumption of fuel wood in Central America. This is owing to two factors: (1) Panama is the most urbanized country in Central America, and (2) some of the country's rural poor buy inexpensive propane for cooking. Of total energy supply in 1984, fuel wood accounted for on 1 y 25 percent compared to 60 percent in Honduras, for example. About 58 percent of Panama's population are urban dwellers, and of that, about 90 percent use gas and electricity. Unlike the rural poor in Honduras who solely use fuel wood for cooking purposes owing to its availability at no cost, 
only the very poor use wood in the rural areas in Panama. Even so, Panama is faced with a deforestation problem that has developed over the years as a result of rapid population growth since the mid-nineteenth century. It has been estimated that only 37 percent of Panama is at present covered in forest, and of particular concern is the deforestation that has taken place in the watershed of the Panama canal. The operation of the canal depends on the existence of forests that provide a stable water regime, and approximately 60 percent of the 326,000 hectares of this vital watershed are at present deforested. In an effort to remedy this problem, Panama is engaged in plans for planting and regenerating forests.

In order to foster the use of LPG, its real price has not been increased much since 1970. During the latter part of the 1970s, the price of LPG increased somewhat and fuel wood usage also increased slightly in response. When LPG prices decreased during the early part of the 1980s, fuel-wood consumption also decreased. Thus it would seem that in addition to the reforestation $p l a n s$ that are already underway in Panama, the continued and even increased use of LPG rather than fuel wood for cooking should be fostered by continuing to subsidize this substitute fuel.

\section{B. Recommendations}

The energy situation of Panama differs significantly from that of the other countries in the region. Panama does not have as large a hydroelectric potential as some of the other countries, nor does it have favorability for large geothermal resources. The country is far more oil dependent, partly because of its higher level of development and partly because it still generates a relatively large amount of its electricity from $0 i l$ products. It also has a higher per capita use of electricity, caused in part by a large air-conditioning demand in the capital. Panama's economy is service oriented whereas the other economies in the region are agriculturally oriented, which affects consumption patterns. The following recommendations for the country are shaped in part by its unique nature.

- Provide assistance to CONADE for surveys of energy consumption in the transport and industrial sectors.

An operational energy demand model exists now, but more detailed and accurate data in these two sectors is needed to strengthen energy planning.

- Assist CONADE in improving their energy planning model. 
Although a model is now operational at CONADE, the following improvements and extensions are necessary. First, energy price effects must be included in the demand forecasts. (The present model is not capable of modeling pricing policy scenarios.) Second, a model to test the consistency of macroeconomic scenarios is needed. This model should also allow energy sector effects to influence the macroeconomic scenarios.

- Assist Panama in a resource evaluation of peat and coal and their potential end uses.

Significant peat deposits were discovered in a recent Los Alamos mission to Panama, and in general, the geography is favorable for a large peat resource. Coal is known to exist in the country and has been mined in the past. Geologists will need assistance in better defining these resources, and the end uses for peat and coal need to be determined through prefeasibility analysis. Peat might be able to be substituted for fuel wood, and both fuels could displace some imported oil.

- Assist Panama in controlling the deforestation problem, especially in the critical Canal watershed.

Of all of the Central American countries, Panama relies least on fuel wood as a source of energy. However, fuel wood is still important--it supplied 25 percent of the country's energy use in 1984, and the potential for fuel wood shortages exists in some parts of the country. Current reforestation efforts should be supported, as should the promotion of more efficient forestry policies in general (perhaps to increase the use of a fuel-wood substitute such as LPG, or the use of better cooking stoves).

- Provide assistance to Panama to evaluate and promote efficiency of energy use.

Opportunities exist for improving the efficiency of energy use in Panama. For example, the amount of air conditioning required in the commercial sector is a potential target of conservation measures. CONADE is considering imposing higher tariffs on the import of energyinefficient private autos. Incentives to encourage pubiic transportation rather than private transportation also need to be evaluated.

- Assist IRHE in improving the efficiency of its operation, where possible.

IRHE has high operating costs for a number of reasons, including a relatively high peak load, the large labor force that the utility must employ, and high debt service on short-term loans for the Fortuna hydroelectric project. Because of institutional and political constraints, some of IRHE's problems cannot be solved easily through 
technical assistance. However, help could be provided to possibly decrease transmission and distribution losses, and to optimally manage generation. Such measures have the potential for decreasing operating costs and allowing lower electricity prices.

\section{REFERENCES}

1. Panama, A Country Study, Richard F. Nyrop, ed. (U.S. Government Printing Office) Washington, D.C., 1981).

2. "Countries of the World and Their Leaders Yearbook 1985" (GaTe Research Company, Detroit, Michigan 48226, 1984).

3. "The World Factbook, Nineteen Hundred and Eighty-Three," Central Inte11igence Agency report CR 83-11300 (May 1983).

4. "Panamanians Struggle With Life After Torijos," Albuquerque Journal, August 4, 1985.

5. "Worldgram--Growing Tension in Panama," U.S. News \& World Report, October 14,1985, p.31.

6. "Tropical Forest Development Projects: Status of Environmental and Agriculture Research," Hearing before the Subcommittee on Natural Resources, Agriculture Research and Environment of the Committee on Science and Technology, U.S. House of Representatives, Ninety-Eighth Congress, Second Session, No. 143, September 19, 1984.

7. USAID/Panama, "Development Policy Studies," project number 525-0250, November 1984.

8. United Nations, "Economic Survey of Latin America and the Caribbean, 1982," Vol. 1, Economic Commission for Latin America and the Caribbean, United Nations Publication, November 1984.

9. United Nations, "Economic Survey of Latin America, 1981," report by Economic Commission for Latin America, United Nations, Santiago, Chile, 1983.

10. Nasser Saidi, "Public Debt, Expenditure and Revenue, Panama 1956-1983: Assessment and Policy Recommendations" (University of Geneva, Geneva, Switzerland, July 1984).

11. John L. Kmetz and Joseph L. Rykie1, "A Preliminary P1an for the Development of Renewable Energy in the Republic of Panama," executive summary. Prepared for Hydraulic Resources and Electrification (Republic of Panama) under contract No. 31-80-DG by the Institute of Energy Conversion, University of Delaware, Newark, Delaware.

12. The Economist Intelligence Unit, "Mexico, Central America and the Caribbean, Economic Structure and Analysis," The Economist Publications Ltd., 1985.

13. Comision Nacional de Energia (CONADE), "Balance Energetico Nacional, Serie Historica 1970-1980," Programa Energetica del Istmo Centroamericano RLA/76/012, Volumen I, Republica de Panama, diciembre 1981. 
14. "Balance de Energia Primaria," "Balance de los Centros de Transformacion," "Balance de Energia Secundaria," and "Consumo de Energia," 1981-1984.

15. Inter-American Development Bank, "Economic and Social Progress in Latin America, External Debt: Crisis and Adjustment, " report, Inter-American Development Bank, 808 17th Street, N.W., Washington, D.C. 20577 (1985).

16. Comision Nacional de Energia (CONADE), "Diagnostico Sobre la Actual Refineria," Resumen Ejecutivo, enero 1983.

17. "Como se Fijan los Precios de los Derivado de Petroleos en Panama," Seccion Economia de la Energia, Secretaria Tecnica de la Comision Nacional de Energia, ano 1985.

18. Comision Nacional de Energia (CONADE), "Diagnostico Global del Sector Energia, Anos: 1970-1980, Volumen II del Balance Energeico Nacional," Programa Energetico del Istmo Centroamericano RLA-76-012, Republica de Panama, diciembre 1981 . 


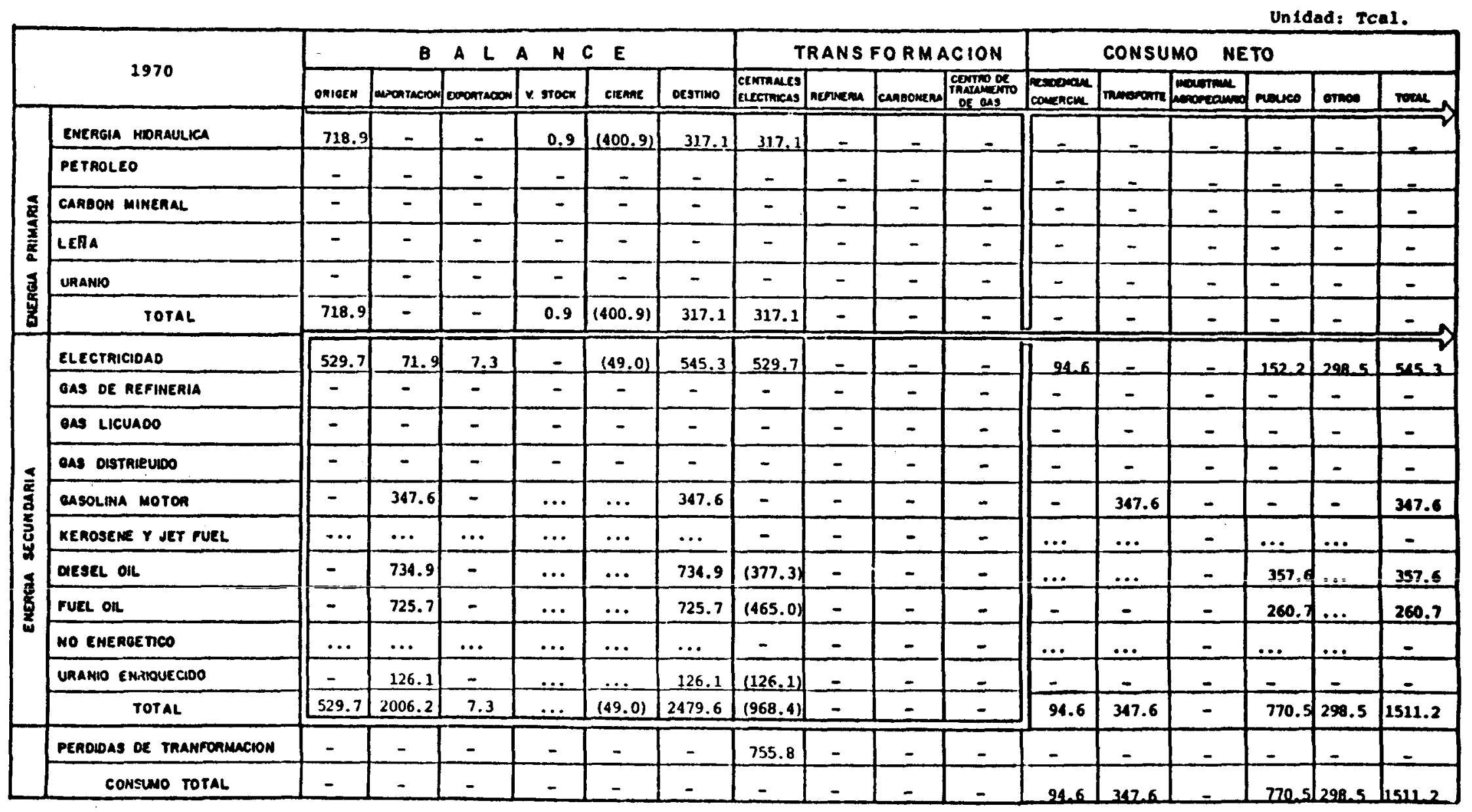

Source: Comision Nacional de Energia (CONADE), "Balance Energetico Nacional, Serie Historica 1970-1980," Programa Energetico del Istmo Centroamericano RLA/76/012, Volumen I, Republica de Panama, diciembre 1981. 
Un1dad, Tcal.

\begin{tabular}{|c|c|c|c|c|c|c|c|c|c|c|c|c|c|c|c|c|c|}
\hline & \multirow[b]{2}{*}{1971} & \multicolumn{2}{|r|}{$\mathbf{B}$} & \multirow{2}{*}{$\begin{array}{ll}A L \\
0\end{array}$} & \multirow{2}{*}{\begin{tabular}{|l|l|} 
& $N C$ \\
& $C$ srock \\
\end{tabular}} & \multicolumn{2}{|l|}{$E$} & \multicolumn{4}{|c|}{ TRANS FO RMACION } & \multicolumn{6}{|c|}{ CONSUMO NETO } \\
\hline & & onisern & montincionf & & & ciemane & Desrino & \begin{tabular}{|l|} 
CENThNACS \\
ELECTReas
\end{tabular} & nemenn & contonemen & 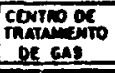 & $\begin{array}{l}\text { anconoux } \\
\text { conencm }\end{array}$ & movom & movoriman & menco & ormose & noen \\
\hline \multirow{6}{*}{ 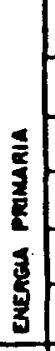 } & ENERGIA HORAULICA & 478.6 & - & - & (16.8) & $(198.4)$ & 297.0 & 297.0 & - & - & - & - & - & - & - & - & - \\
\hline & PETROLEO & - & - & - & - & - & - & - & - & - & - & - & - & - & - & $=$ & - \\
\hline & CARBON MINEAAL & - & - & - & - & - & - & - & - & $=$ & - & $=$ & $=$ & - & $=$ & $=$ & $=$ \\
\hline & LENA & - & - & - & - & - & - & - & - & - & - & - & - & $=$ & - & $=$ & $=$ \\
\hline & URANIO & - & - & - & - & - & - & - & - & - & - & - & - & $=$ & - & $=$ & $=$ \\
\hline & TOTAL & 478.6 & - & $=$ & (16.8) & $(198.4)$ & 297.0 & 297.0 & - & - & - & - & - & - & - & $=$ & - \\
\hline \multirow{13}{*}{ 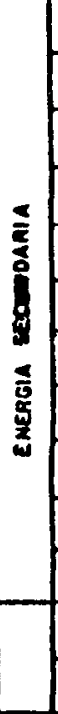 } & ELECTMICAOAD & 578.8 & 44.5 & 4.9 & - & (59.5) & 558.9 & 578.8 & - & - & - & 95.4 & - & - & 159.1 & 304.4 & $558.9^{2}$ \\
\hline & GAS OE REFIMERIA & - & - & - & - & - & - & - & - & - & - & - & - & - & - & - & - \\
\hline & GAS LICUADO & - & - & - & - & - & - & - & - & - & - & - & $=$ & - & - & - & - \\
\hline & GAS OLSTHEUDOD & - & - & - & - & - & - & - & - & - & $=$ & - & 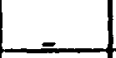 & $=$ & - & 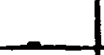 & \\
\hline & Gasolima moron & - & 442.2 & - & 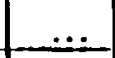 & $\ldots$ & 442.2 & - & - & - & - & - & 442.2 & - & $=$ & - & 442.2 \\
\hline & KEROSENE Y JET FUEL & & & i.. & . & ... & $\ldots$ & - & - & - & - & ع & عend & - & ... & $\mu$ & - \\
\hline & OEESEL OIL & - & 781.6 & - & $\ldots$ & $\ldots$ & 781.6 & $(472.5)$ & - & - & - & - & $\ldots$ & - & 309.1 & $\ldots$ & 309.1 \\
\hline & FUEL OIL & - & 824.7 & - & $\ldots$ & $\ldots$ & 824.7 & (532.0) & - & - & - & - & - & - & 292.7 & $\ldots$ & 292.7 \\
\hline & NO ENERGE NCO & $\cdots$ & $\ldots$ & $\ldots$ & & & & - & - & - & - & .. &. & - & 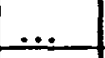 & $\ldots$ & - \\
\hline & UAANIO EMPIOUECIDO & - & 200.7 & - & $\ldots$ & $\ldots$ & 200.7 & $(200.7)$ & - & - & - & - & - & - & - & - & - \\
\hline & rotal & 578.8 & 2293.7) & 4.9 & $\ldots$ & $(59.5)$ & 2808.1 & (a205.2) & - & - & - & 95.4 & 412.2 & - & 760.9 & 304.4 & 1602.9 \\
\hline & PERODOAS OE TRANFORMUCION & - & - & - & - & - & - & 923.4 & - & - & - & - & - & - & - & - & - \\
\hline & CONSUNO TOTAL & - & - & - & - & - & - & - & - & - & - & 95.4 & $4+2.2$ & - & 760.9 & 304.4 & 1602.9 \\
\hline
\end{tabular}


Unidad, Tcal.

\begin{tabular}{|c|c|c|c|c|c|c|c|c|c|c|c|c|c|c|c|c|c|}
\hline & \multirow{2}{*}{1972} & \multicolumn{2}{|r|}{$\mathbf{8}$} & \multirow{2}{*}{ 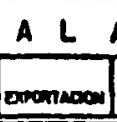 } & \multirow{2}{*}{$\frac{N}{N \text { noex }}$} & \multicolumn{2}{|l|}{$E$} & \multicolumn{4}{|c|}{ TRANS FORMACION } & \multicolumn{6}{|c|}{ COMSUMO NETO } \\
\hline & & onioen & monincons & & & cume & ocenno & $\begin{array}{l}\text { cenmars: } \\
\text { easemaces: }\end{array}$ & newen & censonene & 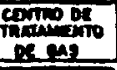 & mosomax & monomens & monominam & mouses & ornese & roone \\
\hline \multirow{6}{*}{ 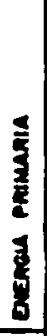 } & EMEAOIA MDAULUKA & 377.3 & - & - & 0.4 & (150.1) & 226.8 & 226.8 & $=$ & - & $=$ & - & - & - & - & - & - \\
\hline & PETROLEO & - & - & - & - & -1 & - & - & - & - & - & - & - & - & - & - & - \\
\hline & canoow mimeane & - & - & - & - & - & - & - & - & - & - & - & - & - & - & - & - \\
\hline & LEFA & - & - & - & - & - & - & - & - & - & - & - & - & - & - & - & - \\
\hline & UAAMNO & - & $=$ & - & - & - & - & - & - & - & - & - & - & $=$ & - & - & - \\
\hline & Total & 377.3 & - & - & 0.4 & (150.1) & 226.8 & 226.8 & - & - & - & - & - & - & - & - & - \\
\hline \multirow{13}{*}{$\begin{array}{l}5 \\
5 \\
5 \\
5 \\
5\end{array}$} & ELECTAICIOAD & 207.8 & 33.6 & 10.8 & - & (146.4) & 576.2 & 707.8 & $=$ & - & - & 103.2 & - & - & 164,3 & 308.7 & 526.2 \\
\hline & OAS DE MEFIMEALA & - & - & - & - & - & - & - & - & - & - & - & - & - & - & - & - \\
\hline & OAS LICUAODO & - & - & - & - & - & - & - & - & - & - & - & - & - & - & - & - \\
\hline & Cas Dastniaudo & - & - & - & - & - & - & - & - & - & - & - & - & - & - & - & - \\
\hline & ensolima moton & - & 457.6 & - & $\ldots$ & $\ldots$ & 457.6 & - & - & - & - & - & 457.6 & - & - & - & 457.6 \\
\hline & nenosede Y jêT FuEL & $\ldots$ & $\ldots$ & $\ldots$ & $\ldots$ & $\ldots$ & $\ldots$ & - & - & - & - & $\ldots$ & $\ldots$ & $=$ & $\ldots$ & $\ldots$ & - \\
\hline & acser or & - & 734.9 & - & $\ldots$ & $\ldots$ & 734.9 & (397.3) & - & $=$ & - & $\ldots$ & $\ldots$ & - & 337.6 & $\ldots$ & 337.6 \\
\hline & FuRt on & - & 1309.6 & - & $\ldots$ & $\ldots$ & 1309.6 & a024.7) & $=$ & - & - & - & - & - & 284.9 & $\ldots$ & 284.9 \\
\hline & MO ENEMGE TICO & $\ldots$ & $\ldots$ & $\ldots$ & $\ldots$ & $\ldots$ & $\ldots$ & - & $=$ & $=$ & $=$ & $\ldots$ & $\ldots$ & - & $\ldots$ & $\ldots$ & - \\
\hline & URANIO ENMIOUECIDO & - & 212.1 & - & $\ldots$ & $\therefore$ & 212.1 & (212.1) & - & $=$ & - & - & - & - & - & - & - \\
\hline & TOTAL & 707.8 & 2747.8 & 18.8 & $\ldots$ & $(146.4)$ & 3290.4 & 0634.1 & - & - & - & 103.2 & 457.6 & - & 786.8 & 308.7 & 1656.3 \\
\hline & PEROIDAS DE TRAMPORMACION & - & - & - & - & - & - & 1153.1 & - & - & - & - & - & - & - & - & - \\
\hline & conseno total & - & - & - & - & - & - & - & - & - & - & 103.2 & 457.6 & - & 786.8 & 308.7 & 1656.3 \\
\hline
\end{tabular}




\begin{tabular}{|c|c|c|c|c|c|c|c|c|c|c|c|c|c|c|c|c|c|}
\hline & \multirow[b]{2}{*}{1973} & \multicolumn{2}{|r|}{$\mathbf{B}$} & \multirow{2}{*}{$\begin{array}{ll}A & 1 \\
0 & \end{array}$} & \multirow{2}{*}{ A N N } & \multicolumn{2}{|l|}{ C E } & \multicolumn{4}{|c|}{ TRANS FO RMACION } & \multicolumn{6}{|c|}{ CONSUMO NETO } \\
\hline & & ontern & maninacon & & & eneme & ocrmo & $\begin{array}{l}\text { etrmanes } \\
\text { enermaces }\end{array}$ & nemen & cencousen & 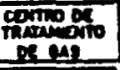 & ponesome & menowners & volomine & manes & onen & $m$ \\
\hline \multirow{6}{*}{$\begin{array}{l}\mathbf{5} \\
\mathbf{3} \\
\mathbf{z} \\
\mathbf{z} \\
8 \\
8\end{array}$} & ENEneNa monulurea & 406.6 & - & - & 16.3 & $(181.9)$ & 208.4 & 208.4 & - & - & - & - & - & - & - & - & - \\
\hline & PETMOLEO & - & - & - & - & - & - & - & - & - & - & - & - & - & - & - & - \\
\hline & CAMBON MIMERAL & - & - & - & - & - & - & - & - & - & - & - & - & - & - & - & - \\
\hline & LERA & - & - & - & - & - & - & - & - & - & - & - & - & - & - & - & - \\
\hline & UAAMNO & - & - & - & - & - & - & - & - & - & - & - & - & - & - & - & - \\
\hline & TOTAL & 106.6 & - & - & 16.3 & (181.9) & 208.4 & 208.4 & - & - & - & - & - & - & - & - & - \\
\hline \multirow{13}{*}{ 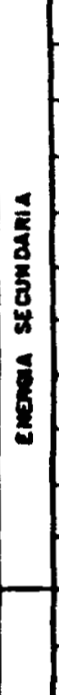 } & ELECTRICIOAD & 591.7 & 59.6 & 16.1 & - & $(55.2)$ & 579.7 & 591.7 & - & - & $=$ & 106.6 & - & - & 268.6 & 304.5 & 579.7 \\
\hline & OAS DE ACPINERIA & - & - & - & - & - & - & - & - & - & - & - & - & $=$ & - & - & $=$ \\
\hline & GAS LicundoO & - & - & - & - & - & - & - & - & - & - & - & - & - & - & - & $=$ \\
\hline & oas desthudeuso & - & - & - & - & - & - & - & - & $=$ & - & - & - & - & - & - & - \\
\hline & assolima moton & - & 431.1 & - & $\ldots$ & $\ldots$ & 431.1 & - & - & - & - & - & $\$ 31.1$ & $=$ & - & - & 431.1 \\
\hline & KEnOSERE Y JET FuRL & $\cdots$ & & $\ldots$ & $\ldots$ & $\ldots$ & $\ldots$ & - & - & $=$ & - & $\ldots$ & $\ldots$ & $=$ & & & $=$ \\
\hline & arsa or & - & 1013.6 & - & $\ldots$ & $\ldots$ & 1013.6 & (683.4) & - & - & - & $\ldots$ & & $=$ & 330.2 & & 330,2 \\
\hline & ruel on & - & 948.7 & - & $\ldots$ & $\ldots$ & 948.7 & (693.1) & - & - & - & - & - & $=$ & 255.6 & 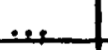 & 259,6 \\
\hline & mo enERGE TICO & م.ر. & $\ldots$ & & 122 & & & - & - & - & - & معب & & - & & & - \\
\hline & uaAno enarouscono & - & 151.9 & - & $\ldots$ & $\ldots$ & 151.9 & (151.9) & $=$ & $=$ & - & - & - & - & - & $=$ & - \\
\hline & TOTAL & 591.7 & 2604.9 & 16.4 & $\ldots$ & (55.2) & 3125.0 & 0528.4 & - & - & - & 106.6 & 431.1 & - & 754.4 & 304.5 & 1596.6 \\
\hline & PERODAS OE TAAMPOAMACION & - & - & - & - & - & - & 1145.1 & - & - & - & $=$ & - & - & - & - & - \\
\hline & CONSUNO TOTAL & - & - & - & - & - & - & - & - & - & - & 106.6 & 431.1 & - & 754.4 & 304.5 & 1596.6 \\
\hline
\end{tabular}


Unidad: Tcal.

\begin{tabular}{|c|c|c|c|c|c|c|c|c|c|c|c|c|c|c|c|c|c|}
\hline & \multirow{2}{*}{1974} & \multicolumn{2}{|r|}{ B } & \multirow{2}{*}{ 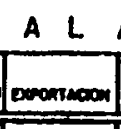 } & \multirow{2}{*}{$\begin{array}{l}0 \mathrm{NO} \\
\mathrm{aroen} \\
\end{array}$} & \multicolumn{2}{|l|}{$E$} & \multicolumn{4}{|c|}{ TRANS FORMACION } & \multicolumn{6}{|c|}{\begin{tabular}{|c|} 
CONSUMO NETO \\
\end{tabular}} \\
\hline & & onveren & montracoun & & & eleme & ocerno & \begin{tabular}{|l|} 
CEmTanes \\
ascmucas \\
\end{tabular} & numen & canconenen & 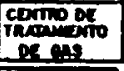 & 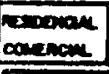 & manown & movem & noues & (1) & nom \\
\hline \multirow{6}{*}{ 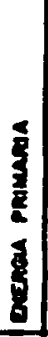 } & ENERGIA HoReuruea & 363.9 & - & - & $(11.0)$ & 176.5 & (198.5) & 198.5 & - & - & - & - & - & - & - & - & - \\
\hline & PETMOLEO & - & - & - & - & - & - & - & - & - & - & - & - & - & - & - & - \\
\hline & CAnDON MIMEnaL & - & - & - & - & - & - & - & - & - & - & - & - & - & - & - & - \\
\hline & LENA & - & - & - & - & - & - & - & - & - & - & - & - & - & - & - & - \\
\hline & URANuo & - & - & - & - & - & - & - & - & - & - & - & - & - & - & - & - \\
\hline & TOTAL & 363.9 & - & - & $(11.0)$ & 176.5 & $(198: 5)$ & 198.5 & - & - & - & $\therefore$ & - & - & - & - & - \\
\hline \multirow{13}{*}{ 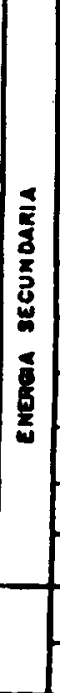 } & ELECTRIGDAO & 595.2 & 15.8 & $(14.9)$ & - & $(55.2)$ & 540.9 & 595.2 & - & - & - & 96,3 & - & - & 153.1 & 291,5 & 540.9 \\
\hline & CAS DE mEFIMERIA & - & - & - & - & - & - & - & - & - & - & - & - & - & - & - & - \\
\hline & oAs LICUAdO & - & - & - & - & - & - & - & - & - & - & - & - & - & - & - & - \\
\hline & eas otstavidus & - & - & - & - & - & - & - & - & - & - & - & - & - & - & - & - \\
\hline & ensolman moton & - & 182.8 & - & $\ldots$ & $\ldots$ & 182.8 & - & - & - & - & & 182.8 & - & - & - & 182.8 \\
\hline & KEAOSENE Y JET PURL & $\cdots$ & $\ldots$ & $\cdots$ & $\cdots$ & $\cdots$ & $\cdots$ & - & - & - & - & ... & $\ldots$ & - & $\ldots$ & $\ldots$ & - \\
\hline & MESEL ON. & - & 919.8 & - & $\ldots$ & $\ldots$ & 919.8 & $(510.2)$ & - & - & - & $\ldots$ & $\ldots$ & - & 409.6 & & 409.6 \\
\hline & Fues on & - & 1170.6 & - & $\ldots$ & $\ldots$ & 1170.6 & (912.7) & - & - & - & - & - & - & 257.9 & $\ldots$ & 257.9 \\
\hline & NO ENERGE TICO & $\ldots$ & $\ldots$ & $\ldots$ & $\ldots$ & $\ldots$ & $\ldots$ & - & - & - & - & $\ldots$ & $\ldots$ & - & $\ldots$ & $\ldots$ & - \\
\hline & UAANNO EMRIOUECIOO & - & 77.4 & - & ... & $\ldots$ & 77.4 & $(77.4)$ & - & - & - & - & - & - & - & - & - \\
\hline & TOTAL & 595.2 & 2366.4 & $(14,9)$ & $\ldots$ & $(55.2)$ & 2891.5 & $(0500.3)$ & - & - & - & 96.3 & 182.8 & - & 820.6 & 291.5 & 1391.2 \\
\hline & PEnODAs oe tmanronmucion & - & - & - & - & - & - & 1103.6 & - & - & - & - & - & - & - & - & - \\
\hline & consuno total & - & - & - & - & - & - & - & - & - & - & 96.3 & 182.8 & - & 820.6 & 291.5 & 1391.2 \\
\hline
\end{tabular}


Untded: roal.

\begin{tabular}{|c|c|c|c|c|c|c|c|c|c|c|c|c|c|c|c|c|c|}
\hline & \multirow{2}{*}{1975} & \multicolumn{6}{|c|}{ B } & \multicolumn{4}{|c|}{ TRANS FORMACION } & \multicolumn{6}{|c|}{ CONSUMO NETO } \\
\hline & & onicen & mantacion & aromiacon & ×. grock & cirme & oEstimo & 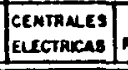 & nenvern & censonger & 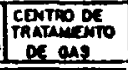 & \begin{tabular}{|l|} 
rescomalu \\
coirencie
\end{tabular} & menenore & movoritien & mouco & onco & toren \\
\hline \multirow{6}{*}{ 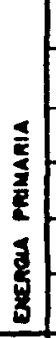 } & EMEAGIA MDRAULICA & 497.3 & - & - & 11.3 & (237.2) & 248.8 & 248.8 & - & - & - & - & - & - & - & - & - \\
\hline & PETROLEO & - & - & - & - & - & - & - & - & - & - & - & - & - & - & - & - \\
\hline & CARBON MINEAAL & - & - & - & - & - & - & - & - & - & - & - & - & - & - & $=$ & - \\
\hline & LENA & - & - & - & - & - & - & - & - & - & - & - & - & - & - & $=$ & - \\
\hline & URANIO & - & - & - & - & - & - & - & - & - & $=$ & - & - & - & $=$ & - & - \\
\hline & TOTAL & 497.3 & - & - & 11.3 & (237.2) & 248.8 & 248.8 & $=$ & - & $=$ & $=$ & - & - & - & $=$ & - \\
\hline \multirow{11}{*}{ 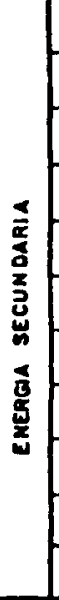 } & ELECTRICIOAD & 599.0 & 12.7 & 25.9 & - & $(6.2)$ & 599.0 & 599.0 & - & - & $=$ & 94.6 & - & - & 101.5 & 383.5 & 579.6 \\
\hline & oAS dE nEFImERIA & - & - & - & - & - & - & $=$ & - & - & $=$ & - & - & - & - & - & $=$ \\
\hline & GAS LICUADO & - & - & - & - & - & - & - & - & - & - & - & - & - & - & - & - \\
\hline & GAS DISTRLEUDDO & - & - & - & - & - & - & - & - & - & - & - & - & - & - & - & - \\
\hline & CASOLIMA MOTOR & - & 163.0 & $=$ & $\ldots$ & $\ldots$ & 163.0 & - & - & - & - & \pm & 163.0 & - & - & - & 163.0 \\
\hline & KEROSENE Y JET FUEL & $\ldots$ & $\ldots$ & $\ldots$ & $\ldots$ & $\ldots$ & $\ldots$ & - & - & - & $=$ & $\ldots$ & & - & & & - \\
\hline & DESEL, OIL & - & 452.8 & - & $\ldots$ & $\ldots$ & 452.8 & $(263.8)$ & - & - & - & & & $=$ & 189.0 & & 189.0 \\
\hline & FUEL ON & - &, 327.8 & - & $\ldots$ & $\ldots$ & $1,207.8$ & $(1,000.9$ & - & - & $=$ & & & $=$ & 327.0 & & 327.0 \\
\hline & NO ENEAGE TICO & $\ldots$ & $\ldots$ & $\ldots$ & $\ldots$ & $\ldots$ & $\ldots$ & - & - & - & $=$ & 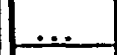 & $\mathrm{A}$ & - & & & \\
\hline & UAANDO EMRTOUECIDO & $=$ & 91,6 & $=$ & & & 21.6 & 01.6 & - & - & $=$ & - & $=$ & $=$ & & & \\
\hline & TOTAL & 599.0 & $2.047,9$ & 25,9 & $\ldots$ & $(6.2)$ & 2614,8 & $\mid(1.356 .21 \mid$ & - & $=$ & $=$ & 94.6 & 163.0 & - & 617.5 & 383.5 & 258.6 \\
\hline & PEROIDAs de tramponmacion & - & - & - & - & - & - & $1,006.0$ & - & - & - & - & - & - & - & - & - \\
\hline & CONSLMO TOTAL & - & - & - & - & - & - & - & - & - & - & 94.6 & 163.0 & - & 617.5 & 383.5 & 4.258 .6 \\
\hline
\end{tabular}


Unided: Toal.

\begin{tabular}{|c|c|c|c|c|c|c|c|c|c|c|c|c|c|c|c|c|c|}
\hline & \multirow[b]{2}{*}{1976} & \multicolumn{2}{|r|}{ B } & \multirow{2}{*}{$\begin{array}{l}\text { A L } \\
\text { Dominacon }\end{array}$} & \multirow{2}{*}{$\begin{array}{l}A \mathrm{~N} \\
\text { v. stock }\end{array}$} & \multicolumn{2}{|l|}{$C E$} & \multicolumn{4}{|c|}{ TRANS FORMACION } & \multicolumn{6}{|c|}{ CONSUMO NETO } \\
\hline & & onveln & menticion & & & cieme & oestino & $\begin{array}{l}\text { CEntRauts } \\
\text { Euetracas }\end{array}$ & nenwern & craponena & 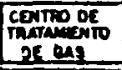 & $\begin{array}{l}\text { pesoovare } \\
\text { courencer }\end{array}$ & mowom & mowinum & numes & ornos & rooue \\
\hline \multirow{6}{*}{$\begin{array}{l}5 \\
8 \\
8 \\
8 \\
8 \\
8\end{array}$} & EMEAGIA HOMAULLA & 271.8 & - & - & $(31.4)$ & $(140.3)$ & 162.9 & 162.9 & - & - & - & - & - & - & - & - & - \\
\hline & PETROLLO & - & - & - & - & - & - & - & - & - & - & - & - & - & - & - & - \\
\hline & CAAZON MINERAL & - & - & - & - & - & - & - & - & - & - & - & - & - & - & - & - \\
\hline & LERA & - & - & - & - & - & - & - & - & - & - & - & - & - & - & - & - \\
\hline & UAANIO & - & - & - & - & - & - & - & - & - & - & - & - & - & - & - & - \\
\hline & TOTAL & 271.8 & - & $=$ & (31.4) & (140.3) & 162.9 & 162.9 & - & - & - & - & $=$ & $=$ & - & - & - \\
\hline \multirow{13}{*}{ 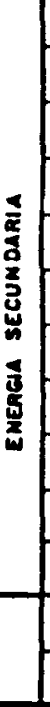 } & ELECTRICIOAO & 592.5 & 33.2 & 7.9 & $=$ & $(63.5)$ & 554.3 & 592.5 & - & - & - & 83.4 & - & $=$ & 102.3 & 362.6 & 50.1 \\
\hline & oAS de merimeaia & - & - & - & - & - & - & - & - & - & - & - & - & - & - & - & - \\
\hline & GAS LICUADO & - & - & - & - & - & - & - & - & - & - & - & - & - & - & - & - \\
\hline & ons otstriaudos & - & - & - & - & - & - & - & - & - & - & - & - & - & - & - & - \\
\hline & Gasoliria moron & - & 167.6 & - & $\ldots$ & $\ldots$ & 167.6 & - & - & - & - & - & 167.6 & - & - & - & 167.6 \\
\hline & KEROSEIE $Y$ JET FUEL & $\ldots$ & $\ldots$ & $\ldots$ & $\ldots$ & $\ldots$ & $\ldots$ & - & - & - & - & $\ldots$ & & - & & & \\
\hline & OESEL OIL & - & 285.2 & - & $\ldots$ & $\ldots$ & 285.2 & (184.6) & - & - & - & $\ldots$ & & $=$ & 100,6 & & 100.6 \\
\hline & FUEL OR & - & E. 307.9 & - & $\ldots$ & $\ldots$ & 307.9 & 0,0549 & $=$ & - & - & - & - & $=$ & 253.0 & & 253.0 \\
\hline & NO ENERGE TICO & $\ldots$ & $\ldots$ & $\ldots$ & $\ldots$ & $\ldots$ & 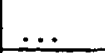 & - & - & - & - & & & $=$ & & & - \\
\hline & URANO EMALOUECIDO & $=$ & 25.8 & $=$ & & & 75.8 & $(25.8)$ & $=$ & $=$ & ـ & & & $=$ & & & \\
\hline & TOTAL & 592,5 & 1.869 .7 & 7,9 & & $(63.5)$ & 2.390 .8 & $11,315,3$ & - & $=$ & $=$ & 83.4 & 167.6 & - & 455.9 & 368.6 & 1,0055 \\
\hline & PEAODAS oE TMANROAMACION & - & - & - & - & - & - & 835.7 & - & - & - & - & - & - & - & - & - \\
\hline & Consuno TOTAL & - & - & - & - & - & - & - & - & - & - & 83.4 & 168.2 & - & 487.5 & 368.6 & 1075.5 \\
\hline
\end{tabular}


Unidad: ronl.

\begin{tabular}{|c|c|c|c|c|c|c|c|c|c|c|c|c|c|c|c|c|c|}
\hline & \multirow{2}{*}{$\begin{array}{llll}1 & 9 & 7 & 7\end{array}$} & \multicolumn{2}{|r|}{$\mathbf{B}$} & \multirow{2}{*}{$\begin{array}{l}A L \\
\text { Ononionow }\end{array}$} & \multirow{2}{*}{ A $N$} & \multicolumn{2}{|l|}{ C E } & \multicolumn{4}{|c|}{ TRANS FO RMACION } & \multicolumn{6}{|c|}{ CONSUMO NETO } \\
\hline & & onisen & monticoun & & & sereme & ocorivo & $\begin{array}{l}\text { esmmucs } \\
\text { exemuens }\end{array}$ & nemenn & cencourese & 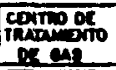 & 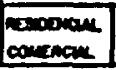 & moneocis & movionis & nmicos & 0 & $\min$ \\
\hline \multirow{6}{*}{$\begin{array}{l}5 \\
5 \\
8 \\
8 \\
8 \\
8 \\
8\end{array}$} & EMERGIA MDRMULCA & 273.3 & - & - & 25.5 & $(113.7)$ & 134.1 & 134.1 & - & - & - & - & - & - & - & - & - \\
\hline & PETMOLEO & - & - & - & - & - & - & - & - & - & - & - & - & - & - & - & - \\
\hline & CAMBON MIHERAL & - & - & - & - & - & - & - & - & - & - & - & - & - & - & - & - \\
\hline & LeRA & - & - & - & - & - & - & - & - & - & $=$ & - & - & - & - & $=$ & - \\
\hline & URAMNO & - & - & - & - & - & - & - & - & - & - & - & - & - & - & - & - \\
\hline & TOTAL & 273.3 & - & - & 25.5 & $(113.7)$ & 134.1 & 134.1 & - & - & $=$ & - & $=$ & - & $=$ & - & - \\
\hline \multirow{13}{*}{ 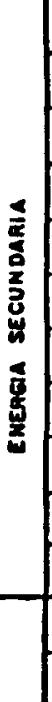 } & ELECTAICIDAO & 515.6 & 80.7 & 14.9 & - & (41.3) & 540.1 & 515.6 & $=$ & $=$ & - & 82.6 & - & - & 99.8 & 357.7 & 5.0 .1 \\
\hline & OAS OE REFIMEMIA & - & - & - & - & - & - & - & - & - & - & - & - & - & $=$ & - & $=$ \\
\hline & OAS LICUADO & - & - & - & - & - & - & - & - & - & - & - & - & - & - & - & - \\
\hline & ans Destanaudoo & - & - & - & - & - & - & - & - & - & - & $=$ & - & - & $=$ & - & $=$ \\
\hline & casolima moton & - & 171.0 & - & $\ldots$ & $\ldots$ & 171.0 & - & - & - & - & $=$ & 171.0 & - & - & - & 272. \\
\hline & KEROSEIE Y JET FUEL & & $\ldots$ & $\ldots$ & & & & - & - & - & $=$ & & & $=$ & & & \\
\hline & OESEL OIL & - & 240.1 & - & & 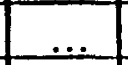 & 240.1 & $(128.4)$ & - & $=$ & $=$ & & & 二 & 111.7 & & I \\
\hline & furL on & - & $1,372.4$ & - & & & $2,372.4$ & $0.107 .6)$ & - & $=$ & - & $=$ & - & - & & & \\
\hline & NO ENEAGE TCO & & & & & & & - & - & - & - & & & - & & & - \\
\hline & UAAMO EMPROUE CIOO & - & - & - & - & - & - & - & - & - & - & - & - & - & - & - & - \\
\hline & TOTAL & 515.6 & $1,864.3$ & 14.9 & $\ldots$ & (41.3) & $2,323.7$ & $(1,2360$ & - & - & - & 82.6 & 171.0 & - & 476.3 & 357.7 & $1,007.7$ \\
\hline & Penowas oe thanronmacion & - & - & - & - & - & - & 854.5 & - & - & - & - & - & - & - & - & - \\
\hline & consuno total & - & - & - & - & - & - & - & - & - & - & 82.6 & 171.0 & - & 476.3 & 357.7 & 1.007 .7 \\
\hline
\end{tabular}


Unided, Tonl.

\begin{tabular}{|c|c|c|c|c|c|c|c|c|c|c|c|c|c|c|c|c|c|}
\hline & \multirow{2}{*}{1978} & \multicolumn{2}{|r|}{$\mathbf{B}$} & \multirow{2}{*}{$\begin{array}{l}\text { A } \mathrm{L} \\
\text { ounorracons }\end{array}$} & \multirow{2}{*}{\begin{tabular}{|l|}
$A$ \\
$\times$ sroex \\
\end{tabular}} & \multicolumn{2}{|l|}{ E } & \multicolumn{4}{|c|}{ TRANS FO RMACION } & \multicolumn{6}{|c|}{ CONSUMO NETO } \\
\hline & & onioen & mentucion & & & cienace & oestino & $\begin{array}{l}\text { exemures } \\
\text { Euctinens }\end{array}$ & aromem & ceneovens & 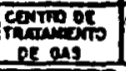 & 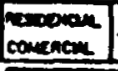 & 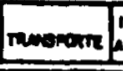 & 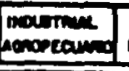 & numes & onsenes & rove \\
\hline \multirow{6}{*}{$\begin{array}{l}5 \\
5 \\
5 \\
5 \\
5 \\
5 \\
5\end{array}$} & exergsa moravica & $\$ 46.3$ & - & - & (5.1) & (181.3) & 270.1 & 270.1 & - & - & - & - & - & - & - & - & - \\
\hline & PETROLLO & - & - & - & - & - & - & -1 & - & - & - & - & - & - & - & - & - \\
\hline & CARBON MIKERAL & - & - & - & - & - & - & - & - & - & - & - & - & - & - & - & - \\
\hline & LERA". & - & - & - & - & - & - & - & - & - & - & - & - & - & $=$ & - & - \\
\hline & unano . & $=$ & - & - & - & - & - & - & - & - & - & - & - & $=$ & - & $=$ & - \\
\hline & TOTAL & 146.3 & $=$ & - & (5.1) & $(181,3)$ & 270.1 & 270.11 & - & $=$ & $=$ & - & - & - & - & $=$ & - \\
\hline \multirow{13}{*}{ 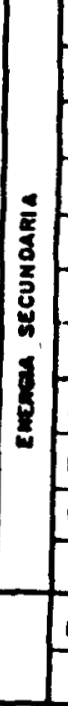 } & ELECTAJCAOAO & 581.4 & 19.9 & 8.9 & - & (59.6) & 532.8 & 581.4 & - & - & - & 77.4 & - & - & 127.3 & 328.1 & $532.8^{2}$ \\
\hline & eAs de nefinenIA & - & - & - & - & - & - & - & - & - & - & - & - & - & - & - & - \\
\hline & OAS LICUADO & - & - & - & - & - & - & - & - & - & - & $=$ & - & - & - & - & - \\
\hline & an Distawousos & - & & - & - & - & - & - & - & - & - & - & - & - & - & - & - \\
\hline & easolman moton & - & 178.0 & - & $\ldots$ & $\ldots$ & 178.0 & - & - & - & - & - & 178.0 & - & $=$ & - & 178.0 \\
\hline & KEMOSENE $Y$ JET FUEL & $\ldots$ & $\ldots$ & $\ldots$ & $\ldots$ & $\ldots$ & $\therefore$ & - & - & - & $=$ & $\ldots$ & $\ldots$ & - & $\ldots$ & $\ldots$ & - \\
\hline & araet oll & - & 296.2 & - & $\ldots$ & $\ldots$ & 196.2 & $(75.2)$ & - & $=$ & $=$ & $\ldots$ & $\ldots$ & - & 121.0 & $\ldots$ & 121.0 \\
\hline & FUEL OR. & - & $\therefore 217.0$ & - & $\ldots$ & $\ldots$ & $1,217.0$ & $(1,024.0)$ & - & $=$ & - & - & - & - & 193.0 & $\cdots$ & 193.0 \\
\hline & NO ENEMGE nCO & $\ldots$ & $\ldots$ & $\ldots$ & $\ldots$ & $\ldots$ & $\ldots$ & - & - & - & - & $\ldots$ & ,. & $=$ & & & - \\
\hline & UnANo EMANuUEcioo & - & - & - & $=$ & - & - & $=$ & - & $=$ & - & - & - & - & $=$ & - & - \\
\hline & TOTAL & 581.4 & 1.611 .2 & B.91 & $\ldots$ & (59.6) & 2124.1 & {$[0,099.2]$} & $=$ & - & - & 77.4 & 178.0 & - & 141.3 & 328.1 & 1,00090 \\
\hline & PEROLAS of TRAMFOAMACION & - & - & - & - & - & - & 787.9 & - & - & - & - & - & - & - & - & - \\
\hline & consumo rotal & - & - & - & - & - & - & - & - & - & - & 27.4 & 178.0 & - & 441.3 & 328.1 & .024 .9 \\
\hline
\end{tabular}


unidedi nol

\begin{tabular}{|c|c|c|c|c|c|c|c|c|c|c|c|c|c|c|c|c|c|}
\hline & \multirow[b]{2}{*}{1979} & & \multirow{2}{*}{$A L$} & \multirow{2}{*}{$\begin{array}{l}A N \\
N \text { S } N C=x\end{array}$} & \multicolumn{2}{|l|}{$E$} & \multicolumn{4}{|c|}{ TRANS FO RMACION } & \multicolumn{6}{|c|}{ CONSUMO NETO } \\
\hline & & onicen Do & Dapoarinaons & & & CIERAE & osstino & \begin{tabular}{l|} 
CEnThuLis \\
Euserinces
\end{tabular} & Aevosine & Carronemeal & 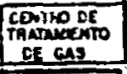 & $\begin{array}{l}\text { Resconver } \\
\text { consencu }\end{array}$ & maverome & movertive & neuce & ormos & Toral \\
\hline \multirow{6}{*}{ 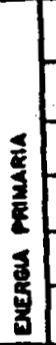 } & ENERGIA MORAULLA & 339.3 & - & - & 10.2 & (118.1) & 211.0 & 211.0 & - & - & - & - & - & - & - & - & - \\
\hline & PETROLEO & - & - & - & - & - & - & - & - & - & - & - & - & $=$ & - & - & - \\
\hline & CARBON MINEAAL & - & - & - & - & - & - & - & - & - & - & . & - & - & - & - & - \\
\hline & LERA & - & - & - & - & - & - & - & - & - & - & - & - & - & - & - & - \\
\hline & URANNo & - & - & - & - & - & - & - & - & - & - & - & - & - & - & - & - \\
\hline & TOTAL & 339.3 & - & - & 10.2 & $\{118,1]$ & 211.0 & 211.0 & - & - & - & - & - & - & - & - & - \\
\hline \multirow{11}{*}{ 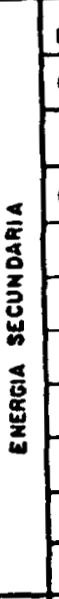 } & ELECTRICIDAD & $\$ 38.6$ & $\div 38.9$ & 5.1 & - & 19.4 & 532.8 & 438.5 & - & - & - & 106.7 & - & - & 136.5 & 289.0 & 532.8 \\
\hline & GAS DE REFINERIA & - & - & - & - & - & - & - & - & - & - & - & - & - & - & - & - \\
\hline & CAS LICUADO & - & - & - & - & - & - & - & - & - & - & - & - & - & - & - & - \\
\hline & Gas olstaibuido & - & - & - & - & - & - & - & - & - & - & - & - & - & - & - & - \\
\hline & GASOLIMA MOTOR & - & 143.9 & - & $\ldots$ & 0.0 & 143.9 & - & - & - & - & - & 143.9 & - & - & - & 243.2 \\
\hline & KEAOSENE $Y$ JET FUEL & - & - & - & - & - & - & - & - & - & - & - & - & - & - & - & - \\
\hline & DIESEL OIL & - & 184.1 & - & $\ldots$ & 0.0 & 234.1 & (67.9) & - & - & - & 14.4 & - & - & 102.2 & - & 116.6 \\
\hline & FUEL OIL & - & 987.0 & - & $\ldots$ & 0.0 & 037.0 & 1779.2 & - & - & - & 63.9 & - & - & 118.9 & - & 207.8 \\
\hline & NO ENERGETICO & - & - & - & - & - & - & - & - & - & - & - & - & - & - & - & - \\
\hline & URAMO EMRIOUECLOO & - & - & - & - & - & - & - & - & - & - & - & - & - & - & - & - \\
\hline & TOTAL & 438.6 & $1,423.9$ & 5.1 & $\ldots$ & (9.6) & $1,847.8$ & $(846 . \lambda$ & - & - & - & 210.0 & 143.5 & - & 357.6 & 289.0 & $1,001.1$ \\
\hline & PERDDOAS DE TRAMFCRMACTOH & - & - & - & - & - & - & 619.1 & - & - & - & - & - & - & - & - & - \\
\hline & CONSEMO TOTAL & - & - & - & - & - & - & - & - & - & - & 210.0 & 143.9 & - & 357.6 & 289.0 & $1,001.1$ \\
\hline
\end{tabular}




\begin{tabular}{|c|c|c|c|c|c|c|c|c|c|c|c|c|c|c|c|c|c|}
\hline & \multirow[b]{2}{*}{$\begin{array}{llll}1 & 9 & 8 & 0\end{array}$} & \multicolumn{2}{|r|}{8} & \multirow{2}{*}{$\begin{array}{l}A \mathrm{~L} \\
\text { Donerricos }\end{array}$} & \multirow{2}{*}{$\begin{array}{l}\text { A } N \\
\times \text { srock }\end{array}$} & \multicolumn{2}{|l|}{$E$} & \multicolumn{4}{|c|}{ TRANS FO RMACION } & \multicolumn{3}{|c|}{ CONSUMO } & \multicolumn{3}{|c|}{ ETO } \\
\hline & & oaveen & montracion & & & cienere & oestimo & $\begin{array}{l}\text { centrukes } \\
\text { cluetricas }\end{array}$ & asprism & erencousenal & 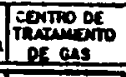 & 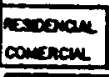 & menomente & novstren & neveo & otmon & Toral \\
\hline \multirow{6}{*}{ 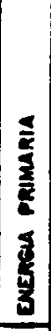 } & EMERGIA MDRALLLA & 334.0 & - & - & (3.1) & (129.5) & 207.6 & 207.6 & - & - & - & - & - & - & - & - & - \\
\hline & PETROLEO & - & - & - & - & - & - & - & - & - & - & - & - & - & - & - & - \\
\hline & CARBON MIMERAL & - & - & - & - & - & - & - & - & - & - & - & - & - & - & - & - \\
\hline & LEAa & - & - & - & - & - & - & - & - & - & - & - & - & - & - & - & - \\
\hline & URAMTO & - & - & - & - & - & - & - & - & - & - & - & - & - & - & - & - \\
\hline & TOTAL & 334.0 & - & - & (3.1) & 1129.5 & 207.6 & 207.6 & - & - & - & - & - & - & _- & - & - \\
\hline \multirow{13}{*}{ 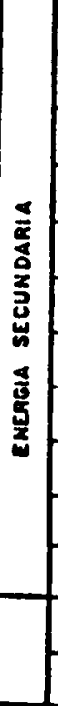 } & ELECTRIGIDAO & 487.0 & 6.9 & 1.6 & - & 013.14 & 429.0 & 487.0 & - & $=$ & $=$ & $68 \Omega$ & & & 894 & 2210 & \\
\hline & GAS OE REFIMERIA & - & - & - & - & - & - & - & - & - & - & - & - & - & - & - & - \\
\hline & GAS UIGUADO & - & - & - & - & - & - & - & - & - & - & - & - & - & - & - & - \\
\hline & ans oustrabudo & - & - & - & - & - & - & - & - & - & - & - & - & - & - & - & - \\
\hline & GASOLMMA MOTOR & - & 22.2 & - & $\ldots$ & 0.0 & 22.2 & - & - & - & - & - & 22.2 & - & - & - & 22.2 \\
\hline & KEROSENE Y JET FUEL & - & - & - & - & - & - & - & - & - & - & - & - & - & - & - & - \\
\hline & DESEL OUL & - & 262.00 & - & $\ldots$ & 0.0 & 262.8 & 1161.2 & - & - & - & 1.1 & - & - & 100.5 & - & 101.6 \\
\hline & FUEL OLL & - & 2089.1 & - & $\ldots$ & 0.0 & 2009.1 & (948.2) & - & - & - & 78.3 & - & - & 62.6 & - & 140.9 \\
\hline & NO ENERGETICO & - & - & - & - & - & - & - & - & - & - & - & - & - & - & - & - \\
\hline & URANIO FRTIOUECIDO & - & - & - & - & - & - & - & - & - & - & - & - & - & - & - & - \\
\hline & TOTAL & 487.01 & $1.381 .0 \mid$ & 1.8 & $\because$ & $1(12,1)$ & $1,853.1$ & $11,109.4$ & - & - & - & 148.2 & 22.2 & - & 251.5 & 321.8 & 743.7 \\
\hline & PEADIOAS DE TRANFORMUCLON & - & - & - & - & - & - & $83 a .0$ & - & - & - & - & - & - & - & - & - \\
\hline & consuno total & - & - & - & - & - & - & - & - & - & - & 148.2 & 22.2 & - & 251.5 & 321.8 & 743.7 \\
\hline
\end{tabular}

